\title{
Development and Application of a Probabilistic Evaluation Method for Advanced Process Technologies (Task 3)
}

\section{Final Report}

\section{H.C. Frey}

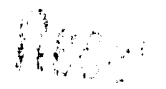

\section{E.S. Rubin}

April 1991

Work Performed Under Contract No.: DE-AC21-88MC24248

For

U.S. Department of Energy

Office of Fossil Energy

Morgantown Energy Technology Center

Morgantown, West Virginia

By

Carnegie-Mellon University

Center for Energy and Environmental Services

Pittsburgh, Pennsylvania

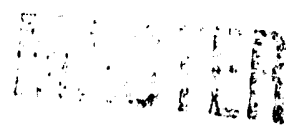




\section{DISCLAIMER}

This report was prepared as an account of work sponsored by an agency of the United States Government. Neither the United States Government nor any agency thereof, nor any of their employees makes any warranty, express or implied, or assumes any legal liability or responsibility for the accuracy, conipleteness or usefulness of any information, apparatus, product, or process disclosed, or represents that its use would not infringe privately owned rights. Reference herein to any specific commercial product, process, or service by trade name, trademark, manufacturer, or otherwise, does not necessarily constitute or imply its endorsement, recommendation, or favoring by the United States Government or any agency thereof. The views and opinions of authors expressed herein do not necessarily state or reflect those of the United States Government or any agency thereof.

This report has been reproduced directly from the best available copy.

Available to DOE and DOE contractors from the Office of Scientific and Technical Information, P.O. Box 62, Oak Ridge, TN 37831; prices available from (615)576-8401, FTS 626-8401.

Available to the public from the National Technical Information Service, U.S. Department of Commerce, 5285 Port Royal Rd., Springfield, VA 22161. 
Development and Application of a Probabilistic Evaluation Method for Advanced Process Technologies (Task 3)

Final Report

H.C. Frey

E.S. Rubin

Work Performed Under Contract No.: DE-AC21-88MC24248

For

U.S. Department of Energy Office of Fossil Energy

Morgantown Energy 'Technology Center

P.O. Box 880

Morgantown, West Virginia 26507-0880

\author{
By \\ Carnegie-Mellon University \\ Center for Energy and Environmental Services \\ Pittsburgh, Pennsylvania 15213
}

April 199? 


\section{Acknowledgments}

This report is an account of research sponsored by the U.S. Department of Energy under Contract No. DE-AC21-88MC24248. The authors gratefully acknowledge the assistance of several engineers at the Morgantown Enery Technology Center. These engineers include: Larry Bissett, Donald Bonk, Donald Geiling, Stanley Kasper, George Lee and Dale Schmidt. In addition, we are grateful for the guidance provided by Leonard Graham and Tom Keech. Finally, we would like to express sincere appreciation for the support and guidance of the METC project manager, Kevin Williams, throughout all phases of this contract. 


\section{Table of Contents}

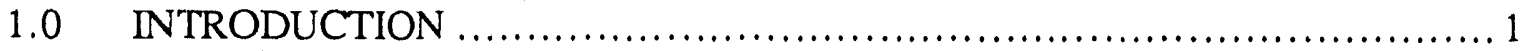

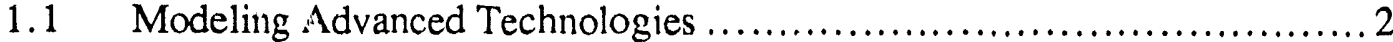

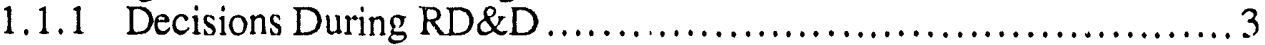

1.1.2 Modeling Performance and Cost................................. 3

1.1.3 Handling Uncertainties ..............................................6 6

1.2 Advanced Coal-Based Power Generation Technology ........................ 8

1.2.1 Current Environmental Regulations................................9 9

1.2.2 Changes in Environmental Regulations.................................9

1.2.3 Emerging Coal-Based Power Generation Technologies..............10

1.3 Objectives ................................................................13

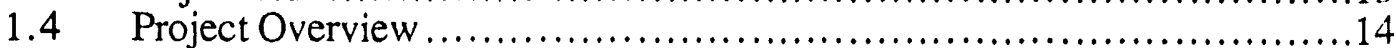

1.4.1 Task 1: Probabilistic Modeling in ASPEN ..........................14

1.4.2 Task 2: Engineering Cost Models of Selected IGCC Systems ....................................................15

1.4.3 Task 3: Scope of This Report .................................15

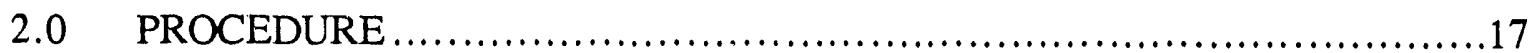

$2.1 \quad$ Identification of Case Studies....................................................

2.1.1 Identifying Decision Criteria .............................................17

2.1.2 Selection of Alternatives..................................................21

2.2 Performance and Cost Modeling ..............................................22

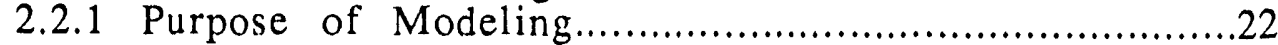

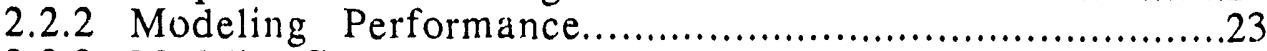

2.2.3 Modeling Cost ............................................23

2.2.4 Role of Regression Analysis in Model Development ..................25

2.3 Characterizing Uncertainties .................................................26

2.3.1 Philosophy of Uncertainty Analysis ................................22

2.3.2 Types of Uncertain Quantities ....................................27

2.3.3 Encoding Uncertainties as Probability Distributions ..................28

2.3.4 Some Types of Probability Distributions...............................3 31

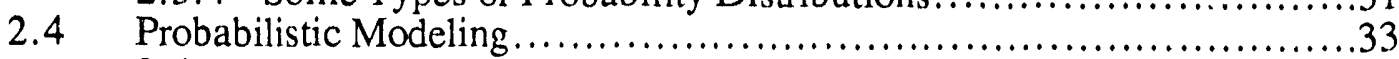

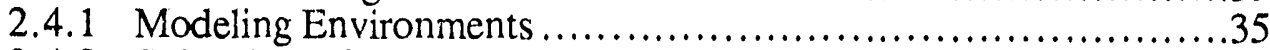

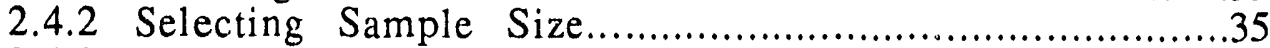

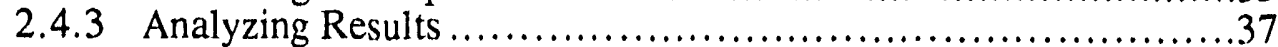

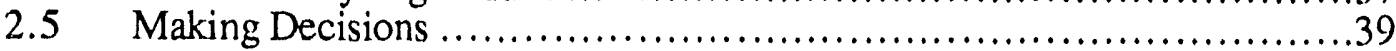

3.0 ENGINEERING MODELS OF SELECTED CLEAN COAL

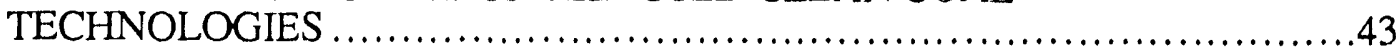

3.1 Selection of Candidate IGCC Systems for Evaluation...........................43

3.2 IGCC System Performance Models.............................................49

3.2.1 ASPEN Modeling Environment .......................................49

3.2.2 ASPEN IGCC Performance Models.....................................50

3.2.2.1 Oxygen-Blown KRW IGCC With Cold Gas

Cleanup............................................51

3.2.2.2 Air-Blown Lurgi IGCC with Hot Gas Cleanup ..............52

$3.3 \quad$ IGCC System Cost Models ..................................................58

3.3.1 Capitai Cost Models........................................................60

3.3.2 Operating Cost Models ..........................................63

3.3.3 Annualized Cost Models..................................................64

3.3.4 Cost Model Implementation...................................64 
4.0 CHARACTERIZING UNCERTAINTIES IN PROCESS

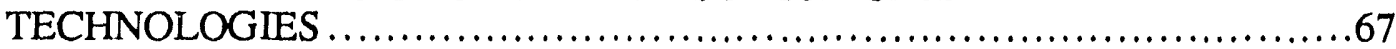

4.1 Approaches to Characterizing Uncertainty .......................................68

4.2 Characterizing Uncertainties in IGCC Systems..................................71

4.2.1 Obtaining Judgments From Technical Experts.........................72

4.2.1.1 Identifying Experts........................................72

4.2.1.2 Briefing Packets.....................................73

4.2.1.3 Expert Reaction to the Briefing Packets ...................75

4.2.1.4 Follow-Up Phone Interviews...............................76

4.2.2 Other Approaches to Characterizing Uncertainties ...................77

4.3 Base Case Estimates of Uncertainty for the Oxygen-blown

KRW-based IGCC System ........................................... 77

4.4 Estimates of Uncertainty for the Air-blown Lurgi-based IGCC

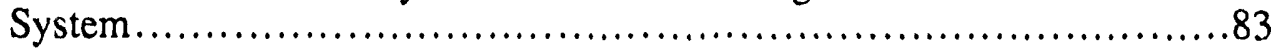

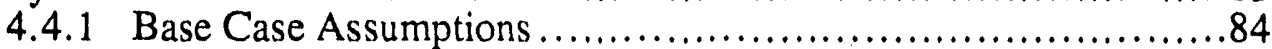

4.4.2 Alternative Expert Judgments...................................... 88

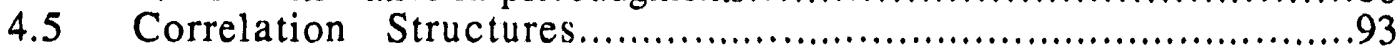

4.6 The "Best Guess" ................................................... 95

5.0 MODELING APPLICATIONS AND RESULTS...................................97

5.1 Running the Models......................................................

5.1.1 Comparing Probabilistic Results with Different Cost

Uncertainty Assumptions..........................................98

5.1.2 Comparing Probabilistic Results from Separate

Simulations........................................................ 100

5.2 Probabilistic Analysis of the Air-Blown IGCC System with Hot

Gas Cleanup ......................................................... 101

5.2.1 Characterization of Uncertainties in Performance and

Cost ......................................................... 101

5.2.1.1 Plant Performance............................................... 103

5.2.1.2 Plant Emissions ........................................ 105

5.2.1.3 Plant Costs.................................................. 107

5.2.2 Identifying Key Uncertainties.......................................... 112

5.2.2.1 Regression Analysis .................................... 112

5.2.2.2 Probabilistic Sensitivity Analysis ........................ 117

5.2.2.3 Screening Analysis....................................... 121

5.2.3 Probabilistic Design Analysis........................................... 124

5.2.3.1 Gas Turbine Fuel Valve ................................... 124

5.2.3.2 Gas Turbine Rich/Lean Combustion........................ 125

5.2 .4 Additional Research........................................... 126

5.2.5 Multiple Experts ................................................... 131

5.2.5.1 Zinc Ferrite Process Area .............................. 131

5.2.5.2 Gasification Process Area................................... 138

5.2.6 Correlation Structures............................................. 142

5.3 Oxygen-Blown KRW-Based IGCC System with Cold Gas

Cleanup........................................................ 144

5.3.1 Characterization of Uncertainties in Performance and

Cost ........................................................ 145

5.3.2 Identifying Key Uncertainties.......................................... 149

5.3.2.1 Regression Analysis ..................................... 149

5.3.2.2 Probabilistic Sensitivity Analysis ......................151

5.3.2.3 Screening Analysis......................................... 152

5.3.3 Additional Research..................................................... 153

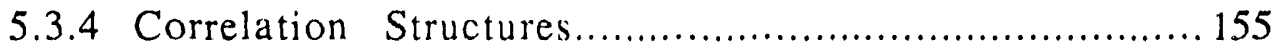


5.4 Comparative Analysis of the IGCC Systems ........................... 156

5.4.1 Pairing Simulations ....................................... 156

5.4.2 Comparing Two Technologies Under Uncertainty ................. 158

5.4.3 Results of the Comparative Case Studies.............................. 160

5.5 An Illustrative Decision Model.............................................. 166

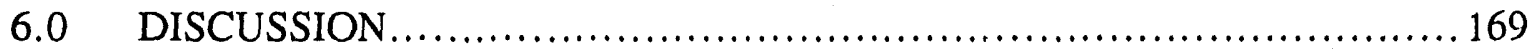

6.1 Information Requirements....................................... 169

6.2 Computational Requirements ................................... 170

6.3 Cost Estimating and Risk Assessment............................... 170

6.4 Comparison of Probabilistic Approach to RAND Cost Growth

Model ............................................................ 171

6.4.1 Rand First-of-a-Kind Plant Cost Growth Model ..................... 171

6.4.2 Cost Growth Case Studies for the IGCC Systems.............. 172

7.0 CONCLUSIONS....................................................... 175

7.1 Technology-Specific Conclusions........................................ 175

7.2 Methodological Conclusions.................................... 178

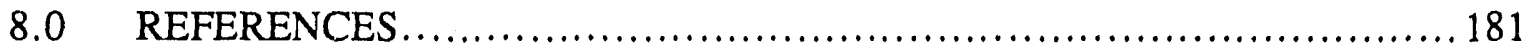

Appendix A

A.0 Technical Background for Process-Related Uncertainties...................... 191

A.1 Briefing Paper Part 1: Introduction to Uncertainty Analysis .............. 193

A.2 Technical Background and Uncertainty Estimates for the

Gasification Process Area ........................................... 205

A.2.1 Lurgi Gasification Process Area ............................205

A.2.1.1 Process Description................................205

A.2.1.2 Key Design and Performance Assumptions ............2210

A.2.1.3 Key Technical Issues ...................................2210

A.2.1.3.1 Caking Coal Operation ..................... 212

A.2.1.3.2 Fines Loading and Carryover $\ldots \ldots \ldots \ldots \ldots \ldots . .212$

A.2.1.3.3 Carbon Conversion..........................2214

A.2.1.3.4 Bottom Ash Sulfur Retention....................2215

A.2.1.3.5 Gasifier Throughput.........................2215

A.2.1.3.6 Ammonia Concentration ...................215

A.2.1.3.7 Gasifier Pressure.................................. 216

A.2.1.3.8 Gasifier Steam Requirement...................2216

A.2.1.3.9 Gasifier Oxidant Requirement.................2217

A.2.1.4 Questionnaire for the Fixed Bed Gasifier Process Area...................................... 218

A.2.1.5 Elicited Technical Judgments About

Uncertainties.................................... 225

A.2.1.5.1 Expert LG-1 ........................... 225

A.2.1.5.2 Expert LG-2 ............................... 230

A.2.1.5.3 Other Uncertainties ......................... 233

A.2.2 Fluidized Bed Coal Gasification Process Area...................... 236

A.2.2.1 Process Description.................................2236

A.2.2.2 Commercial Status of the KRW Gasifier................. 239

A.2.2.3 PDU Data Availability and Applicability .................2.243

A.2.2.4 Key Technical Issues .................................246 
A.2.2.4.1 Oxidant Requirement .........................2246

A.2.2.4.2 Steam Requirement ......................... 246

A.2.2.4.3 Carbon Conversion.............................. 247

A.2.2.4.4 In-Bed Desulfurization ...................... 250

A.2.2.4.5 Effect of Sorbent on Gasifier

Performance........................................... 252

A.2.2.4.6 Ammonia Production........................ 253

A.2.2.4.7 Spent Sorbent Sulfation.....................2254

A.2.2.5 Technical Judgments About Uncertainties .............. 255

A.3 Technical Background and Uncertainty Estimates for the Fixed-

Bed Zinc Ferrite Process Area ........................................ 261

A.3.1 Process Description ....................................... 261

A.3.2 Key Technical Issues .................................... 263

A.3.3 Questionnaire for Fixed Bed Zinc Ferrite Desulfurization.........269

A.3.4 Elicited Technical Judgments About Uncertainties .............. 272

A.3.4.1 Expert ZF-1 .................................... 272

A.3.4.2 Expert ZF-2 ....................................... 277

A.3.4.3 Expert ZF-3 .................................... 282

A.3.5 Other Uncertainties ..................................... 283

A.4 Technical Background and Uncertainty Estimates for the Gas

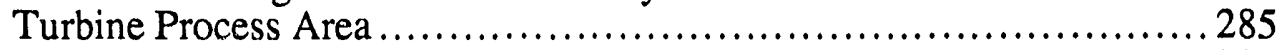

A.4.1 Key Design and Performance Assumptions......................... 285

A.4.2 Commercial Offerings for 2,300 oF Gas Turbines.................. 287

A.4.3 Operating Strategies for Coal Gas Firing........................ 289

A.4.4 Fuel Valve ................................................. 293

A.4.5 Combustion and Emissions ........................................... 294

A.4.5.1 NOx Emissions.....................................295

A 4.5.2 Combustion Efficiency and CO Emissions ............. 300

A.4.5.3 Combustor Pressure Drop ......................... 302

A.4.5.4 Particles ......................................... 302

A.4.5.5 Combustor Life...................................... 302

A.4.6 Turbine .................................................. 302

A.4.6.1 Advanced Cooling Technology .................................. 303

A.4.6.2 Turbine Blade Materials ................................ 304

A.4.6.3 Deposition............................................ 305

A.4.6.4 Erosion .......................................... 306

A.4.6.5 Corrosion ...................................... 306

A.4.7 Questionnaire for Gas Turbine ................................... 308

A.4.8 Judgments About Uncertainties..................................... 315

A.4.8.1 Expert GT-1 ................................... 315

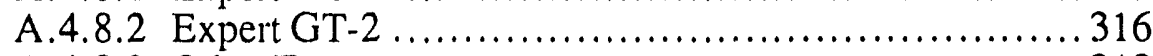

A.4.8.3 Other Experts ................................... 318

A.4.8.4 Discussion of Uncertainties........................... 319

A.5 Other IGCC Process Uncertainties................................ 325

A.5.1 Cost Model Parameter Uncertainties ......................... 325

A.5.2 Direct Capital Cost Uncertainties ............................. 328

A.5.3 Maintenance Cost Uncertainties .............................. 333

A.5.4 Variable Operating Cost Uncertainties .......................... 336

A.5.5 Regression Model Error Terms ............................. 338

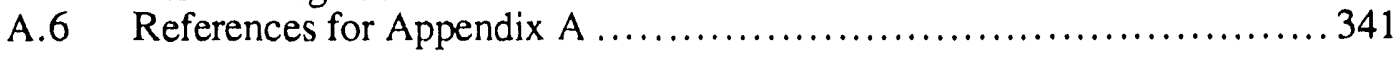


Appendix B

B.0 MODIFICATIONS TO DOE PERFORMANCE MODELS........................ 349

B.1 Gasification Process Area ................................................ 349

B.2 Zinc Ferrite Desulfurization Process Area............................. 350

B.3 Gas Turbine Process Area.............................................. 351

Appendix C

C.0 SAMPLE DETERMINISTIC OUTPUTS FOR IGCC COST MODELS ........ 357

C.1 Oxygen-blown KRW IGCC with Cold Gas Cleanup...................... 357

C.3 Air-blown Lurgi-based IGCC with Hot Gas Cleanup ..................... 360 


\section{List of Figures}

Figure 1. Decisions in the Research, Development, and Demonstration

Process ............................................................. 4

Figure 2. The Concept of Integrated Environmental Control..................................11

Figure 3. Relationship Between Project Elements................................ 14

Figure 4. Method for Evaluation of Advanced Process Technologies ...................18

Figure 5. Some Types of Probability Distributions. .................................32

Figure 6. Power Utility Function ............................................... 41

Figure 7. Schematic of Oxygen-blown KRW-based IGCC System with Cold

Gas Cleanup........................................................... 45

Figure 8. Schematic of Air-blown Dry Ash Lurgi Gasifier IGCC System with

Hot Gas Cleanup.............................................................48

Figure 9. Conceptual Diagram of ASPEN Flowsheet for Oxygen-Blown

KRW-based IGCC System with Cold Gas Cleanup . .........................53

Figure 10. Conceptual Diagram of ASPEN Flowsheet for Air-Blown Lurgibased IGCC System with Hot Gas Cleanup.......................................56

Figure 11. Judgment of Expert LG-1 Regarding Uncertainty in Gasifier Fines

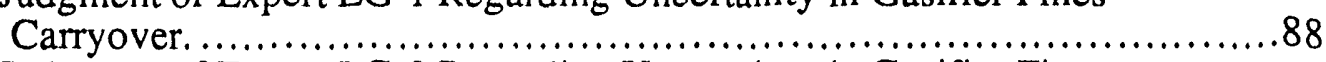

Figure 12. Judgment of Expert LG-2 Regarding Uncertainty in Gasifier Fines

Figure 13. Judgment of Expert LG-1 Regarding Uncertainty in Carbon

Retention in Gasifier Bottom Ash..............................
Figure 14. Judgment of Expert LG-2 Regarding Uncertainty in Carbon .88 Retention in Gasifier Bottom Ash.................................................89

Figure 15. Judgment of Expert LG-1 Regarding Uncertainty in Gasifier Air/Coal Ratio ............................................................99

Figure 16. Judgment of Expert LG-2 Regarding Uncertainty in Gasifier Air/Coal Ratio ..................................................... 90

Figure 17. Judgment of Expert ZF-1 Regarding Uncertainty in Sorbent Sulfur

Figure 18. Judgment of Expert ZF-2 Regarding Uncertainty in Sorbent Sulfur Loading (Judgment ZF-2P) .................................................99

Figure 19. Judgment of Expert ZF-3 Regarding Uncertainty in Sorbent Sulfur Loading. .................................................................92

Figure 20. Judgment of Expert ZF-1 Regarding Uncertainty in Sorbent

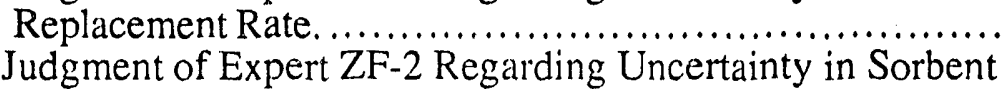

Figure 21. Judgment of Expert ZF-2 Regarding Uncertainty in Sorbent .99

Figure 22. Judgment of Expert ZF-3 Regarding Uncertainty in Sorbent .94

Replacement Rate.......................................................994

Figure 23. Comparison of Deterministic and Probabilistic Results for the Net Plant Thermal Efficiency of the Lurgi-based System....................... 103

Figure 24. Comparison of Deterministic and Probabilistic Results for the Zinc Ferrite Initial Sorbent Charge of the Lurgi-based System....................... 105

Figure 25. Comparison of Deterministic and Probabilistic Results for the SO2 Emissions of the Lurgi-based System................................... 106

Figure 26. Comparison of Deterministic and Probabilistic Results for the NOx Emissions of the Lurgi-based System................................... 106

Figure 27. Comparison of Deterministic and Probabilistic Results for the $\mathrm{CO} 2$ Emissions of the Lurgi-based System. 
Figure 28. Comparison of Deterministic and Probabilistic Results for the Total

Capital Cost of the Lurgi-based System..................................... 108

Figure 29. Comparing Total Capital Cost and the Probability of Cost-Overrun for the Lurgi-based System.......................................... 108

Figure 30. Comparison of Deterministic and Probabilistic Results for the Fixed Operating Cost of the Lurgi-based System.

Figure 31. Comparison of Deterministic and Probabilistic Results for the Variable Operating Cost of the Lurgi-based System..................... 110

Figure 32. Comparison of Deterministic and Probabilistic Results for the Cost of Electricity of the Lurgi-based System. .............................. 111

Figure 33. Sources of Uncertainty for Plant Thermal Efficiency........................ 118

Figure 34. Sources of Uncertainty for Total Capital Cost................................ 119

Figure 35. Performance-Related Sources of Uncertainty for Total Capital Cost ................................................................. 119

Figure 36. Sources of Uncertainty for Cost of Electricity................................ 120

Figure 37. Performance-Related Sources of Uncertainty for Cost of

Electricity. ...................................................... 120

Figure 38. Cost-Related Sources of Uncertainty for Cos` of Electricity.................... 121

Figure 39. Comparison of Uncertainty in Plant Efficiency for Original and Screened Sets of Uncertainties.

Figure 40. Comparison of Uncertainty in Total Capital Cost for Original and Screened Sets of Uncertainties..................................... 123

Figure 41. Comparison of Uncertainty in the Cost of Electricity for Original and Screened Sets of Uncertainties. ................................ 123

Figure 42. Uncertainty in the Difference in Cost of Electricity Between Base Case and Advanced Gas Turbine Fuel Valves....

Figure 43. Uncertainty in NOx Emissions for Conventional and Rich/Lean

Gas Turbine Combustors........................................... 126

Figure 44. Effect of Reductions in Uncertainty on Uncertainty in the Plant Thermal Efficiency..................................................... 129

Figure 45. Effect of Reductions in Uncertainty in Specific Process Areas on Uncertainty in the Total Capital Cost. ...................................... 129

Figure 46. Effect of Reductions in Uncertainty in Specific Process Areas on Uncertainty in the Cost of Electricity................................. 130

Figure 47. Comparison of the Uncertainty in Initial Zinc Ferrite Sorbent Requirement based on the Judgments of Different Experts Regarding the Zinc Ferrite Process Area.

Figure 48. Comparison of the Uncertainty in Total Capital Cost based on the Judgments of Different Experts Regarding the Zinc Ferrite Process Area ................................................................. 136

Figure 49. Comparison of the Uncertainty in Cost of Electricity based on the Judgments of Different Experts Regarding the Zinc Ferrite Process Area .................................................................. 136

Figure 50. Comparison of the Uncertainty in Plant Efficiency based on the Judgments of Different Experts Regarding the Gasification Process Area ............................................................. 141

Figure 51. Comparison of the Uncertainty in Total Capital Cost based on the Judgments of Different Experts Regarding the Gasification Process Area.............................................................. Judgments of Different Experts R.egarding the Gasification Process

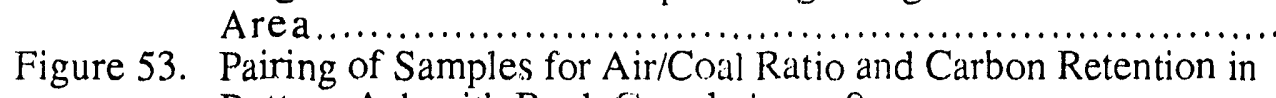
Bottom Ash with Rank Correlation $=0$ 143 
Figure 54. Pairing of Samples for Air/Coal Ratio and Carbon Retention in

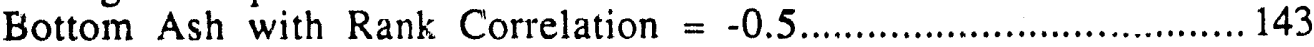

Figure 55. Effect of Assumed Correlations on Uncertainty in Capital Cost. .............. 144

Figure 56. Comparison of Delerministic and Probabilistic Resu'ts for the Net

Plant Thermal Efficieicy of the Oxygen-blown KR.W-based

System.

Figure 57. Comparison of Deterministic and Probabilistic Results for the

Sulfur Dioxide Emissions of the Oxygen-blown KRW-based

System.

Figure 58. Comparison of Deterministic and Probabilistic Results for the Total

Capital Cost of the Oxygen-blown KRW-based System.

Figure 59. Comparison of Deterministic and Probabilistic Results for the Cost

of Electricity of the Oxygen-blown KRW-based Svstem................ 148

Figure 60. Sources of Uncertainty for Cost of Electricity................................ 1: 1

Figure 61. Comparison of Uncertainty in the Cost of Electricity for Original and Screened Sets of Uncertainties.

Figure 62. Effect of Reductions in Selected Input Uncertainties on Uncertainty

in the Net Plant Thermal Efficiency........................................ 154

Figure 63. Effect of Reductions in Sel cted Input Uncertainties on Uncertainty

in the Cost of Electricity............................................. 155

Figure 64. Effect of Correlation in a Selected Input Uncertainty on Uncertainty

in the Cost of Electricity....

Figure 65. Effect of Illustrative Research Outcomes on Fixed Dperating Cost

Savings for Air-blown Lurgi System Compared to Oxygen-blown

KRW System.....................................................

Figure 66. Effect of Illustrative Research Outcomes on Variable Operating
Cost Savings for Air-blown Lurgi System Compared to Oxygen-

blown KRW System ...

Figure 67. Effect of Illustrative Research Outcomes on Cost of Electricity

Savings for Air-blown Lurgi System Compared to Oxygen-blown

KRW Systern...............................................

Figure 68. Effect of Illustrative Research Outcomes on Cost of Electricity
Savings for Air-blown Lurgi System Compared to Oxygen-blown

KRW System.................................................. 165

Figure 69. Conceptual Decision Tree for Decisions Regarding Advanced

Technology Selection and Research Planning......................... 167

Figure 70. Sensitivity of Decision to Pursue Further Research to Discount Rate

and Time for a Risk-Averse Decision-Maker.

Figure A-1. Examples of Distributions Used for Probabilistic Analysis.................. 199

Figure A-2. Simple Schematic of Oxygen-blown KRW-based IGCC System

Figure A-3. Diagram of Lurgi Gasifier (Source ................................... 208

Figure A-4. Judgment of Expert LG-1 Regarding Gasifier Fines Carryover. ............. 227

Figure A-5. Judgment of Expert LG-1 Regarding Fines Cyclone Capture

Efficiency...................................................... 227

Figure A-6. Judgment of Expert LG-1 Regarding Gasifier Coal Throughput. .......... 228

Figure A-7. Judgment of Expert LG-1 Regarding Gasifier Steam

Requirement. ..................................................... 228

Figure A-8. Judgment of Expert LG-2 Regarding Fines Carryover...................... 231

Figure A-9. Judgment of Expert LG-2 Regarding Fines Recycle Cyclone

Capture Efficiency...............................................231

Figure A-10. Judgment of Expert LG-2 Regarding Gasifier Coal Throughput........... 233 
Figure A-11. Simple Schematic of Air-blown Lurgi-based IGCC System Figure A-12. Schematic of the Fluidized-Bed, Agglomerating Ash KRW

Gasifier............................................................. 240

Figure A-13. Simple Schematic of the Fixed-Bed Zinc Ferrite Process. ................... 262

Figure A-14. Simple Schematic of Gas Turbine Mass Balance with

Compressor Air Extraction. 


\section{List of Tables}

Table 1. Procedure for Probabilistic Analysis .......................... ..............19

Table 2. METC ASPEN Model of KRW-Based IGCC System: Plant

Table 3. Sections and Unit Operations..............................................

Hot Gas Cleanup: Plant Sections and Components.............................57

Table 4. Major Plant Sestions in the IGCC Cost Models....................................59

Table 5. Summary of Performance Parameters in the Direct Capital Cost

Models .................................................................61

Table 6. Summary of Key Parameters in the Total Capital Cost Model ...................63

Table 7. Summary of Key Parameters in the Operating Cost Model.....................63

Table 8. Summary of the Financial Assumptions for the IGCC Case

Studies. ................................................................ 78

Table 9. Characteristics of the Coal Assumed for IGCC System Studies ................79

Table 10. Summary of the Base Case Parameters Values and Uncertainties for

the Oxygen-Blown KRW-based IGCC System with Cold Gas

Cleanup ............................................................ 80

Table 11. Summary of the Base Case Parameter Values and Uncertainties for the Air-Blown Lurgi-based IGCC System with Hot Gas Cleanup. ............85

Table 12. Summary of Results from Deterministic and Probabilistic

Simulations of a 650 MW Air-Blown Lurgi-based IGCC System

with Hot Gas Cleanup: Expert Judgments LG-1 and ZF-1 ............... 102

Table 13. Comparison of Rankings of Uncertain Parameters Affecting Plant

Efficiency for the Lurgi-based System. ................................ 113

Table 14. Comparison of Rankings of Uncertain Parameters Affecting Capital

Cost for Lurgi-based System............................................. 114

Table 15. Comparison of Rankings of Uncertain Parameters Affecting Cost

of Electricity for the Lurgi-based System................................ 116

Table 16. Uncertainties Screened Out of Case Studies for Air-Blown Lurgi-

based IGCC System with Expert Judgments LG-1 and ZF-1 ............... 122

Table 17. Illustrative Assumptions Regarding Reduction in Uncertainty in

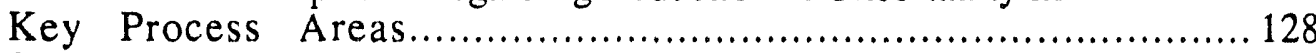

Table 18. Summary of Results from Deterministic and Probabilistic

Simulations of a 650 MW Air-Blown Lurgi-based IGCC System

with Hot Gas Cleanup: Expert Judgments LG-1 and ZF-2P

Table 19. Summary of Results from Deterministic and Probabilistic

Simulations of a $650 \mathrm{MW}$ Air-Blown Lurgi-based IGCC System

with Hot Gas Cleanup: Expert Judgments LG-1 and ZF-2R. .............. 134

Table 20. Summary of Results from Deterministic and Probabilistic

Simulations of a $650 \mathrm{MW}$ Air-Blown Lurgi-based IGCC System

with Hot Gas Cleanup: Expert Judgments LG-1 and ZF-3

Table 22. Summary of Results from Deterministic and Probabilistic

Simulations of a 650 MW Oxygen-Blown KRW-based IGCC

System with Cold Gas Cleanup ........................................... 146

Table 23. Key Uncertainties for Oxygen-Blown KRW-based IGCC Based on

Partial Correlation Coefficients.................................................... 150

Table 24. Uncertainties Screened Out of Case Studies for Oxygen-Blown

KRW-based IGCC System............................................... 152

Table 25. Illustrative Assumptions Regarding Reduction in Uncertainty in

Key Process Areas for the Oxygen-blown KRW-based System............... 153

Table 26. Pairing of Uncertain Parameters for Comparative Study of Oxygen-

Blown KRW- and Air-Blown Lurgi-based IGCC Systems. 
Table 27. Results of Research Information Case Studies: Comparison of Airblown Lurgi and Oxygen-blown KRW Systems ......................... 161

Table 28. Analysis of Cost Grovth and Cost Improvement for the IGCC Systems

Table A-1. Typical Dofault Assumptions for the Lurgi-based IGCC System Case Studies

Table A-2. Summary of Elicited Lurgi Gasifier Technical Judgments from Expert LG 1 ....................................................... 226

Table A-3. Proposed Correlation Matrix for Uncertain Parameters LG-1 .............. 230

Table A-4. Summary of Elicited Lurgi Gasifier Technical Judgments from Expert LG 2 ................................................. 232

Table A-5. Proposed Correlation Matrix for Uncertain Parameters LG-2 $\ldots . . . . . . . . . . .234$

Table A-6. Default Characteristics for the Design Illinois No. 6 Coal .................. 238

Table A-7. Summary of KRW Gasifier Design Assumptions from Selected System Studies.

Table A-8. Summary of Assamed Uncertainties for the KRW Gasifier Process

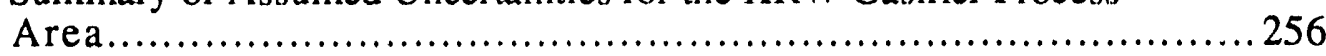

Table A-9. Proposed Correlation Matrix or KRW Gasification Uncertain Parameters .............................................................. 259

Table A-10. Summary of Elicited Zinc Ferrite Technical Judgments from Expert ZF-1

Table A-11. Proposed Correlation Matrix for Judgments ZF-1

Table A-12. Summary of Zinc Ferrite System Default Assumptions Used by Expert ZF-2

Table A-13. Summary of Elicited Zinc Ferrite Technical Judgments ZF-2P from Expert ZF-2.

Table A-14. Summary of Elicited Zinc Ferrite Technical Judgments ZF-2R from Expert ZF-2

Table A-15. Proposed Correlation Matrix for Judgments ZF-2.

Table A-16. Summary of Elicited Zinc Ferrite Technical Judgments from Expert ZF-3

Table A-17. Gas Turbine Default Assumptions and Typical Performance Estimates for Case Studies.

Table A-18. Representative 2,300 oF Firing Temperature Heavy-Duty Gas Turbine Commercial Offerings..................................... 288

Table A-19. Summary of Assumed Gas Turbine Process Area Uncertainties .............. 324

Table A-20. Summary of Assumed Values and Uncertainties for IGCC. Cost Model Parameters.

Table A-21. Summary of Assumed Values and Uncertainties for IGCC Process Area Direct Capital Cost.

Table A-22. Summary of Assumed Values and Uncertainties for IGCC Process Area Maintenance Cost. .

Table A-23. Summary of Assumed Values and Unceitainties for IGCC Variable Operating Cost Parameters

Table A-24. Summary of Regression Model Standard Errors for IGCC Cost and Auxiliary Power Equations. 


\subsection{INTRODUCTION}

The purpose of research, development, and demonstration (RD\&D) is to ovide and improve information regarding the feasibility, promising applications, optimal designs, uncertainties, and risks associated with a new process technology. The information generated from research can be used by process developer's to refine the technology and ultimately by potential process adopters to make a decision about whether, and under what circumstances, to use the new technology. Of concern to a process developer is the selection of appropriate technologies for research and the prioritization of research needs.

Particularly in process engineering fields, proper research planuing is often hindered by the unreliability of performance and cost estimates prepared during early stages of technology develcpment. According to Hess and Myers (1989):

Ultimately, all advanced technology R\&D programs directed at the marketplace, be they public or private efforts, raust be guided in very substantial part by the cosi of the product of advanced technology relative to the current technology. Unfortunately, accurate assessment of the costs of advanced technologies has always been one of the most difficult and uncertain tasks facing an R\&D planner. [p.1]

Preliminary performance and cost estimates for a new technology are inherenily uncertain because of the lack of large scale experience required to verify expectations. In spite of this, these estimates are often presented as deterministic point-values without regard to their degree of confidence. Poorly informed decisions regarding research planning and technology adoption may result, at considerable cost in terms of wasted resources devoted to projects that, given a more complete characterization of known information, might not have been pursued or might have been pursued differently. An important aspec. of any RD\&D program should be a systematic method for identifying and prioritizing research activities, allocating funds to RD\&D, and maximizing the probability of success for an RD\&D program.

This research addresses issues related to iesearch planning for advanced technologies which are in an early stage of research or development. Explicit characterization of uncertainty in process performance and cost is postulated as a key feature of a robust research planning method. A number of questions motivate such an approach to research planning, including:

- What is the expected commercial performance of the new technology based oir what is known from small scale tests and mass and energy balances?

- How reliable are these performance and estimates for a mature, commercial plant? 
- How do variations in design affect cost?

- What are the key factors driving uncertainty in process performance and cost?

- What are the risks and pay-offs of the new technology vis-a-vis conventional technology?

- What are the potential market niches for the new technology?

- What are the expected results from further process RD\&D?

- How much does RD\&D cost?

- Is it worth it?

In this research, a systematic quantitative method is developed and applied to help answer these questions. The key features of the research planning method are:

- Selection of candidate technologies for evaluation;

- Development of engineering performance and cost models of the technologies to be evaluated, based on available performance and cost information;

- $\Lambda$ probabilistic modeling capability to incorporate uncertainties about performance and cost parameters;

- Elicitation or development of technical judgments regarding performance and cost parameter uncerrainties,

- Exercising of the models to answer these questions:

- What are the key process design trade-offs?

- What are the uncertainties that most affect overall costs?

- What are the potential pay-offs and risks vis-a-vis conventional technology?

- What is the likely effect and value of additional research?

- What are the likely real costs of a first-of-a-kind demonstration of the new technology?

- Decision analysis regarding:

- How policy-based objectives and decision maker's preferences influence selection of the optimal technology for further RD\&D; and

- How policy-based objectives and decision maker's preference influence planning RD\&D strategies for a given technology.

This report documents a procedure and exemplary case study for probabilistic analysis of process technologies. The research planning method described above is applied to case studies of an advanced clean coal technology for electric power generation. The case studies are intended to demonstrate the probabilistic evaluation method and to yield technology-specific conclusions regarding research strategies and potential application niches.

\subsection{Modeling Advanced Technologies}

Shortcomings in traditional approaches to predicting the performance and cost of advariced process technologies are a key motivation for this research. These shortcomings revolve around the incomplete characterization of the limitations of data and assumptions in 
performance and cost parameters. In addition, an incomplete scope of modeling of new technologies may fail to reveal important process interactions that affect technical and economic feasibility.

\subsubsection{Decisions During RD\&D}

An advanced technology is a concept which departs in some fundamental way from existing technology and which holds the promise of a significant improvement in performance and/or cost over conventional technology. The transformation of an advanced concept into a commercialized technology involves many decisions at various stages of development, as shown in Figure 1. Figure 1 is based on a discussion in Merrow et al (1981). Typically, a new coricept may be evaluated theoretically and tested at a small (e.g., bench-top) scale. If promising technical results are obtained, a preliminary cost estimate of a commercial scale design may be made. If the cost estimates are high, the project may be dropped or research may continue to identify less costly variants of the technology. If the costs are promising, research is likely to continue to a larger scale test and to a development phase. Several pilot plants, of varying size and design, may be built during the research and development phase. As confidence in the technology improves, a more definitive cost estimate may be commissioned from an outside group as a final screening prior to designing a full-scale demonstration plant. At this stage, there may still be significant uncertainties in cost and performance that only a full-scale demonstration plant would help resolve.

The types of decisions made during RD\&D include whether the new technology should be rejected as infeasible, identification and prioritization of technical uncertainties for focused research, and identification of improvements that can be made to optimize the process. In practice, decisions about research prioritization are often made based on incompiete consideration of potential interactions between the new technology and its operating environment. For example, in identifying research priorities for a new emission control technology, research planners may fail to consider potential interactions between the new technology and the power plant.

\subsubsection{Modeling Performance and Cost}

Predictions of the performance of commercial implementations of an advanced concept may involve several challenges. In the very early stages of process development, predictions may be based on limited experimental work and rely heavily on simple ma: $\mathrm{s}$ and energy balances. These estimates may tend to assume ideal conditions and to overlook 


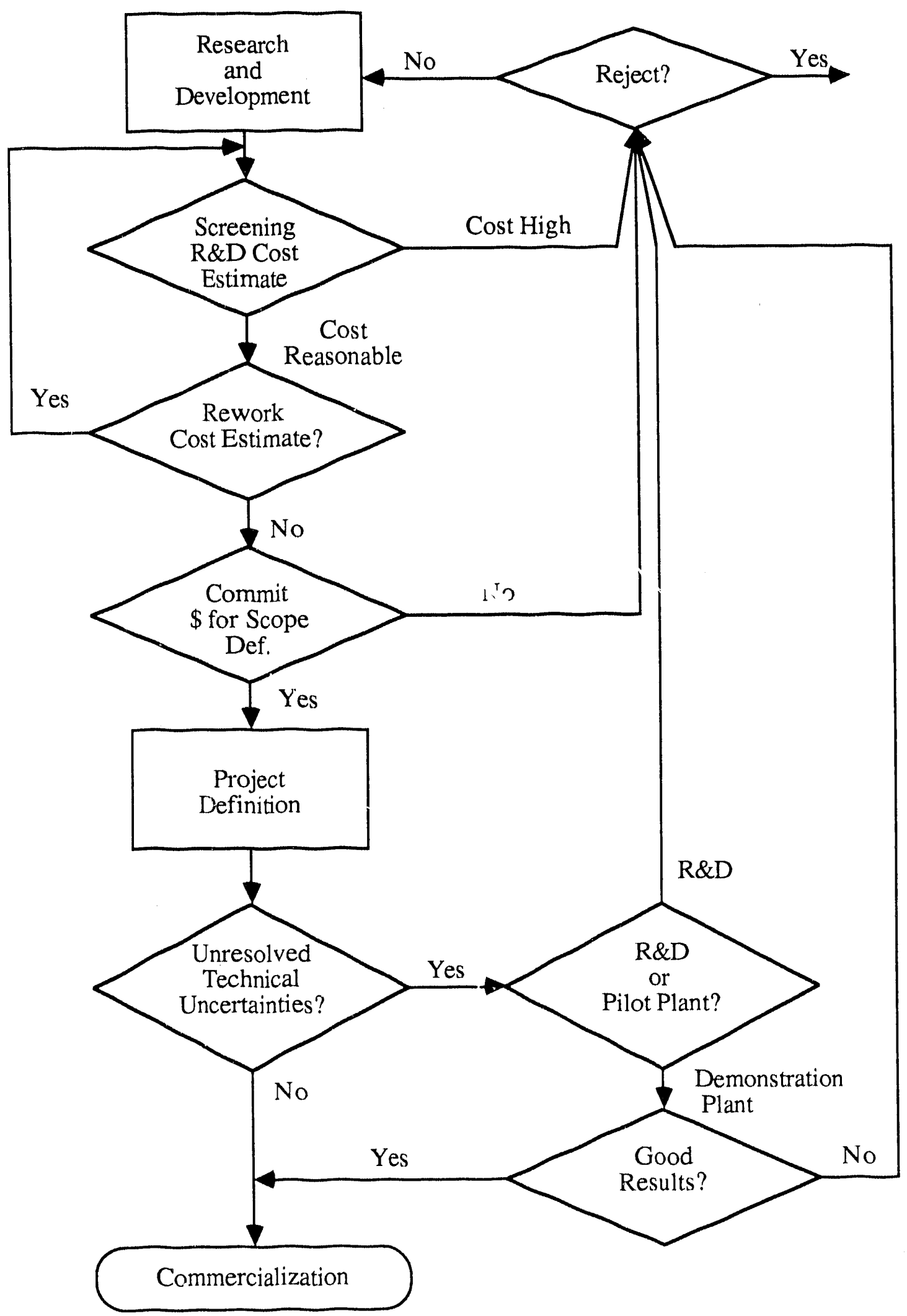

Figure 1. Decisions in the Research, Development, and Demonstration Process 
potential limitations, such as reaction kinetics or energy losses in the system. As a concept proceeds to a small scale testing or pilot plant phase, laboratory data may become available to $h \mathrm{l} l \mathrm{l}$ identify more realistic values for key process parameters. However, uncertainties in interpretation of test data stem from: (1) statistical errors in the data; (2) differences in configuration between the PDU and a commercial-scale plant, and (3) potential problems in scale-up from the PDU to commercial-size equipment.

Uncertainties in key performance parameters of an advanced process typically result in uncertainty in predicting key performance or environmental characteristics of the technology, such as plant efficiency and emissions of pollutants Uncertainties in system performance (e.g, flowrates, pressures) lead to uncertainties in the required size of process equipment and the consumption of materials (e.g., sorbent) and parasitic power. This results in uncertainties in capital and operating costs, which, along with key performance characteristics, are the ultimate measures of interest for comparative analysis. Furthermore, even if process performance were known with certainty, uncertainties regarding the costs of equipment (particularly equipment not previously used in commercial scale service) and reagents remain. For example, preliminary cost estimates may not capure all of the costs that would be revealed by a final estimate based on more detailed engineering analysis. Therefore, the process area costs developed in conceptual design studies may tend to be underestimated. Potential problems that could be encountered in a commercial-scale plant, such as corrosion or fouling, also may not be anticipated. Hence, performance and cost estimates developed in early stages of technology development could prove incorrect.

The Rand Corporation has performed a number of studies regarding problems with estimating the performance and cost of first-of-a-kind advanced process plants. These studies include: evaluation of cost growth and performance shorffalls for the first-of-akind (demonstation) plant (Merrow, Phillips, and Myers, 1981); evaluation of the potential benefits of building a first-of-a-kind plant (Hess, 1985); an assessment of problems and R\&D requirements for technology that involves processing of solids (E.W. Merrow, 1986); evaluation of factors involved in construction schedule slippage and increased startup costs for first-of-a-kind plant (Myers and Shangraw, 1986); an evaluation of industry's approach to developing contingency factors for cost estimates (Milanese, 1987); and an evaluation of cost estimating methods used for evaluating coal-to-substitute natural gas (SNG) systems (Hess and Myers, 1989).

Typical of the findings of the Rand are: (1) bias and uncertainty in performance and cost estimates results from low levels of process and project understanding, particularly for 
new technologies; (2) cost-underestimation of new technologies is wides read and systematically related to low levels of project definition and the amount of unproven technology employed; and (3) performance over-estimation is associated with unproven technology in a process concept (Merrow et al, 1981).

\subsubsection{Handling Uncertainties}

Nearly all analyses of process technologies, such as energy and environmental control technologies, that are still in the research phase involve uncertainties. In developing performance and cost estimates of technologies that are in early stages of development, the most common approach is for engineers to assume a "best guess" point-value judgment for key parameters. These judgments may be intended to represent neither undue optimism or pessimism regarding the technology, or they may be intended to incorporate a degree of conservatism. However, the basis for many assumptions, and the scope of thought that went into them, are often not explicitly documented in conceptual design studies. Thus, the degree of confidence that a decision-maker should place in the performance and cost estimate is often not rigorously considered.

The most common approach to handling uncertainties is either to ignore them or to use simple "sensitivity" analysis. In sensitivity analysis, the value of one or a few model input parameters are varied, usually from "low" to "high" values, and the effect on a model output parameter is observed. Meanwhile, all other model parameters are held at their "nominal " values. In practical problems with many input variables which may be uncertain, the combinatorial explosion of possible sensitivity scenarios (e.g., one variable "high", another "low," and so on) becomes unmanageable. Furthermore, sensitivity analysis provides no insight into the likelihood of obtaining any particular result. Thus, while they may indicate that a range of possible values may be obtained, sensitivity results do not provide any explicit indication of how a decision-maker should weigh each possible outcome.

A specific approach to handling uncertainty in capital cost estimates, whether for a new or existing technology or for a preliminary or detailed cost estimate, employs "contingency factors." The contingency of ten is the single largest expense in the cost estimate, and yet it is also the least documented. A contingency is used to represent additional costs that are likely to occur, but that are not included explicitly in the cost estimate (Milanese, 1987). 
Generally, all capital cost methods involve estimating one or more contingency factors. In the electric power industry, perhaps the most widely used cost estimating method for research planning is that of the Electric Power Research Institute (EPRI). EPRI uses two types of contingency factors: project and process contingency (EPRI, 1986). The project contingency is intended to cover the costs of additional equipment or other costs that would result from a more detailed design of a definitive project at a specific site. This implies that as costing proceeds from a preliminary to a detailed final estimate, the project contingency factor should be reduced. The process contingency is intended to quantify the uncertainty in the technical performarice and cornmercial scale cost of a new technology. Uncertainties in performance are implicitly assumed only to affect equipment design and not to affect the overall performance characteristics of the technology. This contingency factor is reduced as a terhnology proceeds from bench scale to full commercial use. Both of these contingency factors are deterministic estimates of additional costs that are expected to occur. In the EPRI Technical Assessment Guide, there is little substantive discussion of how these factors should be derived; suggestions for selecting values of both the project and process contingency values appear to be merely "rule-of-thumb" recommendations.

The Gas Research Institute (GRI) also sponsers studies of clean coal technologies. GRI requires an estimate of "process development allowances" (PDA) for all major plant sections (GRI, 1983). The PDA is intended to account for increases in cost as the design definition of a new technology is increased, revealing additional equipment required for a commercial-scale plant, and as a technology proceeds from early stages of development through commercialization. The PDA is an average of assessments, on a percentage of direct cost basis, of expected cost increases based on the state of the technology, the availability of experimental data, assumptions in the performance and cost estimate that have not been tested, and expected difficulty of control and operation. For each of these categories, the GRI Guidelines suggest a number of areas to consider when developing the assessments. The PDA is similar to the EPRI definition of process contingency.

Contingency factors are only applied to capital cost estimates. Analogous factors are not used for annual (fixed and variable operating cost) estimates, nor are they used explicitly in developing performance estimates.

The contingency factor approaches used by EPRI and others have not been validated by actual data. The Rand Corporation conducted a survey of 18 companies in the chemical and petroleum industries to determine the actual methods used to develop contingency factors (Milanese, 1987). The study indicates that contingency factors are 
badly under-estimated, which may be leading to bad decisions about certain projects. Factors such as project definition, owner characteristics, nature of the company (oil vs. non-oil), state of the technology (innovation or proven), project characteristics, management characteristics, and who actually estimated the contingency (e.g., project engineer or management) where considered in the study. The results were that what little theory exits regarding contingency factors is not applied, and that some of the factors which seem intuitively to be important are not captured in the contingency factor. Rand recommends the greater and more formalized use of experience, the use of a "delphi" technique to get multiple expert inputs, and the inclusion of costs associated with risks and innovation.

Although some conceptual design studies prepared :or the Electric Power Research Institute (EPRI) have included a "risk analysis" involving yrobabilistic simulation, such as a recent study of an advanced clean coal technology by Heager and Heavan (1990), the specification of uncertainties has been only on cost-related parameters. Furthermore, the analysis of uncertainty has been confined only to capital costs, and most analyses are insufficiently documented to allow critical evaluation of the modeling results.

\subsection{Advanced Coal-Based Power Generation Technology}

Because of current environmental, economic, security, and political concerns, the U.S. government and others are becoming extensively involved in research, development, and demonstration (RD\&D) of so-called "clean coal technologies." These are coal-based energy conversion technologies in which emissions of potentially harmful pollutants (gas, liquid, and solids) are reduced compared to commercially available technology. Improvements in plant efficiency and reductions in plant cost are also being sought.

The largest consumer of coal in the United States is the electric utility sector. In 1985, the utility sector used 15.5 quads (quadrillion Btu) of the total of 18.2 quads of coal used in the U.S. (EIA, 1987). Emissions of sulfur dioxide from coal-burning power plants were estimated to be 15.6 million tons in 1985, and the emissions of nitrogen oxides were approximately 6 million tons. Total emissions of these pollutants in the U.S. are approximately 23 and 20 million tons for sulfur dioxide and nitrogen oxides, respectively (DOE, 1987).

Although the environmental impacts of coal combustion pose significant challenges to emission control design, coal is the most abundant of the U.S. domestic fossil fuel resources. The demonstrated coal reserve base could supply current needs for 260 years 
(EIA, 1987). While increasing concern over the environmental impact of power plants will make siting and permitting of these facilities more difficult, the use of indigenous and abundant coal may be economically less risky than natural gas as a long term utility (or independent power producer) fuel. Therefore, it is important to identify and promote development of coal-fueled power plant technologies that are both environmentally acceptable and economically attractive.

\subsubsection{Current Environmental Regulations}

Current U.S. Environmental Protection Agency (EPA) new source performance standards (NSPS) applicable to coal-fired power plants require up to 90 percent sulfur dioxide $\left(\mathrm{SO}_{2}\right)$ removal, over 99 percent particulate matter (PM) removal, and moderate (about 50 percent) reduction of nitrogen oxides $\left(\mathrm{NO}_{\mathrm{x}}\right)$ emissions. A conventional emission control system for a new pulverized coal (PC) power plant typically consists of a wet limestone flue gas desulfurization (FGD) system for $\mathrm{SO}_{2}$ control, an electrostatic precipitator (ESP) for $\mathrm{PM}$ removal, and combustion controls for $\mathrm{NO}_{\mathrm{x}}$ reduction. These systems are all commercially available and well-demonstrated. However, recent commercial experience in Japan and Germany with selective catalytic reduction (SCR) indicates that 80 to 90 percent $\mathrm{NO}_{\mathrm{x}}$ removal may be feasible, although SCR has not yet been applied with U.S. coals (Cichanowicz and Offen, 1987; Damon and Giovanni, 1987).

Alternatives to conventional PC combustion, such as integrated coal gasification combined cycle (IGCC) systems, are capable of $\mathrm{NO}_{\mathrm{x}}$ emissions below thoese of PC plants equipped with $\mathrm{SCR}$, as well as high (over 95 percent) levels of $\mathrm{SO}_{2}$ control (Cool Water, 1986). Furthermore, changing environmental regulations may lead to requirements for very low emission rates of key pollutants. Thus, there is incentive to develop technology options to reliably achieve stringent ernissions reductions at minimum cost in a timely fashion.

\subsubsection{Changes in Environmental Regulations}

The most recent major revision in environmental control strategy in the U.S. is the Clean Air Act Amendment (CAAA) signed by the President on November 15, 1990. Prior to 1995,110 of the largest $\mathrm{SO}_{2}$-emitting stations are targeted for specific emission reductions. By 2000, the CAAA requires a reduction in national $\mathrm{SO}_{2}$ emissions by 10 million tons/year compared to 1980 levels. After 2000, a nationwide $\mathrm{SO}_{2}$ emission cap of 8.9 million tons/year will be in effect. In addition, emissions from virtually all power plants larger than 75-MW will be required not to exceed $1.2 \mathrm{lb} \mathrm{SO}_{2}$ per million BTU 
(lb/MMBtu) of coal consumed. In its full implementation, the CAAA is a market-based approach to emission control, unlike the "command and control" NSPS regulations now in effect. Under the market-based system, each emitter must possess an emission allowance for each ton of $\mathrm{SO}_{2}$ emited annually. In principle, emitters are free to buy, sell, and bank. emission credits to meet their needs and to comply with the national emission cap at lowest cost (Leone, 1990).

Under the CAAA, each emitter faces economic incentive to reduce emissions to the point where the marginal cost of pollution control equals the cost of an emission credit. Technologies which can economically achieve high removal efficiencies can provide a direct financial benefit to the utility. Thus, the CAAA may promote more rapid innovation in clean coal technology.

The CAAA also calls for a 2 million ton/year reduction in national $\mathrm{NO}_{\mathrm{x}}$ emissions by 2000 (Lee, 1991). EPA is required to set command-and-control $\mathrm{NO}_{\mathrm{x}}$ standards for tangentially-fired and dry-bottom wall-fired boilers, as well as for other boilers specified in the amendment. EPA must also set new NSPS for other fossil-fueled units. Trading between $\mathrm{SO}_{2}$ and $\mathrm{NO}_{\mathrm{x}}$ is not part of the current CAAA, but may be studied later for ossible inclusion in a future amendment (Leone, 1990).

\subsubsection{Emerging Coal-Based Power Generation Technologies}

With the prospect of increasingly stringent emission control has evolved the concept of integrated environmental control. This concept is illustrated in Figure 2. The concept has several dimensions. One is to consider interactions among control methods for air, water, and solid waste emissions, so that reductions in one type of discharge do not unduely increase others. Another is the integrated use of pre-combustion, combustion, and post-combustion control methods (as distinct from one approach alone). A third dimension is the development of new processes for combined pollutant removal in lieu of separate processe: for individual pollutants. Other process innovations not directly related to emission control may also affect emissions. Thus, integrated environmental control represents good design practice and provides opportunities to minimize costs for a given set of emission reduction requirements (Carr, 1986).

Key objectives of emissions control research, embodied in the notion of integrated environmental control, have been system simplification and cost reduction. Examples of integrated concepts for pulverized coal-fired power plants include combining flue gas $\mathrm{SO}_{2}$ 


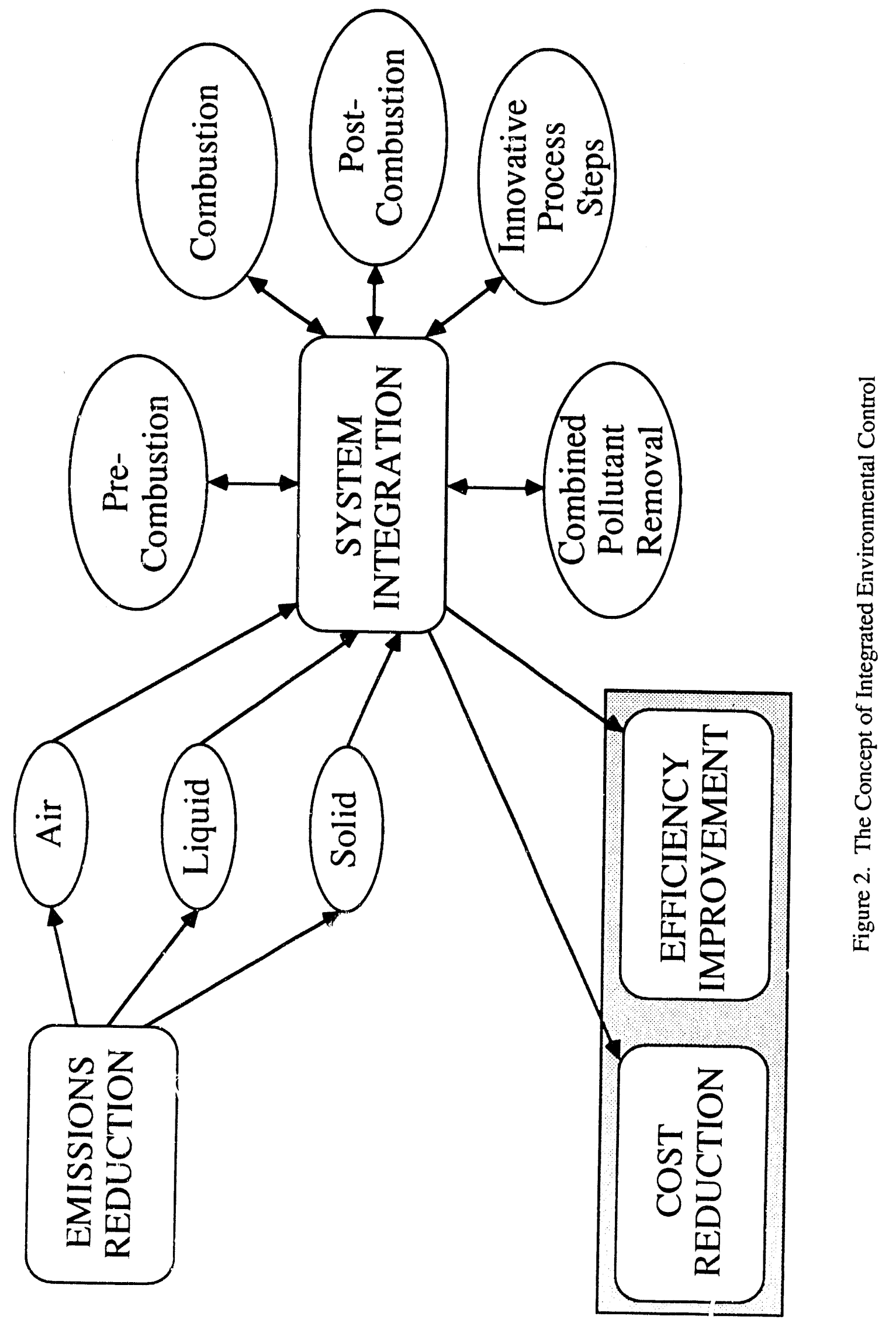


and $\mathrm{NO}_{\mathrm{x}}$ removal in a single reactor vessel, and coupling the designs of the power plant and emission control systems.

DOE and others have supported development of more advanced alternatives for control of $\mathrm{SO}_{2}$ and $\mathrm{NO}_{\mathrm{x}}$ emissions from coal-fueled power plants. One alternative, IGCC systems, represents a new approach for the clean and efficient use of coal in electric power generation. As emission control requirements have increased, so has the cost of conventional PC power plants, while their thermal efficiency has decreased, due to power requirements for emission control systems (DOE, 1987). Natural gas- and oil-fired systems based on gas turbine combined cycle technology have high efticiencies, but consume expensive premium fuels. In a combined cycle plant, fuel is burned in a gas turbine, and the hot exhaust gas is used to generate steam for a steam cycle. Electric generators on both the gas turbine and steam turbine generate electricity. By substituting synthetic fuel gas derived from coal for natural gas or oil, a coal-fueled gas turbine combined cycle pnwer plant results. By integrating the steam cycle to generate steam from the high temperature coal gasification process, the overall thermal efficiency can be optimized. Advantages of IGCC over PC plants include higher thermal efficiency, a capábility for high (over 95 percent) sulfur removal efficiency, lower $\mathrm{NO}_{\mathrm{x}}$ emissions, low particulate emissions, reduced solid waste due to byproduct recovery of elemental sulfur, reduced cooling water requirements (because gas turbines, rather than boiler/furnaces, generate a large portion of the power), reduced land requirements and a capability to burn coal, oil, or natural gas (SFA, 1983).

Unlike PC plants, IGCC systems are characterized by a modular design which allows phased construction of the system, flexibility in fuel use, and flexibility in design. A phased approach to IGCC construction might be based on an initial natural gas- or oilfired simple cycle gas turbine. In later phases a combined cycle and a coal gasification system are added, gradually increasing the electrical output of the facility and resulting ultimately in an IGCC power plant. The advantage of phased construction is that a utility can add new capacity incrementally, reducing the amount of capital that is at risk at any given time to uncertain electric load growth forecasts. The lead time required for simple cycle and combined cycle power plants is significantly less than that for PC power plants. Furthermore, the utility is not commited to natural gas or oil as a long-term fuel in a phased IGCC project (Fluor, 1986). Because IGCC plants are modular, they can be built in a wide range of sizes and with a variety of options for specific equipment, such as gasifiers and gas turbines. 
Compared to PC power plants, the notion of integrated environmental control is extended further in IGCC processes. In IGCC systems, environmental control is required not just to meet environmental regulations, but also for proper plant operation. For example, pollutants such as sulfur species and ash particles have deleterious effects on key components of IGCC systems, such as the gas turbine, and therefore must be controlled. In addition, the environmental control systems significantly affect the thermal cycle and, hence, plant efficiency.

\subsection{Objectives}

The objective of this work is to develop and apply a method for research planning for advanced process technologies. While current approaches to technology modeling and decision making may be appropriate for well-established, commercial technology, they are inadequate as a basis for research planning. Deterministic performance and cost estimates based on "best-guess" assumptions are not likely to provide insight into interactions among uncertainties which are sources of performance shortfall or cost growth. They are not likely to provide explicit insight into the specific process parameters which may contribute to technical or cost risk, nor are they likely to provide an explicit quantitative measure of the likelihood that a new technology will fail compared to conventional technology.

The Rand studies have indicated that a systematic approach to incorporating expert judgments about potential sources of performance shortfalls and cost growth is needed. In any type of modeling effort, the limitations of data and of knowledge about the system should be reflected in the model results. Clearly, uncertainties abound in the early stages of technology development, and they must be considered as an integral part of research planning.

To satisfy requirements for research planning, it is necessary to: (1) identify robust solutions to process design questions in the face of uncertainty to eliminate inferior design options; (2) identify key problem areas in a technology that should be the focus of further research to reduce the risk of technology failure; (3) compare competing technologies on a consistent basis to determine the risks associated with adopting a new technology; and (4) evaluate the effects that additional research might have on comparisons with conventional technology.

An important class of process technologies are electric power plants. In particular, advanced clean coal technologies are expected to play a key role in the energy and environmental future of the U.S., as well as in other countries. Research planning for 


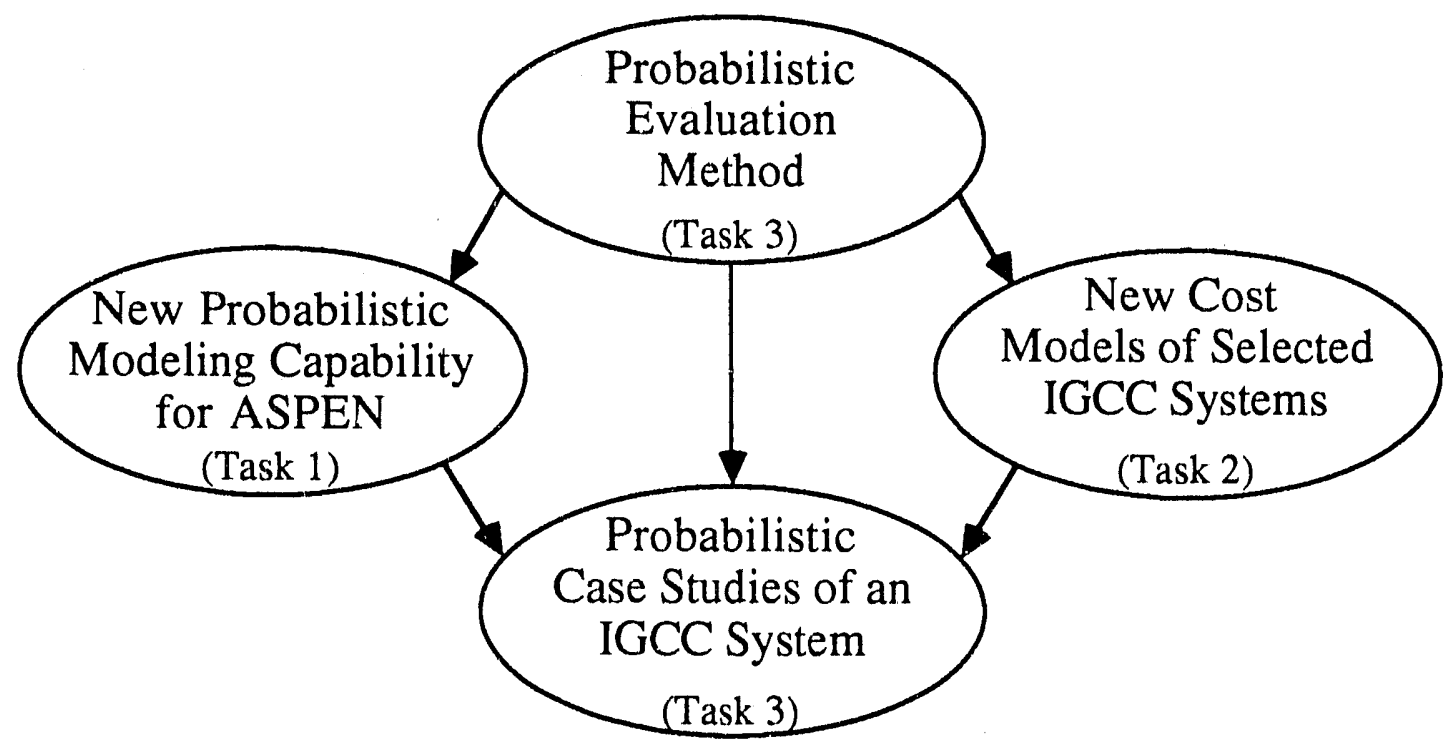

Figure 3. Relationship Between Project Elements

advanced clean coal technology development is an important part of energy and environmental policy. Thus, the research planning method developed here is applied to case studies focusing on a specific clean coal technology. The purpose of the case studies is both to demonstrate the research planning method and to obtain technology-specific conclusions regarding research strategies.

\subsection{Project Overview}

To support the development of a probabilistic method for technology evaluation and research planning, previous work under this contract has focused on two major areas. The first was the development of a general probabilistic modeling environment for modeling uncertainties in process technologies. The second was the development of technologyspecific engineering models. The engineering models of specific IGCC technologies are used here, together with the probabilistic modeling capability, for a series of probabilistic case studies. The relationship between the major project elements is shown schematically in Figure 3. The previous contract efforts are described briefly, followed by a discussion of the scope of this report.

\subsubsection{Task 1: Probabilistic Modeling in ASPEN}

Deterministic performance models of a number of IGCC systems have been developed by the U.S. Department of Energy's Morgantown Energy Technology Center (DOE/METC) using the Advanced System for Process ENgineering (ASPEN) process simulator (MIT, 1987). However, estimates of the performance of IGCC systems which 
have not yet been commercially demonstrated involve many uncertainties. The METC "enhanced" version of the ASPEN simulator does have a special "case study block," plus a Fortran "sensitivity block," which can be utilized for sensitivity analysis. The case studies or sensitivity analyses involve running multiple simulations by varying one or more parameters at a time. This type of analysis is restrictive in that it does no take into consideration the simultaneous interactions among many of the uncertain model parameters. Furthermore, such analysis provides no explicit insight into the likelihood of obtaining any particular outcome. This, a key limitation of the ASPEN simulator has been the ability to systematically analyze uncertainties in process technologies.

To address these shortcomings, a general stochastic simulation framework was developed for the ASPEN simulator by Carnegie Mellon under Task 1 of this research effort. The new stochastic modeling capability is documented in the Task 1 Topical Report prepared by Rubin and Diwekar (1989). The stochastic modeling capability can be used to evaluate uncertainties in the performance or cost of any chemical process plant which can be modeled using the ASPEN simulator. This capability will be disussed in more detail in later sections of this report.

\subsection{Task 2: Engineering Cost Models of Selected IGCC Systems}

Performance models for several IGCC systems have been developed by DOE/METC using the ASPEN simulator. A limitation of the existing IGCC process models has been a lack of directly coupled cost models, which prevented the simultaneous evaluation of process performance and economics in a single computer simulation. To evaluate the process economics of selected IGCC systems, new cost models, which estimate capital, annual, and levelized costs, have been developed. These cost models are documented in the Task 2 Topical Report prepared by Frey and Rubin (1990). The cost models have been directly coupled to the corresponding DOE/METC performance models. Two of these cost models are used in the exemplary case studies in this report, and are discussed in more detail in later sections.

\subsubsection{Task 3: Scope of This Report}

A research planning method is developed and applied to analyze res 2 arch strategies for advanced coal-fueled power plant technologies. The generalizable features of the methodology are discussed in Chapter 2. The procedure given in Chapter 2 is intended to serve as a guide for application of the probabilistic evaluation method. 
An advanced IGCC technology was selected to demonstrate application of the research planning method. Chapter 3 describes the selection and modeling of this system. In addition, a second IGCC technology, comprised of more conventional subsystems, was selected as a base ine for comparison with the advanced system.

Technical judgments about uncertainties in performance, cost, and economic parameters in the engineering and economic models are required as part of the quantitative approach to RD\&D planning. The basis for the uncertainties assigned to model parameters for the advanced system investigated in this work are documented in Chapter 4. Many of the uncertainties are characterized based on expert technical judgments elicited from process engineers.

In Chapter 5, the models discussed in Chapters 3 are applied using the judgments about uncertainty described in Chapter 4 and the methodology for uncertainty and decision analysis discussed in Chapter 2. A variety of case studies are given in Chapter 5 which illustrate ways in which probabilistic analysis can provide insights not readily obtained from traditional deterministic or sensitivity analysis.

Several implications of the probabilistic modeling approach and the case study results are discussed in Chapter 6. Conclusions regarding both the genera'izable features of the methodology employed here and the specific results of the case studies for each technology are given in Chapier 7.

A considerable effort was devoted to the elicitation of judgments about uncertainties from technical experts. In particular, a series of detailed uncertainty briefing packets for specific IGCC process areas were developed and distributed to selected process engineers. The complete documentation of these aspects of the research was not appropriate for the main body of the dissertation. For the interested reader, however, the briefing materials are included in Appendix A. These materials include considerable engineering detail on the key process areas for the advanced IGCC system. Also included in Appendix A are the expert responses to the briefing packets.

Several modifications to the IGCC performance models used in the case studies are described in Appendix B. Sample deterministic outputs from the cas study analyses are given in Appendix $\mathrm{C}$. 


\subsection{PROCEDURE}

In Section 1.3, objectives for a research planning method are discussed. In this Chapter, a method which satisfies these objectives is presented. The method is shown schematically as a flow diagram in Figure 4. The step-by-step procedure for applying the method is given in Table 1. The purpose of the method is to provide a more robust and useful tool than traditional approaches for evaluation of advanced process technologies. The method also provides a quantitative means for research planning. Each of the major features of the method are discussed in the following sections. These include: (1) selection of candidate technologies for detailed evaluation; (2) development of appropriate engineering models of the selected technologies; (3) elicitation of expert technical judgments about uncertainties; (4) a modeling environment for performing probabilistic analysis; and (5) applications of the probabilistic models to address concerns in research planning. These applications include: characterizing uncertainty in key measures of plant performance, emissions, and cost; identifying robust design trade-off decisions in the face of uncertainty; identifying the key uncertainties in model input parameters that drive uncertairty in model output variabies for the purpose of research prioritization; and comparison of alternative technologies when faced with uncertainty.

Technologies which continue to look promising after the detailed evaluation are then considered for further research. Probabilistic analysis of a technology provides a quantitative basis for focusing research expenditures on the specific aspects of the process which most significantly contribute to the risk of technology failure. The probabilistic analysis also provides a basis for bounding the expenditures that should be committed to further research, by providing a quantitative measure of the expected pay-off from further research.

\subsection{Identification of Case Studies}

Prior to performing an analysis, one must decide on criteria by which alternatives are to be judged and select a set of alternatives that are to be evaluated.

\subsubsection{Identifying Decision Criteria}

In the context of government-sponsored research, there are public policy concerns such as emissions, consumption of key natural resources, and cost which motivate the selection of decision criteria for evaluating and selecting advanced process technologies. In the context uf corporate-sponsored research, concerns may be similar, but approached 


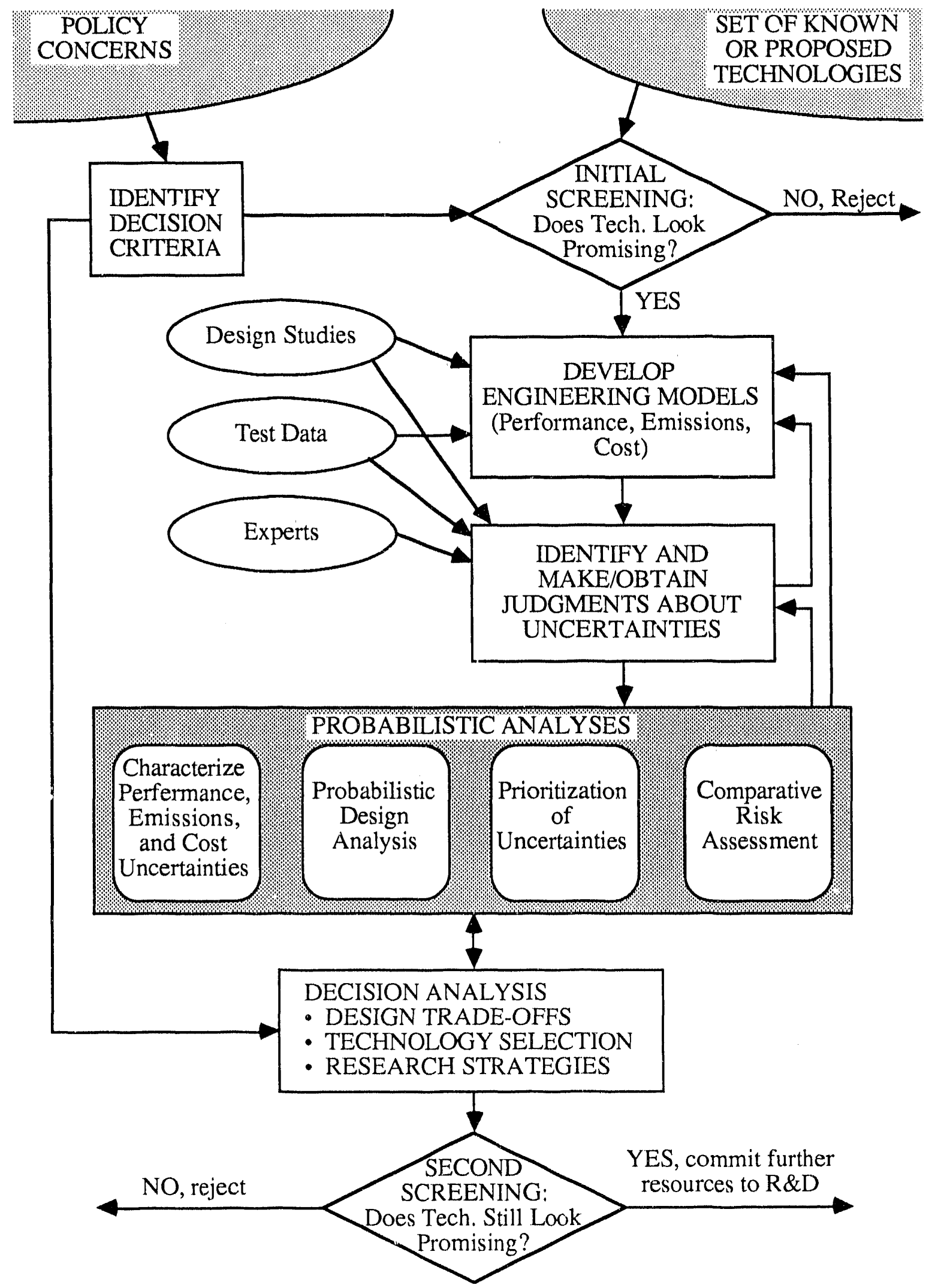

Figure 4. Method for Evaluation of Advanced Process Technologies 
1. Identify decision criteria based on policy or technical considerations.

2. Identify a preliminary set of potential candidate technologies.

3. Based on the decision criteria, select a subset of the candidate technologies for detailed evaluation.

4. Develop engineering performance and cost models for each candidate technology.

5. Identify specific parameters in the performance and cost models which are uncertain. Types of parameters that are uncertain may include:

- Performance (e.g., chemical reaction conversion rates)

- Capital Cost (e.g., process area direct capital cost estimates)

- Maintenance Cost (e.g., maintenance cost factors)

- Variable Operating Cost (e.g., unit costs of consumables)

- Financial (e.g., assumptions used to calculate fixed charge factor)

- Other (e.g., error terms for regression models).

The sources of uncertainty for each parameter may include:

- Statistical error

- Systematic error

- Variability

- Lack of empirical basis

6. Identify sources of information for each parameter for the purpose of characterizing uncertainties, such as:

- Data

- Literature (e.g., design studies)

- Technical Experts

7. Choose an appropriate technique for characterizing uncertainty in specific parameters, such as:

- Statistical analysis

- Elicitation of expert judgment

8. Implement engineering models in a probabilistic modeling environment, and code statistical analysis or expert judgments regarding uncertainties as probability distributions in model input parameters.

9. Select a sample size (number of repetitions) to use in the probabilistic analysis.

10. Analyze results:

- Statistical techniques (e.g., partial correlation coefficients)

- Plot cumulative distribution functions (cdfs) for key output variables

- Probabilistic sensitivity analysis

- Probabilistic screening analysis

11. Apply approach for:

- Characterization of uncertainties in key measures of plant performance, emissions, and cost.

- Probabilistic design analysis (comparison of alternative desigun under uncertainty)

- Prioritization of input uncertainties for further research

- Comparative risk assessment 
from a different perspective. For example, cost-related concerns may be more important, and environmental concerns only considered to the extent that they are imposed by existing environmental standards. In contrast, publicly-sponsored research may be more concerned with identifying long-term technology options capable of achieving substantial improvements or reductions in areas such as resource consumption and emissions.

From the electric utility perspective, decisions regarding the adoption of a new electric power generating technology for commercial use are made on the basis of a number of attributes, such as familiarity with the process, previous experience with similar systems, perceptions about the risk that the new system will have either poor performance or high cost compared to conventional technology, and ability of the new technology to comply with environmental regulations.

Analysis of case studies in this work will focus on consideration of objective measures of plant performance, cost, and environmental discharges. Other considerations can easily be included in a decision analysis framework, if desired. Various measures of the attractiveness of a new technology can be combined into a single multi-variate "utility" function which weights various attributes according to the preferences of a decision-maker. Decision analysis techniques are discussed further in Section 2.5.

Engineering models can be exercised to estimate key rileasures of plant performance and cost. These include material requirements, plant efficiency, emissions, total capital cost, annual operating costs, and the levelized cost of electricity. Examples of parameters that could be compared across electric power generation process flowsheets are:

- Plant thermal efficiency (percent of input chemical heating value converted to electricity delievered at plant fenceline)

- Normalized emission rates (e.g., $\mathrm{lb} \mathrm{SO}_{2} / \mathrm{MMBtu}, \mathrm{lb} \mathrm{CO}_{2} / \mathrm{kWh}$ )

- Normalized consumption rates (e.g., raw water or coal flow per $\mathrm{kWh}$ )

- Normalized waste flows (e.g., lb ash/kWh)

- Capital Cost $(\$ / \mathrm{kW})$

- Fixed Operating Cost $(\$ / \mathrm{kW}-\mathrm{yr})$

- Incremental Variable Operating Cost (mills/kWh)

- Byproduct Credit (mills/kWh)

- Fuel Cost (mills/kWh)

- Cost of Electricity (mills/kWh)

- Construction Time (years)

- Modularity (increments of capacity that can be added at a time, MW)

A technology would be favored if it had higher efficiency, reduced material consumption, reduced emissions and waste discharges, reduced cost, reduced construction time, and 
increased modularity compared to conventional technology. A technology would be rejected if it could not comply with environmental standards, regardless of the other attributes.

The cost of electricity (COE) usually provides the single most important measure of process feasibility, if all other minimum requirements are met. Because the cost of electricity is based on levelized capital and annual costs normalized to the plant energy output, the effects of plant efficiency, costs of consumables, and partial costs of some environmental discharges (e.g., ash disposal, pollution control) are already included. Other costs, such as externalities arising from air emissions, are not included. However, the new Clean Air Act will result in an equivalent price for $\mathrm{SO}_{2}$ emissions which can be included in a decision analysis.

In a decision analysis framework, a research planner would seek to select alternative research strategies which maximize a policy-based utility function. The utility function can consider multiple attributes and timing of outcomes. For example, the cost of electricity would be one attribute by which technologies could be selected. As previously discussed, this attribute takes into account a variety of interactions among performance and cost in the power plant, including plant efficiency. However, the environmental insult from the technology may need to be considered apart from the cost of electricity. Thus, a multi-attribute utility function might include cost of electricity, and emissions of pollutants such as $\mathrm{SO}_{2}, \mathrm{NO}_{\mathrm{x}}$, and $\mathrm{CO}_{2}$ as attributes.

\subsubsection{Selection of Alternatives}

When evaluating advanced clean coal technololgy, the objective is to identify the most promising candidates which hold promise of reduced emissions, improved plant efficiency, and reduced costs compared to conventional technology. Initially, there may be a large set of potential candidate technologies that could be selected for more detailed evaluation. An initial screening of such technologies may Lie required to identify a manageable subset for further study'. The screening would be based on the decision criteria identified based on policy or other concerns.

The selection of process flowsheets for analysis should be based on expectations regarding system configurations that are likely to adopted into commercial use, if key uncertainties can be resolved with positive outcomes during research and development. Usually, candidates for RD\&D are identified based on early estimates which indicate 
promising performance and cost. More detailed modeling and evaluation should then be completed to help focus and bound expenditures for further research.

\subsection{Performance and Cost Modeling}

A key step in evaluating a process technology is the development of an appropriately detailed engineering model. The scope of a complete engineering model includes mass and energy balances for major process areas (plus additional technical cietail as warranted), characterization of emissions of key pollutants, and characterization of capital, annual, and levelized plant costs. The selection of chemical species to include in the model for analysis of environmental discharges is motivated by the same set of policy concerns that influences decision criteria. For example, if acid rain is of concern, decision criteria will include $\mathrm{SO}_{2}$ and $\mathrm{NO}_{\mathrm{x}}$ emissions, which must then also be included in the engineering models.

\subsubsection{Purpose of Modeling}

The purpose of engineering models of advanced technologies that are in early stages of research is to reasonably and completely characterize the existing state of knowledge about the new technology. A second objective is to try to predict the performance and cost of a commercialized system based on the existing knowledge. However, existing knowledge about an advanced concept is often incomplete. The model can then be used to identify the key weaknesses in understanding that require further investigation, if uncertainties in knowledge can be explicitly represented in the model.

An engineering model should be sensitive to key parameters that are known to affect either performance or cost. An engineering model should be sufficiently detailed to capture: (1) performance interactions among process areas, include feedbacks or recycle streams; and (2) interactions between specific performance and design parameters and cost. However, while it may often be possible to build complex models involving hundreds of variables, usually only a handful of variables are found to be important determinants of performance and cost. Thus, there is usually a decreasing return in investment for building larger and more complex models than are needed.

The modeling philosophy used here is to build models of sufficient complexity to capture all expected important interactions or all known sources of uncertainty, but to keep the models within a manageable size to facilitate running the models and interpreting results. Thus, the models are developed to characterize generic features of the process technologies. They are not intended to include all of the detail that would be needed for 
equipment sizing for every piece of equipment in the plant or for estimating the costs of a site-specific construction project.

\subsubsection{Modeling Performance}

A number of fundamental constraints on process performance exist which can form the basis for modeling any process technology in the earliest phases of research. Because many aspects of the technology may be poorly understood initially, the most robust approach to developing performance models is to begin with relatively simple mass and energy balances. In a simple model, key performance areas which are poorly understood or which require additional empirical data can often be parameterized. For example, conversion rates of chemical reactions may be specified as model inputs rather than calculated based on reaction kinetics, which may be poorly understood. In this manner, it is possible to include structural features in the model that represent important process interactions, even when faced with limited information. Furthermore, it is possible to represent uncertainty in those features as uncertainties in specific model parametr s. Thus, if the chemistry of a particular reaction is poorly understood, the reaction conversion rate may be treated as uncertain.

In addition to estimating major performance measures, such as the consumption of key reagents or plant efficiency, a performance model should be sufficiently detailed to track the key environmental species of concern. This may require mass balances for dozens of chemical species, depending on the system being modeled.

As more information is obtained from early research, the models can be refined to include additional information regarding reaction kinetics or other details as appropriate. Additional constraints on the mass and energy balances, or new features of the technology, may be added at varying stages of technology development based on theoretical expectations, experience with analogous systems, or preliminary experimental results with small-scale versions of the advanced system. Also, as the quality of information about the technology improves, the values assumed for performance and cost parameters in the model can also be refined. Thus, model development should be considered as an iterative process.

\subsubsection{Modeling Cost}

There are a variety of approaches to developing cost estimates for process plants. These approaches differ in the level of detail with which costs are disaggregated into separate line items, as well as in the simplicity or complexity of analytic relationships used 
to estimate line item costs. The level of detail appropriate for the cost estimate depends on: (1) the state of technology development for the process of interest; and (2) the intended use of the cost estimates. The models developed for research planning are often intended to estimate the costs of advanced coal-to-electricity systems for the purpose of evaluating the comparative economics of alternative process configurations. The models are intended to be used only for preliminary or "study grade" estimates using representative (generic) plant designs and parameters.

In the electric utility and chemical process industries, there are generally accepted guidelines regarding the approach to developing cost estimates. EPRI (1986) has defined four types of cost estimates: simplified, preliminary, detailed, and finalized. For research planning purposes, "preliminary" cost estimates are often used. The differences between different types of cost estimates are briefly described below.

A simplified cost estimate is based on information about major stream flow rates and design parameters from a simple process flow diagram. The cost information used in a simplified estimate typically includes published cost curves on scaling relationships for generic process areas or for the plant as a whole. A simplified cost estimate may also be based on adjusting costs from similar published or in-house work on the basis of a single performance parameter. A simplified estimate is thus sensitive to only one (or a few) major performance parameter(s), such as the coal feed rate or the plant electrical output.

A preliminary cost estimate is based on a more disaggregated consideration of the costs of specific process areas and specific equipment items. A preliminary estimate also includes the use of ratio or scaling relationships to adjust costs for a variety of operating conditions. The preliminary estimate is sensitive to a larger number of performance parameters (perhaps a few dozen) than the simplified estimate.

Detailed and finalized cost estimates are generally developed only for site-specific projects that are intended for construction. For a large process plant, these types of estimates may cost millions of dollars to prepare. They are based on vendor quotations for specific equipment costs in response to specifications developed by an architect/engineering firm.

For the purposes of evaluating alternative technologies, and for research planning, preliminary cost estimates are the most appropriate. Preliminary cost estimates are sensitive to the performance ard design parameters that are most influential in affecting costs. 
A major constraint on cost model development is the availability of data from which to develop cost versus performance relationships for specific process areas or for major equipment items. Data from published studies can be used to develop cost models for specific process areas using regression analysis. Regression analysis has been used extensively for cost model development as part of Task 2 of this project (Frey and Rubin, 1990) and elsewhere. An overview of the key concepts of regression analysis, and the philosophy assumed here for applying regression techniques, is given briefly in the next section. Alternatively, cost models for process areas consisting of only one major equipment item can be based on published equipment cost curves, either in place of or as a supplement to regression analysis.

\subsubsection{Role of Regression Analysis in Model Development}

Regression analysis is used to help understand the interrelationships among a given set of variables. The use of regression analysis in cost model development is oriented toward developing useful and reasonable relationships primarily between process area costs and key performance parameters. It is also used to develop useful relationships between performance variables. The emphasis here is not on the use of extensive formal statistical tests but rather on the practical application of regression analysis for model development. Thus, some statistical tests, along with engineering judgments and the availability of data, are used to guide the selection of parameters, the representation of relationships in the regression models, and validation of the models. The "goodness" of the regression models are indicated with common summary statistics, graphical comparison of the model predictions with the actual data, and evaluation of the appropriateness of the model relationships with a priori engineering expectations.

The approach used in the development of regression models in the earlier modeling efforts of this project is described in detail in the Task 2 Topical Report (Frey and Rubin, 1990). The issues related to developing the regression models include developing a data set for analysis, selecting parameters for inclusion in the model, and validating the model. One measure of how well a regression model fits the data upon which it is based is the standard error of the model. The standard error is one type of uncertainty that can be explicitly considered as part of probabilistic modeling of the clean coal technologies. It represents the variability in cost (or other quantity predicted by the model) that is not explained by the regression model. 


\subsection{Characterizing Uncertainties}

As discussed in Section 1.1.3, analyses of technologies that are still in the research phase involve uncertainties, which are often ignored or treated in a limited way using sensitivity analysis. However, sensitivity analysis suffers from shortcomings resulting from the difficulty in evaluating the effect of simultaneous variations in several parameters and the lack of insight into the likelihood of obtaining any particular result.

A more robust approach is to represent uncertainties in model parameters using probability distributions. Using probabilistic simulation techniques, simultaneous uncertainties in any number of model input parameters can be propagated through a model to determine their combined effect on model outputs. The result of a probabilistic simulation includes both the possible range of values for model output parameters and information about the likelihood of obtaining various results. This provides insights into the risks or potential pay-offs of a new technology. Statistical analysis on the input and output data can be used to identify trends (e.g., key input uncertainties affecting output uncertainties), without need to re-run the analysis. Thus, probabilistic analysis can be used as a research planning tool to identify the uncertainties in a process that matter the most, thereby focusing research efforts where they are most needed. Probabilistic analysis may be referred to elsewhere as "range estimating" or "risk assessment."

There are three general areas of uncertainty that should be explicitly reflected in engineering models. These are uncertainties in: (1) process performance parameters (e.g., flowrates), (2) process area capital costs, and (3) process operating costs. For example, in calculating the cost of a gasifier, there may be uncertainty (because of the lack of commercial experience, with the design) in the coal flow rate required to achieve a given electrical output. This leads to uncertainty in the size (hence, cost) of the gasifier for a particular system. However, for a given gasifier size and type, there is also a probability that the equipment cost could be higher or lower than the nominal estimate (e.g., due to expected improvements in equipment design and cost, or to potential problems with fouling and corrosion, requiring more expensive materials, design modifications, or additional maintenance). The same type of uncertainties may apply to operating and maintenance cost factors. The uncertainties associated with adyanced systems or subsystems will typically be much larger than for conventional technology. A probabilistic engineering modeling framework is required to evaluate the overall uncertainty in process cost as a result of performance and cost uncertainties in specific process areas to determine the overall technical and cost risks and to identify research priorities. 
The development of ranges and probability distributions for model input parameters can be based on information available in published studies, statistical data analysis and/or the judgments of process engineers with relevant expertise. The approaches to developing probability distributions for model parameters are similar in may ways to the approach one might take to pick a single "best guess" number for deterministic (point-estimate) analysis or to select a range of values to use in sensitivity analysis. However, the development of estimates of uncertain usually requires more detailed thinking about possible outcomes and their relative likelihoods.

\subsubsection{Philosophy of Uncertainty Analysis}

The "classical" approach in probability theory requires that estimates for probability distributions must be based on empirical data. However, in many practical cases, the available data may not be relevant to the problem at hand. For example, test results from a process development unit (PDU) under a given set of conditions may not be directly applicable to estimating the performance of a fifth-of-a-kind commercial scale plant under a different set of operating conditions. Thus, statistical manipulation of data may be an insufficient basis for estimating uncertainty in a real system of interest. Engineering analysis or judgments about the data may be required.

An alternative approach differs in how probability distributions are interpreted. In the so-called "Bayesian" view, the assessment of the probability of an outcome is based on a "degree of belief" that the outcome will occur, based on all of the relevant information an analyst currently has about the system. Thus, the probability distribution may be based on empirical data and/or other considerations, such as technically-informed judgments or predictions. People with different information may estimate different distributions for the same variable (Morgan and Henrion, 1990). The assessment of uncertainties requires one to think about all possible outcomes and their likelihoods, not just the "most likely" outcome. This is an advantage for the analyst, because by thinking systematically and critically about uncertainties, one is more likely to anticipate otherwise overlooked problems, or to identify otherwise overlooked potential pay-offs of a system.

\subsubsection{Types of Uncertain Quantities}

There are a number of types of uncertainty that one might consider when developing a probability distribution for a variable. Some of these are summarized briefly here. 
Statistical error is associated with imperfections in measurement techniques. Statistical analysis of test data is thus one method for developing a representation of uncertainty in a variable.

Empirical measurements also involve systematic error. The mean value of a quantity may not converge to the "true" mean value because of biases in measurement and procedures. Such biases may arise from imprecise calibration, faulty reading of meters, and inaccuracies in the assumptions used to infer the actual quantity of interest from the observed readings of other quantities. Estimating the possible magnitude of systematic error may involve an element of engineering judgment. For example, data on sorbent attrition in a PDU may be used to estimate the sorbent attrition in a fifth-of-a-kind commercial-scale system. The conditions in the PDU differ from that in the commercial scale unit; therefore, there may be a systematic error involved in using the PDU data for design purposes.

Variability can be represented as a probability distribution. Some quantities are variable over time. For example, the composition of a coal (or perhaps a sorbent) may vary over time.

Uncertainty may also arise due to lack of actual experience with a process. This type of uncertainty often cannot be treated statistically, because it requires predictions about something that has yet to be built or tested. This type of uncertainty can be represented using technical estimates about the range and likelihood of possible outcomes. These judgments may be based on a theoretical foundation or experience with analogous systems.

\subsubsection{Encoding Uncertainties as Probability Distributions}

As indicated in the previous sections, there are two fundamental approaches for encoding uncertainty in terms of probability distributions. These include statistical estimation techniques and engineering judgments. A combination of both methods may be appropriate in many practical situations. For example, a statistical analysis of measured test data may be a starting point for thinking about uncertainties in a hypothetical commercial scale system. One must then consider the effect that systematic errors, variability, or uncertainties about scaling-up the process might have on interpreting test results for commercial scale design applications.

\section{Statistical Techniques}

Statistical estimation techniques involve estimating probability distributions from available data. The fit of data to a particular probability distribution function can be 
evaluated using various statistical tests. For example, the cumulative probability distribution of a set of data may be plotted on "probability" paper. If the data plot as a straight line, then the distribution is normal. Procedures for fitting probability distribution functions are discussed in many standard texts on probability and are not reviewed here. Rather, the focus of this discussion is on the situations where statistical analysis alone may be insufficient, because engineering insights may be required to interpret whatever limited data are available.

\section{Judgments about Uncertainties}

In making judgments about a probability distribution for a quantity, there are a number of approaches (heuristics) that people use which psychologists have observed. Some of these can lead to biases in the probability estimate. Three of the most common are briefly summarized. 1

1) Availability. The probability that experts assign to a particular possible outcome may be linked to the ease (availability) with which they can recall past instances of the outcome. For example, if tests have yielded high sorbent durability, it may be easier to imagine obtaining a high sorbent durability in the future than obtaining lower durabilities. Thus, one tends to expect experts to be biased toward outcomes they have recently observed or can easily imagine, as opposed to other possible outcomes that have not been observed in tests.

2) Representativeness has also been termed the "law of small numbers." People may tend to assume that the behavior they observe in a small set of data must be representative of the behavior of the system, which may not be completely characterized until substantially more data are collected. Thus, one should be cautious in inferring patterns from data with a small number of samples.

3) Anchoring and adjustment involves using a natural starting point as the basis for making adjustments. For example, an expert might choose to start with a "best guess" value, which represents perhaps a median or most likely (modal) value, and then make adjustments to the best guess to achieve "worst" and "best" outcomes as bounds. The "worst" and "best" outcomes may be intended to represent a 90 percent probability range for the variable. However, the adjustment from the central "best guess" value to the extreme values is often insufficient, with the result that the probability distribution is too

\footnotetext{
1 The discussion here is based on Morgan and Henrion, Uncertainty: A Guide to Dealing wilh Uncertainty in Quantitative Risk and Policy Analysis, Cambridge University Press, 1990.
} 
tight and biased toward the central value. This phenomena is overconfidence, because the expert's judgment reflects less uncertainty in the variable than it should. The "anchor" can be any value, not just a central value. For example, if an expert begins with a "worst" case value, the entire distribution may be biased toward that value.

Judgments also may be biased for other reasons. One common concern is motivational bias. This bias may occur for reasons such as: a) a person may want to influence a decision to go a certain way; b) the person may perceive that they will be evaluated based on the outcome and might tend to be conservative in their estimates; $c$ ) the person may want to suppress uncertainty that they actually believe is present in order to appear knowledgeable or authoritative; and d) the expert has taken a strong stand in the past and does not want to appear to contradict himselves by producing a distribution that lends credence to alternative views.

\section{Designing an Elicitation Protocol}

From studies of how well calibrated judgments about uncertainty are, it appears that the most frequent problem encountered is overconfidence (Morgan and Henrion, 1990). Knowledge about how most people make judgments about probability distributions can be used to design a procedure for eliciting these judgments. The appropriate procedure depends on the background of the expert and the quantity for which the judgment is being elicited. For example, if an expert has some prior knowledge about the shape of the distribution for the quantity, then it may be appropriate to ask him/her to think about extreme values of the distribution and then to draw the distribution. On the other hand, if a technical expert has little statistical background, it may be more appropriate to ask him/her a series of questions. For example, the expert might be asked the probability of obtaining a value less than or equal to some value $x$, and then the question would repeated for a few other values of $x$. The judgment can then be graphed by an elicitor, who would review the results of the elicitation with the expert to see if he/she is comfortable with the answers.

To overcome the typical problem of overconfidence, it is usual to begin by thinking about extreme high or low values before asking about central values of the distribution. In general, experts' judgments about uncertainties tend to improve when: (1) the expert is forced to consider how things could turn out differently than expected (e.g., high and low extremes); and (2) the expert is asked to list reasons for obtaining various outcomes.

While the development of expert judgments may be flawed in some respects, it does permit a more robust analysis of uncertainties in a process when limited data are available. Furthermore, in many ways, the assessment of probability distributions is qualitatively no 
different than selecting single "best guess" values for use in a deterministic estimate. For example, a "best guess" value often represents a judgment about the single most likely value that one expects to obtain. The "best guess" value may be selected after considering several possible values. The types of heuristics and biases discussed above may play a similar role in selecting the value. Thus, even when only a single "best guess" number is used in an analysis, a seasoned engineer usually has at least a "sense" for "how good that number really is." This may be why engineers are often able to make judgments about uncertainties easily, because they implicitly make these types of judgments routinely.

\subsubsection{Some Types of Probability Distributions}

Examples of several types of probability distributions are shown in Figure 5 as both probability density functions (pdf's) and cumulative distribution functions (cdf's). The pdf is a graphical means of representing the relative likelihood or frequency with which values of a variable may be obtained. The pdf also clearly illustrates whether a probability distribution is symmetric or skewed. In a symmetric unimodal distribution, the mean (average), median (50th percentile), and mode (peak) coincide. In a positively skewed distribution (e.g., lognormal), the mean is greater than the median, and both are greater than the mode.

An alternative way to represent a probability distribution is the cdf. The cdf shows probability fractiles on the $y$-axis and the value of the distribution associated with each fractile on the $x$-axis. The cdf is a way to represent any probability distribution when there is information about various fractiles of the distribution (e.g., the values of the 5th, 50th and 95 th percentiles).

A brief description of several types of probability distributions and their applications is given here:

- Uniform: Uniform probability of obtaining a value between upper and lower limits. Useful when an expert is willing to specify a finite range of possible values, but is unable to decide which values in the range are more likely to occur than others. The use of the uniform distribution is also a signal that the details about uncertainty in the variable are not known. Useful for screening studies.

- Triangle: Similar to uniform except a mode is also specified. Use when an expert is willing to specify both a finite range of possible values and a "most likely" (mode) value. The triangle distribution may be symmetric or skewed (as in Figure 5). Like the uniform, this distribution indicates that additional details about uncertainty are not yet known. The triangle distribution is excellent for screening studies and easy to obtain judgments for. 

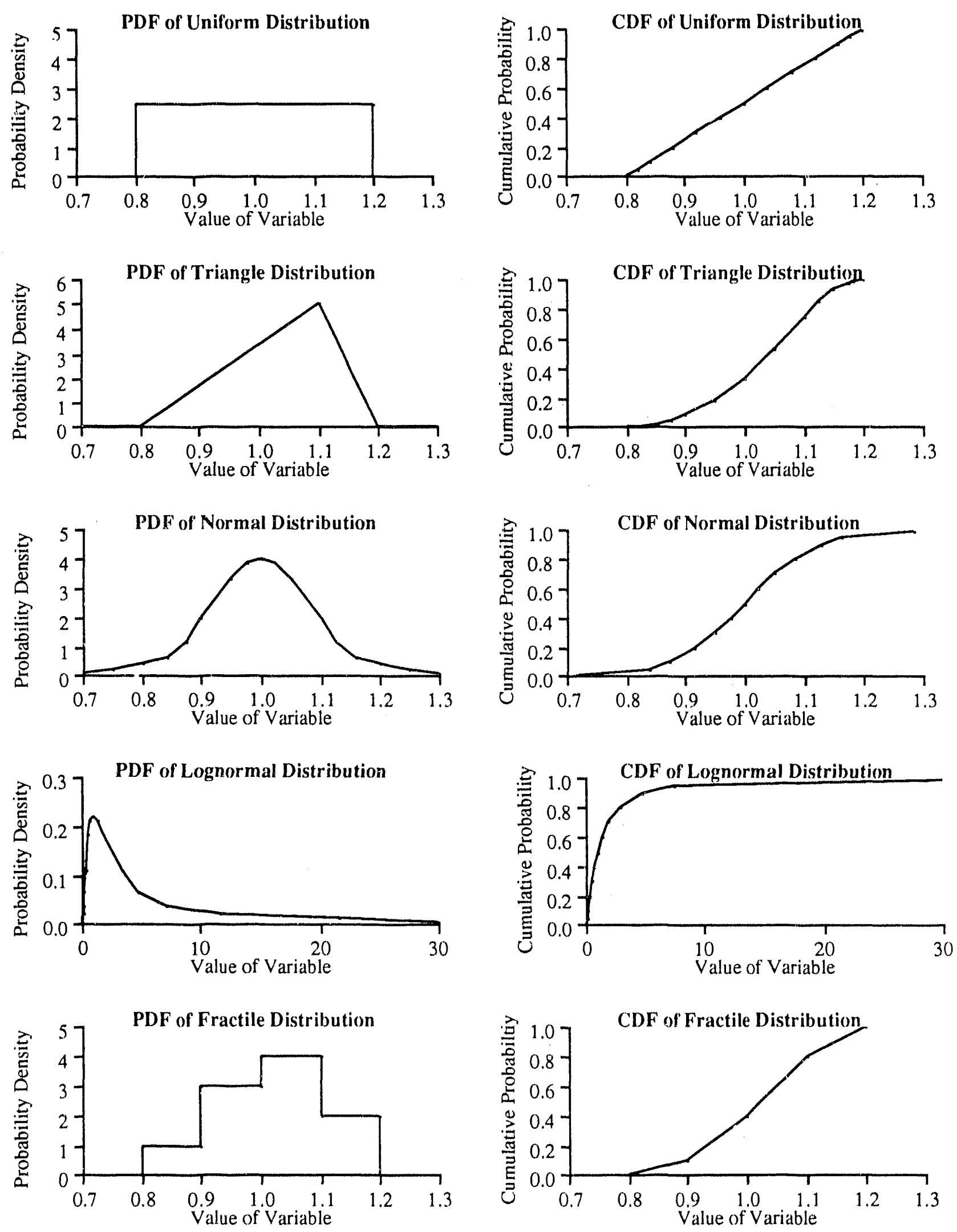

Figure 5. Some Types of Probability Distributions. 
- Normal: A symmetric distribution with mean, mode, and median at the same point. Often assumed in statistical analysis as the basis for unbiased measurement errors. The normal distribution has infinite tails; however, over 99 percent of all values of the normal distribution lie within plus or minus three standard deviations of the mean. Thus, when used to represent uncertainty in physical quantities which much be greater than zero, the standard deviation should not be more than about 20 or 30 percent of the mean, or else the distribution must be truncated.

- Lognormal: A positively skewed distribution (it has a long tail to the right). This distribution is usually used to represent uncertainty in physical quantities which must be non-negative and are positively skewed, such as the size of an oil spill or the concentration of a pollutant. This distribution may be used when uncertainties are expressed on a multiplicative order-of-magnitude basis (e.g., factor of 2) or when there is a probability of obtaining extreme large values.

- Loguniform: A uniform distribution in log space (each decade has equal probability, not shown in Figure 5).

- Fractile: The finite range of possible values is divided into subintervals. Within each subinterval, the values are sampled uniformly according to a specified frequency for each subinterval. This distribution looks like a histogram and can be used to represent any arbitrary data or judgment about uncertainties in a parameter, when the parameter is continuous. Explicitly shows detail of the judgments about uncertainties.

- Chance: This is like the fractile distribution, except that it applies to discrete, rather than continuous, variables. An example of a discrete variable is the number of trains of equipment, which must be an integer (e.g., $30 \%$ chance of one train, $70 \%$ chance of two).

\subsection{Probabilistic Modeling}

In order to analyze uncertainties in advanced process technologies, a probabilistic modeling environment is required. A typical approach is the use of Monte Carlo simulation, as described by Ang and Tang (1984) and others. In Monte Carlo simulation, a model is run repeatedly, using different values for each of the uncertain input parameters each time. The values of each of the uncertain input parameters are generated based on the probability distribution for the parameter. If there are two or more uncertain input parameters, one value from each is sampled simultaneously in each repetition in the simulation. Over the course of a simulation, perhaps $20,50,100$, or even more repetitions may be made. The result, then, is a set of sample values for each of the model output variables, which can be treated statistically as if they were an experimentally or empirical observed set of data.

Although the generation of sample values for model input parameters is probabilistic, the execution of the model for a given set of samples in a repetition is deterministic. The advantage of Monte Carlo methods, however, is that these deterministic 
simulations are repeated in a manner that yields important insights into the sensitivity of the model to variations in the input parameters, as well as into the likelihood of obtaining any particular outcome.

Monte Carlo methods also allow the modeler to use any type of probability distribution for which values can be generated on a computer, rather than to be restricted to forms which are analy tically tractable.

In random Monte Carlo simulation, a random number generator is used to generate uniformly distributed numbers between 0 and 1 for each uncertain variable. Note from Figure 5 that all cdf's have an ordinate axis ranging from zero to one. Thus, uniformly distributed random numbers are used to represent the fractile of the random variable for which a sample is to be generated. The sample values for the random variables are calculated using the inverse cdf functions based on the randomly generated frictiles.

Using Monte Carlo techniques, it is therefore possible to represent uncertainty in a model of a process technology by generating sample values for uncertain variables, and running the model repetitively. Instead of obtaining a single number for model outputs as in deterministic simulation, a set of samples is obtained. These can be represented as cdf's and summarized using typical statistics such as mean and variance.

An alternative to random Monte Carlo simulation is Latin Hypercube Sampling (LHS). In LHS methods, the fractiles that are used as inputs to the inverse cdf are not randomly generated. Instead, the probability distribution for the random variable of interest is first divided into ranges of equal probability, and one sample is taken from each equal probability range. However, the ranking (order) of the samples is random over the course of the simulation, and the pairing of samples between two or more random input variables is usually treated as independent. In median LHS, one sample is taken from the median of each equal-probability interval, while in random LHS one sample is taken from random within each interval (Morgan and Henrion, 1990).

LHS methods guarantee that values from the entire range of the distribution will be sampled proportional to the probability density of the distribution. Because the distributions are sampled over the entire range of probable values in LHS, the number of samples required to adequately represent a distribution is less for LHS than for random Monte Carlo sampling. LHS is the technique employed in this study. 


\subsubsection{Modeling Environments}

A newly developed probabilistic modeling environment is used in this study. The modeling environment features a modification to ASPEN, a chemical process simulator. ASPEN is described further in Chapter... As part of DOE-supported research at CarnegieMellon University, a probabilistic modeling capability has been added to the publicly available version of ASPEN, as documented in the Task 1 Topical Report (Rubin and Diwekar, 1989). An initial step in this effort was the identification of suitable software for sampling probability distributions and performing output analysis (Rubin and Frey, 1988). A Fortran program developed by Iman and Shortencarier (1984) using Latin hypercube sampling (LHS) was identified as the best publicly available program for assigning probability distributions to model parameters and generating samples from those distributions. A Fortran program developed by Iman, Shortencarier, and Johnson (1985) was identified for analysis of model output. This program uses partial correlation coefficients and standardized regression coefficients for measuring linear correlations and partial rank correlation coefficients and standardized rank regression coefficients for measuring nonlinear correlations.

The LHS sampling and output analysis programs have been implemented into ASPEN through a new unit operation block, which is documented in a new user's manual and technical reference manual (Diwekar and Rubin, 1989). The stochastic block assigns user-specified distributions to the key input parameters selected by the user, uses the LHS program to generate samples from the distributions, and passes the sampled values of each uncertain parameter to the flowsheet. After a flowsheet simulation is run, the output variables of interest are collected. The simulation is then repeated for a new set of samples selected from the probabilistic input distributions. A new Fortran block is used to control the cycling of the stochastic block, and another Fortran block is used to access and assign samples to model parameters. The probabilistic modeling capability in ASPEN has both Monte Carlo and random LHS options. There is also a capability to specify rank order correlations in input variables.

\subsubsection{Selecting Sample Size}

The sample size corresponds to the number of repetitions used in the probabilistic simulation. The selection of sample size is usually constrained at the upper end by the limitations of computer software, hardware, and time, and at the lower end by the acceptable confidence interval for model results. In cases where the analyst is most interested in the central tendency of distributions for output variables, the sample size can 
often be relatively small. However, in cases were the analyst is interested in low probability outcomes at the tails of output variable distributions, large sample sizes may be needed. As sample size is increased, computer runtime, memory use, and disk use may become excessive. Therefore, it may be important to use no more samples than are actually needed for a particular application.

One approach to selecting sample size is to decide on an acceptable confidence interval for whatever fractile level is of most concern in the investigation (Morgan and Henrion, 1990). For example, we may wish to obtain a given confidence that the value of the $\mathrm{p}^{\text {th }}$ fractile will be bounded by the $\mathrm{i}^{\text {th }}$ and $\mathrm{k}^{\text {th }}$ fractiles. In a Monte Carlo simulation, we can use the following relations to estimate the required sample size:

$$
\begin{aligned}
i & =m p-c \sqrt{m p(1-p)} \\
k & =m p+c \sqrt{m p(1-p)}
\end{aligned}
$$

The relations in Equations (1) and (2) yield a confidence interval for the $\mathrm{p}^{\text {th }}$ fractile if the sample size is known, where $c$ is the standard deviation of the standard normal distribution associated with the confidence level of interest. To calculate the number of samples required, the expressions above can be rearranged to calculate the confidence interval $\left(Y_{p-\Delta p}, Y_{p+\Delta p}\right)$ as follows:

$$
m=p(1-p)\left(\frac{c}{\Delta p}\right)^{2}
$$

For example, if we wish to be 90 percent confident that the value of the 90 th percentile will be enclosed by the values of the 85 th and 95 th fractiles, then $\mathrm{c}$ would be 1.65 and $m$ would be 98 .

However, another factor to consider in selecting sample size is whether a high degree of simulation accuracy is really needed. In screening studies based on a first-pass set of expert judgments, it may be unnecessary to obtain a high degree of confidence in specific fractiles of the output distribution, because initial estimates of uncertainty may be subject to considerable empirical uncertainty themselves.

In the work described here, computational limitations, particularly with respect to time, are significant factors in limiting sample size. For most studies, sample sizes of 100 or 150 have been found to be adequate to reasonably characterize the cumulative distribution functions for output variables. The relations in Equations (1) and (2) can be used to develop an explicit confidence interval for an entire CDF. In general, the 
magnitudes of the confidence intervals for the central fractiles of the distribution are "tighter" than for the tails. The confidence interval on the CDF is an indicator of how "good" the simulation is at estimating the "true" value of the CDF assuming that all model input assumptions are "true," but the true value of the CDF may remain uncertain based on limitations of the input assumptions.

The approach to selecting sample size described above is appropriate for use with the Monte Carlo simulation technique. In this work, LHS is employed as discussed previously. The approach to estimating the precision of modeling results based on confidence intervals will typically overestimate the required sample size needed with LHS.

\subsubsection{Analyzing Results}

Sample correlation coefficients are a simple but useful tool for identifying the linear correlations between uncertain variables. Other techniques are available as well in the newly implemented probabilistic capability for the ASPEN process simulator, as developed by Iman, Shortencarier, and Johnson (1985). These output analysis techniques are described here briefly.

A partial correlation coefficient (PCC) analysis is used to identify the degree to which correlations between output and input random variables may be linear, and it is estimated in conjunction with multi-variate linear regression analysis. In PCC analysis, the input variable most highly correlated the output variable of interest is assumed as the starting pointing for construction of a linear regression model. In the regession model, the output variable is treated as the dependent variable and the most highly correlated input variable is treated as a predictive variable. The partial correlation technique then searches for another input variable which is most highly correlated with the residuals of the regression model already containing the first input variable. The residual is the difference between the actual sample value of the dependent variable and the estimated sample values, using the linear regression model containing the first input variable. The process is repeated to add more variables in the analysis. The partial correlation coefficient is a measure of the unique linear relationship between the input and dependent variables that cannot be explained by variables already included in the regression model.

Standardized regression coefficients (SRC) can be used to measure the relative contribution of the uncertainty in the input variables on the uncertainty of the output variables. This analysis involves standardization of all the sample values for the model input variables and a multi-variate regression of an output variate based on the inputs. The 
regression coefficients for each input variate then indicate the relative importance of that variate as a factor determining the output. SRCs measure the shared contribution of the input to the output, because all of the simulation input uncertainties are included in the regression anlaysis simultaneously. The SRCs are the partial derivatives of the output variable with respect to each input variable. Because PCCs are a measure of the unique contribution of each parameter, and SRCs measure the shared contribution, they do not always lead to the same conclusions.

PCC and SRC analysis is limited to cases where the relationship between input and output variables is linear; however, by basing the regression analysis on the ranks of the samples for each variable, rather than on the values of the samples, the PCC and SRC techniques can be extended to non-linear cases. These techniques are known as partial rank correlation coefficients (PRCC) and standardized rank regression coefficients (SRRC) (Iman, Shortencarier, and Johnson, 1985).

While regression analysis of input and output sample vectors is an important tool for prioritizing input uncertainties that are most "sensitive," it is important to understand the limitations of partial correlation coefficients when using a given sample size. Edwards (1984) provides a clear discussion of tests of significance for correlation coefficients. When using partial correlation coefficients for output analysis, we are interested in testing the null hypothesis that the coefficient is equal to zero. For independent random variables, the $t$-test can be used and the value of $t$ is calculated as follows:

$$
t=\frac{r}{\sqrt{1-r^{2}}} \sqrt{m-n}
$$

The degrees of freedom $m-n$ is given by the number of samples $m$ and the number of input variables $n$ used in the regression analysis. The $t$ statistic calculated in Equation (4) can then be compared to values in a table of the t-distribution for a given significance level and degrees of freedom. If the statistic calculated above is greater than the value from the table, the null hypothesis is regarded as sufficiently improbable that it can be rejected. As an example, for 100 samples, 50 independent variables used in a regression analysis, and a significance level of 0.01 for a one-sided test, an obtained value for $r$ of greater than 0.322 or less than -0.322 would be grounds for rejection of the null hypothesis. Treatment of partial rank correlation coefficients is similar. 


\subsection{Making Decisions}

Data nbtained from probabilistic analysis of process technologies can be used to answer several questions, such as:

- Is one technology preferred over another?

- Is additional research merited?

- What should be the research strategy?

- How much is additional research worth?

- Under what conditions does the decision strategy change? (How robust is the decision strategy?)

These questions can be answered using decision analysis as an analytical tool for evaluating alternative technology options and research strategies. Decision anlaysis techniques are discussed in many texts (e.g., Clemen, 1988; Dawes, 1988; Watson and Buede, 1987). First, we will consider decisions based on a single attribute, such as expected cost savings, and then briefly consider a more detailed decision model incorporating the risk attitudes of a decision maker and the time value of research outcomes. The approach can be extended to consider other de c ision attributes.

There are two general types of decisions that are considered in technology evaluation. The first is a choice between an advanced process based on current knowledge of the process and a conventional technology. The second type of decision is that regarding specific options for further research and development of the advanced process. It is assumed here that additional research would not eliminate uncertainty in the advanced process. Instead, research is expected to reduce the range of uncertainties in one or more uncertain model input variables. This would affect the uncertainty in the performance or cost of the technology. Thus, additional research would change the probability distribution for the difference in cost between the advanced and conventional technologies.

As discussed previously, the levelized cost of electricity is perhaps the most important attribute that a decision maker would consider when comparing t:vo competing technologies. The technology with the highest probability of lower cost would usually be preferred by a decision maker. However, there may be a possibility that the advanced technology could result in higher costs, even though it may be likely to have lower costs. A decision-maker may be adverse to the possibility of a bad outcome. A sufficiently risk averse decision maker may prefer to stay with the conventional technology, rather than take a risk of higher cost from the new technology. 
The decision model can easily be refined to consider the risk attitude of a particular decision maker using expected utility, rather than expected cost savings, as the basis for decision making. Utility is a measure of the personal value a decision maker places on a specific outcome, and it may differ from the monetary value of the outcome (Dawes, 1988). Furthermore, because the results of research may not be obtained for 5 to 15 years, the time value of the outcomes can be modeled using discounting. One possible utility function for such a decision model is thus:

$$
u(x)=\left\{\frac{x(i, n)-x_{l}(i, n)}{x_{h}(i, n)-x_{l}(i, n)}\right\}^{b}
$$

where,

$$
x(i, n)=\frac{x}{(1+i)^{n}}
$$

and,

$$
\begin{aligned}
& \mathrm{x}=\text { discounted outcome of a given alternative } \\
& \mathrm{i}=\text { discount rate } \\
& \mathrm{n}=\text { time period (years) } \\
& \mathrm{x}_{1}=\text { lower limit of } \mathrm{x} \text { for all alternatives } \\
& \mathrm{x}_{\mathrm{h}}=\text { upper limit of } \mathrm{x} \text { for all alternatives } \\
& \mathrm{b}=\text { risk attitude exponent }
\end{aligned}
$$

For a risk neutral decision-maker, $b=1$. A risk averse decision maker prefers a sure outcome over an alternative with a slightly higher expected value and a risk of a loss. Thus, a risk averse decision maker tends to be "conservative." For a risk averse decision maker, $b<1$. Conversely, a risk seeking decision maker is willing to forfeit an increase in expected value to play a riskier game, and in this case $b>1$. The utility function is plotted for normalized values of $x$ and selected values of $b$ in Figure 6 . A nominal value of $b=0.6$ (risk averse) is considered a reasonable assumption in expected utility analysis.

When comparing two technologies, the timing of outcomes may be important. The conventional technology assumed as a baseline in a comparison may be available immediately. The advanced technology may be available in the near term, but with considerable uncertainty in performance and cost. Alternatively, additional research may be conducted on the new technology to reduce the uncertainties. However, the pay-offs from such research may take 5 to 20 years. Therefore, in making comparisons, the decisionmaker may choose between the conventional technology, the advanced technology based on current information, or the advanced technology based on reductions in uncertainty that would be obtained in 5 to 20 years. The decision maker may prefer an outcome today to the same outcome in 10 years. Thus, the time preference of the decision maker may be represented using discounting, as indicated in Equation (5). 


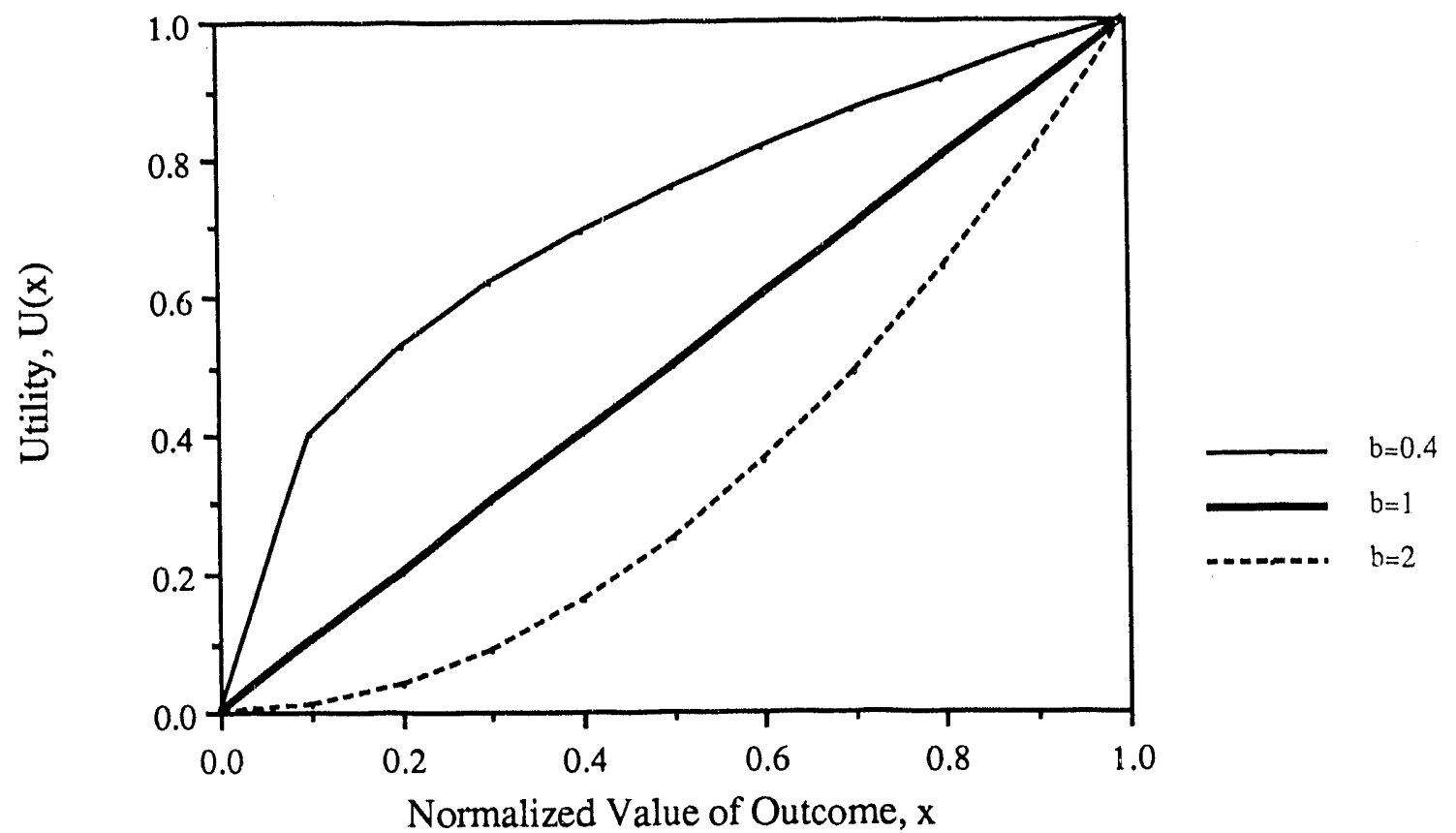

Figure 6. Power Utility Function

Decisions regarding technology selection and research planning may be sensitive not only to the comparisons of performance and cost between the two technologies, but also to the assumptions regarding risk attitude, timing of outcomes, and the discount rate.

In cases where more than one attribute is important to a decision maker, a multiattribute utility function can be used. For example, if differences in emission rates for key pollutants are criteria for selecting one .echnology over another, in addition to cost criteria, an additive utility function might be used which weighs each criteria according the decision maker's preference (e.g., Clemen, 1988). 
This page left blank intentionally. 


\subsection{ENGINEERING MODELS OF SELECTED CLEAN COAL TECHNOLOGIES}

This chapter provides a description of the coal-based power generation and integrated environmental control systems selected for case studies in this research. An advanced system was selected on the basis of promising costs, plant performance, and emission reductions. A baseline system, representative of conventional technology, was also selected for the purpose of comparative analysis. The engineering performance, emissions, and cost models of each system are also described.

\subsection{Selection of Candidate IGCC Systems for Evaluation}

This section discusses the basis for selecting candidate IGCC systems for detailed evaluation. Two IGCC systems were selected for case studies. One is representative of advanced technology that is of current research interest to DOE and others. The second is representative of more conventional technology. The focus of the case studies here is on the advanced system. The baseline system is used for comparative analysis with the advanced system, to indicate the potential pay-offs and risks of the advanced technology. While each system has unique features, they also have many process areas in common. The technical description of each system is provided in this section. In Section 3.2, the performance models for the IGCC technologies are described. In Section 3.3, the approach used to develop cost models for each technology is discussed. In addition, the interested reader will find complete documentation of the IGCC capital, annual, and levelized cost models in the Task 2 Topical Report (Frey and Rubin, 1990).

A number of variations of IGCC power plant designs exist, based primarily on differences in the coal gasifier technology. Both oxygen and steam are necessary reactants in the coal gasification process, which produces a syngas containing carbon monoxide and hydrogen. Alternate gasifier designs may use either oxygen or air as the oxidant. The primary difference in gasifier design is the type of reactor bed in which the coal is gasified. The three generic types of gasifiers are moving-bed, fluidized-bed, and entrained-flow. In a moving bed gasifier, coal flows downward counter-current with the steam and oxidant, and the highest temperatures are reached toward the bottom of the reactor. A prominent example of this type of gasifier is the Lurgi design. In a fluidized bed reactor, the coal is well-mixed with steam and oxidant, leading to a more uniform temperature distribution in the gasifier. The Kellogg-Rust-Westinghouse (KRW) gasifier is an example of a fluidized bed design. In an entrained flow gasifier, the coal is gasified in a plug flow reactor in 
which the coal and reactants move co-currently through the reactor. The Texaco gasifier is the most common entrained-flow design. The gasifier design affects the temperature of the fuel gas, composition of the fuel gas (e.g., methane content, presence of tars and oils), ability to handle certain coals (e.g., caking coals), ability to handle fines, and oxidant and sieam requirements, among other factors (Simbeck et al, 1983).

The Electric Power Research Institute (EPRI), a privately funded research consortium in the electric utility industry, has sponsored a number of performance and cost evaluations of IGCC technologies. These include technologies based on the Texaco, KRW, Shell, British Gas Corporation/Lurgi (BGC/L), and Dow gasifier technologies (e.g., Fluor, 1983a, 1983b; Fluor, 1984; Fluor, 1985; Parsons, 1985; Fluor Daniel, 1989). Most of the studies sponsored by EPRI have focused on the entrained-flow Texaco gasifier technology. This is partly because the Texaco gasifier has more operating experience on the demonstration plant level than other technologies such as Shell, KRW, and British Gas/Lurgi (Simbeck et al, 1983). EPRI, in cooperation with others, has cosponsored the Cool Water gasification program, the first IGCC demonstration plant, based on the Texaco technology. The Cool Water IGCC plant was in service for five years. Emissions of $\mathrm{SO}_{2}$ and $\mathrm{NO}_{\mathrm{x}}$ were well below both NSPS and the more stringent local emission permit limits for Cool Water (Cool Water, 1988).

An oxygen-blown (oxygen used as the oxidant) KRW-based system may offer some advantages over a comparable Texaco-based system, including reduced oxygen consumption, a lower temperature and pressure gasifier, a syngas with a higher heating value, and fewer parasitic loads (due largely to reduced oxygen consumption). Initial comparisons of Texaco and KRW based systems indicate that the heat rates (efficiency), capital costs, and levelized costs for these systems are nearly identical, even though a larger capital cost contingency factor was used for the KRW cost estimate (Fluor, 1985). A schematic of an oxygen-blown KRW-based IGCC system is shown in Figure 7.

Lurgi gasification technology is the oldest of the technologies most commonly considered for IGCC systems. The Lurgi ciry ash coal gasification process was developed in the 1930s in Germany, and over 150 gasifiers have been installed internationally since, most notably nearly 90 gasifiers in South Africa. Because the Lurgi gasifier is a movingbed design in which the coal flows countercurrently with the steam and oxidant, the temperature varies throughout the reactor. The exiting gas temperature is lower than for other gasifier designs, and the "cold gas efficiency" (percent of chemical energy in the coal contained in the syngas) is higher than for other gasifier designs (Simbeck et al, 1983). 


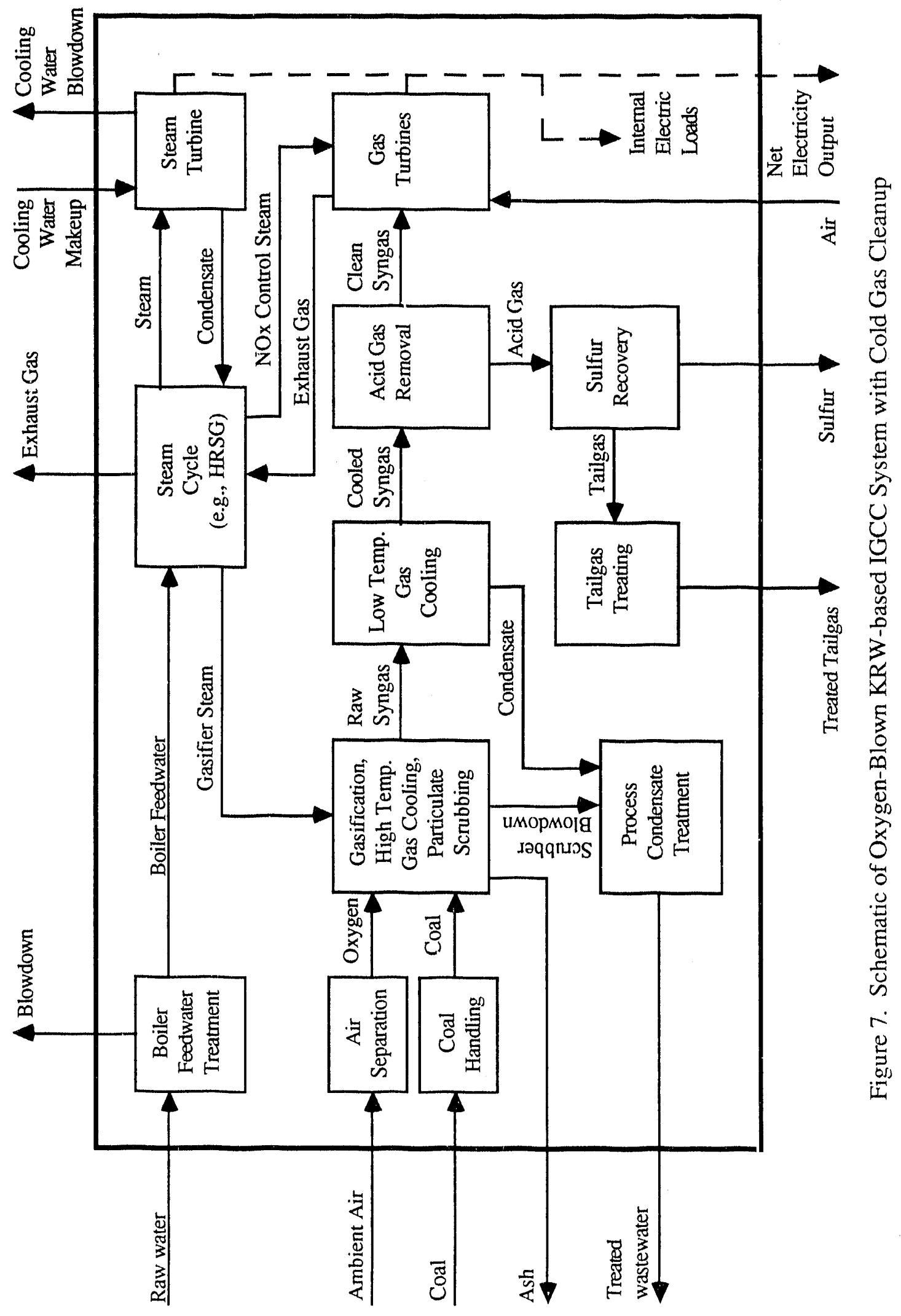


However, because of the dry ash removal design, large quantities of steam, compared to other gasifier designs, are required as a thermal diluent to prevent slagging. Also, the lower temperature syngas from Lurgi gasifiers typically contains oils and tars, which must be removed from the syngas in conventional IGCC designs to avoid deposition on downstream equipment. The removal of tars and oils reduces the heating value of the syngas, and requires additional scrubbing equipment, increasing capital costs (Parsons, 1985; Bechtel et al, 1988c). Alternatives to conventional gas cleanup systems may eliminate the requirement for syngas cooling in Lurgi-based systems, therefore preventing the condensation of tars and oils and eliminating the associated gas scrubbing equipment, resulting in significant cost savings (Corman, 1986).

The U.S. Department of Energy's Morgantown Energy Technology Center (DOE/METC) has sponsored, and continues to sponsor, a number of system analysis studies to identify potentially promising advanced IGCC process configurations and to provide performance and, in some cases, cost data for these. These include conceptual design studies of new and repowered Texaco-based IGCC plants (UTC, 1983), a phased Westinghouse (now KRW)-based plant (WEC, 1983), oxygen-blown Lurgi-based systems for power generation and synthetic natural gas production (Cincotta, 1984; Zahnstecher, 1984), simplified air-blown (air used as the oxidant) systems using Lurgi gasifiers and "hot" gas cleanup (Corman, 1986), and the performance and cost of "hot" gas cleanup and sulfur recovery systems (Klett et al., 1986; O'Hara, Chow, and Findley, 1987), as opposed to the lower temperature "cold" gas sulfur removal systems assumed in EPRI studies. A METC-sponsored study, prepared by Southern Company Services, of airblown KRW-based IGCC systems featuring "hot" gas cleanup will soon be published, as of Spring 1991.

Conventional IGCC designs, such as that of the Cool Water demonstration project, are based on "cold" gas cleanup, in which the fuel gas from the gasifier is cooled to a sufficiently low temperature (e.g., 100 of) that the Selexol or similar sulfur removal process can be used to separate $\mathrm{H}_{2} \mathrm{~S}$ from the fuel gas. A focus of research at the METC is the development of "hot" gas cleanup systems, in which sulfur compounds may be removed from the gasifier or the fuel gas at high temperature (e.g., 1,000 of). Hot gas cleanup eliminates the capital cost associated with heat exchangers needed to the cool the fuel gas and process condensate treatment systems needed to handle condensate resulting from fuel gas cooling. Hot gas cleanup also reduces the thermal efficiency penalty associated with gas cooling, allowing the sensible heat of the high temperature fuel gas to be supplied directly to the gas turbine. 
One of the most promising hot gas cleanup configurations is an air-blown Lurgi gasifier-based IGCC system. A schematic of this technology is shown in Figure 8 . The exit temperature of syngas from a Lurgi or similar gasifier provides a direct match with the temperature window of hot gas cleanup systems than other gasifiers, such as the KRW gasifier. Therefore, the requirement for syngas cooling is completely eliminated. Lurgibased IGCC systems with hot gas cleanup therefore offer the potential for simplified plant designs. General Electric, under contract to METC, has been involved in analysis, testing, and development of hot gas cleanup systems for simplified Lurgi-based IGCC plants. These efforts include conceptual cost and design studies (Cincotta, 1984; Corman, 1986), proof-of-concept system design studies (e.g., Smith, 1987), and construction of a proofof-concept system for a moving bed gasifier with hot gas cleanup (e.g., Cook, 1989).

The hot gas cleanup system system features sulfur removal from the fuel gas with a zinc ferrite sorbent, and high efficiency cyclones for particulate removal. In the fixed-bed zinc ferrite process, sulfur is removed from the syngas by reaction with a sorbent consisting of zinc ferrite pellets. Absorption occurs until just before "breakthrough", at which point the sorbent is saturated. The absorber is then taken off-line, and the syngas is diverted to another zinc ferrite reactor vessel containing regenerated sorbent. Sulfided sorbent is regenerated using air as a reactant and steam as a diluent, to prevent the heat released in the exothermic regeneration reactions from sintering the sorbent. The regeneration off-gas containing sulfur dioxide is then processed for byproduct sulfuric acid recovery.

The advantage of the simplified Lurgi-based IGCC system compared to a base case oxygen-blown system with cold gas cleanup is that: (1) it does not require an expensive and energy consuming oxygen plant, (2) it eliminates the capital costs associated with fuel gas cooling, and (3) it eliminates the energy penalties associated with fuel gas cooling, thereby improving the plant thermal efficiency.

General Electric has conducted research and testing on a moving-bed zinc ferrite desulfurization system, in which sorbent circulates continuously between an absorber and regenerator vessel, as opposed to the fixed-bed system in which the sorbent remains in one vessel which is cycled between absorption and regeneration duty. The moving bed design offers advantages in terms of a steady flow of regeneration off-gases and the elimination of a requirement for steam as a diluent (Smith, 1987). However, at this time, only limited design data and no detailed cost data are publicly available for this proprietary system. 


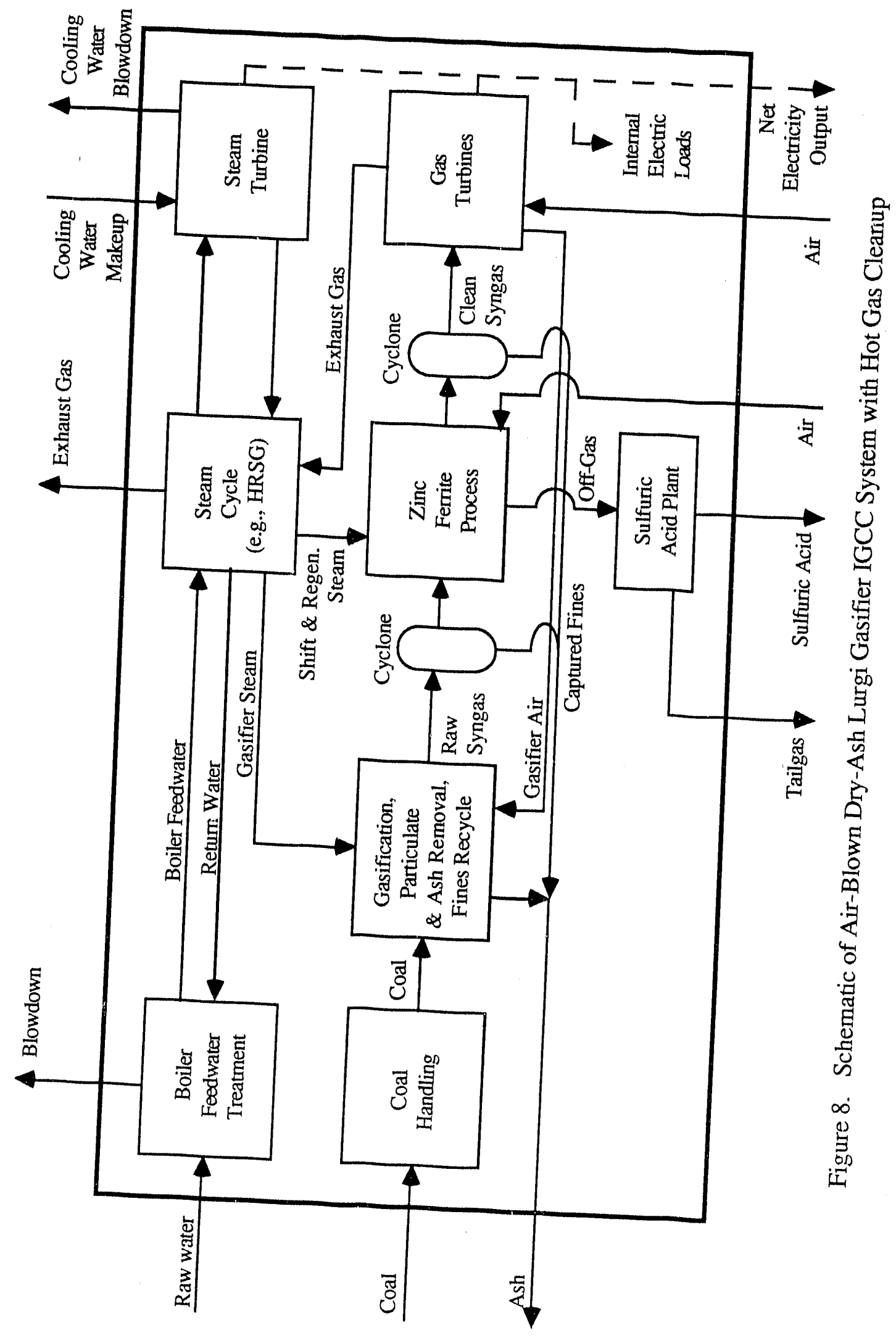


Based on a review of published design studies and research efforts, two IGCC technologies were selected for evaluation here. These include one system featuring cold gas cleanup up, which is intended to be representative of conventional IGCC technology, and an advanced alternatives featuring hot gas cleanup, representing advanced process technologies. These systems are:

- Oxygen-blown KRW-based IGCC with cold gas cleanup (Figure 7)

- Air-blown Lurgi-based IGCC with hot gas cleanup, featuring external fuel gas bulk desulfurization using the fixed bed zinc ferrite process (Figure 8)

The focus of the case studies is on the advanced system, with the conventional system used only for comparative analysis with the advanced system.

Additional details regarding the performance of these technologies is included in Appendix A. In particular, detailed technical reviews of information about the Lurgi gasifier, KRW gasifier, zinc ferrite desulfurization system, and gas turbine process areas are given in Appendices A.2, A.3, and A.4, respectively.

\subsection{IGCC System Performance Models}

Performance models developed by the U.S. Department of Energy were availab'le and obtained as a starting point for modeling the IGCC systems studied in this research. However, several modifications to the performance models were required. Furthermore, no cost models for these systems were available, and these had to be developed. The development of cost models for the two IGCC systems is described in Section 3.3.

\subsubsection{ASPEN Modeling Environment}

METC has developed a number of performance simulations of IGCC systems in the ASPEN (Advanced System for Process ENgineering) modeling environment. ASPEN is a Fortran-based deterministic steady-state chemical process simulator developed by the Massachusetts Institute of Technology (MIT) for DOE to evaluate synthetic fuel technologies (MIT, 1987). The ASPEN framework includes a number of generalized unit operation "blocks", which are models of specific process operations or equipment (e.g., chemical reactions, pumps). By specifying configurations of unit operations ard the flow of material, heat, and work streams, it is possible to represent a process plant in ASPEN. In addition to a varied set of unit operation blocks, it is possible to include Fortran programs within the simulation models as "Fortran blocks," or to call external Fortran subroutines. ASPEN contains an extensive physical property database, which allows a modeler to include a wide range of chemical species in the model. ASPEN also includes 
convergence algorithms for calculating results in closed loop systems, which are modeled using "design specification." A design specification causes part or all of the simulation model to be executed iteratively, varying the value of a selected flowsheet input variable to achieve a specified value of a key design variable within a given tolerance. These combinations of features make ASPEN a powerful tool for process simulation.

The METC IGCC performance models are used by DOE to calculate mass and energy balances for IGCC systems, to conduct sensitivity analyses of performance parameters, and to evaluate the effect of design modifications on plant performance. The IGCC designs that have been modeled to date include oxygen-blown systems with cold gas cleanup based on the Texaco, BGC/L, and KRW gasifier technologies, an air-blown KRW-based system with in-bed limestone desulfurization and hot gas zinc ferrite sulfur removal, and an air-blown Lurgi-based system with hot gas zinc ferrite sulfur removal. In some cases, such as the air-blown KRW and Lurgi based systems, documentation is not available for these models, other than the ASPEN input file. These models typically consist of about 80 unit operation blocks and 4 to 8 major flowsheet sections. While the bulk of the models are comprised of generalized unit operation blocks, there are a number of Fortran blocks and design specifications which are specific to IGCC systems or to a flowsheet. There also are user models to handle coal properties, and there is a Fortran block used as a summary report writer to concisely present plant performance results. The flowsheets have been developed in a modular approach to allow sections to be "borrowed" from other flowsheets, substantially reducing development time of new IGCC simulation models (Stone, 1985).

As noted in Section 2.4, a newly developed probabilistic modeling capability for ASPEN is available for evaluating process technologies in the face of uncertainty. This capability is utilized here for the evaluation of uncertainties in advanced IGCC system concepts.

\subsubsection{ASPEN IGCC Performance Models}

The performance models adopted from METC for each of the two systems evaluated as part of this study are described in the following sections. However, several modifications to these models were required. These are summarized briefly here, and in more detail in Appendix B.

- A new design specification was added to both flowsheets to set the gas turbine compressor inlet air flow rate based on choked conditions at the turbine inlet nozzle (see Appendix A for a discussion of choked flow at the turbine inlet). This feature is required so that the size of the gas turbines in the performance model 
properly corresponds with the basis for the gas turbine cost model. The flowsheet input variables were adjusted to represent plant performance based on three gas turbines.

- The gas turbine model was modified by adding more a detailed representation of the cooling air circuit, which is required to accurately estimate gas turbine efficiency.

- $\mathrm{NO}$ and $\mathrm{NO}_{2}$ were added to the component list of all the flowsheets, and chemical reactions representing both thermal and fuel $\mathrm{NO}_{\mathrm{x}}$ generation were added to the gas turbine combustor unit operation block. This modification was needed to characterize the environmental performance of the IGCC systems more completely than in the original DOE versions of the models. With the modification, it is now possible to specify the fraction of fuel bound nitrogen (i.e. ammonia) converted to $\mathrm{NO}_{\mathrm{x}}$ in the gas turbine combustor, the proportion of $\mathrm{NO}$ to $\mathrm{NO}_{2}$, and the formation of thermal $\mathrm{NO}_{\mathrm{x}}$. See Appendix $\mathrm{A}$ for more discussion of $\mathrm{NO}_{\mathrm{x}}$ emissions from the gas turbine.

- A new Fortran block was added to provide one location for initializing the key design parameters that were previously initialized in individual unit operation blocks, Fortran blocks, and design specifications. This facilitates specification of assumptions for both deterministic and probabilistic case studies.

- A new stochastic flowsheet section was added for flowsheet control, variable assignment, and output analysis for the purpose of probabilistic simulation, using the newly developed stochastic block for the ASPEN simulator.

- A new Fortran block was added to the flowsheet for the system with hot gas cleanup to specify the ammonia yield from the gasifier based on the inlet coal nitrogen content. The assumptions for gasifier ammonia yield are discussed in Appendix A.

- A set of unit operation and Fortran blocks were added for the system with hot gas cleanup to represent the consumption of fuel gas for reductive regeneration of the zinc ferrite sorbent used for fuel gas desulfurization.

- The flowsheet of the Lurgi-based system originally included a performance model of a moving-bed zinc ferrite desulfurization system. This was replaced by a model of the fixed-bed zinc ferrite system "borrowed" from the flowsheet of the KRW-based system with hot gas cleanup.

- Information regarding environmental discharges from the IGCC systems are summarized using Fortran blocks. These include plant $\mathrm{SO}_{2}, \mathrm{NO}_{\mathrm{x}}, \mathrm{CO}$, and $\mathrm{CO}_{2}$ emissions, as well as solid waste and wastewater discharges, plant water consumption, and byproduct production.

- Detail regarding plant auxiliary power requirements is modeled as part of the newly developed cost models. The auxiliary power requirements affect the net plant thermal efficiency. These models are discussed in the Task 2 Topical Report (Frey and Rubin, 1990).

\subsubsection{Cxygen-Blown KRW IGCC With Cold Gas Cleanup}

The ASPEN simulation of the oxygen-blown fluidized-bed KRW IGCC system with cold gas cleanup was originally based on a conceptual design of a $570 \mathrm{MW}$ plant (Bechtel and WE, 1983c), and is documented in a METC report (Stone, 1985). An 
updated version is based on a more recent study (Fluor, 1985), but is not documented. The only information about the recent flowsheet is the input file itself (Stone and Craig, 1988). The main difference between the earlier and recent version of the flowsheet is in the pressure levels assumed in the steam cycle. Figure 9 shows a diagram of the flowsheet sections for the ASPEN flowsheet. The components or characteristics included in each flowsheet section, the number of unit operation blocks used in the ASPEN simulation, and a brief description of the function of each section are listed in Table 2. The material stream flows that link each flowsheet section are shown in Figure 9. Not shown in detail are "information" streams that show the flow of heat from various flowsheet sections to the steam cycle. As discussed above, several modifications have been included in the performance model regarding the characterization of the emissions from and performance of the gas turbine.

\subsubsection{Air-Blown Lurgi IGCC with Hot Gas Cleanup}

An ASPEN model of a fixed bed gasifier-based IGCC system with hot gas cleanup has been developed at METC. The only model documentation is the ASPEN input file (Klara, Rastogi, and Craig, 1988). The flowsheet includes a gasifier section, hot gas desulfurization using a fixed bed zinc ferrite process, a model of General Electric MS7000F gas turbine, and a model of the steam cycle. The model assumes that the off-gas from the zinc ferrite process is converted to sulfuric acid. A simple diagram of the ASPEN flowsheet is shown in Figure 10. Table 3 lists the features of the model. A new Fortran block has been added for specifying gasifier ammonia yield

The zinc ferrite section of the flowsheet includes models of sulfur absorption and sorbent regeneration based on a fixed-bed design. Prior to absorption, the raw syngas is mixed with steam to promote the water-gas shift reaction for improved catalyst performance. The shift reaction is modeled using an equilibrium reaction model. The raw syngas and steam mixture is then mixed with the zinc ferrite sorbent, and the desulfurization reactions are modeled using a stoichiometric reactor model, in which the reaction conversion rates are specified. The clean fuel gas is an output of this flowsheet. section.

The regeneration of the sorbent occurs in two steps. The first step, oxidative regeneration, involves exothermic chemical reactions, requiring air as a reactant and steam as a diluent to prevent sintering of the sorbent. A stoichiometric reactor model, in which conversion rates are specified, is used to represent the regeneration reaction. The off-gas from the regenerator is cooled against the incoming diluent and recycled to the gasifier. 


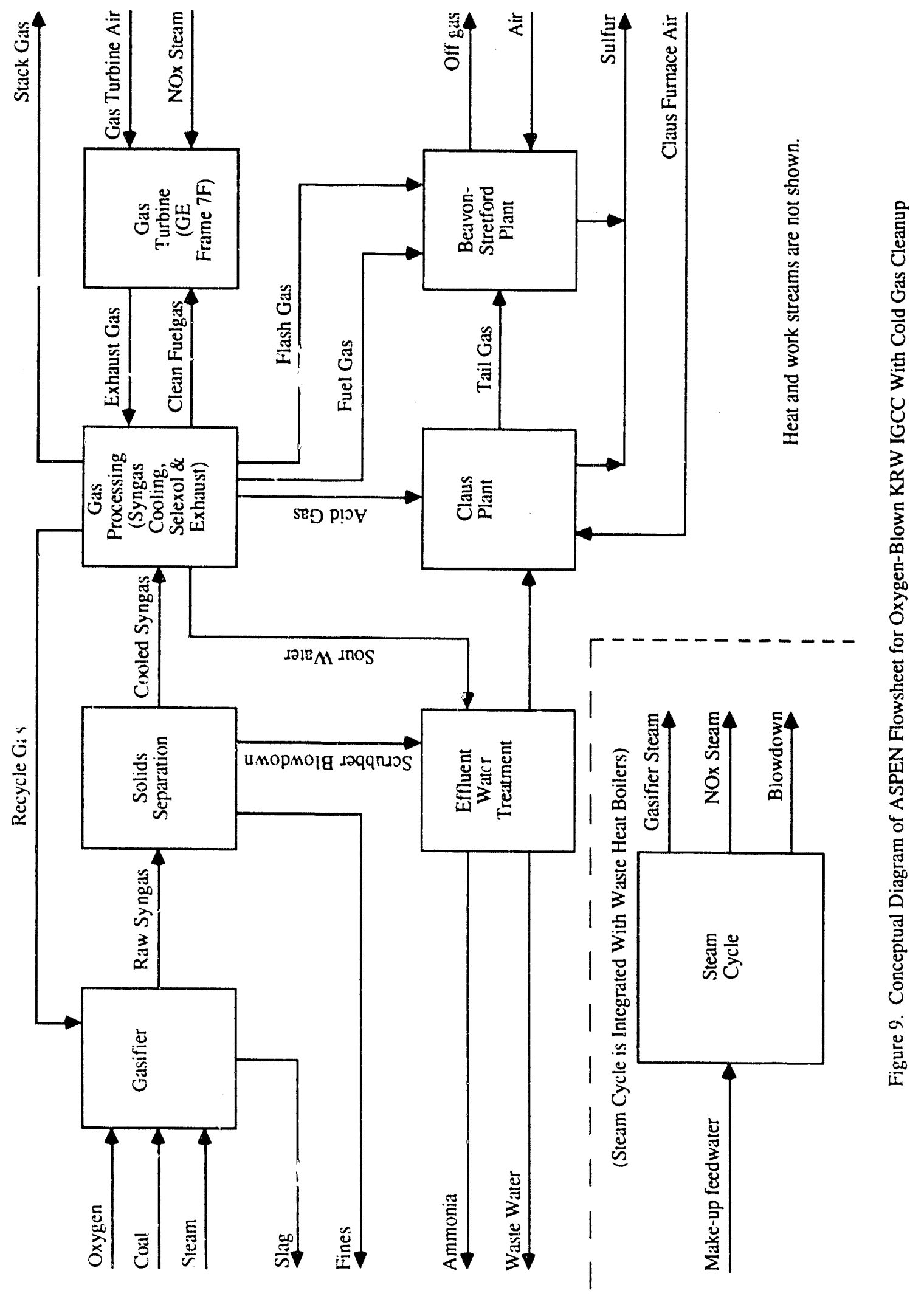


Table 2. METC ASPEN Model of KRW-Based IGCC System: Plant Sections and Unit Operations

Flowsheet Sectiona

Components/Processes/Comments

Gasifier (6)

Coal decomposed based on ultimate analysis;

Stoichiometric reactor model for slag and fines;

Mix decomposed coal, steam, oxygen, recycle;

Equilibrium reactor model for gasification;

Ash removal after cyclones.

Solids Separation (4)

Gas cooling

Particulate scrubbing to separate liquids and solids from gas, and split effluent to fines and purge water;

Cooling (to reheat clean fuel gas);

Water vapor knock-out, recycled to scrubber.

Gas Processing (8) (Cleanup and cooling)

Gas Turbine (18)

Effluent Water Treatment (4)
Ammonia separation;

Fuel gas recycle (to gasifier); ammonia/ $\mathrm{H}_{2} \mathrm{~S}$ to effluent water treatment system;

Selexol: acid gas removal to Claus plant, flash gases to Beavon-Stretford unit;

Fuel split: fuel gas to Stretford unit;

Reheat fuel gas (from Solid Sep. cooling);

Cooling of gas turbine exhaust in high-pressure and low pressure HRSG.

Reheated fuel gas mixed with steam and compressed air;

Mixture burned in stoichiometric reactor;

Multi-stage compression of air, bleeds for turbine blade cooling (added more detail);

Multi-stage expansion of combustion gases;

Heat loss and pressure drop considered.

New design specification for estimating compressor inlet air mass flow rate.

$\mathrm{NO}_{\mathrm{x}}$ Emissions (newly added)

Purge water (scrubber) stream class change; Mix purge water with ammonia/ $\mathrm{H}_{2} \mathrm{~S}$ stream; Ccol mixture, separate wastewater, $\mathrm{H}_{2} \mathrm{~S}$ (to Claus), and ammonia.

(Continued on next page) 
Table 2 (Continued). METC ASPEN Model of KRW-Based IGCC System: Plant Sections and Unit Operations

Flowsheet Section ${ }^{\mathrm{a}}$

Claus Plant (7)

Beavon-Stretford Unit (7)

Steam Cycle (33)

HRSG (9)

Auxiliaries (11)

Steam Turbine (7)
Components/Processes/Comments

Compress air, mix with acid gas and $\mathrm{H}_{2} \mathrm{~S}$ from water treatment section;

Three stoichiometric reactor models to convert 95 percent of $\mathrm{H}_{2} \mathrm{~S}$ to elemental sulfur;

Waste heat boiler;

Separate sulfur and tail gas.

Compress air, compress Claus tail gas;

Mix air, tail gas, fuel gas, and flash gas from the Selexol unit;

Three stoichiometric reactor models to eliminate remaining $\mathrm{H}_{2} \mathrm{~S}$;

Separate sulfur and off-gas.

Linked to other sections by heat streams;

Condenser, makeup water, pump, deaerator;

Steam sides of HRSG and associated pumps;

Heat recovery from Claus, Stretford, effluent water treatment;

Four stage, no reheat; Steam from or split to removal.

a Numbers in parenthesis are number of unit operation blocks in each ASPEN flowsheet section 


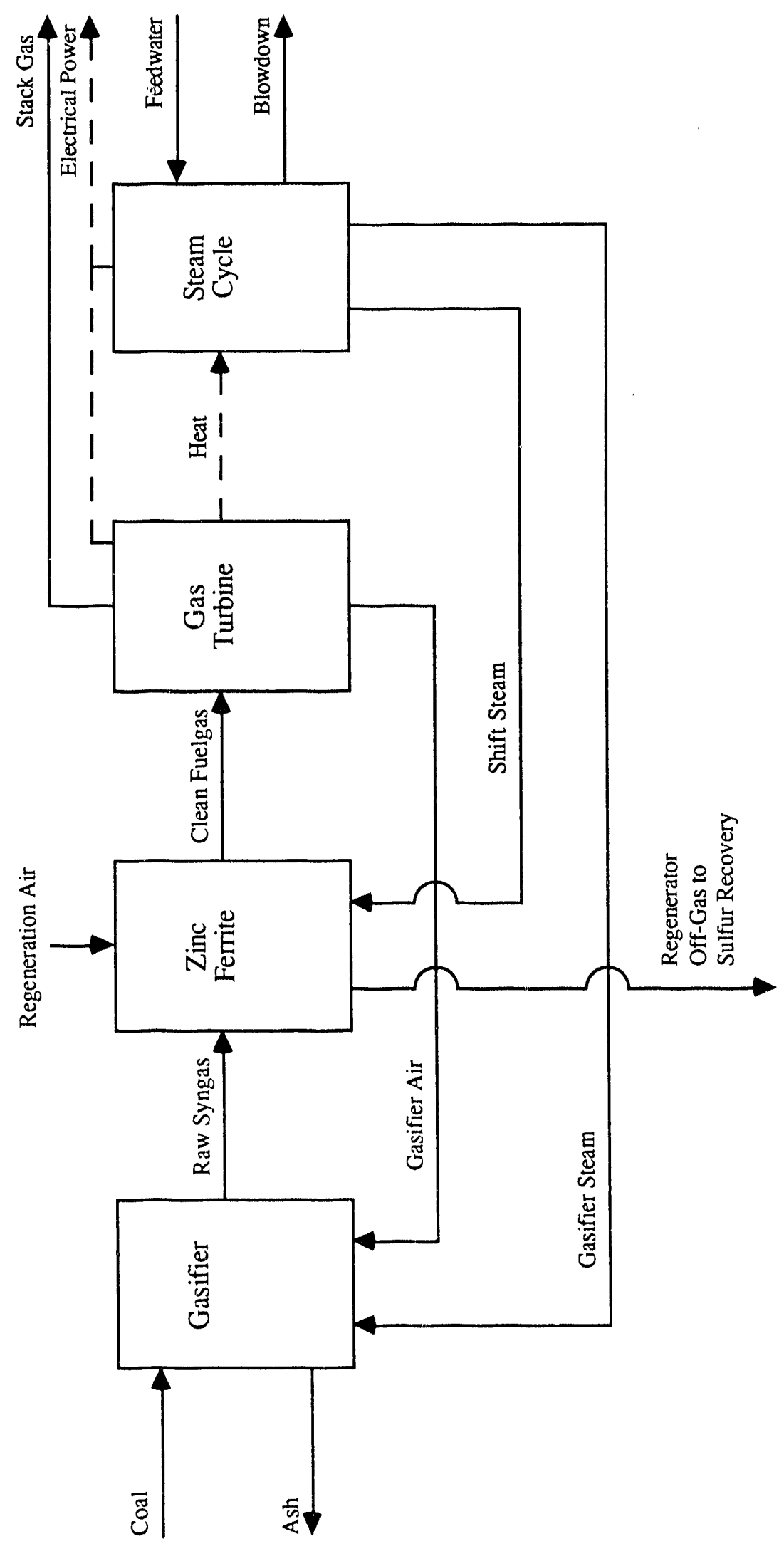

荡 
Table 3. METC ASPEN Model of an Air-Blown Lurgi IGCC System With Hot Gas Cleanup: Plant Sections and Components

Flowsheet Sectiona

Gasifier (11)

Zinc Ferrite (18)

Stream Class Change (6)

Absorption (5)

Regeneration (7)

Gas Turbine (26)

Compressors (6)

Combustion (5)

Turbines (7)

Booster (4)

HRSG (4)

Steam Cycle (22)

HRSG (6)

Steam Turbine (8)

Miscellaneous (12)
Components/Processes/Comments

Air-blown generic fixed-bed i $y$-ash gasifier; characterization of coal, fines based on chemical analysis, gasification reactions based on equilibrium reaction model, allowance for specification of carbon conversion and fines carryover, provisions for in-bed desulfurization but not used in this input file; newly added Fortran block for gasifier $\mathrm{NH}_{3}$ yield.

Two-vessel zinc ferrite desulfurization system; ASPEN feature for handling gases and solids; Mixing of steam and raw syngas for shift equilibrium to protect sorbent, sulfidation reactions;

Mixing of diluent steam, regeneration air, and spent sorbent, preheating of inlet gas streams against outlet gas streams, regeneration reactions; newly added blocks for reductive regeneration using fuel gas.

General Electric model MS7000F Gas Turbine with air extraction; boost compressor for gasifier and zinc ferrite regeneration air; and gas-side heat exchange in HRSG;

Three stage compression, pressure ratio of 12 , extraction for turbine vane cooling;

New design specification for estimating compressor inlet air mass flow rate.

Stoichiometric reactor model for combustion reactions, heat loss, temperature control for gas turbine firing temperature (e.g., 2,300 oF);

Two stage expansion, inlet vane cooling air; $\mathrm{NO}_{\mathrm{x}}$ Emissions (newly added)

Booster compressor for gasification air, compressor precoolers;

Exhaust gas cooling.

Steam cycle, including steam-side HRSG, steam turbine, condenser, and deaerator.

1545 psia and 570 psia steam generation, 1465 psia superheated steam at $975 \mathrm{oF}, 510$ psia reheated steam;

Reheat steam turbine;

Deaerator, condenser, pumps, splitting of steam flows to gasifier, and zinc ferrite absorber shift reaction.

a Numbers in parenthesis are number of unit operation blocks in each ASPEN flowsheet section 
Oxidative regeneration usually does not completely remove sulfur from the sorbent, and may leave residual amounts of zinc and iron sulfates.

The second step, reductive regeneration, involves reaction with the sulfates. This oxidized species must be reduced prior to the next absorption cycle. The sulfates may be converted to sulfides by reaction with hydrogen or carbon monoxide. Therefore, a portion of the fuel gas is used for reductive regeneration. Several new unit operation and Fortran blocks have been added to the original performance model to characterize reductive regeneration and the effect it has on fuel gas consumption.

The flowsheet section for the MS7000F gas turbine includes three stages for the compressor (including air extraction for turbine vane cooling), combustion of the syngas (including heat losses and combustor pressure drop), two stages of turbines with a 2,300 oF turbine inlet temperature, and a gas-side heat recovery steam generator model. As part of recent modifications, $\mathrm{NO}_{\mathrm{x}}$ emissions have been characterized and additional detail has been added to the representation of cooling air circuits. The steam cycle model includes pumps, economizers, boilers, a superheater, a reheater, a deaerator, condensate pumps, condenser, and a reheat steam turbine with high pressure, intermediate pressure, low pressure, and very low pressure stages.

\subsection{IGCC System Cost Models}

Capital, annual, and levelized cost models for the two IGCC systems used here for case studies are documented in the Task 2 Topical Report (Frey and Rubin, 1990). The cost models are summarized here for the convenience of the reader.

The cost models were developed based on a review of approximately 30 comprehensive conceptual design studies prepared for DOE, EPRI, and the Gas Research Institute (GRI), as well as other studies which focused on specific process components. The models provide "preliminary" estimates of process capital and operating costs based on the standard method developed by EPRI (1986). To link process flowsheet parameters with economic cost models, the methodological approach was to model all costs at the level of major plant sections for each IGCC technology. Table 4 shows a list of the sections used for the two IGCC systems. For each system, there are approximately a dozen major process sections. The cost models chaiacterize direct and total capital costs, fixed operating costs, variable operating costs, and the annualized cost of electricity. The cost models provide a consistent basis for comparative cost analysis between baseline and 
Table 4. Major Plant Sections in the IGCC Cost Models

\begin{tabular}{|c|c|c|}
\hline $\begin{array}{l}\text { Area } \\
\text { No. }\end{array}$ & $\begin{array}{l}\text { Oxygen-Blown KRW } \\
\text { with Cold Gas Cleanup }\end{array}$ & $\begin{array}{l}\text { Air-Blown Lurgi } \\
\text { with Hot Gas Cleanup }\end{array}$ \\
\hline 10 & Oxygen Plant & Air Boost Compression \\
\hline 20 & Coal Handling & Coal Handling \\
\hline 30 & $\begin{array}{l}\text { Gasification, High } \\
\text { Temperature Gas } \\
\text { Cooling, Particulate } \\
\text { and Ash Removal, } \\
\text { Coal Pressurization }\end{array}$ & $\begin{array}{l}\text { Gasification, } \\
\text { Coal Pressurization, } \\
\text { Ash Depressurization }\end{array}$ \\
\hline 31 & -- & $\begin{array}{l}\text { Coke Handling, } \\
\text { Fines Agglomeration, } \\
\text { Ash Removal }\end{array}$ \\
\hline 32 & -- & $\begin{array}{l}\text { High Temperature } \\
\text { Cyclones }\end{array}$ \\
\hline 40 & $\begin{array}{l}\text { Low Temperature } \\
\text { Gas Cooling, Fuel Gas } \\
\text { Saturation }\end{array}$ & -- \\
\hline 50 & $\begin{array}{l}\text { Selexol Sulfur } \\
\text { Removal }\end{array}$ & $\begin{array}{l}\text { Zinc Ferrite } \\
\text { Desulfurization }\end{array}$ \\
\hline 60 & $\begin{array}{l}\text { Claus Sulfur } \\
\text { Recovery }\end{array}$ & Sulfuric Acid Plant \\
\hline 70 & Tail Gas Treating & -- \\
\hline 80 & $\begin{array}{l}\text { Steam, Condensate, } \\
\text { Boiler Feed Water }\end{array}$ & $\begin{array}{l}\text { Steam, Condensate, } \\
\text { Boiler Feed Water }\end{array}$ \\
\hline 85 & $\begin{array}{l}\text { Process Condensate } \\
\text { Treatment }\end{array}$ & -- \\
\hline 90 & Combined Cycle & Combined Cycle \\
\hline 100 & General Facilities & General Facilities \\
\hline
\end{tabular}


advanced technology options, as well as a basis for evaluation of each technology individually.

\subsubsection{Capital Cost Models}

The capital cost models consist of two parts: a series of models for the direct cost of major plant sections; and a generic framework for estimating indirect and other capital costs.

The direct cost models are based on key plant performance parameters. There are 10 to 12 major plant sections per IGCC technology (excluding general facilities), as shown in Table 4. The direct capital cost of each process section was estimated separately, based on analytic relationships between direct cost and key performance parameters. These relationships were developed from published data, typically based on regression analysis.

The performance parameters used in the direct cost models for the two selected IGCC technologies are summarized in Table 5. Typically, several performance variables, in addition to design variables such as the number of spare and operating trains of equipment, are included in the direct cost models. By summing the individual section costs, the total direct cost of each IGCC system is sensitive to approximately two dozen performance parameters, in addition to process design parameters.

The direct cost models therefore represent an intermediate level of detail, in contrast to either a detailed estimate for an actual plant (involving hundreds of separate equipment items and an equivalent number of performance and design parameters), or a simplified estimate in which the total direct capital cost is estimated based on scaling of a single parameter such as plant size. The direct cost models provide sufficient detail to evaluate the effect of changes in key performance and design parameters on the total capital cost. The direct cost models can also be modified as new or more detailed information on the cost of key plant sections becomes available.

The total capital cost for an IGCC plant is estimated based on the direct costs for each plant section and a number of other capital cost items. A summary of the key parameters in the total capital cost model is given in Table 6 . In addition to the parameters required for the direct cost model, the total capital cost model requires specification of approximately 60 parameters, including contingency factors, and the various factors associated with the preproduction and initial catalyst and chemical costs. These include

maintenance cost factors for each plant section, number of operating 
Table 5. Summary of Performance Parameters in the Direct Capital Cost Models

\begin{tabular}{|c|c|c|c|}
\hline \multirow[b]{2}{*}{ Description } & \multicolumn{3}{|c|}{ Direct Cost Model Performance Parameter(s)a,b } \\
\hline & $\begin{array}{l}\text { Area } \\
\text { No. }\end{array}$ & $\begin{array}{l}\text { KRW with Cold } \\
\text { Gas Cleanup }\end{array}$ & $\begin{array}{l}\text { Lurgi with Hot } \\
\text { Gas Cleanup }\end{array}$ \\
\hline Oxidant Feed & 10 & $\begin{array}{l}\text { Ambient temperature } \\
\text { Oxygen flow rate } \\
\text { Oxygen purity }\end{array}$ & $\begin{array}{l}\text { Compressor work } \\
\text { Precooler heat } \\
\text { transfer area }\end{array}$ \\
\hline Coal Handling & 20 & Gasifier coal feed & AR coal feed \\
\hline Gasification & 30 & $\begin{array}{l}\text { Oxidant feed } \\
\text { Coal feed (MAF) } \\
\text { Ash removal rate }\end{array}$ & $\begin{array}{l}\text { Number of units } \\
\text { (based on } \\
\text { coal throughput) }\end{array}$ \\
\hline $\begin{array}{l}\text { Coke, Fines, } \\
\text { and Ash }\end{array}$ & 31 & -- & Gasifier coal feed \\
\hline Cyclones & 32 & -- & $\begin{array}{l}\text { Syngas pressure } \\
\text { Syngas volume flow } \\
\text { rate }\end{array}$ \\
\hline Gas Cooling & 40 & $\begin{array}{l}\text { Syngas outlet temp. } \\
\text { Syngas outlet pres. } \\
\text { Syngas flow rate }\end{array}$ & -- \\
\hline Selexol & 50 & $\begin{array}{l}\text { Syngas flow rate } \\
\mathrm{H}_{2} \mathrm{~S} \text { removal eff. }\end{array}$ & -- \\
\hline Zinc Ferrite & 50 & -- & $\begin{array}{l}\text { Sorbent loading } \\
\text { Sulfur flow rate } \\
\text { Sorbent bulk density } \\
\text { Syngas volume flow } \\
\text { Design pressure }\end{array}$ \\
\hline Claus Plant & 60 & $\begin{array}{l}\text { Recovered sulfur } \\
\text { flow rate }\end{array}$ & -- \\
\hline Sulfuric Acid & 60 & (Continued on nex & $\begin{array}{l}\text { Off-gas flow rate } \\
\text { Concentration of } \\
\text { sulfur dioxide } \\
\text { Off-gas temp }\end{array}$ \\
\hline
\end{tabular}


Table 5 (Continued). Summary of Parameters in the Direct Capital Cost Models

\begin{tabular}{|c|c|c|c|}
\hline \multirow[b]{2}{*}{ Description } & \multicolumn{3}{|c|}{ Direct Cost Model Parameter(s) ${ }^{a, b}$} \\
\hline & $\begin{array}{l}\text { Area } \\
\text { No. }\end{array}$ & $\begin{array}{l}\text { KRW with Cold } \\
\text { Gas Cleanup }\end{array}$ & $\begin{array}{l}\text { Lurgi with Hot } \\
\text { Gas Cleanup }\end{array}$ \\
\hline $\begin{array}{l}\text { Tail Gas } \\
\text { SCOT }\end{array}$ & 70 & $\begin{array}{l}\text { Recovered sulfur } \\
\text { flow rate from Claus }\end{array}$ & -- \\
\hline $\begin{array}{l}\text { Beavon- } \\
\text { Stretford }\end{array}$ & & $\begin{array}{l}\text { Recovered sulfur } \\
\text { flow rate from B-S }\end{array}$ & -- \\
\hline $\begin{array}{l}\text { Boiler Feed } \\
\text { Water }\end{array}$ & 80 & $\begin{array}{l}\text { Raw water feed rate } \\
\text { Polished water } \\
\text { flow rate }\end{array}$ & $\begin{array}{l}\text { Raw water feed rate } \\
\text { Polished water } \\
\text { flow rate }\end{array}$ \\
\hline $\begin{array}{l}\text { Process Cond. } \\
\text { Treatment }\end{array}$ & 85 & $\begin{array}{l}\text { Particulate scrubber } \\
\text { blowdown }\end{array}$ & -- \\
\hline Comb. Cycle & 90 & & \\
\hline Gas Turbine & 91 & $\begin{array}{l}\text { Number of units } \\
\text { (power output) }\end{array}$ & $\begin{array}{l}\text { Number of units } \\
\text { (power output) }\end{array}$ \\
\hline HRSG & 92 & $\begin{array}{l}\text { Pressure of high } \\
\text { pressure steam } \\
\text { High pressure } \\
\text { steam flow rate }\end{array}$ & $\begin{array}{l}\text { Pressure of high } \\
\text { pressure steam } \\
\text { High pressure } \\
\text { steam flow rate }\end{array}$ \\
\hline Steam Turb. & 93 & Power output & Power output \\
\hline General Fac. & 100 & $\begin{array}{l}\text { Fraction of other } \\
\text { direct costs }\end{array}$ & $\begin{array}{l}\text { Fraction of other } \\
\text { direct costs }\end{array}$ \\
\hline
\end{tabular}

a Abbreviations are: temp. = temperature; pres. = pressure; eff. = efficiency; $A R=$ as-received; and $B-S=$ Beavon-Stretford; MAR = moisture- and ash-free.

$\mathrm{b}$ The direct cost models are presented in detail for these two systems in the Task 2 Topical Report (Frey and Rubin, 1990). 
Table 6. Summary of Key Parameters in the Total Capital Cost Model

Indirect capital cost factor (default $=0.25$ )

Sales tax (default $=0.06$ )

Engineering and home office cost factor (default $=0.15$ )

Cost of environmental permits (default $=\$ 1$ million)

Process contingency factors (see Task 2 Topical Report)

Project contingency factor (default $=0.20$ )

Interest for funds spent during construction (default $=0.10$ )

Inflation rate (default $=0$, constant dollar basis)

Preproduction costs

Depend on all parameters that affect operating costs

Initial catalyst and chemicals

Depend on material requirements and unit costs for each material

Table 7. Summary of Key Parameters in the Operating Cost Model

Average labor rate (default $=\$ 19.70 /$ hour)

Shift factor (default $=4.75$ )

Number of operators per shift for each process area (See Task 2 Topical Report)

Maintenance cost factor for each process area (See Task 2 Topical Report)

Unit costs of fuel, consumables, ash disposal, and byproduct credits

(See Task 2 Topical Report)

Mass requirements for fuel, consumables, ash disposal, and byproducts

\subsubsection{Operating Cost Models}

personnel for each plant section, and unit costs for labor, fuel, consumables, ash disposal, and byproduct credits.

In a probabilistic analysis, process and project contingency factors are replaced with explicit representations of uncertainty in capital cost using probability distributions. See Appendix A.5 for more discussion of the treatment of capital cost-related uncertainties.

The operating costs are estimated based on approximately 40 to 50 cost parameters (depending on the type of plant), which also influence the preproduction and initial catalyst and chemicals costs, as previously indicated. In addition, the material requirements for catalyst and chemicals, fuel, consumables, ash disposal, and byproduct sales are estimated based on key plant performance parameters. A summary of these parameters is given in Table 7. Therefore, the combined capital and operating cost models are based on approximately 100 performance, design, and cost paa ameiers for ea.h IGCC technology. 


\subsubsection{Annualized Cost Models}

The total capital and operating costs are used in conjunction with an estimate of the net electric power production of the plant to estimate the cost of electricity produced by the plant. To accurately determine the net plant electrical output, estimates of the auxiliary power requirements of key plant sections were developed. The cost of electricity therefore depends on the parameters summarized in Tables 5, 6, and 7, plus an additional set of parameters. These additional parameters include the economic assumptions in the capital recovery factor and the performance parameters used to estimate the auxiliary power requirements.

\subsubsection{Cost Model Implementation}

The cost models developed in Task 2 are intended to be directly coupled with an existing set of IGCC performance models developed by METC in the ASPEN simulation environment. The cost models for the IGCC systems have been coded into Fortran and implemented as subroutines along with the corresponding ASPEN performance models. The performance models determine the key material flow rates and process parameters required by the cost model to calculate capital and annual costs. Each IGCC cost model subroutine consists of a main program in which capital and annual costs are estimated based ( ..: the equations developed in the previous chapters. The cost model subroutine calls additional subroutines as needed for: (a) estimating the number of trains for selected process areas, (b) range-checking the predictive variables for the direct cost regression models, (c) estimating the fixed charge factor, and (d) estimating the variable cost levelization factor. The last two subroutines were adapted to Fortran from BASIC programs listed in the EPRI Technical Assessment Guide (1986), and they are required to estimate the total revenue requirement and the cost of electricity. Each subroutine contains extensive comments to document the code.

To implement the cost models with the ASPEN performance models, ASPEN Fortran blocks were developed to access the flowsheet performance variables required as inputs to the cost models. The Fortran blocks call the cost model subroutine and transfer the values for the performance variables via common blocks. The Fortran blocks also contain the initializations for the input parameters of the cost models, to facilitate the specification of values for both deterministic and probabilistic case studies. Key cost model results are returned to the Fortran block from the cost model subroutines. These results are collected for statistical analysis when running probabilistic simulations. The cost model subroutines record the values of the input variables and cost results to the 
simulation report file in a detailed summary format. Examples of the cost model outputs for deterministic analyses of each of the two IGCC systems are given in Appendix C. 
This page left blank intentionally. 


\subsection{CHARACTERIZING UNCERTAINTIES IN PROCESS TECHNOLOGIES}

The advanced clean coal technology discussed in Chapter 3 represents a promising new approach for the clean and efficient use of coal for power generation, offering low levels of $\mathrm{SO}_{2}$ and $\mathrm{NO}_{\mathrm{x}}$ emissions. However, making predictions regarding the mature commercial-scale performance and cost of such technologies is inherently uncertain, as discussed in Chapter 1. A conceptual estimate may be intended to represent the cost of a mature fifth-of-a-kind commercial plant for the process of interest. However, such a plant may not be built for another 10 or 20 years, and currently avai'able information for making predictions may be based on only small scale tests or theoretical models.

Yet decisions must be made today regarding which technologies to select for further research, and how to focus research on specific aspects of the technology. Historically, predictions about innovative process technologies have been biased toward optimistic outcomes, leading to potentially costly mistakes in decision-making. A feature of traditional approaches to handling unceitainty, as discussed in Section 1.1.3, is the use of simple multipliers, called "contingency factors," to represent expected cost increases associated with either process or project-related uncertainties. However, the application of contingency factors is often poorly documented. In contrast, the tendency of costs for innovative process plants to be underestimated when using contingency factors has been well-documented by RAND (Merrow et al, 1981).

Predictions about the performance and cost of innovative technologies should reflect the degree of confidence that engineers have in the input assumptions used to generate the predictions. In this research, the approach taken is to explicitly quantify both the range and likelihood of values for parameters used as inputs to the engineering models. Using probabilistic simulation techniques previously discussed, the simultaneous effect of input parameter uncertainties can be propagated through the model to yield an explicit indication of the uncertainty in output values. The uncertainty in the output variables, such as total capital cost or plant efficiency, represents uncertainty in the analyst's ability to predict performance or cost based on the limited nature of current informatic about the technology. Suppressing this unceitainty, as is done routinely in deterministic cos: estimates. may give a misleading sense of confidence. In fact, the prediction may be uncertain by a significant range, whether the analyst chooses to acknowledge this or not. The range of uncertainty may 'ze important information to a decision maker, and it should be expiicitiy considered. 
The approach used to develop the estimates of uncertainty in specific model parameters in this study is discussed in the next section. In Section 4.2, the approach used here for eliciting judgments about uncertainties from technical experts is described in ronre detail. Then, the parameter uncertainty estimates used for each process technology are summarized. Correlation structures among model input parameter uncertainties are briefly discussed in Section 4.5, followed by a discussion of "best guess" versus uncertainty estimates for model parameters. Considerable detail on the basis for developing estimates of uncertainty in $\mathrm{s}_{\mathbf{1}}$ scific parameters is given in Appendix $\mathrm{A}$.

\subsection{Approaches to Characterizing Uncertainty}

As discussed in Section 1.1.3 and Section 2.3.2, there are a number of types of uncertainty that an analyst faces in trying to pred:ct the commercial scale performance and cost of an innovative process technology. The categorization of these uncertainties involves two dimensions. The first dimension is the type of uncertainty, such as statistical error, sysiematic error, variability, and lack of any empirical basis at all. The latter is true of concepts for which no testing has been done. The other dimension is the aspect of the evaluation that is subject to uncertainty. These aspects include process performance variables, equipment sizing parameters, process area capital costs, requirements for initial catalysts and chemicals, indirect capital costs, process area maintenance costs, requirements for consumables during plant operation, and the unit cost of consumables, byproducts, wastes, and fuel, to indicate a representative set. Model parameters in any one of these areas may be uncertain, depending on the state of development of the technology, the level of detail of the perfornance and cost estimate, future market conditions for new chemicals, catalysts, byproducts, and wastes, and so on.

As indicated in Section 2.3, it may not always be possible to develop estimates of uncertainty based on classical statistical analysis, nor would such an approach be appropriate in many cases. Particuli: ' $y$ for innovative process technologies, data may be lacking regarding the sources of uncutainty a process engineer or analyst knows to exist. Thus, data analysis alone would be an insufficient basis for estimating uncertainty in a variable. When data are lacking, estimates of uncertininty must rely on the informed judgments of technical experts. Engineers are often said to have a "horse sense" about the quality of data they use is. evaluations. The development of judgments about uncertainties merely requires the analyst or expert to quantify their "horse sense." As discussed in Section 2.3.3, judgments regarding uncertainties can be encoded as probability distributions. 
Deyeloping estimates of uncertainty in specific process parameters involves several steps. These include:

- Review the technical basis for uncertainty in the process

- Identify specific parameters that should be treated as uncertain

- Identify the source of information regarding uncertainty for each parameter

- Depending on the availability of information, develop estimates of uncertainty based on:

- Published judgments in the literature (rarely available)

- Published information, both quantitative and qualitative, that can be used to infer a judgment about uncertainty

- Statistical analysis of data

- Elicitation of judgments from technical experts.

Both as part of model building and uncertainty analysis, the analyst must develop an understanding of the process technology being evaluated. Published conceptual design studies or test results from small scale testing are often a valuable source of information regarding uncertainties. For example, understanding of mechanisms by which key chemical reactions occur in a process vessel, such as a gasifier, may be incompletely understood. This may result in uncertainty in predicting the amount of reagents needed to achieve a given conversion rate. These types of concerns may be discussed, if only briefly, in published studies. Estimates used in conceptual design studies may be based on extrapolation of results from small scale tests. There may be some key assumptions in such an extrapolation which are subject to uncertainty. Further, the results of testing may be subject to considerable uncertainty that could be characterized as statistic error, systematic error, or variability.

A review of published information can provide insights into the aspects of the process technology which are uncertain. In addition, technical experts can be asked which aspects of a process they think are uncertain. By developing an understanding of the underlying mechanisms that contribute to uncertainty in a process, it then becomes possible to identify the specific model parameters that should be treated as uncertain. The identification of these is specific to each process area.

In some cases, information about uncertainty can be taken directly from the literature. In rare cases, there may be explicit statements in published studies regarding high, low, and most likely values of a parameter that could be used to develop a probabilistic representation of uncertainty. More often, there may be differences in 
assumptions used across design studies, that reflect different judgments by process evaluators. These differing judgments can be used as information by the analyst to develop an initial repr sentation of uncertainty for a screening study. For example, the analyst may be able to make a preliminary judgment regarding the lowest, most likely, and highest values that would be obtained for a given parameter based on a review of assumptions in design studies and the reasons given for the assumptions. Preliminary judgments regarding uncertainties in model parameters can be used in a probabilistic screening study as inputs to the engineering models. The models can then be run to identify which of the input uncertainties were most important in driving uncertainty in key output variables. Then the analyst can prioritize the input parameters for which more detailed information about uncertainty is warranted. If a particular preliminary judgment about uncertainty is found to have an influential effect in the model, then it should become a candidate for more detailed evaluation.

In an initial screening analysis of uncertainties, it is important not to prematurely eliminate potentially uncertain parameters from probabilistic treatment. For example, literature or a technical expert may indicate that a particular uncertainty is not believed to be an important determinant of uncertainty in process performance or cost. However, unless there has been a quantitative analysis to support such a conclusion, and unless the analysis was done with a sufficiently integrated performance and cost model and a sufficient variance on the uncertain parameters, there may be no reason to accept the conclusion. A screening analysis serves the purpose of identifying key uncertainties in a rigorous quantitative manner. Sometimes, results contrary to "conventional wisdom" are obtained, because conventional wisdom is often based on incomplete consideration of process interactions and potential ranges of uncertainty.

In cases were data are available to support a statistical analysis, the development of estimates of uncertainty may be straightforward. However, it is important to recognize the potential differences in the system from which the data were obtained and the system for which predictions are sought. As discussed in Section 2.3.2, there may be uncertainty in predicting information about a commercial scale system based on test results from a small scale experiment, due to statistical and systematic errors. Thus, a degree of expert judgment may be required to interpret the results of a statistical analysis for application to process evaluation.

A common approach to data analysis and model development is regression analysis. Regression models are of ten used by engineers to develop predictions of the mean value of 
a dependent (output) variable based on a set of independent (predictive) variables. However, a more appropriate perspective is that regression models are used to explain the variance in observed values of the dependent variable based on corresponding observed values of the independent variables. There is almost always a portion of the variance in the dependent variable that cannot be explained by the regression model, resulting in a "standard error" rerm (see Appendix A.2.4 for a detailed discussion of regression analysis and its application to process evaluation). In an uncertainty analysis, it is possible to explicitly represent the standard error of the estimate for the dependent variable with a probability distribution.

Another approach to developing estimates of uncertainties is to elicit technicallyinformed judgments from process experis. The approach to eliciting judgments about uncertainties is discussed in Section 2.3.3.

\subsection{Characterizing Uncertainties in IGCC Systems}

The characterization of uncertainties in the IGCC systems was a major effort in this research. The complete documentation of the effort is given in Appendix A. In this section, the approach used to elicit judgments regarding uncertainties in specific model parameters from technical experts is described.

Because the two IGCC systems have several common process areas, the approach taken was to characterize uncertainties in the performance in each process area with consideration of its application in different systems. For example, the gas turbine process area is common to both IGCC systems. The technical review of information about uncertain considers both types of process environments. The characterization of uncertainties also explicitly considers the differences in the set of uncertain parameters, and magnitude (variance) of uncertainties, depending on which IGCC system is assumed. Thus, uncertainties between competing technologies are characterized on a common basis that permits comparative analysis.

The characterization of process performance uncertainties focused on four major process areas. These are:

- Lurgi gasification, including the fines recycle cyclone.

- KRW gasification.

- Zinc ferrite desulfurization, which is a component of the Lurgi-based IGCC system with hot gas cleanup. 
- Gas turbine, which is common to both IGCC systems. However, there are significant differences between the IGCC process environments related to fuel gas heating value, ammonia concentration in the fuel gas, environmental performance, and cost.

In addition, uncertainties in other IOCC performance and cost model parameters were characterized. These include

- Cost model parameters common to all three IGCC systems. These include indirect capital costs, operating cost parameters, and financial assumptions

- Direct capital costs for each process area

- Maintenance costs for each process area

- Unit costs of consumables, byproducts, and wastes associated with variable costs

- Error terms for regression models of direct capital cost and plant auxiliary power requirernents.

The approach used to develop estimates of uncertainties for the IGCC systems will be described, with particular focus on the elicitation of judgments from technical experts.

\subsubsection{Obtaining Judgments From Technical Experts}

A key focus of the IGCC case studies was the development of a practical yet detailed approach to the characterization of uncertainties in the cases where expert judgments are required. One challenge to obtaining judgments is distance, which may make face-to-face interviews unpractical. Another is availability. Many experts are busy people. Thus, it is often difficult to schedule visits, particularly when several experts are to be approached. A solution to the difficulty in obtaining access to specific experts was the development of an elicitation briefing packet and the use of follow-up phone conversations to clarify expert responses to the briefing packets. This eliminated the need for complex travel arrangements, but allowed for interaction with each of the experts. The following sections describe how experts were selected and how their judgments were elicited.

\subsubsection{Identifying Experts}

The primary source for expert judgments regarding process area uncertainties was DOE/METC. METC both conducts in-house and funds externally contracted research on process technologies that are components of IGCC and other coal gasification-based systems. METC process engineers have extensive practical experience obtained from work on internal research projects and their project management work on externally funded contracts. This work includes experimental and modeling studies. Many METC process engineers also have previous employment experience with companies that have been involved in research on the process areas of interest in this study. Therefore, technical 
experts at METC were approached for their judgments regarding uncertainties. Because their expertise is strongly performance-oriented, and less cost-oriented, the focus of the uncertainty elicitations was on performance uncertainties.

Originally, four key process areas were identified for which expert judgments regarding uncertainties were desired. Briefing packets for each of these, as discussed in the following section, were developed. For each process area, specific experts at METC were identified in cooperation with METC management. However, because of personnel and time constraints within METC, only three process areas could be addressed. These are: Lurgi gasification; zinc ferrite desulfurization; and gas turbine.

Initially, three experts were selected for each of the three process areas. METC management distributed the briefing packets provided by the authors to the experts. The responses were collected and returned. For the zinc ferrite process area, all three experts responded. For the other two process areas, two of the three experts responded. For bookkeeping purposes, these experts are assigned arbitrary designations. The three zinc ferrite experts are referred to as Experts ZF-1, ZF-2, and ZF-3. The two Lurgi gasification experts are referred to as Experts LG-1 and LG-2. Similarly, the two gas turbine experts are referred to as Experts GT-1 and GT-2. Expert ZF-1 is the same person as Expert LG1.

In addition to formal elicitations of uncertainty from METC process engineers, other engineers in industry were approached for information regarding uncertainties in key process areas. However, a major obstacle to obtaining information about uncertainties for some process areas involves concern about proprietary information and the competitive position of specific companies. Several of the process areas evaluated in this study involve technologies that are considered proprietary by the companies involved in developing them, even in cases where a portion of the development is government-funded. Therefore, experts within those companies may often be reticent about providing detailed information regarding the technologies, other than that which has already been published. Thus, for those cases where companies were unable or unwilling to provide detailed information regarding their technologies, the authors relied on published information to make preliminary characterizations of uncertainty.

\section{2,1.2 Briefing Packets}

The major source of expert information regarding uncertainties involved responses to detailed briefing packets for three major process areas. A total of seven questionnaire responses were obtained from six engineers at DOE/METC. One engineer provided 
responses for two process areas. The briefing packets included three parts. These were: (1) Part 1, introduction to uncertainty analysis; (2) Part 2, technical background for uncertainties in the process area of interest; and (3) Part 3, a questionnaire regarding uncertainties in specific process area performance parameters, and in a few cases cost parameters also.

Part 1 was common to all of the process areas for which judgments were sought. It was written as an informal nine page paper. It included a discussion of the philosophy of uncertainty analysis, types of uncertain quantities, and methods for characterizing uncertainties. Part 1 is included in Appendix A.

Part 2 was specific to each process area. Packets for four major process areas were developed, including Lurgi gasification, KRW gasification, zinc ferrite desulfurization, and gas turbine. These technical background papers included a description of the process area, a description of the IGCC process environments to which the process area is applied, a review of key design and performance assumptions, and a detailed review of the specific aspects of the process areas which may contribute to uncertainty in either performance or cost. The reviews were based primarily on information in published literature. These technical background papers are included in Appendix A for each of the four process areas.

The uncertainty questionnaire, Part 3, was also specific to each process area. While questionnaires were developed for the four major process areas, only three could be distributed to experts within DOE/METC, as previously indicated. The questionnaires for the three process areas are given in Appendix A.

The questionnaires were designed to provide the expert with some flexibility in responding. For example, the expert was asked to review the key design assumptions for each process area, and to provide alternative suggestions if not happy with them. The expert was also asked to explain the basis for any changes. Similarly, the expert was given a list of parameters which the elicitor believed should be treated as uncertain. The expert was asked to examine the list, and suggest any additions or deletions. For the parameters included in the list for which the expert was able to provide judgments of uncertainty, the expert was asked to consider "worst" and "best" outcomes, before considering median or modal values. An important part of the questionnaire was to request also a basis for the judgments. The questionnaire was intended to encourage the expert to think systematically about the range and likelihood of possible outcomes for each uncertain variable, and to explain the mechanisms by which such outcomes would be obtained. In particular, the design of the questions was sensitive to some of the concerns discussed in Section 2.3, 
such as overconfidence and the tendency to obtain better judgments when explanations are required.

\subsubsection{Expert Reaction to the Briefing Packets}

The overall reaction of the experts to the briefing materials was favorable. Generally, the experts indicated that the information contained in Part 1 was more than they needed to respond to the questionnaire, although one expert noted that the examples given in Part 1 helped in framing responses to the questionnaires.

With respect to the technology-specific background papers, all comments were positive. One zinc ferrite process area expert stated in the response to the questionnaire that "the summary in Part 2 was useful, and perhaps essential to this exercise." Another zinc ferrite expert wrote, "the briefing information was needed and about the right amount of depth to stimulate thought without being too cumbersome." A Lurgi gasifier expert characterized the summary information as "useful," while the other said "Part 2 was well done." A gas turbine expert wrote, "Part 2 was very well done," and characterized the summary as "objective and unbiased." The other gas turbine expert did not respond directly to the issue of the briefing material, but indicated that the technical background paper provided a thorough summary of published information.

The response of the experts to the questionnaires varied, depending on tire constraints and the availability of information. For the Lurgi gasifier and zinc ferrite process areas, the experts responded to as many questions as the scope of their expertise allowed, and they were quite candid in pointing out questions for which they could not provide a response. For the gas turbine process area, perhaps due partly to propriety concerns that limit the information available to DOE engineers, and perhaps due to time constraints, the experts were unable to provide quantitative answers to most of the questions. The gas turbine questionnaire also was the most difficult of the three that were distributed, because it contained more questions and more detail within each question. This is because the gas turbine is common to both IGCC systems, and there are significant differences between the apl lications that require explicit characterization.

One Lurgi gasifier expert indicated that the questionnaire was "not too difficult" to respond to, and that his experience with METC's 42-inch diameter fixed bed gasifier helped him to provide judgments about the Lurgi gasifier assumed in the study. The other Lurgi gasifier expert indicated that he did not have operating experience with fixed-bed gasifiers, and that "it was difficult to develop [estimates of] the range of values for various variables due to lack of abundant actual operating data." 
The zinc ferrite experts responded similarly. One stated, "considerable thinking was required in order to provide "good" judgments." Another, who provided an alternative set of judgments in addition to the case requested, stated: "it was fairly easy to make the judgments of uncertainty; however, much thought was required to arrive at what seemed like meaningful inputs." The third zinc ferrite expert did not comment on the briefing materials.

With respect to the gas turbine questionnaire, one expert indicated that the information he would require to answer the questions was not available to him. He stated:

To answer these questions, I would need detailed and extensive statistical data in these areas. This data is not available to DOE/METC personnel. Gas turbine manufacturers would be the prime source of this data, if it exists. Usually, these data would be proprietary ...

The expert indicated that gas turbine manufacturers would be reluctant to release information of the type requested because they spend millions of dollars of internal research funds to develop new systems. Release of the results of such work could impair their competitive position. Furthermore, while manufacturers provide emission guarantees based on current regulations and market demands, they must be careful about releasing information that would subject them to "ever-racheting lower levels of emissions." Thus, the expert was unable to respond to questions about uncertainty because of the limited information available to him. However, he was able to comment on the design assumptions proposed in the questionnaire. The other responding gas turbine expert provided a broader scope of qualitative information in response to the questionnaire.

In general, the briefing packets appeared to be successful in communicating technical background information regarding the specific process areas. In most cases, particularly when the expert ! d sufficient time and a detailed knowledge base, the responses to the questionnaire:, were detailed and complete. In the case of the gas turbine process area, the questionnaire was perhaps too ambitious. An initial questionnaire focusing on just one case, such as the air-blown Lurgi system, might have been more appropriate than the lengthy questionnaire that tried to cover both IGCC systems. However, limitations in propriety information regarding the gas turbine would still limit the responses.

\subsubsection{Follow-Up Phone Interviews}

For all seven of the responses received, a follow-up phone call was made to the expert to clarify ambiguities, to obtain elaboration on the basis for specific judgments, and to obtain judgments for parameters that were either not included on the questionnaire or for 
which responses were not obtained. These phone conversations typically lasted about half an hour, with a few lasting closer to an hour. In some cases, detailed supporting information was obtained regarding mechanisms by which various outcomes could be obtained. In one case, an expert indicated that he would be willing to provide judgments about two parameters in the zinc ferrite process area that were not included in the questionnaire. These judgments were obtained during the follow-up phone conversation.

\subsubsection{Other Approaches to Characterizing Uncertainties}

In addition to the elicitation of expert judgments regarding uncertainties, two other approaches were used. One of these was the use of published information as the basis for making preliminary characterizations of uncertainty. This approach was necessary for the KRW gasification process area, for which expert judgments could not be obtained. In addition, this approach was used for many of the cost-related uncertainties. The other approach was the use of regression analysis. Regression analysis was used extensively to develop the cost models for the three IGCC systems, as detailed in the Task 2 Topical Report (Frey and Rubin, 1990). Regression models were developed for process area direct capital costs, consumable material requirements for plant operation, and auxiliary power requirements. The standard error from the regression model can be explicitly represented in a probabilistic simulation.

\subsection{Base Case Estimates of Uncertainty for the Oxygen-blown KRW- based IGCC System}

In this section, the base case assumptions regarding uncertainty in specific performance and cost parameters of the oxygen-blown KRW-based IGCC system engineering models are given. In addition, assumptions common to both IGCC systems are also given. These include financial parameters and the coal properties. More details regarding the assumptions are given in Appendix A.

The financial assumptions made for all of the IGCC systems are given in Table 8. These include the cost year in which all cost estimates are reported and financial parameters used to calculate the fixed charge factor and variable cost levelization factor. These factors are calculated using the standard approach described by EPRI (1986). Based on the assumptions in Table 8 , the fixed charge factor is $10.34 \% / y r$ and the variable cost levelization factor is 1 . The fixed charge factor is also known as the capital carrying charge or capital recovery factor, and it is the levelized annual cost for repaying the plant total capital cost as a percentage of the capital cost. Here, the fixed charge factor is calculated using an inflation rate of zero. This results in an estimate using "constant" dollars. For ail 
Table 8. Summary of the Financial Assumptions for the IGCC Case Studies.

\begin{tabular}{lll}
\hline Description & Units & Value \\
\hline Cost Year & & January 1989 \\
Chemical Engineering Plant Cost Index & (index) & 351.5 \\
Chemicals Cost Index & (index) & 411.3 \\
Construction Interest & $\% / y r$ & 10 \\
Construction Years & years & 4 \\
Booklife & years & 30 \\
Inflation Rate & $\% / y r$ & 0.0 \\
Sales Tax & $\%$ & 5 \\
Real Return on Debt & $\% / y r$ & 4.6 \\
Real Return on Preferred Stock & $\% / y r$ & 5.2 \\
Real Return on Equity & $\% / y r$ & 8.7 \\
Debt Ratio & fraction & 0.50 \\
Preferred Stock Ratio & fraction & 0.15 \\
Federal and State Tax Rate & fraction & 0.38 \\
Investment Tax Credit & fraction & 0.0 \\
Property Taxes and insurance & $\% / y r$ & 2.0 \\
\hline
\end{tabular}

of the IGCC systems, an unwashed Illinois No. 6 coal is assumed. The characteristics of the assumed coal are given in Table 9.

The key assumptions regarding parameters for the oxygen-blown KRW-based IGCC system with cold gas cleanup are summarized in Table 10. A total of 41 parameters are treated as uncertain. These include assumptions regarding the performance of the gasifier and gas turbine process areas, capital cost parameters, direct capital cost, maintenance costs, labor rate, unit costs, and regression model error terms for direct capital and auxiliary power models. The deterministic values used here are based on assumptions used in published design studies.

For this IGCC system, the characterizations of uncertainty were developed by the authors. Estimates of uncertainty in the gasification and gas turbine process areas are based on detailed reviews of technical information. The technical background information and the basis for each of the uncertainties for these two process areas are discussed in detail in Appendices A.2 and A.4, respectively. From the technical reviews, model parameters which were believed to be uncertain and to significantly affect either plant performance, emirsions, or cost were selected for uncertainty analysis.

The estimates of uncertainty in the capital cost parameters, including engineering and home office fees, indirect construction factor, and project uncertainty, are based on 
Table 9. Characteristics of the Coal Assumed for IGCC System Studies

$\begin{array}{lr}\text { Proximate Analysis, wt-\%, run-of-mine basis } & \\ \text { Moisture } & 12.0 \\ \text { Fixed Carbon } & 47.8 \\ \text { Volatile Matter } & 31.4 \\ \text { Ash } & 8.8 \\ \text { Ultimate Analysis, wt-\%, dry basis } & 69.53 \\ \text { Carbon } & 5.33 \\ \text { Hydrogen } & 1.25 \\ \text { Nitrogen } & 0.00 \\ \text { Chlorine } & 3.86 \\ \text { Sulfur } & 10.03 \\ \text { Oxygen } & 10.00 \\ \text { Ash } & 2,300\end{array}$

typical ranges of values for these parameters suggested by EPRI (1986). The basis for these estimates is discussed further in Appendix A.5.1.

For the direct costs, the deterministic values reported in Table 10 represent the process contingency factors assumed in published design studies (e.g., Dawkins et al, 1985). As a preliminary characterization of uncertainty in capital cost, it was assumed that the process contingency factors were intended to represent the mid-point of a symmetric uncertainty distribution for process area direct cost. The relative magnitudes of the contingency factor was assumed to suggest the relative magnitude of the variances that should be used between process areas. As a best case assumption, it was assumed that the capital cost would be no lower than the unadjusted estimate obtained from the direct cost models. As a worst case assumption, it was assumed that the cost could be equivalent to that obtained with double the nominal contingency factor. The one exception is the low temperature gas cooling process area, which is represented in the literature as being commercial available without any technical risk. For this process area, a chance of a small decrease in cost compared to the direct cost model estimate is assumed. In most cases, a uniform distribution between the best and worst values was assumed, while in a few other cases, a triangular distribution was assumed. The effect of a triangular distribution, compared to a uniform distribution, is to place more "weight" on the outcomes near the published contingency factor then on the extreme high or low outcomes. The triangular distribution was used in cases where the authors felt that the published contingency factors were carefully developed. 
Table 10. Summary of the Base Case Parameters Values and Uncertainties for the OxygenBlown KRW-based IGCC System with Cold Gas Cleanup.

\begin{tabular}{|c|c|c|c|c|c|c|c|}
\hline Description & Units & Deterministic & Distribution & \multicolumn{4}{|c|}{ Parameters ${ }^{a}$} \\
\hline GASIEIER PROCESS & EA & & & & & & \\
\hline Gasifier Pressure & psia & 465 & & & & & \\
\hline Gasifier Temperature & of & 1,850 & & & & & \\
\hline $\begin{array}{l}\text { Overall Carbon } \\
\text { Conversion }\end{array}$ & $\begin{array}{l}\text { wt-\% of feed } \\
\text { coal carbon }\end{array}$ & 95 & Triangular & 75 & to & 95 & $(95)$ \\
\hline Oxygen/Carbon Ratio & lbmole $\mathrm{O}_{2} / \mathrm{C}$ & 0.34 & Uniform & 0.33 & to & 0.35 & \\
\hline Steam/Oxygen Ratio & lbmole $\mathrm{H}_{2} \mathrm{O} / \mathrm{O}_{2}$ & 1.35 & Uniform & 1.1 & to & 1.6 & \\
\hline $\begin{array}{l}\text { Sulfur Retention in } \\
\text { Bottom Ash }\end{array}$ & $\begin{array}{l}\text { mol-\% of } \\
\text { inlet sulfur }\end{array}$ & 15 & Triangular & 10 & to & 20 & $(15)$ \\
\hline GAS TURBINE PRO & SAREA & & & & & & \\
\hline Pressure Ratio & ratio & 13.5 & & & & & \\
\hline Turbine Inlet Temp & oF & 2,300 & & & & & \\
\hline Exhaust Flow & $\mathrm{lb} / \mathrm{sec}$ & 938 & & & & & \\
\hline Thermal $\mathrm{NO}_{\mathrm{x}}$ & $\begin{array}{l}\text { fraction of air } \\
\text { nitrogen fixated }\end{array}$ & $5.0 \times 10^{-5}$ & Uniform & $2.5 \times 10^{-5}$ & to & & $7.5 \times 10^{-5}$ \\
\hline Unconverted $\mathrm{CO}$ & $\begin{array}{l}\text { wt-\% of CO } \\
\text { in fuel gas }\end{array}$ & 0.99985 & Uniform & 0.9998 & to & & 0.9999 \\
\hline CAPITAL COST PAF & AETERS & & & & & & \\
\hline $\begin{array}{l}\text { Engineering and } \\
\text { Home Office Fee }\end{array}$ & fraction & 0.10 & Triangular & 0.07 & to & 0.13 & $(0.10)$ \\
\hline $\begin{array}{l}\text { Indirect Construction } \\
\text { Cost Factor }\end{array}$ & fraction & 0.20 & Triangular & 0.15 & to & 0.25 & $(0.20)$ \\
\hline Project Uncertainty & fraction & 0.175 & Uniform & 0.10 & to & 0.25 & \\
\hline General Facilities & fraction & 0.20 & & & & & \\
\hline DIRECT COSTS ${ }^{b}$ & & & & & & & \\
\hline Coal Handling & $\%$ of DC & 5 & Uniform & 0 & to & 10 & \\
\hline Oxidant Feed & $\%$ of $D C$ & 5 & Uniform & 0 & to & 10 & \\
\hline Gasification & $\%$ of $\mathrm{DC}$ & 20 & Triängular & 0 & to & 40 & (20) \\
\hline Selexol & $\%$ of $D C$ & 10 & Triangular & 0 & to & 20 & (10) \\
\hline $\begin{array}{c}\text { Low Temperature } \\
\text { Gas Cooling }\end{array}$ & $\%$ of DC & 0 & Triangular & -5 & to & 5 & $(0)$ \\
\hline Claus Plant & $\%$ of $D C$ & 5 & Triangular & 0 & to & 10 & (5) \\
\hline Beavon-Stretford & $\%$ of $D C$ & 10 & Triangular & 0 & to & 20 & (10) \\
\hline Boiler Feed Water & $\%$ of DC & 0 & & & & & \\
\hline $\begin{array}{l}\text { Process Condensate } \\
\text { Treatment }\end{array}$ & $\%$ of $L C$ & 30 & Triangular & 0 & to & 50 & (30) \\
\hline
\end{tabular}


Table 10 (Continued). Summary of the Base Case Parameters Values and Uncertainties for the Oxygen-Blown KRW-based IGCC System with Cold Gas Cleanup.

\begin{tabular}{|c|c|c|c|c|c|c|c|}
\hline \multirow{3}{*}{$\begin{array}{l}\text { Description } \\
\text { Gas Turbine }\end{array}$} & \multirow{3}{*}{$\begin{array}{l}\text { Units } \\
\% \text { of DC }\end{array}$} & \multirow{3}{*}{$\begin{array}{c}\begin{array}{c}\text { Determinis } \\
\text { Value }\end{array} \\
12.5\end{array}$} & \multirow{3}{*}{$\frac{\text { Distribution }}{\text { Uniform }}$} & \multirow{2}{*}{\multicolumn{4}{|c|}{ Parameters $^{\mathbf{a}}$}} \\
\hline & & & & & & & \\
\hline & & & & 0 & to & 25 & \\
\hline HRSG & $\%$ of DC & 2.5 & Uniform & 0 & to & 5 & \\
\hline Steam Turbine & $\%$ of $\mathrm{DC}$ & 2.5 & Uniform & 0 & to & 5 & \\
\hline General Facilities & $\%$ of DC & 5 & Uniform & 0 & to & 10 & (5) \\
\hline \multicolumn{8}{|c|}{ MAINTENANCE COSTS } \\
\hline Coal Handling & $\%$ of $\mathrm{TC}$ & 3 & & & & & \\
\hline Oxidant Feed & $\%$ of $\mathrm{TC}$ & 2 & & & & & \\
\hline Gasification & $\%$ of TC & 4.5 & Triangular & 3 & to & 6 & (4.5) \\
\hline Selexol & $\%$ of TC & 2 & Triangular & 1.5 & to & 4 & (2) \\
\hline $\begin{array}{c}\text { Low Temperature } \\
\text { Gas Cooling }\end{array}$ & $\%$ of TC & 3 & Triangular & 2 & to & 4 & (3) \\
\hline Claus Plant & $\%$ of TC & 2 & Triangular & 1.5 & to & 2.5 & (2) \\
\hline Beavon-Stretford & $\%$ of TC & 2 & & & & & \\
\hline Boiler Feed Water & $\%$ of TC & 1.5 & & & & & \\
\hline Process Condensate & & & & & & & \\
\hline Treatment & $\%$ of TC & 2 & Triangular & 1.5 & to & 4 & (2) \\
\hline Gas Turbine & $\%$ of TC & 1.5 & Triangular & 1.5 & to & 2.5 & (1.5) \\
\hline HRSG & $\%$ of TC & 1.5 & & & & & \\
\hline Steam Turbine & $\%$ of TC & 1.5 & & & & & \\
\hline General Facilities & $\%$ of $\mathrm{TC}$ & 1.5 & & & & & \\
\hline \multicolumn{8}{|c|}{ OTHER FIXED OPERATING COST PARAMETERS } \\
\hline Labor Rate & $\$ / h r$ & 19.70 & Normal & 17.70 & to & 21.70 & \\
\hline \multicolumn{8}{|c|}{ VARIABLE OPERATING COST PARAMETLRS } \\
\hline Ash Disposal & $\$ /$ ton & 10 & Triangular & 10 & to & 25 & $(10)$ \\
\hline Sulfur Byproduct & $\$ /$ ton & 125 & Triangular & 60 & to & 125 & $(125)$ \\
\hline Byproduct Marketing & fraction & 0.10 & Triangular & 0.05 & to & 0.15 & $(0.10)$ \\
\hline \multicolumn{8}{|c|}{ DIRECT COST REGRESSION MODEL ERROR TERMS ${ }^{d}$} \\
\hline KRW Coal Handling & \$ Million & 0 & Normal & -10 & to & 10 & \\
\hline Oxygen Plant & multiplier & 1.012 & Lognormal & 0.78 & to & 1.29 & \\
\hline KRW Gasification & $\$$ Million & 0 & Normal & -20.5 & to & 20.5 & \\
\hline $\begin{array}{c}\text { Low Temperature } \\
\text { Gas Cooling }\end{array}$ & \$ Million & 0 & N/A & & & & \\
\hline Selexol & \$ Million & 0 & Normal & -5.1 & to & 5.1 & \\
\hline Claus & $\$$ Million & 0 & N/A & & & & \\
\hline Beavon-Stretford & $\$$ Million & 0 & N/A & & & & \\
\hline
\end{tabular}


Table 10 (Continued). Summary of the Base Case Parameters Values and Uncertainties for the Oxygen-Blown KRW-based IGCC System with Cold Gas Cleanup.

\begin{tabular}{|c|c|c|c|c|c|c|}
\hline \multicolumn{7}{|c|}{ Deterministic } \\
\hline Boiler Feedwater & $\$$ Million & 0 & $\mathrm{~N} / \mathrm{A}$ & & & \\
\hline Process Condensate & \$ Million & 0 & N/A & & & \\
\hline HRSG & \$ Million & 0 & Normal & -17.3 & to & 17.3 \\
\hline Steam Turbine & \$ Million & 0 & Normal & -15.8 & to & 15.8 \\
\hline \multicolumn{7}{|c|}{ AUXILIARY POWER REGRESSION MODEL ERROR TERMS } \\
\hline KRW Coal Handling & MW & 0 & Normal & -1.6 & to & 1.6 \\
\hline Oxygen Plant & MW & 0 & Normal & -6.6 & to & 6.6 \\
\hline $\begin{array}{l}\text { KRW Gasification } \\
\text { Low Temperature }\end{array}$ & MW & 0 & Normal & -0.52 & to & 0.52 \\
\hline Gas Cooling & MW & 0 & $\mathrm{~N} / \mathrm{A}$ & & & \\
\hline Selexol & MW & 0 & Normal & -0.55 & to & 0.55 \\
\hline Claus Plant & MW & 0 & N/A & & & \\
\hline Beavon-Stretford & MW & 0 & N/A & & & \\
\hline Boiler Feedwater & MW & 0 & N/A & & & \\
\hline Process Condensate & MW & 0 & $\mathrm{~N} / \mathrm{A}$ & & & \\
\hline General Facilities & MW & 0 & N/A & & & \\
\hline
\end{tabular}

a For Uniform distributions, the lower and upper bounds are given. For the triangular distribution, the mode is given in parentheses. For the fractile distribution, the lower and upper bounds for each range are given, along with the probability of sampling within that range. For normal and lognormal distributions, the 99.8 percent probability range is given.

b For direct costs, the deterministic values represent "contingency factors" as defined by EPRI (1986) and others. For probabilistic studies, uncertainty in capital cost is represented by an uncertainty factor, which is described by a probability distribution. $D C=$ process area direct cost.

$\mathrm{c} \mathrm{TC}=$ process area total cost, including indirects and contingency

$d$ Negligibly small error terms were not included in the simulation. 
An exception to the approach described above is the estimate of uncertainty in the gas turbine process area. Design studies tend to assume very low contingency factors (e.g., five percent or less) for this process area, in spite of the fact that the gas turbine requires modifications to the fuel valve to handle medium-BTU coal gas. Gas turbine capital cost uncertainty is discussed further in Appendix A.4.

Similar to the estimates of uncertainty in direct cost, estimates of uncertainty in maintenance cost factors use published deterministic values as a starting point. However, in many cases it is believed that it is more likely that maintenance costs would increase than decrease compared to the deterministic values. The underlying reason for this belief is that IGCC systems must handle material streams containing various contaminants derived from coal conversion. These contaminants are likely to cause deposition, erosion, and corrosion problems in various parts of the system, or to cause deactivation of solvents or catalysts. A response to such problems would be increased maintenance. The basis for these judgments is discussed also in Appendix A.5.3.

Other operating cost parameters include the operating labor rate, unit costs for ash disposal and byproduct sales, and a factor to account for byprodust marketing costs. These uncertainties are discussed in Appendix A.5.4.

The last category of uncertainties include regression model error terms for both direct cost and auxiliary power requirement models. These models were developed as part of the IGLC cost models. The error terms are derived from statistical analysis of the models. See the Task 2 Topical Report (Frey and Rubin, 1990) for details regarding these models and Appendix A.5.5 for a brief summary of the regression model error terms.

\subsection{Estimates of Uncertainty for the Air-blown Lurgi-based IGCC System}

The base case assumptions regaruing the values and distributions for key model parameters for the Lurgi-based IGCC system are summarized in the next section. For two process areas, there are alternative assumptions regarding performance uncertainties. For example, there are four sets of assessments of uncertainty for the zinc ferrite process area. Similarly, there are two sets of assessments of uncertainties in the performance of the fixed bed gasifier. A few examples of the uncertainty judgments of different experts are illustrated in Section 4.4.2. However, these alternative cases are not summarized in detail here in the main body of the report. i. stead, they are documented in detail in Appendix A. 


\subsubsection{Base Case Assumptions}

The base case deterministic and uncertainty assumptions for the air-blown Lurgibased IGCC system are summarized in Table 11. A total of 47 performance and cost parameters are treated probabilistically. Performance uncertainties in three major process areas are characterized. These process areas are Lurgi gasification, zinc ferrite desulfurization, and gas turbine. For the gasification process area, the judgments of Expert LG-1 are taken as the base case assumptions. Expert LG-1 provided uncertainty characterizations for nine process performance variables. Notably, Expert LG-1 provided estimates of gasifier coal throughput conditioned on the gasifier pressure, and estimates of the gasifier steam requirement conditioned on the gasifier oxidant requirement. The latter is a case in which the expert explicitly considcred the correlation structure between two uncertainties. In later comparative case studies, the judgment of Expert LG-2 is also used.

For the zinc ferrite process areas, the judgments of Expert ZF-1 are taken as a base case. The judgment sets LG-1 and ZF-1 are the only pair of separate process areas for which judgments were obtained from the same individual. Expert ZF-1 provided estimates of uncertainties for five parameters in the zinc ferrite process area, as well as suggestions for other key deterministic design assumptions, which are included in Table 11. The judgments obtained from Experts ZF-2 and ZF-3 are also considered in later comparative analysis.

Complete details regarding the technical judgments of the gasification and zinc ferrite desulfurization experts are given in Appendix A. The basis for the estimates by Expert LG-1 are discussed in detail in Appendix A.2. The judgments of Expert ZF-1 are discussed in Appendix A.3. The judgments of the other gasifier and zinc ferrite experts are also described in Appendicr:s A.2 and A.3, respectively.

The estimates of uncertainty in the gas turbine process area were developed by the authors based on published data and discuss ons with process engineers, as discussed in Appendix A.4. The capital cost parameter, direct cost, maintenance cost, labor rate, unit cost, and regression model uncertainties were estimated in the same manner as for the KRW system. See Appendix A.5 for more discussion of these. 
Table 11. Summary of the Base Case Parameter Values and Uncertainties for the AirBlown Lurgi-based IGCC System with Hot Gas Cleanup.

\begin{tabular}{|c|c|c|c|c|c|c|c|}
\hline & & eterminis & & & & & \\
\hline Description & Units & Value & Distribution & & rame & $e r s^{a}$ & \\
\hline GASIEIER PROCESS & REA & & & & & & \\
\hline Gasifier Pressure & psia & alculated) & & & & & \\
\hline Gasifier Temperature & ${ }^{\circ} \mathrm{F}$ & 1,100 & & & & & \\
\hline $\begin{array}{l}\text { Fines Carryover } \\
\text { from Gasifier }\end{array}$ & $\begin{array}{l}\text { wt- } \% \text { of } \\
\text { Coal Feed }\end{array}$ & 5.0 & Fractile & $\begin{array}{r}5 \%: \\
20 \%: \\
25 \%: \\
25 \%: \\
15 \%: \\
5 \%: \\
5 \%:\end{array}$ & $\begin{array}{r}0 \\
1 \\
3.5 \\
5 \\
8 \\
15 \\
20\end{array}$ & $\begin{array}{l}\text { to } \\
\text { to } \\
\text { to } \\
\text { to } \\
\text { to } \\
\text { to } \\
\text { to }\end{array}$ & $\begin{array}{r}1 \\
3.5 \\
5 \\
8 \\
15 \\
20 \\
30\end{array}$ \\
\hline $\begin{array}{l}\text { Fines Capture in } \\
\text { Recycle Cyclone }\end{array}$ & $\begin{array}{l}\% \text { of } \\
\text { Carryover }\end{array}$ & 95 & Fractile & $\begin{array}{l}25 \%: \\
25 \%: \\
25 \%: \\
25 \%:\end{array}$ & $\begin{array}{l}50 \\
90 \\
95 \\
97\end{array}$ & $\begin{array}{l}\text { to } \\
\text { to } \\
\text { to } \\
\text { to }\end{array}$ & $\begin{array}{l}90 \\
95 \\
97 \\
98\end{array}$ \\
\hline $\begin{array}{c}\text { Fines Carbon } \\
\text { Content }\end{array}$ & $\begin{array}{l}\text { wt-\% of } \\
\text { fines }\end{array}$ & 79 & Fractile & $\begin{array}{r}5 \%: \\
20 \%: \\
25 \%: \\
25 \%: \\
25 \%:\end{array}$ & $\begin{array}{l}65 \\
70 \\
75 \\
79 \\
84\end{array}$ & $\begin{array}{l}\text { to } \\
\text { to } \\
\text { to } \\
\text { to } \\
\text { to }\end{array}$ & $\begin{array}{l}70 \\
75 \\
79 \\
84 \\
87\end{array}$ \\
\hline $\begin{array}{l}\text { Carbon Retention } \\
\text { in Bottom Ash }\end{array}$ & $\begin{array}{l}\text { wt-\% of coal } \\
\text { feed carbon }\end{array}$ & 2.5 & Triangular & 0.75 & to & 10 & $(2.5)$ \\
\hline $\begin{array}{l}\text { Sulfur Retention } \\
\text { in Bottom Ash }\end{array}$ & $\begin{array}{l}\text { wt-\% of coal } \\
\text { feed sulfur }\end{array}$ & 3.0 & Triangular & 1.5 & to & 6 & (3) \\
\hline Gasifier Coal Throughpu & & & & & & & \\
\hline 250 psia & lb DAF/(hr-ft $\left.{ }^{2}\right)$ & 266 & Triangular & 133 & to & 333 & (266) \\
\hline $300 \mathrm{psia}$ & $\mathrm{lb} \mathrm{DAF} /\left(\mathrm{hr}-\mathrm{ft}^{2}\right)$ & 305 & Triangular & 152 & to & 381 & (305) \\
\hline $350 \mathrm{psia}$ & lb DAF/(hr-ft $\left.{ }^{2}\right)$ & 341 & Triangular & 170 & to & 426 & (341) \\
\hline $\begin{array}{l}\text { Gasifier Ammonia } \\
\text { Yield }\end{array}$ & $\begin{array}{l}\text { Equiv. fraction } \\
\text { of coal } \mathrm{N} \text { to } \mathrm{NH}_{3}\end{array}$ & 0.9 & Triangular & 0.5 & to & 1.0 & $(0.9)$ \\
\hline Gasifier Air/Coal Ratio & lb air/lb DAF & 3.1 & Triangular & 2.7 & to & 3.4 & $(3.1)$ \\
\hline $\begin{aligned} \text { Gasifier Steam Requirem } & \\
\text { Air } / \text { coal } & =2.7 \\
\text { Air } / \text { coal } & =3.1 \\
\text { Air } / \text { coal } & =3.4\end{aligned}$ & $\begin{array}{l}\mathrm{nt} \\
\mathrm{lb} \mathrm{H}_{2} \mathrm{O} / \mathrm{lb} \mathrm{DAF} \\
\mathrm{lb} \mathrm{H} \mathrm{H}_{2} \mathrm{O} / \mathrm{lb} \mathrm{DAF} \\
\mathrm{lb} \mathrm{H}_{2} \mathrm{O} / \mathrm{lb} \mathrm{DAF}\end{array}$ & $\begin{array}{l}0.81 \\
1.55 \\
2.38\end{array}$ & $\begin{array}{l}\text { Uniform } \\
\text { Uniform } \\
\text { Uniform }\end{array}$ & $\begin{array}{l}0.54 \\
1.24 \\
2.04\end{array}$ & $\begin{array}{l}\text { to } \\
\text { to } \\
\text { to }\end{array}$ & $\begin{array}{l}1.08 \\
1.86 \\
2.72\end{array}$ & \\
\hline ZINC EERRITE DESUI & FURIZATION PRO & CESS A & & & & & \\
\hline $\begin{array}{c}\text { Residual Sulfate After } \\
\text { Oxidative Regen. }\end{array}$ & $\begin{array}{l}\text { mol-\% of } \\
\text { captured S }\end{array}$ & 7.5 & Triangular & 3 & to & 11 & $(7.5)$ \\
\hline $\begin{array}{l}\text { Residual Sulfide After } \\
\text { Reductive Regen. }\end{array}$ & $\begin{array}{l}\text { mol-\% of } \\
S \text { in sulfate }\end{array}$ & 85 & Triangular & 50 & to & 90 & (85) \\
\hline Sorbent Sulfur Loading & $\begin{array}{l}\text { wt-\% } \mathrm{S} \text { in } \\
\text { sorbent }\end{array}$ & 17 & Normal & 2.16 & to & 31.84 & (17) \\
\hline
\end{tabular}

(Continued on next page) 
Table 11 (Continued). Summary of the Base Case Parameter Values and Uncertainties for the Air-Blown Lurgi-based IGCC System with Hot Gas Cleanup.

\begin{tabular}{|c|c|c|c|c|c|c|c|}
\hline \multirow{2}{*}{$\frac{\text { Description }}{\text { Sorbent Attrition Rate }}$} & \multirow{2}{*}{$\begin{array}{l}\text { Units } \\
\begin{array}{l}\text { wt-\% sorbent } \\
\text { loss/cycle }\end{array}\end{array}$} & \multirow{2}{*}{$\begin{array}{c}\begin{array}{c}\text { Deterministic } \\
\text { Value }\end{array} \\
1.0\end{array}$} & \multirow{2}{*}{$\begin{array}{l}\text { Distribution } \\
\text { Fractile }\end{array}$} & \multicolumn{4}{|c|}{ Parameters ${ }^{a}$} \\
\hline & & & & $\begin{array}{r}5 \%: \\
20 \%: \\
25 \%: \\
25 \%: \\
20 \%: \\
5 \%:\end{array}$ & $\begin{array}{r}0.17 \\
0.34 \\
0.5 \\
1 \\
1.5 \\
5\end{array}$ & $\begin{array}{l}\text { to } \\
\text { to } \\
\text { to } \\
\text { to } \\
\text { to } \\
\text { to }\end{array}$ & $\begin{array}{r}0.34 \\
0.5 \\
1 \\
1.5 \\
5 \\
25\end{array}$ \\
\hline Absorber Pressure Drop & $\mathrm{psi} / \mathrm{ft}$ bed height & 0.4 & Triangular & 0.29 & to & 0.53 & $(0.4)$ \\
\hline Absorption Cycle Time & hours & 30 & & & & & \\
\hline Max. Vessel Diameter & $\mathrm{ft}$ & 12.5 & & & & & \\
\hline Max. Vessel Height & $\mathrm{ft}$ & 37.5 & & & & & \\
\hline \multicolumn{8}{|c|}{ GAS TURBINEPROCESS AREA } \\
\hline Turbine Inlet Temp & $\mathrm{oF}$ & 2,300 & & & & & \\
\hline Exhaust Flow & $\mathrm{lb} / \mathrm{sec}$ & 938 & & & & & \\
\hline Thermal $\mathrm{NO}_{\mathrm{x}}$ & $\begin{array}{l}\text { fraction of air } \\
\text { nitrogen fixated }\end{array}$ & $4.25 \times 10^{-5}$ & Uniform & $1.0 \times 10^{-5}$ & to & & $7.5 \times 10^{-5}$ \\
\hline Fuel $\mathrm{NO}_{\mathrm{x}}$ & $\begin{array}{l}\% \text { conversion of } \\
\mathrm{NH}_{3} \text { to } \mathrm{NO}_{x}\end{array}$ & 90 & Triangular & 50 & to & 100 & (90) \\
\hline Unconverted $\mathrm{CO}$ & $\begin{array}{l}\text { wt-\% of CO } \\
\text { in fuel gas }\end{array}$ & 0.9885 & Uniform & 0.9772 & to & & 0.9999 \\
\hline \multicolumn{8}{|c|}{ CAPITAL COST PARAMETERS } \\
\hline $\begin{array}{l}\text { Engineering and } \\
\text { Home Office Fee }\end{array}$ & fraction & 0.10 & Triangular & 0.07 & to & 0.13 & $(0.10)$ \\
\hline $\begin{array}{l}\text { Indirect Construction } \\
\text { Cost Factor }\end{array}$ & fraction & 0.20 & Triangular & 0.15 & to & 0.25 & $(0.20)$ \\
\hline Project Uncertainty & fraction & 0.175 & Uniform & 0.10 & to & 0.25 & \\
\hline General Facilities & fraction & 0.20 & & & & & \\
\hline \multicolumn{8}{|l|}{ DIRECT COSTS ${ }^{b}$} \\
\hline Coal Handling & $\%$ of DC & 5 & Uniform & 0 & to & 10 & \\
\hline Oxidant Feed & $\%$ of DC & 10 & Uniform & 0 & to & 20 & \\
\hline Gasification & $\%$ of DC & 20 & Uniform & 10 & to & 30 & \\
\hline Cyclones & $\%$ of DC & 5 & Uniform & 0 & to & 10 & \\
\hline Zinc Ferrite & $\%$ of $\mathrm{DC}$ & 40 & Uniform & 0 & to & 80 & \\
\hline Sulfuric Acid Plant & $\%$ of $\mathrm{DC}$ & 10 & Uniform & 0 & to & 20 & \\
\hline Boiler Feed Water & $\%$ of $\mathrm{DC}$ & 0 & & & & & \\
\hline Gas Turbine & $\%$ of DC & 25 & Uniform & 0 & to & 50 & \\
\hline HRSG & $\%$ of $D C$ & 2.5 & Uniform & 0 & to & 5 & \\
\hline Steam Turbine & $\%$ of $\mathrm{DC}$ & 2.5 & Uniform & 0 & to & 5 & \\
\hline General Facilities & $\%$ of DC & 5 & Uniform & 0 & to & 10 & \\
\hline
\end{tabular}

(Continued on next page) 
Table 11 (Continued). Summary of the Base Case Parameter Values and Uncertainties for the Air-Blown Lurgi-based IGCC System with Hot Gas Cleanup.

\begin{tabular}{|c|c|c|c|c|c|c|c|}
\hline Description & Units & $\begin{array}{l}\text { etermini } \\
\text { Value }\end{array}$ & Distribution & \multicolumn{4}{|c|}{ Parameters ${ }^{\mathrm{a}}$} \\
\hline \multicolumn{8}{|c|}{ MAINTENANCE COSTS ${ }^{c}$} \\
\hline Coal Handling & $\%$ of TC & 3 & & & & & \\
\hline Oxidant Feed & $\%$ of TC & 2 & Triangular & 1 & to & 3 & (2) \\
\hline Gasification & $\%$ of TC & 3 & Triangular & 2 & to & 12 & (3) \\
\hline Cycknes & $\%$ of TC & 3 & Triangular & 1.5 & to & 4.5 & (3) \\
\hline Zinc Ferrite & $\%$ of TC & 3 & Triangular & 3 & to & 6 & (3) \\
\hline Sulfuric Acid Plant & $\%$ of TC & 2 & & & & & \\
\hline Boiler Feed Water & $\%$ of TC & 1.5 & & & & & \\
\hline Gas Turbine & $\%$ of $\mathrm{TC}$ & 2 & Triangular & 1.5 & to & 6 & (2) \\
\hline HRSG & $\%$ of TC & 1.5 & & & & & \\
\hline Steam Turbine & $\%$ of TC & 1.5 & & & & & \\
\hline General Facilities & $\%$ of TC & 1.5 & & & & & \\
\hline \multicolumn{8}{|c|}{ OTHER FIXED OPERATING COST PARAMETERS } \\
\hline Labor Rate & $\$ / \mathrm{hr}$ & 19.70 & Normal & 17.70 & to & 21.70 & \\
\hline \multicolumn{8}{|c|}{ VARIABLE OPERATING COST PARAMETERS } \\
\hline Zinc Ferrite Sorbent & $\$ / 1 b$ & 3.00 & Triangular & 0.75 & to & 5.00 & $(3.00)$ \\
\hline Ash Disposal & $\$ /$ ton & 10 & Triangular & 10 & to & 25 & $(10)$ \\
\hline Sulfuric Acid Byproduct & $\$ /$ ton & 40 & Triangular & 0 & to & 60 & $(40)$ \\
\hline Byproduct Marketing & fraction & 0.10 & Triangular & 0.05 & to & 0.15 & $(0.10)$ \\
\hline \multicolumn{8}{|c|}{ DIRECT COST REGRESSION MODEL ERROR TERMS } \\
\hline Boiler Feedwater & multiplier & 0 & Normal & -0.78 & to & 0.78 & \\
\hline HRSG & \$ Million & 0 & Normal & -17.3 & to & 17.3 & \\
\hline Steam Turbine & $\$$ Million & 0 & Normal & -15.8 & to & 15.8 & \\
\hline Boost Air Compressor & \$ Million & 0 & Normal & -0.66 & to & 0.66 & \\
\hline Lurgi Coal Handling & $\$$ Million & 0 & Normal & -14.4 & to & 14.4 & \\
\hline Sulfuric Acid Plant & $\$$ Million & 0 & Normal & -4.0 & to & 4.0 & \\
\hline \multicolumn{8}{|c|}{ AUXILIARY POWER REGRESSION MODEL ERROR TERMS } \\
\hline Lurgi Coal Handling & MW & 0 & Normal & -0.35 & to & 0.35 & \\
\hline
\end{tabular}

${ }^{a}$ For Uniform distributions, the lower and upper bounds are given. For the triangular distribution, the mode is given in parentheses. For the fractile distribution, the lower and upper bounds for each range are given, along with the probability of sampling within that range. For normal and lognormal distributions, the 99.8 percent probability range is given.

b For direct costs, the deterministic values represent "contingency factors" as defined by EPRI (1986) and others. For probabilistic studies, uncertainty in capital cost is represented by an uncertainty factor, which is described by a probability distribution. $\mathrm{DC}=$ process area direct cost.

$\mathrm{c} \mathrm{TC}=$ process area total cost, including indirects and contingency 


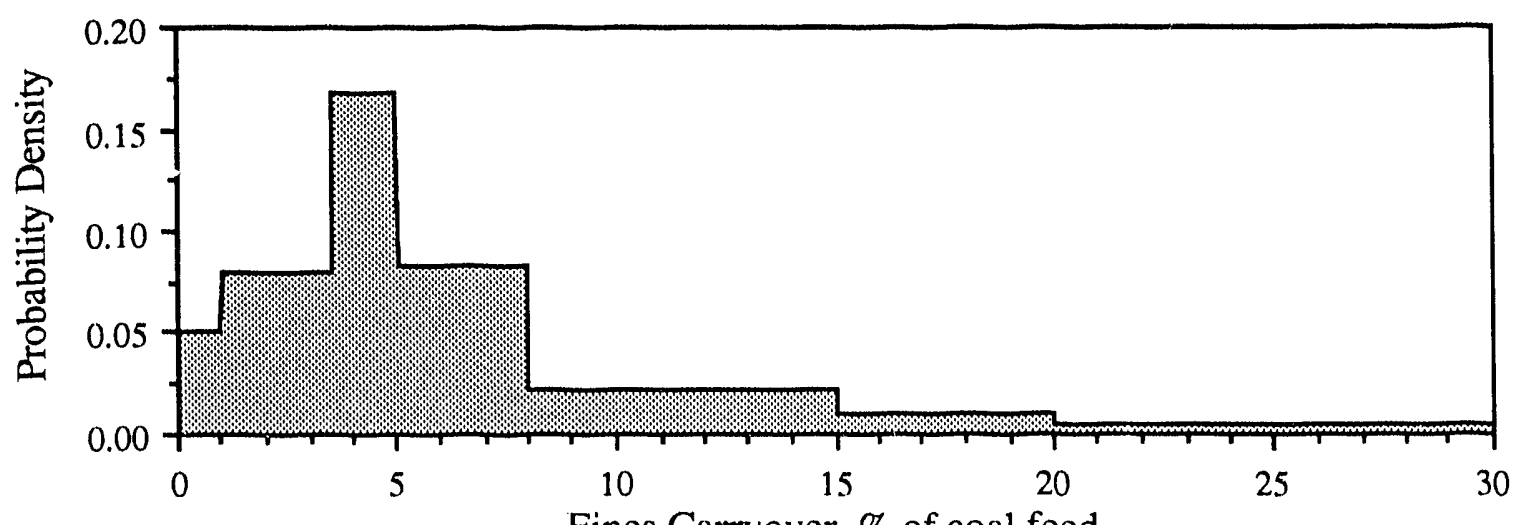

Fines Carryover, $\%$ of coal feed

Figure 11. Judgment of Expert LG-1 Regarding Uncertainty in Gasifier Fines Carryover.

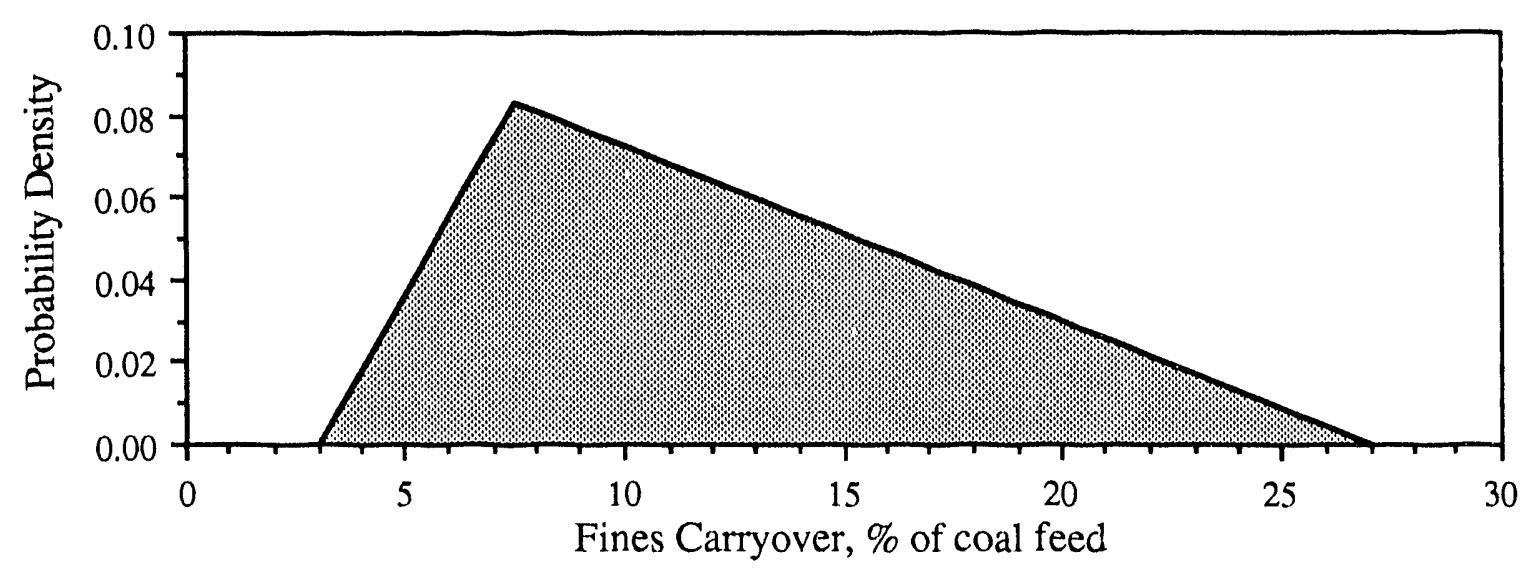

Figure 12. Judgment of Expert LG-2 Regarding Uncertainty in Gasifier Fines Carryover.

\subsubsection{Alternative Expert Judgments}

As indicated previously, for two of the major process areas for the Lurgi-based IGCC system, technical judgments regarding uncertainties were obtained from more than one expert. A few examples of how different experts characterized uncertainties for a few key performance parameters are summarized here. Additional detail regarding these judgments is given in Appendix A.

Two experts provided responses regarding uncertainties in the Lurgi gasification process area. Their judgments for a few key performance parameters are compared graphically. One parameter in the gasification process area which affects plant performance is the coal fines carryover from the gasifier into the exiting raw fuel gas. In the design assumed here, 30 percent of the coal feed, on a weight basis, consists of coal fines less than $1 / 4$ inch in size. There is uncertainty regarding what portion of the coal fines may simply pass through the gasifier into the exiting raw gas without conversion. The judgments of Experts LG-1 and LG-2 regarding uncertainty in gasifier fines carryover are shown graphically in Figures 11 and 12, respectively. 


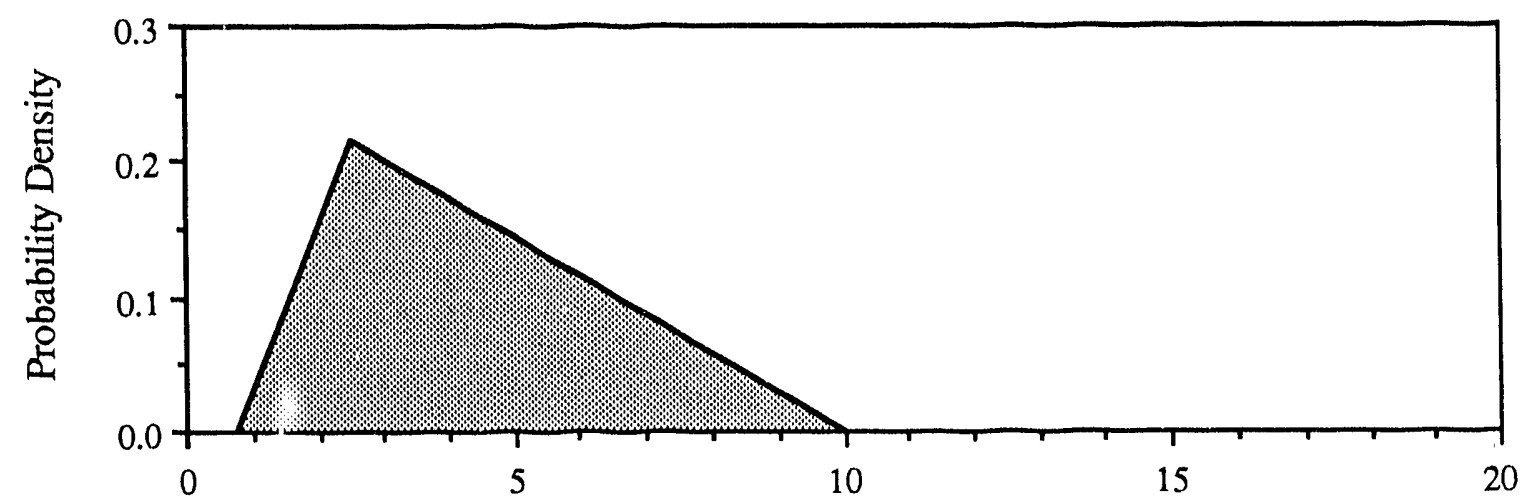

Carbon Retention in Bottom Ash, \% of coal feed carbon

Figure 13. Judgment of Expert LG-1 Regarding Uncertainty in Carbon Retention in Gasifier Bottom Ash.

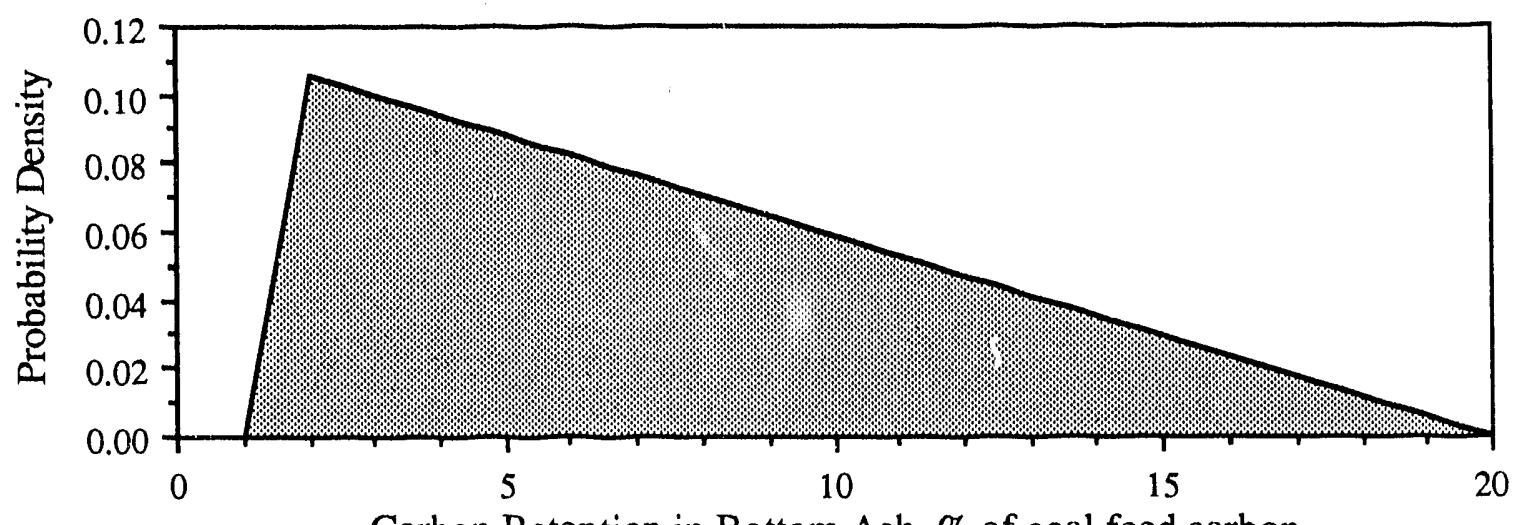

Carbon Retention in Bottom Ash, \% of coal feed carbon

Figure 14. Judgment of Expert LG-2 Regarding Uncertainty in Carbon Retention in Gasifier Bottom Ash.

The two experts made qualitatively similar judgments, although they chose to express their judgments using two different types of probability distributions. Both experts indicated that the uncertainty in coal fines carryover is positively skewed. The judgment of Expert LG-1 was that the coal fines carryover is likely to be 3.5 to 5 percent of the coal feed rate, but that there is a small probability that it could be over 20 percent. Expert LG-2 indicated that the "most likely" (modal) value for coal fines carryover is 7.5 percent of the coal feed rate, but that there is a possibility of obtaining higher values. There is considerable overlap between the judgments of the two experts, although the judgment of Expert LG-2 tends to lead to higher values of fines carryover than that of Expert LG-1.

Experts LG-1 and LG-2 also made qualitatively similar judgments regarding uncertainty in the amount of carbon retention in the gasifier bottom ash. These judgments are sh, wn graphically in Figure 13 and 14 for Experts LG-1 and LG-2, respectively. Both judgments are positively skewed, with modal values near 2 percent of the carbon in the feed coal. The judgments differ primarily in the range of possible outcomes assur ned, with 


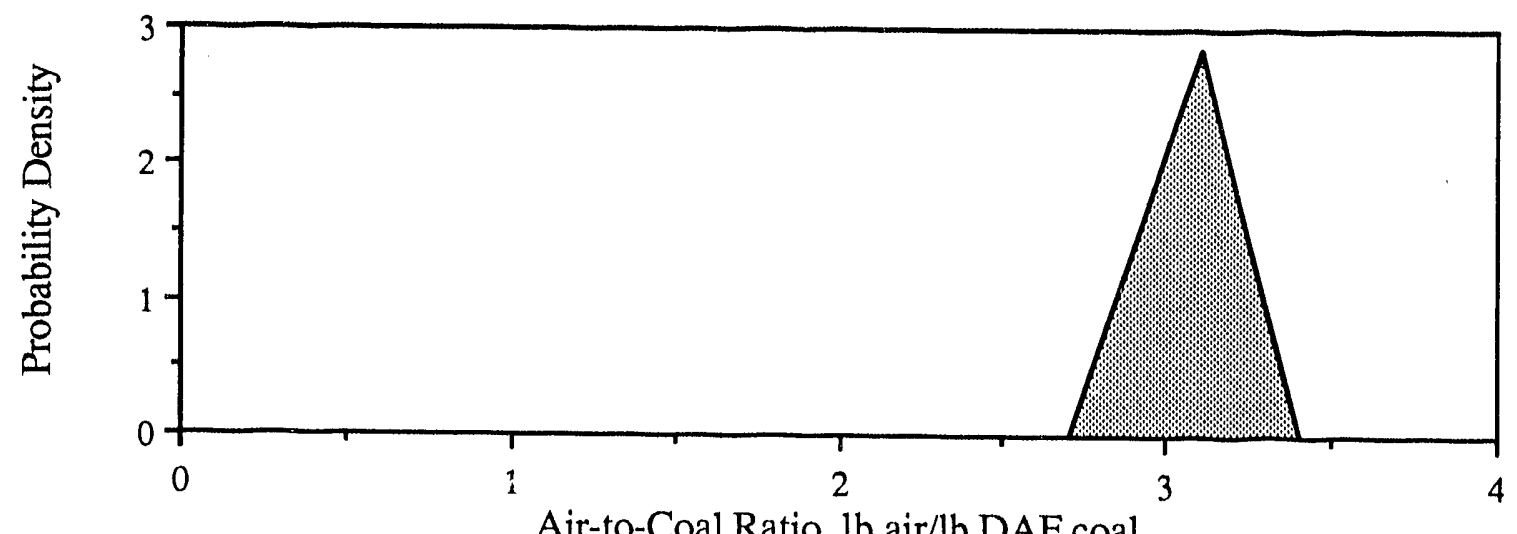

Figure 15. Judgment of Expert LG-1 Regarding Uncertainty in Gasifier Air/Coal Ratio.

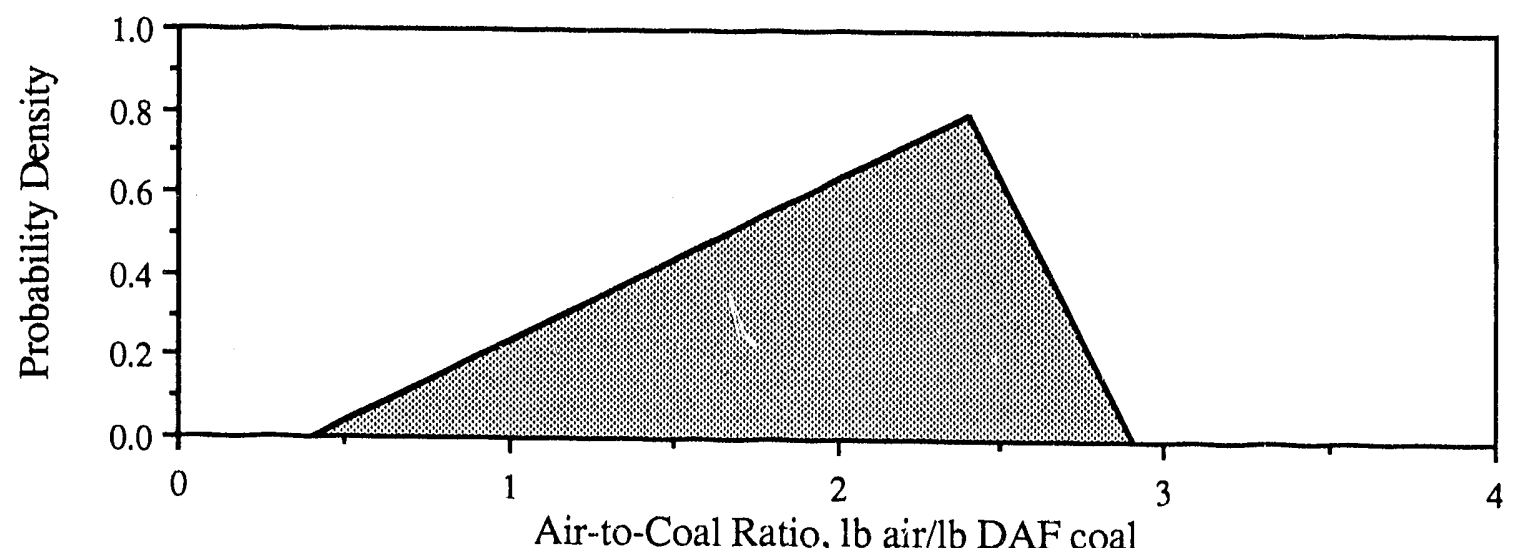

Figure 16. Judgment of Expert LG-2 Regarding Uncertainty in Gasifier Air/Coal Ratio.

Expert LG-2 indicating that outcomes of 10 to 20 percent carbon retention are possible. In contrast, Expert LG-1 indicated that there was no probability of obtained more than 10 percent carbon retention in the bottom ash.

While the two experts manifested qualitative agreement for the previous two examples, they disagreed regarding uncertainty in the gasifier air/coal ratio required for full load gasifier operation. The air/coal ratio affects gasifier performance and plant efficiency. The latter impact is mostly due to the auxiliary power requirement for compressing the gasification air, which is proportional to the air/coal ratio. As shown in Figure 15, Expert LG-1 indicated a relatively narrow range of uncertainty for the air/coal ratio, with a slight negative skewness. Expert LG-2 indicated a wide range of uncertainty, with a more pronounced negative skewness toward very low values (see Figure 16). There is very little overlap between the judgments of the two experts. In addition, the most likely (modal) values for the air/coal ratio are substantially different. Expert LG-1 indicated that the most likely air/coal ratio was $3.1 \mathrm{lb}$ air/lb coal, whereas Expert LG-2 indicated a value of $2.41 \mathrm{lb}$ 
air/lb coal. The implication of these differing judgments is explored in the case studies in the next chapter.

A total of four sets of judgments were obtained from three experts for the zinc ferrite process area. The judgments of the three experts for two of the key performance parameters are compared here. One expert, ZF-2, provided two sets of judgments for two alternative design configurations of the fixed bed zinc ferrite process. For the base case design assumptions proposed by the authors, Expert ZF-2 provided a set of judgments that is labeled as ZF-2P. The expert also chose to recommend an alternative set of design assumptions. The judgments regarding uncertainties based on the recommended design assumptions is referred to as $\mathrm{ZF}-2 \mathrm{R}$. Here, the set $\mathrm{ZF}-2 \mathrm{P}$ is used in comparisons with the other two experts, because the design assumptions are more consistent with the other two experts.

The zinc ferrite sorbent sulfur loading capacity is a key performance parameter that determines the sorbent requirements. The sorbent requirement, in turn, affects the sizing of the absorber pressure vessels and, hence, direct capital cost. The judgments of Experts $\mathrm{ZF}-1, \mathrm{ZF}-2$, and $\mathrm{ZF}-3$ regarding uncertainty in the sorbent sulfur loading requirement are shown in Figures 17, 18, and 19, respectively.

Expert ZF-1 chose to express the uncertainty in the sorbent sulfur loading capacity as a normal distribution, with a mean, median, and mode at 17 weight percent. Expert ZF2 elected to specify the uncertainty as a fractile distribution, with a median value of 15 weight percent. Expert ZF-3 also expressed the uncertainty as a fractile distribution. In the latter case, the median value is 10 weight percent. Thus, while Experts ZF-1 and ZF-2 agree relatively closely regarding the median sorbent sulfur loading, the judgment of Expert ZF-3 is toward lower values.

There is sonsiderable overlap between the three experts regarding the central values of the uncertainty estimates. However, in the judgment of Expert ZF-1, sorbent sulfur loadings greater than 20 percent are possible, while the other two experts did not indicate that such outconies were possible. Both Experts ZF-1 and ZF-3 indicated that sorbent sulfur loadings as low as one percent are possible, although there is more likelihood of such an outcome according to Expert ZF-3 compared to Expert ZF-1. 


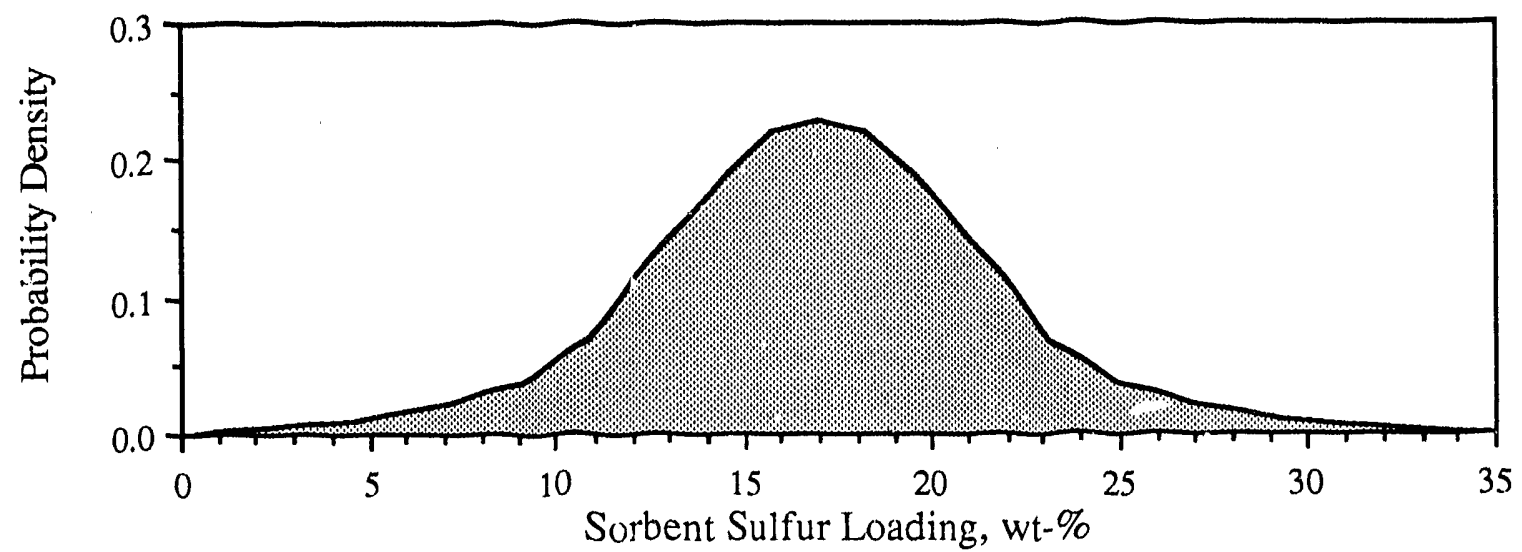

Figure 17. Judgment of Expert ZF-1 Regarding Uncertainty in Sorbent Sulfur Loading.

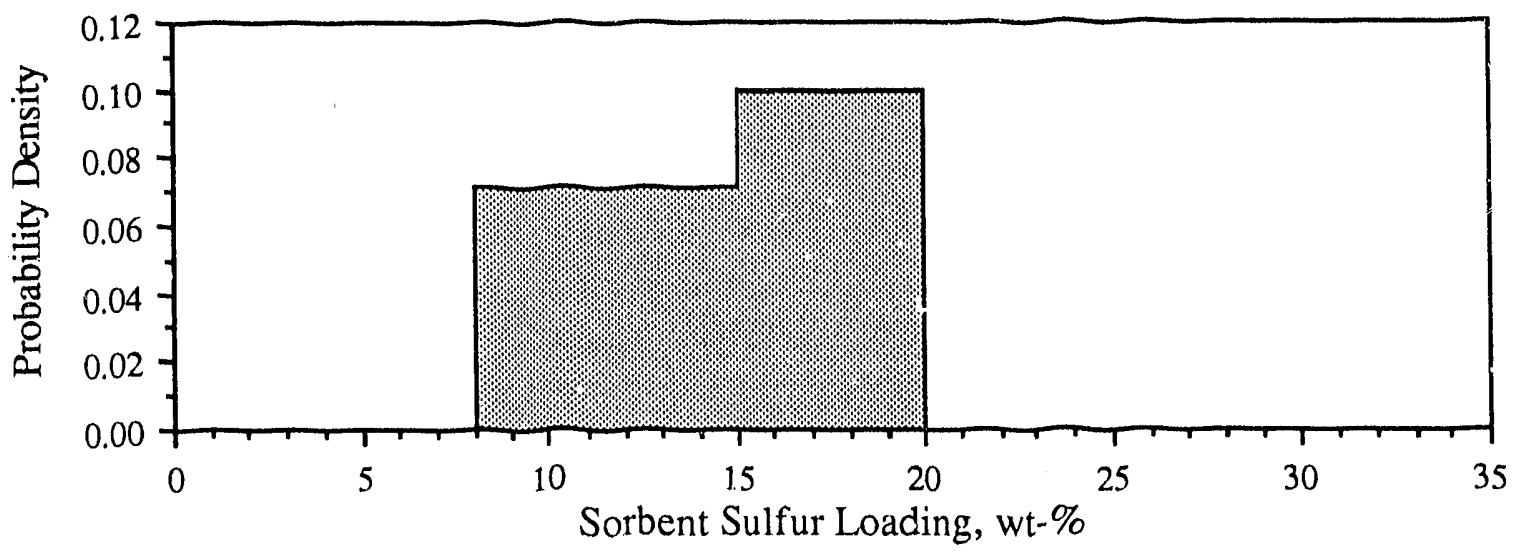

Figure 18. Judgment of Expert ZF-2 Regarding Uncertainty in Sorbent Sulfur Loading (Judgment ZF-2P).

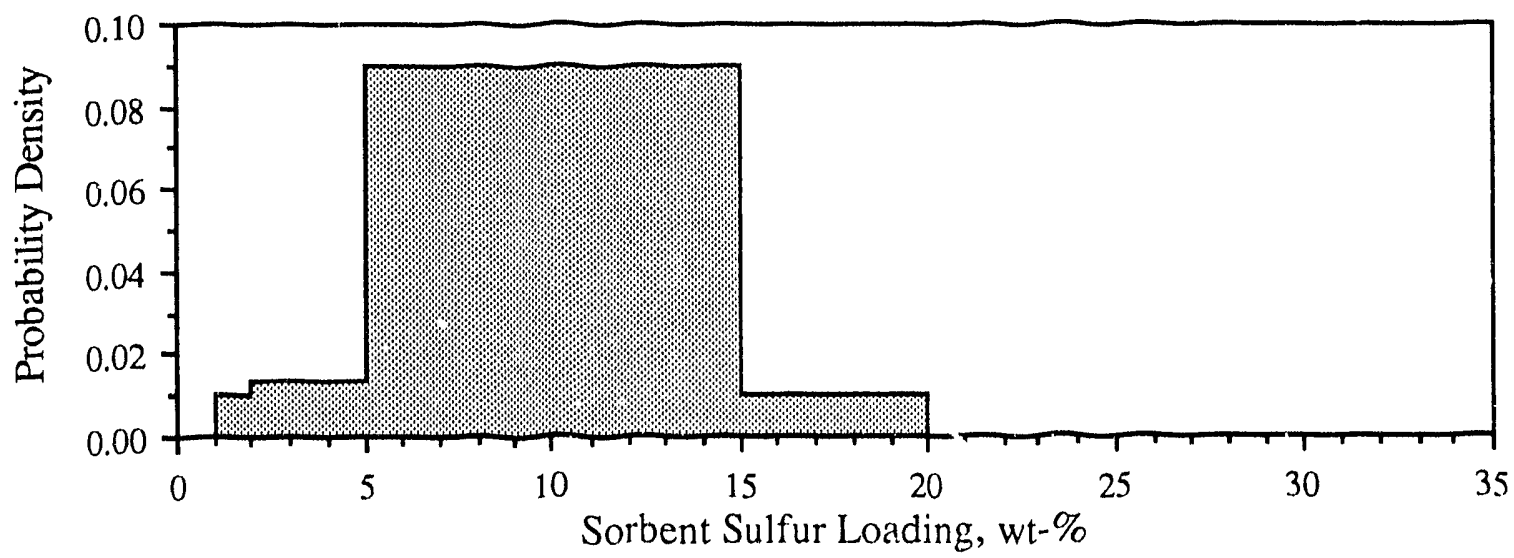

Figure 19. Judgment of Expert ZF-3 Regarding Uncertainty in Sorbent Sulfur Loading. 
The judgment of Expert ZF-1 is symmetric. The judgment of Expert ZF-3 is negligibly skewed, whereas the judgment of Expert ZF-2 is more noticeably negatively skewed.

Overall, there appears to be agreement between Experts ZF-1 and ZF-2 regarding the central tendency of uncertainty in the zinc ferrite sorbent sulfur loading. The judgment of Expert ZF-3 differs from the other two in that generally more probability is assigned to low sorbent sulfur loading outcomes than for the other two experts.

The three experts differ more noticeably with respect to the so:her.t replacement rate, expressed as a percentage of the total sorbent charge that must be replaced per absorption/regeneration cycle. The judgments of Experts ZF-1, ZF-2, and ZF-3 are shown in Figures 20,21, and 22, respectively. The sorbent replacement rate affects plant variable operating costs. While all of the experts provided uncertainty coumates that are positively skewed, they differed on both the central tendency and possible range of outcomes. For example, Expert ZF-3's judgment indicates that there is a very low probability of obtaining sorbent replacement rates greater than 1 percent per absorption/regeneration cycle. In contrast, the judgment of Expert ZF-2, for the base case design assumptions, is that replacement rates of less than 1 percent per cycle are not possible. The assumed range of possible outcomes was greatest for Expert ZF-1. Thus, the three experts do not share a consensus regarding sorbent replacement requirements. The implications of the these different opinions are discussed in the next chapter.

\subsection{Correlation Structures}

While the judgment set of Expert LG-1 provides an exampic of judgment regarding correlated uncertainties (i.e. gasifier oxidant and steam requirements), the other judgments regarding uncertainties were elicited or developed assuming no correlations. For the base case assumptions, the uncertain parameters are assumed to be statistically independent. However, the results of a probabilistic could be influenced by correlation structures among uncertain variables, depending on the strength of the correlations. While correlations were not elicited from the technical experts, an effort was made to identify mechanisms which would tend to cause simultaneous effects in two or more parameters. For example, according to Expert LG-1, the mechanism by which organically-bound sulfur is released from the coal is associated with the carbon conversion rate. Therefore, high carbon conversions tend to result in high sulfur release. 


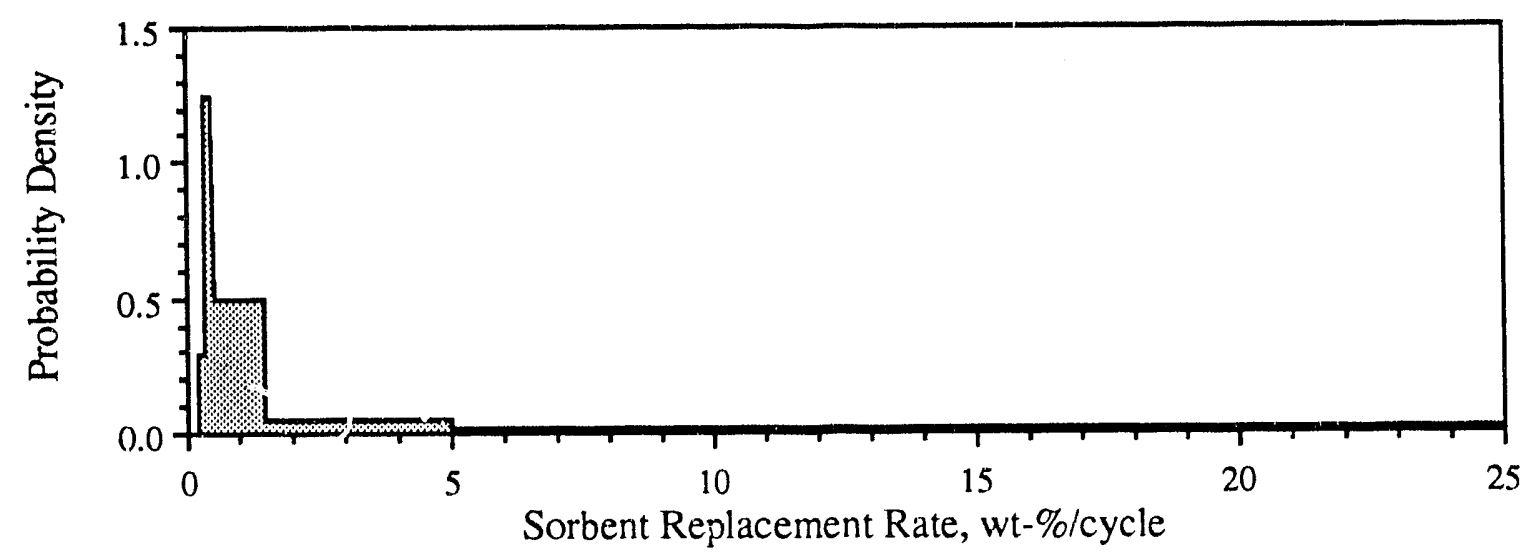

Figure 20. Judgment of Expert ZF-1 Regarding Uncertainty in Sorbent Replacement Rate.

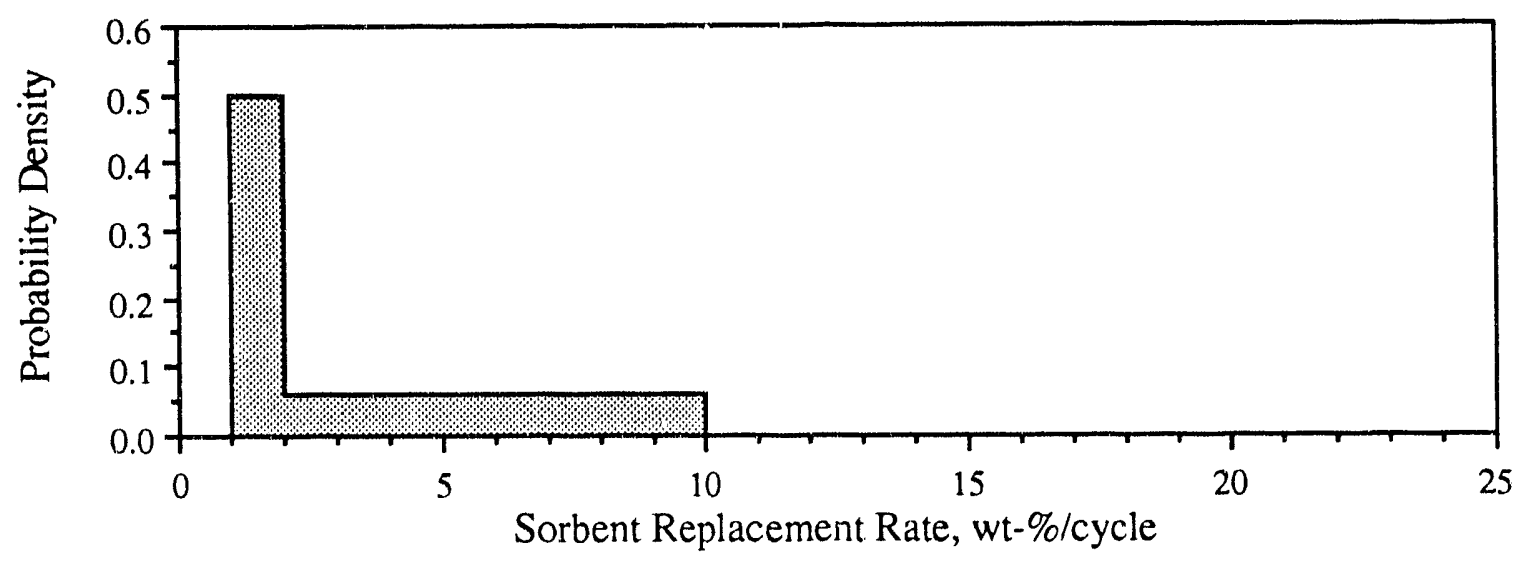

Figure 21. Judgment of Expert ZF-2 Regarding Uncertainty in Sorbent Replacement Rate (Judgment ZF-2P).

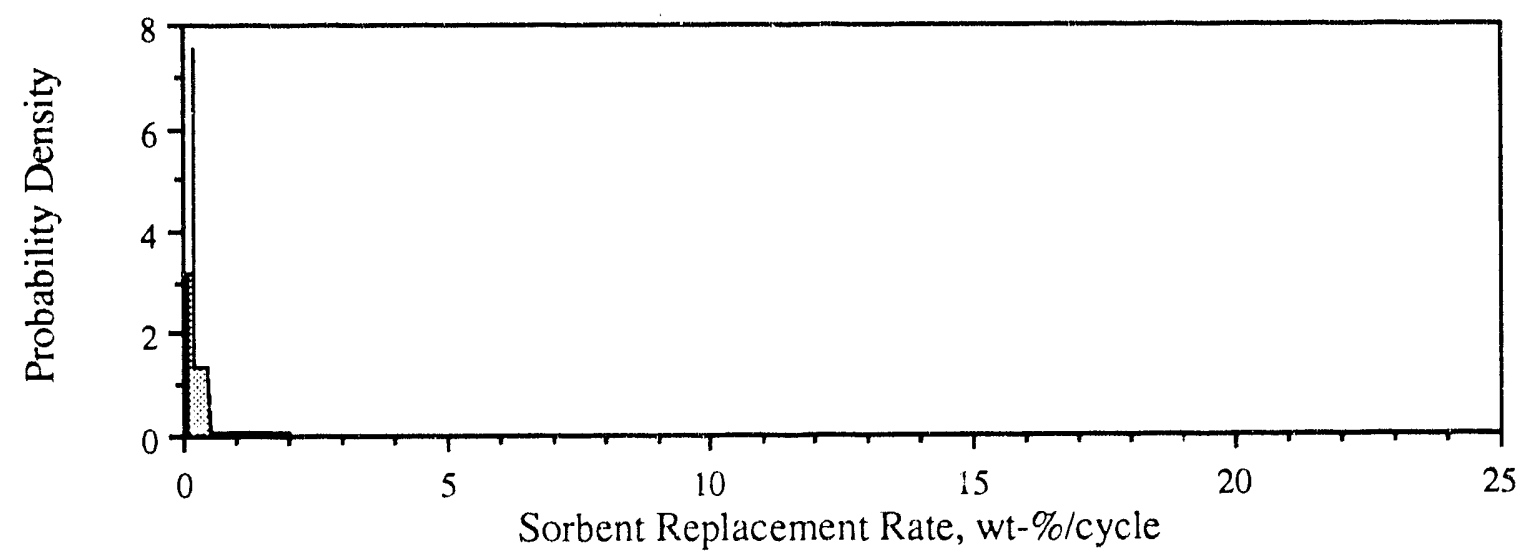

Figure 22. Judgment of Expert ZF-3 Regarding Uncertainty in Sorbent Replacement Rate. 
The information obtained from experts regaiding pussible relationships among performance variables was used to construct illustrative $c c$ relation structures for the gasification and zinc ferrite process areas. These assumptions are described $n$ Appendix B. The correlation structures are considered as probabilistic "sensitivity" cases in comparison to the uncorrelated base case assumptions. The implications of correlation structures are considered in later sections.

\section{4.: The "Best Guess"}

The point values used here for performance and cost parameters in deterministic case studies correspond to a central value of the uncertainty. Depending on the type of distribution, the deterministic value may be the same as the mode, median, or mean of the probability distribution. The experts whose judgments were obtained in this study indicated that the "best guess" was the same as the median or mode. For a symmetric probability distribution, the mean, mode, alld median coincide. However, for skewed distributions, these three measures of the central tendency may be different. For example, in a unimodal positively skewed distribution, the mean is greater than the median, which is greater than the mode. Thus, the use of the mode as a best guess leads to an underestimate of the average of the distribution. 
This page left blank intentionally. 


\subsection{MODELING APPLICATIONS AND RESULTS}

Two IGCC systems are evaluated using probabilistic engineeriig models. These models include the air-blown Lurgi and oxygen-blown KRW systems. The most detailed information regarding process uncertainties was obtained for the Lurgi-based syctem. Therefore, the analysis of this system is presented first. Furthermore, the analysis of the Lurgi-based system is more comprehensive than for the other system, due to the availability of alternative expert judgments regarding uncertainties.

The capabiiity and constraints of the modeling environment used for the IGCC case studies influenced the manner in which simulations were developed. These issues are discussed next. Then, the results of probabilistic analyses of the two IGCC systems are presented. Finally, probabilistic comparisons between the systems are developed. The comparison between the air-blown Lurgi system and the base case oxygen-blown KRW system is explored further from a decision anail $/$ sis perspective.

\subsection{Running the Models}

As described in Chapter 3, the IGCC system performance rnodels are implemented in the ASPEN chemical process simulation modeling environment. The IGCC cost models are Fortran subroutines that are called from the performance models. All pcrformance variables are calculated prior to calling the cost model subroutines. Therefore, it is possible to perform cost sensitivity ana'ysis for a given set of performance results. This is done by iteratively calling the cost subroutine for varying assumptions regarding cost model parameters.

The IGCC models were run on a DEC VAXStation 3200 mini-computer using the public U.S. Department of Energy version of ASPEN. Ruining an ASPEN flowsheet involves several steps. The first is "input translation," in which a performance modei, written in ASPEN's keyword-based input language, is read by the ASPEN package and converted to a Fortran program. This step takes approximately 5 to $10 \mathrm{CPU}$ minutes. The ASPEN-generated Fortran program is then compiled and linked, which may take about 5 minutes. After linking, the flowshiet program is executed. The last step in an ASPEN simulation is report generation. The ASPEN simulator writes a report file containing the results of the simulation. Report writing may take severd minutes, particularl; if the user has requested detailed information regarding the simulation. 
For a single run of an IGCC flowsheet, representing either a deterministic analysis or a single repetition during a stochastic analysis, the run time may take approximately 2 to 10 minutes, depending on the flowsheet, initiai guesses for key variables, and limits specified in ASPEN design specifications (see MIT (1987) for a description of the structure oi ASPEN models). Thus, a deterministic analysis may take approximately 20 to 30 minutes to run, including input translation, compiling, linking, execution, and report generation. In the case of a probabilistic simulation, the flowsheet is executed many times, with a different set of values (samples) assigned to uncertain input parameters each time. Thus, a probabilistic analysis with a sample size of 100 may take 6 to 12 hours to run, depending on the flowsheet. During a probabilistic analysis, the run time for a particular sample varies, depending on the results of the previous simulation (which are used as initial guesses) and the sample values assigned to uncertain variables for a particular sample. It is not unusual for run times to vary from, 2 to 5 or 10 minutes for any given sample in a probabilistic simulation.

\subsubsection{Comparing Probabilistic Results with Different Cost Uncertainty Assumptions}

There are many cases in which it is instructive to make comparisons between two alternatives when both are uncertain. For example, we may wish to compare the effect that including or excluding a set of input uncertainty assumptions would have on, say, uncertainty in plant efficiency or cost of electricity. Or, we may wish to compare the capital cost of two different technologies. By carefully planning and specifying the input uncertainties in a simulation, it is possible to generate properly paired samples for the uncertainties that are to be directly compared. In particular, when there are input uncertainties that are common to the two alternatives being compared, both alternatives should be analyzed using the same set and ranking of samples for those input uncertainties. Probabilistic analyses that can be made with the ASPEN simulator include comparisons of alternative assumptions regarding cost and/or performance. The first case is discussed here.

A key insight that can be obtained from probabilistic analysis is the effect that interactions among uncertainties in performance and cost parameters can have on total system costs (e.g., total capital cost, levelized cost of electricity). Therefore, it is useful to compare the uncertainty in total cost that is obtained when performance uncertainties only are specified to the case when uncertainties in both performance and cost parameters are considered. To make such a comparison, two results for total capital cost uncertainty are needed. Furthermore, these results should be based on the same set (and ranking) of 
samples for the uncertain performance variables which are common to both cases. This allows the results for both cases to be directly compared, sample by sample.

Because the cost model subroutines can be called iteratively for a given set of performance variable values, it is possible to perform several probabilistic case studies as part of a single simulation. For exarnple, interactions between performance and cost uncertainties can be examined by generating cost results based on performance uncertainties only, and comparing them to results tased on both performance and cost uncertainties. Such a comparisons is done by:

- Calculating flowsheet performance results based on the sample values of the uncertain performance parameters;

- For each repetition, calling the cost model subroutine based on the deterministic "best guess" assumptions for cost model parameters and the performance results obtained based on sampled values of uncertain performance parameters;

- For each repetition, reinitializing the uncertain cost model parameters to their probabilistic sample values, for the same set of performance results, and calling the cost model subroutines a second time.

Thus, several probabilistic "sensitivity" cases involving alternative assumptions for costrelated parameters can be performed as part of a single performance simulation. For example, the uncertainty in the cost of electricity resulting from interactions of uncertainties in performance, capital cost, and operating and maintenance (O\&M) cost parameters can be evaluated by calling the cost model subroutine several times, with appropriate assumptions regarding cost model parameters. Furthermore, this approach has the advantage that the same set of samples are used for the performance uncertainty assumptions in all cases. The ability to perform cost-related sensitivity analysis as part of a single performance simulation eliminates the need to run the performance flowsheet several times, at a cost of 6 to 12 hours per run, to obtain the desired case studies.

Alternatively, uncertainties in cost may be evaluated apart from uncertainties in performance. This is done by running the cost model subroutines in a stand-alone mode, with a deterministic set of assumptions for the input performance variables required by the model. The cost model can then be run probabilistically by using the stochastic block in ASPEN to assign sample values to cost model parameters. The ASPEN flowsheet used for such a simulation consists only of the stochastic flowsheet section and a Fortran block to call the cost model. The run time for a cost uncertainty-only simulation is approximately 5 CPU seconds per sample, or about 20 minutes including all steps from input 1 anslation to report writing. The cost uncertainty-only simulation can be run using the same set of 
sample values for cost uncertainties as for the full performance and cost uncertainty simulation. The method for doing this is described in the next section.

\subsubsection{Comparing Probabilistic Results from Separate Simulations}

Although comparisons of the effect of alternative assumptions regarding input uncertainties in cost can be performed in the context of a single probabilistic simulation of performance, comparison of alternative assumptions regarding performance uncertainties requires separate simulations. Furthermore, as indicated above, analysis of uncertainties in total cost resulting from uncertainties only in cost model parameters requires a separate simulation. However, it is essential that such comparisons take into account the underlying correlation between the cases. For example, if we wish to rerun a performance uncertainty analysis and change the variance in only one input uncertainty, then for all other input uncertainties we should use the same set of sample values and the same ranking of values. In the case of the parameter whose variance is reduced, we should use the same ranking of samples, although the specific values of each sanple will differ compared to the base case.

Such comparisons can be made using the newly added probabilistic capability of the ASPEN simulator. As long as the same random seed, the same number of uncertain variables, and the same correlation structure between the uncertain variables are used, then the same ranking of sample values for each uncertain variable will result. This is because probabilistic sampling is based on use of inverse cumulative distribution functions, as described in Section 2.4. Rather than directly sample from a probability distribution, probabilistic simulation techniques generate uniformly distributed random numbers from zero to one for each uncertain variable. These random numbers represent the fractile that is to be sampled. Then, using the inverse $\mathrm{cdf}$, the actual sample value associated with a given fractile is calculated. For a given set of uncertain variables, correlations between variables, and a random seed, the program developed by Iman and Shortencarier (1984), which is the underlying basis of the ASPEN probabilistic modeling capability, will always generate the same set and ranking of fractiles for each uncertain distribution. These fractiles are converted to actual sample values based on the type of probability distribution and the distribution parameters (e.g, variance) specified by the user.

Thus, it is possible to use reproducible samples for uncertain variables when comparing two or more performance uncertainty simulations. When comparing performance uncertainty simulations, the approach is:

- Always specify the same number of random variables to be generated for the simulations to be compared, even if only a subset are actually used in any given 
simulation. An unused random variable is simply not assigned to any input parameters in the ASPEN IGCC model.

- Always use the same underlying correlation structure. (In this work, comparisons are made assuming independent random variables, although a few sensitivity cases involving correlation structures are considered).

- Always use the same random seed. There is a default random seed which is the same for all cases.

The result of properly specifying uncertainties for comparative analysis is that the samples for any given run can be directly paired between cases. Therefore, it is possible, for example, to estimate the probability distribution for the difference in efficiency or cost taking into account uncertainties which are common to both cases. A probability distribution for a difference is estimated by pairing the samples from the two simulations, and then subtracting the paired samples accordingly.

\subsection{Probabilistic Analysis of the Air-Blown IGCC System with Hot Gas Cleanup}

For the air-blown Lurgi-based IGCC system with hot gas cleanup, judgments were obtained from several experts regarding the performance of both the gasifier and the hot gas cleanup system. The judgments of Expert LG-1 regarding uncertainties in the Lurgi gasifier and of Expert ZF-1 regarding uncertainties in the zinc ferrite desulfurization process are assumed as a base case. The implications of alternative expert judgments are also explored. These analyses developed here include: (1) characterization of uncertainties in key measures of plant performance and cost; (2) identification of the key model uncertainties that are the most important determinants of uncertainty in model outputs; (3) comparison of design trade-offs under uncertainty; (4) evaluation of the reductions in uncertainty that may be obtained from further research; (5) evaluation of the alternative judgments of different experts as they affect model results; and (6) evaluation of the importance of correlation structures on results.

\subsubsection{Characterization of Uncertainties in Performance and Cost}

The engineering performance and cost models of the Lurgi-based IGCC system were run using the set of judgments regarding uncertainties in process performance and cost shown in Table 11 (see Chapter 4). In addition, a deterministic simulation of the Lurgi-based system was run. The deterministic simulation is based on "best guess" values for the parameters which are treated as uncertain in the probabilistic simulation, as described in Chapter 4. The deterministic simulation is intended to be representative of the estimates for plant performance and cost that would be obtained in lieu of probabilistic 
Table 12. Summary of Results from Deterministic and Probabilistic imulations of a 650 MW Air-Blown Lurgi-based IGCC System with Hot Gas Cleanup: Expert Judgments LG1 and $\mathrm{ZF}-1 .^{\mathrm{a}}$

\begin{tabular}{|c|c|c|c|c|c|c|c|}
\hline \multirow[b]{2}{*}{ Parameterb } & \multicolumn{3}{|c|}{ "Best } & \multirow[b]{2}{*}{$\mu$} & \multirow[b]{2}{*}{$\sigma$} & \multirow[b]{2}{*}{ f.05 - } & \multirow[b]{2}{*}{$\mathrm{f} .95$} \\
\hline & Units $\mathrm{c}$ & Guess"d & f. .50 & & & & \\
\hline \multicolumn{8}{|l|}{ Plant Performance } \\
\hline The & $\%, \mathrm{HHV}$ & 38.5 & 37.7 & 37.5 & 1.3 & $35.3-$ & 39.3 \\
\hline $\mathrm{Co}$ & $\mathrm{lb} / \mathrm{kWh}$ & & & 0.811 & 0.029 & & 0.861 \\
\hline Process Water Consump & p. $\mathrm{lb} / \mathrm{kWh}$ & 1 & 1.602 & 1.635 & 0.261 & 1.215 & 2.129 \\
\hline ZF Sorbent Charge & $10^{6} \mathrm{lb}$ & & 6.51 & 7.29 & 2.95 & & 12.38 \\
\hline Sulfuric Acid Pr & n $\mathrm{lb} / \mathrm{kl}$ & 0.1 & 0.0 & 0.087 & 0.003 & $0.082-$ & 0.093 \\
\hline \multicolumn{8}{|l|}{ Plant Discharges } \\
\hline & $\mathrm{lb} / \mathrm{MMBtu}$ & 0.042 & 0.040 & 0.040 & 0.001 & $0.038-$ & 0.042 \\
\hline & $\mathrm{lb} / \mathrm{MN}$ & & 2. & 2.19 & 0.402 & 1.53 & 2.84 \\
\hline & $\mathrm{lb} / \mathrm{k}$ & 0.0 & 0.0 & 0.0 & & 0.0 & 0.006 \\
\hline & & & 1. & & & & 1.78 \\
\hline Solid Was & $\mathrm{lb} / \mathrm{k}$ & 0.0 & 0.096 & 0.098 & 0.015 & $0.079-$ & 0.125 \\
\hline \multicolumn{8}{|l|}{ Plant Cos } \\
\hline & $\$ / \mathrm{k}$ & 1,4 & 1,463 & 1,465 & 127 & $1,281-$ & 1,696 \\
\hline & $\$ / \mathrm{kI}$ & & & & 10.6 & & \\
\hline Variable Operati & mills $/ \mathrm{kWh}$ & 18 & 19.0 & 21 & 8 & & 36.1 \\
\hline Coal & & 16 & 16. & 16.7 & & $15.9-$ & 17.7 \\
\hline & & & & & & $(0.4$ & (2.0) \\
\hline & & & & & & & 18 \\
\hline Cost of Electricity & miils/kWh & 51.7 & 56.7 & 59.0 & 9.8 & $49.9-$ & 73 \\
\hline
\end{tabular}

a The notation in the table heading is defined as follows: $f_{n}=n^{\text {th }}$ fractile ( $f .50=$ median), $\mu=$ mean; and $\sigma=$ standard deviation of the probability distribution. The range enclosed by f.05 to f.95 is the 90 percent probability range. All costs are January 1989 dollars.

b Coal consumption is on an as-received basis. Water consumption is for process requirements including makeup for steam cycle blowdown, gasifier steam, and zinc ferrite steam. Solid waste includes gasifier bottom ash and nonrecycled fines from fuel gas cyclones.

c $\mathrm{HHV}=$ higher heating value; $\mathrm{MMBtu}=$ million Btu.

d Based on a deterministic simulation in which median or modal values of uncertain variables are assumed as "best guess" inputs to the model

analysis. However, a deterministic analysis is not required when doing a probabilistic analysis; it is developed here merely for comparative purposes.

From the probabilistic simulation, frequency distributions for variables calculated in the performance and cost models can be estimated. The results of a simulation can be summarized using statistics, such as the mean or standard deviation, or using graphs of the cumulative distribution function (cdf). The results of both a deterministic and probabilistic simulation of a nominal $650 \mathrm{MW}$ Lurgi-based IGCC power plant are summarized in Table 12. The table summarizes selected results for plant performance, environmental discharges, and costs. The "best guess" value is that obtained from deterministic analysis. 


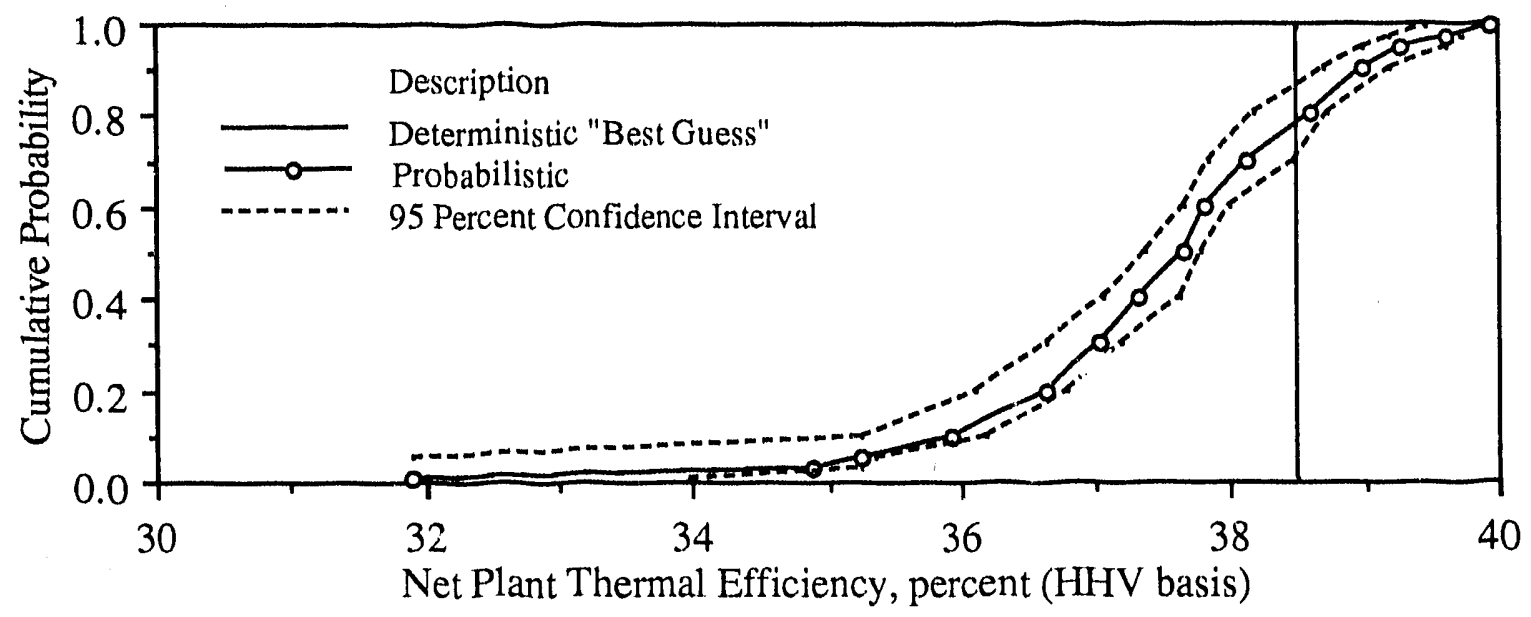

Figure 23. Comparison of Deterministic and Probabilistic Results for the Net Plant Thermal Efficiency of the Lurgi-based System.

The deterministic estimates for capital cost include so-called "process contingency" and "project contingency" factors, based on typical values used in the literature (see the Task 2 Topical Report). Several results from Table-12 are graphed as cdfs.

\subsubsection{Plant Performance}

The uncertainty in plant thermal efficiency is shown in Figure 23. The deterministic "best guess" result is shown as a vertical line in the graph. In addition to the cdf obtained from the probabilistic simulation of the ASPEN performance model of the Lurgi-based system, dotted lines are shown to indicate the 95 percent confidence interval for the cdf. The ccnfidence interval is estimated using, the technique described in Chapter 2. As the sample size is increased, the confidence interval more tightly approaches the cdf. However, the range of values enclosed by the confidence interval is usually higher at the very low or very high fractiles, particularly in cases where a distribution has a "long" tail. For example, note in Figure 23 that at the 5th percentile, the range of efficiencies enclosed by the 90 percent confidence interval is from 31.9 to 35.3 percent, whereas at the 50th percentile the range is from 37.4 to 37.8 percent. The confidence interval is an indication of the "accuracy" of the probabilistic simulation in estimating the cdf based on limited sample size. It is not, however, a measure of the "accuracy" of the judgments or data analysis that went into developing the model input uncertainties from which the cdf was estimated.

For the analyses of IGCC systems, a sample size of 100 was chosen as a compromise between generating smooth cdfs which could be reasonably reproduced even when using different random seeds, and a need for simulation run times that would permit two or three case studies in a 24 hour period. 
The deterministic estimate of plant thermal efficiency for this case is 38.5 percent. However, from the probabilistic simulation, the median (50th percentile) value of efficiency is 37.7 percent, and the mean (average) value is even lower at 37.5 percent (see Table 12). From Figure 23, it is apparent that the probability distribution for efficiency is negatively skewed, with a long tail below the 10 th percentile. Thus, there is a 10 percent probability that efficiency could be less than 35.9 percent, and it may go as low as 32 percent. There is only about a 20 percent chance that efficiency would be higher than the deterministic estimate, and it could go as high as 40 percent.

The negative skewness of the uncertainty in plant thermal efficiency results from the assumptions regarding input uncertainties. For example, Expert LG-1, who provided the judgments regarding uncertainties in the gasifier process area used in this example, indicated that the most likely value for coal carbon retention in the bottom ash of the gasifier was 2.5 percent of the carbon in the coal feed. This value was used in the deterministic estimate. However, while the expert indicated that the carbon retention could be as low as 0.75 percent, he also indicated it could be as high as 10 percent. Carbon retained in the bottom ash represents a significant efficiency penalty on the IGCC system, because it is not combusted in the gasifier nor converted to f:tel gas. Thus, the positively skewed assumption regarding uncertainty in carbon retention is likely to be a contributing factor to the negatively skewed uncertainty regarding plant thermal efficiency. The identification of key uncertainties in input assumptions is discussed further in the next section.

A brief way to summarize the results of the probabilistic simulation with a few simple numbers would be to use the mean value and the 90 percent probability range to characterize the central tendency and variation in efficiency. For example, from Table 12, the plant efficiency has a mean value of 37.5 percent with a 90 percent probability of being between 35.3 and 39.3 percent. Alternatively, the result might be expressed as an efficiency of $37.5(+1.8 /-2.2)$ percent . However, such a simple characterization of uncertainty does not provide any indication of the long tail at the lower end of the distribution. Thus, the cdf is the preferred method for communicating results about uncertainty in key variables used in decision making, because it more completely represents the entire range of possible outcomes.

For the Lurgi-based IGCC system with hot gas cleanup, a key performance variable which affects plant costs is the amount of zinc ferrite sorbent that must be charged to all fuel gas desulfurization reactor vessels prior to plant startup. The amount of sorbent charge is a key determinant of the number and size of the reactor vessels, and the sorbent can 


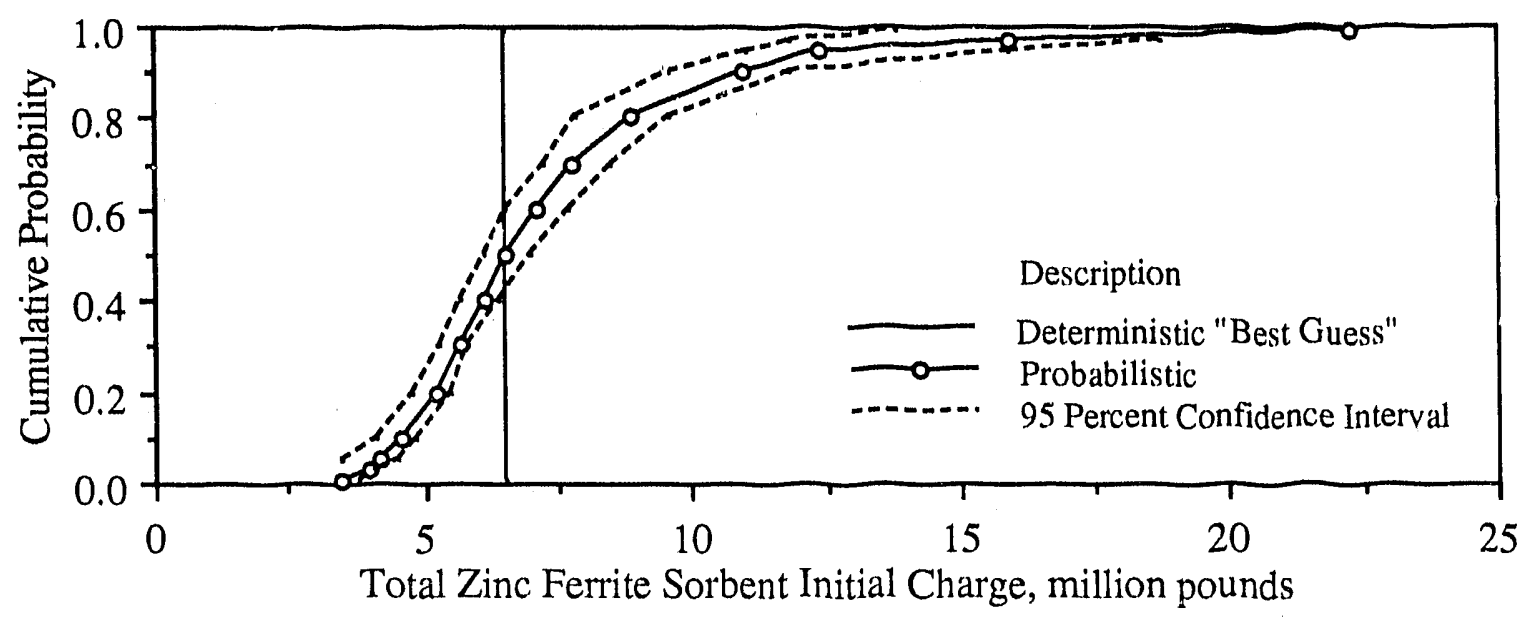

Figure 24. Comparison of Deterministic and Probabilistic Results for the Zinc Ferrite Initial Sorbent Charge of the Lurgi-based System.

represent a significant portion of the capital cost for initial chemicals and catalysts. The uncertainty in the sorbent charge is shown as a cdf in Figure 24. In this case, the deterministic "best guess" coincides with the median value of the probabilistic result.

The judgment of Expert ZF-1 was that uncertainty in sorbent sulfur loading is normally distributed, with a mean (and median) at 17 weight percent. This value was used in the deterministic analysis. The sorbent charge requirement is a nonlinear function of sorbent sulfur loading (see Appendix A.3). Therefore, the resulting uncertainty in sorbent charge is positively skewed. Thus, while the median sorbent charge is almost the same as the deterministic "best guess" value at 6.5 million pounds, the mean value is higher, at 7.3 million pounds. Furthermore, there is a 5 percent chance that the sorbent charge would be more than 12.4 million pounds, and in the worst case the sorbent charge could be over a factor of three greater than the deterministic estimate. Here again, as with the uncertainty in plant efficiency, use of just deterministic or mean values in a performance estimate would mask the risk a process adopter faces that sorbent charge could be substantially higher.

\subsubsection{Plant Emissions}

Uncertainties in plant performance affect plant emissions. Probabilistic results for selected plant environmental discharges are shown as cdfs in Figures 25, 26, and 27 for $\mathrm{SO}_{2}, \mathrm{NO}_{\mathrm{x}}$, and $\mathrm{CO}_{2}$ emissions, respectively. In the case of $\mathrm{SO}_{2}$ emissions, the probabilistic simulation indicates that the best guess value obtained from deterministic analysis may in fact be overly pessimistic. There is about an 80 percent probability that $\mathrm{SO}_{2}$ emissions would be lower than the deterministic estimate. Similarly, there is over a 90 percent probability that $\mathrm{NO}_{\mathrm{x}}$ emissions would be less than the deterministic estimate. 


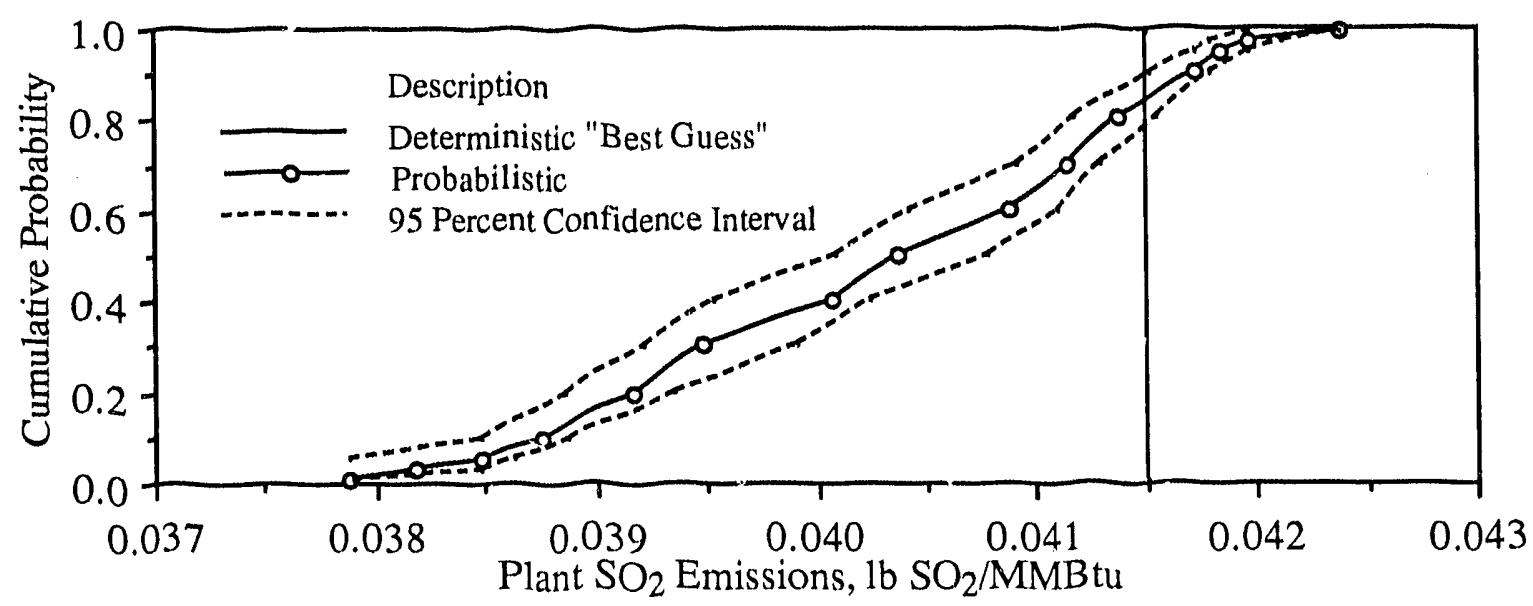

Figure 25. Comparison of Deterministic and Probabilistic Results for the $\mathrm{SO}_{2}$ Emissions of the Lurgi-based System.

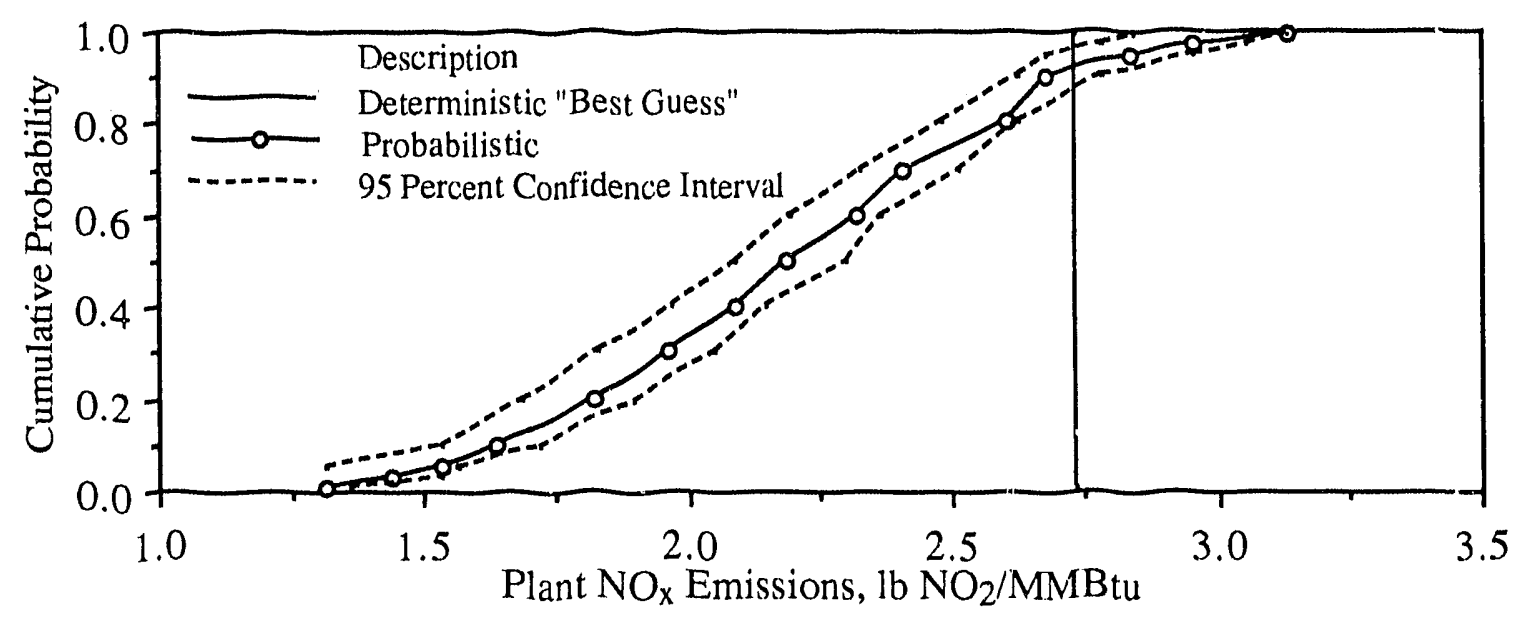

Figure 26. Comparison of Deterministic and Probabilistic Results for the $\mathrm{NO}_{\mathrm{x}}$ Emissions of the Lurgi-based System.

These results are obtained due to the skewness in several of the model input uncertainties. For example, the $\mathrm{NO}_{\mathrm{x}}$ emission rate depends on the ammonia yield in the gasifier and the conversion of ammonia to $\mathrm{NO}_{\mathrm{x}}$ in the gas turbine combustor. Expert LG-1's judgment regarding the ammonia yield from the gasifier was negatively skewed. The judgment of the author regarding the fraction of ammonia converted to $\mathrm{NO}_{\mathrm{x}}$ in the gas turbine combustor was also negatively skewed. Therefore, the uncertainty in the $\mathrm{NO}_{\mathrm{x}}$ emission rate is also negatively skewed.

The $\mathrm{CO}_{2}$ emission rate is normalized based on plant efficiency, which is penalized for carbon retained in the bottom ash. However, retained carbon retained is not emitted to the atmosphere. Therefore, the $\mathrm{CO}_{2}$ emission rate does not share the strongly negatively skewed shape of the piant efficiency curve, as would be expected if all carbon were emitted as $\mathrm{CO}_{2}$. 


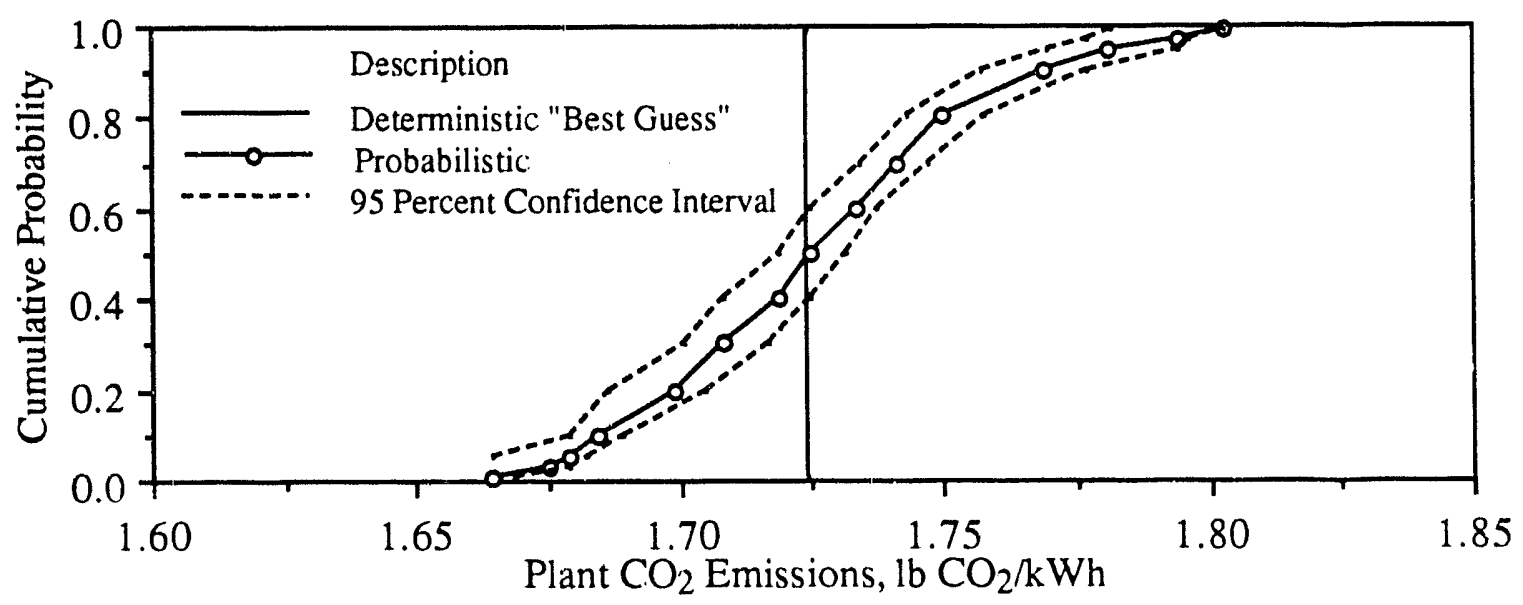

Figure 27. Comparison of Deterministic and Probabilistic Results for the $\mathrm{CO}_{2}$ Emissions of the Lurgi-based System.

\subsubsection{Plant Costs}

Uncertainties in plant performance parameters, in interaction with uncertainties in process cost parametcrs, lead to uncertainties in the key measures of cost often used for process evaluation.

The uncertainty in the plant total capital cost, expressed on a normalized basis of dollars per net kilowatt of plant capacity, is shown in Figure 28. The deterministic estimate of capital cost is also shown. The uncertainty in capital cost covers a wide range, from about $\$ 1,200 / \mathrm{kW}$ to over $\$ 1,800 / \mathrm{kW}$. The mean $(\$ 1,465 / \mathrm{kW})$ and median $(\$ 1,465 / \mathrm{kW})$ are higher than the deterministic estimate of $\$ 1,409 / \mathrm{kW}$. Compared to the deterministic estimate, there is almost a 70 percent probability that the capital cost would be higher. As indicated previously, the deterministic capital cost estimate includes so-called "contingency" allowances, which are intended to account for both performance and project related uncertainties. In this case, the contingency factors appear to be inadequate (too low), and use of the deterministic cost estimate would expose a decision-maker to a substantial chance of cost overrun.

For simulations of limited sample size, it is important to consider whether inc:easing the sample size could lead to qualitatively different model results. The confidence interval on the $\mathrm{cdf}$ can be used to place a confidence interval on the probability of cost overrun. In this case, the 95 percent confidence interval is a 60 to 75 percent probability of cost overrun. Thus, even if the sample size of the probabilistic simulation were to be increased, we would still expect to find a greater probability of cost overrun than cost overrun, compared to the deterministic estimate. 


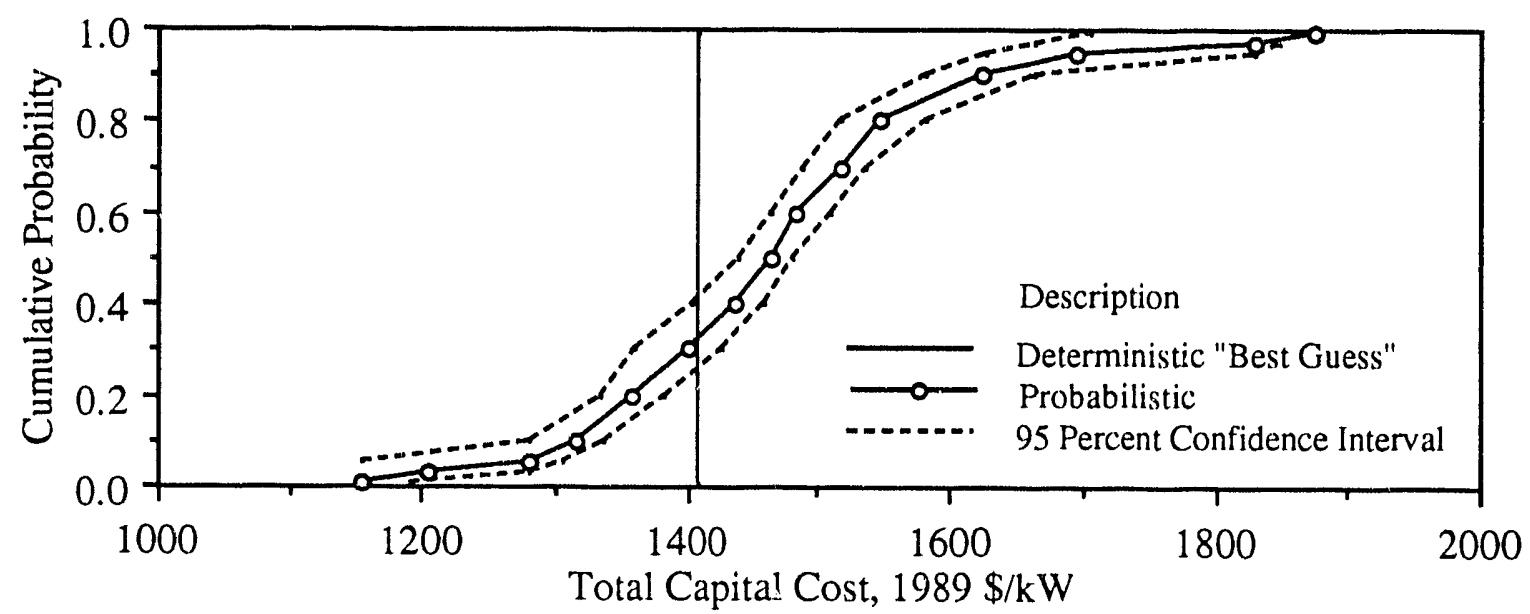

Figure 28. Comparison of Deterministic and Probabilistic Results for the Total Capital Cost of the Lurgi-based System.

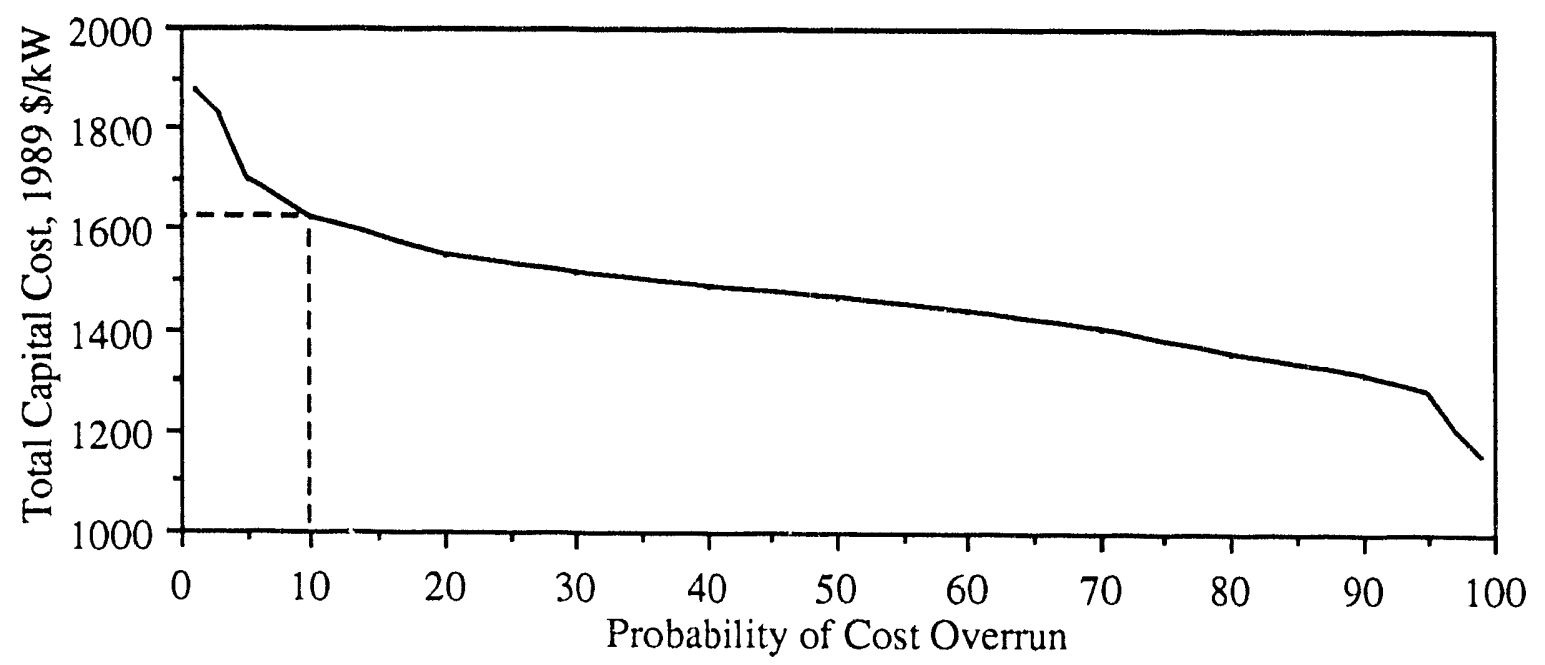

Figure 29. Comparing Total Capital Cost and the Probability of Cost-Overrun for the Lurgi-based System.

An alternative representation of uncertainty in capital cost is shown in Figure 29. In this graph, the probability of cost overrun is shown on the $x$-axis, and the total capital : ost is shown on the y-axis. A decision-maker could select an acceptable probability of cost overrun according to his/her own preferences, and then choose a corresponding budgetary value of capital cost. This approach bypasses the need to make a separate deterministic analysis with contingency factors. For example, if a decision maker would accept only a 10 percent probability of cost overrun, the budget estimate should be $\$ 1,624 / \mathrm{kW}$ (as shown in Figure 29). A capital cost estimate can be uniquely specified, therefore, based on the probability of cost overrun associated with it. However, with a scant few exceptions, conceptual cost estimates provide no indication of the risk of cost overrun associated with the assumed contingency factors. 


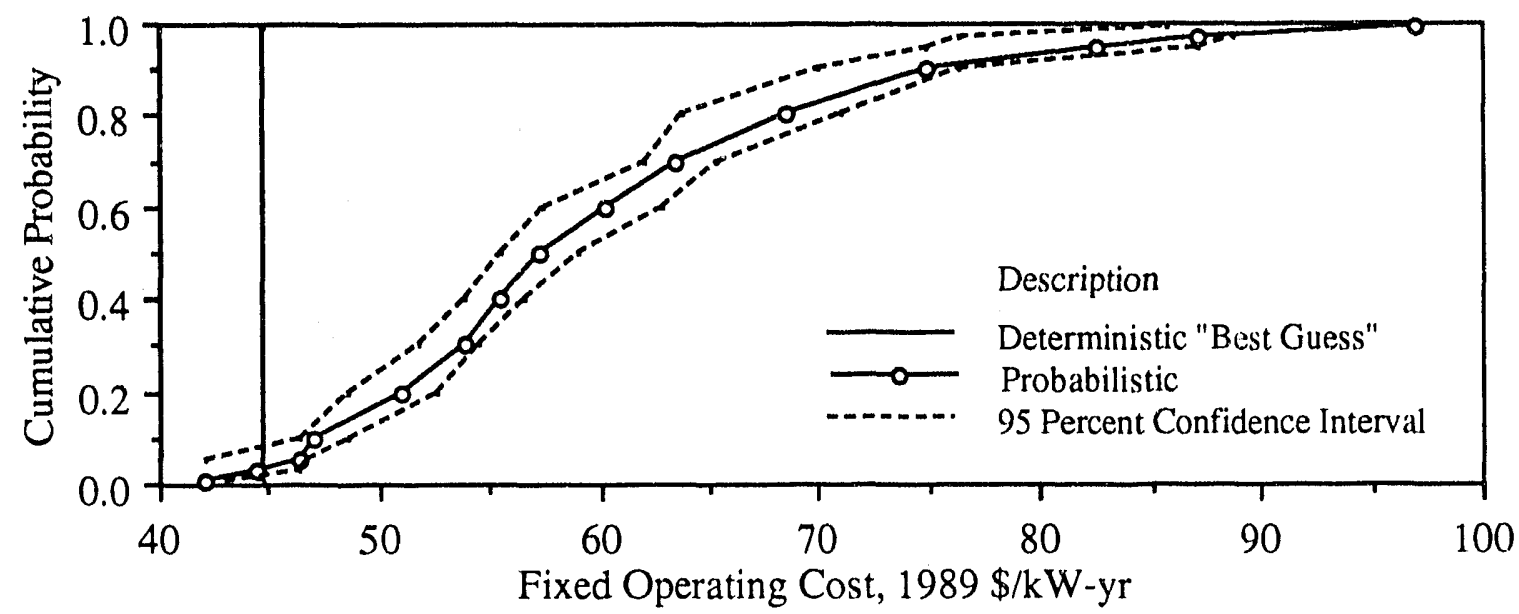

Figure 30. Comparison of Deterministic and Probabilistic Results for the Fixed Operating Cost of the Lurgi-based System.

The notion of uncertainty is extended here to operating and maintenance (O\&M) cost estimates. Early in the development of a process technology, maintenance costs may be poorly anticipated. The deterministic and uncertainty estimates of fixed operating costs are shown in Figure 30. Fixed operating costs include maintenance materials, maintenance labor, operating labor, and administrative and supervisory labor. These costs are incurred regardless of the operating schedule of the power plant, because maintenance and operating staff are required to be on-site on a regular schedule. For this reason, the cost is reported on a normalized basis of annual dollars per kilowatt of plant capacity. Of the cost-related variables, the fixed operating cost manifests the largest discrepancy between the deterministic and probabilistic cost estimates. There is about a 95 percent probability that the fixed operating cost would be higher than the "best guess" estimate.

Uncertainty in fixed operating costs stems from uncertainties in both the capital cost of each process area and the annual maintenance costs expressed as a percentage of process area capital cost. While the process area capital cost uncertainties are symmetrically distributed around the deterministic contingency factor values (see Appendix A.5.2), several of the maintenance cost factors are positively skewed. For example, the maintenance cost factor for the Lurgi gasification process area is based on an elicited expert judgment. The most likely annual maintenance cost is 3 percent of the process area capital cost. The lowest possible maintenance cost is estimated to be 2 percent, while the highest is estimated to be 12 percent. Similarly, the best guess maintenance cost factor for the zinc ferrite process area is taken to be a lower bound, with a chance that the cost could be higher. See Appendix A for more detail regarding judgments about uncertainty in maintenance cost factors. 


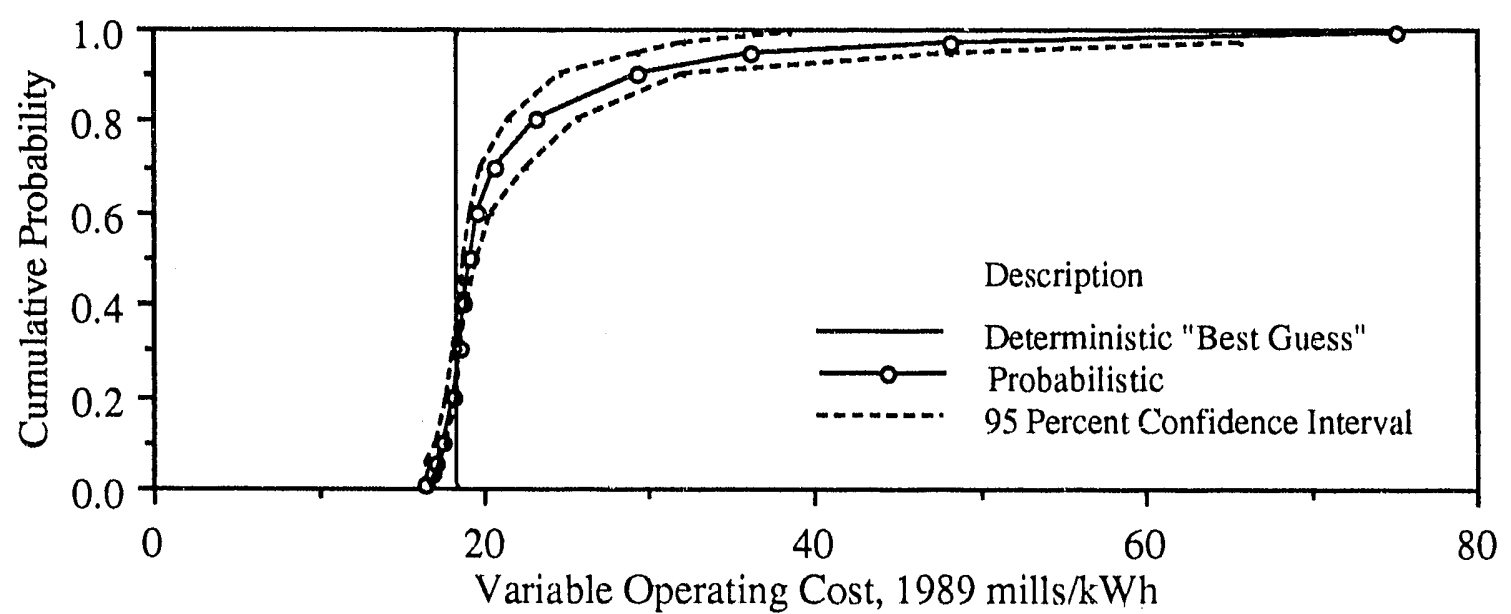

Figure 31. Comparison of Deterministic and Probabilistic Results for the Variable Operating Cost of the Lurgi-based System.

The best guess and uncertainty estimates for variable operating cost are shown in Figure 31. A striking feature of this graph is the extremely long tail of the probability distribution. The variable operating cost includes the cost of consumable materials (e.g., chemicals, catalyst, coal), disposal costs for ash, and a byproduct credit for the sale of sulfuric acid. The cost is expressed on the basis of kilowatt-hours of plant output, because these costs are incurred only if the plant is operating. The deterministic best guess estimate from Table 12 is $18.2 \mathrm{mills} / \mathrm{kWh}$ (a mill is one-thousandth of a dollar). There is about a 25 percent probability that the variable operating cost could be lower than this estimate. However, there is a 10 percent probability that the cost could be greater than 30 mills $/ \mathrm{kWh}$, and it could go as high as 75 mills/kWh.

The extreme skewness of this distribution is the result of interactions among uncertainties in performance and cost parameters. One example is the uncertainty in makeup zinc ferrite sorbent cost. The annual requirement for makeup sorbent depends on both the size of the sorbent charge and the percentage of sorbent that is lost due to attrition per absorption and regeneration cycle. As already discussed, the uncertainty in sorbent charge shown in Figure 24 is the result of uncertainty in the zinc ferrite sorbent sulfur loading capacity, and $\mathrm{i}^{\star}$ is positively skewed. The judgment regarding uncertainty in sorbent attrition obtained from Expert ZF-1 (see Appendix A.3) is also positively skewed. The interaction of these two uncertain variables contributes to the characterization of uncertainty in variable operating cost. The extremely high values for variable operating cost are associated with the possibility of low sorbent sulfur loading capacity and high sorbent attrition rates. 


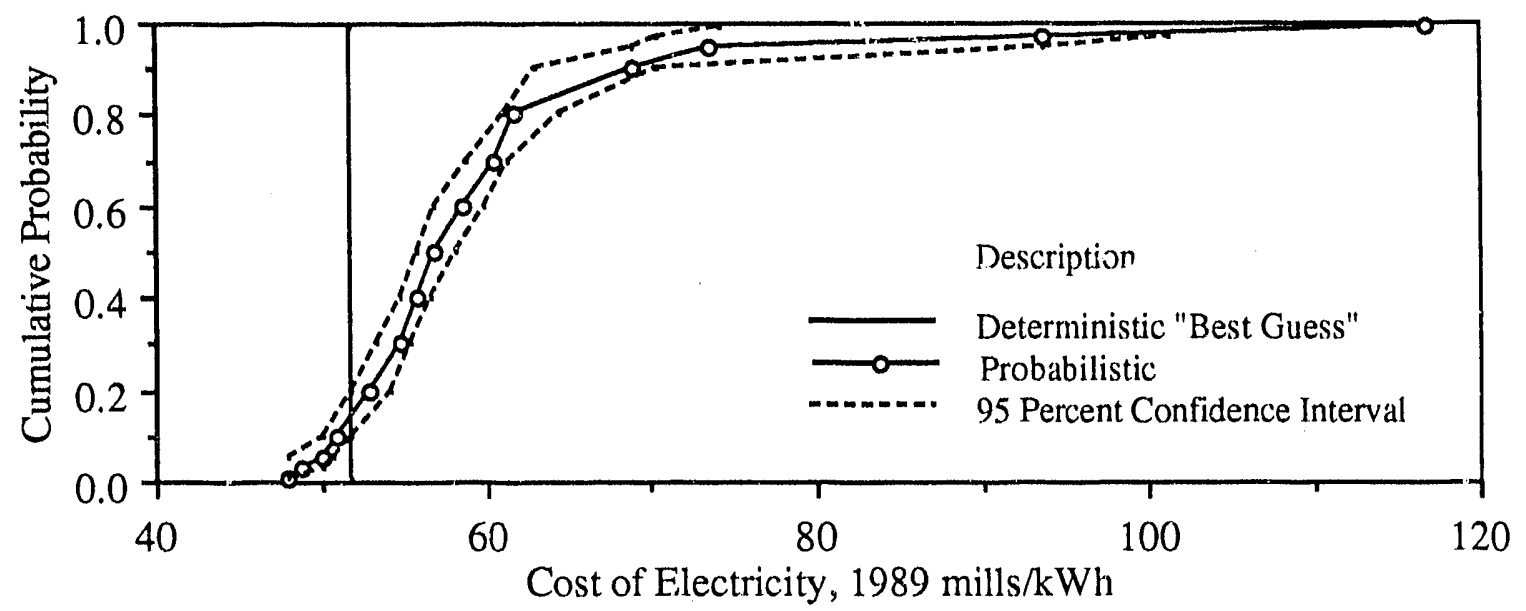

Figure 32. Comparison of Deterministic and Probabilistic Results for the Cost of Electricity of the Lurgi-based System.

The levelized cost of electricity is the single most comprehensive measure of plant cost, because it is based on (and sensitive to) all of the factors which affect capital, fixed operating, and variable operating costs. Because it is expressed on a net electricity production basis, it is also sensitive to the plant thermal efficiency. For the deterministic

st estimate, the contribution to the cost of electricity from leveiized capital cost is 50 rarcent, from fixed operating cost is 15 percent, and from variable operating cost is 35 percent. For the probabilistic cost estimate, the relative contribution of the three varies. For example, for the sample where variable operating cost was $75 \mathrm{mills} / \mathrm{kWh}$, the contribution of variable operating cost to the cost of electricity was 64 percent.

Like the uncertainties in fixed and variable operating cost, the uncertainty in the cost of electricity is positively skewed, as shown in Figure 32. In addition, the central values of the probability distribution are higher than the "best guess" estimate. The median value is 5 mills/kWh higher than the deterministic estimate. There is only a 15 percent probability that the cost of electricity could be less than the deterministic estimate. There is a 20 percent probability that the cost could be higher than $62 \mathrm{mills} / \mathrm{kWh}$, and it could go over 100 mills $/ \mathrm{kWh}$. The range of uncertainty in the cost of electricity varies by a factor of 2.5 from the lowest to the highest values.

This section has focused on characterization of uncertainties in key measures of plant performance, emissions, and cost. In some cases, the uncertainty in the Lurgi-based system is shown to be quite large, particularly for the variable operating cost and the cost of electricity. Because of interactions among the input uncertainty assumptions, many of which are positively skewed, the central values of the probabilistic results, such as the median and the mean, tend to be higher than the deterministic estimate. A research planner 
is interested in knowing what factors contribute most to the uncertainties described here. Thus, identifying and prioritizing key input uncertainties, in order to better understand the model output uncertainties, is the next step.

\subsubsection{Identifying Key Uncertainties}

Several approaches to identifying key uncertainties are possible in probabilistic analysis. One approach involves statistical analysis using regression techniques. Regression techniques can be used to help identify input variables which are most highly correlated with output variables. Another approach is probabilistic sensitivity analysis, in which alternative assumptions about uncertainties are compared. From this approach, it is often possible to gain insights into the interaction between different subsets of uncertain input variables as they affect uncertainty in an output variable. A third approach, which is similar to the second, is to confirm the results of a regression or sensitivity analysis by deleting uncertainties from the model which are not believed to be important. This is an uncertainty screening study. The results of a screening study can be compared to the results obtained from the original probabilistic analysis. If the results are similar, then the deleted uncertainties need not be considered probabilistically in further studies. The development of improved judgments regarding uncertainties can then focus on the key uncertainties remaining after the screening study.

\subsubsection{Regression Analysis}

As part of the probabilistic modeling capability in the ASPEN simulator, four alternative approaches to regression analysis are available for analyzing model results. These were discussed earlier in Section 2.4. The output analysis capability utilizes a program developed by Iman et al (1985). For the Lurgi system, all four techniques will be compared. These are: (1) partial correlation coefficients (PCC); (2) standardized regression coefficients; (3) partial rank correlation coefficients (PRCC); and (4) standardized rank regression coefficients (SRCC).

When running a stochastic simulation in ASPEN, the user may specify which type of output analysis is desired. The results are reported in the form of a table. For each output, a series of coefficients is reported representing either the partial correlation or standardized regression coefficient between the output variable and each of the uncertain input variables. In addition, the ranks of the magnitudes of the coefficients are also given. Thus, the user can use the output as one basis for ranking the relative importance of input uncertainties. However, such results must be interpreted with care. The regression analysis is $r$ ed on a linear model. There may be significant non-linearities that might bias 
Table 13. Comparison of Rankings of Uncertain Parameters Affecting Plant Efficiency for the Lurgi-based System.

\begin{tabular}{lllll} 
& \multicolumn{4}{c}{ Type of Output Analysis ${ }^{\mathrm{a}, \mathrm{b}}$} \\
Rank & PCC & SRC & PRCC & SRRC \\
\hline 1 & Carbon to ash & Carbon to ash & Carbon to ash & Carbon to ash \\
2 & Air/Coal ratio & Air/Coal ratio & Air/Coal ratio & Air/Coal ratio \\
3 & Fines capture & Fines capture & Fines capture & Fines capture \\
4 & Fines carryover & Fines carryover & Fines carryover & Fines carryover \\
5 & ZF resid. sulfate & ZF resid. sulfate & (see note) & (see note) \\
6 & NH3 yield & NH3 yield & &
\end{tabular}

aAbbreviations for type of analysis: PCC = partial correlation coefficients; SRC = standardized regression coefficients; $\mathrm{PRCC}=$ partial rank correlation coefficients; $\mathrm{SRRC}=$ standardized rank regression coefficients. ${ }^{b}$ Abbreviations for uncertain parameters: $\mathrm{CH}=$ coal handling; $\mathrm{DC}=$ direct cost; HRSG = heat recovery steam generator; $\mathrm{ICC}=$ indirect construction cost; $\mathrm{SE}=$ standard error; $\mathrm{STG}=$ steam turbine-generator; Unc. $=$ uncertainty; $\mathrm{ZF}=$ zinc ferrite.

${ }^{c}$ At about the seventh most important parameter, the correlation or regression coefficients become sufficiently small to no longer be statistically significant. Therefore, rankings below six are not shown.

${ }^{\mathrm{d}}$ The partial rank correlation coefficients become sufficiently small to no longer be statistically significant at the fifth-ranked parameter. Trerefore, rankings below four are not shown. The same result is assumed applicable for the standardized rank regression coefficients.

the results from a linear regression analysis. Thus, regression analysis on the sample ranks, rather than the sample values, of the input and output variables may be preferred.

A comparison of the rankings obtained from the four approaches of key uncertainties affecting plant thermal efficiency is shown in Table 13. Only those uncertainties for which the coefficients were found to be statistically significant (see Section 2.4) are included in the list. Insignificant correlations are often easily recognized. For example, the seventh ranked input uncertainty according to PCC analysis, which was statistically insignificant and is not shown in the table, was zinc ferrite unit cost. Clearly, the uncertainty in the unit cost of zinc ferrite has no relationship to uncertainty in plant efficiency.

According to Table 13, all four regression techniques yield the same ranking for the top four uncertainties affecting plant efficiency. Thus, regardless of whether partial correlation or standardized rank regression coefficients are used, and regardless of whether sample values or sample ranks are used, the same relative result is obtained. However, the fifth and sixth ranked uncertainties obtained from sample regression are not significant in lite rank regressions. There are two contributing reasons for this. One is that the sample 
Table 14. Comparison of Rankings of Uncertain Parameters Affecting Capital Cost for Lurgi-based System.

\begin{tabular}{lllll}
\hline & \multicolumn{4}{l}{ Type of Output Analysis ${ }^{\mathrm{a}, \mathrm{b}}$} \\
Rank & PCC & SRC & PRCC & SRRC \\
\hline 1 & Coal throughput & Coal throughput & Coal throughput & Coal throughput \\
2 & Project Unc. & Project Unc. & Project Unc. & Project Unc. \\
3 & Gas Turbine DC & Gas Turbine DC & Gas Turbine DC & Gas Turbine DC \\
4 & ZF Loading & ZF Loading & ZF Loading & ZF Loading \\
5 & Gasifier DC & Gasifier DC & ICC & ICC \\
6 & ICC & ICC & SE HRSG & SE HRSG \\
7 & Carbon to Ash & Carbon to Ash & Gasifier DC & Gasifier DC \\
8 & SE STG & SE STG & Carbon to Ash & Carbon to Ash \\
9 & SE HRSG & ZF Attrition & ZF DC & ZF DC \\
10 & SE CH & SE HRSG & SE CH & SE CH \\
\hline
\end{tabular}

aAbbreviations for type of analysis: PCC = partial correlation coefficients; $\mathrm{SRC}=$ standardized regression coefficients; PRCC = partial rank correlation coefficients; SRRC $=$ standardized rank regression coefficients. ${ }^{b}$ Abbreviations for uncertain parameters: $\mathrm{CH}=$ coal handling; $\mathrm{DC}=$ direct cost; $\mathrm{HRSG}=$ heat recovery steam generator; $\mathrm{ICC}=$ indirect construction cost; $\mathrm{SE}=$ standard error; $\mathrm{STG}=$ steam turbine-generator; Unc. $=$ uncertainty; $\mathrm{ZF}=$ zinc ferrite.

${ }^{c}$ At about the tenth most important parameter, the correlation or regression coefficients become sufficiently small to no longer be statistically significant. Therefore, rankings below 10 are not shown.

correlations are relatively weak for these two input uncertainties $(-0.45$ and -0.33 , respectively). The other is that these uncertainties are skewed. Thus, in the sample regression, there a few extreme values near the tails that become "compressed" in the rank regression and, therefore, are less influential in the regression model.

The key uncertainties affecting uncertainty in plant thermal efficiency are shown to be associated with the gasification process area. There is a weak relationship between uncertainty in the zinc ferrite sorbent residual sulfate content after oxidative regeneration and plant thermal efficiency. Thus, the gasification process is the primary source of uncertainty in efficiency, for the assumptions used in this case study.

The results of the alternative regression analyses for plant total capital cost are shown in Table 14. As in the case of plarit efficiency, the four approaches agree with respect to the ranking of the first four input uncertainties. Furthermore, the two analyses based on rank regression agree on the relative ordering of all ten input uncertainties shown in the table. The two analyses based on sample regression agree on the relative ordering of 
the first eight input uncertainties shown. However, they disagree on the remaining ones, with the SRC analysis indicating a stronger influence from zinc ferrite sorbent attrition than PCC analysis. In the capital cost model, sorbent attrition affects costs because it influences the quantity of zinc ferrite sorbent that must be stored in reserve and how much must be used for plant startup. The difference in result indicates that the partial derivative of capital cost with respect to sorbent attrition is higher than with respect to the standard error of the HRSG direct capital cost model. However, the PCC analysis indicates that removing the HRSG standard error from a linear regression model would have a larger effect on the coefficient of determination than removing the sorbent attrition rate.

The sample and rank regression analyses disagree after the fourth ranked uncertainty. For example, the gasifier direct cost uncertainty drops from fifth to seventh in the rankings, while the indirect construction cost uncertainty jumps from sixth to fifth. The gasifier direct cost is uniformly distributed, whereas the indirect capital cost (ICC) factor is triangularly distributed. Hov'ever, the ranks for any input variable are uniformly distributed. Thus, the underlyıng basis for the probability distributions used in rank regression may differ significantly from that in sample regression. Variables which are relatively "peaky" (having values concentrated near the mode) will tend to become more influential in rank regression, where they are treated as uniformly distributed. The effect here for the ICC is to more heavily weigh the high and low outcomes in rank regression than is the case for sample regression. Similarly, the standard error for the HRSG is normally distributed. Rank regression treats this variable as uniformly distributed, leading to more influence in the rank regression than in the sample regression.

The results in Table 14 illustrate the importance of considering uncertainties in both performance and cost parameters when estimating uncertainty in capital cost. Uncertainties in performance parameters of both the gasification and zinc ferrite process area are shown to be important determinants of uncertainty in capital cost. These performance parameters, such as gasifier coal throughput and zinc ferrite sorbent sulfur loading, affect the sizing and number of vessels for the respective process areas. Uncertainties in cost parameters interact with the uncertainties in performance. The sources of cost-related uncertainties include direct process area costs, project-related capital costs, indirect construction costs, and the standard error of several of the process area direct cost regression models. The latter indicates that uncertainty in the cost estimate could be reduced, to some degree, by developing better process area cost models. The explicit characterization of standard errors thus allows the analyst to quantitatively identify specific models for which further development effort is warranted. 
Table 15. Comparison of Rankings of Uncertain Parameters Affecting Cost of Electricity for the Lurgi-based System.

\begin{tabular}{lllll}
\hline & \multicolumn{4}{c}{ Type of Output Analysis ${ }^{\mathrm{a}, \mathrm{b}}$} \\
\cline { 2 - 5 } Rank $^{\mathrm{c}}$ & PCC & SRC & PRCC & SRRC \\
\hline 1 & ZF Attrition & ZF Attrition & ZF Attrition & ZF Attrition \\
2 & ZF Loading & ZF Loading & Coal throughput & Coal throughput \\
3 & Coal throughput & Coal throughput & Project Unc. & Project Unc. \\
4 & Gas Turbine DC & Gas Turbine DC & Carbon to Ash & Carbon to Ash \\
5 & Gasifier MC & Gasifier MC & Gasifier MC & Gasifier MC \\
6 & Project Unc. & Project Unc. & ZF Loading & ZF Loading \\
7 & ZF Unit Cost & ZF Unit Cost & ZF Unit Cost & ZF Unit Cost \\
8 & Gasifier DC & Gasifier DC & Gas Turbine DC & Gas Turbine DC \\
\hline
\end{tabular}

aAbbreviations for type of analysis: $\mathrm{PCC}=$ partial correlation coefficients; $\mathrm{SRC}=$ standardized regression coefficients; $\mathrm{PRCC}=$ partial rank correlation coefficients; SRRC $=$ standardized rank regression coefficients. ${ }^{b}$ Abbreviations foi uncertain parameters: $\mathrm{CH}=$ coal handling; $\mathrm{DC}=$ direct cost; $\mathrm{HRSG}=$ heat recovery steam generator; $\mathrm{ICC}=$ indirect construction cost; $\mathrm{SE}=$ standard error; $\mathrm{STG}=$ steam turbine-generator; Unc. $=$ uncertainty; $\mathrm{ZF}=$ zinc ferrite.

${ }^{\mathrm{c}}$ At about the ninth most important parameter, the correlation or regression coefficients become sufficiently small to no longer be statistically significant. Therefore, rankings below eight are not shown.

A third example of regression analysis is shown in Table 15 for the influence of input uncertainties on uncertainty in the levelized cost of electricity. In this example, both sample regression approaches produce the same rankings. Also, both rank regression approaches produce the same rankings. However, the rankings obtained from sample and rank regression do not agree, and the differences are quite strong. The four approaches agree only with respect to the top-ranked uncertainty. However, the second most imporiant uncertainty according to sample regression, zinc ferrite sorbent sulfur loading, is only the sixth most important uncertainty obtained from rank regression.

The difference between the two results is attributable to the nonlinearity of the zinc ferrite performance model. As shown in Figure 24, the uncertainty in the zinc ferrite sorbent charge is positively skewed, with the extremely high values almost a factor of three greater than the median. The uncertainty in sorbent charge is driven primarily by uncertainty in sorbent sulfur loading, and it affects both capital and operating costs through the initial and annual makcup sorbent requirements. However, in rank regression, the use of rank values eliminates the influence that the extreme sample values, associated with low 
sorbent loading, have in the linear regression model. Thus, the relative importance of sorbent loading is much less according to rank than sample regression.

For other switches in the ordering of uncertainties, the effects are similar to those observed for total capital cost. "Peaky" distributions, such as coal throughput and project uncertainty, tend to rise through the rankings when comparing rank to sample regression results. Uniform distributions, such as gas turbine direct cost, tend to fall through the rankings, because they are represented as uniform distributions in both approaches, while peaky distributions in sample regression are represented as uniform in rank regression. Thus, their relative influence in the linear regression model tends to decrease.

The uncertainty in levelized cost is shown to be influenced by both performance and cost uncertainties, and by uncertainties in all three major process areas. The key performance-related uncertainties include zinc ferrite attrition rate and sorbent sulfur loading, that result in uncertainty in the requirements for chemicals and other consumables. The key cost-related uncertain parameters include direct capital costs (e.g., gas turbine direct cost), maintenance costs (e.g, gasifier maintenance cost), and variable operating costs (e.g., sorbent unit cost).

In spite of the difference: in rankings that can be obtained using different approaches, it is often possible nonetheless to obtain a robust list of key uncertainties. For example, in the cases where all four analysis approaches agree on rankings, the results can be considered to be robust. Groups of variables may be identified as important in common between the techniques, but their rankings may differ slightly from one to the other. In these cases, the entire grouping of variables may be assumed to important, even if it is not possible to find agreement among the approaches regarding the ordering within the group.

\subsubsection{Probabilistic Sensitivity Analysis}

Another approach to identifying key uncertainties is probabilistic sensitivity analysis. Insight into the sensitivity of output variaile uncertainties to the assumptions regarding uncertainties in input variables can be obtained by comparing the effect that different assumptions have on the result. One type of useful insight is the relative importance of uncertainties in performance parameters versus cost parameters. Another is the relative contribution to uncertainty from different process areas. Through probabilistic sensitivity analysis, it is possible to characterize the effect that specific uncertainties or groups of uncertainties have on specific output variables. In cases were uncertainties are excluded from a case study, the probability distribution for the parameter is replaced by its deterministic value. 


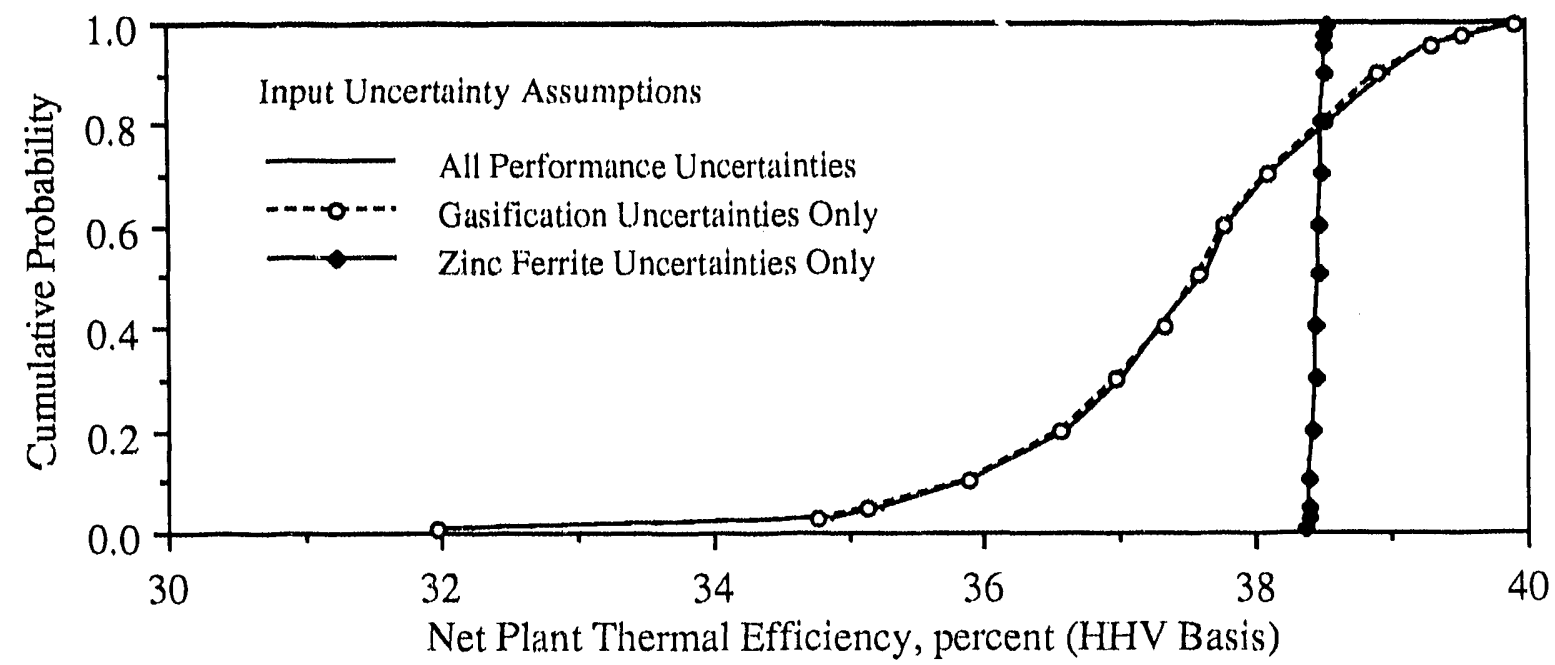

Figure 33. Sources of Uncertainty for Plant Thermal Efficiency.

An example of probabilistic sensitivity analysis is shown in Figure 33. The uncertainty in plant thermal efficiency resulting from all of the performance uncertainties from Table 11 is compared to that resulting from uncertainties in the gasification and zinc ferrite process areas, considered separately. The figure clearly indicates that uncertainty in the gasification process area is almost completely responsible for the uncertainty in plant thermal efficiency. The range of uncertainty in efficiency resulting from the zinc ferrite process area is very small.

Figure 34 compares the uncertainty in total capital cost attributable to either performance or cost parameter uncertainties alone with the result from including all uncertain parameters in the simulation. Uncertainty in cost alone results in a 90 percent probability range of approximately a $\$ 250 / \mathrm{kW}$, while uncertainty in performance alone results in a range of approximately $\$ 325 / \mathrm{kW}$. However, in addition to the effect on variance, the assumptions regarding performance uncertainties also shift the central value of the distribution upward by about $\$ 100 / \mathrm{kW}$, compared to the results from cost uncertainties alone. The reasons for the shift can be seen in Figures 23 and 24. The performancerelated uncertainties tend to be skewed, resulting in the negatively skewed distribution for plant efficiency and the positively skewed distribution for zinc ferrite sorbent charge. Both of these results tend to increase capital costs, compared to the deterministic values and compared to the case with cost-related uncertainties only. In contrast, the cost-related uncertainties are more symmetric. Thus, the uncertainty due to cost parameters leads to an increase in the variance of total capital cost when considered simultaneously with uncertainty in performance. 


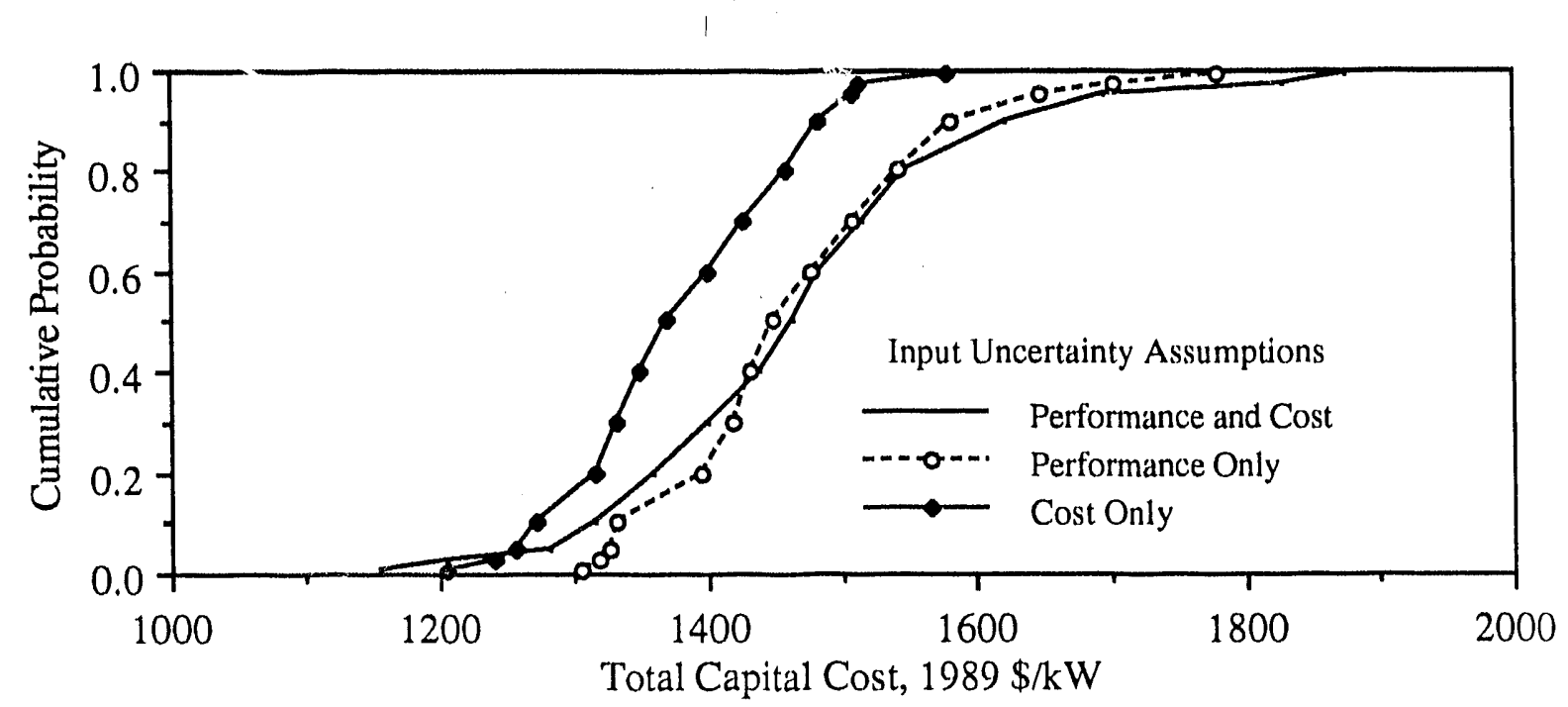

Figure 34. Sources of Uncertainty for Total Capital Cost.

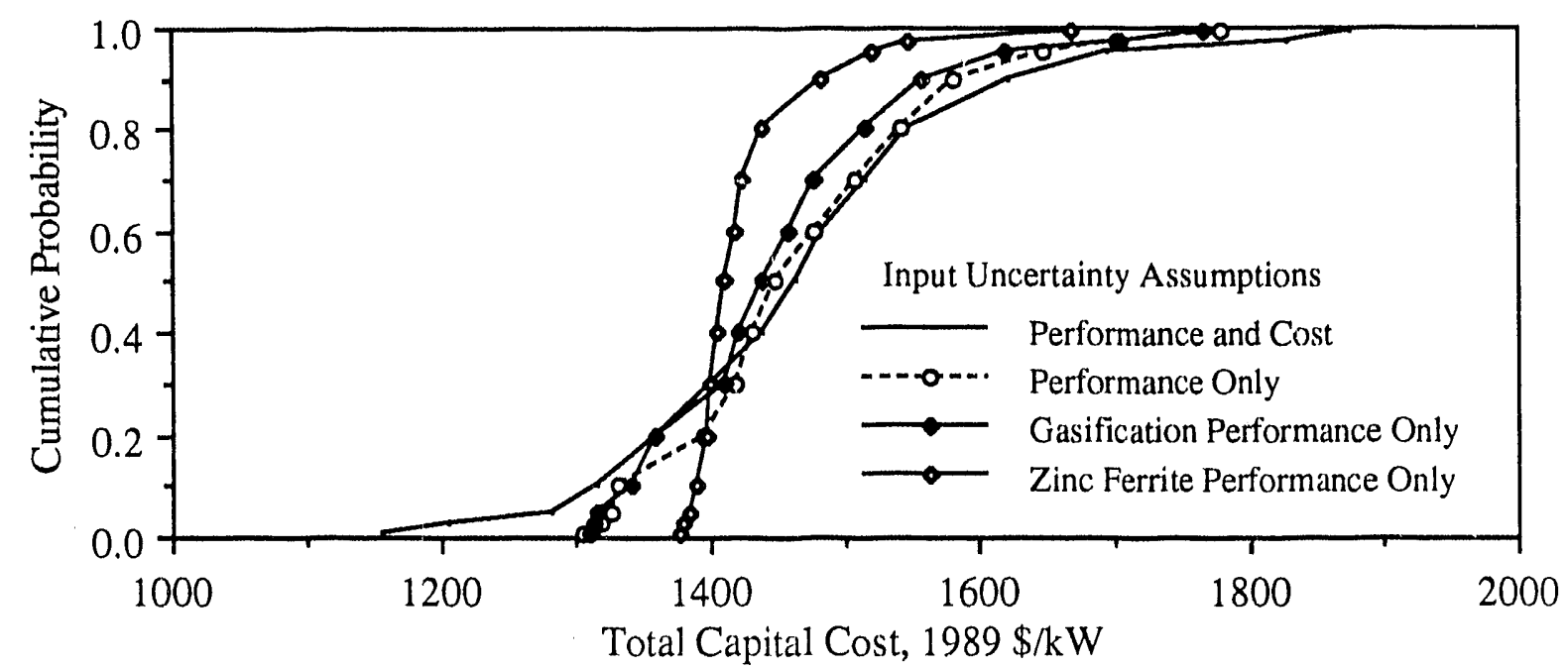

Figure 35. Performance-Related Sources of Uncertainty for Total Capital Cost.

The effect of assumptions regarding performance uncertainties are examined in more detail in Figure 35. In the case where performance uncertainty in the gasification process area only is considered, the resulting uncertainty in capital cost is similar to that obtained when all performance-related uncertainties are considered. Performance uncertainties in the zinc ferrite process alone result in a positively skewed uncertainty in capital cost. The interactions between uncertainties in the zinc ferrite and gasification process areas result in the positively skewed distribution for capital cost resulting from all performance related uncertainties.

A comparison of uncertainty estimates for the cost of electricity is shown in Figure 36. The graph shows the effect of specifying uncertainties in performance and cost either separately or combined. Because the cost of electricity is sensitive to most of the 47 


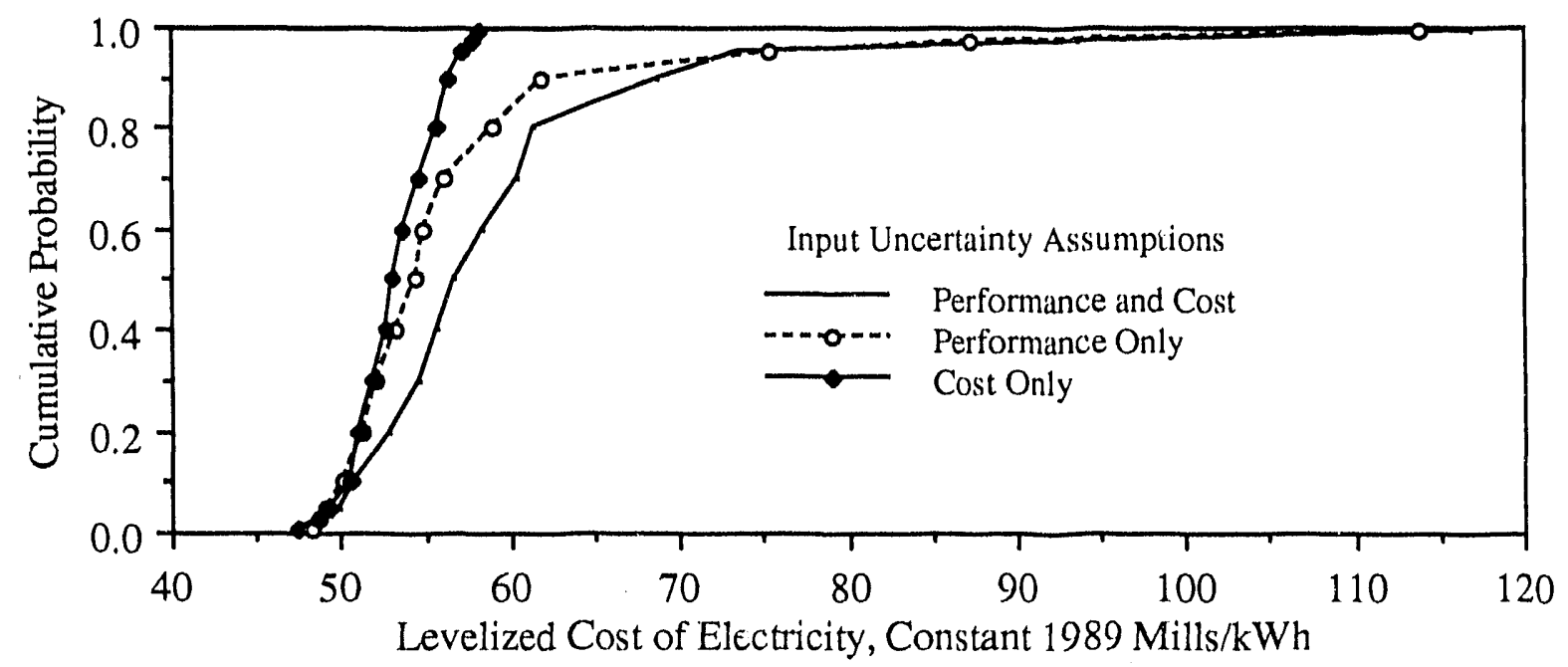

Figure 36. Sources of Uncertainty for Cost of Electricity.

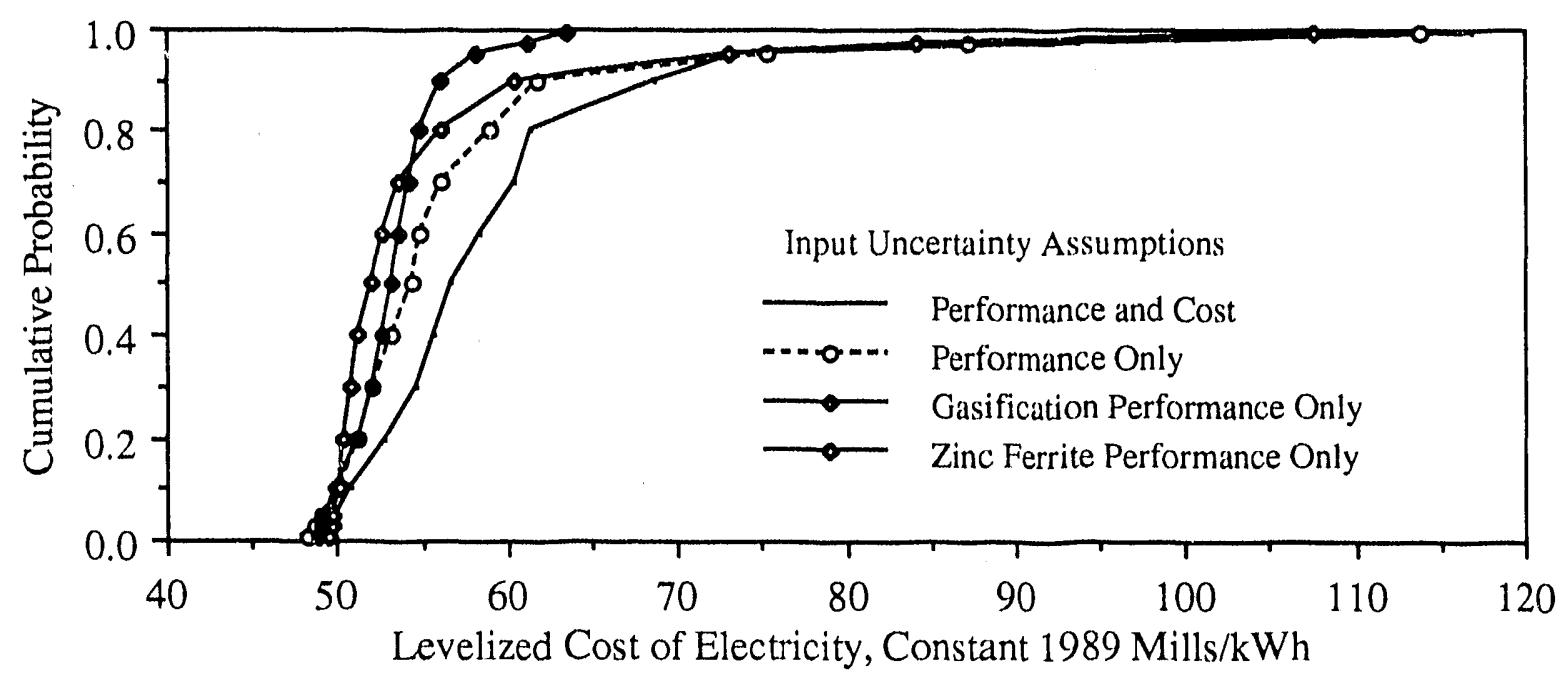

Figure 37. Performance-Related Sources of Uncertainty for Cost of Electricity.

uncertainties assumed in Table 11, the interactions among uncertainties are complex. In this case, neither performance nor cost uncertainties taken alone are shown to adequately describe the overall uncertainty in the cost of electricity. However, performance-related uncertainties are responsible for the positive skewness of the distribution.

The interactions of uncertainties in performance parameters are explored further in Figure 37. The graph clearly illustrates that uncertainties in the zinc ferrite process area are primarily responsible for the positive skewness of the uncertainty in the cost of electricity. The uncertainty resulting from gasification performance parameters is also positively skewed. However, the 90 percent probability range resulting from gasification uncertainties alone is only approximately $8 \mathrm{mill} / \mathrm{s} / \mathrm{kWh}$, whereas the corresponding range resulting from zinc ferrite uncertainties alone is approximately $23 \mathrm{mills} / \mathrm{kWh}$. The 


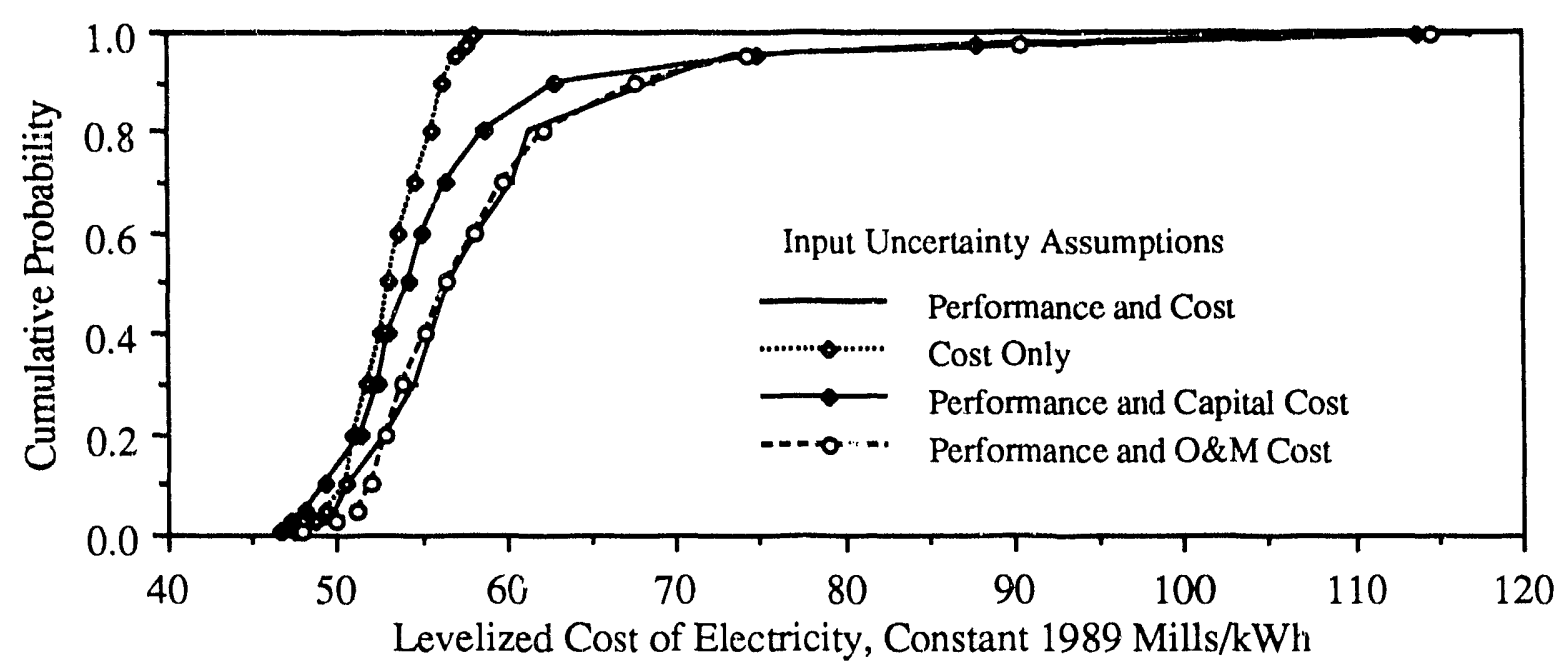

Figure 38. Cost-Related Sources of Uncertainty for Cost of Electricity.

extremely high cost outcomes are driven by uncertainty in the performance of the zinc ferrite sorbent.

The interactions between uncertainties in performance and cost are detailed in Figure 38. Uncertainties in cost parameters alone results in a modest range of values for the cost of electricity. If performance and capital cost uncertainties are considered simultaneously, the probability distribution begins to shift toward higher costs, in addition to becoming positively skewed. However, it is clear that uncertainties in operating and maintenance costs, simultaneous with uncertainties in performance, have a more pronounced effect than uncertainties in capital cost on the cost of electricity. This indicates that uncertainties in operating costs are key determinants of uncertainty in levelized annual costs.

\subsubsection{Screening Analysis}

A final approach considered here for identifying key uncertainties is a screening analysis. In this approach, uncertainties which were found to be insignificant in the regression analyses are removed from the model. The model is then run again, and the results compared to the simulation in which all uncertainties were sncluded. The uncertainties which were found to be statistically insignificant, or which were found to have very weak relationships with uncertainties in key output variables, are listed in Table 16. The key output variables considered were efficiency, total capital cost, cost of electricity, and $\mathrm{SO}_{2}, \mathrm{NO}_{\mathrm{x}}$, and $\mathrm{CO}_{2}$ emissions. A total of 19 uncertainties were screened from further case studies, leaving 28 of the original 47 uncertain parameters. The uncertain parameters removed from the screening case study were assigned their respective deterministic "best guess" values. 
Table 16. Uncertainties Screened Out of Case Studies for Air-Blown Lurgi-based IGCC System with Expert Judgments LG-1 and ZF-1.

Fines Carbon Content

Residual Sulfide in Zinc Ferrite After Reductive Regeneration

Zinc Ferrite Absorber Pressure Drop

Thermal $\mathrm{NO}_{\mathrm{x}}$

Coal Handling Direct Capital Cost

Cyclone Direct Capital Cost

Oxidant Feed Direct Capital Cost

HRSG Direct Capital Cost

Steam Turbine Direct Capital Cost

General Facilities Direct Capital Cost

Standard Error of Oxidant Feed Direct Capital Cost Model

Standard Error of Sulfuric Acid Direct Capital Cost Model

Standard Error of Boiler Feedwater Direct Capital Cost Model

Standard Error of Auxiliary Power Model for Coal Handling

Maintenance Cost for Oxidant Feed

Maintenance Cost for Cyclones

Maintenance Cost for Zinc Ferrite

Byproduct Marketing Cost

Operating Labor Rate

The results of the screening analysis are shown graphically for the plant efficiency, capital cost, and cost of electricity in Figures 39, 40, and 41, respectively. For all three output variables, the results obtained from the screened uncertainties are virtually indistinguishable from the results obtained when all 47 uncertainties are included in the simulation. This verifies that the 19 uncertainties listed in Table 16 are unimportant. These uncertainties can be eliminated from further data collection efforts. 


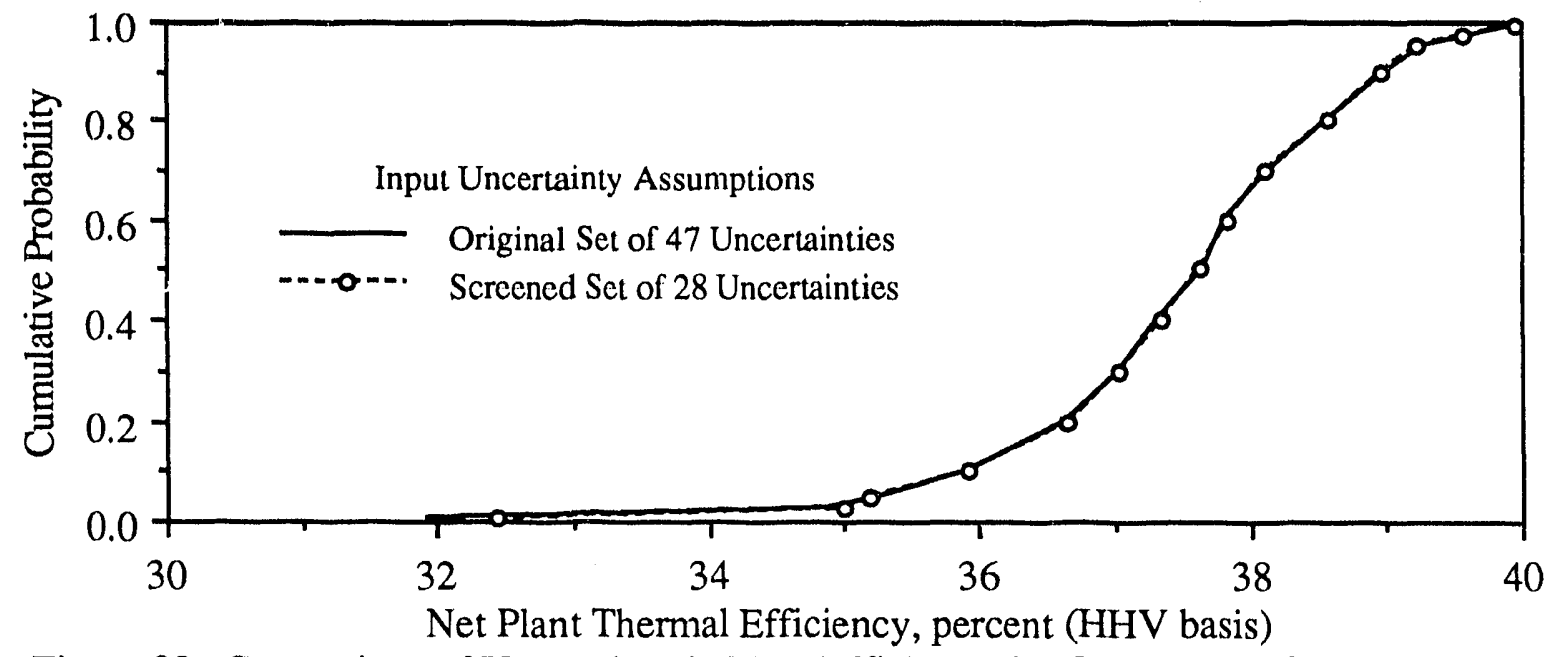

Figure 39. Comparison of Uncertainty in Plant Efficiency for Original and Screened Sets of Uncertainties.

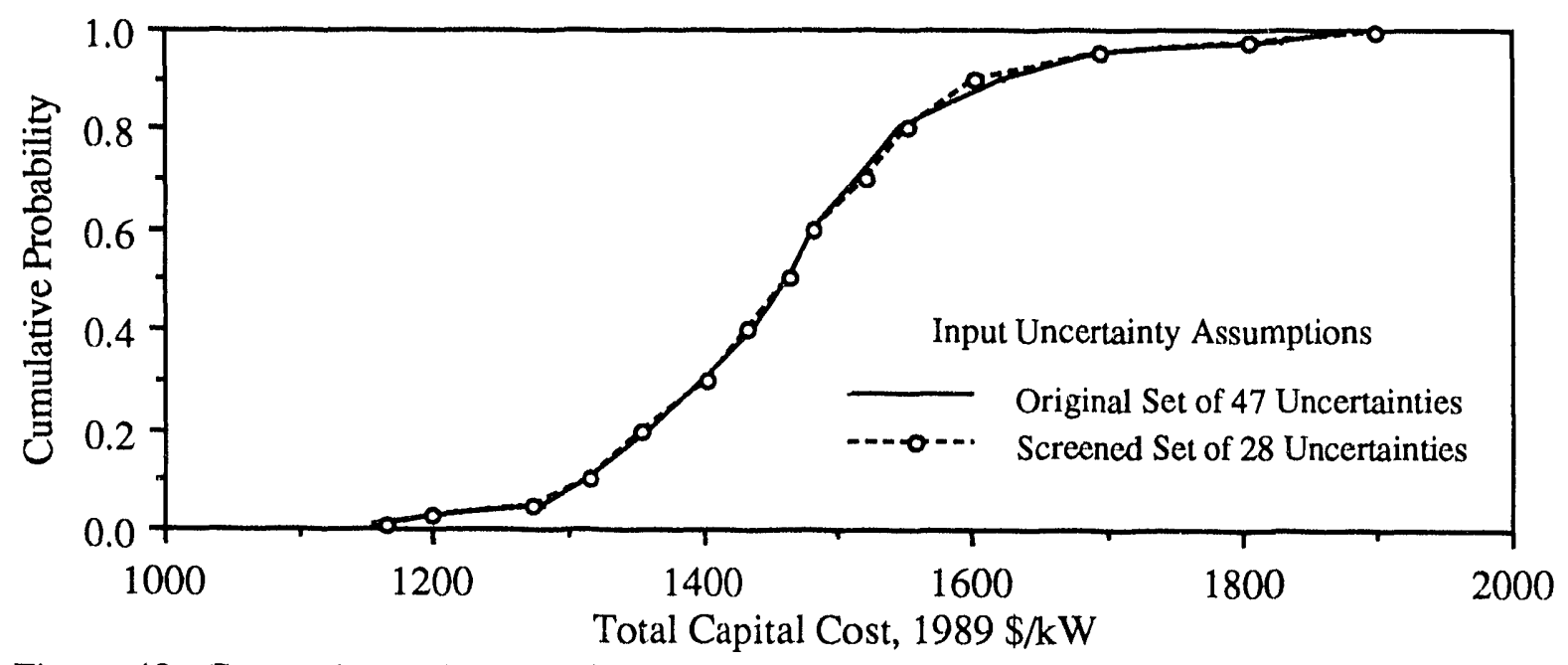

Figure 40. Comparison of Uncertainty in Total Capital Cost for Original and Screened Sets of Uncertainties.

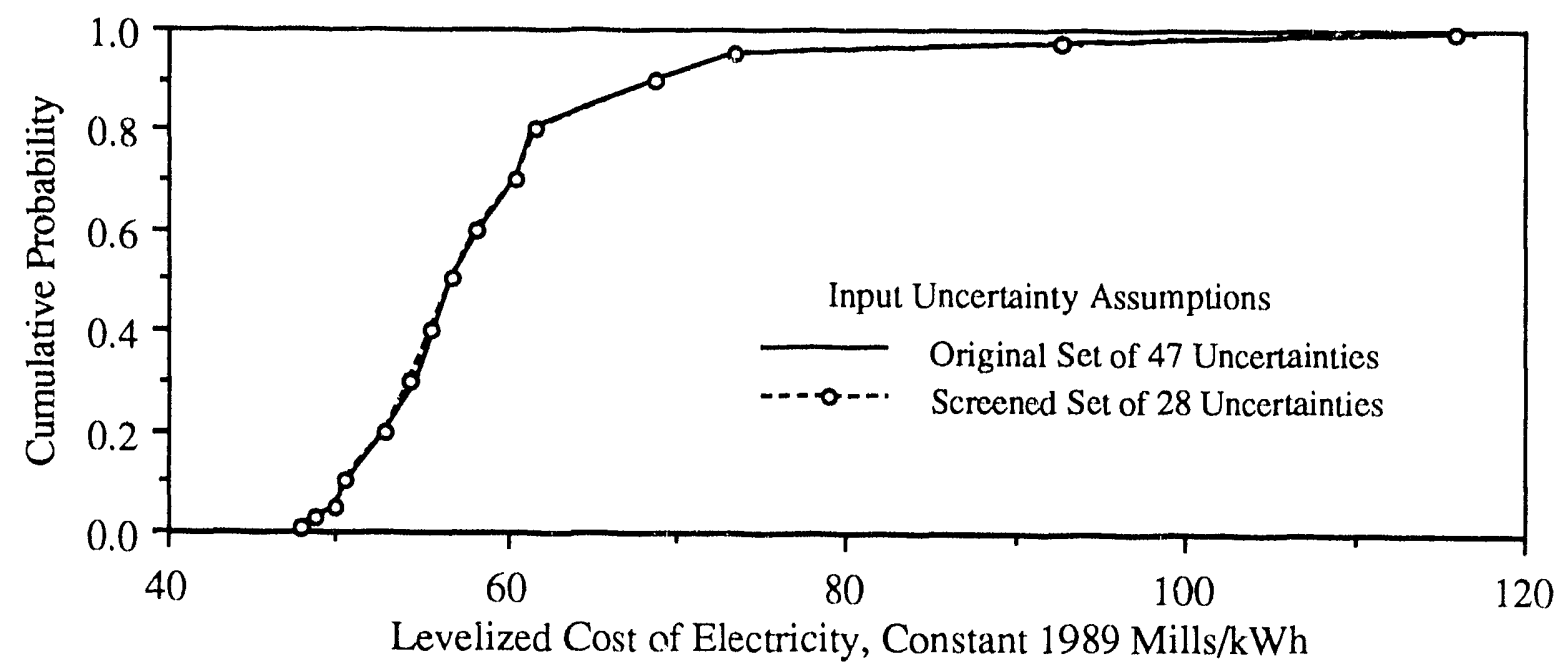

Figure 41. Comparison of Uncertainty in the Cost of Electricity for Original and Screened Sets of Uncertainties. 


\subsubsection{Probabilistic Design Analysis}

In this section, several examples of probabilistic design analysis are considered. In each case, two alternative design assumptions are compared probabilistically. The design issues include the gas turbine fuel valve pressure drop, rich/lean gas turbine combustion for $\mathrm{NO}_{\mathrm{x}}$ control, an incremental improvement in gas turbine design, and zinc ferrite sorbent regeneration temperature. The effect of these design modifications on plant performance and cost are evaluated.

\subsubsection{Gas Turbine Fuel Valve}

One process development that is being sought by DOE and others is the development of a low pressure drop fuel valve for gas turbine applications. As discussed in Appendix A.4, current gas turbine models commonly assumed for IGCC systems have fuel gas pressure drops of about $70 \mathrm{psi}$. This pressure drop represents an energy penalty to the IGCC system, because gasifier blast air must be pressurized to overcome the pressure drop between the gasifier and the gas turbine combustor. Process engineers expect future fuel gas valves to have pressure drops of $20 \mathrm{psi}$ or less. Therefore, an IGCC system with a low pressure drop ( $20 \mathrm{psi}$ ) fuel valve was compared to on with a conventional fuel valve (70 psi pressure drop). Differences in gas turbine cost, if any, associated with the advanced fuel gas valve are not considered.

The 50 psi reduction in pressure drop between the gasifier exit and the gas turbine combustor results in a mean efficiency savings of 0.8 percentage points, or a 2.2 percent improvement in plant efficiency compared to the base case design. There is very little uncertainty regarding the efficiency savings; it varies from a low of about 0.7 to a high of 0.9 percentage points.

However, the effect of the reduced pressure drop on process costs is quite different. The gasifier coal throughput is a function of gasifier pressure. As pressure is reduced, the gasifier coal throughput is reduced. Therefore, more gasifier vessels, which are of a standard size, must be utilized to accommodate the total coal flow. Furthermore, as system pressure is reduced, the fuel gas volumetric flow rate increases. This results in increased vessel size requirements for the cyclone and zinc ferrite desulfurization process areas. These interactions are considered in the performance and cost model.

The combined effect of these trade-offs is shown in Figure 42, which shows a probability distribution for the difference in cost between the systems with the advanced and conventional fuel valves. A positive number indicates that the advanced fuel valve reduces levelized cost, neglecting any incremental costs associated with the new fuel valve 


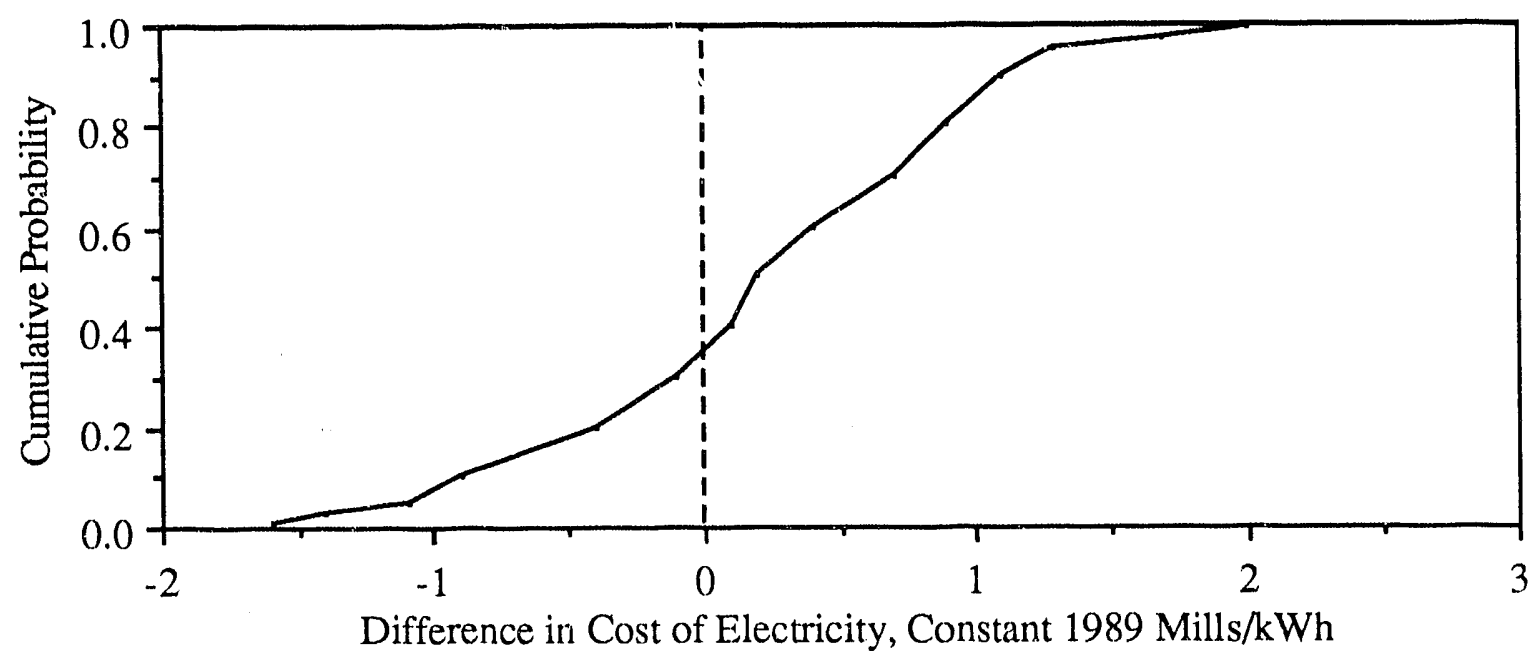

Figure 42. Uncertainty in the Difference in Cost of Electricity Between Base Case and Advanced Gas Turbine Fuel Valves.

itself. The mean cost savings is $0.2 \mathrm{mills} / \mathrm{kWh}$. However, there is approximately a 35 percent probability that levelized costs will be higher for the advanced option, even in spite of the casic iency savings. For many of the outcomes in the probabilistic analysis, the increased costs associated with larger or more numerous process vessels offset the cost savings associated with higher plant efficiency.

\subsubsection{Gas Turbine Rich/Lean Combustion}

$\mathrm{NO}_{\mathrm{x}}$ emissions from air-blown IGCC systems are a concern, because hot gas cleanup systems typically do not remove fuel bound-nitrogen species from the fuel gas prior to combustion in the gas turbine. The primary fuel-bound nitrogen specie in the fuel gas is ammonia, which may react almost completely to form $\mathrm{NO}_{\mathrm{x}}$ during combustion. In contrast, cold gas cleanup systems remove essentially all of the ammonia from the fuel gas prior to combustion. Uncontrolled fuel- $\mathrm{NO}_{\mathrm{x}}$ emissions from air-blown systems may be unacceptable, requiring the use of post-combustion emission control using SCR or the development of advanced combustors that minimize fuel $\mathrm{NO}_{\mathrm{x}}$ formation.

As discussed in Appendix A.4, there has been research on "rich/lean" combustors. These combustors burn the fuel gas in two stages. In the first stage, fuel is combusted in an oxygen-deficient atmosphere. Most of the ammonia in the fuel gas is converted to diatomic nitrogen during rich combustion. Then the products from the rich combustion stage, along with additional fuel gas, enter a lean combustion stage. Here, conditions are such that only a portion of the diatomic nitrogen is converted to "thermal $\mathrm{NO}_{\mathrm{x}}$." Overall, the ammonia conversion rate to $\mathrm{NO}_{\mathrm{x}}$ in commercial rich/lean combustors, which have yet to be developed, is predicted to be as high as 20 percent to as low as less than one percent. In 


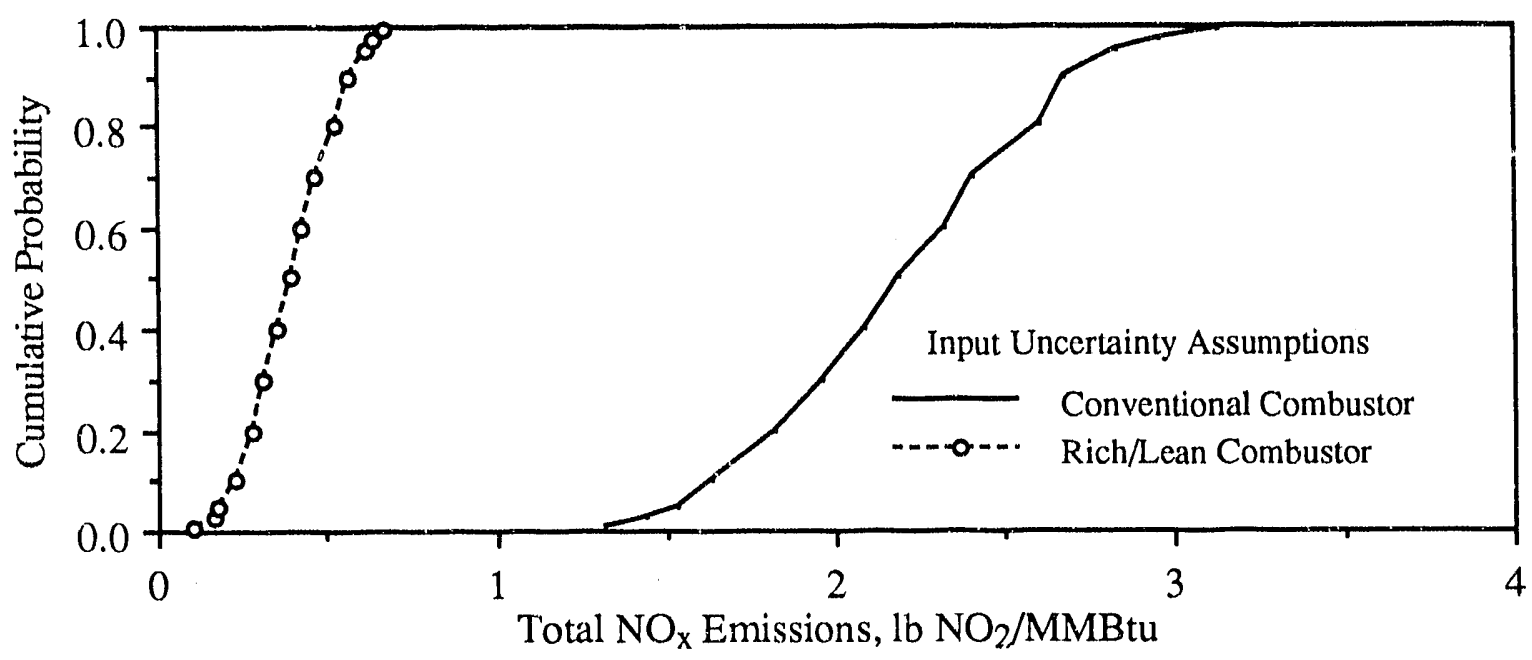

Figure 43. Uncertainty in $\mathrm{NO}_{\mathrm{x}}$ Emissions for Conventional and Rich/Lean Gas Turbine Combustors.

contrast, conventional gas turbine combustors may convert 50 to 100 percent of ammonia to $\mathrm{NO}_{\mathrm{x}}$. See Appendix A.4 for more discussion of uncertainty for the rich/lean combustor.

The $\mathrm{NO}_{\mathrm{x}}$ emission rates for conventional and rich/lean combustors are compared in Figure 43. The uncertainty in emission rates for both cases is attributable to uncertainty in the performance of the combustor as well as uncertainty in the ammonia yield from the gasifier. For the conventional combustor, even the most optimistic outcome is approximately $1.3 \mathrm{lb} \mathrm{NO} / \mathrm{MMBtu}$, which significantly exceeds typical allowable emission rates for natural gas and distillate oil-fired gas turbines. The results for the rich/lean combustor indicate a 90 percent probability range from 0.2 to $0.6 \mathrm{lb} \mathrm{NO} / \mathrm{MMBtu}$. Because of increasingly stringent environmental permitting practices, it is not clear if emission rates of this magnitude will be acceptable for an IGCC system.

\subsubsection{Additional Research}

Several factors must be considered in determining the value of research. First, judgment is required to estimate the likely results from a research effort. The value of research depends also on the circumstances of actual adoption of the new technology, which determines the ultimate cost savings compared to other technology. Judgment is required regarding the likely plant sizes, byproduct markets, coal characteristics, and other influencing factors that will face the new technology. It is unlikely that any single cost estimate can be used for such an anaiysis; rather, several case studies representative of different applications may be required. A third factor influencing the value of research is the possibility of simultaneous improvement in information about or design of competing 
processes. Therefore, any prior estimate of the value of research is conditioned on the judgments regarding research results, technology diffusion, and improvements in competing processes.

In this analysis, the primary emphasis is on estimating the effect of possible research results on the comparative performance and cost of the advanced IGCC system versus a conventional IGCC system. It is assumed that research can reduce the uncertainties about several key process variables, and thus provide "imperfect information" 1 about the technology. More study of specific process areas could reasonably be expected to reduce uncertainties regarding specific performance and cost parameters. Therefore, it is instructive to analyze the effect on total performance or cost from reductions in the uncertainty in key parameters that could result from further research.

As an illustrative case study, hypothetical reductions in uncertainty in performance and cost parameters for three major process areas are considered. These assumptions are shown in Table 17. For each uncertain parameter shown in the table, the "reduced" uncertainty assumes no change in the central value of the probability distribution, as represented by the median for fractile and uniform distributions, or by the mode for normal and triangular distributions. However, the ranges between the central value and the upper and lower limits are reduced by 50 percent. For fractile distributions, corresponding adjustments were made for fractiles between the median and the upper and lower limits. Thus, in all cases, the reduced uncertainties retain the qualitative features of the original assumptions; e.g., if the original distribution was positively skewed, the reduced uncertainty distribution is also positively skewed.

The effect of reducing uncertainties in performance parameters on plant efficiency is shown in Figure 44. The uncertainty in efficiency based on the reduced input parameter uncertainties has a smaller variance than for the base case. In addition, the mean efficiency increases from 37.5 in the base case to 38.0 in the reduced uncertainty case, due to the skewness of uncertainty assumptions in both the base and reduced uncertainty cases. Thus, based on the assumptions regarding results obtainable from further research, both a reduction in the risk of poor performance and an increase in the expected value of

1 As opposed to perfect information, which would remove all uncertainties and would allow a potential process adopter to avoid any loss in selecting between FGD and copper oxide systems. 
Table 17. Illustrative Assumptions Regarding Reduction in Uncertainty in Key Process Areas

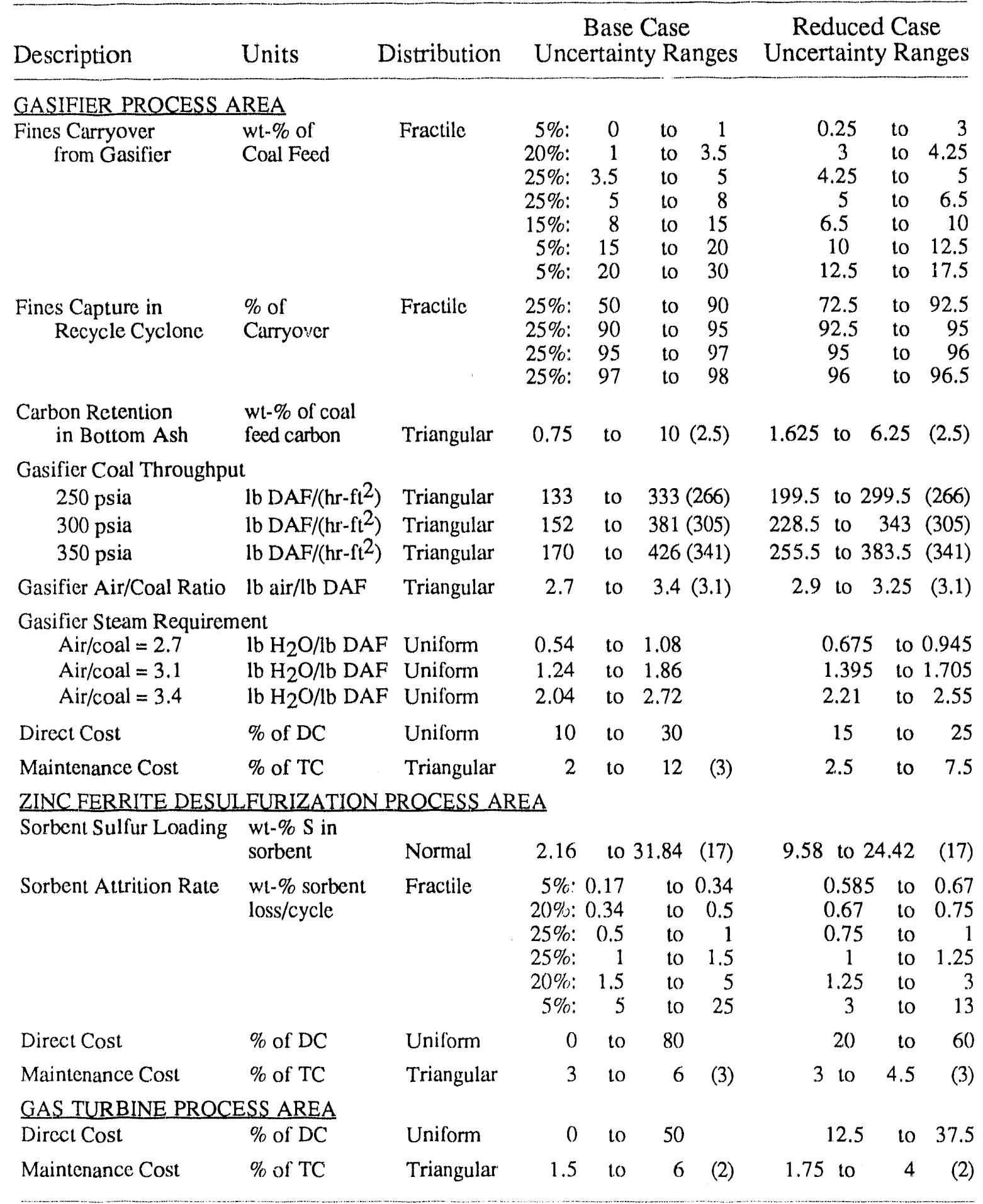




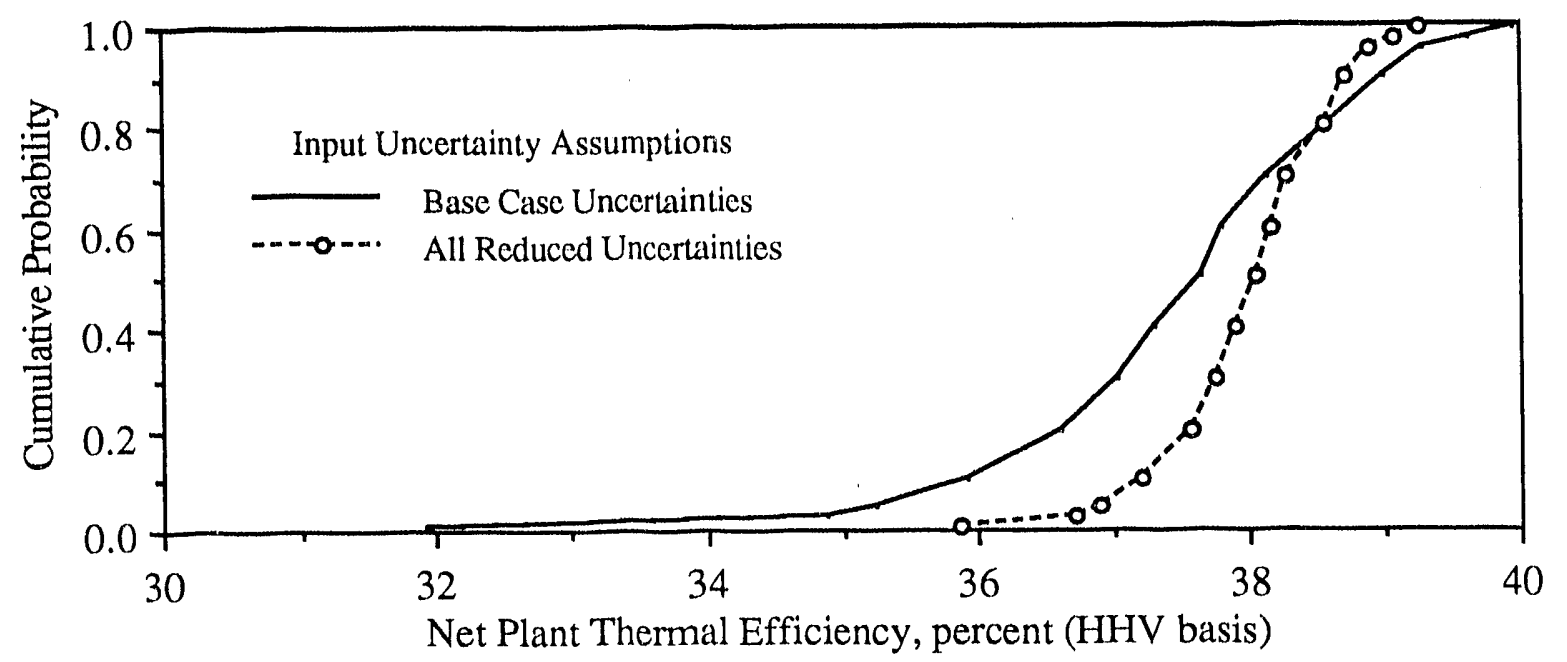

Figure 44. Effect of Reductions in Uncertainty on Uncertainty in the Plant Thermal Efficiency.

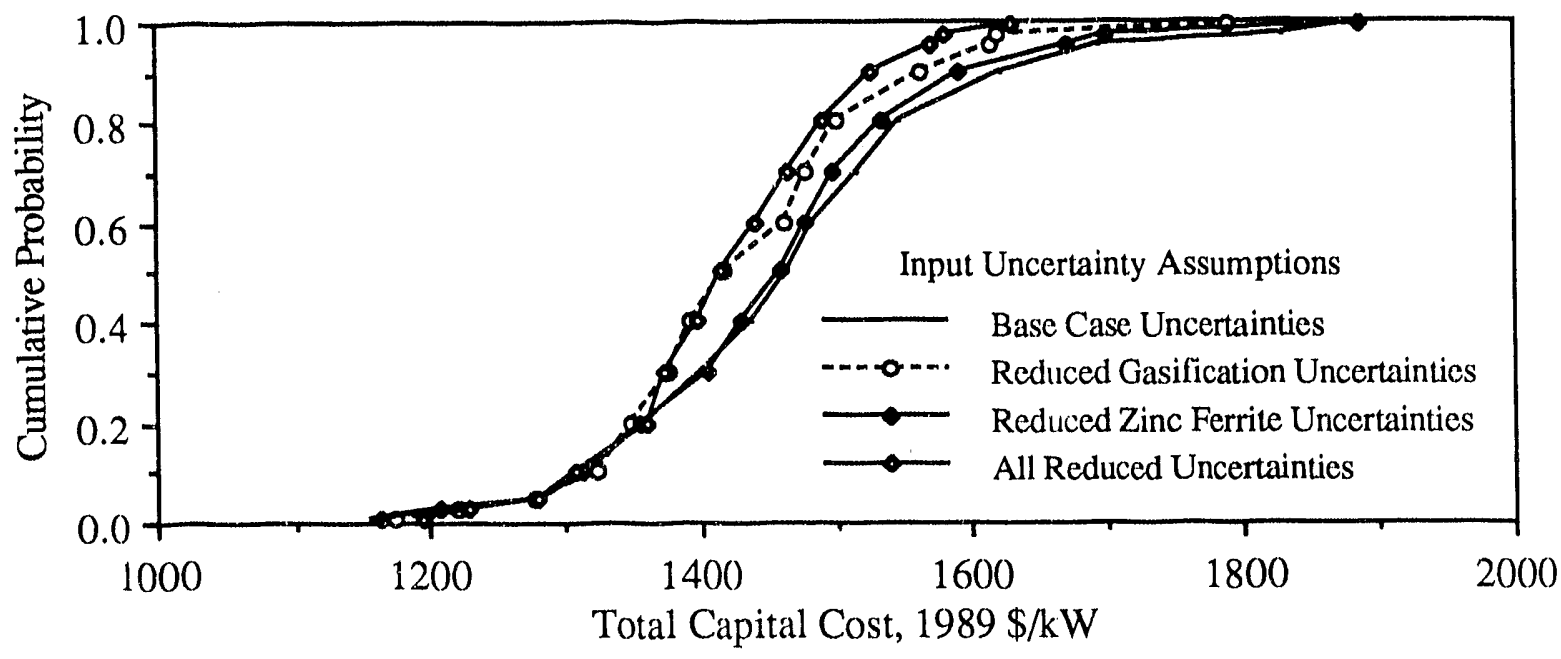

Figure 45. Effect of Reductions in Uncertainty in Specific Process Areas on Uncertainty in the Total Capital Cost.

performance are obtained. The reduced uncertainties in the gasification process area play a predominate role, with uncertainties in the zinc ferrite process area having a negligible effect. This result is consistent with that obtained in the identification of key uncertainties.

The interaction among alternative groupings of reduced uncertainties as they affect capital cost is shown in Figure 45. Here, the base case uncertainties are compared to cases where reduced uncertainties in only the gasification or zinc ferrite process areas are considered, and to the case when all of the reduced uncertainties, including those of the gas turbine process area, are included. Reductions in uncertainty in the gasification process area alone yield a greater effect than reductions in uncertainty in the zinc ferrite process area. The mean total capital cost is reduced from $\$ 1,465 / \mathrm{kW}$ to $\$ 1,431 / \mathrm{kW}$ due to 


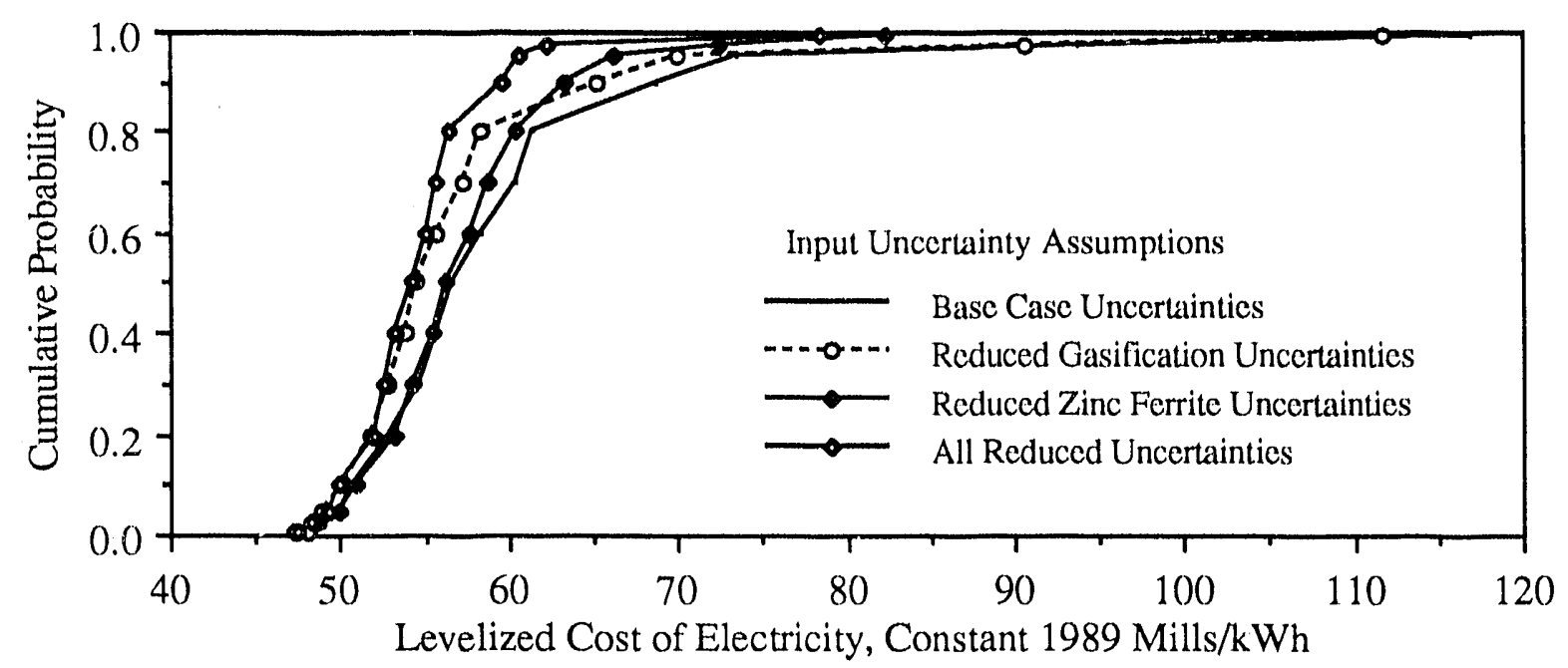

Figure 46. Effect of Reductions in Uncertainty in Specific Process Areas on Uncertainty in the Cost of Electricity.

assumptions in the gasification process area. When all reduced uncertainties are considered, the mean is ciecreased further to $\$ 1,420 / \mathrm{kW}$. Thus, a mean cost savings of $\$ 45 / \mathrm{kW}$ would result if reduced uncertainties could be obtained from further research.

Furthermore, the risk of high capital cost is also reduced. For example, in the base case there is a 10 percent probability that cost could exceed $\$ 1,625 / \mathrm{kW}$, whereas in the case where all reduced uncertainties are assumed, the corresponding value is $\$ 1,525 / \mathrm{kW}$. Further research can be expected to reduce both the expected costs and the risks of high costs. This result will be explored later when the IGCC systems are compared.

A similar result is obtained for the cost of electricity, as shown in Figure 46. However, the effect of reducing uncertainties in the zinc ferrite process area on the extreme high values obtained in the base case is more pronounced. While reducing uncertainty in the zinc ferrite process has only a modest effect on the median (a reduction less than 1 mill/kWh), it has a more pronounced effect on the mean and particularly on the upper fractiles of the distribution. The mean is reduced by $1.8 \mathrm{mill} / \mathrm{kWh}$. At the 95 th percentile, the cost is reduced by 7.3 mills $/ \mathrm{kWh}$, and at the $97 \mathrm{th}$ fractile the reduction is $21 \mathrm{mills} / \mathrm{kWh}$. These reductions are associated with the differences in assumptions regarding sorbent sulfur loading and attrition rate.

When all reduced uncertainties are considered, the mean cost of electricity is reduced by over 4 mills/kWh, and there is only a five percent probability that cost would exceed 60.6 mills $/ \mathrm{kWh}$. In the base case, the probability that cost would exceed 60.6 mills/kWh is over 20 percent. Thus, as with capital cost, reduced process performance and 
cost uncertainties are shown to reduce the mean cost and the risk associated with high cost outcomes.

The preceding comparisons of base case and reduced uncertainties can be viewed as

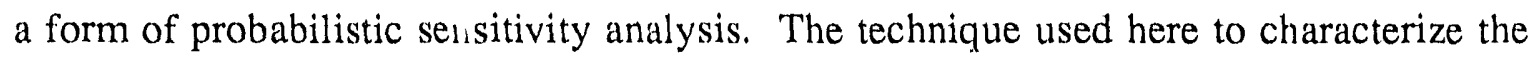
possible effects of further research illustrates the interactions among uncertainties in several process areas. These types of insights are not obtained from traditional deterministic sensitivity analysis.

\subsubsection{Multiple Experts}

In many cases, there may be more than one expert from whom judgments could be elicited regarding uncertainties in a process technology. Experts may have differing beliefs regarding the range and probability of possible outcomes for specific parameters. They may have different opinions as to the set of parameters that should be treated probabilistically.

For the Lurgi-based IGCC systems, judgments from more than one expert were obtained for the zinc ferrite and gasification process areas. The implications of these alternative judgments are investigated in the following two sections.

The approach taken here is to prepare separate case studies of process performance and cost based on alternative sets of judgments from different experts. Then, the results of the case studies are compared to obtain insights into whether the experts "agree" and t) identify the uncertainties that result in significant differences. This approach is preferred to combining the judgments of several experts for each input parameter and then running a single case study. In the latter case, little insight would be obtained regarding whether the differences in expert judgments would lead to different results if considered separately. Furthermore, combining judgments is problematic, because it requires a comparative weighting of the judgments. This introduces an additional element of subjectivity into the analysis.

\subsubsection{Zinc Ferrite Process Area}

Judgments from three experts were obtained regarding uncertainties in the zinc ferrite process area. In this section, these judgments are compared, with all other uncertainties held at their base case values as given in Table 11. The base case assumptions include the judgment of Expert $\mathrm{ZF}-1$ regarding the zinc ferrite process areas.

Expert ZF-2 provided two sets of judgments, based on different design assumptions. These are discussed in detail in Appendix A.3. The two sets of judgments 
are labeled ZF-2P and ZF-2R. For ZF-2P, the expert accepted the assumptions given in the elicitation briefing package. These included the use of high efficiency cyclones for upstream particulate removal, a maximum zinc ferrite process vessel length-to-diameter ratio of 4 and a maximum diameter of 12.5 feet. However, Expert ZF-2 recommended an alternative set of assumptions. These include the use of barrier filters, rather than cyclones, for particulate control, a maximum vessel diameter of 14 feet, a maximum length-todiameter ratio of 2.5 , and the use of a chloride guard upstream of the zinc ferrite sorbent to remove hydrochloric acid from the fuel gas.

Barrier filters are believed to result in higher particulate collection efficiencies, particularly for smaller size particles. The higher particulate removal efficiency is believed to result in lower pressure drops in the zinc ferrite absorber associated with the deposition of particles in the bed. Chlorine "attacks" the sorbent, reducing its sorbent absorption capacity and leading to higher sorbent makeup requirements. Because cost data regarding barrier filters and the chloride guard were not available, the case study for judgment ZF-2R does not include any incremental costs associated with these options. However, it is not expected that they would add significantly to capital or operating costs.

The judgment of Expert ZF-3 is described in Appendix A.4. While Experts ZF-1 and ZF-2 indicated that the central value of the sorbent sulfur loading capacity would be between 15 and 18 weight percent, Expert ZF-3's judgment was that the median sorbent sulfur loading capacity would be 10 percent for a commercial scale system. However, Expert ZF-3 expects a lower sorbent replacement rate than Experts ZF-1 and ZF-2.

Four probabilistic case studies were made in which all uncertainty assumptions were the same except for the differences between the zinc ferrite experts. The results of the base case study with the judgments of Expert ZF-1 were given previously in Table 12 . The results of the case studies with the alternative judgments regarding zinc ferrite process area uncertainties are given in Tables 18,19 , and 20 for judgment sets $\mathrm{ZF}-2 \mathrm{P}, \mathrm{ZF}-2 \mathrm{R}$, and $\mathrm{ZF}$ 3 , respectively. The results for three key measures of plant performance and cost are also compared graphically. These are zinc ferrite sorbent requirement, total capital cost, and cost of electricity, as shown in Figures 47,48 , and 49 , respectively.

Of the four sets of results shown in Figure 47, three are relatively close together, while the fourth indicates substantially higher sorbent requirements than for the other three. Based on the judgments of Experts ZF-1, ZF-2P, and ZF-2R, the sorbent charge is less than 20 million pounds, and the mean values are between 7 and 10 million pounds. 
Table 18. Summary of Results from Deterministic and Probabilistic Simulations of a 650 MW Air-Blown Lurgi-based IGCC System with Hot Gas Cleanup: Expert Judgments LG1 and $\mathrm{ZF}-2 \mathrm{P}$.

\begin{tabular}{|c|c|c|c|c|c|c|c|}
\hline Parameter & Units $^{\mathrm{C}}$ & $\begin{array}{r}\text { "Best } \\
\text { Guess"d }\end{array}$ & $\mathrm{f} .50$ & $\mu$ & $\sigma$ & f.05- & f. 95 \\
\hline \multicolumn{8}{|l|}{ Plant Performance } \\
\hline Thermal Efficiency & $\%, \mathrm{HHV}$ & 38.6 & 37.7 & 37.5 & 1.3 & $35.1-$ & 39.4 \\
\hline Coal Consumption & $\mathrm{lb} / \mathrm{kWh}$ & 0.786 & 0.805 & 0.811 & 0.029 & 0.770 & 0.865 \\
\hline Process Water Consum! & pp. lb/kWh & 1.60 & 1.600 & 1.634 & 0.261 & $1.209-$ & 2.119 \\
\hline ZF Sorbent Charge & $10^{6} \mathrm{lb}$ & 9.31 & 9.15 & 10.25 & 3.00 & $6.82-$ & 16.43 \\
\hline Sulfuric Acid Productior & on $\mathrm{lb} / \mathrm{kWh}$ & 0.085 & 0.087 & 0.087 & 0.003 & $0.083-$ & 0.093 \\
\hline \multicolumn{8}{|l|}{ Plant Discharges } \\
\hline $\mathrm{SO}_{2}$ Emissions & $\mathrm{lb} / \mathrm{MMBtu}$ & 0.042 & 0.040 & 0.040 & 0.001 & $0.038-$ & 0.042 \\
\hline $\mathrm{NO}_{\mathrm{x}}$ Emissions & $\mathrm{lb} / \mathrm{MMBtu}$ & 2.74 & 2.19 & 2.19 & 0.402 & $1.53-$ & 2.84 \\
\hline CO Emissions & $\mathrm{lb} / \mathrm{kWh}$ & 0.003 & 0.003 & 0.003 & 0.003 & $0.003-$ & 0.006 \\
\hline $\mathrm{CO}_{2}$ Emissions & $\mathrm{lb} / \mathrm{kWh}$ & 1.72 & 1.72 & 1.72 & 0.032 & $1.67-$ & 1.78 \\
\hline Solid Waste & $\mathrm{lb} / \mathrm{kWh}$ & 0.083 & 0.096 & 0.098 & 0.015 & $0.080-$ & 0.125 \\
\hline \multicolumn{8}{|l|}{ Plant Costs } \\
\hline Total Capital Cost & $\$ / \mathrm{kW}$ & 1,442 & 1,511 & 1,522 & 131 & $1,306-$ & 1,739 \\
\hline Fixed Operating Cost & $\$ / \mathrm{kW}$-yr & 45.1 & 57.2 & 59.6 & 10.5 & $46.9-$ & 81.7 \\
\hline Variable Operating & mills/kWh & 20.88 & 30.1 & 33.2 & 11.5 & $20.7-$ & 59.5 \\
\hline Coal & & 16.2 & 16.6 & 16.7 & 0.6 & $15.9-$ & 17.7 \\
\hline Byproduct & & $(1.5)$ & $(1.4)$ & $(1.3)$ & 0.5 & $(0.4)-$ & $(2.0)$ \\
\hline Other & & 6.3 & 14.8 & 17.9 & 11.4 & $5.4-$ & 43.1 \\
\hline Cost of Electricity & mills/kWh & 55.0 & 67.6 & 71.3 & 12.6 & $55.5-$ & 100.5 \\
\hline
\end{tabular}

a The notation in the table heading is defined as follows: $f_{n}=n^{\text {th }}$ fractile (f.50 $=$ median), $\mu=$ mean; and $\sigma=$ standard deviation of the probability distribution. The range enclosed by $f .05$ to $f .95$ is the 90 percent probability range. All costs are January 1989 dollars.

b Coal consumption is on an as-received basis. Watcr consumption is for process requirements including makeup for steam cycle blowdown, gasifier steam, and zinc ferrite steam. Solid waste includes gasifier bottom ash and nonrecycled fines from fuel gas cyclones.

c $\mathrm{HHV}=$ higher heating value; $\mathrm{MMBtu}=$ million Btu.

d Based on a deterministic simulation in which median or modal values of uncertain variables are assumed as "best guess" inputs to the model 
Table 19. Summary of Results from Deterministic and Probabilistic Simulations of a 650 MW Air-Blown Lurgi-based IGCC System with Hot Gas Cleanup: Expert Judgments LG1 and $\mathrm{ZF}-2 \mathrm{R}$. ${ }^{\mathrm{a}}$

\begin{tabular}{|c|c|c|c|c|c|c|c|}
\hline Parameter ${ }^{b}$ & Units $^{c}$ & $\begin{array}{r}\text { "Best } \\
\text { Guess"d }\end{array}$ & f. 50 & $\mu$ & $\sigma$ & $\mathrm{f} .05-$ & f.95 \\
\hline \multicolumn{8}{|l|}{ Plant Performance } \\
\hline Thermal Efficiency & $\%, \mathrm{HHV}$ & 38.8 & 37.9 & 37.7 & 1.3 & $35.5-$ & 39.6 \\
\hline Coal Consumption & $\mathrm{lb} / \mathrm{kWh}$ & 0.783 & 0.801 & 0.806 & 0.029 & $0.767-$ & 0.856 \\
\hline Process Water Consum & p. $1 \mathrm{~b} / \mathrm{kWh}$ & 1.59 & 1.59 & 1.62 & 0.258 & $1.206-$ & 2.114 \\
\hline ZF Sorbent Charge & $10^{6} \mathrm{lb}$ & 7.66 & 7.69 & 8.54 & 2.16 & $6.15-$ & 13.06 \\
\hline Sulfuric Acid Productio & n $1 \mathrm{~b} / \mathrm{kWh}$ & 0.085 & 0.086 & 0.087 & 0.003 & 0.082 & 0.093 \\
\hline \multicolumn{8}{|l|}{ Plant Discharges } \\
\hline $\mathrm{SO}_{2}$ Emissions & lb/MMBtu & 0.042 & 0.040 & 0.040 & 0.001 & 0.038 & 0.042 \\
\hline $\mathrm{NO}_{\mathrm{x}}$ Emissions & lb/MMBtu & 2.74 & 2.19 & 2.19 & 0.402 & $1.53-$ & 2.84 \\
\hline CO Emissions & lb/kWh & 0.003 & 0.003 & 0.003 & 0.002 & 0.003 & 0.006 \\
\hline $\mathrm{CO}_{2}$ Emissions & $\mathrm{lb} / \mathrm{kWh}$ & 1.71 & 1.71 & 1.71 & 0.030 & 1.67 - & 1.77 \\
\hline Solid Waste & $\mathrm{lb} / \mathrm{kWh}$ & 0.082 & 0.096 & 0.098 & 0.015 & $0.079-$ & 0.124 \\
\hline \multicolumn{8}{|l|}{ Plant Costs } \\
\hline Total Capital Cost & $\$ / \mathrm{kW}$ & 1,409 & 1,475 & 1,477 & 123 & 1,297 - & 1,696 \\
\hline Fixed Operating Cost & $\$ / \mathrm{kW}-\mathrm{yr}$ & 44.6 & 57.7 & 60.0 & 10.6 & $46.4-$ & 84.9 \\
\hline Variable Operating & mills/kWh & 17.9 & 19.4 & 19.9 & 1.9 & $17.4-$ & 23.9 \\
\hline Coal & & 16.1 & 16.5 & 16.6 & 0.6 & $15.8-$ & 17.6 \\
\hline Byproduct & & $(1.5)$ & $(1.4)$ & $(1.3)$ & 0.5 & $(0.4)$ - & $(2.0)$ \\
\hline Other & & 3.4 & 4.2 & 4.7 & 1.7 & $2.8-$ & 8.2 \\
\hline Cost of Electricity & mills/kWh & 51.4 & 56.9 & 57.3 & 4.3 & 50.7 & 65.4 \\
\hline
\end{tabular}

a The notation in the table heading is defined as follows: $f_{n}=n^{\text {th }}$ fractile $(f .50=$ median), $\mu=$ mean; and $\sigma=$ standard deviation of the probability distribution. The range enclosed by $f .05$ to $f .95$ is the 90 percent probability range. All costs are January 1989 dollars.

b Coal consumption is on an as-received basis. Water consumption is for process requirements including makeup for steam cycle blowdown, gasifier steam, and zinc ferrite steam. Solid waste includes gasifier bottom ash and nonrecycled fines from fuel gas cyclones.

c $\mathrm{HHV}=$ higher heating value; $\mathrm{MMBtu}=$ million Btu.

d Based on a deterministic simulation in which median or modal values of uncertain variables are assumed as "best guess" inputs to the model 
Table 20. Summary of Results from Deterministic and Probabilistic Simulations of a 650 MW Air-Blown Lurgi-based IGCC System with Hot Gas Cleanup: Expert Judgments LG1 and $\mathrm{ZF}-3 .^{\mathrm{a}}$

\begin{tabular}{|c|c|c|c|c|c|c|c|}
\hline Parameter ${ }^{b}$ & Units $^{c}$ & $\begin{array}{r}\text { "Best } \\
\text { Guess"d }\end{array}$ & $\mathrm{f} .50$ & $\mu$ & $\sigma$ & $\mathrm{f} .05-$ & f.95 \\
\hline \multicolumn{8}{|l|}{ Plant Performance } \\
\hline Thermal Efficiency & $\%, \mathrm{HHV}$ & 38.6 & 37.6 & 37.5 & 1.3 & $35.2-$ & 39.3 \\
\hline Coal Consumption & $\mathrm{lb} / \mathrm{kWh}$ & 0.786 & 0.807 & 0.811 & 0.029 & $0.773-$ & 0.864 \\
\hline Process Water Consum & p. $\mathrm{lb} / \mathrm{kWh}$ & 1.599 & 1.601 & 1.636 & 0.261 & $1.212-$ & 2.124 \\
\hline ZF Sorbent Charge & $10^{6} \mathrm{lb}$ & 25.1 & 26.2 & 32.5 & 21.1 & $16.4-$ & 54.7 \\
\hline Sulfuric Acid Productio & n $\mathrm{lb} / \mathrm{kWh}$ & 0.085 & 0.087 & 0.087 & 0.003 & $0.083-$ & 0.094 \\
\hline \multicolumn{8}{|l|}{ Plant Discharges } \\
\hline $\mathrm{SO}_{2}$ Emissions & $\mathrm{lb} / \mathrm{MMBtu}$ & 0.042 & 0.040 & 0.040 & 0.001 & 0.038 & 0.042 \\
\hline $\mathrm{NO}_{\mathrm{x}}$ Emissions & $\mathrm{lb} / \mathrm{MMBtu}$ & 2.74 & 2.19 & 2.19 & 0.402 & $1.53-$ & 2.84 \\
\hline CO Emissions & $\mathrm{lb} / \mathrm{kWh}$ & 0.003 & 0.003 & 0.003 & 0.002 & $0.003-$ & 0.006 \\
\hline $\mathrm{CO}_{2}$ Emissions & $\mathrm{lb} / \mathrm{kWh}$ & 1.71 & 1.73 & 1.73 & 0.031 & $1.68-$ & 1.78 \\
\hline Solid Waste & $\mathrm{lb} / \mathrm{kWh}$ & 0.083 & 0.096 & 0.098 & 0.015 & $0.079-$ & 0.125 \\
\hline \multicolumn{8}{|l|}{ Plant Costs } \\
\hline Total Capital Cost & $\$ / \mathrm{kW}$ & 1,568 & 1,685 & 1,735 & 273 & $1,392-$ & 2,161 \\
\hline Fixed Operating Cost & $\$ / k W-y r$ & 46.0 & 63.0 & 64.7 & 11.7 & $49.0-$ & 89.0 \\
\hline Variable Operating & mills/kWh & 16.7 & 18.0 & 18.6 & 2.2 & $16.3-$ & 23.5 \\
\hline Coal & & 16.2 & 16.6 & 16.7 & 0.6 & $15.9-$ & 17.8 \\
\hline Byproduct & & $(1.5)$ & $(1.4)$ & $(1.3)$ & 0.5 & $(0.4)-$ & $(2.0$ \\
\hline Other & & 2.1 & 2.6 & 3.2 & 2.0 & $1.8-$ & 6.1 \\
\hline Cost of Electricity & mills/kWh & 53.3 & 60.3 & 61.5 & 7.6 & $51.7-$ & 74.7 \\
\hline
\end{tabular}

a The notation in the table heading is defined as follows: $f_{n}=n^{\text {th }}$ fractile $(f .50=$ median), $\mu=$ mean; and $\sigma=$ standard deviation of the probability distribution. The range enclosed by $f .05$ to $f .95$ is the 90 percent probability range. All costs are January 1989 dollars.

b Coal consumption is on an as-received basis. Water consumption is for process requirements including makeup for steam cycle blowdown, gasifier steam, and zinc ferrite steam. Solid waste includes gasifier bottom ash and nonrecycled fines from fuel gas cyclones.

c $\mathrm{HHV}=$ higher heating valuc; $\mathrm{MMBtu}=$ million $\mathrm{Btu}$.

d Based on a deterministic simulation in which median or modal values of uncertain variables are assumed as "best guess" inputs to the model 


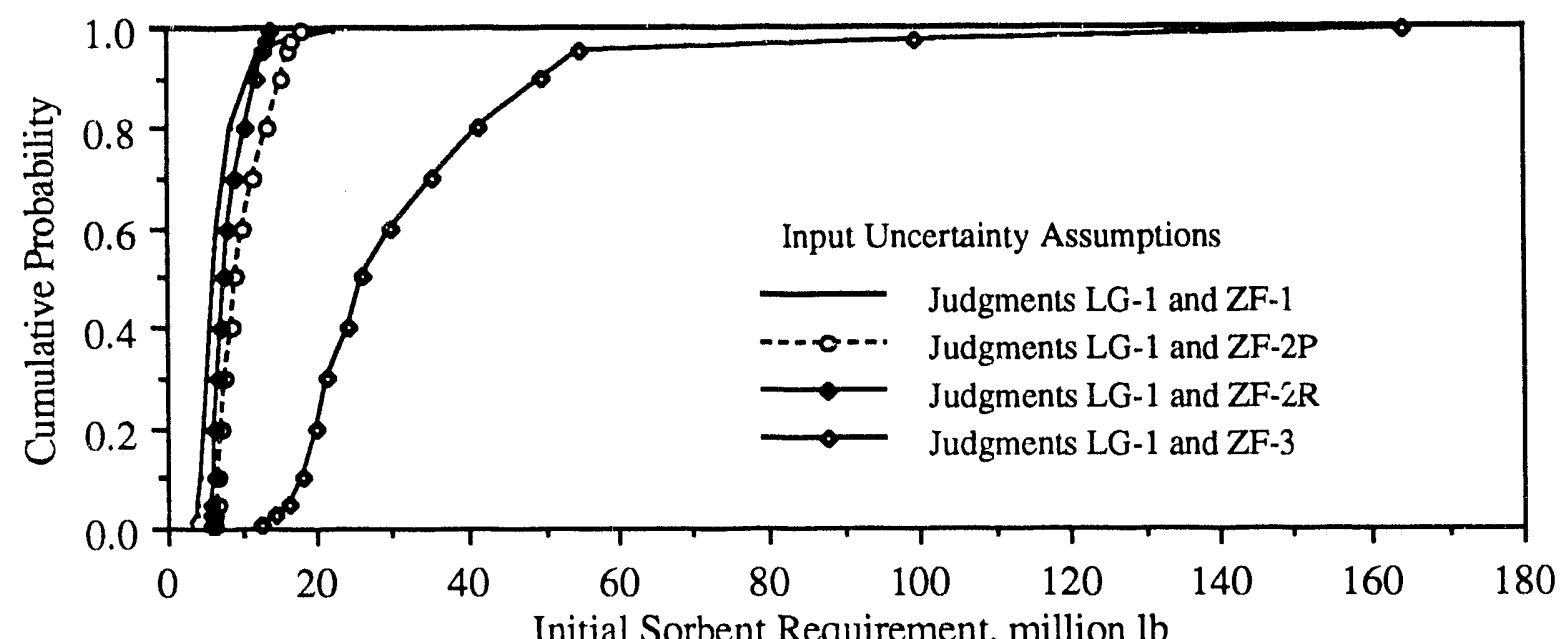

Figure 47. Comparison of the Uncertainty in Initial Zinc Ferrite Sorbent Requirement based on the Judgments of Different Experts Regarding the Zinc Ferrite Process Area.

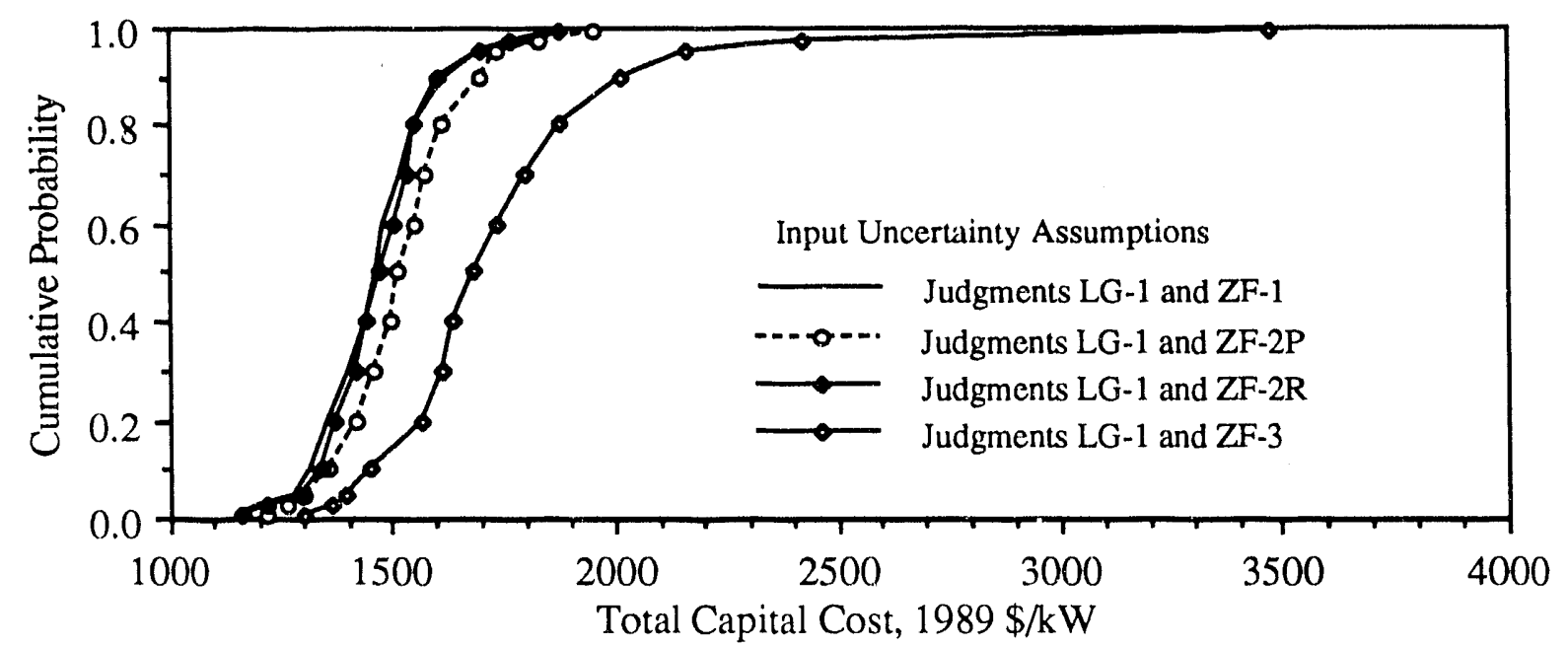

Figure 48. Comparison of the Uncertainty in Total Capital Cost based on the Judgments of Different Experts Regarding the Zinc Ferrite Process Area.

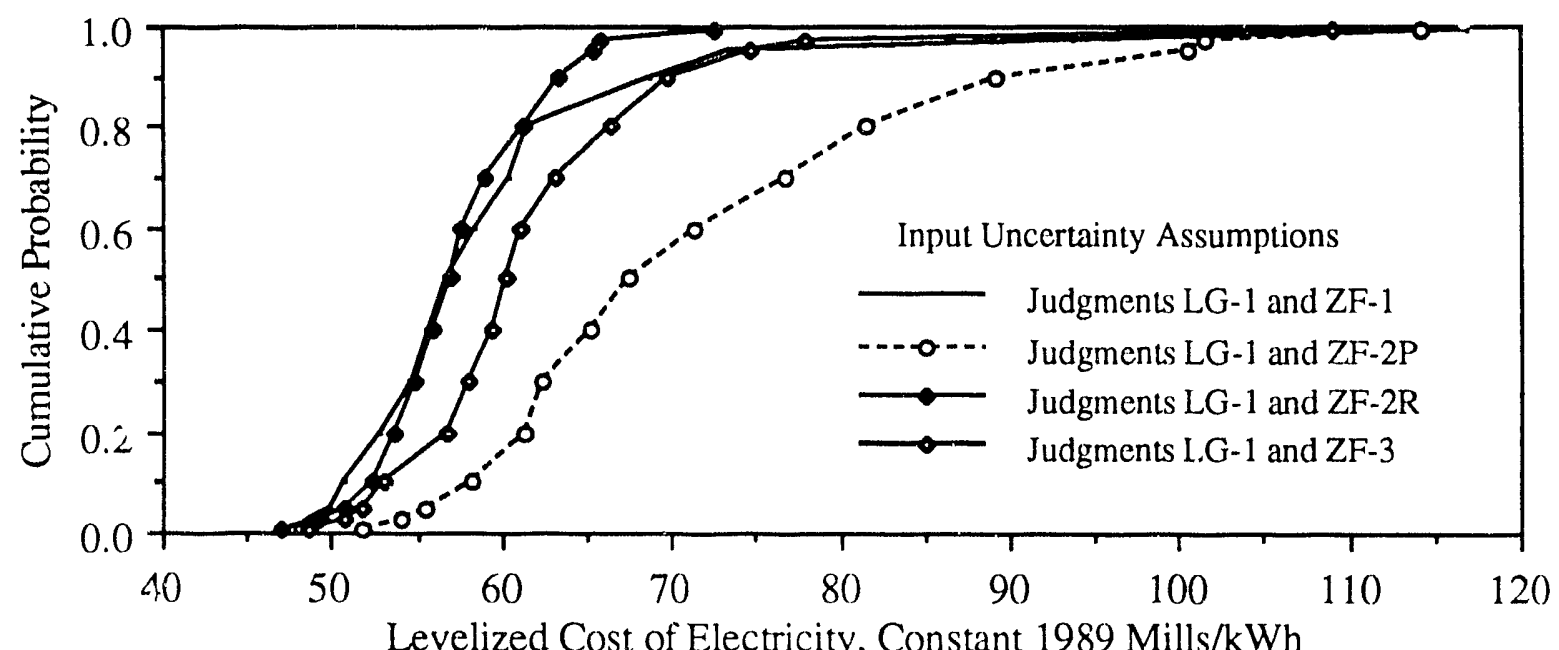

Figure 49. Comparison of the Uncertainty in Cost ef Electricity based on the Judgments of Different Experts Regarding the Zinc Ferrite Process Area. 
Comparing cases $\mathrm{ZF}-2 \mathrm{P}$ and $\mathrm{ZF}-2 \mathrm{R}$, the effect of including barrier filtration and a chloride guard is a reduction in mean sorbent charge of 1.7 million pounds. However, even in case 'F-2R, the sorbent requirement is higher than for case ZF-1, reflecting differences in the assumptions regarding zinc ferrite sorbent sulfur capacity. The sorbent requirement based on Expert ZF-2R tends to be about one to two million pounds greater than that estimated based on Expert ZF-1.

In contrast, the results based on Expert ZF-3 are a mean value of 32.5 million pounds, which is 22 to 25 million pounds greater than for the other three cases. In addition, there is a five percent probability that the requirement could be over 55 million pounds. As indicated previously, Expert ZF-3 assumed lower values for sorbent sulfur loading than the other experts. In addition, the expert also assumed a negatively skewed distribution, with a chance of obtaining very low loadings that the other experts did not consider possible. Because of the nonlinearity of the relationship between sorbent sulfur loading and the sorbent requirement, the low loading outcomes result in large sorbent requirements. These outcomes are revealed as a lo:ig tail in Figure 47.

The results obtained for zinc ferrite sorbent sulfur loading directly affect capital cost, as shown in Figure 48. Qualitatively, the same results are obtained: the results based on the judgments of Experts ZF-1 and ZF-2 are clustered together, while those based on Expert ZF-3 lead to higher capital costs than for thi other three cases.

The differences between the four sets of judigments become more evident when comparing results for the cost of electricity, as shown in Figure 49. Unlike the results for capital cost, the judgment of Expert ZF-3 does not result in the highest cost of electricity. Instead, the highest cost result is obtained based on the judgment set ZF-2P.

The results for the cost of electricity are influenced both by the sorbent sulfur loading requirement and the annual makeup sorbent requirement due to sorbent attrition and deactivation. As shown graphically in Chapter 4, the judgment of Expert ZF-3 regarding the sorbent replacement rate is lower than for the other experts. Although Expert ZF-3 generally predicted lower sorbent sulfur loadings for a commercial scale zinc ferrite process, the expert also predicted lower sorbent attrition rates than assumed in the other three cases. Therefore, in spite of the higher initial sorbent requirement obtained using the judgments of Expert ZF-3, the net effect of the interactions of uncertainties in sorbent loading and sorbent replacement leads to a lower cost of electricity uncertainty estimate than obtained from Expert ZF-2P. 
The judgments ZF-1 and ZF-2R result in similar central tendencies. However, there is less of a risk of extremely high costs based on ZF-2R than for the other three cases. This is because Expert ZF-2 indicated that sorbent performance would be improved with the use of a chloride guard and barrier filtration, allowing for high sorbent sulfur loadings and increased sorbent life. Without a chloride guard or barrier filtration, the judgments of Expert ZF-2P lead to an upward shift in the central values of the distribution for cost of electricity, and a long tail, due to the possibility of low sorbent capacity, loss of sorbent due to chloride attack, and a short life cycle.

The mean and median values for the cost of electricity for cases ZF-1, ZF-2P, and $\mathrm{ZF}-3$ fall between 55 and 60 mills/kWh. For case ZF-2P, the mean value is 71.3 mills $/ \mathrm{kWh}$. Within a tolerance of about $5 \mathrm{mills} / \mathrm{kWh}$, the first three cases are in approximate agreement, while case $\mathrm{ZF}-2 \mathrm{P}$ represents a substantial departure from the other three. With respect to extreme values, the case based on $\mathrm{ZF}-2 \mathrm{R}$ is a departure from the other three. The other three cases indicate that outcomes of well over $70 \mathrm{mills} / \mathrm{kWh}$ are possible, while such outcomes are not indicated based on ZF-2R. The implication here is that the use of barrier filtration and a chloride guard could substantially reduce the risk of poor sorbent performance.

Do the experts agree? There appears to be reasonable agreement among three of the cases with respect to zinc ferrite sorbent charge and total capital cost. However, all four cases lead to differences in either the central tendency or high fractiles of the cost of electricity, representing the more complex interactions among assumptions that affect sorbent charge and makeup sorbent. Furthermore, although the results from the judgment $\mathrm{ZF}-2 \mathrm{R}$ agrees with the central tendency of the result based on Expert ZF-1, the design assumptions differ substantially. The results suggest that the experts do not agree with respect to the factors that influence the sorbent replacement rate, although most of the judgments result in similar results for the initial sorbent charge and capital cost.

\subsubsection{Gasification Process Area}

Two sets of judgments were obtained regarding uncertainties in the Lurgi gasification process area. The judgments of Expert LG-2 are discussed in detail in Appendix A.2. Here, the results obtained based on the judgments of Experts LG-1 and LG-2 are compared. Two sets of comparisons are considered: one assumes the judgments of Expert ZF-2P for the zinc ferrite process area, while the other assumes the judgments $\mathrm{ZF}-2 \mathrm{R}$. In both cases, the uncertainties in all other process variables are the same as given in Table 11. 
The experts differ primarily in the assessment of uncertainty in the air-to-coal ratio of the gasifier. Expert LG-1 estimated that uncertainty in the air/coal ratio is triangularly distributed, with minimum and maximum values of 2.7 and $3.4 \mathrm{lb}$ air/lb dry ash-free (DAF) coal and a mode at 3.1. In contrast, Expert LG-2 estimated that the mode of the uncertainty in the air/coal ratio required to achieve a "good fuel gas" is $2.41 \mathrm{lb}$ air/lb coal, and that the range of uncertainty is from 0.4 to 2.9. Thus, the modal value assumed by Expert LG-2 is substantially lower than that assumed by Expert LG-1. Furthermore, the judgment of Expert LG-2 is negatively skewed toward low values. Because the air flow rate to the gasifier directly affects the plant auxiliary power requirement for boost air compression, high air/coal ratios result in a significant reduction in net plant efficiency.

The results of a probabilistic case study based on LG-2 are summarized in Table 21. In addition, results from case studies with the judgments of Experts LG-1 and LG-2 are compared graphically for plant efficiency, total capital cost, and the cost of electricity in Figures 50, 51, and 52, respectively. For both of the gasifier experts, results are shown assuming zinc ferrite uncertainties based on judgments ZF-2P and ZF-2R. The purpose of showing the results with different zinc ferrite uncertainty judgments is to indicate the robustness of the differences between the two Lurgi experts. For example, with respect to plant efficiency, the results based on Expert LG-2 indicate both a higher expected value (mean) and higher variance than for Expert LG-1, regardless of which zinc ferrite uncertainties are assumed. The mean efficiency obtained is 1.5 percentage points higher. There is more probability of obtaining an efficiency below 35 percent based on Expert LG2, but also about a 40 percent probability of obtaining an efficiency greater than 40 percent. In contrast, based on Expert LG-1, there is no chance of an efficiency greater than 40 percent. Efficiencies as high as 45 percent may be attainable, based on the judgment of Expert LG-2. These differences are strongly dependent on the the differences in assumptions regarding the air/coal ratio.

Using the judgments of Expert LG-2, substantially lower capital and levelized costs are obtained, regardless of which assumptions are used for the zinc ferrite process area. The mean capital cost is about $\$ 200 / \mathrm{kW}$ lower, while the mean cost of electricity is about 8 mills/kWh lower. These results are strongly affected by the air/coal ratio assumption. 
Table 21. Summary of Results from Deterministic and Probabilistic Simulations of a 650 MW Air-Blown Lurgi-based IGCC System with Hot Gas Cleanup: Expert Judgments LG2 and ZF-2P. ${ }^{\mathrm{a}}$

\section{"Best}

Parameter ${ }^{b}$

Unitsc Guess"d

f. 50

$\begin{array}{llll}\mu & \sigma & \mathrm{f} .05 & -\end{array}$

Plant Performance

Thermal Efficiency

Coal Consumption

$\%, \mathrm{HHV}$

$\mathrm{lb} / \mathrm{kWh}$

Process Water Consump. lb/kWh

$10^{6} \mathrm{lb}$

ZF Sorbent Charge

$\mathrm{lb} / \mathrm{kWh}$

Sulfuric Acid Production

Plant Discharges

$\mathrm{SO}_{2}$ Emissions
$\mathrm{NO}_{x}$ Emissions
$\mathrm{CO}$ Emissions
$\mathrm{CO}_{2}$ Emissions
Solid Waste
Plant Costs
Total Capital Cost
Fixed Operating Cost
Variable Operating
$\quad$ Coal
Byproduct
Other

Cost of Electricity

$\begin{array}{rrrrrrr}\text { lb/MMBtu } & 0.036 & 0.035 & 0.035 & 0.002 & 0.031- & 0.039 \\ \text { lb/MMBtu } & 1.60 & 1.43 & 1.43 & 0.325 & 0.901- & 1.98 \\ \text { lb/kWh } & 0.003 & 0.003 & 0.003 & 0.002 & 0.003- & 0.006 \\ \text { lb/kWh } & 1.59 & 1.61 & 1.61 & 0.11 & 1.41- & 1.79 \\ \text { lb/kWh } & 0.077 & 0.112 & 0.115 & 0.029 & 0.079- & 0.184 \\ & & & & & & \\ \text { \$/kW } & 1,250 & 1,317 & 1,313 & 105 & 1,152- & 1,516 \\ \text { \$/kW-yr } & 37.6 & 46.4 & 47.6 & 6.5 & 39.0- & 59.4 \\ \text { mills/kWh } & 19.09 & 28.5 & 31.1 & 10.2 & 19.0- & 52.2 \\ & 14.9 & 16.1 & 16.1 & 1.4 & 14.0- & 19.1 \\ & (1.3) & (1.1) & (1.1) & 0.4 & (0.3)- & (1.8) \\ \text { mills/kWh } & 58.5 & 13.8 & 16.1 & 9.9 & 5.1- & 36.4 \\ & 48.4 & 61.7 & 63.3 & 11.4 & 49.4- & 87.0\end{array}$

a The notation in the table heading is defined as follows: $f_{n}=n^{\text {th }}$ fractile ( $f_{.50}=$ median), $\mu=$ mean; and $\sigma=$ standard deviation of the probability distribution. The range enclosed by $f .05$ to $f .95$ is the 90 percent probability range. All costs are January 1989 dollars.

b Coal consumption is on an as-received basis. Watcr consumption is for process requirements including makeup for steam cycle blowdown, gasifier steam, and zinc ferrite steam. Solid waste includes gasifier bottom ash and nonrecycled fines from fuel gas cyclones.

c $\mathrm{HHV}=$ higher heating value; $\mathrm{MMBtu}=$ million $\mathrm{Btu}$.

d Based on a deterministic simulation in which median or modal values of uncertain variables are assumed as "best guess" inputs to the model 


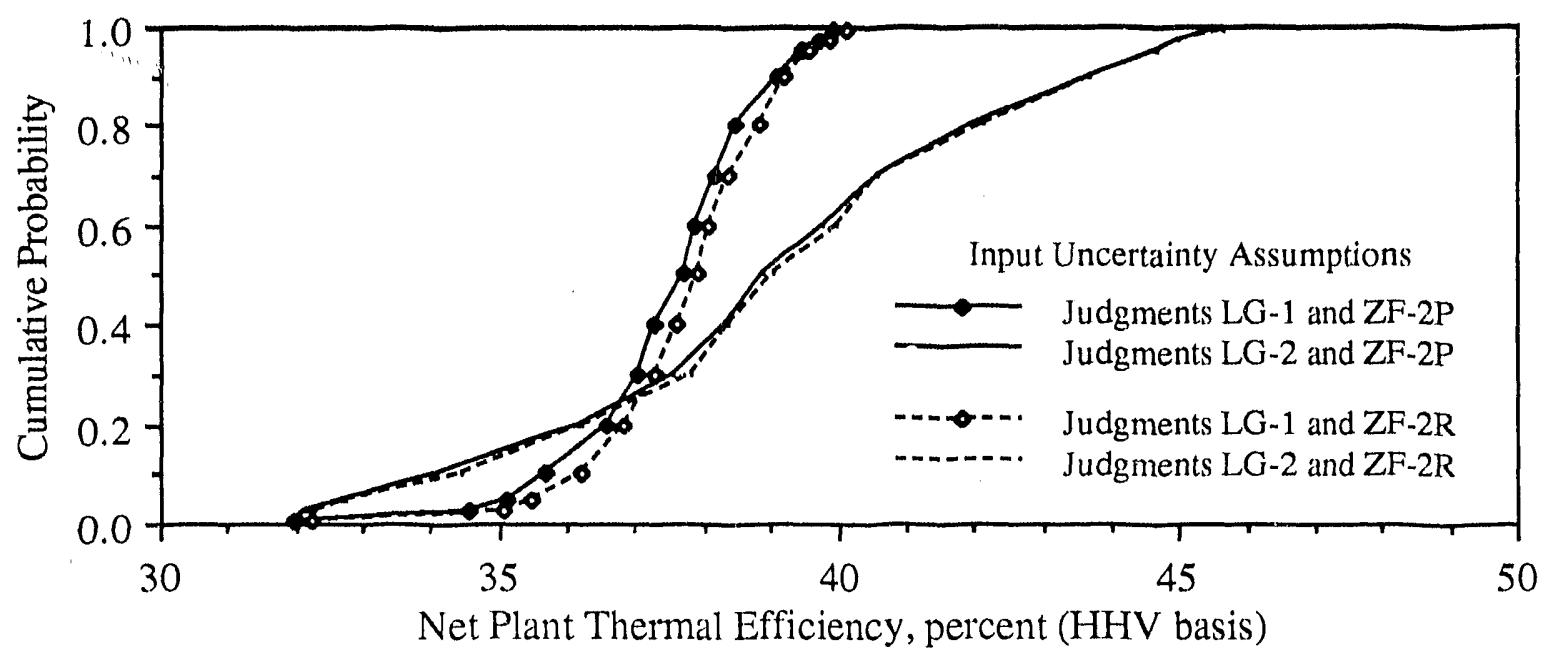

Figure 50. Comparison of the Uncertainty in Plant Efficiency based on the Judgments of Different Experts Regarding the Gasification Process Area.

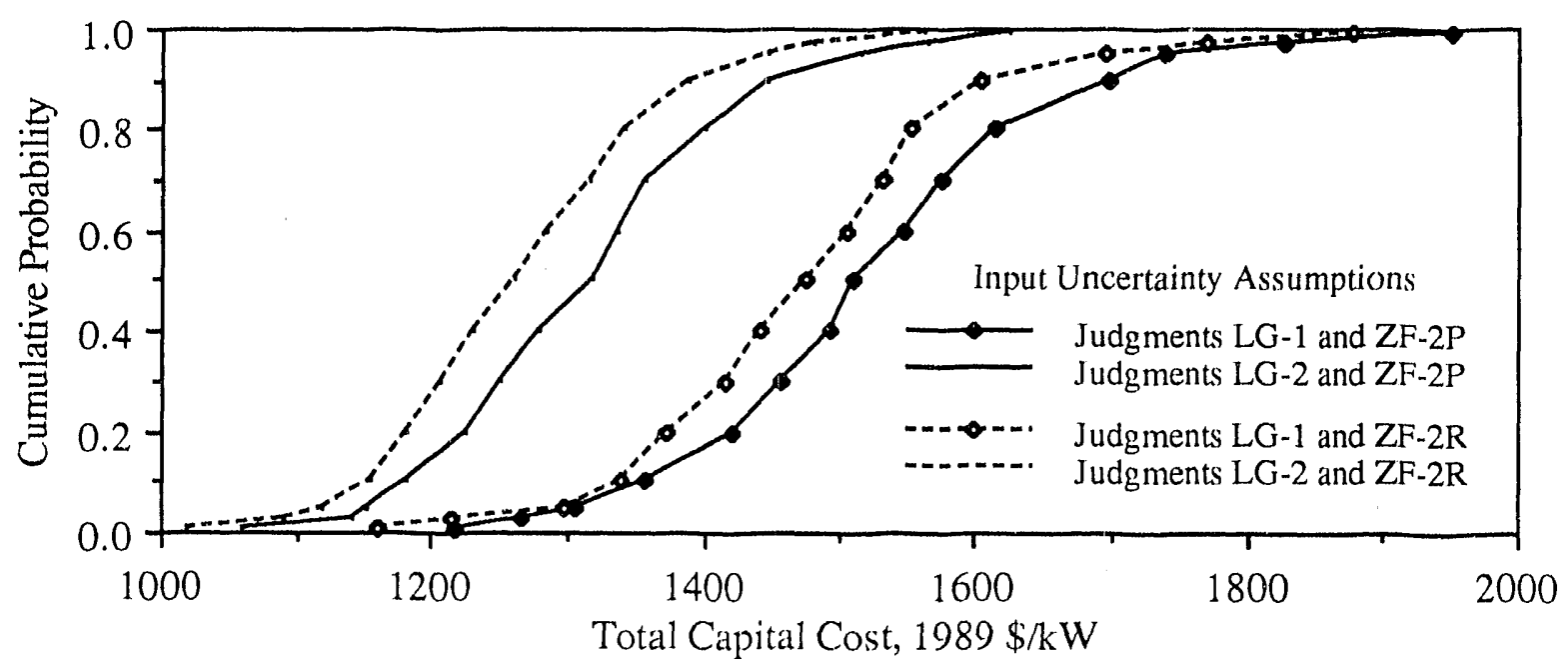

Figure 51. Comparison of the Uncertainty in Total Capital Cost based on the Judgments of Different Experts Regarding the Gasification Process Area.

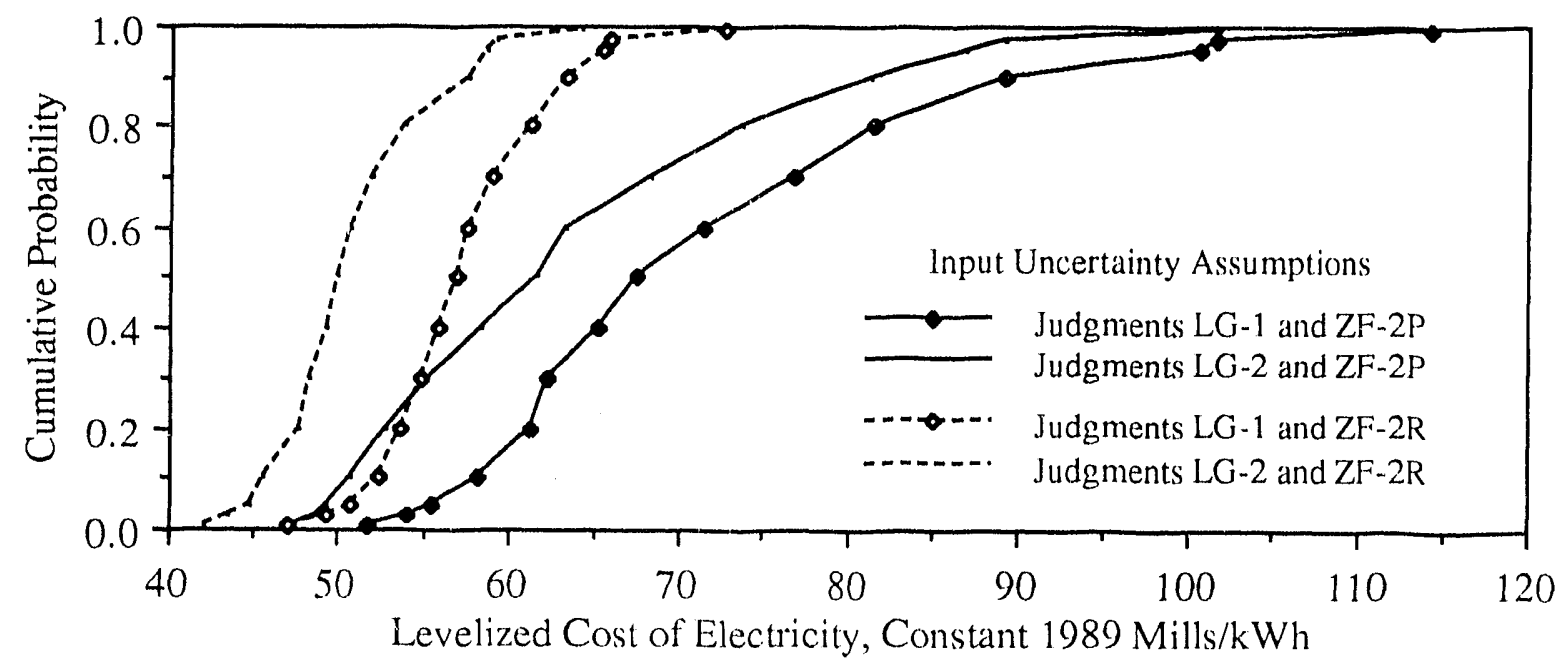

Figure 52. Comparison of the Uncertainty in Cost of Electricity based on the Judgments of Different Experts Regarding the Gasification Process Area, 
Thus, the judgments of Experts LG-1 and LG-2 have significantly different implications for process performance and cost. With respect to performance, the judgment of Expert LG-2 leads to a larger magnitude of uncertainty, but also a greater probability of favorable outcomes. With respect to cost, the variance of the capital and levelized costs are slightly reduced; however, the outcomes are generally substantially lower than those based on Expert LG-1.

\subsubsection{Correlation Structures}

The preceding analyses, except in the cases of probabilistic comparisons of two alternative systems, have assumed that the model input probability distributions are uncorrelated. While this assumption is often reasonable, there may be cases when correlations are known or believed to exist between input uncertainties. In this section, the effect of possible correlations in input uncertainties is considered.

A number of possible correlation structures are discussed in Appendix A. The identification of these correlations was based on the explanations given by the experts of the reasons for obtaining various outcomes for performance parameters. In many cases, the same mechanism may be responsible for high or low outcomes in two or more variables. For example, uncertainty carbon and sulfur retention in the gasifier bottom ash may vary together. Correlations in the gasification process area are discussed further in Appendix A.2, and for the zinc ferrite process area in A.3.

The correlations assumed for the gasification process area tend to mitigate both high and low outcomes, but only slightly. For example, the carbon retention in the bottom ash is assumed to be negatively correlated with the air/coal ratio. As the air/coal ratio is increased, the carbon retention would be expected to tend to decrease, as more carbon would tend to be either combusted or gasified. Thus, there is less chance of obtaining high carbon retentions and high air/coal ratios simultaneously when correlations are imposed. The effect of correlation on the pairing of samples for these two parameters is revealed in a comparison of Figures 53 and 54. In the first figure, the pairing of the 100 samples of both the air/coal ratio and the carbon retention in the bottom ash is shown when no correlation is assumed. Note that both uncertain variables are assumed to have triangular distributions. Thus, we expect a concentration of samples near the intersection of the model values, which are an air/coal ratio of 3.1 and a carbon retention of 2.5 percent. In the second figure, a correlation of -50 percent is imposed. The pairing is thus more ordered than in the previous case. 


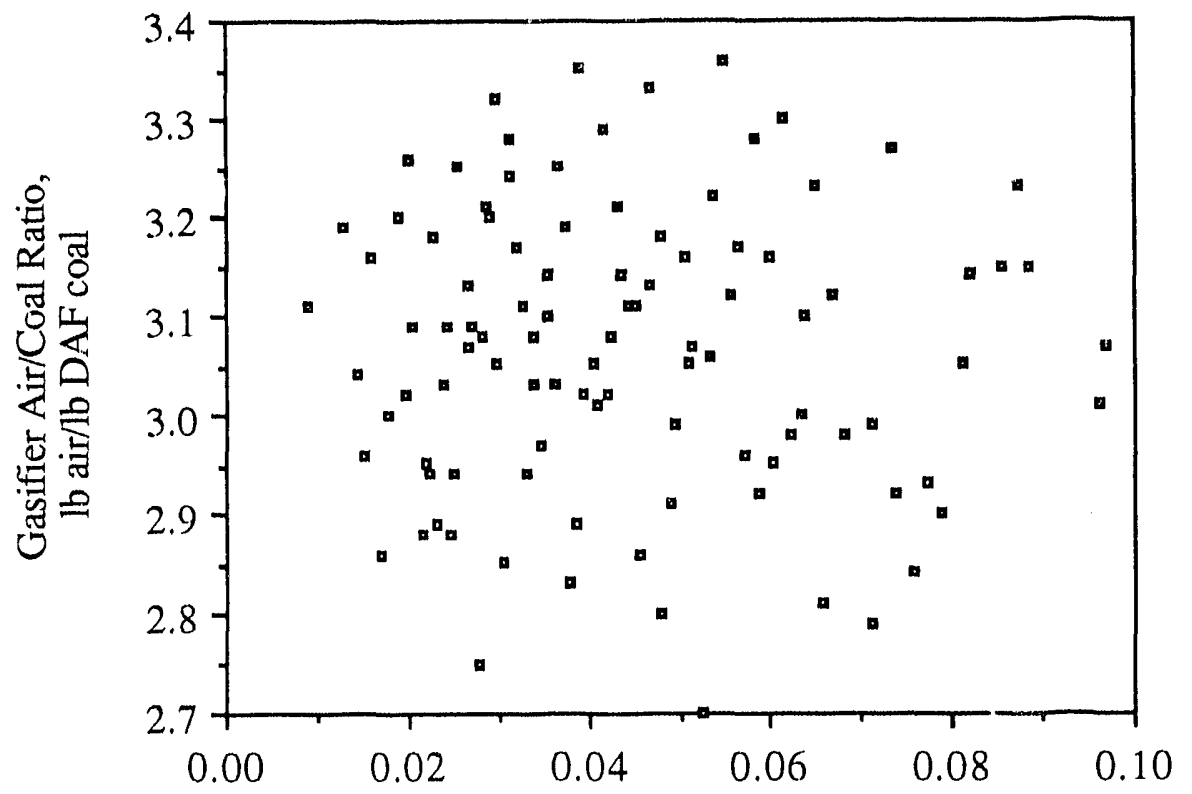

Carbon Retention in Bottom Ash, fraction of carbon in feed coal

Figure 53. Pairing of Samples for Air/Coal Ratio and Carbon Retention in Bottom Ash with Rank Correlation $=0$

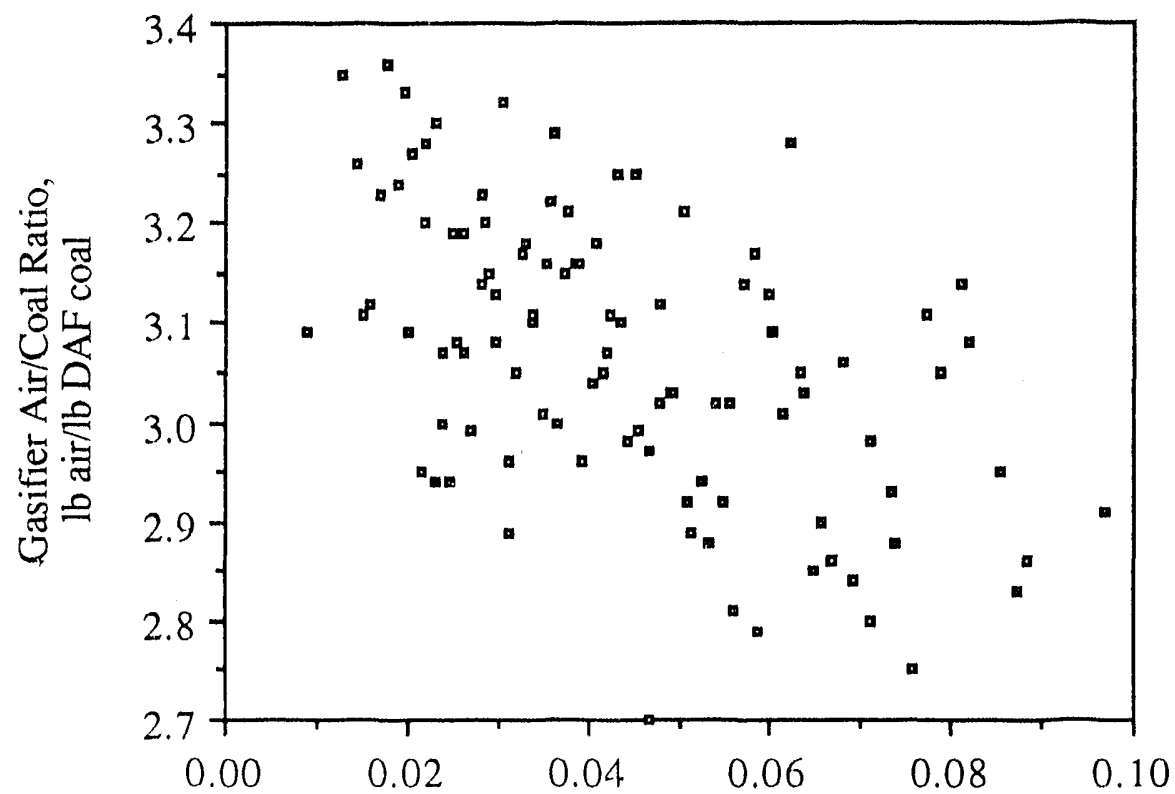

Carbon Retention in Bottom Ash, fraction of carbon in feed coal

Figure 54. Pairing of Samples for Air/Coal Ratio and Carbon Retention in Bottorn Ash with Rank Correlation $=-0.5$

- The effect of the assumed correlation between the air/coal ratio and carbon retention, and the other correlations assumed also, is shown for the capital cost in Figure 55. The results from the correlated case are approximately the same as from the base case. Although many of the performance parameters for which correlations were assumed are 


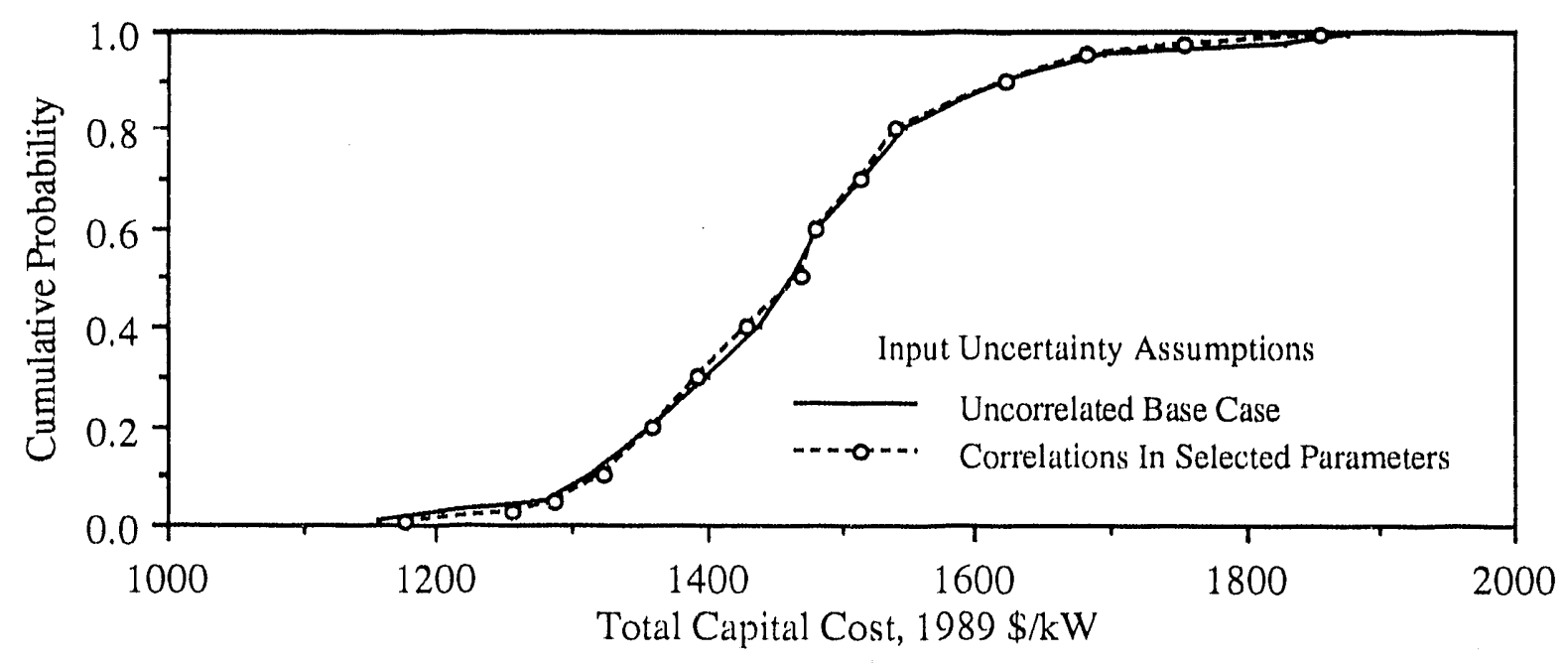

Figure 55. Effect of Assumed Correlations on Uncertainty in Capital Cost.

key uncertainties in the model, the correlations apparently were not of sufficient magnitude to result in a significant difference in results.

Other correlation cases were evaluated, including for case studies with the judgments of Expert LG-2. Only minor effects on the results were obtained with respect to performance. In addition, correlations among the direct and maintenance cost uncertainties in the gasification, zinc ferrite, and gas turbine process areas were also considered. These, too, produced only minor effects on the results. Therefore, for convenience, in later comparative case studies, the results based on uncorrelated sampling are used. However, in most cases where correlations were assumed, only modest correlation coefficients were used, such as of magnitude 0.5 or less. In cases where an analyst believes that strong correlations exist, their effect on the result may be stronger and should to be evaluated.

\subsection{Oxygen-Blown KRW-Based IGCC System with Cold Gas Cleanup}

The probabilistic case studies of the oxygen-blown KRW-based IGCC system with cold gas cleanup are based upon the assumptions regarding values and uncertainties in key model parameters given in Table 10. The analysis of this system included: (1) characterization of uncertainties in model output variables; (2) identification of key uncertainties; (3) evaluation of the effect that additional research might have on output uncertainties; and (4) evaluation of the effect that a correlation structure might have on the results. 


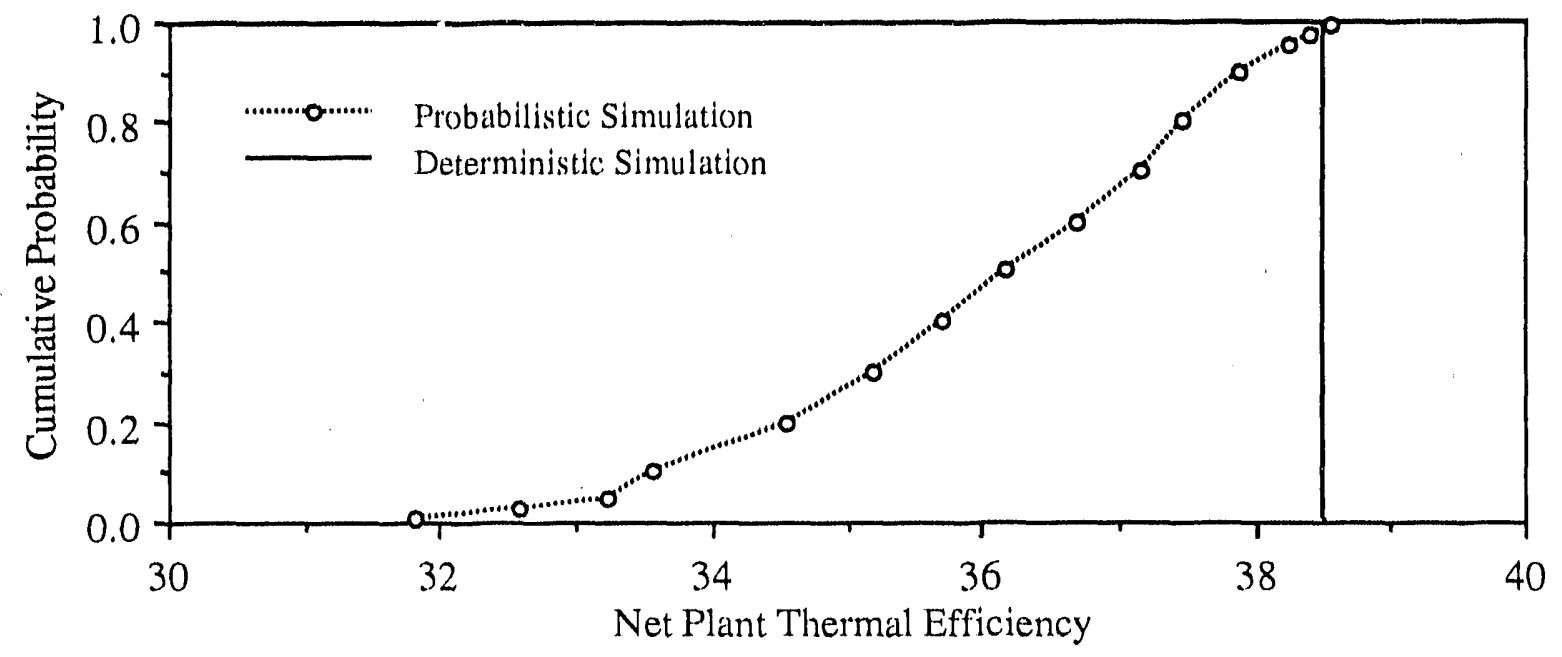

Figure 56. Comparison of Deterministic and Probabilistic Results for the Net Plant Thermal Efficiency of the Oxygen-blown KRW-based System.

\subsubsection{Characterization of Uncertainties in Performance and Cost}

Results of the simulation with the base case uncertainty assumptions are given in Table 22. The results for plant thermal efficiency, $\mathrm{SO}_{2}$ emissions, total capital cost, and the cost of electricity are shown as cdfs in Figures 56, 57, 58, and 59, respectively.

Because of the negative skewness of the assumption regarding uncertainty in the gasifier carbon conversion efficiency, the plant thermal efficiency is also negatively skewed. The mode of the uncertainty in carbon conversion was taken to be at the upper bound of the distribution, and the modal value was used as the "best guess" in the deterministic analysis. The modal value of 95 percent carbon conversion is also widely assumed in conceptual design studies (e.g., Dawkins et al, 1985; Gallaspy et al, 1990). However, scale-up risks and inherent design limitations for the KRW gasifier may lead to lower carbon conversions and, hence, lower plant efficiencies, than commonly assumed (Shinnar et al, 1987). See Appendix A.2 for a more detailed discussion of uncertainties in the KRW gasifier.

The KRW gasifier may retain a significant portion of coal sulfur in the bottom ash, thereby reducing the sulfur burden to the cold gas cleanup system and reducing $\mathrm{SO}_{2}$ emissions. The uncertainty in $\mathrm{SO}_{2}$ emissions is illustrated in Figure 57, indicating that emissions may be lower than the "best guess" assumption. The $\mathrm{SO}_{2}$ emissions are normalized to the inlet heating value flow associated with the coal feed. The higher probability of obtaining values lower than the "best guess" is associated with the interactions between the symmetric distribution assumed for sulfur retention and the 
Table 22. Summary of Results from Deterministic and Probabilistic Simulations of a 650 MW Oxygen-Blown KRW-based IGCC System with Cold Gas Cleanup.a

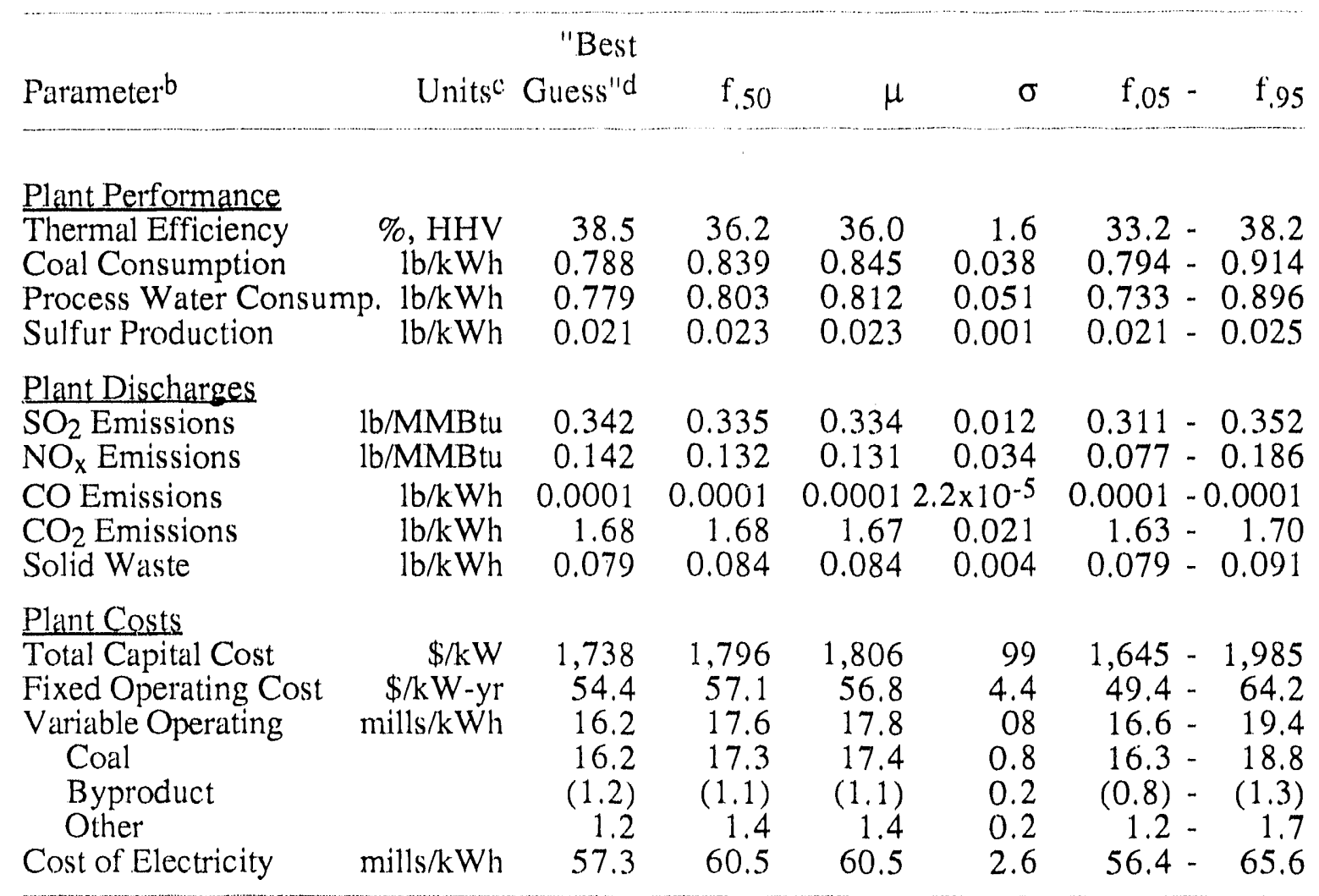

a The notation in the table heading is defined as follows: $f_{n}=n^{\text {th }}$ fractile ( $f .50=$ median), $\mu=$ mean; and $\sigma=$ standard deviation of the probability distribution. The range enclosed by $f .05$ to $f .95$ is the 90 percent probability range. All costs are January 1989 doilars.

b Coal consumption is on an as-received basis. Water consumption is for process requirements including makeup for steam cycle blowdown, gasifier steam, and zinc ferrite steam. Solid waste includes gasifier bottom ash and nonrecycled fines from fuel gas cyclones.

c $\mathrm{HHV}=$ higher heating value; $\mathrm{MMBtu}=$ million Btu.

d Based on a deterministic simulation in which median or modal values of uncertain variables are assumed as "best guess" inputs to the model 


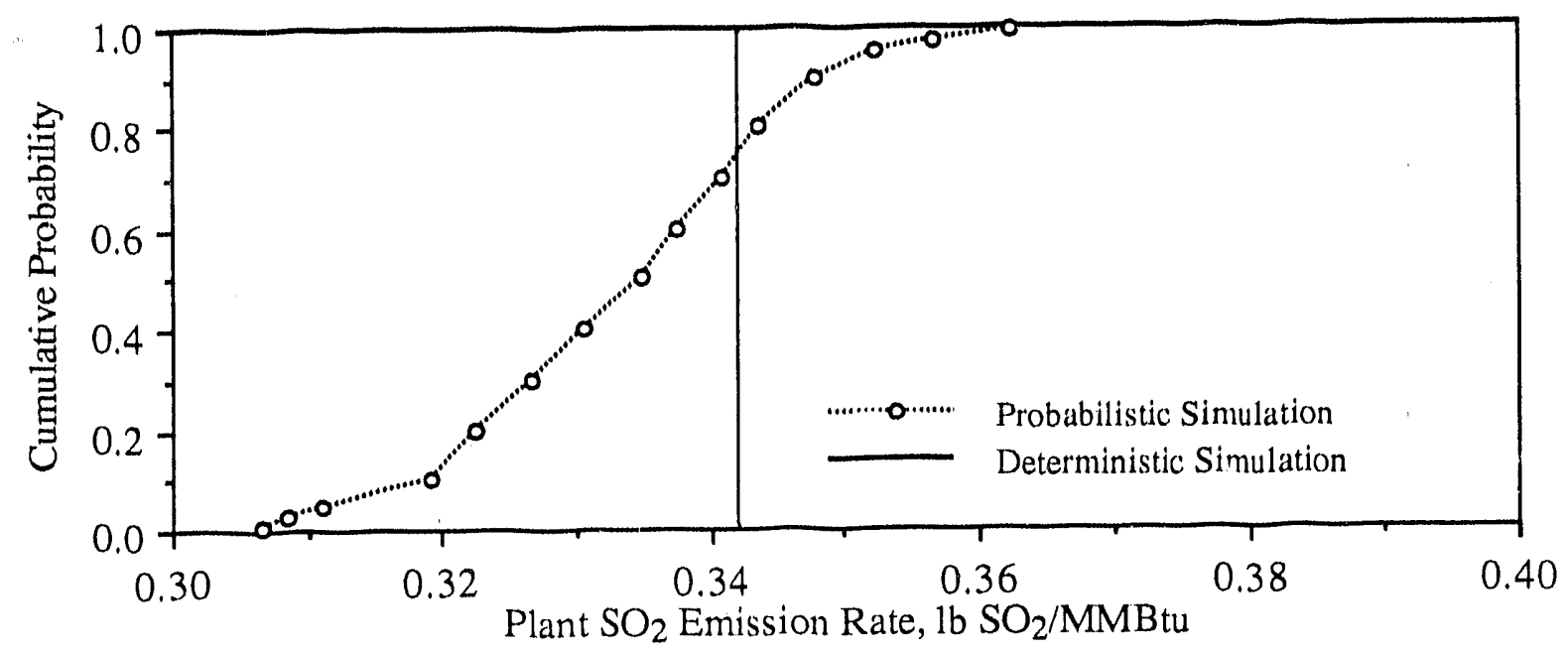

Figure 57. Comparison of Deterministic and Probabilistic Results for the Sulfur Dioxide Emissions of the Oxygen-blown KRW-based System.

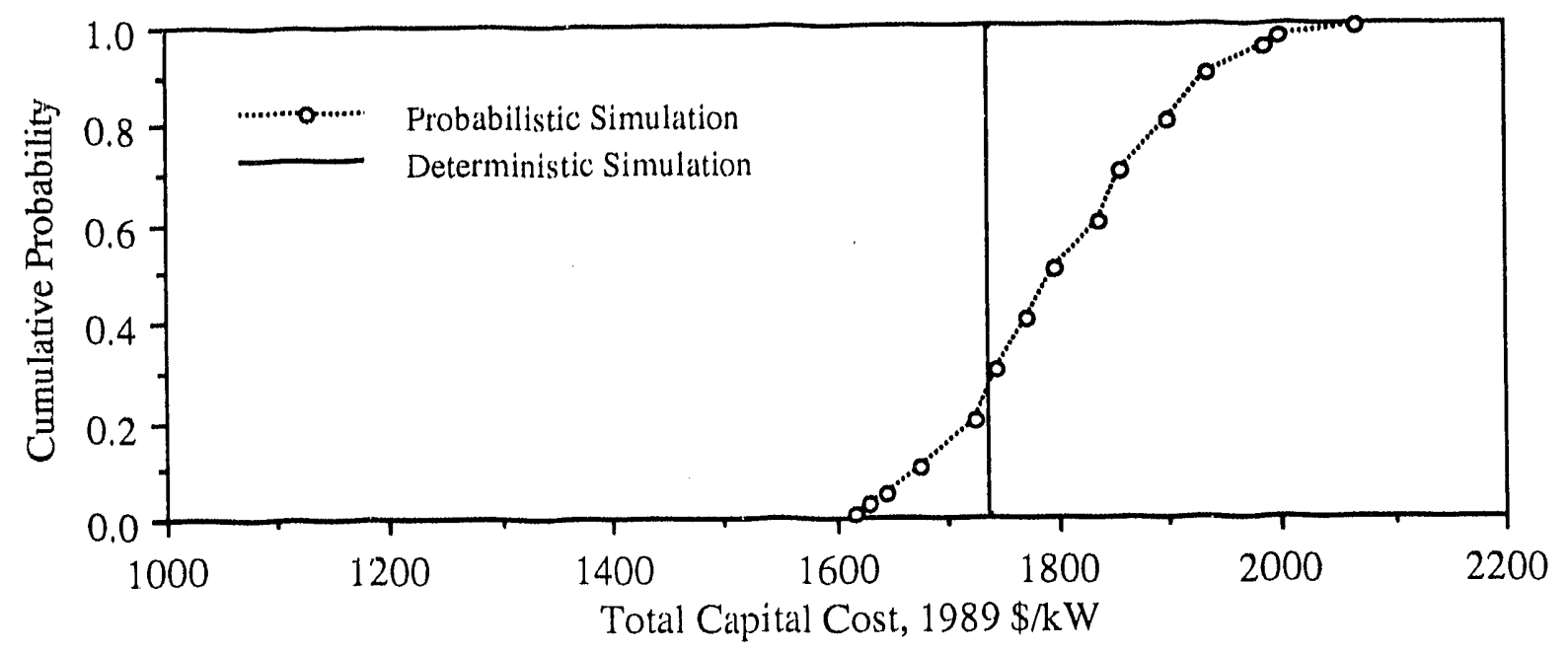

Figure 58. Comparison of Deterministic and Probabilistic Results for the Total Capital Cost of the Oxygen-blown KRW-based System.

negatively skewed distribution assumed for carbon conversion. The latter results in a positively skewed distribution for coal feed rate and, hence, total heating value entering the IGCC plant. Higher heating value flows are associated with low carbon conversions and low plant efficiencies. As heating value increases, the normalized emission rate tends to decrease.

Although the oxygen-blown KRW system considered here represents elements of "convertional" IGCC technology, particularly the cold gas cleanup system, there is still considerable performance and cost risk associated with the gasification process area. Uncertainty in plant performance and capital cost-related parameters result in the uncertainty in total capital cost shown in Figure 58. Compared to the deterministic "best guess" 


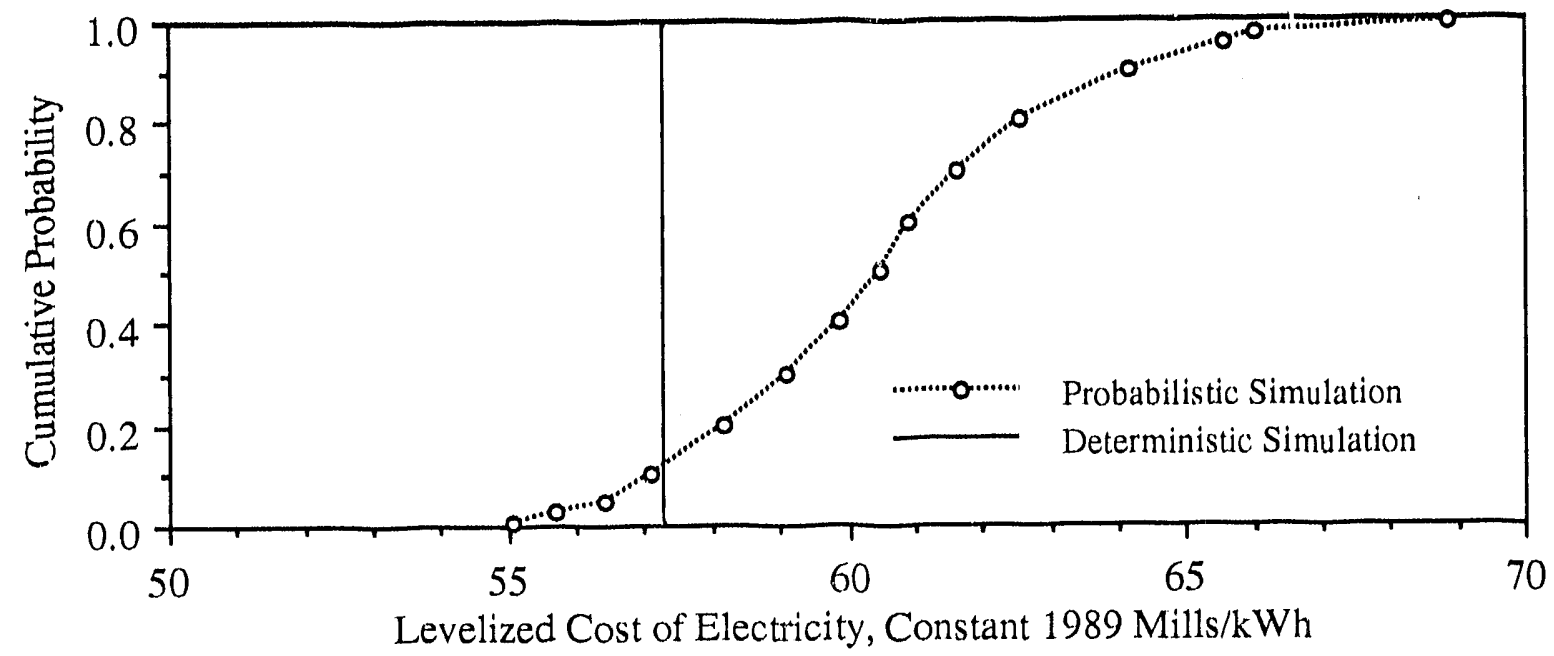

Figure 59. Comparison of Deterministic and Probabilistic Results for the Cost of Electricity of the Oxygen-blown KRW-based System.

estimate, which includes values of both process and project contingency factors typically assumed in the literature, there is a 70 percent probability of cost overrun. While estimates of uncertainties in capital cost parameters, including process area direct costs, were based on symmetric probability distributions, the underlying negative skewness of the major measures of plant performance, such as efficiency and coal consumption, shift the resulting capital cost uncertainty toward higher values than the "best guess." Thus, the interactions among performance and cost uncertainties, considered here, are shown to have important implications for capital cost.

The difference between the deterministic and probabilistic estimates of cost are more pronounced for the levelized cost of electricity, as shown in Figure 59. Recall that while typical cost estimating practices include capital cost contingency factors, there is no accepted systematic notion of contingencies with respect to fixed and variable operating costs. Here, the possibility of additional maintenance cost requirements for the gas turbine process area is represented by a positively skewed distribution for maintenance cost. Performance uncertainties play a key role also. The negative skewness of the carbon conversion rate leads to positive skewness in consumable requirements such as fuel (coal) and process water, and in the ash disposal rate. Furthermore, the unit costs associated with both ash disposal and byproduct recovery were assumed to have skewed distributions. In the case of ash disposal, it was assumed that costs could go up, but not down, due to increasingly stringent landfill requirements and associated difficulty in siting and complying with regulations. In the case of byproduct sale price, a negative skewness was assumed, 
representing the likelihood that market conditions at any given location in the U.S. may not be favorable to obtaining the maximum world market price.

The interactions among uncertainties in performance, capital cost, maintenance cost, and unit cost uncertainties result in the difference between the deterministic and probabilistic estimates for cost of electricity. Here, the deterministic estimate has an associated 90 percent probability of cost overrun. Furthermore, while the cost of electricity could be perhaps 2 mills/kWh less than the "best guess," it could be over 10 mills $/ \mathrm{kWh}$ higher.

\subsubsection{Identifying Key Uncertainties}

As :or the previous case study of the Lurgi-based IGCC system, the key uncertainties in the oxygen-blown KRW system were identified using regression analysis and probabilistic sensitivity analysis. These iechniques were used to identify uncertainties which were unimportant in influencing uncertainties in key output variables. A screening analysis was then done to confirm that the removal of the unimportant uncertainties would not significantly change the results.

\subsubsection{Regression Analysis}

The results of a regression analysis using partial correlation coefficients are shown in Table 23. Three key measures of plant performance and cost were selected for detailed analysis. These are plant efficiency, total capital cost, and the cost of electricity. Other output variables that were considered, but not shown in the table, include $\mathrm{SO}_{2}, \mathrm{NO}_{\mathrm{x}}$, and CO emissions.

The output analysis indicated that only one performance parameter was significantly correlated with uncertainty in plant efficiency. Uncertainty in carbon conversion dominated the other uncertain parameters which were expected to affect plant efficiency. Because the variance of the carbon conversion uncertainty was large relative to the uncertainties in gasifier reagent feed ratios (oxygen/carbon, steam/oxygen), the ratios had little effect on the uncertainty in plant efficiency.

For both the total capital cost and cost of electricity, uncertainty in several of the cost model parameters s.o., project cost uncertainty, indirect construction cost, engineering and home office fees) were found to be influential. Total capital cost uncertainty was found to have significant linear correlation to direct cost uncertainties in several process areas and also to performance uncertainties that affect vessel sizing. An 
Table 23. Key Uncertainties for Oxygen-Blown KRW-based IGCC Based on Partial Correlation Coefficients.

\begin{tabular}{|c|c|c|}
\hline \multicolumn{3}{|c|}{ Partial Correlation Coefficients } \\
\hline Efficiency & TCC & $\mathrm{COE}$ \\
\hline Carbon Conv. (.99) & Project Unc. (.99) & Project Unc. (.99) \\
\hline-- & Gasifier DC (.95) & Carbon Conv. (-.98) \\
\hline-- & SE Gasification (.93) & Gasifier DC (.96) \\
\hline-- & Indirect Const. (.92) & Gasifier Maint (.94) \\
\hline-- & SE Air Separation (.89) & SE Gasification (.94) \\
\hline-- & SE HRSG (.89) & Indirect Const. (.92) \\
\hline-- & Carbon Conv. $(-.89)$ & Engr \& Home (.89) \\
\hline-- & Gas Turbine DC (.89) & Gas Turbine DC (.88) \\
\hline$-\cdots$ & Engr \& Home Fees $(.89)$ & SE Air Sep. (.88) \\
\hline-- & SE Steam Turbine $(.85)$ & SE HRSG (.87) \\
\hline-- & SE Coal Handling (.82) & Steam/Oxygen $(.86)$ \\
\hline-- & Steam/Oxygen Ratio (.76) & SE Steam Turb. (.83) \\
\hline-- & General Facilities DC (.66) & SE Coal Hd DC (.82) \\
\hline- & Oxygen/Carbon (.61) & SE Air Sep. Pwr (.71) \\
\hline-- & SE Air Sep. Power (.61) & Oxygen/Carbon (.68) \\
\hline-- & SE Selexol DC (.57) & General Fac. DC (.63) \\
\hline-- & Air Separation DC (.53) & SE Selexol (.56) \\
\hline-- & -- & Gas Turb. Maint (.52) \\
\hline-- & -- & Sulfur Price $(-.52)$ \\
\hline-- & -- & Air Sep. DC (.50) \\
\hline-- & -- & Ash Disp. Cost $(.40)$ \\
\hline-- & -- & SE Coal Hd Pwr (.33) \\
\hline
\end{tabular}




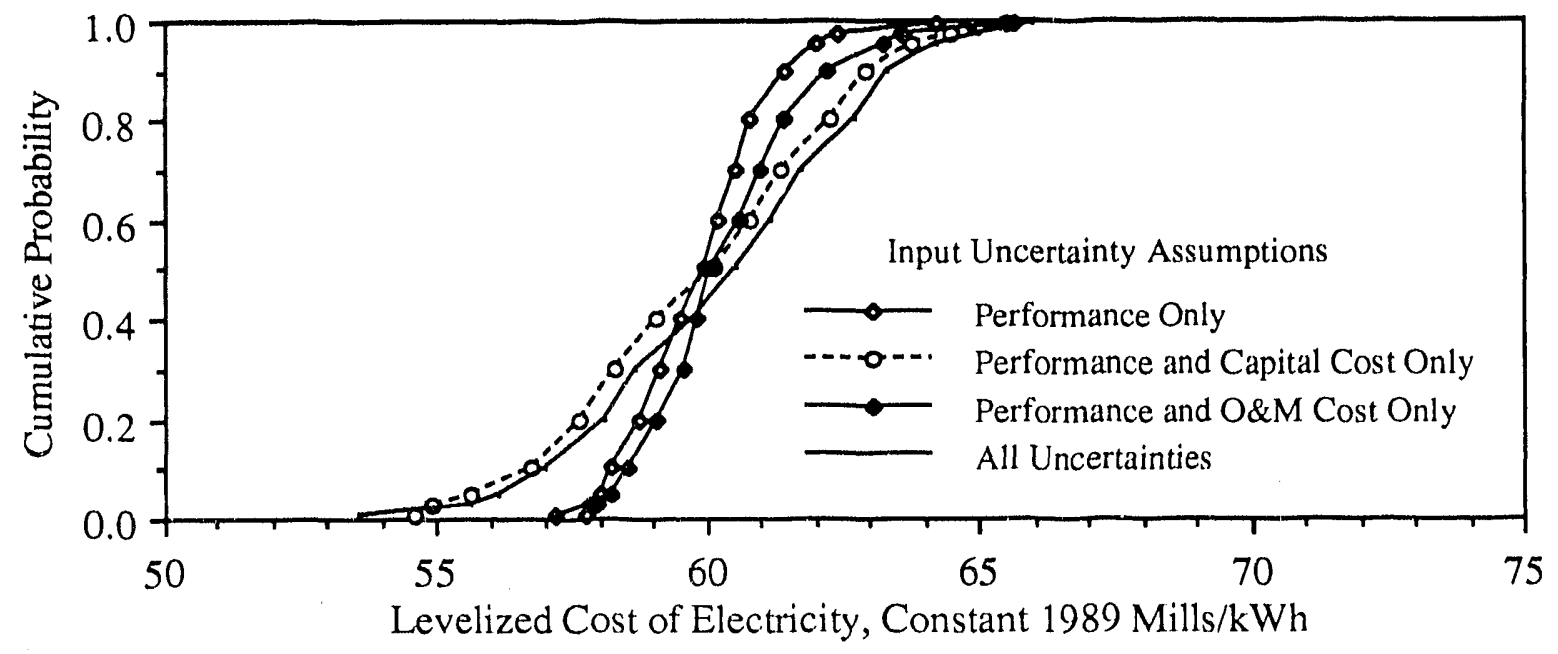

Figure 60. Sources of Uncertainty for Cost of Electricity.

example of the latter is the oxygen/carbon ratio, which affects the capacity requirement for the air separation plant. Several regression model standard errors were found to be significant, indicating that addition regression model development should be focused on the air separation plant, HRSG, steam turbine, and coal handling direct cost models. The standard error of the air separation auxiliary power model was also found to be significantly correlated with total capital cost.

The uncertainty in the cost of electricity is significantly correlated with uncertainties in performance, capital cost, maintenance cost, and unit costs, as well as with several regression model standard error terms. Thus, interactions among among many uncertainties involving multiple aspects of performance and cost are shown to have an important influence on uncertainty in the cost of electricity.

\subsubsection{Probabilistic Sensitivity Analysis}

An example of probabilistic sensitivity analysis is shown in Figure 60 to illustrate the interaction among uncettainties in different groups of parameters in the performance and cost model. Uncertainty in performance only leads to a 90 percent probability range in the cost of electricity from 58 to 62 mills $/ \mathrm{kWh}$, a range of 4 mills $/ \mathrm{kWh}$. When uncertainties in capital cost parameters, including process area direct costs and indirect capital costs, are considered in acldition, the 90 percent range encompasses the values between 55.6 and $63.7 \mathrm{mills} / \mathrm{kWh}$, a range of $8.1 \mathrm{mills} / \mathrm{kWh}$. Because the uncertainties in capital cost are symmetric, the mean of the uncertainty for the cost of electricity remains near 59.9 mills/kWh for both cases. 
However, the skewness of some of the assumptions regarding the unit costs of consumables, and regarding several maintenance cost factors, results in a shift in the central value of the uncertainty in the cost of electricity when uncertainties in performance and operating cost are considered. The mean increases by $0.4 \mathrm{mills} / \mathrm{kWh}$. The simultaneous interactions among all uncertainties in performance and cost result in a 90 percent probability range for the cost of electricity extending from 56.2 to $64.2 \mathrm{mills} / \mathrm{kWh}$. This range has the same magnitude as the uncertainty resulting from interaction between performance and capital cost; however, it is shifted upward in value due to the uncertainties in operating costs.

\subsubsection{Screening Analysis}

Based on the regression analysis and sensitivity analysis, a set of 16 uncertainties were preliminarily identified as being unimportant to the results of the probabilistic simulation. These uncertainties are listed in Table 24 . A sensitivity case study was then run to compare the results obtained with a screened set of uncertainties to those from the original set of uncertainties. In the screening study, the uncertainties shown in Table 24 were assigned their deterministic "best guess" values.

Table 24. Uncertainties Screened Out of Case Studies for Oxygen-Blown KRW-based IGCC System.

Gas Turbine CO Conversion

Coal Handling Direct Capital Cost

Beavon-Stretford Direct Capital Cost

Process Condensate Direct Capital Cost

Standard Error KRW Gasification Power

Standard Error Selexol Power

Low Temperature Gas Cooling Direct Capital Cost

Selexol Direct Capital Cost

Claus Plant Direct Capital Cost

HRSG Direct Capital Cost

Steam Turbine Direct Capital Cost

Process Condensate Maintenance Cost

Selexol Maintenance Cost

Low Temperature Gas Cooling Maintenance Cost

Claus Plant Maintenance Cost

Operator Labor Rate 


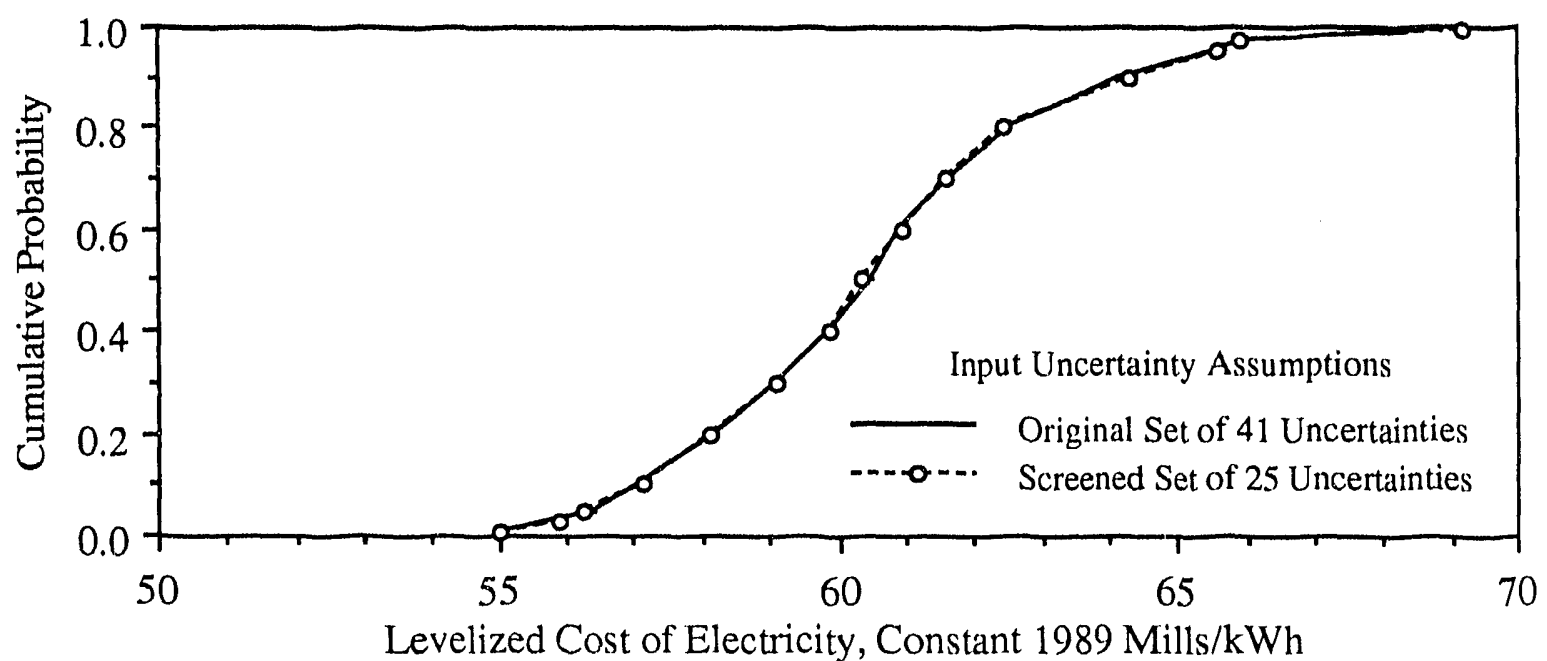

Figure 61. Comparison of Uncertainty in the Cost of Electricity for Original and Screened Sets of Uncertainties.

Several output variables were analyzed to compare the results from the original and screened uncertainty cases. The comparison for the cost of electricity is shown in Figure 61. There is little difference between the two cases. Thus, the uncertainties screened out of the case studies need not be the subject of any further study.

\subsubsection{Additional Research}

As discussed for previous case studies, additional research would be likely to result in a reduction in the variance in the uncertainties in specific model parameters. Therefore, an evaluation of the results of additional research may be based on probabilistic sensitivity analysis, in which the range of uncertainty in selected parameters is reduced. An illustrative set of assumptions for reductions in uncertainty for the oxygen-blown KRW system are shown in Table 25. As for the case study of the Lurgi-based system, a nominal 50 percent reduction in the range above and below the central value of each distribution is assumed. In the case of carbon conversion, the reduction in uncertainty is one-sided, because the mode of the distribution is at the upper end-point.

The effects of these assumptions on the uncertainty in plant thermal efficiency and the cost of electricity are shown in Figures 62 and 63, respectively. As expected, the uncertainty in the plant thermal efficiency responded directly to the change in the uncertainty in carbon conversion. The range of uncertainty, and particularly the risk of high costs, is reduced for the cost of electricity. 
Table 25. Illustrative Assumptions Regarding Reduction in Uncertainty in Key Process Areas for the Oxygen-blown KRW-based System

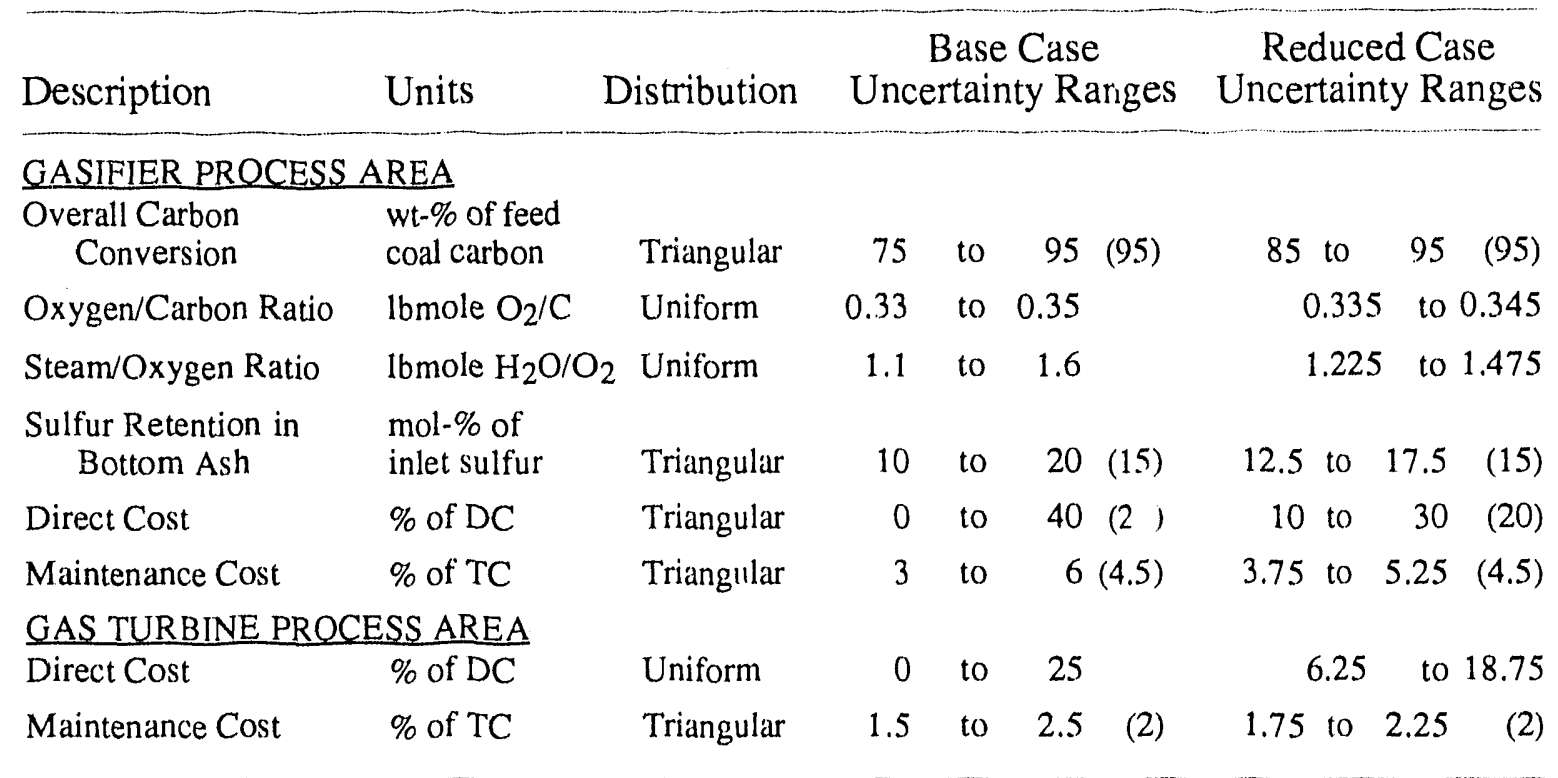

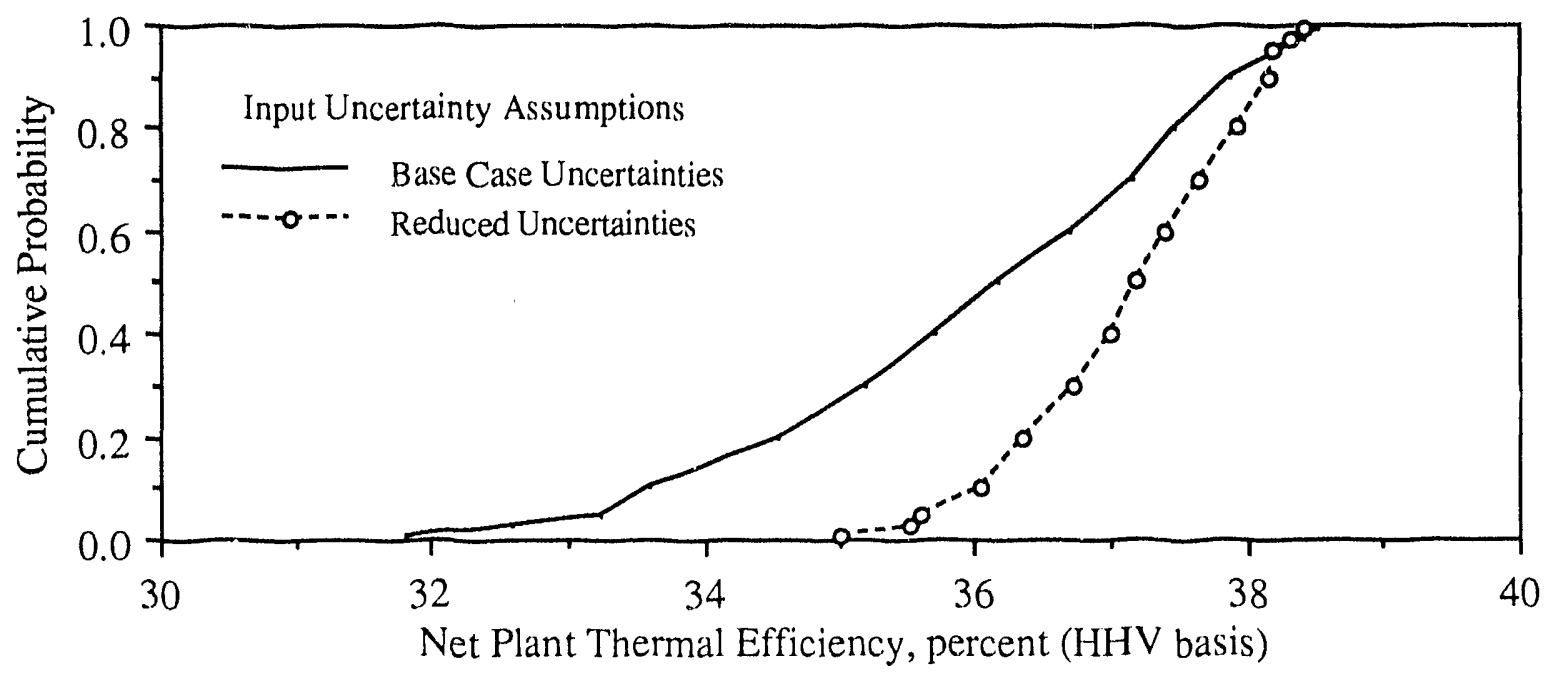

Figure 62. Effect of Reductions in Selected Input Uncertainties on Uncertainty in the Net Plant Thermal Efficiency. 


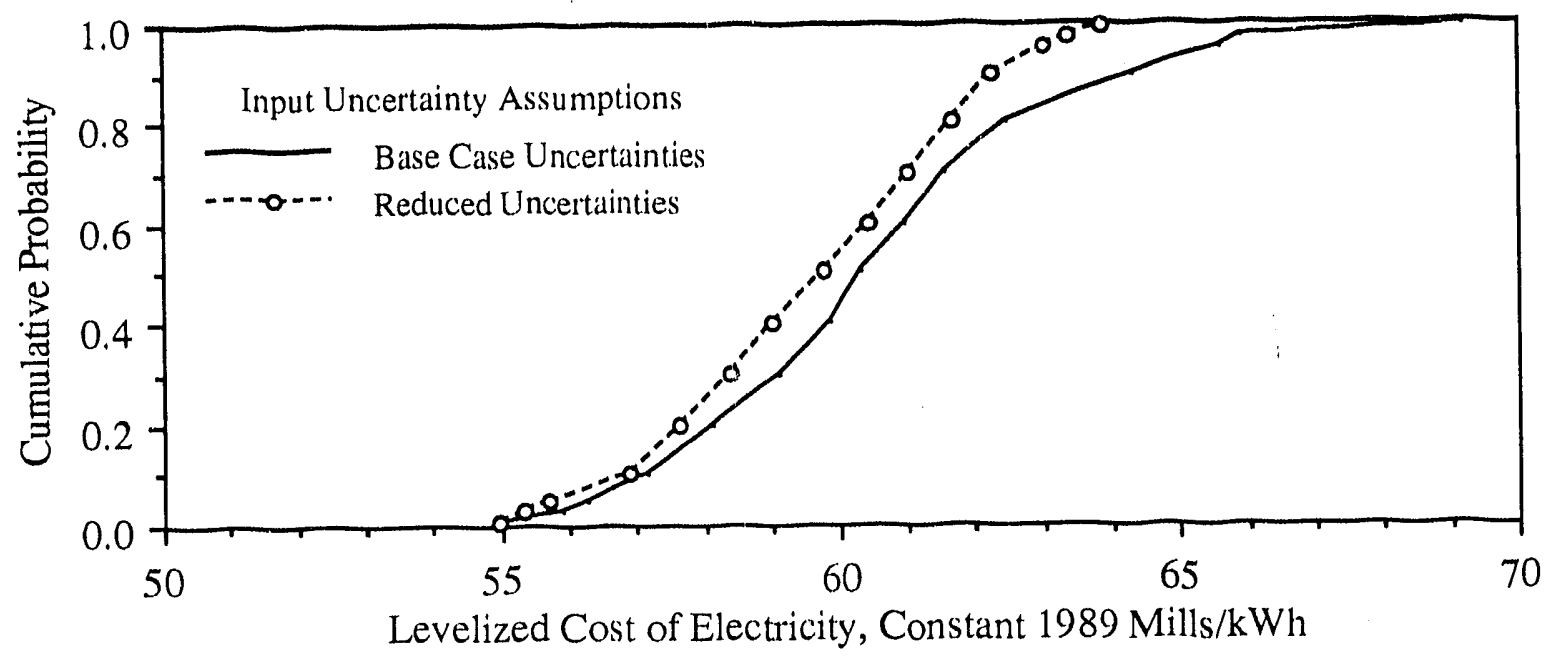

Figure 63. Effect of Reductions in Selected Input Uncertainties on Uncertainty in the Cost of Electricity.

\subsubsection{Correlation Structures}

A probabilistic sensitivity analysis was made to identify the effect that a possible correlation between the carbon conversion rate and steam/oxygen ratio would have on modeling results. A correlation coefficient of 0.75 was assumed. The comparison of the correlated and uncorrelated cases for the cost of electricity is given in Figure 64. The two results are statistically indistinguishable.

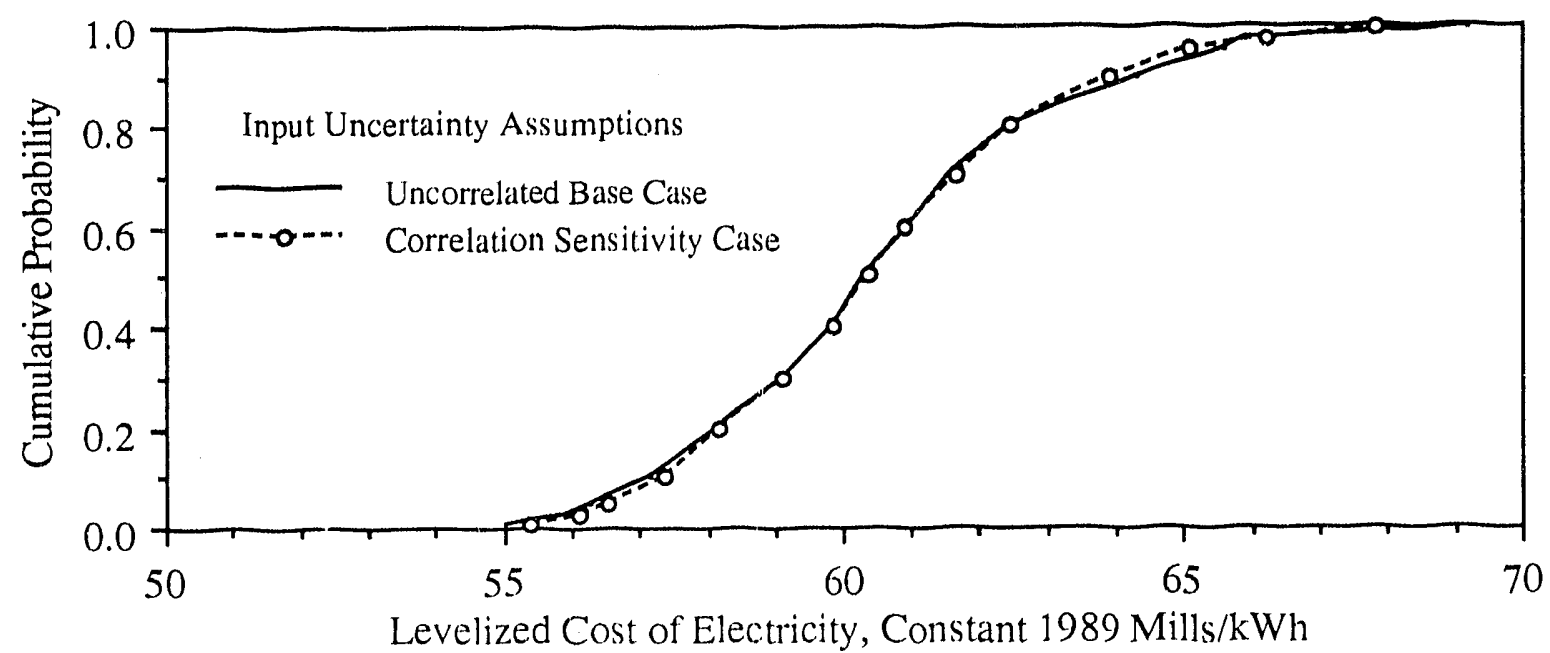

Figure 64. Effect of Correlation in a Selected Input Uncertainty on Uncertainty in the Cost of Electricity. 


\subsection{Comparative Analysis of the IGCC Systems}

The preceding sections have focused on case studies of individual IGCC technologies. In this section, the two systems will be compared in the face of uncertainty. These comparisons are based on key measures of plant performance, emissions, and cost.

For both technologies, additional research is likely to reduce uncertainties in both performance and cost. Therefore, sensitivity cases based on alternative assumptions regarding process uncertainties are considered.

\subsubsection{Pairing Simulations}

For comparative analysis of the Lurgi and oxygen-blown KRW systems, the key uncertainties identified in the screening studies for the respective technologies were used. Furthermore, in cases where uncertainties are assumed to be common to both systems, the same set of sample values and ranking of values were used in the probabilistic simulation of both technologies. Comparisons between the two technologies are based on probability distributions for the differences in performance, emissions, and cost. Because parameters common to both systems are given the same sample values in corresponding repetitions of the probabilistic simulation, the probability distributions of the differences account for any underlying correlations between the two systems.

The pairing of uncertain parameters between the two technologies for the probabilistic comparisons is shown in Table 26. Parameters which are similar or the same between the two technologies are shown on the same line. Parameters which are assumed to have the same set and ranking of sample values between the two simulations are indicated. These parameters include the gas turbine direct cost, standard errors of regression models common to both systems, ash disposal cost, and indirect capital cost uncertainties. The gas turbine direct cost is partly a function of modifications required for application to the IGCC process environment and of market conditions. The modifications and market conditions faced by the two cases are assumed to be sufficiently similar to treat the uncertainty in capital cost as 100 percent correlated.

The regression model error terms are generic to the HRSG and steam turbine direct cost models. If a high result is obtained for one system, it would be expected for the other as well. Therefore, the error terms are assumed to be 100 percent correlated between the two cases. 
Table 26. Pairing of Uncertain Parameters for Comparative Study of Oxygen-Blown KRW- and Air-Blown Lurgi-based IGCC Systems.

\begin{tabular}{l} 
Oxygen-blown KRW \\
\hline Desc \\
\\
Carbon Conversion \\
Oxygen/Carbon Ratio \\
Steam/Oxygen Ratio \\
Sulfur Retention in Ash
\end{tabular}

Thermal $\mathrm{NO}_{x}$

SE Air Separation Aux. Power

SE Coal Hndg Aux. Power

Air Separation DC

Gasification DC

Gas Turbine DC

General Facilities DC

SE Coal Hndg DC

SE Air Separation DC

SE Gasification DC

SE Selexol DC

SE HRSG DC

SE Steam Turbine DC

Gasification Maintenance

Gas Turbine Maintenance

Ash Disposal Cost

Sulfur Byproduct

Byproduct Marketing

Engr \& Home Office Fees

Indirect Construction Cost

Project Cost Uncertainty
Gasification DC

Zinc Ferrite DC

Sulfuric Acid Plant DC

Gas Turbine DC

SE Coal Hndg DC

\section{SE HRSG DC}

SE Steam Turbine DC

Gasification Maintenance

Gas Turbine Maintenance

Unit Cost of Zinc. Ferrite Sorb.

Ash Disposal Cost

No

No

Correlated $^{b}$

Fines Carryover

Carbon Retention in Ash

Gasifier Coal Throughput

Air/Coal Ratio
Steam/Coal Ratio

Zinc Ferrite Residual Sulfate

Fuel $\mathrm{NO}_{\mathrm{x}}$ Conversion

Gas Turbine CO Conversion

Sulfuric Acid Byproduct

Engr \& Home Office Fees $\quad$ Yes

Indirect Construction Cost Yes

Project Cost Uncertainty Yes

\footnotetext{
a Uncertain parameters which are analogous or the same between the two technologies are listed on the same line.

b The term "correlation" is used here to indicate parameters for which the same vector and ranking of samples was used in uncertainty analysis of both technologies. Parameters which are unique to one technology are not correlated with any other uncertain parameters. Parameters which are similar across technologies may be uncorrelated, as indicated, becaluse of differences in the underlying technologies. See text for explanation of basis for correlations.
} 
Ash disposal cost depends on the plant siting. The assumption here is that either technology could be selected for the same plant site. Therefore, uncertainty in ash cost between the two systems is taken to be the same.

The uncertainty in indirect capital costs depend in part on the particular architect/engineer firm and construction team involved in building an actual plant. These uncertainties may be partly resolved by developing a more finalized, site-specific estimate of the cost of constructing a particular IGCC system at a particular site. However, a substantial portion of the uncertainty may remain unresolved until "all the bills are in." It is assumed here that, regardless of which type of IGCC system is constructed, the same uncertainties regarding indirect costs are faced.

Other uncertain parameters that are similar between the systems are assumed to be uncorrelated. For example, although the performance of the two gasifiers can be characterized using similar parameters, the systems are sufficiently different that no correlations are assumed to exist among them. The direct cost of the coal handling systems are calculated using different regression models. Therefore, the standard errors for these two models are assumed to be uncorrelated. As a third example, even though gas turbine direct costs are assumed to be correlated, the maintenance costs are not. This is because the factors that would lead to high maintenance cost (e.g., alkali deposition) would not be expected to occur simultaneously for the two systems.

Based on the pairing of input uncertainties in Table 26, properly paired probabilistic simulations of both technologies were run using the ASPEN simulator. The results of the simulations for several key measures of plant performance, emissions, and cost, were then paired, sample by sample. Each pair of samples was subtracted, and the resulting set of sample differences were used to construct cdfs for the performance, emissions, or cost savings of the advanced technology compared to the conventional technology.

\subsubsection{Comparing Two Technologies Under Uncertainty}

The risk that the new technology will be more expensive can be quantified using the partial mean of the cosi difference distribution for all negative values. The downward and upward partial means are defined as (Buck and Askin, 1986):

$$
\mu_{d}(x) \equiv \int_{-\infty}^{0} x f(x) d x
$$




$$
\mu_{u}(x) \equiv \int_{0}^{\infty} x f(x) d x
$$

where $f(x)$ is the probability density function for the random variable $x$. Buck and Askin define the conditional partial mean based on the partial mean and the probability that a loss or gain has occurred. The expected value of a loss, given that a loss has occurred, is:

$$
\mu_{\mathrm{d} \mid \mathrm{x}<0}(\mathrm{x}) \equiv \frac{\mu_{\mathrm{d}}(\mathrm{x})}{\mathrm{P}(\mathrm{x}<0)}
$$

where $\mathrm{P}(\mathrm{x}<0)$ is the probability that the random variable $\mathrm{x}$ has a value less than zero. The expected value of a gain, given that a gain has occurred, is defined similarly.

The information provided by this analysis can be used to answer questions about the risks and potential pay-offs of the new technology compared to conventional technology. While the Lurgi-based IGCC system is unlikely to be commercialized for another 5 to 15 years, process research will ultimately be used by potential adopters to make a decision about which IGCC system to use for a specific application. Therefore, it is reasonable to look at the decision a hypothetical adopter would make with currently available information vis-a-vis information expected to be yielded from research over the next several years.

The opportunity loss from a hypothetical decision to adopt the Lurgi-based IGCC system is given by the downward partial mean (Moore and Chen, 1984). The downward partial mean is the same as the expected value of perfect information (EVPI) for the case where the loss function, $\mathrm{L}(\mathrm{x})$, of a potential adopter is represented as linear for all negative outcomes and zero for all positive outcomes, i.e.:

$$
E[L(x)]=\int_{-\infty}^{\infty} L(x) f_{x}(x) d x
$$

where,

$$
L(x)=\left\{\begin{array}{l}
x, x<0 \\
0, x>0
\end{array}\right\}
$$

The downward partial mean is the maximum amount that a decision-maker (with the giver. loss function) would be willing to pay to obtain perfect information that would be used to avoid the downward risk. Although research is unlikely to completely resolve uncertainties, research which leads to a reduction in the probability of a loss through 
process improvements, or which provides insight into situations in which the conventional system is less expensive than the advanced technology, has value as "information" to a potential process adopter. The value of information is one measure by which to bound the expenditures on research, development, and demonstration.

\subsubsection{Results of the Comparative Case Studies}

As described in previous sections, additional research on both the Lurgi and oxygen-blown KRW systems can be expected to reduce the uncertainties in these technologies. Reduction in the uncertainty in one or both technologies affects the probability distribution for the differences between the two. Therefore, several comparisons are made for each key variable, based on alternative combinations of base case and reduced uncertainties for the two technologies. The multiple set of comparisons provides insight into whether the advantage seen for one technology is robust when the underlying assumptions change.

For the base case uncertainties of both systems, the Lurgi-based system is likely to be superior to the oxygen-blown KRW-based system with respect to capital cost, levelized cost of electricity, net plant thermal efficiency, and coal consumption. The Lurgi system is certain to have lower $\mathrm{SO}_{2}$ emissions. However, the KRW system is likely to have lower fixed and variable operating costs, and lower $\mathrm{CO}_{2}$ emissions. In addition, the $\mathrm{KRW}$ system is certain to have lower $\mathrm{NO}_{\mathrm{x}}$ emissions and lower water consumption. The results of comparisons for plant efficiency, capital cost, fixed operating cost, variable operating cost, and the cost of electricity are given in Table 27.

Note that while the differences between the Lurgi-based and conventional IGCC systems were obtained as continuous probability distributions, the uncertainties in the differences between the two systems are represented in Table 27 as discrete outcomes (i.e. loss or gain) using the statistics discussed previously. These statistics include the probability that the advanced system may be more expensive than the conventional system, the downward partial mean, the downward and upward conditional partial means, and the mean for the entire distribution. For the Lurgi-based system, the hypothesized research results reduced the downward partial mean of the differences for all cases, and therefore reduced the risk of an opportunity loss to a potential process adoplci. A set of comparisons is also included assuming that further research reduces uncertaimics in the conventional technology. Several of the results are discussed here and shown graphically. 
Table 27. Results of Research Information Case Studies: Comparison of Air-blown Lurgi and Oxygen-blown KRW Systems

\begin{tabular}{|c|c|c|c|c|c|c|c|}
\hline Research Areaa & $\begin{array}{l}\text { robability } \\
\text { of a } \\
\text { Loss }(\%)\end{array}$ & $\begin{array}{c}\text { Downward } \\
\text { Partial } \\
\text { Mean }\end{array}$ & $\begin{array}{l}\text { Expected } \\
\text { Value } \\
\text { of a Loss }\end{array}$ & $\begin{array}{l}\text { Expected } \\
\text { Value } \\
\text { of a Gain }\end{array}$ & Mean & $\begin{array}{c}\text { Reduction } \\
\text { in } \\
\text { Risk }\end{array}$ & $\begin{array}{c}\text { Value } \\
\text { of } \\
\text { Research }\end{array}$ \\
\hline \multicolumn{8}{|l|}{ Plant Efficiency, percent } \\
\hline Baseline & 20 & 0.25 & 1.2 & 2.2 & 1.5 & $\ldots$ & $\cdots$ \\
\hline Gasification & 9 & 0.06 & 0.6 & 2.3 & 2.0 & 0.19 & 0.5 \\
\hline Zinc Ferrite Desulfurization & 20 & 0.25 & 1.2 & 2.2 & 1.5 & 0 & 0 \\
\hline All & 9 & 0.06 & 0.6 & 2.3 & 2.0 & 0.19 & 0.5 \\
\hline Base Case ALH vs. All OKC & 35 & 0.40 & 1.1 & 1.2 & 0.4 & - & - \\
\hline All ALH vs. All OKC & 15 & 0.09 & 0.6 & 1.2 & 0.9 & 0.31 & 0.5 \\
\hline \multicolumn{8}{|l|}{ Total Capital Cost. $1989 \$ / \mathrm{kW}$} \\
\hline Baseline & 1 & 1.4 & 144 & 342 & 337 & $\ldots$ & $\cdots$ \\
\hline Gasification & 0 & 0 & 0 & 371 & 371 & 1.4 & 34 \\
\hline Zinc Ferrite Desulfurization & 1 & 1.3 & 132 & 353 & 348 & 0.1 & 11 \\
\hline All & 0 & 0 & 0 & 383 & 383 & 1.4 & 46 \\
\hline Base Case ALH vs. All OKC & 1 & 1.7 & 172 & 331 & 331 & - & - \\
\hline All ALH vs. All OKC & 0 & 0 & 0 & 372 & 372 & 1.7 & 41 \\
\hline \multicolumn{8}{|c|}{ Eixed Operating Cost. $1989 \$ / \mathrm{kW}$-yr } \\
\hline Baseline & 55 & 5.8 & 10.5 & 6.7 & -2.7 & - & - \\
\hline Gasification & 32 & 1.4 & 4.3 & 6.9 & 3.3 & 4.4 & 6.0 \\
\hline Zinc Ferrite Desulfurization & 55 & 5.7 & 10.5 & 6.8 & -2.6 & 0.1 & 0.1 \\
\hline All & 16 & 0.5 & 3.7 & 7.2 & 5.4 & 5.3 & 8.1 \\
\hline Base Case ALH vs. All OKC & 51 & 5.3 & 10.4 & 5.7 & -2.5 & $\ldots$ & $\cdots$ \\
\hline All ALH vs. All OKC & 15 & 0.4 & 2.4 & 7.1 & 5.7 & 4.9 & 8.2 \\
\hline \multicolumn{8}{|c|}{ Variable Operating Cost. 1989 mills/kWh } \\
\hline Baseline & 82 & 4.3 & 5.3 & 0.8 & -4.2 & $-\infty$ & - \\
\hline Gasification & 77 & 4.0 & 5.2 & 0.8 & -3.8 & 0.3 & 0.4 \\
\hline Zinc Ferrite Desulfurization & 87 & 2.8 & 3.2 & 0.8 & -2.7 & 1.5 & 1.5 \\
\hline All & 83 & 2.5 & 3.0 & 0.8 & -2.3 & 1.8 & 1.9 \\
\hline Base Case ALH vs. All OKC & 92 & 4.7 & 5.1 & 0.5 & -4.7 & -- & - \\
\hline All ALH vs. All OKC & 94 & 2.9 & 3.1 & 0.4 & -2.9 & 1.8 & 1.8 \\
\hline \multicolumn{8}{|c|}{ Levelized Cost of Electricity. Constant 1989 mills $/ \mathrm{kWh}$} \\
\hline Baseline & 27 & 2.6 & 9.5 & 5.5 & 1.5 & - & $\ldots$ \\
\hline Gasification & 16 & 1.9 & 11.7 & 6.4 & 3.5 & 0.7 & 2.0 \\
\hline Zinc Ferrite Desulfurization & 21 & 1.0 & 5.0 & 5.4 & 3.2 & 1.6 & 1.7 \\
\hline All & 6 & 0.4 & 6.8 & 6.4 & 5.6 & 2.2 & 4.1 \\
\hline Base Case ALH vs. All OKC & 32 & 2.7 & 8.4 & 5.1 & 0.8 & $\ldots$ & $\cdots$ \\
\hline All ALH vs. All OKC & 9 & 0.4 & 4.9 & 5.9 & 4.9 & 2.3 & 4.1 \\
\hline
\end{tabular}

a For each parameter used for comparison, the results are grouped separately for comparisons of the airblown Lurgi system with hot gas cleanup (ALH) to the base case and "All" reduced uncertainties case for the oxygen-blown KRW-based system with cold gas cleanup (OKC). 


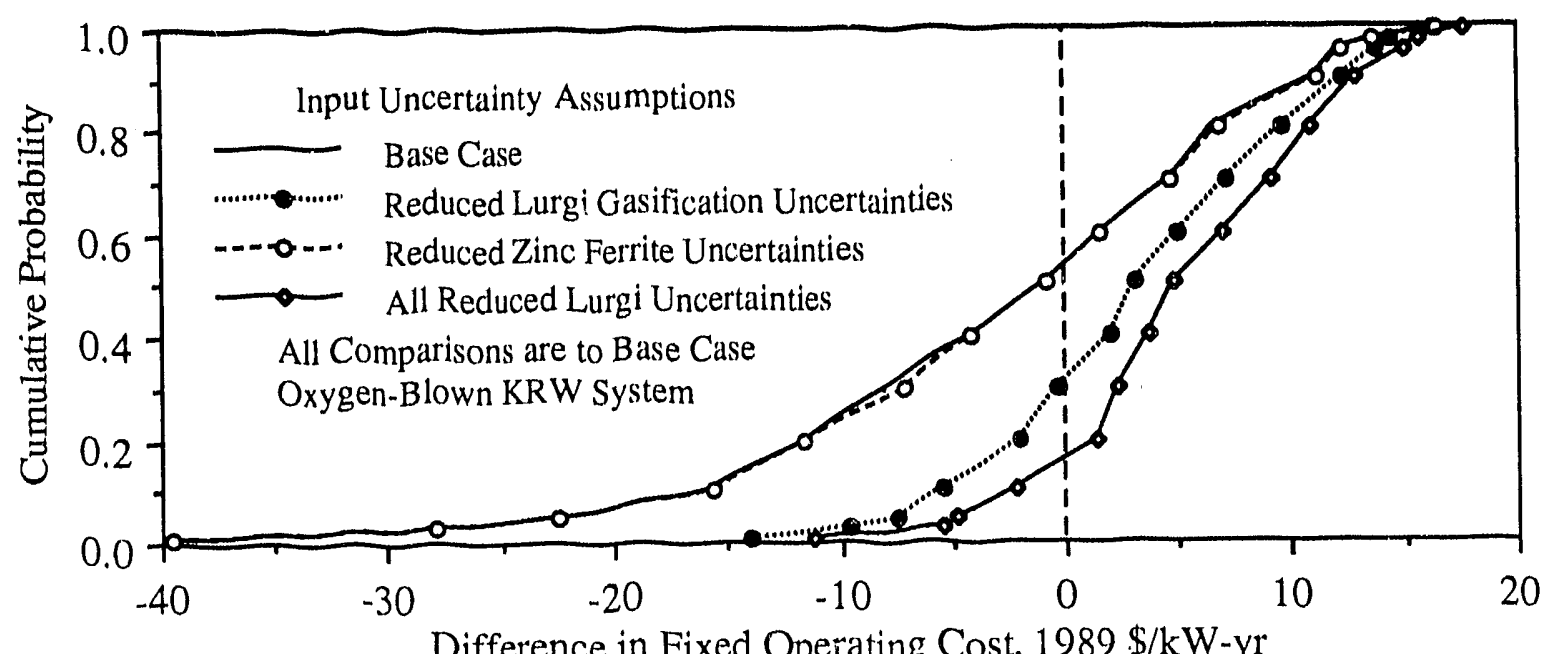

Figure 65. Effect of Illustrative Research Outcomes on Fixed Operating Cost Savings for Air-blown Lurgi System Compared to Oxygen-blown KRW System

The higher efficiency and lower capital cost of the Lurgi system is expected, because it is a "simplified" IGCC system featuring hot gas cleanup. Therefore, it does not have the expensive fuel gas cooling and cleanup equipment associated with cold gas cleanup in the KRW system, leading to substantial capital cost savings. The mean capital cost savings is $\$ 337 / \mathrm{kW}$, for the base case uncertainties. For this case, there is a 46 percent correlation between the capital costs of the two systems, due to the assumed pairin's of input uncertainties between them. Additional research on the Lurgi system is likely to improve the cost savings. For the assumptions used in this study, the capital cost difference increases to $\$ 383 / \mathrm{kW}$. However, research may simultaneously reduce uncertainties in the KRW system. The cost savings for this scenario is relatively unchanged, at $\$ 372 / \mathrm{kW}$. Thus, regardless of whether research is conducted on the KRW system, research on the Lurgi system is expected to yield both a reduction in the downside risk that capital cost could be more expensive, and an increase in the mean cost savings.

However, the Lurgi system is more risky from a maintenance standpoint. Cold gas cleanup will remove many of the trace contaminants that result in uncertainties for the hot gas cleanup system. For example, alkali and particulate matter are removed to a high degree in cold gas cleanup. However, the performance of high efficiency cyclones may not be as good for alkali and particulate control. Therefore, downstream equipment, such as the zinc ferrite process and gas turbine, may be faced with high maintenance costs.

The probability differences for the fixed operating cost for several alternative assumptions regarding Lurgi system uncertainties is shown in Figure 65. All of the comparisons in the figure are based on the base case uncertainty assumptions for the KRW 


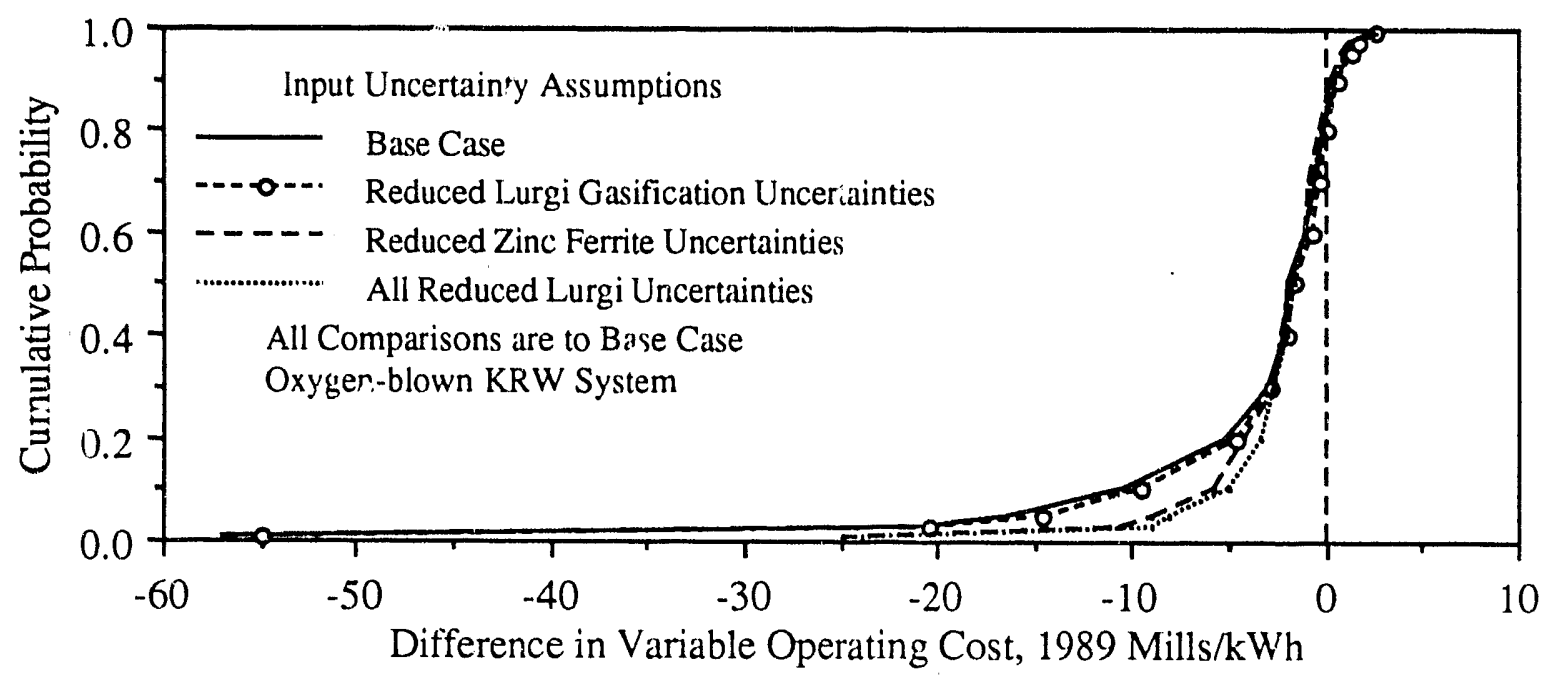

Figure 66. Effect of Illustrative Research Outcomes on Variable Operating Cost Savings for Air-blown Lurgi System Compared to Oxygen-blown KRW System

system. Based on current understanding of uncertainty for the Lurgi system, there is a 55 percent probability that the Lurgi system will have higher fixed operating costs than the KRW system. Furthermore, the conditional expected value of higher fixed operating costs (see Table 27) is higher than the conditional expected value of lower costs, and the mean of the distribution is a net loss of $\$ 3 / \mathrm{kW}$-yr for the I.urgi system.

The outcomes of further research in the Lurgi system would reduce the probability of higher fixed operating cost, and would decrease the risk associated with higher costs. In the "all reduced uncertainties" case, there is only a 16 percent chance of higher fixed operating costs, and a mean cost savings of $\$ 5 / \mathrm{kW}$-yr. Thus, the effect of additional research in this case is to yield an advantage for the Lurgi system. As indicated in Table 27, a similar result is obtained even if further research reduces uncertainties in the KRW system.

The Lurgi system suffers from high variable operating costs associated with the zinc ferrite sort nt. Thus, regardless of the assumptions regarding research ouicomes, there is a high probability, around 80 percent, that the Lurgi system will have higher variable operating costs than the KRW system, as indicated in Fig: re 66. Furthermore, there is a risk that the cost could be over 10 mills $/ \mathrm{kWh}$ higher, even with a reduction in uncertainties from further process research. While further research will not eliminate the probability of more expensive costs, it will reduce the downward partial mean of higher costs and increase the mean of the distribution, thereby reducing the expected value of the higher costs, as incicated in Table 27. Thus, there is value obtained from research with respect to reducing the difference in variable operating costs between the two systems. 


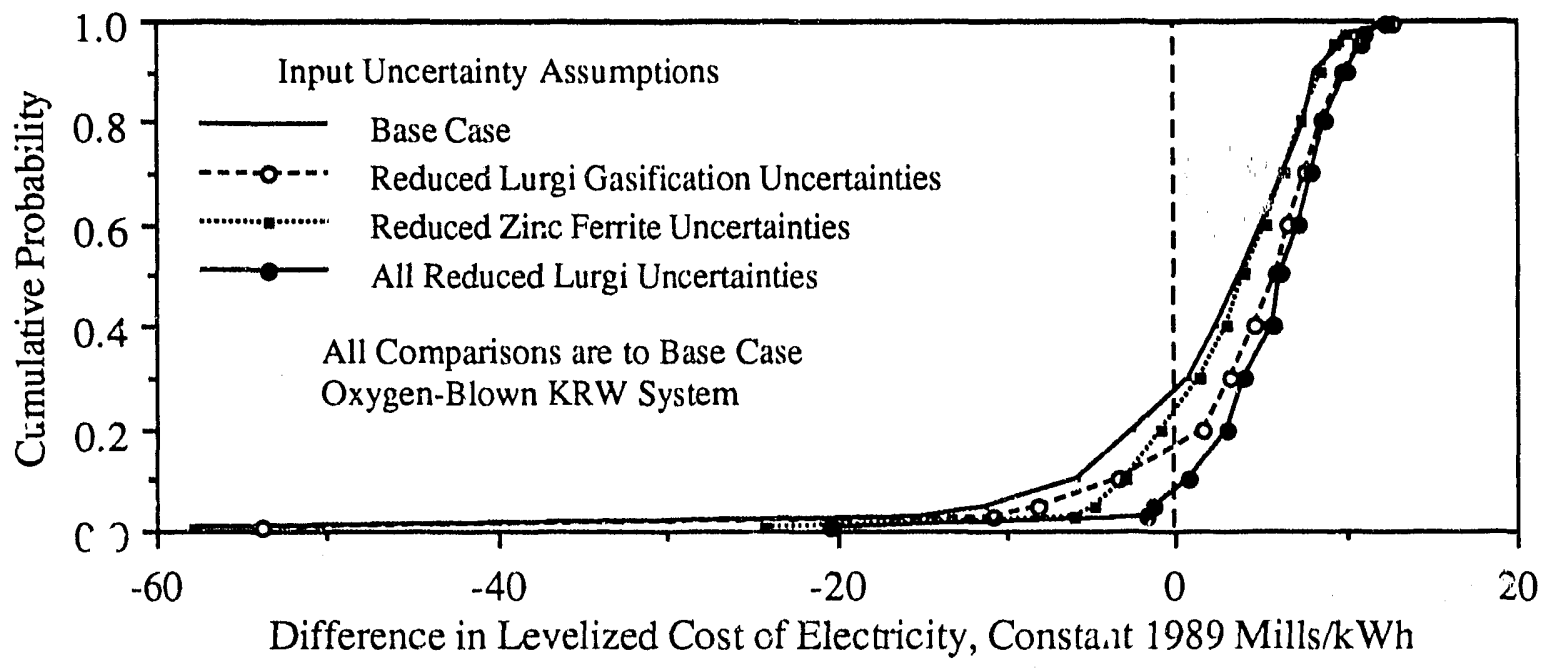

Figure 67. Effeci of Illustrative Research Outcomes on Cost of Electricity Savings for Airblown Lurgi System Compared to Oxygen-blown KRW System

Perhaps the single most important variable for comparative analysis is the levelized cost of electricity. The probability distributions for the difference in cost between the Lurgi and KRW systems are shown in Figure 67, assuming the base case uncertainty values for the KRW system. For all cases, the Lurgi system is likely to be less expensive than the KRW system. However, the risk of higher costs for the base case is 27 percent, and the expected value of a loss, given that a loss has occurred, is 9.5 mills $/ \mathrm{kWh}$. Research in the gasification process area reduces the probability of a loss to 16 percent, and it reduces the downward partial mean by 0.7 mills $/ \mathrm{kWh}$. However, it does not eliminate the long tail associated with the loss. Therefore, the conditional expected value of a loss actually goes up. Reduced gasification uncertainties result in an upward shift in the central values of the distribution, due to the skewness of uncertainties in the model. Therefore, the expected net cost savings increases by $2 \mathrm{mills} / \mathrm{kWh}$.

Research on the zinc ferrite process area is expected to reduce the risks associated with poor sorbeni perfo ance. Therefore, the long tail of the distribution is substantially reduced. Although zinc ferrite research only reduces the probability of a loss to 21 percent, it has a more substantial effect on the other measures of downside risn, compared to gasification research outcomes. The downward partial mean is reduced by $1.6 \mathrm{mills} / \mathrm{kWh}$. Reduction in zinc serrite uncertainty does not lead to a major change in the central values of the cost difference. For this reasor, the expected net cost savings is less than for gasification research, in spite of the stronger effect on downside risk.

When all research areas are combined, the probability of higher cost is reduced to six percent, and the expected net cost savings increases by $4.1 \mathrm{mills} / \mathrm{kWh}$. Thus, 


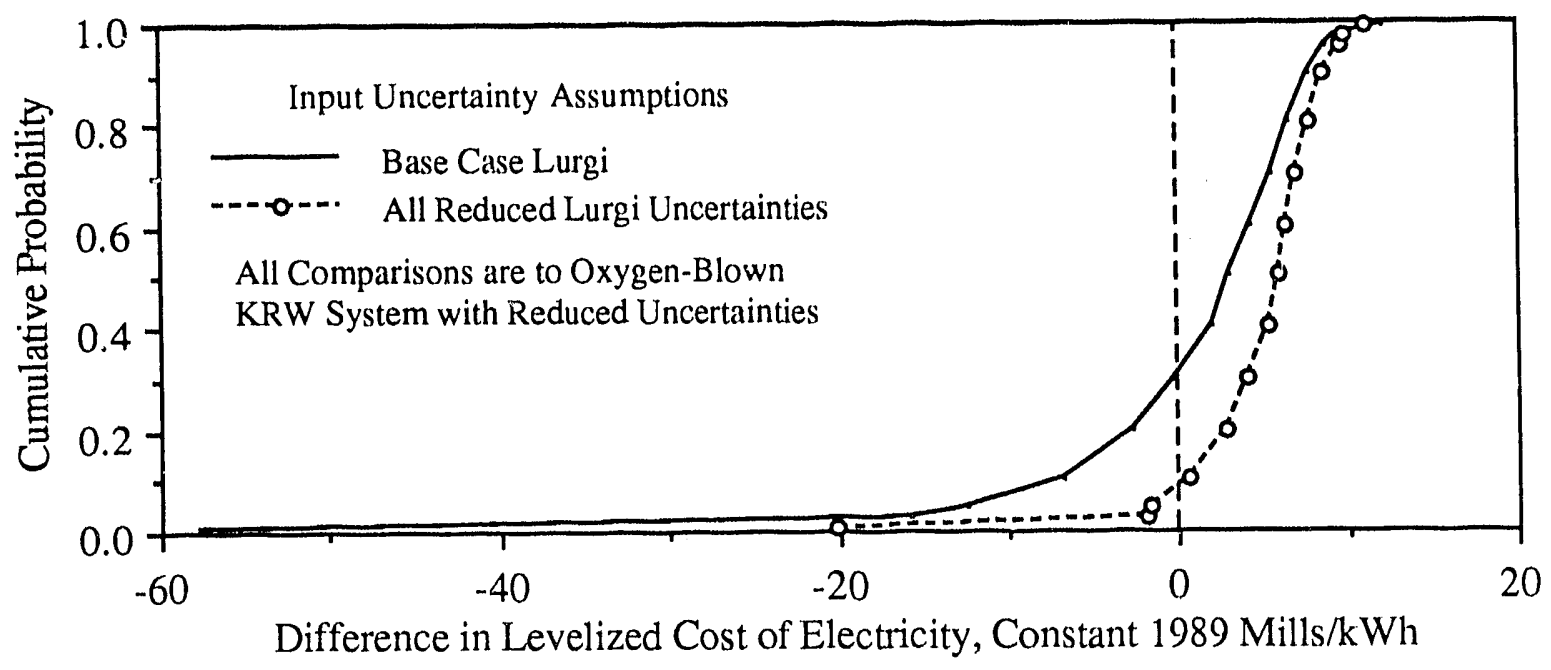

Figure 68. Effect of Illustrative Research Outcomes on Cost of Electricity Savings for Airblown Lurgi System Compared to Oxygen-blown KRW System

additional research on the Lurgi system may yield substantial pay-offs, both in terms of risk reduction and net cost savings. Similar results are obtained even if uncertainties in the KRW system are reduced, as shown in Figure 68 and given in Table 27, indicating that the results for the Lurgi system are robust.

The cost of electricity depends on the plant capacity factor. As already discussed, although the Lurgi holds substantial capital cost advantages, it is likely to have higher operating costs. Therefore, for high capacity factors, which lead to a relatively higher weighting of operating costs in the cost of electricity, the advantage of the Lurgi system is reduced. For a capacity factor of 90 percent, the Lurgi system enjoys a 65 percent probability of cost savings, assuming base case uncertainties. However, because of the long tail associated ivith poor zinc ferrite sorbent performance, the mean value of the distribution for the difference in cost is negative, indicating that the Lurgi system is expected to be 0.08 mills $/ \mathrm{kWh}$ more expensive than the KRW system. For capacity factors slightly below 90 percent, the Lurgi system has an expected cost savings. Capacity factors of 90 percent are not often achieved in the electric utility industry. Therefore, this represents perhaps an overly stringent comparison point for the Lurgi system.

The Lurgi system will have lower $\mathrm{SO}_{2}$ but higher $\mathrm{NO}_{\mathrm{x}}$ emissions than the $\mathrm{KRW}$ system. The lower $\mathrm{SO}_{2}$ emissions are due to the very high efficiency (e.g., 99.8 percent) of the hot gas cleanup system. The higher $\mathrm{NO}_{\mathrm{x}}$ emissions are due to conversion of fuel vound nitrogen (ammonia) in the conventional gas turbine combustor. In spite of the higher efficiency of the Lurgi system, the KRW system will tend to have lower $\mathrm{CO}_{2}$ emissions. This is because the KKW system tends to have higher carbon retention in the 
bottom ash than the Lurgi system, leading to sequestering of carbon in the solid waste stream that otherwise would be emitted as $\mathrm{CO}_{2}$. The $\mathrm{KRW}$ system also has a substantially lower process water requirement, because the higher temperature KRW gasifier does not require as much steam for the purpose of temperature control, as compared to the Lurgi gavifier.

\subsection{An Illustrative Decision Model}

In this section, the results of the comparative case study of the air-blown Lurgi and oxygen-blown KRW systems are used as inputs to a decision model. The purpose of the decision model is to represent the preferences of a decision maker, such as a research planner or process adopter, who is faced with choices between competing innovative technologies under uncertainty. The decision model accounts for the decision maker's attitude toward risk. In addition, the model used here is sensitive to the timing of research outcomes.

A simple conceptual diagram of a decision tree representing the alternatives of selecting a conventional technology or one of several research strategies for an advanced technology is shown in Figure 69. The conventional technology represents the status quo, and has an associated cost savings of zero. If the advanced technology is selected based on current knowlcdge, it is expected to have a cost savings of $1.47 \mathrm{mills} / \mathrm{kWh}$. However, there is a risk that the Lurgi system would be more expensive than the conventional technology, as discussed in Section 5.4. Instead of choosing the technology "as is," a process adopter could opt to wait for the results of further research. Depending on the specific process areas which are targeted for research, the expected cost savings would increase to as high as $5.6 \mathrm{mills} / \mathrm{kWh}$. However, these outcomes may not be available for another 5 to 20 years. A decision maker may prefer an outcome this year to the same outcome obtained next year. Therefore, the time value of the outcomes are modeled here using discounting.

A decision model based on the utility function given in Section 2.5 was used to model the preferences of a decision maker. Assuming that the results of further research could be obtained instantaneously, only an extremely risk averse decision maker would choose the conventional techuology over the advanced technology. In all other cases, the decision maker would prefer the advanced technology "as is" to the conventional technology. Furthermore, the decision maker would obtain the highest expected utility from pursuing research in several major process areas simultaneously. 


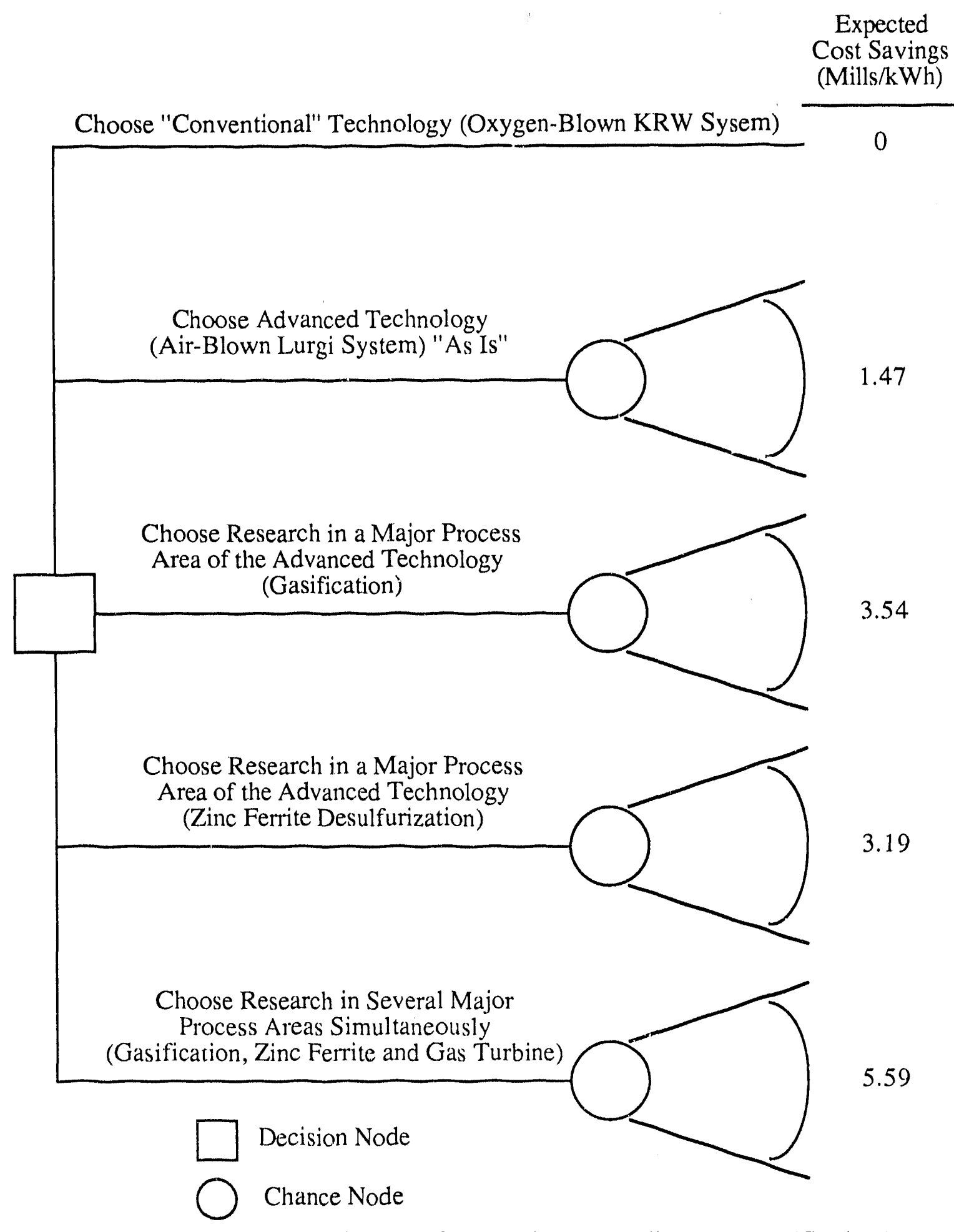

Figure 69. Conceptual Decision Tree for Decisions Regarding Advanced Technology Selection and Research Planning 


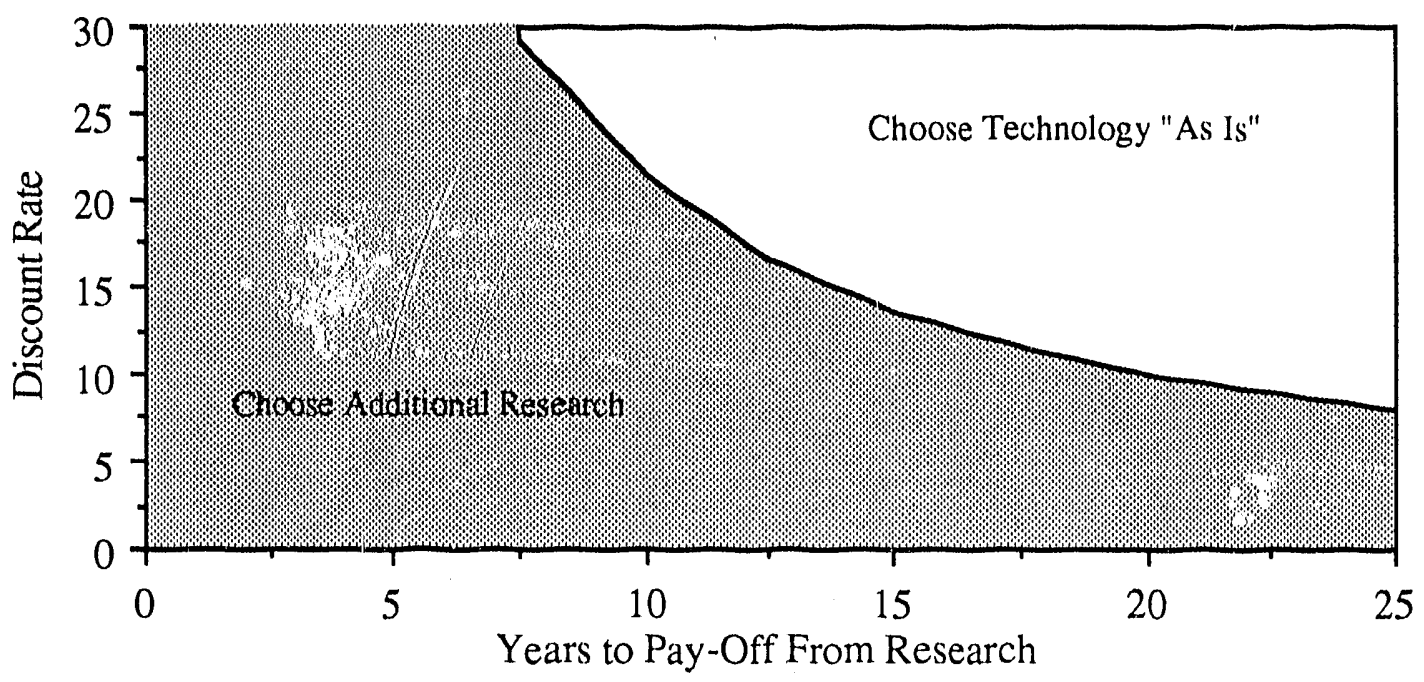

Figure 70. Sensitivity of Decision to Pursue Further Research to Discount Rate and Time for a Risk-A verse Decision-Maker

The timing of research outcomes affects the expected utility of the three research options shown in Figure 69. For a moderately risk averse decision maker, the expected utility of the research option for all process areas remains higher than all other alternative as long as the research outcomes are obtained within 15 years at a discount rate lower than 14 percent. The sensitivity of the decision to pursue further research to the time to pay-off and the discount rate is given in Figure 70. In all cases, the expected utility of research into all process areas is higher than for research in a single process area.

In addition to a decision analysis based on the single-attribute of levelized cost, a multi-attribute analysis was considered that included differences in $\mathrm{SO}_{2}, \mathrm{NO}_{\mathrm{x}}$, and $\mathrm{CO}_{2}$ emissions between the two technologies. Both the $\mathrm{SO}_{2}$ and $\mathrm{NO}_{\mathrm{x}}$ emission rates were converted to a plant energy output basis for the comparison. Thus, the environmental impact and cost associated with $1 \mathrm{kWh}$ of plant output was considered for both technologies. The emission rates were converted to a mills/kWh basis by assuming a unit cost per amount of emitted pollutant. As a nominal assumption, the external costs of $\mathrm{SO}_{2}$, $\mathrm{NO}_{\mathrm{x}}$, and $\mathrm{CO}_{2}$ were assumed to be $\$ 2,000 /$ ton, $\$ 1,000 /$ ton, and $\$ 25 /$ ton, respectively. However, including these pollutants in the decision analysis with these assumed external prices did not significantly change the model results. 


\subsection{DISCUSSION}

The generic features of the probabilistic modeling approach are discussed here in comparison to traditional approaches to technology evaluation and to the work of the Rand Corporation. Rand has conducted a number of quantitative studies regarding the development of performance and cost estimates of advanced process technologies.

\subsection{Information Requirements}

Compared to deterministic analysis, the probabilistic modeling approach requires that more detailed judgments be made regarding the values assigned to performance and cost parameters in an engineering model. Thus, the time required to develop estimates of uncertainty is usually higher than the time that would be required to make a "best guess" estimate. However, by systematically thinking about uncertainties in specific parameters, an analyst is more likely to uncover potential sources of cost growth or performance shortfalls that would otherwise be overlooked.

A tendency that has been observed in this research and by others is for best guess estimates to be more similar to the median or mode than to the mean of a distribution. For symmetric distributions, there is no difference. However, for skewed distributions, the mean may differ substantially from the median and the mode. People tend to think more in terms of the single "most likely" outcome (mode) or the outcome for which there is a 50-50 chance of higher or lower outcomes (median). It is much more difficult to evaluate the average value of a distribution (mean), particularly if, in making a best guess judgment, the analyst does not consider both the range and probability of outcomes for an uncertain parameter. As shown in many of the case studies, the influence of skewed distributions on model results can be important. They tend to shift the central tendency of resulting uncertainties in performance and cost, and can lead to long tails representing unfavorable outcomes. These types of interactions cannot be evaluated systematically in deterministic analysis.

Thus, while the information requirements may be more demanding for probabilistic analysis, there is a benefit obtained in return. The benefit is more realistic estimates of performance and cost. Also, thinking about uncertainties is an important way to gain understanding into the key factors that drive the risk of failure for an advanced process technology. 


\subsection{Computational Requirements}

The computational requirements for probabilistic modeling depend on the complexity of the engineering model and the probabilistic modeling environment. For the IGCC systems, the case studies took 6 to 12 hours for a sample size of 100 , and required a powerful mini-computer. However, because probabilistic case studies provide a systematic means to capture the effects of simultaneous variations in many input parameters, they eliminate the need for a combinatorial explosion of "sensitivity" case studies that would be typical of deterministic analysis. Furthermore, the results of a probabilistic simulation are more meaningful and more easily interpreted than would be the results of a sensitivity analysis.

\subsection{Cost Estimating and Risk Assessment}

As shown in the case studies of the copper oxide process and IGCC systems, probabilistic analysis provides explicit insights into the range and likelihood of outcomes for key measures of plant performance and cost. In many cases, there is a probability of obtaining extreme outcomes, such as low performance or high cost, that would result in technology failure. The characterization of uncertainties in performance and cost results from the simultaneous interaction of uncertainties in many input parameters. These types of insights cannot be obtained from deterministic analysis.

Furthermore, although the notion of uncertainty is claimed to be imbedded in socalled "contingency factors," in most cases contingency factors are inadequate for providing reliable cost estimates for advanced process technologies. This is due, in part, to the tendency for judgments about deterministic point values to correspond to the median or modal values that would be revealed by an uncertainty analysis. In the case of skewed distributions, or where there are nonlinearities in an engineering model, the mean outcomes may often tend to be "worse" than the best guess outcomes. Thus, there is often a high probability of cost overrun compared to the deterministic analysis. Uncertainties in key measures of plant performance and cost result from often complex interactions among uncertain input parameters in the model. These types of interactions simply cannot be captured using a multiplier applied to a cost estimate after it has been developed without regard to uncertainty.

Contingency factors provide no insight into the variance of the capital cost estimate. They also do not allow identification of the specific performance or cost parameters which are the source of potential cost growth and variance in the cost estimate. By suppressing 
information about uncertainties, deterministic estimates may give a false sense of confidence regarding the certainty of the estimate.

Uncertainties in performance, capital cost, and O\&M costs have been shown to contribute significantly to uncertainty in the levelized cost of electricity. However, in most cost estimates, the notion of contingency is not extended to O\&M costs, nor to the levelized cost of electricity.

Through regression and probabilistic sensitivity analysis, it is possible to isolate the key input uncertainties which drive the variance in key measures of plant performance and cost. Therefore, it is possible to identify the specific areas for further process research that would lead to significant reductions in the risk for the advanced process. Such insights are not obtained using contingency factors.

The results of a probabilistic engineering analysis can be used as inputs to a decision model that represents the preferences of a decision maker. The effect that a risk of low performance or high cost, compared to conventional technology, has on decisions regarding technology adoption and research planning can be evaluated quantitatively.

\subsection{Comparison of Probabilistic Approach to RAND Cost Growth Model}

The Rand Corporation has conducted a number of studies for DOE regarding the difference between cost estimates and the actual costs incurred for a technology project. Results of these studies, based on a database of cost estimates and reported actual costs for chemical process plants, were first published in 1981 (Merrow, Phillips, and Myers). A more recent report applies the Rand cost growth estimation method to a first-of-a-kind magneto-hydrodynamic power station (Hess, Merrow, and Pei, 1987). The method is based on a regression analysis of a database prepared by Rand that contains 106 cost estimates for 44 pioneer chemical process plants. The cost estimites, of which there may be several prepared for one plant during various stages of development, range in scope and detail.

In this section, the results obtained from probabilistic analyses of the IGCC systems are compared to the results obtained using the Rand cost growth model. First, the Rand model is briefly summarized.

\subsubsection{Rand First-of-a-Kind Plant Cost Growth Model}

The cost growth model is summarized as follows: 


\begin{tabular}{|c|c|c|c|c|}
\hline Cost Growth Factor & $=1.12$ & $\begin{array}{ll}- & 0.00297 \\
- & 0.0213 \\
- & 0.0114 \\
+ & 0.00111 \\
- & 0.0401 \\
- & 0.0235\end{array}$ & $\begin{array}{l}x \\
x \\
x \\
x \\
x \\
x \\
P\end{array}$ & $\begin{array}{l}\text { Percent New } \\
\text { Impurities } \\
\text { Complexity } \\
\text { Inclusiveness } \\
\text { Project Definition } \\
\text { (Project Definition x } \\
\text { cess Development) }\end{array}$ \\
\hline
\end{tabular}

The coefficient of determination $\left(R^{2}\right)$ of the equation is 0.83 .

The terms in the equations are:
Cost Growth Factor:
ratio of estimated to actual capital cost.
Percent New:
Percent of capital cost associated with new technology
Impurities:
Scale of 0 to 5 assessment of level of difficulty
Complexity: encountered with process stream impurities.
Inclusiveness:
Number of linked process blocks.
Completeness of cost estimate (100 percent if costs
for land, initial catalyst and chemicals inventory, and
Project Definition: $\quad$ Scale of 2 (well-defined) to 8 (poorly defined). startup personnel are included) A value of 7 is typical for generic cost estimates which are not site-specific.
Process Development: 0 well understood, 1 significant R\&D issues.

\subsubsection{Cost Growth Case Studies for the IGCC Systems}

An assessment of the cost growth for first-of-a-kind IGCC plants was made on the basis of the regression model given above. The assumptions used in the Rand cost growth model for the oxygen-blown KRW-based IGCC system with cold gas cleanup and the airblown Lurgi-based IGCC system with hot gas cleanup are summarized in Table 28. The IGCC capital cost estimates used as the basis for this analysis inciude a 10 percent overall contingency factor, because this is the average contingency Rand reports for their cost database (Hess et al 1987).

The values assigned to each parameter in Table 28 are within the range of values contained in the pioneer plant database, and so it is not unreasonable to use these models. The regression models do not imply causality; however, they are a statistically-derived representation of the data base regarding chemical process plants. As such, the models can be expected to reasonably represent, at least in a qualitative sense, a new process plant such as an IGCC system.

The construction and operation of a pioneer first-of-a-kind plant can lead to significant cost reductions in subsequent plants, assuming that an effort is made to incorporate information about the pioneer plant into the design and operating philosophy of the subsequent plants. Improvements in capital costs can be substantial for subsequent 
Table 28. Analysis of Cost Growth and Cost Improvement for the IGCC Systems

\begin{tabular}{|c|c|c|}
\hline Description & $\begin{array}{l}\text { Oxygen-blown } \\
\text { KRW with } \\
\text { Cold Gas Clearinp }\end{array}$ & $\begin{array}{l}\text { Air-blown } \\
\text { Lurgi with } \\
\text { Hot Gas Cleanup }\end{array}$ \\
\hline $\begin{array}{l}\text { Deterministic Total Capital } \\
\text { Cost Estimate }(\$ / \mathrm{kW}) \\
\quad \text { (with } 10 \% \text { contingency) }\end{array}$ & 1,490 & 1,170 \\
\hline Percent New Technology & 23.0 & 32.5 \\
\hline Level of Impurities & 2 & 3 \\
\hline Complexity (No. Linked Process Areas) & 12 & 11 \\
\hline Inclusiveness & 100 & 100 \\
\hline Process Development & 1 & 1 \\
\hline $\begin{array}{l}\text { Cost Improvement from First to } \\
\text { Fifth Plant, percent }\end{array}$ & 30 & 30 \\
\hline $\begin{array}{c}\text { Cost Growth Factor } \\
\text { Proj Def }=7 \\
\text { Proj Def }=6\end{array}$ & $\begin{array}{l}1.86 \\
1.66\end{array}$ & $\begin{array}{l}2.00 \\
1.77\end{array}$ \\
\hline $\begin{array}{r}\text { 1st Plant cost } \\
\text { Proj Def }=7 \\
\text { Proj Def }=6 \\
\text { 5th Plant Cost }\end{array}$ & $\begin{array}{l}2,770 \\
2,475\end{array}$ & $\begin{array}{l}2,330 \\
2,065\end{array}$ \\
\hline $\begin{array}{l}\text { Proj Def }=7 \\
\text { Proj Def }=6\end{array}$ & $\begin{array}{l}1,940 \\
1,730\end{array}$ & $\begin{array}{l}1,632 \\
1,445\end{array}$ \\
\hline $\begin{array}{l}\text { "Best Guess" } \\
\text { Mean from Probabilistic Simulation }\end{array}$ & $\begin{array}{l}1,730 \\
1,806\end{array}$ & $\begin{array}{l}1,410 \\
1,465\end{array}$ \\
\hline
\end{tabular}

plants with similar site conditions. For example, the demonstration of a relatively standard technology can result in 10-15 percent cost reduction in later plants, while demonstration of a highly advanced process can result in perhaps : 30 percent subsequent cost reduction (Hess, 1985).

The cost estimates developed in this research are intended to be representative of a fifth-of-a-kind plant. Therefore, in order to compare the results from the Rand cost growth model with the case study results in Chapter 5, it is necessary to consider the cost improvement that would result from the first- to fifth-of-a-kind plant. A 30 percent cost improvement is assumed, which could be expected to result if an effort is made to apply experience gained in the pioneer application to later plants.

The results obtained from the Rand model are highly sensitive to the assumption regarding "project definition." Hess and Myers (1989) point this out in a study prepared by Rand for GRI regarding cost growth in coal-to-SNG plants. The project definition may 
only take discrete integer values, according to the Rand studies. As indicated in Table 28, the difference in results between a project definition of 6 and 7 is on the order of several hundred dollars per kilowatt for the cost of a first-of-a-kind plant. When a project definition of 7 is used, the Rand cost growth model, combined with an assumption of 30 percent cost improvement between the first and fifth plants, yields a cost estimate $\$ 130 / \mathrm{kW}$ to $\$ 170 / \mathrm{kW}$ higher than the mean value from the probabilistic simulation. However, when a project definition of 6 is assumed, the results agree with $\$ 20 / \mathrm{kW}$ for the air-blown system, and with $\$ 80 / \mathrm{kW}$ for the oxygen-blown KRW-based system.

The probabilistic modeling approach and the Rand cost growth model are shown to yield qualitatively similar results. However, because the probabilistic approach is based on a disaggregated analysis of specific risk factors for advanced technologies, it provides a more detailed means to identify the potential sources of cost growth. For example, although the Rand model and assumptions regarding cost improvement may provide similar estimates of the central tendency of capital cost as the probabilistic approach, it does not provide the insight into the risk of extremely high costs for the Lurgi-based system associated with zinc ferrite sorbent performance. Furthermore, the Rand approach does not provide a technology-specific indication of the range of uncertainty associated with the cost estimate. 


\subsection{CONCLUSIONS}

Conclusions specific to the case studies of the advanced clean coal technologies are discussed briefly, followed by some closing remarks with respect to the methodological approach employed in this research.

\subsection{Technology-Specific Conclusions}

An integrated model performance and cost model of the air-blown Lurgi-based IGCC system has permitted the evaluation of interactions involving the gasification, hot gas cleanup, and power generation process areas that affect performance, emissions, and cost. Identification of important interactions provides the basis for determining research priorities, such as evaluating the key input uncertainties that most significantly influence uncertainty in total costs. The explicit characterization of uncertainty in the model provides additional insights that may be overlooked in deterministic analysis, as demonstrated with the gas turbine fuel valve pressure drop analysis.

Probabilistic comparisons of advanced and conventional technologies provides quantitative information about the risk that a new technology may be more expensive, and the potential pay-off of process research. By explicitly considering uncertainties and key process interactions, the probabilistic engineering models can be used to improve research planning and ultimately to assist potential process adopters in decision making.

For the air-blown Lurgi-gasifier based IGCC system with hot gas cleanup, uncertainties in gasifier performance are the most significant factor affecting p!ant efficiency. Thus, to reduce the risks of poor plant efficiency, further research should $f_{i}$ is on ways to reduce the uncertainties specific to the gasification process area. As shown in the case studies, reductions in the uncertainty in specific parameters that affect gasification performance lead to substantial reductions in the risk of low plant efficiency. Furthermore, in addition to reducing the downside risk of low efficiency, further research is likely to increase the mean plant efficiency.

Uncertainty regarding the performance of the zinc ferrite sorbent strongly affects variable operating costs. In particular, uncertainties in sorbent sulfur loading and sorbent makeup requirements interact to yield a low probability of extremely high variable operating costs, which in turn affects the cost of electricity. These results are based on characterizations of uncertainty in model parameters obtained from several technical experts. Nonlinearities in the engineering model, as well as the skewness of the 
uncertainties elicited from the technical experts, lead to skewed uncertainties in key measures of performance and cost. These factors also lead to higher cost outcomes than obtained from deterministic analysis. Additional research on sorbent performance may substantially reduce the risk of very high variable operating costs.

While uncertainties in efficiency and variable operating cost can be traced to specific process areas, interactions among uncertainties in performance and cost parameters in several process areas are nonetheless significant. For example, performance-related uncertainties, such as gasifier coal throughput, contribute substantially to uncertainties in capital, annu, and levelized costs. The case studies illustrate the importance of considering the interactons among uncertainties in performance, capital cost, and operating costs when evaluating uncertainty in the levelized cost of electricity.

Probatilistic analysis can be used to focus only on those input uncertainties which are important. Probabilistic screening studies for both the air-blown Lurgi and oxygenblown KRW IGCC systems indicate that it is often possible to identify both the input uncertainties that most significantly drive uncertainty in a key output, as well as the input uncertainties which are insignificant. For example, in the Lurgi case study, it was possible to eliminate 19 of the original 47 input uncertainties without changing the model results. Thus, probabilistic analysis allows critical evaluation of uncertainties to be focused only where it is most needed.

With sufficiently detailed and integrated performance and cost models, probabilistic analysis of design trade-offs can reveal insights not easily obtained from point-estimate techniques. For example, while decreasing the pressure drop across the gas turbine fuel valve is certain to improve plant efficiency, there is a significant probability that the cost of electricity will also be higher, due to uncertainties regarding the capacity of the gasifier as a function of pressure.

Further research may reduce uncertainties in specific model parameters. For cases in which skewed input cistributions substantially affect model results, reductions in the uncertainty in specific model parameters lead to reductions in the downside risk of the technology and an increase in the expected value for key measures of performance and cost. These outcomes can be used to bound research expenditures, and to identify specific process areas for which research would yield pay-olfs. For example, reductions in uncertainties in performance and cost parameters of three process areas would reduce the mean cost of electricity and decrease the probability of extremely high cost outcomes for the Lurgi sistem. 
The implicatic ns of the judgments of several experts were evaluated. Three experts provided judgments regarding uncertainty in the zinc ferrite process area, and two regarding the Lurgi gasifier process area. The implications of these alternative judgments were used to identify areas where robust conclusions regarding performance and cost could be made, and, conversely, areas where disagreement among the experts exists. The sources of disagreement in the zinc ferrite process area include sorbent sulfur loading capacity and sorbent replacement requirements. Substantial disagreement was found between the two Lurgi gasifier experts, based primarily on differing judgments regarding the gasifier air/coal ratio. These specific parameters should be the focus of further elicitations.

For the oxygen-blown KRW-based system with cold gas cleanup, the major source of performance-related uncertainty is carbon conversion in the gasifier. While hot gas cleanup systems are often viewed as a major source of performance and cost risk, uncertainties in the gasification process area for both the oxygen-blown KRW and airblown Lurgi systems were important contributors to uncertainty in overall process performance and cost.

Correlation structures among input uncertainties for individual process technologies were not found to be important in the case studies evaluated here. However, when comparing two technologies or alternatives for a given technology, correlations between them due to uncertainties which are common to both may be important. Thus, probabilistic estimates of differences between alternatives must be based on proper pairing of samples from the probabilistic simulations.

Overall, the Lurgi-based IGCC system looks promising compared to the conventional system featuring cold gas cleanup. In the coinparative analysis of the advanced and conventional IGCC systems, the simplified Lurgi-based system was found to almost certainly have lower capital costs than the conventional tecinnology. The Lurgibased system is likely to have higher efficiency than the oxygen-blown KRW system, but it will tend to have higher variable operating costs attributable to the zinc ferrite process area. The Lurgi system may incur high zinc ferrite sorbent replacement costs associated with potentially poor sorbent performance, in interaction with other process uncertainties. However, reducing uncertainties in specific parameters in the gasifier and zinc ferrite process areas will substantially reduce the downside risks and increase the expected payoffs, even if the conventional systcm also improves. Thus, the modeling results indicate that risks of lower efficiency and higher variable operating costs can be isolated to a few 
specific model input parameters. These specific input uncertainties can then become the focus for further research.

With respect to environmental performance, the Lurgi-based system with a conventional gas turbine combustor suffers from high fuel $\mathrm{NO}_{\mathrm{x}}$ emissions, but offers significantly lower $\mathrm{SO}_{2}$ emissions than the conventional system with cold gas cleanup. Alternative $\mathrm{NO}_{\mathrm{x}}$ control strategies, such as rich/lean combustion or post-combustion exhaust gas cleanup would likely be required for the air-blown system.

Other process flowsheet designs may lead to differing conclusions. For example, there are several other advanced IGCC concepts which have been of research interest to DOE and others. Ongoing work by General Electric is focused on the development of a moving bed zinc ferrite process, which is believed to have lower capital cost than the fixed bed process examined here. In addition, other types of gasifiers, such as the KRW gasifier, may be employed in systems with hot gas cleanup. Hot gas cleanup may include a combination of gasifier in-bed desulfurization as well as external fuel gas desulfurization. These alternative flowsheets were not evaluated as part of this study. However, the probabilistic modeling approach can be applied to evaluate these systems as well to yield quantitative measures of the potential risks and pay-offs of these concepts.

\subsection{Methodological Conclusions}

Significant uncertainties inevitably surround advanced environmental control technologies in the early stages of development. Thus, engineering performance and cost models developed to evaluate process viability must be capable of adequately analyzing and displaying the consequences of these uncertainties. Toward this end, the probabilistic modeling approach described here allows the effect of uncertainties in multiple performance and cost parameters to be evaluated explicitly and systematically. The results give a measure of overall uncertainty in key model outputs, such as cost, and serve to identify the key process variables that contribute most to overall uncertainty.

A detailed approach to the elicitation of expert judgments was employed for the IGCC system case studies. The results of the elicitations indicate that process engineers are able to make detailed judgments regarding both the range and likelihood of outcomes for specific parameters. They also were able to provide detailed explanations for the basis of the judgments. In many cases, the judgments were skewed, representing the risks often associated with advanced process technologies. 
Using probabilistic modeling techniques, explicit and quantitative characterizations of uncertainty in key measures of plant performance, emissions, and cost may be obtained, based on the judgments regarding model input uncertainties. The probabilistic results indicate the range of possible outcomes, the likelihood of obtaining particular outcomes, the risk of unfavorable outcomes, and the probability of pay-offs associated with favorable outcomes.

The probabilistic approach is shown to be superior to deterministic estimating approaches using contingency factors for estimating process performance and cost. The probabilistic approach is sensitive to the skewness of uncertainties that may exist in key performance and cost parameters. The implications of skewed distributions are not easily captured in deterministic estimates, due to the observed tendency to use most likely or median values, instead of mean values, as the "best guess" inputs to a point-estimate.

Probabilistic analysis is recommended as a replacement to deterministic cost estimating approaches. When explicitly evaluating uncertainties, contingency factors are not needed. Instead, budgetary cost estimates for capital and O\&M costs can be selected based on the acceptable probability of cost overrun.

Using probabilistic modeling techniques, the key uncertainties that drive uncertainty in model output variables can be identified using regression techniques. Also, key groups of uncertain parameters, such as for performance uncertainties in individual process areas, can be identified usin; probabilistic sensitivity analysis. Conversely, unimportant uncertainties can be eliminated from further cor isideration using probabilistic screening analysis. This allows further research or estimating work to be prioritized where reductions in uncertainty would most significantly lead to reduced uncertainty in key measures of performance and cost.

Probabilistic comparisons between convention: and advanced techrology can be used to estimate the likely cost savings and the risks of a new technology. Judgments about the outcome of further process research can be combined with probabilistic modeling to estimate the value of research information to a potential process adopter, and to estimate the risk reduction and cost savings from process improvement. The value of the research, coupled with judgment about the extent and nature of technology diffusion, can be used to bound research expenditures. Whether research is feasible depends also on the costs of the first commercial scale demonstration plant. Becal" ; these costs are potentially large, care must be exercised in the selection of an appropriate first application. 
Decisions regarding research strategies when faced with uncertainties may be quantitatively evaluated using decision models. Such models are used to capture the preferences of a decision maker with respect to risk and the timing of outcomes. Thus, robust research strategies can be identified based on the results of both the engineering and decision models.

When there are multiple experts, the implications of their judgments regarding uncertainties should be evaluated separately. Then, the results may be compared to determine if there are robust conclusions resulting from agreement, or if there are key areas of disagreement that warrant further study. Arbitrarily combining the judgments of multiple experts in a single analysis would mask any differences between them.

The results of probabilistic analysis are shown to be qualitatively similar to those obtained from the use of Rand's cost growth models. However, because probabilistic analysis is based on a disaggregated consideration of technology-specific uncertainties, it may yield different results on an absolute basis than the Rand approach. Furthermore, it allows identification of specific sources of uncertainty. Such insight is not obtained with the Rand model.

The probabilistic modeling approach developed here has been applied to detailed case studies of selected IGCC systems. However, the approach is applicable to the evaluation of any process technology for which characterizations of uncertainty can be obtained.

Probabilistic modeling is shown here to be a versatile tool for technology evaluation, cost estimating, process design, risk assessment, research planning, and technology selection. Of course, as with any other modeling approach, probabilistic methods rely on data and judgments that must be provided by the user. To be sure, different judgments or assumptions can alter the results. But forcing process developers and evaluators to consider uncertainties explicitly (rather th. in ignore them) in probabilistic engineering models can help improve research planning and management by allowing the implications of alternative judgments to be tested. Indeed, the process of thinking about key parameter uncertainties, as inputs to a model, often is the most valuatle component of this approach that fosters improved understanding of the systems being modeled. 


\subsection{REFERENCES}

Ang, A. H.-S., and W.H. Tang (1984). Probability Concepts in Engineering Planning and Design. Volume 2, Decision, Risk and Reliability. John Wiley and Sons. New York.

Banchik, I.N., and A.E. Cover (1988). IGCC Economics Using the KRW Gasifier With Hot Gas Cleanup. Presented at the Fifth Annual International Pittsburgh Coal Conference. Pittsburgh, PA. September 12-16.

Barish, N.N., and S.K. Kaplan (1978). Economic Analysis: For Engineering and Managerial Decision Making. Second Edition. McGraw Hill. New York.

Bechtel (1988a). An Evaluation of Integrated Gasification-Combined-Cycle and Pulverized-Coal-Fired Steam Plants: Volume 1, Base Case Studies, and Volume 2, Sensitivity Studies and Appendices. Prepared by Bechtel Group, inc. for Electric Power Research Institute, Palo Alto, CA. EPRI A P-5950. September.

Bechtel (1988b). Survey of Gasification Combined Cycle Plant Site Requirements. Prepared by Bechtel Group, Inc. for Electric Power Research Institute, Palo Alto, CA. EPRI AP-6027. October.

Bechtel et al. (1988c). A 180-MWe British Gas/Lurgi-Based IGCC Power Plant: Feasibility Study at Virginia Power and Detroit Edison. Prepared by Bechtel Group, Inc., Bricish Gas plc, Virginia Power, Babcock Woodall-Duckham, Ltd, and Lurgi GmbH for Electric Power Research Institute, Inc. Palo Alto, CA. EPRI AP-6011. September 1988.

Bechtel and Westinghouse (1983c). Design of Advanced Fossil Fuel Systems (DAFFS), A Study of Three Developing Technologies for Coal-Fired, Base-Load Electric Power Generation: Integrated Gasification Combined Cycle Power Plant With Westinghouse Gasification Process. Prepared by Bechtel Group, Inc., and Westinghouse Electric Corporation, Synthetic Fuels Division, for the U.S. Department of Energy Argonne National Laboratory. Argonne, Illinois. ANL/FE-83-17. June.

Bechtel et al. (1988). A 180. MWe British Gas/Lurgi-Based IGCC Power Plant: Feasibility Study at Virginia Power and Detroit Edison. Prepared by Bechtel Group, Inc., British Gas plc, Virginia Power, Babcock Woodall-Duckham, Ltd, and Lurgi GmbH for Electric Power Research Institute, Inc. Palo Alto, CA. EPRI AP-6011. September.

BGE (1989). Baltimore Gas and Electric Company's Study of a Shell-Based GCC Power Plant. Prepared by Baltimore Gas and Electric Company for Electric Power Research Institute, Palo Alto, CA. EPRI GS-6283. March.

Buck, J.R., and R.G. Askin (1986). Partial Means in the Economic Risk Analysis of Projects. The Engineering Economist, 31, pp. 189-211.

Carr, R.C. (1986). Integrated Environmental Control in the Electric Utility Industry. Presented at the APCA/ASME/EPRI Third Symposium on Integrated Environmental Controls, Pittsburgh, PA. February.

Cichanowicz, J.E., and G.P. Offen (1987). Applicability of European SCR Experience to U.S. Utility Operation. Presented at the EPA/EPRI 1987 Joint Symposium on Stationary Combustion NOx Control, New Orleans, LA. March 23-26, 1987. 
Cincotta, G.A. (1984). Gas Turbine Systems Research and Development Program. Prepared by the General Electric Company for the U.S. Department of Energy Morgantown Energy Technology Center. Morgantown, WV. DOE/MC/20315-1767. September 1984.

Cincotta, G.A. (1985). Gas Turbine Systems Research and Development Program, Executive Summary. Prepared by the General Electric Company for the U.S. Department of Energy Morgantown Energy Technology Center. Morgantown, WV. DOE/MC/203151767-Exec. Summ. February.

Clemen, R. (1988). Making Hard Decisions: An Introduction to Decision Analysis. University of Oregon.

Cook, C.S., et al (1989). Integrated Operation of a Pressurized Fixed-Bed Gasifier and Hot Gas Desulfurization System. Proceedings of the Ninth Annual Gasification and Gas Stream Cleanup Systems Contractors Review Meeting, Volume 1. U.S. Department of Energy, Morgantown. DOE/METC-89/6107. p. 37-46.

Cool Water (1982). Cool Water Coal Gasification Program: First Annual Progress Report. Prepared by Bechtel Power Corporation, General Electric Company, Southern California Edison Co., and Texaco, Inc. for the Elestric Power Research Institute, Inc. Palo Alto, C'A. EPRI AP-2487. July.

Cool Water (1986). Cool Water Coal Gasification Program: Fourth Annual Progress Report. Prepared by Cool Water Coal Gasification Program, Bechtel Power Corporation, and Radian Corporation for the Electric Power Research Institute, Palo Alto, CA. EPRI AP-4832. October.

Cool Water (1988). Cool Water Coal Gasification Program: Fifth Annual Progress Report. Prepared by Cool Water Coal Gasification Program, Bechtel Power Corporation, and Radian Corporation for the Electric Power Research Institute, Palo Alto, CA. EPRI AP-4832. October.

Corman, J.C. (1986). System Analysis of Simplified IGCC Plants, Topical Report. Prepared by General Electric Company for U.S. Department of Energy, Morgantown Energy' Technology Center, Morgantown, West Virginia. DOE/ET/14928-2233. September.

Craig, K.R. (1988). ASPEN Input File: KRW Fluidized Bed IGCC Power Plant (Hot Gas Cleanup). U.S. Department of Energy Morgantown Energy Technology Center. Morgantown, West Virginia. June 22, 1988.

Damon, J.E., and D.V. Giovanni (1987). Updated Technical and Economic Review of Selective Catalytic Reduction NOx Systems. Presented at the EPA/EPRI 1987 Joint Symposium on Stationary Combustion on NOx Cinllol, New Orleans, LA. March 23-26.

Dawes, R.M. (1988). Rational Choice in An Uncertain World. Harcort Brace Jovanovich. San Diego.

DeGroot, M.H. (1986). Probability and Statistics, Second Edition. Addison-Wesley, Reading, Massachusetts. $607 \mathrm{pp}$. 
Diwekar, U.M., E.S. Rubin, and H.C. Frey (1989). Stochastic Model of Integrated Coal Gasification Combined Cycle Systems Using ASPEN. Proceedings, Sixth Annual International Pittsburgh Coal Conference. University of Pittsburgh.

DOE (1987). America's Clean Coal Commitment. Ofice of Fossil Energy, U.S. Department of Energy. Washington, DC. February.

Edwards, A.L (1984). An Introduction to Linear Regression and Correlation. Second Edition. W.H. Freeman and Company. New York.

EIA (1987). Energy Facts 1986. Energy Information Agency.

EPRI (1986). TAG(tm) - Technical Assessment Guide, Volume 1: Electricity Supply 1986. EPRI P-4463-SR. Electric Power Research Institute, Inc. December.

EPRI (1987a). TAG(tm) - Technical Assessment Guide, Volume 3: Fundamentals and Methods, Supply - 1986. EPRI P-4463-SR. Electric Power Research Institute, Inc. May.

EPRI (1987b). Economics of Phased Gasification Combined Cycle Plants: Utility Results. Electric Power Research Institute, Inc. Palo Alto, CA. EPRI AP-5467. November.

EPRI (1988). Economics of Phased Gasification Combined Cycle Plants: Generic System Results. Prepared by Electric Power Research Institute, Inc., and Zaininger Engineering Company, Inc. for Electric Power Research Institute, Inc. Palo Alto, CA. EPRI AP5467. February.

Epstein, M. (1990). "Commercial Size Gasification Projects, Domestic and Foreign," Tenth Annual Gasification and Gas Stream Cleanup Systems Contractors Review Meeting, U.S. Department of Energy, Morgantown, WV, August 28-30, 1990.

Eustis, R.H., M.R. Erbes, and J.N. Phillips (1987). Analysis of the Off-Design Performance and Phased Construction of Integrated Gasification Combined Cycle Power Plants, Volume 1: Results and Conclusions, and Volume 2: Models and Procedures. Prepared by Stanford University for Electric Power Research Institute, Inc. Palo Alto, CA. EPRI AP-5027. February.

Fluor (1983a). Shell-Based Gasification-Combined-Cycle Power Plant Evaluations. Prepared by Fluor Engineers, Inc. for Electric Power Researc's Institute, Palo Alto, CA. EPRI AP-3129. June.

Fluor (1983b). Economic Assessment of the Iinpact of Plant Size on Coal Gasification Combined Cycle Plants. Prepared by Fluor Engineers, Inc. for Electric Power Research Institute. Palo Alto, CA. EPRI AP-3084. May.

Fluor (1984). Cost and Performance for Commercial Applications of Texaco-Based Gasification-Combined-Cycle Plants: Volume 1, Summary and Discussion of Results, and Volume 2, Design Details. Prepared by Fluor Engineers, Inc. for Electric Power Research Institute, Palo Alto, CA. EPRI AP-3486. April.

Fluor (1985). Cost and Performance of Kellogg Rust Westinghouse-based GasificationCombined-Cycle Plants. Prepared by Fluor Engineers, Inc. for Electric Power Research Institute, Palo Alto, CA. EPRI AP-4018. June. 
Fluor (1986a). Gasification Combined Cycle Plant: Part-Load Performance. Prepared by Fluor Engineers, Inc. for Electric Power Research Institute, Palo Alto, CA. EPRI AP4653. July.

Fluor (1986b). Screening Evaluation of Advanced Power Cycles. Prepared by Fluor Engineers, Inc. for Electric Power Research Institute, Palo Alto, CA. EPRI AP-4826. November.

Fluor (1986c). Planning Data Book for Gasification Combined Cycle Plants: Phased Capacity Additions. Prepared by Fluor Engineers, Inc. for Electric Power Research Institute. Palo Alto, CA. EPRI AP-4395. January.

Fluor Daniel (1988). Evaluation of a Texaco Gasification Combined Cycle Plant with Kraftwerk Union Gas Turbines. Prepared by Fluor Daniel, Inc. for Electric Power Research Institute, Inc. Palo Alto, CA. EPRI GS-6160. December.

Fluor Daniel (1989). Evaluation of a Dow-Based Gasification Combined Cycle Plant Using Low-Rank Coals. Prepared by Fluor Daniel, Inc. for Electric Power Research Institute, Inc. Palo Alto, CA. EPRI GS-6318. April.

FPL (1989). Florida Power and Light Company's Study of Shell-Based GCC Power Plants. Prepared by Florida Power and Light Company for Electric Power Research Institute, Inc. Palo Alto, CA. EPRI GS-6176. January.

Frey, H.C., and E.S. Rubin (1990). Stochastic Modeling of Coal Gasification Combined Cycle Systems: Cost Models for Selected Integrated Gasification Combined Cycle (IGCC) Systems, Task 2 Topical Report. Prepared by Carnegie-Mellon University for U.S. Department of Energy, Morgantown, West Virginia. Report DOE/MC/24248-2901 (NTIS No. DE90015345). June.

GAO (1989). Commercializing Clean Coal Technologies. U.S. General Accounting Office. Report No. GAO/RCED-89-80. March.

GAO (1990). Pace and Focus of the Clean Coal Technology Program Need to Be Assessed. U.S. General Accounting Office. GAO/RCED-90-67. March.

Gallaspy, D.T., T.W. Johnson, and R.E. Sears (1990). Southern Company Services' Study of a KRW-Based GCC Power Plant. Prepared by Southern Company Services for the Electric Power Research Institute, Palo Alto, CA. EPRI GS-6876.

Gangwal, S.K., S.M. Harkins, and M.C. Woods (1987). Disposal of Off-Gases from Hot Gas Desulfurization Processes, Yearly Technical Status Report. Prepared by Research Triangle Institute for the U.S. Department of Energy Morgantown Energy Technology Center. Morgantown, WV. DOE/MC/23260-2553. October.

Ghate, M., and J. Longanbach, eds. Coal Gasification: Technology Status Report. U.S. Department of Energy Morgantown Energy Technology Center. Morgantown, WV.

DOE/METC-88/0262. January 1988.

GRI (1983). Guidelines for Evaluation of Commercial Fossil Fuels Gasification Concepts. Gas Research Institute. Chicago, Illinois. GRI-83/0003. March 1983. 
Hackworth, J.H. and A.N. Mann (1988). Cost Estimating Manual for Coal Utilization Process Alternatives. Prepared by KOH Systems, Inc. for U.S. Department of Energy, Morgantown Energy Technology Center, Morgantown, West Virginia. Contract No. DEAC21-85MC22012. December.

Hager, R.L., and D.L. Heaven (1990). Evaluation of a Dow-Based GasificationCombined-Cycle Plant Using Bituminous Coal. Prepared by Fluor Daniel for the Electric Power Research Institute. Palo Alto, CA. EPRI GS-6904.

Haldipur, G.B., K.J. Smith, S. Datta, and P. Cherish (1988). Fluidized Bed Coal Gasification with Hot Gas Cleanup. Proceedings of the Eighth Annual Gasification and Gas Stream Cleanup Systems Contractors Review Meeting, Volume I. V.P. Kothari and J.R. Longanbach, Eds. U.S. Dupartment of Energy Morgantown Energy Technology Center. Morgantown, WV. DOE/METC-88/6092. May 1988.

Hall , R.S., J. Matley, and K. McNaughton (1982). Current Costs of Process Equipment. Chemical Engineering, April 5, 1982.

Hall, R.S., W.M. Vatavuk, and J. Matley (1988). Estimating Process Equipment Costs. Chemical Engineering, November 21, 1988. pp. 66-75.

Henrion, M. (1982). The Value of Knowing How Little You Know: The Advantages of a Probabilistic Treatment of Uncertainty in Policy Analysis. Ph.D. Thesis, School of Urban and Public Affairs, Carnegie-Mellon University, Pittsburgh, PA. March.

Henrion, M., and N. Wishbow (1987). Demos User's Manual: Version 3. Department of Engineering and Public Policy, Carnegie-Mellon University, Pittsburgh, Pa.

Hess, R.W., E.W. Merrow, and R.Y. Pei (1987). An Application of the Pioneer Plants Study Methodology to a First-of-a-Kind MHD Central Station. Prepared by the Rand Corporation for the U.S. Department of Energy. Santa Monica, CA. Rand Publication No. N-2368-DOE. June.

Hess., R.W. (1985) Potential Production Cost Benefit of Constructing and Operating First-of-a-Kind Synthetic Fuel Plants. Prepared by the Rand Corporation for the U.S. Synthetic Fuels Corporation. Santa Monica, CA. Rand Publication No. N-2274-SFC. March.

Hess, R.W., and C.W. Myers (1989). Assessing Initial Cost Growth and Subsequent Long-Term Cost Improvement in Coal-to-SNG Processes. Prepared by RAND Corporation for the Gas Research Institute. Santa Monica, CA. GRI Publication GRI89/0129. June.

Holt, N.A., E.Clark, and A. Col's (1989). "NO Control in Coal Gasification Combined Cycle Systems." In 1989 Symposium on Stationary Combustion Nitrogen Oxide Control, Volume 1. Electric Power Research Institute. GS-6423. July 1989. p. 5A-17 to 5A-28.

IEA (1987). Clean Coal Technology: Programmes and Issues. International Energy Agency, Organization for Economic Cooperation and Development. Paris.

Iman, R.L., and M.J. Shortencarier (1984). A Fortran 77 Program and User's Guide for the Generation of Latin Hypercube and Random Samples for Use With Computer Models. Sandia National Laboratories. Albuquerque, NM. Report No. SAND83-2365. March. 
Iman, R.L., J.D. Da renport, E.L. Frost, and M.J. Shortencarier (1980). Stepwise Regression With PRESS and Rank Regression: Program User's Guide. Sandia National Laboratories. Albuquerque, NM. Report No. SAND79-1472. Januar'.

Iman, R.L., M.J. Shortencarier, and J.D. Johnson (1985). A Fortran 77 Program and User's Guide for the Calculation of Partial Correlation and Standardized Regression Coefficients. Sandia National Laboratories. Albuquerque, NM. Report No. SAND850044. June.

Kasper, S. (1988). Design Basis for Zinc Ferrite Hot Gas Desulfurization Systems. In: Proceedings of the Eight Annual Gasification and Gas Stream Cleanup Systems Contractors Review Meeting, Volume 1. V.P. Kothari and J.R. Longanbach, Eds. U.S. Department of Energy, Morgantown Energy Technology Center, Morgantown, West Virginia. May.

Klara, J.M., A. Rastogi, and K.R. Craig (1988). ASPEN Input File: Fixed-Bed (Gasification) With No In-Bed Sulfur Capture and Moving Bed Zinc Ferrite (Process). U.S. Department of Energy Morgantown Energy Technology Center. Morgantown, West Virginia. 1988.

Klett, M.G., et al. (1986). Conceptual Designs of Advanced High-Temperature Desulfurization Processes: Vo1ume II, Integrated Gasification Combined Cycle, Final Report. Prepared by Gilbert/Commonwealth for U.S. Department of Energy, Morgantown Energy Technology Center, Morgantown, West Virginia. DOE/MC/21098-2248, Vol. 2. December.

KRW (1988). Fluidized Bed Coal Gasification With Hot Gas Cleanup. In: Proceedings of the Eight Annual Gasification and Gas Stream Cleanup Systems Contractors Review Meeting, Volume 1. V.P. Kothari and J.R. Longanbach, Eds. U.S. Department of Energy, Morgantown Energy Technology Center, Morgantown, West Virginia. May.

Lee, B (1991). "Highlights of the Clean Air Act Amendments of 1990," Journal of the Air and Waste Management Association, 41(1), 16-19.

Leone, M. (1990). "Cleaning the Air the Market-Based Way," Power, 134(12), December 1990, p. 9-10.

Makansi, J. (1988). Subsidies to Ensure Coal Option Under Future Control Scenarios. Power Magazine. December.

Manderson, M.C., and C.D. Cooper (1982). Sulfur Supply and Demand and Its Relationship to New Energy Sources. In: Sulfur: New Sources and Uses. M.E.D. Raymont, ed. American Chemical Society Symposium Series. Washington, D.C.

Merrow, E.W. (1986). A Quantitative Assessment of R\&D Requirements for Solids Processing Technology. Prepared by the Rand Corporation for the U.S. Department of Energy and the Private Sector Sponsors Prograr.. Santa Monica, CA. Rand Publication No. R-3216-DOE/PSSP. July.

Merrow, E.W., K.E. Phillips, and C.W. Myers (1981). Understanding Cost Growth and Performance Shortfalls in Pioneer Process Plants. Prepared by the Rand Corporation for the U.S. Department of Energy. Santa Monica, CA. Rand Publication No. R-2569-DOE. September. 
METC (1987). Gas Stream Cleanup: Technology Status Report. Morgantown Energy Technology Center, U.S. Department of Energy. Morgantown, WV. DOE/METC$87 / 0255$. October.

METC (1986). Hot Gas Cleanup for Electric Power Generating Systems. Morgantown Energy Technology Center, U.S. Department of Energy. Morgantown, WV. DOE/METC-86/6038. May.

METC (1986). Physical Gas Stream Cleanup: Technology Status Report. Morgantown Energy Technology Center, U.S. Department of Energy. Morgantown, WV. DOE/METC-86/0243. April.

Milanese, J.J. (1987). Process Industry Contingency Estimation: A Study of the Ability to Account for Unforeseen Costs. Prepared by the Rand Corporation for the Private Sector Sponsors Program. Rand Publication No. N-2386-PSSP. June.

MIT (1987). ASPEN User Manual, Volumes 1 and 2. Prepared by Massachusetts Institute of Technology for U.S. Department of Energy, Morgantown Energy Technology Center, Morgantown, West Virginia. May 1982, Revised 1987.

Moore, W.T., and S-N Chen (1984). The Value of Perfect Information in Capital Budgeting Decisions with Unknown Cash Flow Parameters. The Engineering Economist, 29, pp. 41-51.

Morgan, M.G., and M. Henrion (1990). Uncertainty: A Guide to Dealing with Uncertainty in Quantitative Risk and Policy Analysis. Cambridge University Press. New York.

Myers, C.W., and R.F. Shangraw (1986). Understanding Process Plant Schedule Slippage and Startup Costs. Prepared by the Rand Corporation for the Pitvate Sertor Sponsors Program. Rand Publication No. R/3215-PSSP. June.

NUSCo (1988). Devon Station Repowering Study: Phase 2. Conceptual Design of a Coal Gasification Facility. Prepared by Northeast Utilities Service Company for Electric Power Research Institute, Inc. Palo Alto, CA. EPRI GS-6161. December.

O'Hara, J.B., T.K. Chow, and J.E. Findley (1987). Sulfur Recovery from Hot Coal Gas Desulfurization Processes, Final Report. Prepared by Ralph M. Parsons Company for U.S. Department of Energy, Morgantown Energy Technology Center, Morgantown, West Virginia. DOE/MC/21097-2338. April.

Parsons (1985). Evaluation of the British Gas Corporation/Lurgi Slagging Gasifier in Gasification-Combined-Cycle Power Generation. Prepared by Ralph M. Parsons Company, British Gas Corporation, and Lurgi, GMBH for Electric Power Research Institute, Palo Alto, CA. EPRI AP-3980. March.

Peters, M.A., and K.n. Timmerhaus (1980). Plant Design and Economics for Chemical Engineers. Third Edition. McCraw-Hill, New York.

Pikulik, A., and H.E. Diaz (1977). Cost Estimating for Major Process Equipment. Chemical Engineering. October. 106-122. 
Rubin, E.S., and H.C. Frey (1988). Stochastic Modeling of Coal Gasification Combined Cycle Systems, Progress Report. Prepared by Carnegie-Mellon University for U.S. Department of Energy, Morgantown, West Virginia. October.

Rubin, E.S., and U.M. Diwekar (1989). Stochastic Modeling of Coal Gasification Combined Cycle Systems, Task 1 Topical Report. Prepared by Carnegie-Mellon University for U.S. Department of Energy, Morgantown, West Virginia. Report DOE/MC/24248-2900 (NTIS No. DE90015580). November.

Schwint, K.J. (1985). Great Plains ASPEN Model Development: Evaluation and Enhancment of the ASPEN Cost Estimating System, Final Topical Report. Prepared by Scientific Design Company for U.S. Department of Energy, Morgantown Energy Technology Center, Morgantown, West Virginia. DOE/MC/19163-05. January.

Schwint, K.J. (1986). ASPEN Costing Manual, Topical Report. Prepared by Scientific Design Company for U.S. Department of Energy, Morgantown Energy Technology Center, Morgantown, West Virginia. DOE/MC/21377-2154. July 25.

Scheffel, F.A., and F.D. Skinner (1988). An Engineering Evaluation of Environmental Data From the KRW Coal Gasification Process Development Unit. Topical Report.

Prepared by Radian Corporation for the U.S. Department of Energy Morgantown Energy Technology Center. Morgantown, WV. DOE/MC/21046-2594. January.

SFA Pacific (1987). Process Screening Study of Alternative Gas Treating and Sulfur Removal Systems for IGCC Power Plant Applications. Prepared by SFA Pacific, Inc. for Electric Power Research Institute. Palo Alto, CA. EPRI AP-5505. December.

Shinnar, R (1988). Novel Concepts of System Assessment in Coal Gasification. In: Proceedings of the Eight Annual Gasification and Gas Stream Cleanup Systems Contractors Review Meeting, Volume 1. V.P. Kothari and J.R. Longanbach, Eds. U.S. Department of Energy, Morgantown Energy Technology Center, Miorgantown, West Virginia. May.

Shinnar, R., A.I. Avidan, L. Weng (1988). Evaluation of Fluidized Bed Coal Gasification Present Status and Future Development Problems, Task III. Final Report. Prepared by the City College of the City University of New York for U.S. Department of Energy

Morgantown Energy Technology Center. Morgantown, West Virginia. DOE/MC/212592573. February.

Simbeck, D.R., R.L. Dickenson, and E.D. Oliver (1983). Coal Gasification Systems: A Guide to Status, Applications, and Economice. Prepared by Synthetic Fuels Associates for the Electric Power Research Instutite, Palo Alio, CA. AP-3109. June.

Smelser, S.C. (1986a). Design and Economics of a Lignite-to-SNG Facility Using Lurgi Gasifiers With In-Line Conversion of By-Product Liquids to Methane. Prepared by Fluor Technology, Inc. for Gas Research Institute. Chicago, Ill. GRI-87/0159. November 1986.

Smelser, S.C. (1986b). Design and Economics of a Lignite-to-SNG Facility Using Lurgi Gasifiers For Lignite Gasification With KRW Gasifiers for Gasification of Coal Fines. Prepared by Fluor Technology, Inc. for Gas Research Institute. Chicago, Ill. GRI87/0156. January 1986. 
Smith, D.P., E. Gal, C. Cook, A. Furman (1987). "Design Studies for Hot Gas Cleanup System in a Load Following Mcde", in Proceedings of the Sevent'n Annual Gasification and Gas Stream Cleanup Systeris Contractors Review Meeting. Volume II. U.S. Department of Energy Morgantown Energy Technology Centei. Morgantown, WV. DOE/METC-87/6079. June 1987.

Smith, J.T., and S.C. Smelser (1987). Designs and Economics of Plants to Convert Eastern Bituminous Coal to Methane Using KRW Gasifiers With and Without In-Bed Desulfurization, Topical Report. Prepared by Fluor Technology, Inc. for Gas Research Institute. Chicago, III. GRI-87/0160. January.

Smock, R.W. (1990), "Need Seen for New Utility Capacity ir the '90s," Power Engineering 94(4), April 1990, p. 29-31.

Stone, K.R. (1988). ASPEN Simulations of Fluidized-Bed and Entrained Flow Integrated Gasification Combined-Cycle Power Plants, Technical Note. U.S. Department of Energy, Morgantown Energy Technology Center, Morgantown, West Virginia. July.

Underkoffler, V.S. (1986). Summary and Assessment of METC Zinc Fernte Hot Coal Gas Desulfurization Test Program, Final Report. Volume I and Volume II, Appendices. Prepared by Gilbert/Commonwealth for the U.S. Department of Energy Morgantown Energy Technology Center. Morgantown, WV. DOE/MC/21098-2247-Vol. 1 and -Vol. 2. December.

Union Carbide (1987). Advanced Air Separation for Coal Gasification Combined Cycle Power Plants. Prepared by Union Carbide Corporation for Electric Power Research Institute, Inc. Palo Alto, CA. EPRI AP-5340. August.

Unnasch, S., R. Chang, and H. Mason (1988;. Study of Ammonia Removal in Coal Gasification Processes Using Integrated Systems Approach. Final Report. Prepared by Acurex Corporation for U.S. Department of Energy Morgantown Energy Technology Center. Morgantown, West Virginia. DOE/MC/23275-2589. March.

UTC (1983). Conceptual Integrated Gasifier Combined Cycle Power Plant Lesign, Final Report. Prepared by United Technologies Corporation for U.S. Department of Energy, Morgantown Energy Technology Center, Morgantown, West Virginia. DOE/FE/150661199. July.

Watson, S.R., and D.M. Buede (1987). Decision Synthesis: The Principles and Practice of Decision Analysis. Cambridge University Press. New York.

WEC (1983). Conceptual IGCC Power Plant Design: Volume I, Final Report for the Period September 16,1981 - December 31, 1982. Prepared by Westinghouse Electric Corporation for U.S. Department of Energy, Morgantown Energy Technology Center, Morgantown, West Virginia. DOE/FE/15067-5(Vol. 1). January.

Wolk, R. and N. Holt (1988). The Environmental Performance of Integrated Gasification Combined Cycle Systems. Presented at the Fourth Symposium on Integrated Environmental Control. Washington, DC. March.

Zahnstecher, L.W. (1984). Coal Gasification Via the Lurgi Process. Volume 1. Production of SNG. Prepared by Foster Wheeler Synfuels Corporation for U.S. Department of Energy Morgantown Energy Technology Center. Morgantown, WV. DOE/FE/05081-2197. September 1984. 
Zaininger (1984). Capacity Factors and Costs of Electricity for Conventional Coal Coal and Gasification Combined Cycle Power Plants. Prepared by Zaininger Engineering Company, Inc. for Electric Power Research Institute, Inc. Palo Alto, CA. EPRI AP3551. June. 


\section{A.0 TECHNICAL BACKGROUND FOR PROCESS-RELATLD UNCERTAINTIES}

This appendix documents the basis for the estimates of uncertainty in model parameters used in case studies of two integrated gasification combined cycle (IGCC) technologies. The estimates of uncertainty were developed for selected performance and cost parameters based on several approaches, depending on the availability of information. These approaches include: (1) review of published information indicating variability or uncertainty in specific parameters; (2) statistical analysis of data, typically as part of regression analysis; (3) elicitation of technical judgments from engineers involved in process development or process evaluation; and (4) judgment by the authors based on discussions with technical experts, published information, data analysis, and engineering judgment. For more detail regarding the philosophy and approach to uncertainty analysis, the reader is referred to Chapters 2 and 4.

The two clean coal technologies for which estimates of uncertainty have been developed are:

1) Oxygen-blown fluidized bed gasifier-based integrated gasification combined cycle (IGCC) system with cold gas cleanup;

2) Air-blown fixed bed gasifier-based IGCC system with hot gas cleanup.

These technologies are discussed in Chapter 3.

The two IGCC systems have several process areas which are common to more than one system. Therefore, rather than describe each IGCC system separately, the approach here is to separately document uncertainties in key process areas. These process areas are gasification (fixed bed and fluidized bed), fixed bed zinc ferrite desulfurization, and gas turbine and are described in Sections A.2, A.3, and A.4, respectively. Other IGCC uncertainties not included in these process areas are described in Section A.5.

For several IGCC process areas, a formal approach to eliciting judgments about uncertainties from technical experts was employed. These process areas included the fixed bed gasifier, zinc ferrite desulfurization, and gas turbine. For each of these process areas, a three part briefing package was developed and provided to each technical expert. The briefing package included: (1) a nine page introduction to uncertainty analysis; (2) a process area technical background paper ranging from 12 to 23 pages and citing 16 to 36 references, depending on the process area; and (3) a detailed questionnaire. Part 1 of the briefing package is gi'en in Appendix A.1. Thะ Part 2 technical background papers for 
each process area are included in this appendix in the respective process area sections. Part 3 of the briefing packets, the questionnaires, for the fixed bed gasifier, zinc ferrite desulturization, and gas turbine process areas are given in within sections A.2, A.3, and A.4, respectively. In the cases where judgments were elicited from process area experts, these judgments are summarized following the questionnaire. The approa $h$ to the expert elicitations is also discussed in Chapter 4 of Volume 1.

References for all information discussed in this appendix are given in Section A.6. 


\section{A.1 Briefing Paper Part 1: Introduction to Uncertainty Analysis}

This appendix includes Part 1 of the three part briefing packet distributed to process area technical experts for the purpose of eliciting their judgments regarding uncertainues in selected IGCC systems. The Part 1 briefing paper begins on the next page. 


\section{BRIEFING PAPER PART 1: Introduction to Uncertainty Analysis}

\section{INTRODUCTION}

Nearly all analyses of energy and environmental control technologies that are still in the research phase involve uncertainties. The most common approach to handling uncertainties is either to ignore them or to use simple "sensitivity" analysis. In sensitivity analysis, the value of one or a few model input parameters are varied, usually from "low": to "high" values, and the effect on a model output parameter is observed. Meanwhile, all other model parameters are held at their "nominal " values. In practical problems with many input variables which may be uncertain, the combinatorial explosion of possible sensitivity scenarios (e.g., one variable "high", another "low," and so on) becomes unmanageable. Furthermore, sensitivity ancilysis provides no insight into the likelihood of obtaining any particular result.

A more robust approach is to represent uncertainties in model parameters using probability distributions. Using probabilistic simulation techniques, simultaneous uncertainties in any number of model input parameters can be propagated through a model to determine their combined effect on model outputs. The result of a probabilistic simulation includes both the possible range of values for modtl output parameters and information about the likelihood of obtaining various results. This provides insights into the risks or potential pay-offs of a new technology. Statistical analysis on the input and output data can be used to identify trends (e.g., key input uncertainties affecting output uncertainties), without need to re-run the analysis. Thus, probabilistic analysis can be used as a research planning tool to identify the uncertainties in a process that matter the most, thereby focusing research efforts where they are most needed. You may have seen probabilistic analysis referred to elsewhere as "range estimating" or "risk assessment."

The development of ranges and probability distributions for model input parameters can be based either on statistical data analysis and/or engineering judgments. The approaches to developing probability distributions for model parameters are similar in may ways to the approach you might take to pick a single "best guess" number for deterministic (point-estimate) analysis or to select a range of values to use in sensitivity analysis.

The purpose of this briefing paper is to serve as a foundation for eliciting probability estimates from selected engineers at DOE/METC to characterize uncertainties in IGCC systems. The particular systems and process areas of interest are described in detail in Part 2 of this packet.

The info:mation on uncertainties will be used in case studies being prepared for METC under contract DE-AC21-88MC24248, "Stochastic Modeling of Coal Gasification Combined Cycle Systems." The contractor has developed cost models for three integrated gasification combined cycle (IGCC) systems. These cost models are directly coupled to ASPEN flowsheet models developed at METC. The contractor alsc has developed a capability within the ASPEN chemical process simulator to represent any flowsheet parameter as a probability distribution. Probabilistic results are obtained using a variant of Monte Carlo simulation.

You have been selected to help provide technical input for the development of probability distributions for performance parameters related to the gas turbine process area. This briefing paper (Part 1), and the accompanying technical description (Part 2), will highlight: 
- Some of the typical problems encountered in making estimates of uncertainty

- Some of the technical issues related to uncertainty in the gas turbine process area

The technical review accompanying this Introduction is intended only as a starting point for your own thinking about uncertainties for this system. In Part 3 of this briefing packet, you are requested to provide some information, such as:

1) A list of the parameters which you think are uncertain (regardless of whether you or someone else can provide estimates of the uncertainties);

2) For those parameters about which you are knowledgeable, the range of possible values that the parameters could have in a commercial-scale fifth-of-a-kind system, based on your understanding of the system as it currently stands;

3) A discussion of the basis for your assessment for each parameter, indicating any technical arguments or considerations.

4) A list of other experts who you think are competent to mak $\star$ judgments about uncertainties for this process, including the ir phone numbers and affiliations, if available.

\section{PHILOSOPHY OF UNCERTAINTY ANALYSIS}

If you have had a course in probability theory, you were probably taught what is termed the "classical" approach. This approach requires that estimates for probability distributions must be based on empirical data. However, in many practical cases, the available data may not be relevant to the problem at hand. For example, test results from a process development unit (PDU) under a given set of conditions may not be directly applicable to estimating the performance of a fifth-of-a-kind commercial scale plant under a different set of operating conditions. Thus, statistical manipulation of data may be an insufficient basis for estimating uncertainty in a real system of interest. Engineering analysis or judgments about the data may be required.

An alternative approach differs in how probability distributions are interpreted. In the so-called "Bayesian" view, the probability of an outcome is your "degree of belief" that the outcome will occur, based on all of the relevant information you currently have about the system. Thus, the probability distribution may be based on empirical data and/or other considerations, such as your own technically-informed judgments or predictions. People with different information may estimate different distributions for the same variable. The assessment of uncertainties requires you to think about all possible outcomes and their likelihoods, not just the "most likely" outcome. This is an advantage for you, because by thinking systematically and critically about uncertainties, you are more likely to anticipate otherwise overlooked problems, or to identify otherwise overlooked potential pay-offs of a system.

\section{TYPES OF UNCERTAIN QUANTITIES}

There are a number of types of uncertainty that you might consider when developing a probability distribution for a variable. Some of these are summarized briefly here.

Statistical error is associated with imperfections in measurement techniques. Statistical analysis of test data is thus one method for developing a representation of uncertainty in a variable.

Empirical measurements also involve systematic error. The mean value of a quantity may not converge to the "true" mean value because of biases in measurement and 
procedures. Such biases may arise from imprecise calibration, faulty reading of meters, and inaccuracies in the assumptions used to infer the actual quantity of interest from the observed readings of other quantities. Estimating the possible magnitude of systematic error may involve an element of engineering judgment. For example, data on sorbent attrition in a PDU may be used to estimate the sorbent attrition in a fifth-of-a-kind commercial-scale system. The conditions in the PDU differ from that in the commercial scale unit; therefore, there may be a systematic error involved in using the PDU data for design purposes.

Variability can be represented as a probability distribution. Some quantities are variable over time. For example, the composition of a coal (or perhaps a sorbent) may vary over time.

Uncertainty may also arise due to lack of actual experience with a process. This type of uncertainty often cannot be treated statistically, because it requires predictions about something that has yet to be built or tested. This type of uncertainty can be represented using technical estimates about the range and likelihood of possible outcomes. These judgments may be based on a theoretical foundation or experience with analogous systems.

\section{ENCODING UNCERTAIN'IIES AS PROBABILITY DISTRIBUTIONS}

As indicated in the provious sections, there are two fundamental approaches for encoding uncertainty in terms of probability distributions. These include statistical estimation techniques and engineering juaigmen:ts. A combination of both methods may be appropriate in many practical situations. For example, a statistical analysis of measured test data may be a starting point for thinking about uncertainties in a hypothetical commercial scale system. You must then consider the effect that systematic errors, variability, or uncertainties about scaling-up the process might have on interpreting test results for commercial scale design applications.

\section{Statistical Techniques}

Statistical estimation techniques involve estimating probability distributions from available data. The fit of data to a particular probability distribution function can be evaluated using various statistical tests. For example, the cumulative probability distribution of a set of data may be plotted on "probability" paper. If the data plot as a straight line, then the distribution is normal. Procedures for fitting probability distribution functions are discussed in many standard texts on probability and are not reviewed here. Rather, the focus of this briefing paper is on the situations where statistical analysis alone may be insufficient, because your own engineering insights may be required to interpret whatever limited data are available.

\section{Judgments about Uncertainties}

In nuaking judgments about a probability distribution for a quantity, there are a number of approaches (heuristics) that people use which psychologists have observed. Some of these can lead to biases in the probability estimate. Three of the most common are briefly summarized. ${ }^{1}$

1 The discussion here is taken from Morgan and Henrion, Uncertainty: A Guide to Dealing with Uncertainty in Quantitative Risk and Policy Analysis, Cambridge University Pressis, in press. 
1) Availability. The probability that experts assign to a particular possible outcome may be linked to the ease (availability) with which they can recall past instances of the outcome. For example, if tests have yielded high sorbent durability, it may be easier to imagine obtaining a high sorbent durability in the future than obtaining lower durabilities. Thus, one tends to expect experts to be biased toward outcomes they have recently observ ed or can easily imagine, as opposed to other possible outcomes that have not been observ $\approx d$ in tests.

2) Representativeness has also been termed the "law of small numbers." People may tend to assume that the behavior they observe in a small set of data must be representative of the behavior of the system, which may not be completely characterized until substantially more data are collected. Thus, one should be cautious in inferring patterns from data with a small number of samples.

3) Anchoring and adjustment involves using a natural starting point as the basis for making adjustments. For example, an expert might choose to start with a "best guess" value, which represunts perhaps an average or most likely (modal) value, and then make adjustments to the best guess to achieve "worst" and "best" outcomes as bounds. The "worst" and "best" outcomes may be intended to represent a 90 percent probability range for the variable. However, the adjustment from the central "best guess" value to the extreme values is often insufficient, with the resuli that the probability distribution is too tight and biased toward the central value. This phenomena is overconfidence, because the expert's judgment reflects less uncertainty in the variable than it should. "The "anchor" can be any value, not just a central value. For example, if an expert begins with a "worst" case value, the encire distribution may be biased toward that value.

Judgments also may be biased for other reasons. One common concern is motivational bias. This bias may occur for reasons such as: a) a person may want to influence a decision to go a certain way; b) the person may perceive that they will be evaluated based on the outcome and might tend to be conservative in their estimates; $c$ ) the person may want to suppress uncertainty that they actually believe is present in order to appear knowledgeable or authoritative; and d) the expert has taken a strong stand in the past and does not want to appear to contradict himselves by producing a distribution that lends credence to alternative views.

\section{Designing an Elicitation Protocol}

From studies of how well calibrated judgments about uncertainty are, it appears that the most frequent problem encountered is overconfidence. Knowledge about how most people make judgments about probability distributions can be used to design a procedure for eliciting these judgments. The appropriate procedure depends on the background of the expert and the quantity for which the judgment is being elicited. For exa:nple, if you have some prior knowledge about the shape of the distribution for the quantity, then it may be appropriate to ask you to think about extreme values of the distribution and then to draw the distribution yourself. On the other hand, if you have little statistical background, it may be more appropriate to ask a you series of questions. For example, you might be asked the probability of obtaining a value less than or equal to some value $\mathrm{x}$, and then the question is repeated for a few other values of $x$. Your judgment can then be graphed by an elicitor, who would revicw the results of the elicitation with you to see if you are comfortable with your answers.

To overcome the typical problem of overconfidence, it is usual to begin by thinking about extreme high or low values before asking about central values of the distribution. In 
general, experts' judgments about uncertainties tend to improve when: (1) the expert is forced to consider how things could turn out differently than expected (e.g., high and low extremes); and (2) the expert is asked to list reasons for obtaining various outcomes.

While the development of expert judgments may be flawed in some respects, it does permit a more robust analysis of uncertainties in a process when limited data are available. Furthermore, in many ways, the assessment of probability distributions is qualitatively no different than selecting single "best guess" values for use in a deterministic estimate. For example, a "best guess" value often represents a judgment about the single most likely value that one expects to obtain. The "best guess" value may be selected after considering several possible values. The types of heuristics and biases discussed above may play a similar role in selecting the value. Thus, even when only a single "best guess" number is used in an analysis, a seasoned engineer usually has at least a "sense" for "how good that number really is." This may be why engineers, more so than scientists, are usually better able to make judgments about uncertainties, because they implicitly make these types of judgments routinely.

\section{Some Types of Probability Distributions}

Examples of several types of probability distributions are shown in Figure 1 as both probability density functions (pdf's) and cumulative distribution functions (cdf's). The pdf is a graphical means of representing the relative likelihood or frequency with which values of a variable may be obtained. The pdf also clearly illustrates whether a probability distribution is symmetric or skewed. In a symmetric unimodal distribution, the mean (average), median (50th percentile), and mode (peak) coincide. In a positively skewed distribution (e.g., lognormal), the mean is greater than the median, and both are greater than the mode.

An alternative way to represent a probability distribution is the cdf. The cdf shows probability fractiles on the $y$-axis and the value of the distribution associated with each fractile on the $\mathrm{x}$-axis. The cdf is a way to represent any probability distribution when there is information about various fractiles of the distribution (e.g., the values of the 5th, 50th and 95 th percentiles).

A brief description of several types of probability distributions and their applications is given here:

- Uniform: Uniform probability of obtaining a value between upper and lower limits. Use when you are willing to specify a finite range of possible values, but are unable to decide which values in the range are more likely to occur than others. The use of the uniform distribution is also a signal that the details about uncertainty in the variable are not known. Useful for screening studies.

- Triangle: Similar to uniform except a mode is also specified. Use when you are willing to specify both a finite range of possible values and a "most likely" (mode) value. The triangle distribution may be symmetric or skewed (as in Figure 1). Like the uniform, this distribution indicates that additional details about uncertainty are not yet known. The triangle distribution is excellent for screening studies and easy to obtain judgments for. 
Figure A-1. Examples of Distributions Used for Probabilistic Analysis. 
- Normal: A symmetric distribution with mean, mode, and median at the same point. Often assumed in statistical analysis as the basis for unbiased measurement errors. The normal distribution has infinite tails; however, over 99 percent of all values of the normal distribution lie within plus or minus three standard deviations of the mean. Thus, when used to represent uncertainty in physical quantities which much be greater than zero, the standard deviation should not be more than about 20 or 30 percent of the mean.

- Lognormal: A positively skewed distribution (it has a long tail to the right). This distribution is usually used to represent uncertainty in physical quantities which must be non-negative and are positively skewed, such as the size of an oil spill or the concentration of a pollutant. This distribution may be used when uncertainties are expressed on a multiplicative order-of-magnitude basis (e.g., factor of 2) or when there is a probability of obtaining extreme large values.

- Loguniform: A uniform distribution in log space (each decade has equal probability, not shown in Figure 1).

- Fractile: The finite range of possible values is divided into sıbintervals. Within each subinterval, the values are sampled uniformly according to a specified frequency for each subinterval. This distribution looks like a histogram and can be used to represent any arbitrary data or judgment about uncertainties in a parameter, when the parameter is continuous. Explicitly shows detail of the judgments about uncertainties.

- Chance: This is like the fractile distribution, except that it applies to discrete, rather than continuous, variables. An example of a discrete variable is the number of trains of equipment, which must be an integer (e.g., 30\% chance of one train, $70 \%$ chance of two).

\section{The Use of Judgments in This Project}

A single probability distribution is not an appropriate means for representing disagreements between two or more experts. In this research, judgments will not be "combined" using weights; instead, the ramifications of alternative judgments on model results will be analyzed by separately running the model with each set of judgments. In some cases, disagreements between experts on a specific variable may have little effect on the results of an analysis. In cases where disagreements yield significantly different results, the analysis should focus on differences in the underlying assumptions. In such a case, the modeling is the means to focus engineering discussion on those parameters which matter the most.

In reporting the results from this research, the contractor will refer to experts only by arbitrarily assigned numbers, rather than by name.

\section{A NONTECHNICAL EXAMPLE}

To illustrate the process of eliciting subjective probability distributions, let's turn to a simple example. How long does it take from the time you enter the METC cafeteria to the time you pay the cashier? Assume that you enter at 12:05 pm on Tuesdays and that you purchase your entire meal at the cafeteria. The answer you give may depend on your recent experiences in the cafeteria. Think about the shortest possible time that it could take (suppose nobody else is getting lunch) or the longest possible time (every METC employee, every contractor simultaneous involved in project review meetings, etc). What is the probability that it will take 2 minutes or less? 45 minutes or less? Is the probability that it takes 10 minutes or less greater than 50 percent? etc. After asking a number of questions such as these, it should be possible to draw a distribution for your judgment 
regarding the time require to obtain and purchase lunch at the caieteria. A hypothetical assessment about the time to obtain lunch is given on the following page to illustrate the procedure for developing uncertainty estimates..

\section{A TECHNICAL EXAMPLE}

A second example focuses on a performance parameter for an advanced pollution control system. This parameter has an important effect on system performance and cost.

\section{Example 1: Probability Assessment of Time to Get Lunch at the METC Cafeteria}

This example is intended to illustrate a possible thought process for someone estimating the time to obtain and pay for lunch at the METC cafeteria. A key element of this example is the development of alternative scenarios for possible outcomes. These scenarios provide a basis for justifying the range of outcomes. The assessor makes a judgment the probability of each scenario. Finally, the the probability distribution is drawn and reviewed for reasonableness.

"First, I will consider the best possible case. No one is in line for food, what I want is already prepared or easily obtained, I have exact change ready, no one is in line at the cashier, and the cafeteria employees and cashier respond promptly. In this case, I think it would take only one minute from the time I enter the cafeteria until the time I pay for lunch. However, the probability of this happening is low, given that it is 12:05 pm on a Tuesday. I think there is only a 1 percent chance that it will take a minute or less.

"Next, I consider the worst possible outcome. Everyone at METC, including visitors, decides to go to the cafeteria. Some of them will turn away when they see the line, so not everyone who goes to the cafeteria will stay to get lunch. Even so, when I enter the cafeteria, there is a line of about 25 people at the food counter. By the time it is my turn to order sod, they have just run out of the entree I want and I have to wait for the next batch (I won't eat that other stuff). After I finally get my food, I go to the soft drink island. The first machine I go to is empty, so I have to go to the other side of the island to use the other drink machine, for which there is a line of about eight people. I look for ice but there is none left. I take my food and drink to the line of fifteen people for the cashier (only one register is open). All I have is a $\$ 20$ and the cashier does not have the correct change. I have to wait while the cashier gets change. It takes 25 minutes or more for me to get lunch. I expect that this or an equivalent scenario can happen 5 percent of the time.

"I think that 50 percent of the time, it will take about 10 minutes or less to get lunch, because there will generally be smaller lines and I usually order something that is already prepared. This is closer to what I usually experience at the cafeteria.

"The probability that it will take 15 minutes or more is about 25 percent. The probability that it will take 5 minutes or less is about 10 percent. From these assessments, I can draw a cumulative distribution function. I assume that the distribution is continuous. 


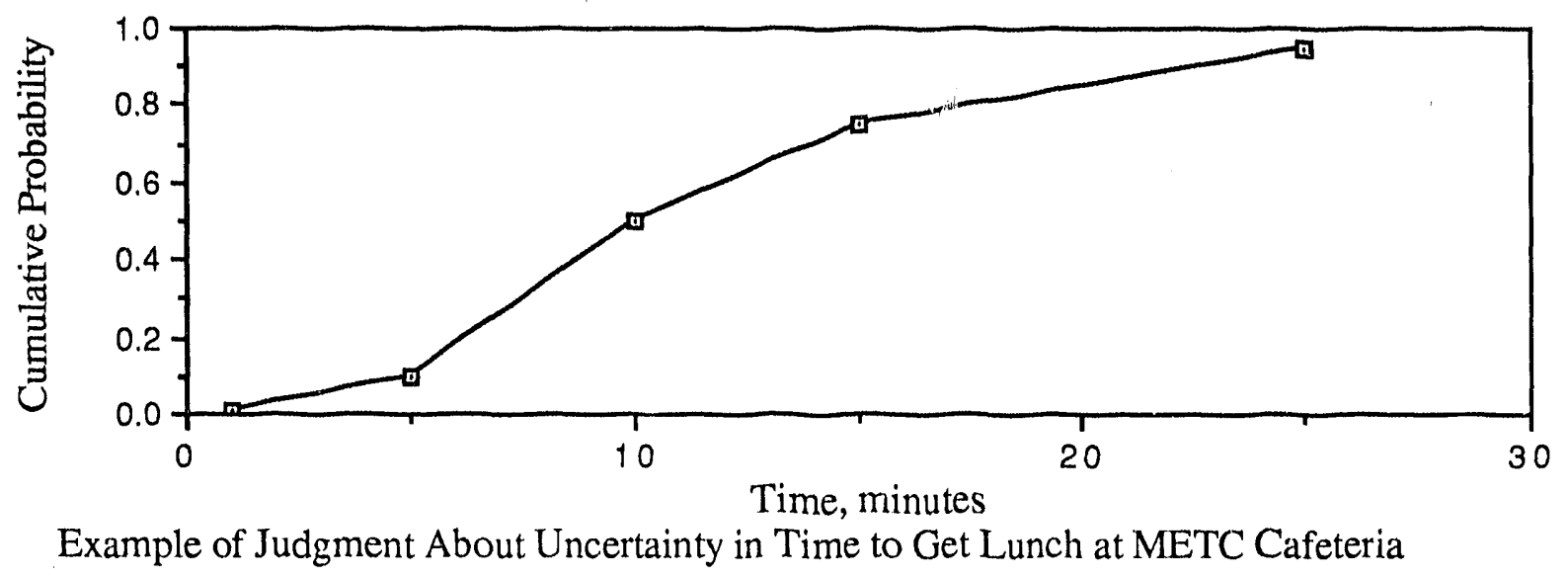

"This is an arbitrary distribution function. It is positively skewed, reflecting my assessment that it can possibly take a long time to get lunch at this time. I am cumfortable that this distribution reflects the range and likelihood of all possible outcomes."

\section{Example 2: Probability Assessment of a Technical Parameter}

This example focuses on an assessment of uncertainty in the performance of an innovative emission control system for coal-fired power plants. In this system, a copper impregnated sorbent circulates between a fluidized bed reactor, where $\mathrm{SO}_{2}$ in the flue gas is removed by chemical reaction with the sorbent, and a regenerator, in which $\mathrm{SO}_{2}$ is evolved in a reaction of the sulfated sorbent with methane. There is no commercial experience with this system; the largest test unit has been sized to handle $100 \mathrm{scfm}$ of flue gas. Furthermore, the test units have used batch, rather than continuous, regeneration. The last complete series of tests was completed in 1987.

One of the key parameters affecting the performance and cost of this system is the regeneration efficiency, which is defined as the fraction of the copper sulfate in the spent sorbent which is converted to elemental copper during regeneration. In small scale tests in which the regeneration efficiency has been estimated, the efficiency was found to be roughly 30 to 50 percent. In a more recent test, the regeneration efficiency was not measured due to instrumentation difficulties; however, it may have been lower than the previously obtained values. Regeneration residence times were typically greater than 30 minutes.

In 1984 a consultant developed a detailed model of the regenerator using ASPEN, and estimated that a properly sized and designed regenerator, coupled with heating of the sorbent to a sufficiently high reaction temperature, would result in a regeneration efficiency of just over 99 percent at a 30 minute residence time.

A potential problem that may be occuring in the test units is that regenerated sorbent in the regenerator may be re-absorbing some of the evolved $\mathrm{SO}_{2}$. However, this was not considered in the 1984 modeling study of the regenerator.

Based on this information, it appears that it may be possible to achieve the design target of over 99 percent regeneration efficiency. Clearly, however, it is possible that the actual efficiency may be substantially less than this target value. As a worst case, we might consider the known test results as a lower bouna. Thus, there is a small chance the regeneration efficiency may be less than 50 percent. We expect the regeneration efficiency 
to tend toward the target value of 99.2 percent. Thus, to represent the expectation that the efficiency will be near the target value, but may be substantially less, we can use a negatively skewed distribution. In this case, we assume a triangle with a range from, say, 50 to 99.2 percent with a mode at 99.2 percent. The triangle in this case gives us a distribution with a mean of about 83 percent and a median of about 85 percent.

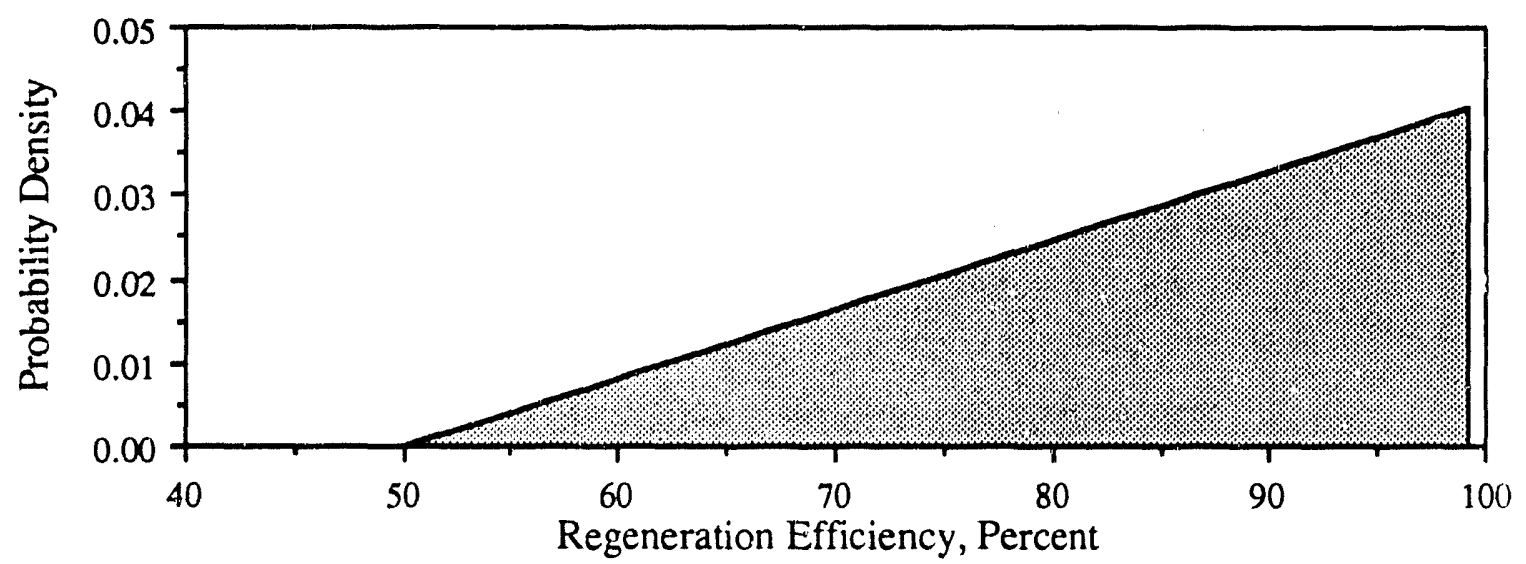

Example Uncertainty Judgment for a Performance Parameter 
This page left blank intentionally. 


\section{A.2 Technical Background and Uncertainty Estimates for the Gasification Process Area}

In this section, the technical background and the basis for characterization of performance related uncertainties for the gasification process areas of two IGCC systems is given. The technical background, uncertainty questionnaire, and summary of elicited technical judgments for the Lurgi gasification process are presented first. For the KRW gasification process area, it was not possible to elicit technical judgments from DOE process engineers. Therefore, characterizations of uncertainty were developed by the authors based on a review of published technical information. The technical background and characterizations of uncertainty for the KRW gasification process area are given in Section A.2.2

\section{A.2.1 Lurgi Gasification Process Area}

For this process area, technical judgments for uncertainties in performance parameters were elicited from two engineers at the U.S. Department of Energy Morgantown Energy Technology Center (DOE/METC). These engineers were provided with a three-part briefing packet, as discussed in Chapter 4. Part One of the briefing packet was an introduction to uncertainty analysis. Part Two was a review of published information about the fixed bed gasifier process area, all of which is included in Sections A.2.1.1 to A.2.1.3. Part Three was a questionnaire to elicit technical judgments about uncertainties, which is included in Section A.2.1.4. The responses of the two experts to the questionnaire are summarized in Section A.2.1.5.

\section{A.2.1.1 Process Description}

The system of interest in this study is a fixed-bed dry-ash Lurgi gasifier as part of a "simplified" IGCC system. This system is shown in Figure A-2 and is based on the design reported by Corman (1986). This technology is discussed in Chapter 3. The gasifier is assumed to operate in air-blown mode using a caking Illinois No. 6 coal with up to 30 percent coal feed as minus $1 / 4$ inch fines. The coal gas from the gasifier passes through a high efficiency cyclone, which captures most of any coal fines entrained in the coal gas. The captured fines are agglomerated and recycled back to the gasifier. The coal gas exiting the cyclone enters a fixed bed zinc ferrite desulfurization system for removal of $\mathrm{H}_{2} \mathrm{~S}$. Regenerated sulfur is recovered as sulfuric acid. The desulfurized coal gas then enters a secondary high efficiency cyclone for removal of entrained sorbent fines and residual particles from the gasifier. The cleaned coal gas is then fed to a gas turbine 


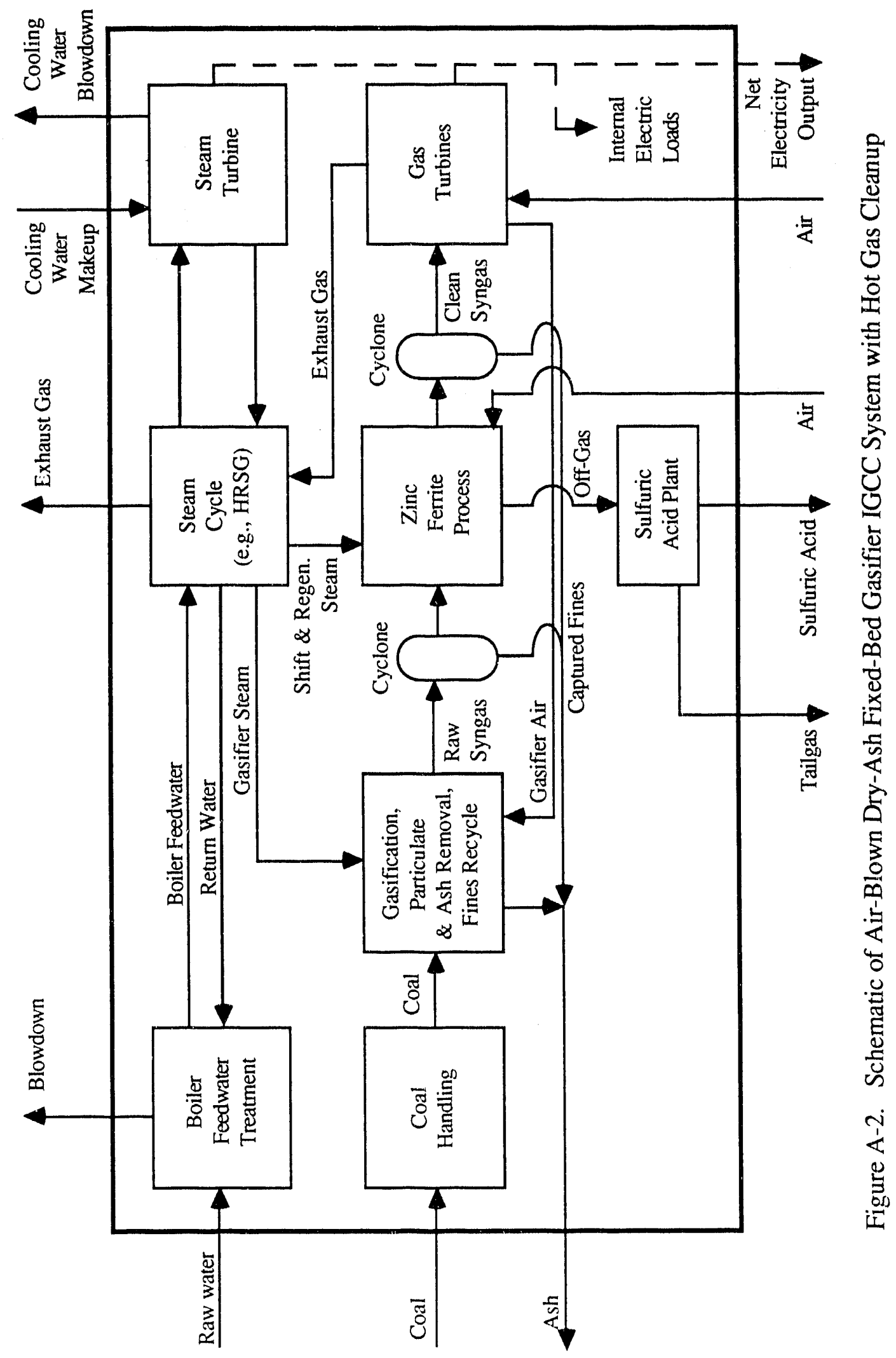


combined cycle system for power generation. Air is extracted from the gas turbine compressor discharge for use in the gasifier. Gasification steam is obtained from the plant steam cycle.

The Lurgi fixed-bed dry-ash gasification process was developed in the early 1930's in Germany. The furst commercial plant was built in 1936. Since then, over 160 Lurgi gasifiers have been built worldwide. Nearly all of these have been oxygen-blown systems operating on lignite or subbituminous coals (Simbeck et al, 1983). Fixed-bed gasifiers have a limited ability to handle coal feed in the form of fines. Lurgi gasifiers have generally been operated with sized coals (i.e. between 2 and $1 / 4$ inches) with no more than about 10 percent of the coal feed as minus $1 / 4$ inch fines. The standard commercial offering for the Lurgi technology is the Mark IV gasifier, which has a working diameter of 12.7 feet (Corman, 1986).

A schematic of the Lurgi gasifier is shown in Figure A-3. Coal from a lockhopper enters the top of the gasifier vessel, where it is distributed onto the fixed bed by a rotating grate. The coal proceeds downward through four zones in the gasifier bed: drying, devolatilizat; $n$, gasification, and combustion. Steam and oxidant (oxy'gen or air) are introduced at he bottom of the gasifier, and flow upward countercurrently to the coal flow. In the top-mosı drying zone, surface and some inherent moisture on the coal is evaporated into the exiting gas stream. The temperature of the exiting raw coal gas is typically 1,000 to 1,100 of for high rank coals and can be as low as 400 to 600 of for high-moisture low rank coals. In the devolatilization zone, volatile matter is released into the exiting gas stream. The volatile matter typically includes tars, oils, phenols and hydrocarbon gases. The devolatilization products exit witn the coal gas. By comparison, in gasifiers with high exit gas temperatures and different bed designs, the devolatilization products would be cracked or reacted with oxygen to form hydrogen, carbon monoxide, or other compounds.

The "cold gas efficiency" of the Lurgi gasifier is approximately 90 percent, if the heating value of hydrocarbon liquids are included. In systems featuring cold gas cleanup, these liquids are condensed out of the fuel gas. In hot gas cleanup systems, these liquids exist in the vapor phase and are contained in the fuel gas delivered to the gas turbine. In the gasification zone, gasification of fixed carbon from the coal with steam and oxidant occurs. The overall gasification reaction is endothermic. Below the gasification zone, combustion oi remainine char occurs. The heat released from combustion is required to supply heat 


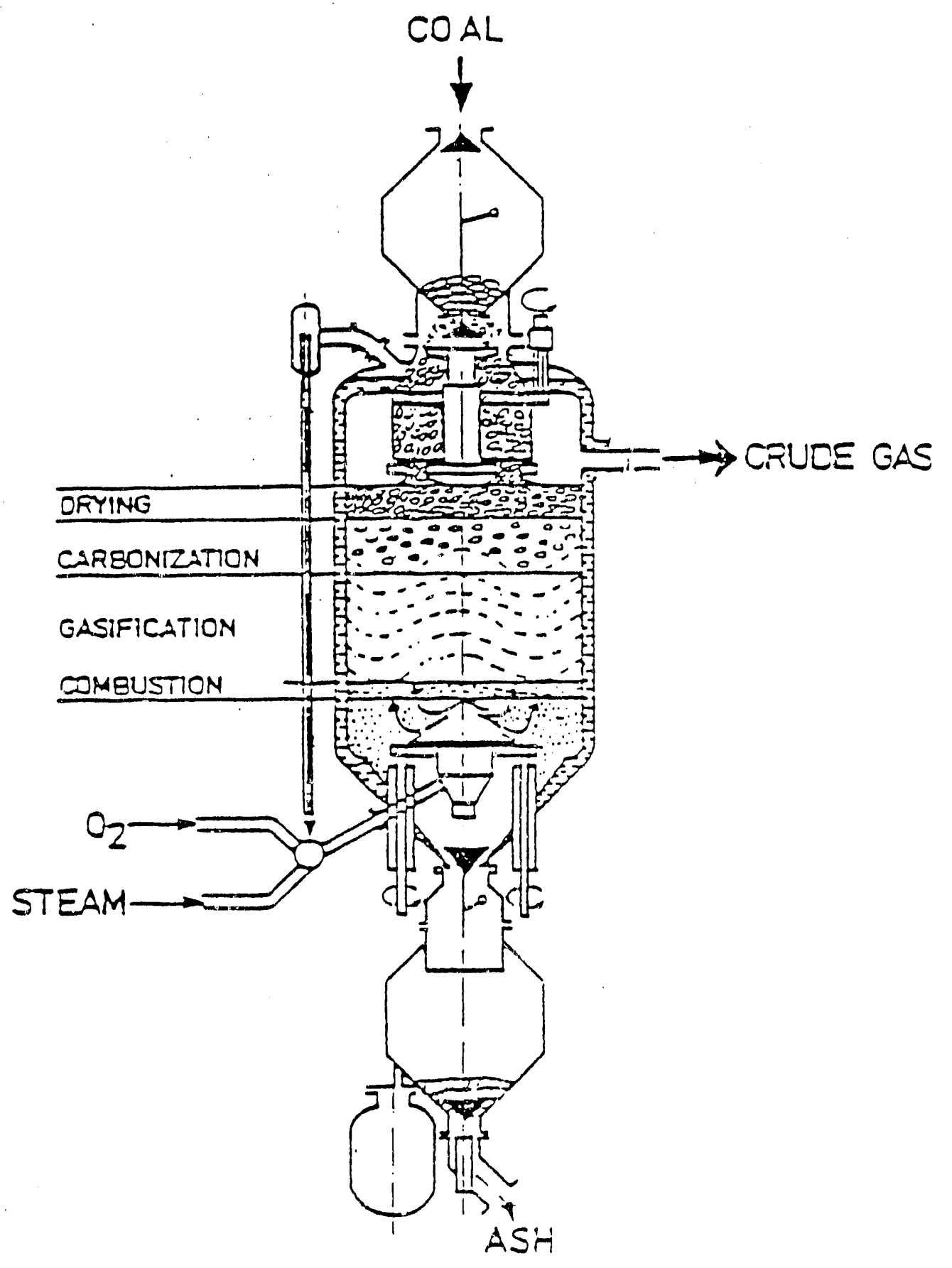

Figure A-3. Diagram of Lurgi Gasifier (Source: Zahnstecher, 1984). 
required for the endothermic gasification reactions and to raise the reactants to gasification temperature. The resulting ash from combustion falls through a rotating grate. The incoming steam and oxidant cool the ash as it leaves the gasifier vessel. The ash is collected at the bottom of the gasifier in a lockhopper.

The gasifier has a high steam requirement to maintain temperatures in the combustion zone below the coal ash fusion temperature and to avoid slagging or the formation of clinkers, which would plug the gasifier. For an Illinois No. 6 coal, the ash fusion temperature is approximately $2,300 \mathrm{oF}$. Steam is used a thermal diluent for the purpose of temperature control. As a result, the total steam requirement to the gasifier exceeds the reactant requirements for coal gasification, and the exiting raw coal gas contains a large fraction of water vapor. For air-blown systems, the steam requirements are less than for oxygen-blown systems due to the increased thermal capacity of the oxidant.

The Lurgi gasifier has a relative low oxidant requirement, due to the excellent heat transfer characteristics of the countercurrent flow of coal and reactants. The excellent heat transfer characteristics presumably reduce the amount of char that must be combusted compared to other gasifier designs to provide heat for the gasification reactions. The reduction in the amount of coal associated with combustion thus reduces the amount of oxygen needed for the combustion reactions.

The advantages of the Lurgi gasifier for simplified IGCC application, compared to other gasifier designs, are (Simbeck et al, 1983; Zahnstecher, 1984; Corman, 1986; Ghate and Longanbach, 1988):

- Stability of operation due to a large bed inventory

- Substantial record of operating experience

- Relatively low oxidant requirements

- High methane yield

- Low gas exit temperature

- High $\mathrm{H}_{2}$ to $\mathrm{CO}$ ratio

- High carbon conversion

- High cold gas efficiency

- Excellent heat transfer within the gasifier

- Good turndown capability and operability

Some of these items are related. For example, high cold gas efficiency implies high carbon conversion. However, the reverse is not true. For example, if the proportion of coal that is combusted is large compared to the amount that is gasified, the carbon conversion would be high, but the resulting gas would have a very low heating value and the cold gas efficiency suld be low. Excellent heat transfer within the gasifier facilitates a high cold 
gas efficiency by reducing the combustion requirements for supplying heat to the gasification zone. The reduced combustion requirement also reduces the amount of oxidant needed, since combustion consumes a larger amount of oxygen than does gasification.

Some potential disadvantages include:

- High steam requirement

- Limited ability to handle coal fines

- Must be modified to handle caking coals

- Long solids residence time results in relatively low capacity

- Product gases contain tars and heavy hydrocarbons

\section{A.2.1.2 Key Design and Performance Assumptions}

The performance and cost case study for this research features air-blown gasification of a caking Illinois No. 6 coal containing up to 30 percent fines (minus $1 / 4$ inch). Table A-1 summarize typical design and performance assumptions used in the current model of this system. These assumptions include coal characteristics, key gasifier operating parameters, and raw coal gas composition. Unlike conventional designs in which the raw coal gas is water-quenched, in the simplified IGCC system concept, the raw coal gas is fed directly to the desulfurization and power trains. In the current ASPEN simulation model of the Lurgi-based IGCC system, the water-gas shift reaction is assumed to reach equilibrium in the zinc ferrite reactor vessel, which increases the $\mathrm{H}_{2} / \mathrm{CO}$ ratio of the fuel gas to the gas turbine compared to the raw coal gas exiting the gasifier.

\section{A.2.1.3 Key Technical Issues}

The key technical issues which may affect the design and performance of a commercial simplified IGCC system include:

- Modifications for caking coal

- Fines loading/fines carryover

- Carbon conversion

- Sulfur remaining in bottom ash

- Gasifier throughput

- Ammonia production

- Gasifier design pressure

- Gasifier steam requirement

- Gasifier oxidant requirement

Each of these issues will be discussed in turn. 
Table A-1. Typical Default Assumptions for the Lurgi-based IGCC System Case Studies ${ }^{a}$

Description Value

Coal Properties

Proximate Analysis, wt-\%, run-of-mine basis

Moisture

12.0

Fixed Carbon

47.8

Volatile Matter

31.4

Ash

8.8

Ultimate Analysis, wt-\%, dry basis

Carbon

69.53

Hydrogen

5.33

Nitrogen

1.25

Chlorine

0.00

Sulfur

3.86

Oxygen

10.03

Ash

10.00

Ash Fusion Temperature, of

2,300

Gasifier Operating Parameters

Pressure, psia

308

Coal Throughput, st/day per gasifier MAF basis

480

Air/Coal Ratio, lb air/lb MAF coal

3.1

Oxygen/Carbon Ratio, lb oxygen/lb cärbon (oxidant feed only)

0.91

Oxygen/Carbon Ratio, lb oxygen/lb carbon (including oxygen in coal)

1.06

Steam/Air Ratio, lb steam/lb air

Steam/Coal Ratio, lb steam/lb MAF coal

0.60

Raw Gas/Coal ratio, $1 b$ raw gas/lb ROM coal

1.8

Inlet Air Temperature, oF

4.77

Inlet Steam Temperature, $\mathrm{oF}$

Fines Carryover, wt- $\%$ of coal feed

Fines Recycle, wt-\% of carryover

618

Fines Carbon Content, wt-\%

Gasifier Bottom Ash Carbon Retention, wt-\% of coal carbon

Gasifier Bottom Ash Sulfur Retention, wt-\% of coal sulfur

Fuel Gas Compositions

Molar Composition, vol-\%

$\mathrm{H}_{2}$

$\mathrm{CO}$

$\mathrm{CH}_{4}$

$\mathrm{CO}_{2}$

$\mathrm{N}_{2}$

$\mathrm{H}_{2} \mathrm{O}$

$\mathrm{H}_{2} \mathrm{~S}$

$\mathrm{NH}_{3}$

Tar

Phenol

Naphtha
Gasifier Exit

12.1

11.0

3.3

8.6

31.4

32.8

0.5

0.2

200 ppmv

400 ppmv

500 ppiñı
Gas Turbine Inlet ${ }^{b}$

17.9

5.1

3.3

14.6

31.4

27.5

10 ppmv

0.2

200 ppmy

$400 \mathrm{ppmv}$

500 ppmv

\footnotetext{
a Based on typical assumptions and results from current ASPEN simulation model.

b Water-gas shift reaction is assumed to be in equilibrium just upstream of zinc ferrite reactor.
} 


\section{A. 2.1.3.1 Caking Coal Operation}

The conventional Lurgi gasifier requires a non-caking sized coal (between $1 / 4$ and 2 inches). Caking coals can cause plugging of the bed due to the formation of agglomerates, which reduces the efficiency of the overall gasification conversion process. Zahnstecher (1984) reported that the conventional Lurgi gasifier is limited to non-caking coals with a free swelling index (FSI) less than 1.0; however, full scale tests using a Mark IV gasifier indicated that bituminous coals with a FSI of 3-4 can be gasified if a water-cooled stirrer is used in the char formation (devolatilization) zone to prevent plugging of the bed. Corman (1986) also reports that commercial tests by Lurgi on both Illinois and Pittsburgh coals with "fixed-position" stirrers (i.e., the vertical location of the stirrer in the gasifier vessel is fixed) indicated feasible operation.

The General Electric Process Evaluation Facility features a fixed-bed gasifier with a vertically-movable stirrer. This gasifier has been operated in air-blown mode with an Illinois No. 6 coal. The 42-inch diameter METC fixed-bed gasifier also features a deep bed stirrer for caking coals (Ghate and Longanbach, 1988). Corman (1986) reports that both GE and METC tests have demonstrated successful operation on bituminous coal with FSI up to 8-1/2 using deep bed stirring. Corman also indicates that little, if any, capacity derate for the Mark IV gasifier is anticipated when operated with an Illinois No. 6 coal with a FSI of 5-6.

For a cold startup, a noncaking coal is required to properly establish the gasification and devolatilization zones within the fixed bed and to limit the caking region to an area accessib' : to the stirrers (Corman, 1986). It is unclear from this statement if fixed-position or vertically-movable stirrers are expected for the Mark IV gasifier. The cost of the stirrer and related components is presumably included in the cost estimate reported by Corman.

\section{A.2.1.3.2 Fines Loading and Carryover}

In the conventional Lurgi gasifier, sized coal is required. Excessive fines in the feed coal will lead to entrainment of fines in the coal gas. As a result, commercial Lurgi gasifiers are typically operated with coal feed containing less than 10 weight percent of minus $1 / 4$ inch coal (Simbeck et al, 1983).

Conceptual designs of conventional Lurgi gasifier systems typically assume that sized coal is delivered to the gasifier. The typical size ranges are $1 / 4$-inch to 2 -inch or $1 / 4$ inch to 4-inch lumps of coal. For example, Zahnstecher (1984) assumes a nominal coal size of $1 / 4$ to 4 inches, with only three percent of the coal feed less than 1/4-inch. Smelser 
(1986a) assumes that lignite coal feed from $1 / 4$ to 2 inches in size is used, and this represents perhaps the most typical coal size assumption (Simbeck et al, 1983).

To accommodate the limitations of the Lurgi gasifier to handle minus $1 / 4$ coal fines, four general approaches for utilizing coal in Lurgi-based plants have been assumed in different studies. These include: (1) separation and return of all or a portion of the fines to the coal supplier (e.g., Cover et al, 1985; Smelser, 1986a and 1986b); (2) separation of sized coal for use in Lurgi gasifiers and fines for use in other types of gasifiers (e.g., KRW) or for combustion in conventional boilers (e.g., Cover et al, 1985; Smelser, 1986a and 1986b); (3) separation of a portion of the fires for injection directly into the gasifier bed via "tuyeres" in the case of the slagging BGC/Lurgi gasifier (e.g., Bechtel, 1983); and (4) agglomeration of separated coal fines into briquettes for feed to the gasifier coal surge bin (e.g., Parsons, 1985; Bechtel et al, 1988).

The assumption in the study by Corman (1986) is that the coal is received as minus 2 -inch size, and that all of the coal, including fines, is fed directly to the gasifier. Only the fines that are captured from the raw coal gas in a primary cyclone are agglomerated into briquettes using bentonite as a binder. The agglomerated fines are then recycled to the coal surge bin.

For a caking Illinois No. 6 coal, General Electric assumed that up to 30 weight percent of the coal feed could be fed as minus $1 / 4$ inch fines. Lurgi indicated that this amount could be handled if the coal is caking and if the minus $1 / 8$ fraction of the material met certain size criteria which are not reported. Lurgi also indicated that the 30 percent fines loading is a maximum for caking coal. Because caking characteristics of bituminous coal tend to suppress fines carryover due to natural agglomeration, it is expected that operation on a non-caking coal would require a reduction in the fines loading to keep fines carryover at reasonable levels (Corman, 1986).

General Electric estimated that the fines carryover for a Lurgi gasifier operating on Illinois No. 6 coal with 30 weight percent feed as minus $1 / 4$ fines would be $2-4$ percent of the coal feed, and that it could be as high as 5 percent. In contrast, if a fully screened coal were used (1/4 to 2 inch) the carryover would be under one percent.

Corman (1986) states that the fines removed by the primary cyclone are expected to contain up to 90 percent carbon as char. However, if there are fines which are entrained prior to drying or devolatilization, such fines would have a carbon content more similar to that of the feed coal. 
General Electric proposes the use of a "high efficiency" cyclone for fines capture. Corman (1986) reports that pilot scale tests of such a cyclone indicated over 98 percent collection of the fines leaving the gasifier. Smith et al (1987) report the same result, based on a 200 hour test using a cyclone designed by GE Environmental Systems, Inc. for operation at $300 \mathrm{psig}$ and $1,200 \mathrm{OF}$.

A General Electric cyclone used in a different application achieved lower removal efficiencies, in the range of 92 to 98 percent. The application was for a KRW gasifier, the carryover of which may have a different particle size distribution than that of the Lurgi gasifier. The performance of this cyclone was below the levels predicted by the manufacturer (Haldipur et al, 1988).

Cincotta (1984) performed a similar evaluation of an IGCC system featuring oxygen-blown slagging BGC/Lurgi gasifiers. This study also assumed the use of a primary cyclone for fines capture. When using $1 / 4$ to 2 inch sized coal, Cincotta estimates a fines carryover equivalent to 0.91 percent of the coal feed, while Lurgi estimated the carryover at 0.5 to 0.8 percent. Cincotta assumed that the carryover contained 90 percent coal fines and 10 percent ash, while Lurgi indicated that the carryover would have about the same composition as the feed coal and partly the composition of char formed from the feed coal.

Any fines not captured or not recycled to the gasifier represents a loss of carbon in the gasification process and affects the gasification efficiency.

\section{A.2.1.3.3 Carbon Conversion}

The carbon conversion in the Lurgi gasifier is typically believed to be around 99 percent. However, the assumptions regarding carbon retention in the gasifier bottom ash are usually not reported in most design studies. Simbeck et al (1983) show a typical mass and energy balance for an oxygen-blown Lurgi gasifier using Illinois No. 6 coal which indicates that 0.64 percent of the carbon in the feed coal is contained in the bottom ash. Zahnstecher (1984) uses a carbon conversion rate of 99.9 percent, implying that 0.1 percent of the carbon is contained in the bottom ash. Smelser (1986a) uses a carbon conversion of 99.45 percent, implying that 0.55 percent of the carbon is retained in the bottom ash. The General Electric design study indicates that about one percent of the coal carbon is retained in the bottom ash (Corman, 1986). The ASPEN simulation model developed at METC of the Lurgi-based IGCC system had a default assumption of 97 percent carbon conversion; however, the basis for this assumption was not documented. 
Also, as mentioned above, unrecycled fines carryover also affects the overall carbon conversion efficiency in the gasifier.

\section{A.2.1.3.4 Bottoli: Ash Sulfur Retention}

The amount of sulfur retained in the bottom ash is often not explicitly stated in design studies. However, it can be inferred if sufficient detail is provided for the gasifier mass balance. Zahnstecher (1984) indicates that about 2.7 percent of the sulfur in a western subbituminous coal is retained in the bottom ash. Cover et al (1985) and Smelser (1986a) indicate that 18.67 percent of the sulfur in the inlet coal is retained in the bottom ash for lignite coal. Simbeck et al (1983) do not provide sufficient detail in the mass balance to fully account for the fate of the sulfur in the Illinois No. 6 feed coal, but up to about 4.4 percent may be retained in the ash or contained in the tars and oils exiting with the raw coal gas.

\section{A.2.1.3.5 Gasifier Throughput}

Simbeck et al (1983) report that the standard Lurgi Mark IV gasifiers have a nominal capacity of approximately $650 \mathrm{st} /$ day of MAF coal. This is presumably based on oxygen-blown operation. However, the design pressure for this throughput is not stated. The capacity of the gasifiers in the Zahnstecher (1984) stucy is approximately 620 st/day MAF coal using subbituminous coal in oxygen-blown mode at 465 psia. The Smelser (1986a) study indicates a capacity of about 630 st/day MAF lignite coal in oxygen-blown mode at a pressure of 430 psia.

Corman (1986) reports that Lurgi estimated the coal throughput in air-blown mode for MAF Illinois No. 6 coal to be $300 \mathrm{lb} / \mathrm{hr}^{-\mathrm{ft}^{2}}$ at 20 atmospheres (294 psia) and $500 \mathrm{lb} / \mathrm{hr}$ $\mathrm{ft}^{2}$ at 40 atmospheres (588 psia). This corresponds to throughputs of $460 \mathrm{st} /$ day and 760 st/day, respectively, for a Lurgi Mark IV gasifier with a working diameter of 12.7 feet. Corman commented that, compared to pilot-scale data, these throughputs "appear somewhat optimistic for air-blown operation," but that they were used nonetheless in the design study. These throughput estimates for air-blown operation appear to be about the same as the estimates given above for oxygen-blown operation. For example, if the throughput is linearly interpolated to a level of, say, $430 \mathrm{psia}$, the estimate would be about 640 tons/day, which is slightly more than the throughput used in the Smelser (1986a) study cited above.

\section{A.2.1.3.6 Ammonia Concentration}

One of the key environmental concerns associated with IGCC systems featuring hot gas cleanup up are $\mathrm{NO}_{\mathrm{x}}$ emissions from the gas turbine associated with fuel bound nitrogen in the fuel gas. The most prominent form of fuel-bound nitrogen is ammonia, which is one 
of the products of the gasification process in the Lurgi gasifier. Corman (1986) assumes a fuel gas composition containing 0.2 volume percent ammonia, resulting from the air-blown gasification of Illinois No. 6 coal. Studies featuring oxygen-blown systems typically assume even higher ammonia concentrations. For example, Simbeck et al (1983) show a gas composition from gasification of Illinois No. 6 coal with 0.3 volume percent ammonia. Smelser (1986a) indicates an ammonia concentration of 0.45 volume percent from the oxygen-blown gasification of lignite. Holt et al (1989) indicate that about 50 to 60 percent of coal-bound nitrogen is converted to ammonia in fixed bed gasifiers.

\section{A.2.1.3.7 Gasifier Pressure}

The pressure of the raw gas exiting the gasifier must be large enough to overcome all of the pressure losses between the gasifier exit and the gas turbine combustor. Sources of pressure loss include piping, valving, cyclones, desulfurization vessels, and the gas turbine fuel valve. The pressure in the gas turbine combustor depends on the gas turbine pressure ratio. In this study, the default design strategy is to specify the gasifier pressure as the sum of the gas turbine combustor pressure and the pressure losses between the gasifier outlet and the gas turbine fuel valve.

The typical pressure ratio for the gas turbine most commonly assumed in IGCC design studies is 13.5 , which implies a gas turbine combustor pressure of 198.5 psia. A standard gas turbine fuel valve has a pressure drop of about 70 psi. Additional pressure losses in the piping and equipment between the gasifier outlet and gas turbine fuel valve inlet may total approximately 30 to $60 \mathrm{psi}$ for typical design cases. Thus, a typical gasifier pressure may be about 300 to 330 psia. However, possible advances in gas turbine fuel valve design may lead to significant reductions in the system pressure losses, allowing gasifiers to be designed for pressures of, say, 240 to 275 psia.

The gasifier pressure affects the cost of the gasification vessel and the coal throughput of the vessel. At lower pressures, the cost per vessel would be lower, but the number of vessels requirement to handle a given amount of coal may need to be increased due to a reduction in the gasifier coal throughput. This type of trade-off can be evaluated in the performance and cost model of the Lurgi-based IGCC system if sufficient data are available regarding the effect of gasifier pressure on gasifier coal throughput.

\section{A.2.1.3.8 Gasifier Steam Requirement}

Lurgi supplied General Electric with estimates for the gasifier steam/air ratio and the gasifier coal throughput. Lurgi estimated that 0.4 to $0.5 \mathrm{lb}$ steam/lb air would be required to maintain the gasifier combustion zone temperature below the ash fusion temperature of 
$2,300^{\circ} \mathrm{F}$ for the design coal. General Electric used a higher value of $0.6 \mathrm{lb}$ steam/lb air as a conservative estimate (Corman, 1986).

\section{A.2.1.3.9 Gasifier Oxidant Requirement}

For the air-blown Lurgi gasifier, Corman assumed an air-to-coal ratio of $2.41 \mathrm{lb}$ air/lb coal. The Illinois No. 6 coal has a run-of-mine carbon content of 60.1 weight percent and oxygen content of 7.57 weight percent. Thus, the oxvgen-to-carbon ratio for the oxidant is $0.93 \mathrm{lb}$ oxygen/lb carbon and the overall oxygen-to-carbon ratio, including oxygen in the feed coal, is $1.06 \mathrm{lb}$ oxygen per $\mathrm{lb}$ of carbon. The stoichiometric ratio for combustion is $2.667 \mathrm{lb}$ oxygen/lb carbon.

For comparison, the assumed overall oxygen-to-carbon ratio in a study of an oxygen-blown system featuring lignite coal is 0.76 (Smelser, 1986b), which represents an oxidant oxygen-to-carbon ratio of 0.49 . For a system gasifying subbituminous coal, the assumed oxidant oxygen-to-carbon ratio is 0.42 , with an overall oxygen-to-carbon ratio of 1.07 including oxygen in the coal (Zahnstecher, 1984). Zahnstecher cites the high reactivity of the Western subbituminous coal and good heat transfer characteristics of the Lurgi gasifier as key factors leading to the relatively low oxygen-to-coal ratio for this study.

The lower rank lignite and subbituminous coals typically have higher gasification reactivity than high-rank eastern coals, and therefore can be gasified at lower temperatures (Shinnar et al, 1988). Thus, the amount of heat needed from char combustion is reduced, which in turn reduces demand for oxygen in the combustion zone of the reactor. Thus, we would expect a higher oxygen requirement for the Illinois coal than for the other coal types to support combustion of coal char. From the design studies cited above, it appears that the assumed oxygen-to-carbon ratio associated with the oxidant feed is about a factor of two greater for the Illinois coal than for the lower rank subbituminous and lignite coals. 


\section{A.2.1.4 Questionnaire for the Fixed Bed Gasifier Process Area}

The following is the complete text of the uncertainty questionnaire distributed to process area technical experts to obtain characterizations of uncertainty in key performance and cost parameters.

Here, you are asked to provide technically-informed judgments about probability distributions for parameters of a fixed-bed dry-ash Lurgi gasifier performance and cost model. You are asked to consider the possibilities of potentially poor performance as well as the probability of obtaining favorable performance, based on current information about the system. The preceding sections provide an overview of uncertainty analysis and some of the technical considerations which might be used as the starting point for your own thinking about technical uncertainties. We are interested in the use of the Lurgi gasifier as part of a "simplified" air-blown integrated gasification combined cycle (IGCC) system with hot gas cleanup, as explained in Part 2. In addition, some of the typical modeling assumptions for the Lurgi-based IGCC system are given in Table 1 of Part 2. Some of the key assumptions are repeated here for convenience:

- The gasifier operating pressure depends on system pressure losses and the gas turbine combustor pressure. The gasifier operating pressure is expected to be between about 240 and 330 psia.

- The raw coal gas exiting the gasifier is at $1,100 \mathrm{oF}$.

- Minus 2 inch Inlinois No. 6 coal, up to 30 weight percent as minus $1 / 4$ inch fines.

- Fines carryover is about 4 percent of feed coal flow rate

- About 98 percent (or less) of the fines are captured, agglomerated, and recycled

- The fines contain up to 90 percent carbon

- About 0.5 percent of the carbon in the coal is retained in the bottom ash

- About 3 percent of the sulfur in the coal is retained in the bottom ash

- The gasifier throughput varies with pressure. A simple assumption is to assume it varies linearly between two points given by Corman (1984).

- The ammonia concentration of the coal gas is around 2,000 ppm, which represents approximately 50 percent conversion of coal-bound nitrogen to ammonia

- The gasifier steam requirement is about $0.6 \mathrm{lb}$ steam/lb air.

- The gasifier oxidant requirement is about $3.1 \mathrm{lb}$ air/lb MAF coal, or about $0.93 \mathrm{lb}$ oxygen/lb carbon.

- The gasifier steam inlet temperature is $618^{\circ} \mathrm{F}$

- The gasifier air inlet temperature is $800 \mathrm{oF}$

- The gasifier is a modification of the standard Mark IV model, with 12.7 feet working diameter.

- The gasifier has a deep bed stirrer to prevent agglomeration and plugging of the bed

- About half of the sulfur in the coal is organic, and the other half is pyritic.

We are interested in your technically-based judgments about uncertainties in key performance and cost parameters of the gasifier process area, such as the ones given above. We intend to model the uncertainty in performance and cost associated with a fifth-of-akind, or mature, system. Thus, we are asking you to make predictions about systems that nave not yet been built or operated. We are asking you to express the range of possible outcomes for these systems using probability distributions, as discussed in Part 1. 
Several questions follow. You may respond to the questions on these pages, or use additional paper as needed. See the Introduction (Part 1) for examples of how you might estimate uncertainty in each parameter.

\section{Question \#1. Comments on Default Assumptions}

Do the default assumptions seem reasonable? If not, adjust accordingly and explain the basis for the clianges. Are there additional assumptions that should be specified for these systems? If so, please add these assumptions and explain why they are needed. Use your updated set of assumptions as the basis for answering the following questions.

Question \#2. Uncertain Parameter Identification are desired.

The following is a list of the specific parameters for which uncertainty distributions

- Fines Carryover

- Fines Capture

- Fines Carbon Content

- Carbon Retention in Bottom Ash

- Sulfur Retention in Bottom Ash

- Gasifier Throughput

- Ammonia Yield

- Gasifier Steam Requirement

- Gasifier Oxidant Requirement

- Gasifier Direct Capital Cost

- Gasifier Maintenance Cost

Are you comfortable making estimates of uncertainty for these parameters? If you are not, who do you think should be approached (preferably within METC) to obtain these estimates?

Are there other parameters which you believe also should be treated probabilistically (whether or not you feel comfortable making the judgment yourself) that are not included in the above list? If so, please specify what these parameters are and supply your judgments about them if you are comfortable doing so (see the following questions for examples of the types of judgments we are looking for). If not, who can we ask to estimate uncertainties for these additional parameters?

\section{Question \#3. Fines Carryover}

What is the uncertainty in the long term typical fines carryover over the life cycle of a Lurgi gasifier fed with Illinois No. 6 coal containing up to 30 weight percent minus $1 / 4$ inch fines? Consider the possibility of high carryover due to, say, entrainment of the incoming coal fines in the outgoing raw gas. Also consider the possibility of low fines carryover due to, say, the caking characteristics of the Illinois No. 6 coal. Express the fines carryover as a weight percentage of the coal feed rate to the gasifier.

- Consider the best possible (lowest) fines carryover that could occur. Explain how such a result could be achieved (e.g, agglomeration of fines in the gasifier reduces entrainment of small fines). How likely is it that the fines carryover could be less than this amount?

- Consider the worst possible (highest) fines carryover that could occur. Explain, as above. How likely is it that the fines carryover could be equal to or more than this value? 
- What do you think is the median (or if you prefer, mean) value of the fines carryover (recall that median implies a 50-50 percent chance that the fines carryover could be higher or lower than this value, while mean implies a probability-weighted average of possible outcomes)? Note that the median value does not have to equally divide the best and worst possible values, nor does it have to be the same as the average (mean) rate that you expect. Alternatively, if you want to express your judgment as a triangle distribution, what is the most likely value (mode) that you expect?

- Can you draw a probability distribution to represent your judgment? You may draw the distribution as either a pdf or a cdf. Can the distribution be represented by one of the functions shown in Figure 1? Please be sure to completely specify the range of possible outcomes in your distribution function (i.e. the distribution must consider the 100 percent range of possible outcomes). If your "worst" and "best" cases above bound only 80 or 90 percent of all outcomes, please consider how the range of outcomes is widened when considering 100 percent percent of all possible outcomes. What are the absolute best and worst possible outcomes (0th and 100th percentiles)?

\section{Question \#4. Fines Capture}

What is the uncertainty, if any, in the long term typical life cycle cyclone collection efficiency for fines which carryover from a Lurgi gasifier using Illinois No. 6 coal with up to 30 weight percent as minus $1 / 4$ fines? If your judgment depends on the fines loading entering the cyclone, please pick three representative values of fines carryover (e.g., worst, median or mean, and best) based on your answer to Question 3 and use these values as a basis for answering this question (in such a case, your answer would include three, rather than one, probability distributions).

- Consider the highest possible fines capture efficiency that might occur? What is this rate and how might it be achieved (e.g., it may depend on a certain particle size distribution, or on agglomeration of fines leaving the gasifier, or design features of the cyclone)? How likely is the capture efficiency to be better than the number you have just estimated?

- Consider the lowest possible fines capture efficiency that might occur? What is this rate and how might it be achieved (e.g., very small fines, very high fines loading). How likely would it be to obtain an actual capture efficiency less than this rate?

-What is the median (50-50 percent of getting higher or lower) capture efficiency?

- Can you estimate the 25 th fractile (i.e. there is a one in four chance that the emission rate is less than this number)? What about the 75th fractile (i.e. a one in four chance that the value is higher than this number)?

- Can you draw a probability distribution to represent your judgement? You may draw the distribution as either a pdf or a cdf. Can it be represented by one of the distributions in Figure 1 of Part 1 ?

\section{Question \#5. Fines Carbon Content}

We are interested in your judgment about uncertainty in the composition of the fines carryover from the Lurgi gasifier. What is the uncertainty, if any, in the carbon composition (weight percent) of the fines leaving the gasifier in the raw coal gas?

- Consider the highest possible carbon composition that might occur. What is this composition and how might it occur (e.g., perhaps coal char is entrained into the 
raw gas from the devolatilization or gasification zones of the gasifier). How likely is the carbon composition to be higher than the number you have just estimated?

- Consider the lowest possible fines carbon content that might occur. What is this rate and how might it be achieved (e.g, incoming coal fines are entrained prior to drying, or ash is entrained from the bottom of the gasifier due to, say, channeling). How likely would it be to obtain actual carbon content below this value?

- What is the median (50-50 percent of getting higher or lower) carbon content? If you prefer to specify a particular type of probability distribution model, such as a triangle distribution, then provide appropriate judgments in lieu of the median (e.g., mode or "most likely" value for a triangle distribution).

- If you haven't already specified and defined the parameters of a probability distribution model (e.g., triangle, normal, lognormal), can you estimate the 25 th fractile (i.e. there is a one in four chance that the carbon content is less than this number)? What about the 75 th fractile (i.e. a one in four chance that the value is higher than this number)?

- Can you draw a probability distribution to represent your judgement? You may draw the distribution as either a pdf or a cdf. Can it be represented by one of the distributions in Figure 1 of Part 1?

Question \#6. Carbon Retention in Bottom Ash

Please provide your judgment about the fraction of carbon in the feed coal that will be retained in the gasifier bottom ash. If there are any key (significant) functional dependencies that you expect, such as with respect to the air/coal ratio, feed coal fines loading, coal throughput, or other factors which you may believe to be uncertain or variable over the life of the plant, please appropriately caveat your judgments or, if you wish, provide a set of judgments for each combination of independent variable values that you select (e.g., one uncertainty distribution for each value of air/coal ratio).

Because the set of judgments may involve several probability distributions, we suggest you might want to use a triangular distribution for simplicity, which requires estimates only for the lowest, highest, and most likely conversion rates. However, feel free to use any type of distribution which best represents your judgment.

- What is the worst (highest) bottom ash carbon retention fraction that you would expect for a Lurgi gasifier operating on Illinois No. 6 coal? How might this high bottom ash carbon retention be realized (e.g., relatively low gasification reactivity of high rank coal, inefficient gasification or char combustion due to agglomeration of caking coal)? What do you think is the probability of obtaining a bottom ash carbon retention higher than the value you have specified?

- What is the best (lowest) bottom ash carbon retention fraction that you would expect? How might this best or optimistic value be explained? How likely would it be to measure a carbon retention rate lower than this value?

- What is the most likely bottom ash carbon retention (as a fraction of the feed coal carbon) that you expect. The most likely value is the mode, or "peak", of the probability distribution. Alternatively, if you prefer to express your judgment as a median, please indicate. 
Question \#7. Sulfur Retention in the Bottom Ash

Please provide your judgment about the fraction of sulfur in the feed coal that will be retained in the gasifier bottom ash. If your answer depends on the type of sulfur in the coal (e.g., organic or pyritic), please explain the dependency (see page 1 for assumptions). As a default, we would like you to express your answer as the fraction of total sulfur in the coal that is retained in the bottom ash. However, if you feel it is more appropriate to use another approach (e.g., fraction of pyritic sulfur retained in the bottom ash), please explain.

- What is the worst (highest) bottom ash sulfur retention fraction that you would expect for a Lurgi gasifier operating on Illinois No. 6 coal? How might this high bottom ash sulfur retention be realized? What do you think is the probability of obtaining a bottom ash sulfur retention higher than the value you have specified?

What is the best (lowest) bottom ash sulfur retention fraction that you would expect? How might this best or optimistic value be explained? How likely would it be to measure a sulfur retention rate lower than this value?

- What is the most likely bottom ash sulfur retention that you expect. The most likely value is the mode, or "peak", of the probability distribution. Alternatively, if you prefer to express your judgment as a median, please indicate.

\section{Question \#8. Gasifier Coal Throughput}

Some studies reviewed in Part 2 suggest that the coal throughput for the Lurgi Mark IV gasifier depends on the oxidant (air or oxygen) and the operating pressure. For example, it is suggested that in air-blown mode, the coal throughput at 300 psia is about 456 tons/day on a dry, ash-free basis (Corman, 1986--see Part 2 for more discussion). Is this value optimistic for air-blown operation? How would the coal throughput differ at 250 psia? 350 psia? Can the throughput at intermediate pressures be interpolated? Could you provide a judgment about the dry, ash-free Illinois No. 6 coal throughput in a Mark IV gasifier (12.7 foot working diameter) for each of the following pressures: 250,300 , and 350 psia? For simplicity, you may want to use a triangular distribution to represent your judgments for each case; however, feel free to use whatever distribution best reflects your judgment. Please note the units you are assuming for coal throughput (e.g., tons DAF coal/day, lb DAF coal/ $/ \mathrm{ft}^{2}$ of grate area)

- For each gasifier operating pressure, consider the best (highest) possible coal throughput rate? Can you explain how such values might be obtained?

- What is the worst (lowest) possible coal throughput that you expect for each operating pressure? Why might these outcomes occur?

- What is the most likely coal throughput that you expect for each operating pressure?

\section{Question \#9. Ammonia Yield}

Consider the formation of ammonia in the fixed-bed dry-ash Lurgi gasifier. We are interested in estimating how much ammonia is contained in the coal gas for the purpose of estimating $\mathrm{NO}_{\mathrm{x}}$ emissions from the gas turbine combustor. Please provide your judgment about how much ammonia is generated in the Lurgi gasifier in an air-blown system operating on Illinois No. 6 coal. Please explain the units you are using. For example, you may wish to express ammonia production in terms of a fractional conversion of coal-bound nitrogen to ammonia. Or, alternatively, you may wish to express your judgment in terms of the ammonia volume concentration in the raw coal gas exiting the gasifier. 
- What is the highest amount of ammonia you would expect to be produced in the Lurgi gasifier when operating on Illinois No. 6 coal? How likely would it be to obtained a measurement of a production rate higher than what you have estimated as the "highest amount"?

- What is the least amount $\mathrm{c} f$ ammonia you would expect to be produced? How likely would it be to measure an ammonia production rate less than what you just estimated?

- What is the most likely amount of ammonia that you expect to be produced?

\section{Question \#10. Steam Requirement}

In Part 2, one of the key performance factors that was discussed was the steam requirement for the air-blown dry-ash Lurgi gasifier. The key deterninant of the steam requirement is reported to be the ash characteristics of the coal. Over the lifetime of a fifthof-a-kind plant using Illinois No. 6 coal, what do you think is the uncertainty or variability in the steam requirement? Please explain the units you are using for the steam requirement (e.g., lb steam/lb DAF coal). If your judgment depends on assumptions about the variability in the ash characteristics of the coal over the life of the plant, could you please share your assumptions? Also, if your assumption is tied to a specific air/coal ratio, please indicate. If so, could you provide a set of three judgments based on a low, middle, and high air/coal ratio. (In the next question, you are asked for your judgment about uncertainty or variability in the air/coal ratio as well).

- Over the life of the plant, what is the highest steam requirement that you would expect (i.e. there is a negligible probability of a higher steam requirement)?

- What is the lowest (i.e. little probability that it would be lower) steam requirement that you would expect?

- What is the median (50th percentile) steam requirement that you expect? Alternatively, if you which to express your judgment as a triangular distribution, what is the most likely steam requirement?

- If you are not using a triangular distribution, please indicate the 25 th and 75 th percentiles of the uncertainty or variability in the steam requirement.

\section{Question \#11. Oxidant Requirement}

We are interested in your judgments about uncertainty or variability in the oxidant requirement over the lifetime of a fifth-of-a-kind air-blown Lurgi-based IGCC system operating on Illinois No. 6 coal. Please indicate what units you are using for your judgment (e.g., lb air/lb DAF coial, lb oxygen in the air/lb carbon in the coal). Also, please indicate if you are including coal-bound carbon in your estimate of the gasifier oxygen requirement. Recall that we are modeling an air-blown system.

- Over the life of the plant, what is the highest air requirement that you would expect (i.e. there is a negligible probability of a higher air requirement)?

- What is the lowest (i.e. little probability that it would be lower) air requirement that you would expect?

- What is the median (50th percentile) air requirement that you expect? Alternatively, if you which to express your judgment as a triangular distribution, what is the most likely air requirement? 
- If you are not using a triangular distribution, please indicate the 25 th and 75 th percentiles of the uncertainty or variability in the air requirement.

Question \#12. Direct Capital and Maintenance Costs

The proposed design for the Lurgi gasifier operating on Illinois No. 6 coal includes a deep bed stirrer to avoid plugging of the gasifier bed. This adds to the gasifier direct capital cost. In addition, the potential of high fines carryover may have implications for potentially increased maintenance costs due to, for example, erosion or deposition in the exiting nozzle. The gasifier maintenance cost is typically estimated as a percentage of the gasifier direct capital cost.

- Can you provide a judgment about the percentage increase in gasifier direct capital cost associated with modifications needed to gasifier caking Illinois No. 6 coal with high (up to 30 weight percent) minus $1 / 4$ inch fines loading? Please explain the basis for your estimate (e.g., additional cost of deep bed stirrers, bearings, motor). What is the range of the cost increase (e.g., highest possible, lowest possible, most likely)? How might these values be obtained?

- Can you provide a judgment about the maintenance cost, as a percentage of the capital investment, for the Lurgi gasifier. For example, typical maintenance cost factors might be 4.5 to 6 percent of the plant facilities investment for the gasifiers. What are the highest, lowest, and most likely maintenance cost factors? (Please give units you are assuming). How might this different outcomes be obtained?

Question \#13. Other Experts

Please suggest other experts whom we should contact for judgments about uncertainties in this system. Please supply their names, titles, area of expertise, phone numbers, and addresses.

Question \#14. Feedback

We would like your comments on how easy/difficult it was to develop judgments about uncertainties and on these briefing materials. Is there any other information about uncertainty analysis you would like to see in Part 1? Was the summary of technical information in Part 2 a useful starting point for your thinking about uncertainties for this process? Was it difficult for you to develop estimates of the range or likelihood of various values for variables which you believe to be uncertain? Please discuss these or any other comments you may have.

Thank you for your contribution to this project. 


\section{A.2.1.5 Elicited Technical Judgments About Uncertainties}

Technical judgments regarding the performance of a commercial-scale fifth-of-akind fixed-bed gasifier based on Lurgi technology were elicited from two engineers at DOE/METC. The two experts will be referred to as LG-1 and LG-2. The engineers were asked to explicitly consider the uncertainty involved in making predictions about a system that has not yet been built or operated. The experts were provided with a three-part briefing paper as described in Chapter 4. The first part was a general introduction to uncertainty analysis. The second part was the review of published information given in the preceding text. The third part was a questionnaire which is given in the preceding section.

\section{A. 2.1.5.1 Expert LG-1}

Expert LG-1 responded with detailed distributions for all performance parameters included in the questionnaire, but was unable to answer the two questions regarding capital and maintenance costs. In some cases, a brief rationale for the judgments was given; in other cases, presumably due to time constraints, the expert did not indicate qualitatively a basis for the values in the distributions. However, this expert provided detailed and intricate judgments regarding conditional uncertainties in two cases: one case involved coal gasifier throughput which depends on pressure, and the second involved the steam/coal ratio, which is correlated to the air/coal ratio. The expert indicated that the elicitation process was "not too difficult," and that "some relatively easy calculations were required to provide "good" judgments." The expert also explained that "it helped to be knowledgeable of METC's 42-inch gasifier work/data," referring to an in-house research program at DOE/METC on an experimental fixed bed gasifier.

The judgments from expert LG-1 are summarized in Table A-2. With respect to fines carryover, the expert commented that low fines carryover could result from "improvements to [the coal] feed system," while high fines carryover could be associated with "process upsets and/or coal attrition due to coal feed system." A graphical representation of Expert LG-1's judgment regarding fines carryover, in the form of a probability density function (pdf), is shown in Figure A-4. The figure illustrates that the expert considers fines carryover of 3.5 to 5 percent to be most likely, but that there is a small probability that the carryover could be as high as the total fines inlet to the gasifier, which is 30 weight percent of the coal feed. The expert provided a judgment regarding fines capture, but indicated that he felt least knowledgeable about this particular parameter. This judgment is shown graphically as a pdf in Figure A-5. The judgment indicates a high probability that the fines capture will be 90 percent or greater, with a chance that the capture could go as low as 50 percent. 
Table A-2. Summary of Elicited Lurgi Gasifier Technical Judgments from Expert LG-1

\begin{tabular}{|c|c|c|c|c|c|c|}
\hline \multirow{2}{*}{$\begin{array}{l}\text { Description } \\
\text { Fines Carryover } \\
\text { from Gasifier }\end{array}$} & \multirow{2}{*}{$\begin{array}{l}\text { Units } \\
\text { wt-\% of } \\
\text { Coal Feed }\end{array}$} & \multirow{2}{*}{$\begin{array}{l}\text { Distribution } \\
\text { Fractile }\end{array}$} & \multicolumn{4}{|c|}{ Parameters ${ }^{\mathbf{a}}$} \\
\hline & & & $\begin{array}{r}5 \%: \\
20 \%: \\
25 \%: \\
25 \%: \\
15 \%: \\
5 \%: \\
5 \%:\end{array}$ & $\begin{array}{r}0 \\
1 \\
3.5 \\
5 \\
8 \\
15 \\
20\end{array}$ & $\begin{array}{l}\text { to } \\
\text { to } \\
\text { to } \\
\text { to } \\
\text { to } \\
\text { to } \\
\text { to }\end{array}$ & $\begin{array}{r}1 \\
3.5 \\
5 \\
8 \\
15 \\
20 \\
30\end{array}$ \\
\hline $\begin{array}{l}\text { Fines Capture in } \\
\text { Recycle Cyclone }\end{array}$ & $\begin{array}{l}\% \text { of } \\
\text { Carryover }\end{array}$ & Fractile & $\begin{array}{l}25 \%: \\
25 \%: \\
25 \%: \\
25 \%:\end{array}$ & $\begin{array}{l}50 \\
90 \\
95 \\
97\end{array}$ & $\begin{array}{l}\text { to } \\
\text { to } \\
\text { to } \\
\text { to }\end{array}$ & $\begin{array}{l}90 \\
95 \\
97 \\
98\end{array}$ \\
\hline $\begin{array}{l}\text { Fines Carbon } \\
\text { Content }\end{array}$ & $\begin{array}{l}\text { wt-\% of } \\
\text { fines }\end{array}$ & Fractile & $\begin{array}{r}5 \%: \\
20 \%: \\
25 \%: \\
25 \%: \\
25 \%:\end{array}$ & $\begin{array}{l}65 \\
70 \\
75 \\
79 \\
84\end{array}$ & $\begin{array}{l}\text { to } \\
\text { to } \\
\text { to } \\
\text { to } \\
\text { to }\end{array}$ & $\begin{array}{l}70 \\
75 \\
79 \\
84 \\
87\end{array}$ \\
\hline $\begin{array}{l}\text { Carbon Retention } \\
\text { in Bottom Ash }\end{array}$ & $\begin{array}{l}\text { wt- } \% \text { of coal } \\
\text { feed carbun }\end{array}$ & Triangular & 0.75 & to & 10 & $(2.5)$ \\
\hline $\begin{array}{l}\text { Sulfur Retention } \\
\text { in Bottom Ash }\end{array}$ & $\begin{array}{l}\text { wt- } \% \text { of coal } \\
\text { feed sulfur }\end{array}$ & Triangular & 1.5 & to & 6 & (3) \\
\hline \multicolumn{7}{|l|}{ Gasifier Coal Throughput } \\
\hline $\begin{array}{l}250 \text { psia } \\
300 \text { psia } \\
350 \text { psia }\end{array}$ & $\begin{array}{l}\text { lb DAF } /\left(\mathrm{hr}^{-} \mathrm{ft}^{2}\right) \\
\text { lb DAF } /\left(\mathrm{hr}-\mathrm{ft}^{2}\right) \\
\text { lb DAF } /\left(\mathrm{hr}-\mathrm{ft}^{2}\right)\end{array}$ & $\begin{array}{l}\text { Triangular } \\
\text { Triangular } \\
\text { Triangular }\end{array}$ & $\begin{array}{l}133 \\
152 \\
170\end{array}$ & $\begin{array}{l}\text { to } \\
\text { to } \\
\text { to }\end{array}$ & $\begin{array}{l}333 \\
381 \\
426\end{array}$ & $\begin{array}{l}(266) \\
(305) \\
(341)\end{array}$ \\
\hline $\begin{array}{l}\text { Gasifier Ammonia } \\
\text { Yield }\end{array}$ & $\begin{array}{l}\text { Equiv. fraction } \\
\text { of coal } \mathrm{N} \text { to } \mathrm{NH}_{3}\end{array}$ & Triangular & 0.5 & to & 1.0 & $(0.9)$ \\
\hline Gasifier Air/Coal Ratio & lb air/lb DAF & Triangular & 2.7 & to & 3.4 & $(3.1)$ \\
\hline $\begin{array}{c}\text { Gasifier Steam Requirem } \\
\text { Air/coal }=2.7 \\
\text { Air/coal }=3.1 \\
\text { Air } / \text { coal }=3.4\end{array}$ & 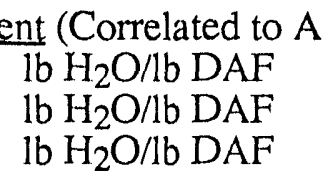 & $\begin{array}{l}\text { ir/Coal Ratio) } \\
\text { Uniform } \\
\text { Uniform } \\
\text { Uniform }\end{array}$ & $\begin{array}{l}0.54 \\
1.24 \\
2.04\end{array}$ & $\begin{array}{l}\text { to } \\
\text { to } \\
\text { to }\end{array}$ & $\begin{array}{l}1.08 \\
1.86 \\
2.72\end{array}$ & \\
\hline
\end{tabular}

a For Uniform distributions, the lower and upper bounds are given. For the triangular distribution, the mode is given in parentheses. For the fractile distribution, the lower and upper bounds for each range are given, along with the probability of sampling within that range. 


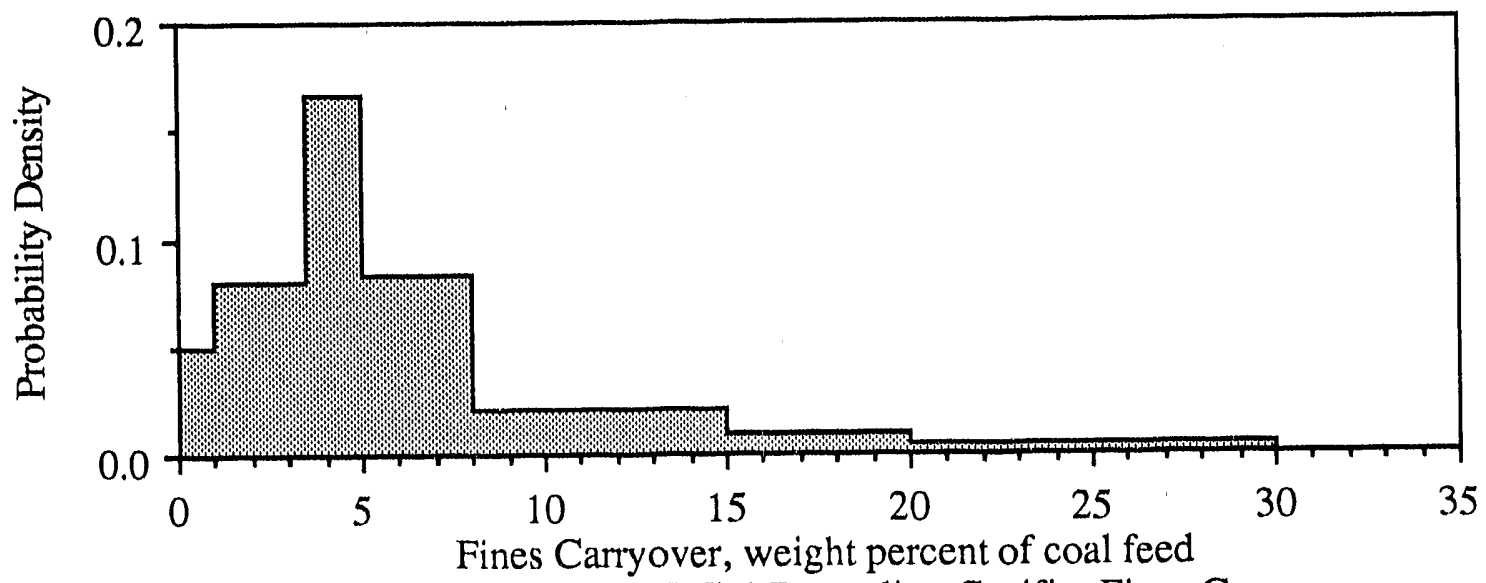

Figure A-4. Judgment of Expert LG-1 Regarding Gasifier Fines Carryover.

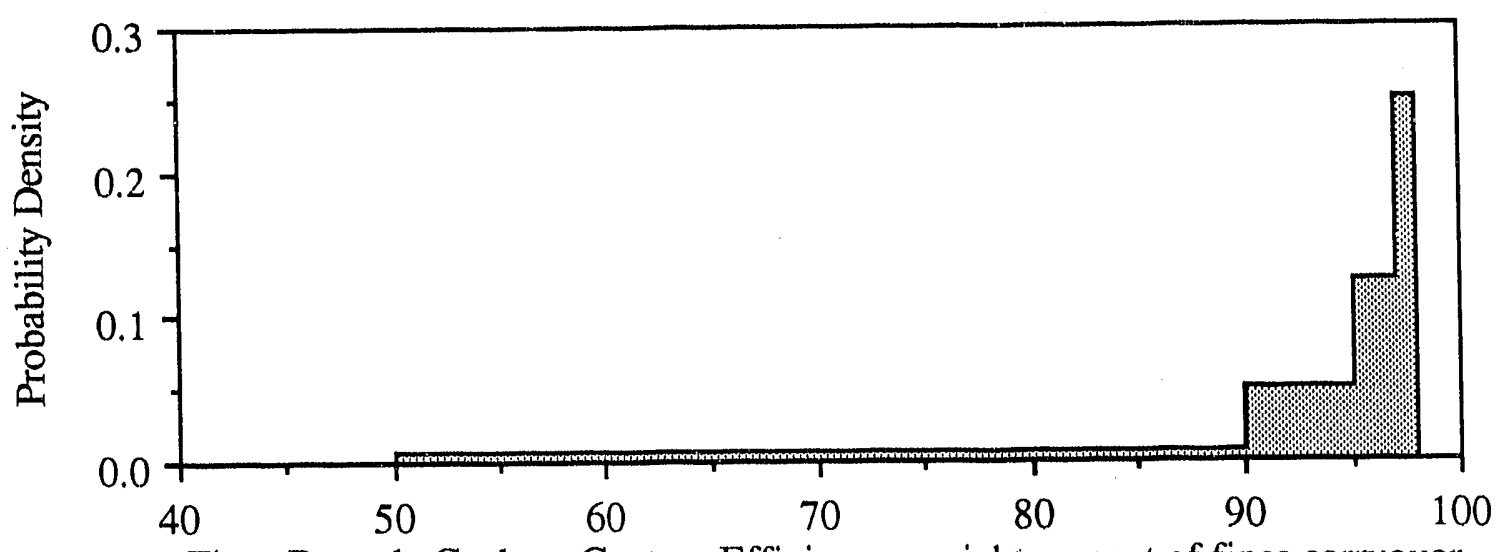

Fines Recycle Cyclone Capture Efficiency, weight percent of fines carryover

Figure A-5. Judgment of Expert LG-1 Regarding Fines Cyclone Capture Efficiency.

High carbon retention in the gasifier bottom ash might be associated with "poor distribution of gas flow through [the] bed due to agglomerates and concentrations of fines," whereas low carbon retention "requires good process control, properly designed grate, and smooth operations." High sulfur retention in the bottom ash might result from "poor carbon conversion" and "excessive channeling in [the] bed," while low retention would be related to "good carbon burnout of ash."

In the questionnaire, the experts were asked to provide judgments about gasifier coal throughput at three different pressures. Expert LG-1 provided a complete response, indicating that high throughputs at a given pressure would be associated with "better feed systems" and "poorer gas quality," while low throughputs would be related to "excessive fines carryover" and "excessive carbon content of bottom ash," implying correlation with fines carryover and carbon retention in the bottom ash. Expert LG-1's judgments regarding gasifier coal throughput for three different pressures are shown in Figure A-6. 


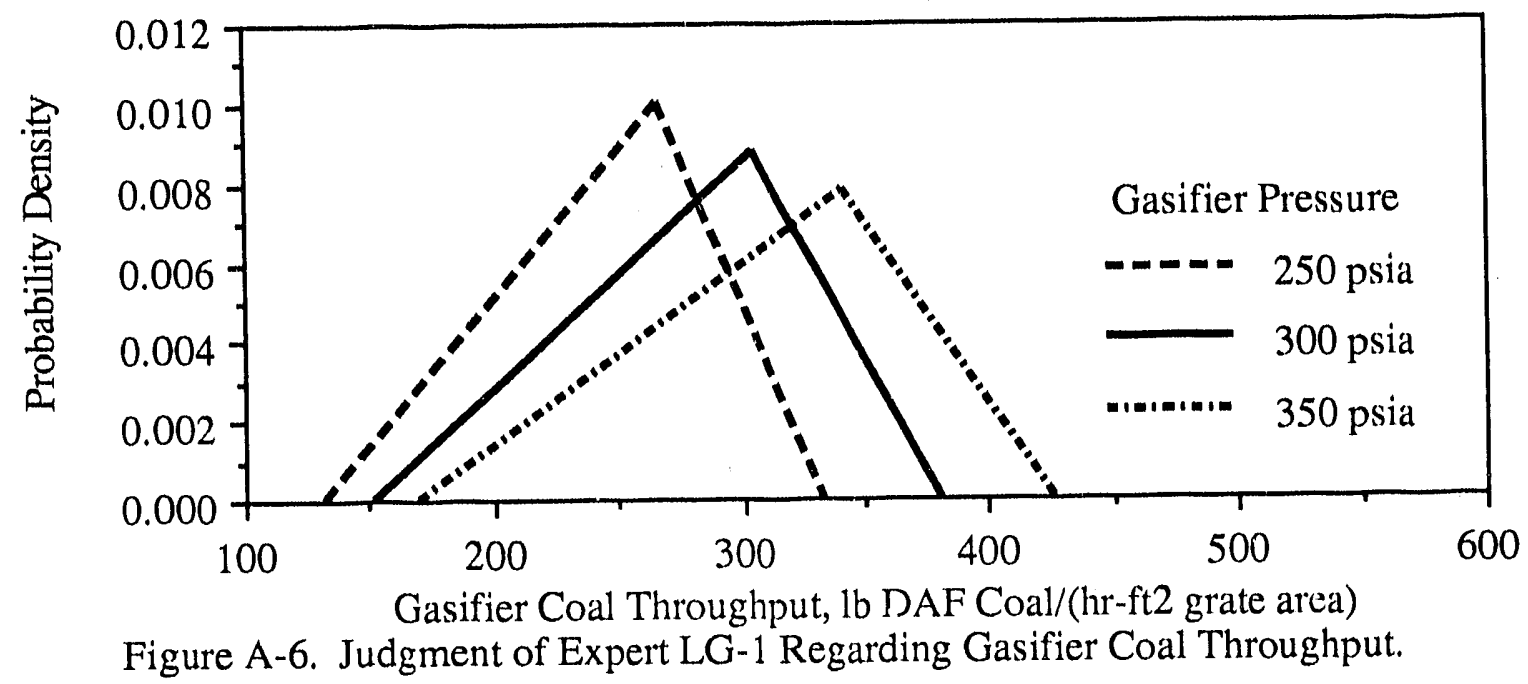

The graph indicates that the variance as well as the mode of the distribution increases as the pressure increases.

Expert LG-1 provided judgments regarding uncertainty in the gasifier steam requirement as a function of the gasifier air/coal ratio, which is also treated probabilistically. The judgments regarding uncertainty in the steam/coal ratio for three different air/coal ratios are shown in Figure A-7. For modeling studies, the uncertainties in the steam/coal ratio for intermediate values of the air/coal ratio can be interpolated. The interpolation is simplified because the steam/coal ratio is assumed to be uniformly distributed for each air/coal ratio. Therefore, the upper and lower limits of the uniform distribution can be interpolated, and a random number generator (uniform distribution) can be used to sample between the interpolated upper and lower limits.

In a follow-up phone conversation, Expert LG-1 was asked to elaborate on the

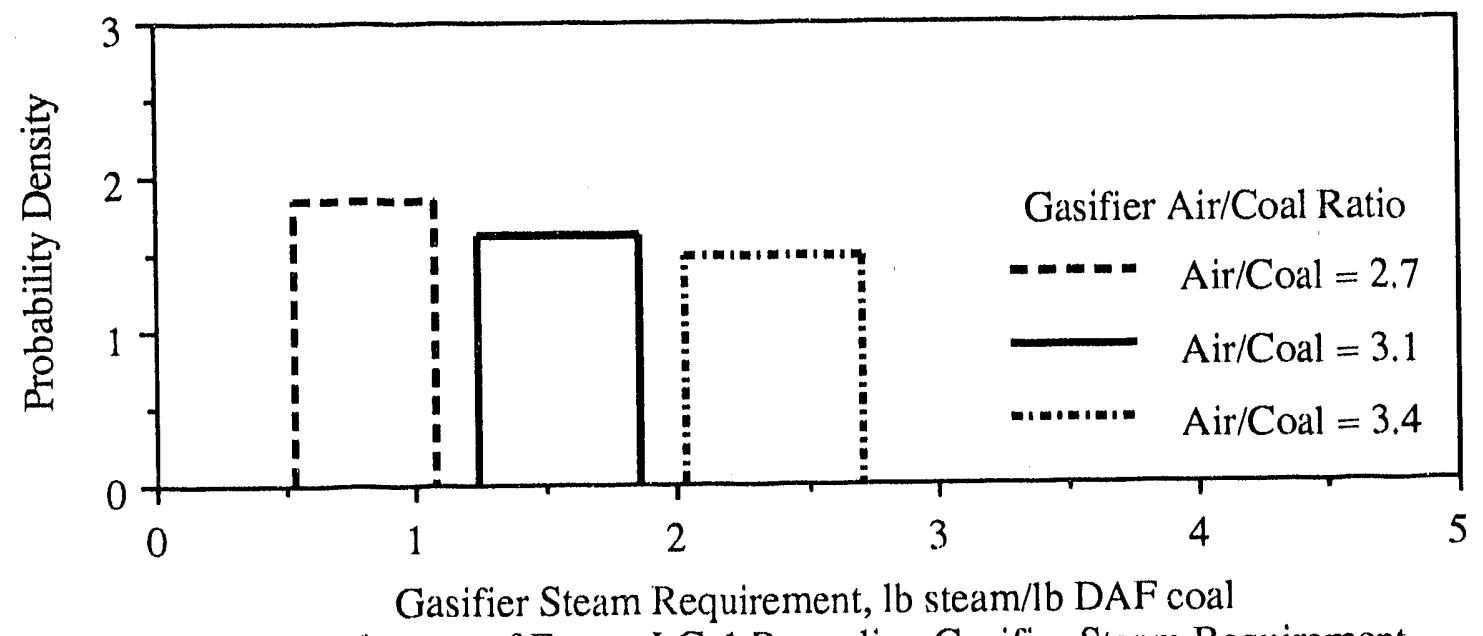

Figure A-7. Judgment of Expert LG-1 Regarding Gasifier Steam Requirement. 
relationships among the parameters. One pair of correlated parameters are the carbon and sulfur retention in the bottom ash. The expert indicated that the inorganic portion of the sulfur in the coal will "come off" readily in the upper portions of the gasifier, while the organically-bound sulfur can be released only as associated carbon is converted. Therefore, there is a tendency to have high sulfur retention associated with high carbon retention in the bottom ash. The expert indicated that the ratio of sulfur-to-coal in the bottom ash would be similar to the ratio of organic sulfur to carbon in the coal.

High carbon retention in the bottom ash, and high fines carryover, is an indicator of poor carbon conversion. To counter such a situation, a plant operator may choose to change the reagent feed ratios or the coal throughput. Thus, uncertainty carbon retention in the bottom ash may be negatively correlated with uncertainty in the air/coal ratio. Similarly, coal throughput may be positively correlated with carbon retention in the bottom ash, because higher coal throughputs imply less residence time in the gasifier, possibly leading to more incomplete carbon conversion. However, it is possible that coal throughput may be constrained due to gasifier bed stirrer design and possible "hang up" of coal or char along the gasifier walls, leading to channeling. Channeling is a possibility particularly with swelling coals. The result of channeling is that some of the coal will not react to the same degree as the rest. In instances of channeli'g, even high reagent feed ratios may not be successful at improving carbon conversion in the gasifier.

Thus, several of the parameters for which judgments were obtained are expected to be correlated. The elicitation of correlation structures among these variables was not attempted, because of the time consuming nature of such an exercise. Instead, the approach taken here is to run the model assuming no correlations and then run a "sensitivity" case with assumed correlations. For example, the bottom ash sulfur and carbon retentions are assumed to be closely correlated, and are given a nominal correlation of 0.5 for the purpose of the correlation screening study. High fines carryover is assumed to be associated with situations involving low carbon conversion in the gasifier, which would be correlated with high bottom ash carbon retention. Therefore, to characterize a possible correlation, the fines carryover is given a correlation of 0.5 with the bottom ash carbon retention. Cases of poor gasification efficiency are likely to be associated with high coal throughput. Therefore, a positive correlation is given between bottom ash carbon retention and gasifier throughput. Also, low carbon conversion may be associated with low regent (air, steam) feed ratios. The sign and magnitude of the assumed correlations is intended to be plausibly indicative of correlations among the variables, but these correlations should be interpreted merely as an illustrative example for comparison to an 
Table A-3. Proposed Correlation Matrix for Uncertain Parameters LG-1

\begin{tabular}{|c|c|c|c|c|c|c|c|c|c|c|}
\hline \multirow[b]{2}{*}{ Description } & \multirow[b]{2}{*}{ Number } & \multirow[b]{2}{*}{1} & \multicolumn{7}{|c|}{ Assumed Correlation Coefficients ${ }^{a}$} & \multirow[b]{2}{*}{9} \\
\hline & & & & & & 5 & & & 8 & \\
\hline $\begin{array}{l}\text { Fines Carryover } \\
\text { from Gasifier }\end{array}$ & 1 & 1.00 & & & & & & & & \\
\hline $\begin{array}{l}\text { Fines Capture in } \\
\text { Recycle Cyclone }\end{array}$ & 2 & -- & 1.00 & & & & & & & \\
\hline $\begin{array}{l}\text { Fines Carbon } \\
\text { Content }\end{array}$ & 3 & -- & -- & 1.00 & & & & & & \\
\hline $\begin{array}{l}\text { Carbon Retention } \\
\text { in Bottom Ash }\end{array}$ & 4 & 0.5 & -- & -- & 1.00 & & & & & \\
\hline $\begin{array}{l}\text { Sulfur Retention } \\
\text { in Bottom Ash }\end{array}$ & 5 & -- & -- & -- & 0.5 & 1.00 & & & & \\
\hline Gasifier Coal Throughput & 6 & -- & -- & -- & 0.50 & -- & 1.00 & & & \\
\hline $\begin{array}{l}\text { Gasifier Ammonia } \\
\text { Yield }\end{array}$ & 7 & -- & -- & -- & -- & $-\cdots$ & -- & 1.00 & & \\
\hline Gasifier Air/Coal Ratio & 8 & -- & -- & -- & -0.5 & -- & - & -- & 1.00 & \\
\hline $\begin{array}{l}\text { Gasifier Steam Requirement } \\
\text { (Correlated to Air/Coal Ratio) }\end{array}$ & 9 & -- & -- & -- & -0.5 & -- & -- & -- & (b) & 1.00 \\
\hline
\end{tabular}

a For uncorrelated parameters, a dashed line "-.$- "$ is shown.

$\mathrm{b}$ The expert explicitly developed a correlation structure between air/coal ratio and the steam requirement. See Table A-2.

uncorrelated case. The proposed correlations among uncertain parameters are summarized in Table A-3

Expert LG-1 did not provide any comments regarding judgments for fines carbon content, ammonia yield, steam requirement, and oxidant requirement.

\section{A.2.1.5.2 Expert LG-2}

Expert LG-2 indicated that he did not have previous operating experience with fixed-bed gasifiers, which made the development of judgments "highly difficult." Expert LG-2 also indicated that "it was difficult to develop the range of various values for variables due to lack of abundant actual operating data." The expert also noted that "the failure of a stirrer may present operational risk which should be assessed." The expert provided quantitative judgments for all but one of the parameters for which judgments were requested. 


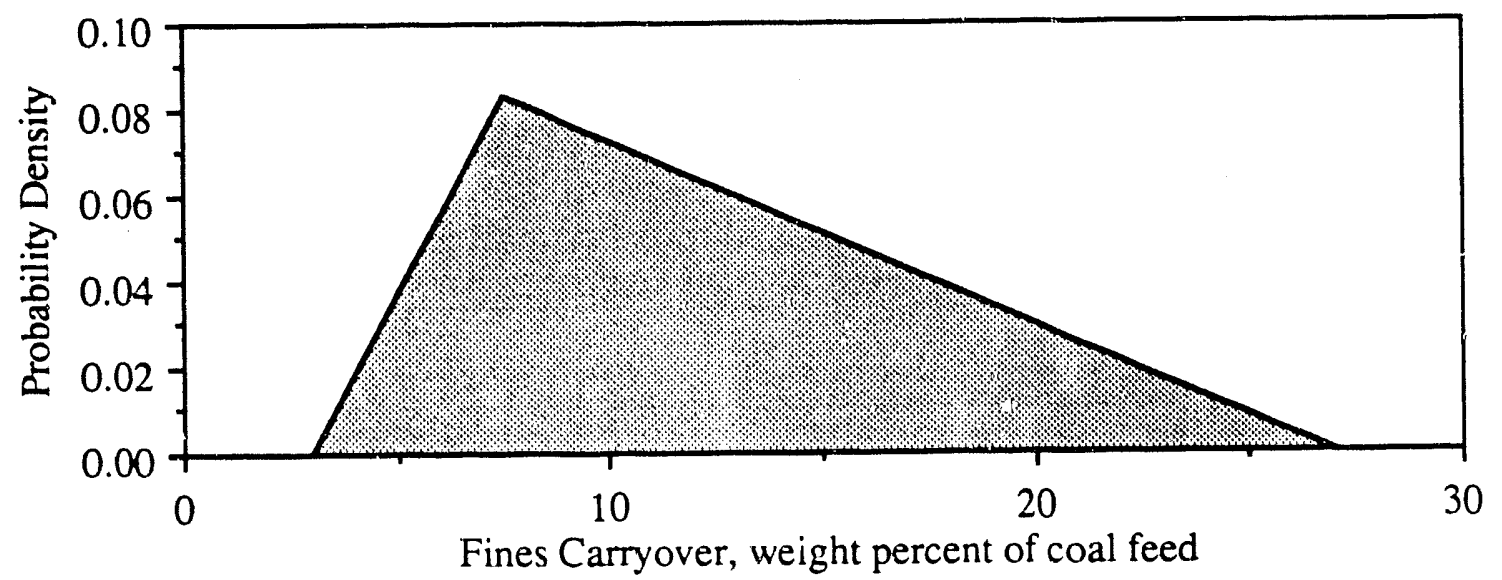

Figure A-8. Judgment of Expert LG-2 Regarding Fines Carryover.

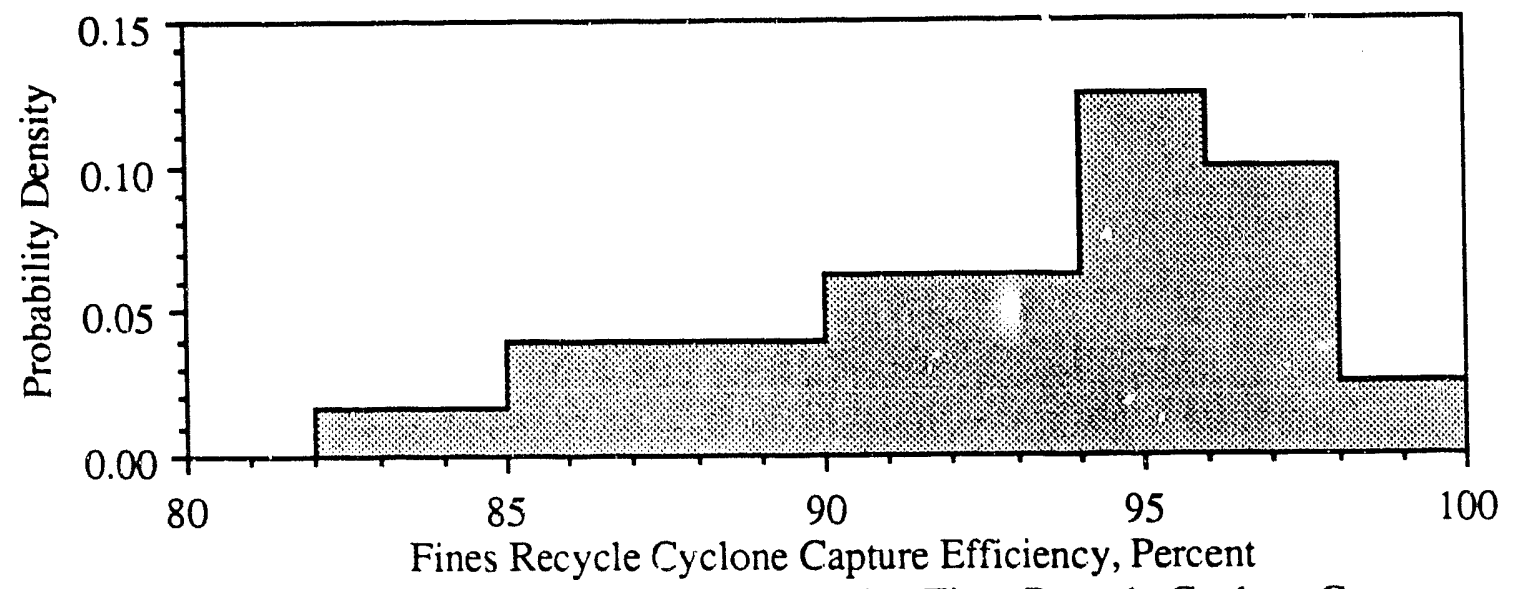

Figure A-9. Judgment of Expert LG-2 Regarding Fines Recycle Cyclone Capture Efficiency.

The quantitative judgments provided by Expert LG-2 are given in Table A-4. The expert's judgment regarding fines carryover is shown graphically as a pdf in Figure A-8. This judgment implies that there will be at least some fines carryover, with a most likely single value of 7.5 percent of the coal feed. The fines recycle cyclone capture efficiency uncertainty judgment is shown in Figure A-9. This graph indicates that the mode of the distribution is a range between 94 and 96 percent fines capture, and that the distribution is negatively skewed.

A low fines carbon content might be associated with "partially gasified chars" that "are broken by stirrer and entrained." A high carbon retention in the bottom ash might be "due to partial agglomeration of caking coal." For gasifier coal throughput, the expert provided "reasonable" numbers for coal throughput and indicated that coal throughput 
Table A-4. Summary of Elicited Lurgi Gasifier Technical Judgments from Expert LG-2

\begin{tabular}{|c|c|c|c|c|c|}
\hline \multirow{2}{*}{$\begin{array}{l}\text { Description } \\
\text { Fines Carryover } \\
\text { from Gasifier }\end{array}$} & \multirow{2}{*}{$\begin{array}{l}\text { Units } \\
\begin{array}{l}\text { wt-\% of } \\
\text { Coal Feed }\end{array}\end{array}$} & \multirow{2}{*}{$\begin{array}{l}\text { Distribution } \\
\text { Triangular }\end{array}$} & \multicolumn{3}{|c|}{ Parameters $^{a}$} \\
\hline & & & 3 & to & $27(7.5)$ \\
\hline $\begin{array}{l}\text { Fines Capture in } \\
\text { Recycle Cyclone }\end{array}$ & $\begin{array}{l}\% \text { of } \\
\text { Carryover }\end{array}$ & Fractile & $\begin{array}{l}5 \%: \\
20 \%: \\
25 \%: \\
25 \%: \\
20 \%: \\
5 \%:\end{array}$ & $\begin{array}{l}82 \\
85 \\
90 \\
94 \\
96 \\
98\end{array}$ & $\begin{array}{lr}\text { to } & 85 \\
\text { to } & 90 \\
\text { to } & 94 \\
\text { to } & 96 \\
\text { to } & 98 \\
\text { to } & 100\end{array}$ \\
\hline $\begin{array}{l}\text { Fines Carbon } \\
\text { Content }\end{array}$ & $\begin{array}{l}\text { wt-\% of } \\
\text { fines }\end{array}$ & Triangular & 70.0 & to & $87.4(78.7)$ \\
\hline $\begin{array}{l}\text { Carbon Retention } \\
\text { in Bottom Ash }\end{array}$ & $\begin{array}{l}\text { wt- } \% \text { of coal } \\
\text { feed carbon }\end{array}$ & Triangular & 1 & to & 20 \\
\hline $\begin{array}{l}\text { Sulfur Retention } \\
\text { in Bottom Ash }\end{array}$ & $\begin{array}{l}\text { wt-\% of coal } \\
\text { feed sulfur }\end{array}$ & Triangular & 4 & to & $30 \quad(10)$ \\
\hline $\begin{array}{c}\text { Gasifier Coal Throughput } \\
250 \mathrm{psia} \\
300 \mathrm{psia} \\
350 \mathrm{psia}\end{array}$ & $\begin{array}{l}\text { tons } \mathrm{DAF} / \text { day } \\
\text { tons } \mathrm{DAF} / \text { day } \\
\text { tons } \mathrm{DAF} / \text { day }\end{array}$ & $\begin{array}{l}\text { Triangular } \\
\text { Triangular } \\
\text { Triangular }\end{array}$ & $\begin{array}{l}279 \\
382 \\
358\end{array}$ & $\begin{array}{l}\text { to } \\
\text { to } \\
\text { to }\end{array}$ & $\begin{array}{l}517(398) \\
593(456) \\
666(512)\end{array}$ \\
\hline $\begin{array}{l}\text { Gasifier Ammonia } \\
\text { Yieldc }\end{array}$ & $\begin{array}{l}\text { Equiv. fraction } \\
\text { of coal } \mathrm{N} \text { to } \mathrm{NH}_{3}\end{array}$ & Triangular & 0.25 & to & $0.75(0.50)$ \\
\hline Gasifier Steam/Air Ratio & lb steam $/ \mathrm{lb}$ air & Fractile & $\begin{array}{l}\text { 50\%: } \\
50 \%:\end{array}$ & $\begin{array}{l}0.30 \\
0.45\end{array}$ & $\begin{array}{ll}\text { to } & 0.45 \\
\text { to } & 0.70\end{array}$ \\
\hline Gasifier Air/Coal Ratiod & $\mathrm{lb}$ air $/ \mathrm{lb}$ coal & Triangular & 0.4 & to & $2.9(2.41)$ \\
\hline $\begin{array}{l}\text { Gasifier Maintenance } \\
\text { Cost Factor }\end{array}$ & $\begin{array}{l}\text { \% of capital } \\
\text { investment }\end{array}$ & Uniform & 4.5 & to & 12.0 \\
\hline
\end{tabular}

a For Uniform distributions, the lower and upper bounds are given. For the triangular distribution, the mode is given in parentheses. For the fractile distribution, the lower and upper bounds for each range are given, along with the probability of sampling within that range.

${ }^{b}$ For this parameter, the expert appears to be combining the concept of process reliability with that of the uncertainty in system operation given that the system is operating. For the purpose of a screening study of uncertainties, the lower bound on the gasifier throughput will be assumed to be 30 percent less than the mode.

c The expert provided judgments as a mixture of fractional conversion of coal nitrogen to ammonia and ammonia concentration in the fuel gas. Here, the result is expressed as an equivalent fractional conversion, for consistency with the other expert.

d This judgment includes a mixture of assumptions regarding plant operation. The low value is reported to be associated with "hot standby condition." However, the intent of the modeling exercise is to evaluate full-load operation of the system. Therefore, for a screening study, a lower limit as shown parenthetically will be used. 


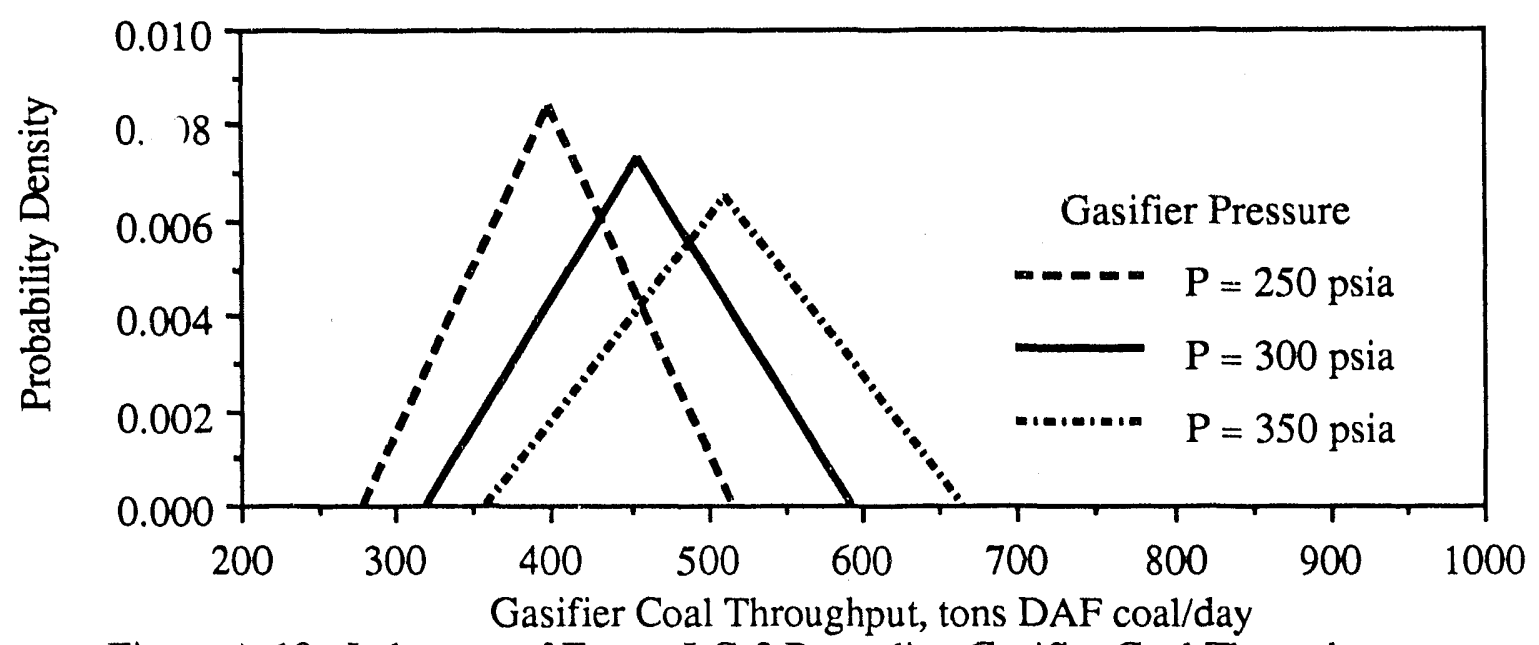

Figure A-10. Judgment of Expert LG-2 Regarding Gasifier Coal Throughput.

could be 30 percent higher "at the expense of carbon conversion," implying a correlation between coal throughput and carbon conversion. The expert indicated that, in the worst case, the coal throughput would be about 30 percent less than the "reasonable" numbers. This set of judgments is shown graphically in Figure A-i0.

Upon a follow-up phone call, the expert indicated that the oxidant requirement can be varied at will, but that to get a "good gas," a lower limit would be about $0.4 \mathrm{lb}$ air/lb coal. Expert LG-2 did not provide comments for any of the other parameters for which judgments were made.

Based on the comment of Expert LG-2 that gasifier coal throughput can be increased at the expense of carbon conversion, a correlation structure among the uncertainty judgments was assumed for the purpose of comparison with an uncorrelated case. This proposed correlation structure is given in Table A-5. The fines carryover and the bottom ash carbon retention are both assumed to be positively correlated with the coal throughput, implying reduced carbon conversion as throughput is increased. Furthermore, it is assumed that the carbon retention in the bottom ash will tend to increase as the air/coal ratio is lowered. Hence, a negative correlation is assumed between these two parameters.

\section{A. 2.1.5.3 Other Uncertainties}

While judgments about uncertainties in the performance of a fifth-of-a-kind fixedbed dry-ash gasifier operating on Illinois No. 6 coal with up to 30 percent fines loading and fines recycle were obtained from technical experts, these experts were generally unable to make judgments about cost-related parameters for this process area. One exception to this is that Expert LG-2 did provide a judgment regarding the maintenance cost factor. This judgment will be included in all Lurgi case studies. 
Table A-5. Proposed Correlation Matrix for Uncertain Parameters LG-2

\begin{tabular}{|c|c|c|c|c|c|c|c|c|c|c|c|}
\hline & & & & Assur & $\operatorname{med} C$ & Correl & ation & Coeff & icients & & \\
\hline Description & No. & 1 & 2 & 3 & 4 & 5 & 6 & 7 & 8 & 9 & 10 \\
\hline $\begin{array}{l}\text { Fines Carryover } \\
\text { from Gasifier }\end{array}$ & 1 & 1.00 & & & & & & & & & \\
\hline $\begin{array}{l}\text { Fines Capture in } \\
\text { Recycle Cyclone }\end{array}$ & 2 & -- & 1.00 & & & & & & & & \\
\hline $\begin{array}{l}\text { Fines Carbon } \\
\text { Content }\end{array}$ & 3 & -- & -- & 1.00 & & & & & & & \\
\hline $\begin{array}{l}\text { Carbon Retention } \\
\text { in Bottom Ash }\end{array}$ & 4 & -- & -- & -- & 1.00 & & & & & & \\
\hline $\begin{array}{l}\text { Sulfur Retention } \\
\text { in Bottom Ash }\end{array}$ & 5 & -- & -- & -- & -- & 1.00 & & & & & \\
\hline Gasifier Coal Throughput & 6 & 0.9 & -- & - & 0.9 & -- & 1.00 & & & & \\
\hline $\begin{array}{l}\text { Gasifier Ammonia } \\
\text { Yield }\end{array}$ & 7 & -- & -- & -- & - & -- & -- & 1.00 & & & \\
\hline Gasifier Steam/Air Ratio & 8 & -- & -- & -- & -- & -- & -- & -- & 1.00 & & \\
\hline Gasifier Air/Coal Ratio & 9 & -- & -- & -- & -0.9 & -- & -- & -- & -- & 1.00 & \\
\hline $\begin{array}{l}\text { Gasifier Maintenance } \\
\text { Cost Factor }\end{array}$ & 10 & -- & -- & - & -- & -- & - & -- & -- & -- & 1.00 \\
\hline
\end{tabular}

a For uncorrelated parameters, a dashed line ".." is shown.

In addition to the maintenance cost factor, a judgment regarding uncertainty is required regarding the gasifier process area capital cost. For example, Corman (1986) commented that operating experience on highly caking coals, such as Illinois No. 6, in the Lurgi gasifier is relatively limited, and that performance estimates are subject to change as more experience is acquired. However, Corman indicates that changes are likely to have more effect on capital costs (e.g., additional vessels for fines handling) rather than on overall system performance. This statement implies that there may be uncertainty in the scope and cost of the gasification process area. This type of uncertainty is traditionally handled using "process contingency factors" as discussed elsewhere in this dissertation (see Chapter 6 of Volume 1). However, Corman assumed a process contingency factor of only 5 percent, which is quite low according to EPRI guidelines. For example, EPRI recommends a factor of 0 to 10 percent for a commercially demonstrated process, 5 to 20 percent for a system in which a full size module has been operated, and 20 to 35 percent for a system for which only small scale test have been performed. However, from the EPRI 
TAG, it is not clear what probability of cost over-run is associated with these "rule-ofthumb" recommendations. Considering that a system with fines recycle has not yet been operated, and that there may be significant uncertainties not only in the fines recycle aspect of the process area, but also related to the gasifier bed stirrer, it appears plausible that a higher level of contingency should be assumed in a deterministic study, and that a relatively wide range of uncertainty should be assumed in initial probabilistic studies. Furthermore, the available cost estimates from which the cost models were developed do not include gasifier bed stirrers. Thus, a suggested uncertainty factor for a screening study of uncertainties is a uniform distribution from 10 to 30 percent on the same basis as the process contingency factor. 


\section{A.2.2 Fluidized Bed Coal Gasification Process Area}

This section reviews uncertainties in, and potential problems of, using fluidized-bed gasifiers in an integrated gasification combined cycle (IGCC) process environment. This review considers uncertainties which arise from: (1) scaling-up of the KRW gasifier process development unit (PDU) to a commercial gasifier design; and (2) applications of the KRW gasifier in two different IGCC process environments. The two IGCC systems under consideration here are:

- Case AKH: Air-blown KRW-based IGCC system with Hot gas cleanup featuring in-bed and external zinc ferrite hot gas desulfurization.

- Case OKC: Oxygen-blown KRW-based IGCC system with Cold gas cleanup.

\section{A.2.2.1 Process Description}

The assumed system configuration for Case OKC is shown in Figure A-11. The schematic for Case OKC is based on elements of design and cost studies prepared for the Electric Power Research Institute (Dawkins et al, 1985) and DOE (Bechtel, 1983) and the configuration assumed in an ASPEN simulation model developed at METC (Stone, 1985). The design basis for Case $\mathrm{AKH}^{2}$ (see Task 2 Topical Report) represents process elements based on design and cost studies prepared for the Gas Research Institute (Smelser, 1986; Earley and Smelser, 1988), DOE (Corman, 1986) and the configuration assumed in the ASPEN simulation model developed at METC (Craig, 1988).

The primary features of the IGCC system of Case AKH compared to Case OKC are: (1) elimination of an oxygen plant and use of air extracted from the gas turbine for oxidant feed; (2) in-situ desulfurization with limestone or dolomite; (3) external desulfurization using a high temperature removal process; (4) reduced requirement for syngas cooling prior to desulfurization; (5) elimination of sulfur recovery and tail gas treating; and (6) addition of a circulating fluidized bed boiler for sulfation of spent limestone (to produce an environmentally acceptable waste) and conversion of carbon remaining in the ash.

2 The design configuration for this system is not shown here. Cost models of this system were developed as part of Task 2, and are reported in the Task 2 Topical Report. However, Case AKH was not t'le subject of model applications as part of the current task, due to time and data constraints. Information regarding Case $\mathrm{AKH}$ is included here because the develop of the KRW gasifier has considered applications to systems represented by Cases $\mathrm{OKC}$ and $\mathrm{AKH}$. 


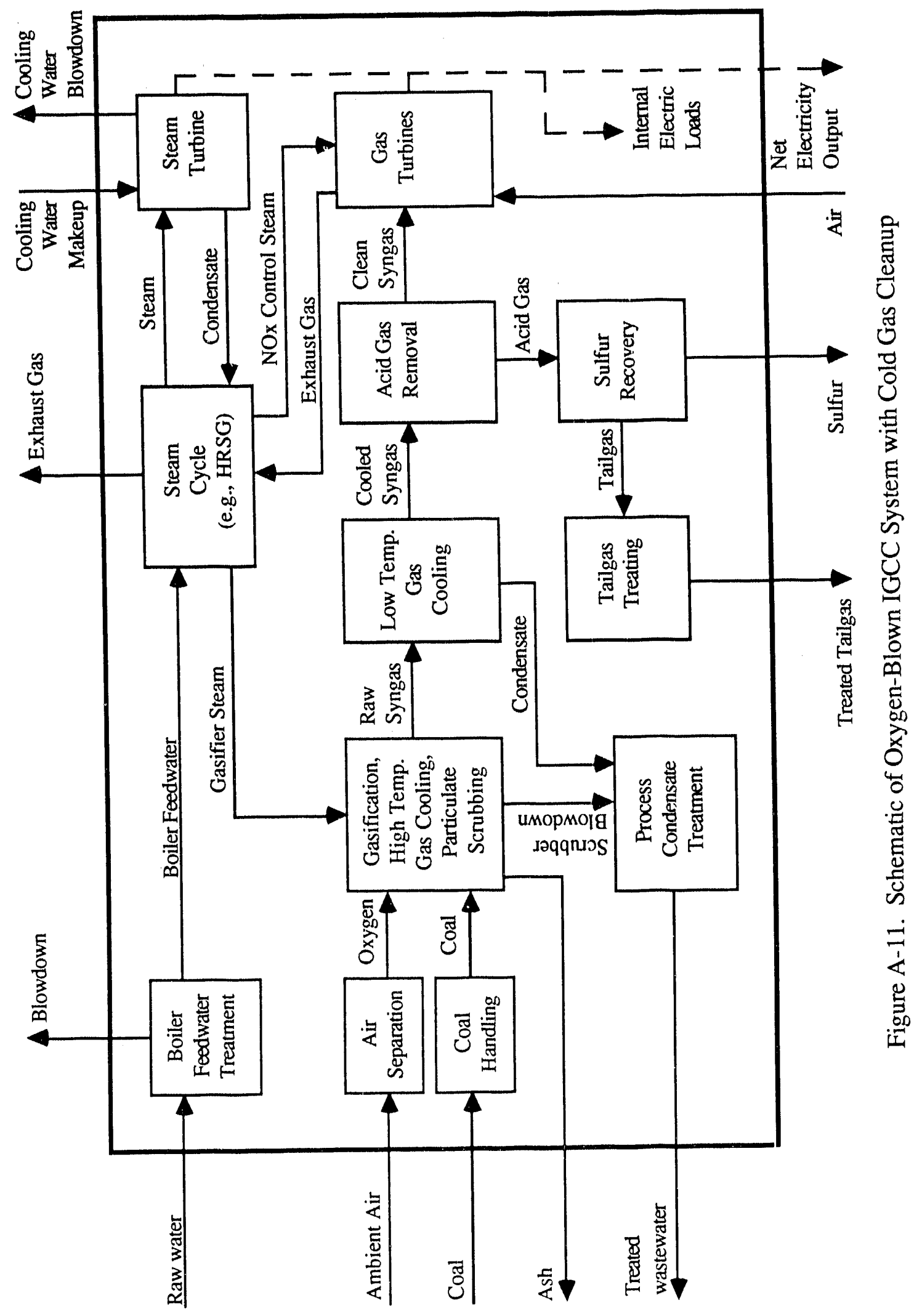


Table A-6. Default Characteristics for the Design Illinois No. 6 Coal

General Description

Rank

Coal Seam

Bituminous

Preparation

Illinois No. 6

Run of Mine

\section{Properties}

Proximate Analysis, as received, wt-\%

Moisture

12.0

Volatile Matter

Fixed Carbon

31.4

Ash

8.8

Ultimate Analysis, dry, wt-\%

Carbon

69.5

Hydrogen

Nitrogen

1.3

Oxygen

10.0

Sulfur

3.9

Ash 10.0

Chlorine

Heating Value of Coal, As Received $\mathrm{Btu} / \mathrm{lb}$ (HHV)

Form of Sulfur as \% of Total Sulfur

Pyritic

Sulfate

Organic

0.0

Ash Fusion Temperature, ${ }^{\circ} \mathrm{F}$ 
The assumed coal for this study for both cases is Illinois No. 6. Some characteristics for this design coal are given in Table A- 6 .

A simple schematic of a KRW gasifier is given in Figure A-12. The basic features include a large refractory lined carbon steel pressure vessel with several "zones," coal and oxidant feed tubes, ash removal annulus, and fines recycle system. The gasifier zones include low velocity ash cooling and removal, moderate velocity ash separation and gasification, and high velocity combustion and devolatilization. In addition, a freeboard disengaging zone is used to reduce the amount of char entrained in the outgoing syngas. The diameter of the gasifier is largest in the freeboard zone, in order to reduce syngas velocity and entrainment of char (Smith et al, 1986).

Pulverized coal is fed with oxidant and transport gas to a combustion jet. The combustion jet supplies the heat required for the endothermic gasification reactions in the fluidized bed, in which steam and oxidant react with the char remaining after partial combustion. A portion of coal char fines are elutriated with the coal gas leaving the gasifier. Most of these fines are captured in a cyclone and recycled to the gasifier. Ash is removed through an annular area around the coal feed tube. The temperature in the ashagglomerating zone is above the softening temperature of some of the eutectics in the ash. This leads to ash agglomeration, as ash particles stick together to form larger particles which are defluidized. Cool raw coal gas is recycled to the ash separation zone to cool the ash and for velocity control in the ash annulus (Simbeck et al, 1983).

Two of the key operating parameters of an IGCC power plant are the gasifier oxidant and steam requirements. The gasifier oxidant requirement can be expressed in terms of the oxygen-to-carbon molar ratio based on oxygen in the oxidant and carbon in the coal feed. The gasifier steam requirement can be expressed in terms of the molar ratio of steam-to-oxygen. Some values of the oxygen-to-coal and steam-to-oxygen ratios are summarized in Table A-7. These include values from PDU tests, theoretical modeling, and conceptual design studies.

\section{A.2.2.2 Commercial Status of the KRW Gasifier}

M.W. Kellogg has operated a 15 to 35 ton per day KRW gasifier process development unit (PDU) at Waltz Mill, PA since 1975. This unit has accumulated over 13,000 hours of operation on a variety of feedstocks, including bituminous, subbituminous, and lignite coals, cokes, and non-U.S. coals (Floyd and Agrawal, 1989). The PDU operates at pressures up to 245 psia and has been run in oxygen- and air-blown modes with and without in-bed desulfurization (Haldipur et al, 1989). 


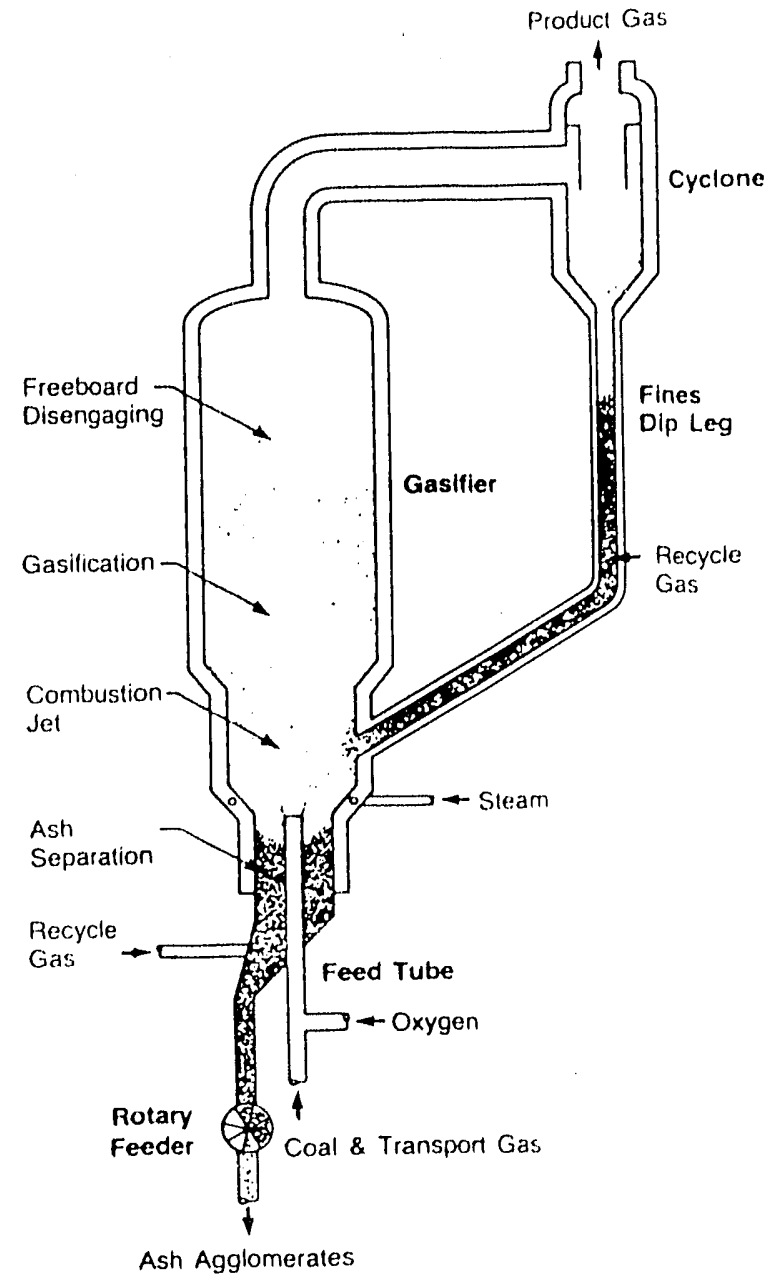

Figure A-12. Schematic of the Fluidized-Bed, Agglomerating Ash KRW Gasifier (Source: Simbeck et al, 1983) 


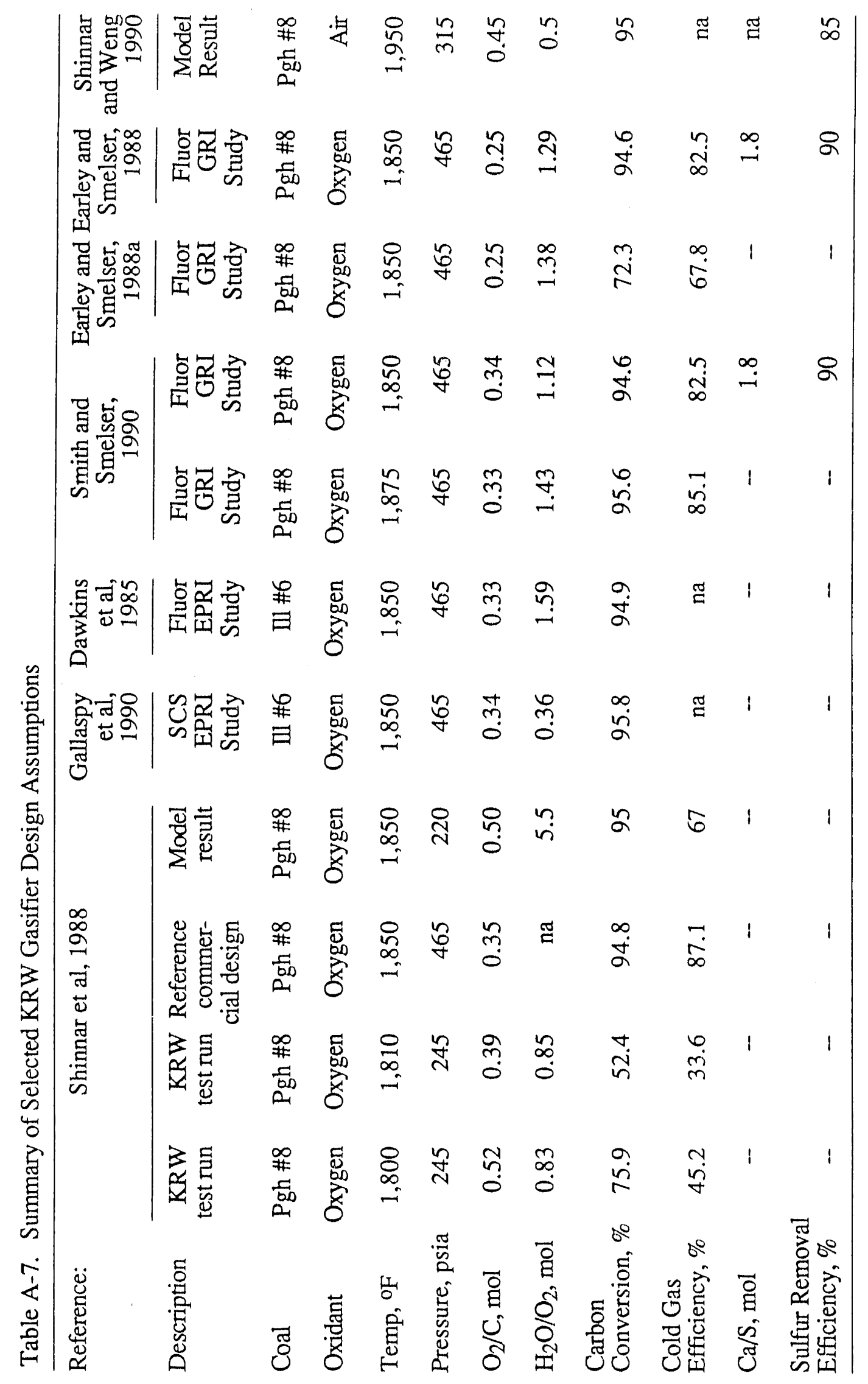


Simbeck et al (198\%) report that in 1981 SASOL of South Africa and Westinghouse (then the owner of the KRW technology) had agreed to fund development and construction of a 1,200 metric ton/day of coal demonstration plant. Dawkins et al (1985) reported that the project was cancelled in mid-1983, but that a detailed performance and economic evaluation of the project had been at least partially completed.

A single train low-BTU gas gasification plant was designed for Fularji Heavy Machinery works in the People's Republic of China in 1985. The plant was to be operated on lignite with a capacity of 350 tons/day. However, the project was cancelled due to "commercial reasons" (Gallaspy et al, 1990).

In April of 1986 M.W. Kellogg submitted an initial proposal to the U.S. Department of Energy (DOE) for an air-blown KRW-based IGCC demonstration plant featuring in-bed desulfurization, external desulfurization, and use of a high-sulfur Eastern bituminous coal. The proposed demonstration is known as the "Appalachian Project." This project was to feature a 500 ton/day KRW gasifier operating at 285 psia (Banchik et al, 1988). However, because Kellogg had difficulties finding a site and negotiating a power supply contract, the project was terminated (Gallaspy et al, 1990). Nonetheless, a substantial amount of design work appears to have gone into the Appalachian Project, supported by testing with the KRW gasifier PDU.

In addition to several attempts at detailed designs for specific construction projects, all of which have been cancelled, there have been a number of conceptual design studies of KRW-based coal-to-substitute natural gas (SNG) and IGCC systems. Some of the most recent studies are mentioned here. These include five studies of IGCC systems (Bechtel, 1983; Dawkins et al, 1985; Smelser, 1986; Earley and Smelser, 1988; and Gallaspy et al, 1990) and four studies of coal-to-SNG systems (Cover et al, 1985; Smith et al, 1986; Smith and Smelser, 1987; Earley and Smelser, 1988b). The Gas Research Institute (GRI) spo ssored a study of the KRW PDU (Blinn et al, 1989) to provide supporting data for performance and cost assumptions used in a previous study (Earley and Smelser, 1988). A paper prepared by M.W. Kellogg discussed, in qualitative terms, the design basis for an air-blown IGCC system with in-bed desulfurization using Illinois No. 6 coal (Banchik and Cover, 1988). Other studies or KRW-based systems have been prepared in the past (e.g., Bostwick et al, 1981) but are not considered as reliable as more recent studies. In addition, a comparative evaluation of air-blown and oxygen-blown KRW-based systems by Southern Company Services ior DOE/METC is currently in the review phase. 
The gasification section definitions are similar in all of the studies which have been reviewed to date. The coal-to-SNG systems are the same as the IGCC systems in the areas of coal pressurization, gasification, and ash removal. In fact, it appears that the physical dimensions of the gasifier are similar across all studies. Typical dimensions are an overall height of about 100 to $115 \mathrm{ft}$, a maximum outer diameter of about $14 \mathrm{feet}$, and a minimum outer diameter of about $5.5 \mathrm{ft}$. All systems use a coal surge bin, coal pressurization lockhopper, coal feed lockhopper, and rotary feed valve to deliver pressurized coal to the gasifier. All systems also use an ash receiving lockhopper and an ash depressurization lock hopper for ash removal. All systems use pneumatic transport of coal from the rotary feed valve to the gasifier, and pneumatic cooling and separation of ash. All systems have a recycle gas compressor and motor.

To accommodate in-bed desulfurization, the gasifier vessel may be slightly increased in size compared to no in-bed desulfurization. For example, one study assumed a gasifier size of 101 feet overall length and 14 feet maximum outside diameter without inbed desulfurization, and 115 feet overall length and 14 feet maximum outside diameter with in-bed desulfurization (Smith and Smelser, 1987). The fluidized bed height for the in-bed desulfurization case is assumed to be approximately 4 feet higher, due to increased bed volume. The limestone addition results in high levels of ash in the bed and higher bed densities than the conventional gasifier. The higher bed density permits a slightly higher superficial velocity $(1.72 \mathrm{ft} / \mathrm{s}$ vs. $1.6 \mathrm{ft} / \mathrm{s}$ ) in the freeboard (uppermost) zone of the gasifier.

The conceptual design studies cited above cover a wide range of coal feedstocks. These include Illinois No. 6, Pittsburgh No. 8, Texas lignite, North Dakota lignite, and Wyodak subbituminous coal as feedstocks, with gasifier coal feed moisture contents ranging from about 1 to 23 percent. For this study, attention is restricted to cases with Eastern bituminous coals.

\section{A.2.2.3 PDU Data Availability and Applicability}

The design and operation of the KRW gasifier PDU differ from the conceptual designs for commercial-scale plants. For example, most design studies assume oxygenblown gasifiers with nominal capacities of 1,000 tons per day of coal, implying a nominal scale-up factor of 40 from the size of the PDU. Alternatively, some studies assume airblown gasifiers with a nominal capacity of 500 tons/day. The test facility has a maximum pressure capability of 245 psia, whereas design studies commonly assume 465 psia. However, the design pressure for the KRW gasifier in the Appalachian Project was reported to be 285 psia (Banchik, Buckman, and Rath, 1988). The basis for this design pressure was not reported. However, it may represent a more efficient matching of the 
gasifier pressure to meet system pressure losses in piping, cyclones, external desulfurization vessels, and gas turbine fuel valves.

The PDU has higher heat losses, higher fines elutriation, higher recycle gas flow rates, higher ash annulus gas velocities, and a lower bed height than most design studies (Shinnar, et al, 1988). Furthermore, Shinnar, et al (1988) assert that the carbon conversions and oxygen-to-coal and steam-to-coal ratios assumed in most design studies cannot be justified based on PDU experience, even accounting for differences in design and operation compared to a full-scale commercial gasifier. This is particularly true, according to the study, for KRW gasifiers operating without in-bed desulfurization:

"Unfortunately, the envisioned performance was never demonstrated in the pilot-plant and our model shows that it is not achievable in an efficient commercial KRW under any circumstances" (p. 155, Shinnar, et al, 1988)

Shinnar et al (1988) indicate that there are several penalties inherent in the KRW design which pose limitations for its gasification efficiency. For example, coal is fed directly into the combustion zone, where volatiles and reactive char combust preferentially. However, it would be preferable to combust unreacted char, such as that from fines recycle. A more efficient design, according to Shinnar et al, would be to feed the unreacted char from fines recycle into the combustion jet, and to feed coal to the fluidized bed above the jet. However, the caking characteristics of a particular coal may make direct injection into the bed infeasible, unless an additive is used to reduce the caking tendency.

Another penalty involves the use of recycled coal gas in the ash removal annulus. The penalty is manifold. The recycled gas has been cooled prior to entering the combustion zone via the ash annulus, thus imposing a sensible energy penalty on the gasifier. Combustion of recycled coal gas competes for oxygen in the oxidant. Use of recycle gas also increases the amount of chiar that has to be gasified for a given net coal gas production. The recycle gas also has a diluting effect on the steam concentration in the gasification zone, reducing the gasification reaction rate.

Uncertainty regarding fines carry-over has been compensated for by designing an over-sized freeboard section for solids transport disengagement and over-designing downstream solids collecting equipment (Smith, Hanny, and Smelser, 1986). Overdesigning to account for uncertainty may lead to unnecessarily expensive systems.

The basic processes involved in gasification are chemical, thermal, and hydrodynamic. Many of the chemical processes do not depend on scale because they take place at a particle level. However, hydrodynamic processes are generally scale-dependent, 
and influence the thermal history of particles and gases in the gasifier. The main areas of design that have the least commercial experience are the combustion jet zone and the ash separation zone. Analytic models of the jetting and ash separation zone have been developed by KRW based on a variety of tests at different scales, ranging from four inch to ten foot diameter for cold flow facilities and four inch to 24 inch diameter for hot flow facilities. Kellogg Rust Synfuels, Inc. (KRSI) claims an excellent correlation between the analytic models and the observed test results (Smith et al, 1986).

Perhaps the most significant scale-up uncertainty is in the jet combustion zone. It is important that the jet surface area and the solid recirculation rate near the jet be sufficient to allow for dissipation of the heat from combustion, otherwise agglomeration, clinkering and sintering of bed material will occur. Commercial designs may require the use of multiple jets, rather than a single jet, for better distribution of heat. However, this alternative may introduce problems if the jet velocities are not uniform. Also, multiple jets may interact to form stagnant regions between jets. KRSI recommends more extensive testing using semicircular and circular models of multiple jets before designing a commercial reactor with multiple jets (Smith et al, 1986).

Gasifier performance for a specific coal is predicted by M.W. Kellogg based on analytic models and empirically-derived data. Experimental data are required to determine reaction rates and the influence of contained mineral matter on coal reactivity. The caking properties of the coal are also important, as is the ash fusion temperature. M.W. Kellogg has devised a number of bench-scale tests that are used to determine the empirical data needed for the analytic models. The combination of bench scale testing and mathematical modeling is reported to yield a good predictive capability for gasifier performance. However, the predictive capability is limited by uncertainties in free-board temperature, bed density, bed carbon content, and ted height (Floyd and Agrawal, 1989).

Other sources of uncertainty in predicting commercial scale gasifier performance stem from the limited understanding of the chemistry of gasification in the KRW gasifier. For example, Shinnar et al (1988) conclude that:

- Kinetics of gasification are insufficiently known, and the reactivity of different chars varies over a wide range;

- Products of coal disintegration due to rapid heating are not well known and influence fines production;

- Insufficient data are available to estimate the maximum bed temperature that can be achieved withcut defluidization due to sintering of ash; 
- It is not currently possible to predict the minimum oxygen requirement needed to prevent clinkering near the inlet nozzle;

- Further work is needed to understand how additives allow increase in bed temperatures;

- Further work is needed to understand how additives reduce the caking tendency of bituminous coals; and

- Further study is needed of the dependence of the gasification rate on carbon conversion, particularly in the 70 to 100 percent conversion range.

\section{A.2.2.4 Key Technicai Issues}

A.2.2.4.1 Dxidant Requirement

Oxygen is required to fuel partial combustion of coal in the KRW gasifier. The heat released during combustion is used to supply the heat of reaction for the endothermic gasification reactions occurring in the fluidized bed. Heat released during combustion is also required to bring the gasification reactants (e.g., steam) to reaction temperature. Thus, any thermal losses, such as conduction through the gasifier vessel walls, radiation to the gasifier freeboard, recycle of cooled recycle gas or fines to the gasifier, and excess steam above reaction requirements, will impose increased demands on oxygen consumption. If oxygen consumption becomes too high, the gasifier will become a partial combustor in which all carbon conversion is achieved by combustion. Steam would then only participate in water-gas shift from carbon monoxide to hydrogen. In gasification reactions, the steam reacts directly with carbon in the coal to form carbon monoxide and hydrogen in an endothermic reaction (Shinnar et al, 1988).

\section{A.2.2.4.2 Steam Requirement}

Steam is required as a reactant for gasification reactions. Because the kinetics of the gasification reactions are finite, excess steam is required for this purpose. In addition, steam is required as a thermal diluent to reduce the temperature in the combustion zone near the oxygen inlet. However, any steam requirement in excess of that needed for combustion zone cooling poses a sensible heat load on the gasifier, which may in turn increase the demand for oxygen to fuel the combustion reactions to heat the excess steam. Also, in the KRW PDU, steam is used as a fluidization gas to prevent large char particles from falling through the ash annulus with the heavier ash agglomerates (Shinnar et al, 1988) The ash removal design of the KRW gasifier thus may impose constraints on the minimum steam requirement necessary for gasifier operability.

The steam requirement may be reduced for air-blown systems, compared to oxygen-biown systems. This is due to the thermal dilution in the combustion jet provided by the nitrogen in the oxidant, which offsets the need for some of the steam. 


\section{A.2.2.4.3 Carbon Conversion}

For the oxygen blown KRW-based system with cold gas cleanup, the design assumptions assumed in most studies for eastern coal do not agree with operating maps developed by Shinnar, Avidan, and Weng (1988) for the performance of the KRW gasifier. The key assumptions in the conceptual designs are for carbon conversion efficiency, oxygen-to-coal ratio, and steam-to-coal ratio. Assumptions for several conceptual design studies, theoretical modeling studies, and PDU tests are given in Table A-7. The carbon conversion efficiencies assumed in design studies are typically around 95 percent (e.g., Dawkins et al, 1985; Smith and Smelser, 1987; Earley and Smelser, 1988). The oxygen-to-coal ratios are typically assumed to be $0.3 \mathrm{lbmole}$ oxygen $/ \mathrm{lbmole}$ carbon in the coal. The steam-to-oxygen ratios vary more widely in the design studies, from about 0.4 to $1.6 \mathrm{lbmole}$ steam/lbmole oxygen in oxygen-blown systems. However, an operating map developed by Shinnar, Avidan, and Weng (1988) for gasifier performance with a Pittsburgh No. 8 coal at $230 \mathrm{psi}$ indicates that at a temperature of about $1,850^{\circ} \mathrm{F}$ and a carbon conversion of about 95 percent, the required feed ratios are $0.5 \mathrm{lbmole}$ oxygen/lbmole carbon in the coal and $5.5 \mathrm{lbmole} \mathrm{steam/lbmole} \mathrm{oxygen.} \mathrm{Alternatively,} \mathrm{for}$ the conditions assumed in the conceptual studies (e.g., Dawkins et al, 1985), the carbon conversion is estimated from the operating map (neglecting differences in gasifier pressure) to be about 75 percent.

The carbon conversion depends on many factors. The gasification reaction rate is a complex and non-linear function of many variables, such as temperature, pressure, carbon conversion rate, and reactant and product partial pressures. The reaction rate is a strong function of temperature. The reaction rate is a nonlinear function of pressure and limited knowledge of the pressure dependency makes it difficult to predici gasifier performance at pressures higher than those experienced in the PDU. While increased pressure will allow a greater gas throughput in the gasifier, the reaction rate may not increase proportionately to allow for constant or increased carbon conversion. Thus, overall performance may suffer as pressure is increased; although throughput is increased, overall carbon conversion may be decreased (Shinnar et al, 1988).

As the carbon conversion rate increases, the gasification reaction rate decreases due to finite kinetics. Recycled tines which have already undergone significant carbon conversion in particular are believed to have very low gasification reaction rates. Also, fines introduced above the combustion zone, as in the KRW design, have a low residence time and a high recycle rate (Shinnar et al, 1988). Thus, fines may recycle through the system several times before conversion or, in some cases, escaping past the cyclone. 
The bed height in the gasifier influences the carbon conversion rate, presumably due to increased residence time and increased opportunities for reactants to interact in the bed. The carbon conversion is believed to increase linearly with the logarithm of bed height. Thus, there are very small benefits to incrementally increasing the bed height for large beds. Bed heights of 40 to 60 feet are believed to be economical. Baffles may improve mixing and avoid bypassing (channeling) in the bed (Shinnar et al, 1988).

The gasification rate increases as the partial pressure of steam, the key gaseous reactant, increases. Thus, design features such as raw gas recycle, which reduce the steam partial pressure, also reduce the gasification rate.

The carbon retention in gasifier bottom ash appears to be low for the KRW gasifier. An apparently common assumption in conceptual design studies is that the carbon retention in the bottom ash is less than one percent of the carbon in the feed coal (e.g., Earley and Smelser, 1988). These assumptions appear to be supported by KRW PDU testing for cases with in-bed desulfurization using calcium-based sorbents (Haldipur et al, 1989).

The major source of carbon loss in the KRW gasifier is commonly reported to be elutriated fines that escape the recycle cyclone. However, detail on the carbon content of such fines, the fines elutriation rate, and the capture efficiency of the recycle cyclone is somewhat lacking in the open literature. It appears that the typical capture efficiency assumed is 95 percent of the inlet fines on a mass basis (B!inn et al, 1989).

The KRW PDU gasifier does not operate near equilibrium. It appears unlikely that a scaled-up KRW gasifier will operate near equilibrium on eastern bituminous coal without changes in design or the use of a catalyst. For example, using dolomite or limestone as a sorbent for in-bed desulfurization, a catalytic effect of six (a six-fold improvement in relative reaction rate) was realized in the KRW PDU, as reported by Shinnar et al (1988). The increased conversion resulting from the catalytic effect implies that carbon conversion can be increased at a given operating temperature. Alternatively, the operating temperature can be increased to further improve the gasification rate.

By comparison with eastern bituminous coals, western subbituminous coals are non-caking, non-swelling, and up to two orders-of-magnitude more reactive in gasification. The non-caking nature of the western coals would facilitate feeding some or all of the coal directly into the fluidized bed, rather than through the combustion jet. Recycled fines could then be combusted by feeding them to the jet, improving the overall carbon conversion by burning high conversion char which would be slow to gasify. 
Eastern coals must be fed through the combustion jet because the intense mixing and devolatilization that occurs during combustion breaks up or prevents formation of char agglomerates. For this reason, the KRW gasifier is capable of directly handling a caking coal with no pretreatment, at the expense of reduced gasifier efficiency.

In the air-blown mode, Shinnar and Weng (1989) report modeling results which indicate that, when using a calcium-based sorbent for 85 percent in-bed desulfurization at 315 psia, an oxygen-to-carbon molar ratio of 0.45 and a steam-to-oxygen ratio of 0.5 is required for 95 percent carbon conversion at $1,950 \mathrm{o} F$.

In a series of KRW PDU tests, bituminous coals ranging from 1.5 to 4.5 percent sulfur content were gasified in air-blown mode using calcium-based sorbents. The carbon conversions estimated over 2,634 hours of testing ranged from 70 to 95 percent, depending on factors such as bed temperature and fines recycle efficiency. The bed temperature ranged from 1,800 to $2,000 \mathrm{oF}$, and the gasifier pressure was 245 psia. The presence of sorbent in the bed was reported to retard the passage of fines through the bed, presumably increasing fines residence time and increasing the per-pass consumption of carbon in recycle fines. Fines consumption was also improved due to the catalytic effect of the sorbent on the gasification reactions. In addition, losses associated with recycle raw gas were reported to be reduced when using calcium based sorbent, because changes in the fines particle size distribution and reduction in fines carryover reduced the the amount of recycle gas required (Haldipur et al, 1989).

Haldipur et al (1989) report that the fines loading into the recycle cyclone is on the order of 100,000 to 200,000 ppmw and that the fines exiting the recycle cyclone with the coal gas are on the order of 20,000 ppmw. Blinn et al (1989) assert that the carbon conversions in the PDU are low due to less than optimum cyclone performance that allows high fines loss. They report that a cyclone capture efficiency of 95 percent would result in a carbon conversion rate of 97 percent for a gasifier-desulfurizer operating on Eastern coal. Blinn et al also indicate that the particulates captured downstream of the recycle cyclone contain a significant amount of carbon, but do not indicate quantitatively the concentration.

Fines may be generated from fines entering with the coal feed that pass through the gasifier, fracturing of larger bed particles, or chemical destruction of large coal feed particles. Fines may be consumed by chemical consumption (e.g., gasification) or agglomeration with the ash. Fines escaping the cyclone are thus derived from various mechanisms of fines production in the gasifier (Haldipur et al, 1988). Fines which originate from the feed coal or from physical breakup of the feed coal are likely to have a 
high carbon concentration, while fines which are obtained from chemical consumption may or may not have a high carbon concentration. For example, some fines may be obtained from the combustion zone, in which devolatilization occurs. This may tend to increase the carbon concentration of the remaining particles.

\section{A. 2.2.4.4 In-Bed Desulfurization}

Sulfur removal during gasification using calcium-based sorbents has been demonstrated in the KRW process development unit (PDU). The sulfur absorption rate depends on the molar calcium-to-sulfur ratio $(\mathrm{Ca} / \mathrm{S})$ of the sorbent, the type of sorbent material used, and the sulfur content of the coal, among other factors. For a given sorbent, the sulfur removal increases as the $\mathrm{Ca} / \mathrm{S}$ ratio is increased. A few different types of calcium-based sorbents have been used in testing, including high-calcium, nagnesium, and dolomitic limestones. The dolomitic limestones have shown the most consistent sulfur removal performance. The sulfur removal efficiency is ultimately limited by equilibrium constraints, and the equilibrium sulfur removal efficiency increases as the coal sulfur content increases (Schmidt, Sadhukhan, and Lin, 1989).

The degree to which the equilibrium limits can be approached depend on kinetic and mass transfer variables. For example, minimizing gasifier temperature promotes sulfur absorption, as does minimizing the water vapor and carbon dioxide content of the fuel gas. A high carbon dioxide content may inhibit calcination of the sorbent, although PDU tests indicate that sorbent calcines almost completely in most cases. Maximizing the bed calcium content and the ratio of bed depth to gas velocity (a measure of gas residence time in the bed) also improves the desulfurization efficiency. Coals with high sulfur content and sorbents with high reactivity also favor high removal efficiency (Haldipur et al, 1989).

KRW Energy Systems, Inc. has developed an in-bed desulfurization model which relies on empirical data regarding reaction kinetics and measurements from PDU testing regarding several key performance parameters. The model is based on adjusting estimates of sulfur removal efficiency based on equilibrium calculations with a correction ter $m$ involving calcium concentration in the bed, gas residence time, the sulfidation rate constant, the fraction of sulfided calcium in the bed, and an empirical reaction order constant. Prediction of several key parameters, such as the weight fraction of calcium in the bed and the density of the bed, is reported to be difficult for commercial gasifiers. Furthermore, prediction of the $\mathrm{H}_{2} \mathrm{O}$ and $\mathrm{CO}_{2}$ content of the fuel gas, which are required to estimate equilibrium sulfur removal conditions, is also reported to be difficult, requiring the development of a fuel gas composition model. KRW Energy Systems has developed empirically-based regression correlations specific to the operating conditions of the PDU 
for the given coal to try to analyze experimental data (Haldipur et al, 1989). The model as it is reported thus does not appear directly appropriate for predicting the performance of a commercial scale gasifier.

In the KRW PDU, 85 to 95 percent overall desulfurization is reported, depending on the coal, using either limestone or dolomite. However, not all of the sulfur in the coal is released during gasification; a portion of it leaves the gasifier in the bottom ash. A reported conservatively high assumption is that 10 percent of the sulfur is not released in the gasifier for an Eastern coal (Haldipur et al, 1989). The amount of sulfur not released from the coal is believed to be higher in the case without in-bed desulfurization. Haldipur et al (1989) report that 10 to 20 percent of the sulfur in the coal was not released in PDU tests conducted without sorbent. Furthermore, it is reported that in previous PDU tests, typically 15 to 20 percent of the sulfur in the coal was not released. These data are based on sulfur balances. Based on an environmental characterization of the KRW PDU, Radian reports a combined 20 percent sulfur retention in ash, tertiary cyclone solids, and hot gas particulates for a Pittsburgh No. 8 coal with no sorbent (Scheffel and Skinner, 1988). The assumptions in conceptual design studies appear to be no sulfur retention or perhaps a nominal one percent sulfur retention in the bottom ash. However, more reasonable assumptions appear to be 10 to 20 percent sulfur retention without a sorbent, and a lower sulfur retention with sorbent. Based on the report by Haldipur et al (1989), it appears that the influence of in-bed calcium-based sorbents on coal sulfur release is not fully understood, but is believed to promote sulfur release.

The nominal expected in-bed desulfurization for a high sulfur (e.g., 4.5 percent) coal is 90 percent (Haldipur et al, 1988). For dolomitic limestone, this removal rate is commonly assumed in conceptual design studies to occur at a $\mathrm{Ca} / \mathrm{S}$ ratio of 1.8 (e.g., Smelser, 1986; Earley and Smelser, 1988). However, the actual $\mathrm{Ca} / \mathrm{S}$ ratio required to achieve 90 percent sulfur removal for a given coal and sorbent also depends on the residence time in the gasifier. Based on a graph presented by Haldipur et al (1988) for the PDU using a 4.5 percent sulfur coal, 90 percent sulfur removal may be achievable with dolomitic limestone at a $\mathrm{Ca} / \mathrm{S}$ ratio as low as 1.4 for a gas residence time of near 18 seconds, or a $\mathrm{Ca} / \mathrm{S}$ ratio of about 1.7 at a residence time of about 13 seconds. In contrast, for a high-calcium limestone, the reported $\mathrm{Ca} / \mathrm{S}$ ratios for the same residence times are approximately 2.4 and 4 , respectively. 
In a more recent study, Haldipur et al (1989) estimate the $\mathrm{Ca} / \mathrm{S}$ ratios for dolomite and high-calcium limestone required to achieve 90 percent sulfur removal for Pittsburgh No. 8 coal as follows:

"In a commercial-scale gasifier, 90 percent sulfur removal is predicted when feeding a dolomitic limestone at a calcium-to-sulfur molar feed ratio ranging from 1.2 to 1.5 . For a high-calcium limestone, a required feed ratio from 2.3 to 2.8 is projected." (p. 66 , vol 1 )

Haldipur et al (1989) report that the estimated gas residence time in the PDU gasifier is about 15 seconds, but that residence times as high as 20 seconds are expected to be feasible for commercial-scale units. For dolomitic limestones, Haldipur et al (1989) report that $\mathrm{Ca} / \mathrm{S}$ ratios as low as 1.1 may be possible, with a more likely value of 1.4 expected for either Pittsburgh No. 8 or Upper Freeport coals. Similarly, high-calcium limestones, which have a lower reaction rate constant than dolomitic limestones, are expected to require a minimum $\mathrm{Ca} / \mathrm{S}$ ratio of 2 and a likely value of about 2.6. The basis for these ranges is not given, and it is unclear whether the ranges are based on possible variations in design or operating conditions in a commercial gasifier, uncertainty in estimates of key performance parameters used to estimate the $\mathrm{Ca} / \mathrm{S}$ ratio, or statistical error based on regression analysis of PDU test data extrapolated to try to predict commercial-scale gasifier performance.

Reduction of the $\mathrm{Ca} / \mathrm{S}$ ratio can be achieved by: lowering the gasifier pressure, lowering the gasifier temperature, lower coal ash content, higher coal sulfur content, and smaller sorbent particle diameter, in addition to other effects discussed previously (Haldipur et al, 1989).

\section{A.2.2.4.5 Effect of Sorbent on Gasifier Performance}

There is general agreement that calcium-based sorbents catalyze the gasification reactions, increasing the reactivity of eastern coals. For example, the reactivity of Pittsburgh No. 8 coal appears to triple with the use of a limestone sorbent (Floyd and Agrawal, 1989). This implies that carbon conversion efficiencies should be higher with inbed desulfurization. A sorbent may also reduce the caking tendency of bituminous coals, thereby allowing the gasifier to operate at higher temperatures, which also would tend to increase carbon conversion as discussed previously (Shinnar, Avidan, and Weng, 1988). Based on PDU tests with limestone, the design operating temperature for the Appalachian clean coal technology demonstration project featuring a KRW gasifier using a high sulfur eastern coal was raised from $1,850^{\circ} \mathrm{F}$ to $1,900^{\circ} \mathrm{F}$ (Banchik, Buckman, and Rath, 1988).

There appears to be less consensus on the effect of calcium sorbents on the environmental performance of the gasifier. For example, a conceptual design study (Earley 
and Smelser, 1988) reports that ammonia production is less with in-bed desulfurization than without, particularly for high calcium limestone. But an environmental study by Radian (Scheffel and Skinner, 1988), based on testing of the PDU, does not indicate any reduction in ammonia production with dolomite compared to without a sorbent. Earley and Smelser (1988) also report that pilot plant data indicate reduced production of methane with sorbents. The increased gasification rate resulting from use of a calcium sorbent is reported to increase fines consumption in the gasifier and reduce fines elutriation (Banchik, Buckman, and Rath, 1988).

\section{A.2.2.4.6 Ammonia Production}

For the KRW system with cold gas cleanup, ammonia yield from the gasifier is not an air pollution concern because the ammonia is almost completely removed by wet scrubbing. However, for the hot gas cleanup system, the ammonia yield will affect $\mathrm{NO}_{\mathrm{x}}$ emissions in the gas turbine combustor because ammonia is not removed in the hot gas cleanup systems assumed in most studies (e.g., Cincotta, 1984). In a conventional gas turbine combustor, about 70 percent of the ammonia in the fuel gas will be converted to $\mathrm{NO}_{\mathbf{x}}$. If the anmonia content of the fuel gas is sufficiently high, alternative gas turbine combustor designs, such as rich/lean staged combustion or catalytic combustion, may be required to maintain $\mathrm{NO}_{\mathrm{x}}$ emissions within applicable standards.

Some conceptual design studies report that the gasifier ammonia yield decreases for in-bed desulfurization compared to gasification without a sorbent and depends on the type of sorbent used (e.g., high calcium limestone or dolomite) (Earley and Smelser, 1988). For example, a conceptual design study (Earley and Smelser, 1988) reports that ammonia production is less with in-bed desulfurization than without, particularly for high calcium limestone. In a summary of testing with the KRW PDU, Haldipur et al (1989) report that when using sorbent in the gasifier the nitrogen yield of the gasifier corresponded to an equivalent of conversion of 0.6 to 8.8 weight percent of the nitrogen in the coal.

An environmental study by Radian (Scheffel and Skinner, 1988) based on testing of the PDU does not indicate any reduction in ammonia production with dolomite compared to gasification without a sorbent. In two set points without dolomite injection, the ammonia production was equivalent to a conversion of 9.1 and 7.8 percent of the coal nitrogen. In a set point with dolomite, the ammonia production was equivalent to a conversion of 10.6 percent of the coal nitrogen. The tests were conducted in air-blown mode using Pittsburgh No. 8 coal with a 1.4 percent nitrogen content on a dry basis. 
For an oxygen-blown system operating without in-bed desulfurization, a recent design study indicates that an equivalent of about 25 percent of the coal-bound nitrogen is converted to ammonia. Because a wet scrubbing system is employed for gas cooling and cleanup in this design, the ammonia is removed prior to firing the fuel gas in the gas turbine (Gallaspy et al, 1990).

\section{A.2.2.4.7 Spent Sorbent Sulfation}

For the air-blown KRW-based system with in-bed desulfurization, the spent sorbent is a component of the gasifier bottom ash waste stream. This sorbent contains calcium sulfide $(\mathrm{CaS})$ which is not acceptable for landfilling. Untreated spent sorbent can release sufficient quantities of hydrogen sulfide to violate RCRA standards when exposed to sulfuric acid. To comply with RCRA, a portion of the CaS must be oxidized to the more stable calcium sulfate $\left(\mathrm{CaSO}_{4}\right)$, which is then suitable for disposal. The oxidation of calcium sulfide can occur by roasting in air, at a temperature high enough for rapid conversion but low enough to avoid excessive $\mathrm{SO}_{2}$ emissions. A pilot plant has achieved 20 to 30 percent conversion of calcium sulfide in spent limestone in the waste stream, which is claimed to be sufficient to meet the nonhazardous waste criteria of the RCRA standards. In the case of dolomite, the conversion rate is significantly higher, and it is reported to be about 55 percent. The leachate from the treated waste also meets the toxicity requirements for $\mathrm{Ag}, \mathrm{As}, \mathrm{Ba}, \mathrm{Cd}, \mathrm{Cr}, \mathrm{Hg}, \mathrm{Pb}$, and $\mathrm{Se}$ under RCRA (Haldipur et al, 1989).

For a commercial plant design, the sulfation unit is envisioned to be a circulating fluidized bed combustor, which is expected to operate at temperatures appropriate for good sulfide conversion and for minimal $\mathrm{SO}_{2}$ emissions. The gasifier ash waste stream also includes unconverted carbon. In addition, nonrecycled fines captured downstream of the gasifier in high efficiency cyclones or other hot gas particulate control devices also contain unconverted carbon. These collected fines can also be sent to the sulfation unit for combustion. Therefore, a sulfation unit can recover the heating value of unconverted carbon. The heat released from the sulfation reaction and combustion of unconverted carbon can be used to generate steam, and thus to reduce the energy penalty associated with incomplete carbon conversion in the gasifier (Earley and Smelser, 1988).

The sulfation unit is an additional emission source. Fluidized bed combustors generally have more uniform flame temperacures than conventional types of systems; therefore, the $\mathrm{NO}_{\mathrm{x}}$ emissions from these systems are comparatively low. The sulfur emissions in the sulfation unit can stem from several sources, including sulfur retained in the coal bottom ash, sulfur retained on unconverted fines, and sulfur chemically bound with calcium. By proper control of the sulfation unit combustion temperatures, sulfur 
release from the sorbent is expected to be minimum. However, according to PDU data, it appears that 10 to 20 percent of the sulfur in the coal feed is retained in the bottom ash and tertiary solids captured from the fuel gas. It is unclear, however, if the sulfur in the ash and fines solids is released in the sulfation unit and, if so, if it is captured by unreacted calcium sorbent in the fluidized bed (recall that the molar feed ratio of calcium to the gasifier exceeds stoichiometric requirements) or emitted as $\mathrm{SO}_{2}$. It is unclear if perhaps additional sorbent might be required to control $\mathrm{SO}_{2}$ emissions from the sulfation unit.

According to Earley and Smelser (1988), the $\mathrm{SO}_{2}$ and $\mathrm{NO}_{\mathrm{x}}$ emission rates from a sulfation circulating fluidized bed combustor are expected to be $0.01 \mathrm{lb} \mathrm{SO} / \mathrm{MMBtu}$ and $0.15 \mathrm{lb} \mathrm{NO} / \mathrm{MMBtu}$, respectively. These are well below the NSPS limits for steam generators fired with bituminous coal. Whether the NSPS standard is applicable to this emission source is not yet known. Particulate emissions are expected to be controlled by a fabric filter to less than $0.03 \mathrm{lb} / \mathrm{MMBtu}$.

To achieve more complete conversion of sulfide to sulfate, additives containing sodium carbonate have ben tested. According to Haldipur et al (1989), under a fairly narrow range of conditions, the additive promotes near complete conversion of calcium sulfide to oxidized products. The conditions evaluated in a small-scale test study include a temperature of $1,831 \mathrm{~F}$ and an oxygen concentration of 10 percent or higher. According to Earley and Smelser (1988), the cost of the additive would have a small effect on levelized plant costs.

\section{A.2.2.5 Technical Judgments About Uncertainties}

Originally, a three-part briefing package was to be distributed to engineers at DOE/METC to obtain expert judgments regarding uncertainties in selected KRW gasifier and related parameters. The briefing package was prepared. However, because of personnel constraints at DOE/METC, the briefing package could not be distributed. Furthermore, engineers at KRW Energy Systems declined to participate in the current study, citing concerns about the proprietary nature of data that might be released. Therefore, judgments regarding initial uncertainties for a probabilistic screening study are made here by the authors based on information in the published literature reviewed in the preceding sections. Each process parameter which was considered for probabilistic treatment is discussed below. The parameters that are treated probabilistically are given in Table A-8. The judgments are confined to the oxygen-blown configuration of the KRW gasifier without the use of an in-bed sorbent for desulfurization. 
Table A-8. Summary of Assumed Uncertainties for the KRW Gasifier Process Area.

\begin{tabular}{|c|c|c|c|c|c|}
\hline Description and Units & Distribution & \multicolumn{4}{|c|}{ Parameters ${ }^{a}$} \\
\hline$\frac{\text { Qverall Carbon Conversion, }}{\text { wt-\% of feed coal carbon }}$ & Triangular & 75 & to & 95 & $(95)$ \\
\hline$\frac{\text { Oxygen/Carbon Ratio, }}{\text { lbmole } \mathrm{O}_{2} / 1 \text { bmole C }}$ & Uniform & 0.33 & to & 0.35 & \\
\hline$\frac{\text { Steam/Oxygen Ratio, }}{\text { lbmole } \mathrm{H}_{2} \mathrm{O} / \mathrm{lbmole} \mathrm{O}_{2}}$ & Uniform & 1.1 & to & 1.6 & \\
\hline$\frac{\text { Carbon Retention in Bottom Ash, }}{\text { wt-\% of coal feed carbon }}$ & Uniform & 0.5 & to & 1.0 & \\
\hline$\frac{\text { Sulfur Retention in Bottom Ash, }}{\text { mol-\% of inlet sulfur }}$ & Triangular & 10 & to & 20 & $(15)$ \\
\hline Gasifier Temperature, of & $\mathrm{n} / \mathrm{a}$ & 1,850 & & & \\
\hline $\begin{array}{l}\text { Gasifier Ammonia Yield, } \\
\begin{array}{l}\text { Equiv. fraction of coal } \mathrm{N} \\
\text { converted to } \mathrm{NH}_{3}\end{array}\end{array}$ & Triangular & 0.10 & to & 0.25 & 0.25 \\
\hline
\end{tabular}

a For Uniform distributions, the lower and upper bounds are given. For the triangular distribution, the mode is given in parentheses. For the fractile distribution, the lower and upper bounds for each range are given, along with the probability of sampling within that range. 
Overall Carbon Conversion and Feed Ratios. Carbon conversion is related to many aspects of gasifier design and operation, as discussed in Section A.2.2.4.3. For the oxygen-blown case, carbon conversions of around 95 percent are typically assumed in the literature. However, for a given oxygen/carbon and steam/oxygen ratio in a commercial scale gasifier, there appears to be uncertainty regarding the carbon conversion that would actualiy be obtained. The approach taken here is to use typical values for the reactant feed ratios based on published conceptual design studies and to assume a resulting characterization of uncertainty in carbon conversion. Most of the conceptual design studies that have been reviewed assume an oxygen-to-carbon ratio of 0.33 to 0.34 (see Table A-7). These studies also assume steam-to-oxygen ratios of 0.36 to 1.59 , with most estimates clustered above 1.1. While carbon conversions of around 95 percent were assumed in these studies, Shinnar et al (1988) indicate that such a high conversion rate cannot be achieved with such low steam/oxygen ratios. In fact, modeling results from Shinnar et al suggest that a carbon conversion of only 75 percent might result from the proposed oxygen and steam feed ratios, although these values are dependent on design and operating details of a particular gasifier. For the initial screening study, the carbon conversion will be assumed to vary from 75 to 95 percent,with values near the upper limit assumed to be more likely than those near the lower limit. A small range of uncertainty for the oxygen/carbon ratio is assumed, representing the variability observed across design studies. The range of values reported in design studies for the steam/oxygen ratio will form the basis for assigning uncertainty to this parameter. However, it is assumed that the steam/oxygen ratio will have a correlation with the carbon conversion rate.

Sulfur Removal. A portion of the sulfur in the coal is expected to be retained in bottom ash or unrecycled fines. As indicated in the technical background discussion, perhaps 10 to 20 percent of sulfur in the coal is not released even when a sorbent is not used. This range is used as the basis for characterizing uncertainty, with the midpoint of the range assumed to be the mode of a triangular distribution. Therefore, the assumed "most likely" value for sulfur capture is 15 percent without sorbent.

Gasifier Bed Temperature. For the oxygen-blown gasifier without in-bed desulfurization, the universally assumed operating temperature for bituminous coal is 1,850 ${ }^{\circ} \mathrm{F}$, and that temperature is adopted here without uncertainty.

Ammonia Yield. Based on the previous technical discussion, it appears that ammonia yield with sorbent is expected to be lower than without sorbent. Without sorbent, ammonia yield may be equivalent to conversion of 25 percent of coal-bound nitrogen, 
although some tests show it to be around 10 percent. With sorbent, tests have indicated equivalent nitrogen conversions as low as 0.6 percent up to about 10 percent. For systems with cold gas cleanup, virtually all of the ammonia will be removed during wet scrubbing. For the case with hot gas cleanup, the anmonia may be converted to $\mathrm{NO}_{\mathrm{x}}$ in the gas turbine combustor. Without sorbent, it is assumed here that 10 to 25 percent of the coal-bound nitrogen may be converted to ammonia. The upper limit is assumed as the mode of a triangular distribution.

Correlations. Proposed correlations structures for the oxygen-blown case without sorbent are shown in Table A-9. It is assumed that carbon conversion will tend to improve as the steam/oxygen ratio is increased. Therefore, a nominal correlation of 0.75 is assumed between carbon conversion and the steam/oxygen ratio. The purpose of inducing this correlation between these two parameters is to identify whether such a correlation significantly changes the answer obtained from the modeling. If the correlation has a significant effect on model results, that would imply that further effort should be developed to modeling the interdependence between the tw'o parameters that is not captured by the current model.

This correlations are intended to be representative of trends observed in the literature. To the extent that these correlations have an important effect on model results, they would indicate that further model development is warranted to better characterize these interdependencies. 
Table A-9. Proposed Correlation Matrix for KRW Gasification Uncertain Parameters: Oxygen-Blown Case Without Sorbent

\begin{tabular}{|c|c|c|c|c|c|c|c|}
\hline \multirow[b]{2}{*}{ Description } & \multirow[b]{2}{*}{ Number } & \multicolumn{5}{|c|}{ Assumed Correlation Coefficients ${ }^{\mathrm{a}}$} & \multirow[b]{2}{*}{6} \\
\hline & & 1 & 2 & 3 & 4 & 5 & \\
\hline Carbon Conversion & 1 & 1.00 & & & & & \\
\hline Oxygen/Carbon Ratio & 2 & $-\infty$ & 1.00 & & & & \\
\hline Stear. Oxygen Ratio & 3 & 0.75 & -- & 1.00 & & & \\
\hline $\begin{array}{l}\text { Carbon Retention } \\
\text { in Bottom Ash }\end{array}$ & 4 & -- & -- & -- & 1.00 & & \\
\hline $\begin{array}{l}\text { Sulfur Retention } \\
\text { in Bottom Ash }\end{array}$ & 5 & - & -- & -- & -- & 1.00 & \\
\hline $\begin{array}{l}\text { Gasifier Ammonia } \\
\text { Yield }\end{array}$ & 6 & -- & -- & -- & -- & -- & 1.00 \\
\hline
\end{tabular}

a For uncorrelated parameters, a dashed line ". -." is shown. 
This page intentionally left blank, with the exception of this sentence. 


\section{A.3 Technical Background and Uncertainty Estimates for the Fixed-Bed Zinc Ferrite Process Area}

This section concerns a concept for removing hydrogen sulfide from the high temper : ure, high pressure raw product gas exiting a gasifier. Hydrogen sulfide is the principle gaseous sulfur species in coal gas and must be removed for compliance with emission regulations and for protection of the gas turbine from deposition of alkali sulfates. The fixed-bed zinc ferrite desulfurization process has been proposed as part of both a fixedbed dry-ash Lurgi gasifier-based IGCC system and a fluidized-bed agglomerated-ash KRW gasifier-based system. The Lurgi-based system, which is the subject of case studies in this study, is shown in Figure A-2 (see Section A.2).

\section{A.3.1 Process Description}

The zinc ferrite process area consists of multiple trains of two-vessel systems, in which one vessel is in sulfur absorption mode while the other vessel is in regeneration mode, as shown in Figure A-13. Absorption occurs at high pressure (e.g., 300 psia) and an inlet syngas temperature of around $1,100 \mathrm{oF}$. Regeneration is assumed to occur at the same pressure. Both IGCC systems are assumed to consume an Illinois No. 6 coal. The product of regeneration is an offgas containing $\mathrm{SO}_{2}$. This offgas may be recycled to the gasifier when in situ desulfurization is employed with a sorbent fed to the gasifier, or sent to a sulfuric acid plant for byproduct recovery.

Two modes of desulfurization are envisioned for zinc ferrite systems. "Bulk desulfurization" is the term given for application of the zinc ferrite process to gas streams with high concentrations (e.g., 5,000 prmv) of gaseous sulfur species, and "polishing desulfurization" is the term for application of the process to streams with low sulfur concentrations (e.g., 1,000 ppmv or less). For the Lurgi-based system, the zinc ferrite process is used for "bulk" desulfurization. One high efficiency cyclone is assumed to be located upstream of the absorber and one cyclone is located downstream of the absorber. The upstream cyclone is required to prevent the build-up of particles in the sorbent bed, which could lead to increased pressure drop across the absorber. The downstream cyclone may be required to prevent entrained sorbent particles and ash particles from entering the gas turbine combustor. The systems use advanced high firing temperature gas turbines. 


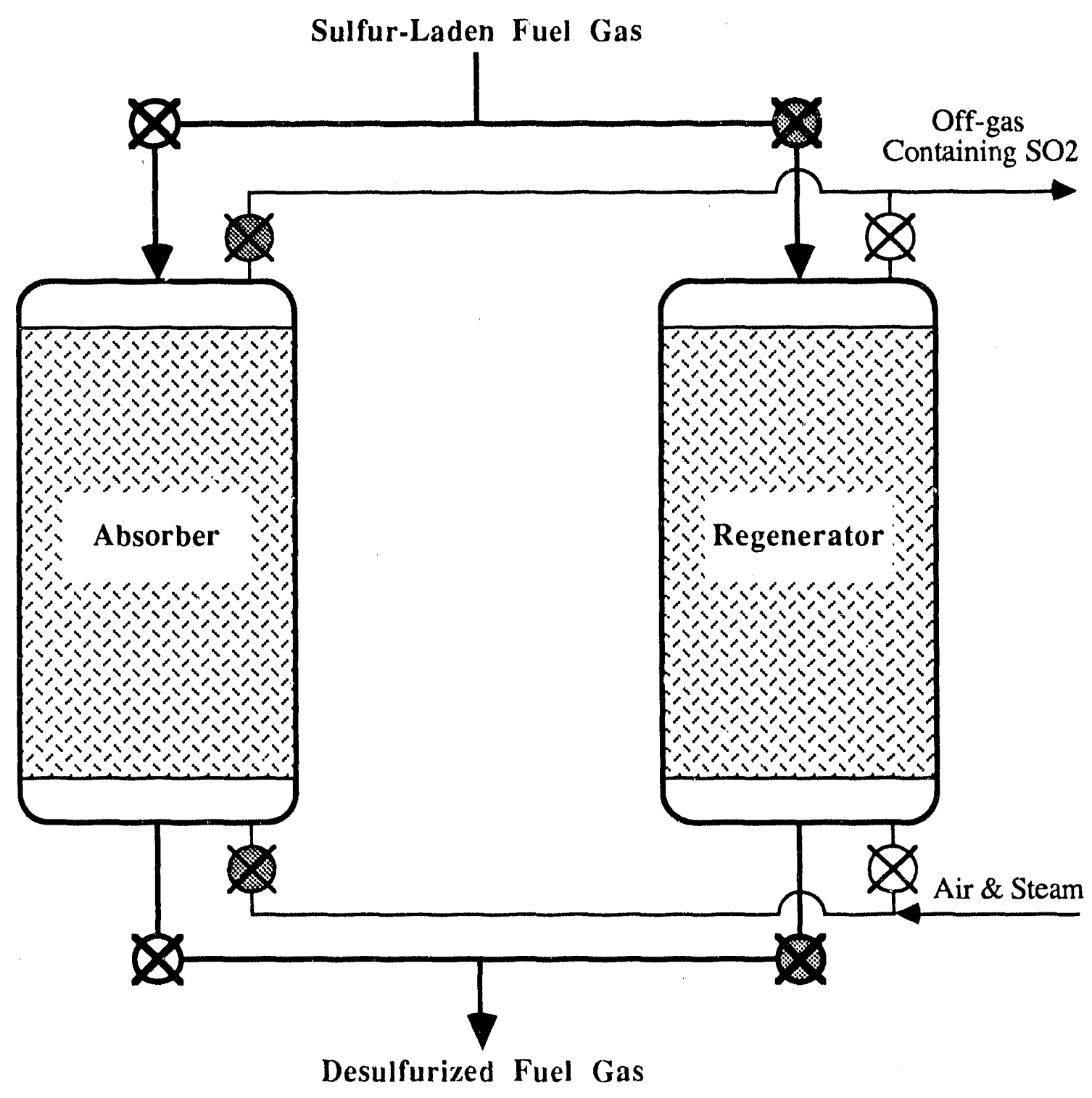

Figure A-13. Simple Schematic of the Fixed-Bed Zinc Ferrite Process. 
The zinc ferrite absorber/regenerator reactors are assumed to be vertical cylinders with a maximum diameter of 12.5 feet and a maximum length-to-diameter ratio of 4 . These sizing constraints are intended to represent rail-shippable size limits and an economical aspect ratio, based on recommendations by Kasper (1988).

\section{A.3.2 Key Technical Issues}

The following is a brief summary of some of the key technical and cost issues which have been identified based on a review of some recent literature and limited discussions with process developer's. Various studies of the fixed-bed zinc ferrite process have included:

- Laboratory and bench scale tests at DOE/METC

- Process development unit (PDU) tests at KRW Energy Systems, Inc.

- Sulfidation models by Louisiana State University

- Sorbent characterizations by Amax

Limitations of the test results include a small number of data points, wide scatter in the data, lack of extended life tests, and testing of only relatively small sorbent beds compared to envisioned commercial-scale systems. In the following sections, factors contributing to uncertainty in several aspects of the fixed-bed zinc ferrite process will be discussed.

Sorbent Sulfur Loading. The theoretical sorbent sulfur loading is about 35 weight percent of the fully sulfated zinc ferrite sorbent. Factors such as space velocity, linear velocity, bed depth, number of regeneration cycles, masking by particulate and coke deposition, and flow channeling are expected to affect the achievable capacity for commercial units. In bench-scale and PDU tests the actual loadings have varied widely. Some reported results are:

- About 15 percent sorbent sulfur lcading in the METC 6-inch diameter absorber with a side-stream from the METC 42 -inch fixed bed gasifier at pressures of about 90 to 150 psig, temperatures of $1,000 \mathrm{oF}$, and space velocities of typically 2000/hr with an Arkwright coal and few regeneration cycles (Underkoffler, 1986).

- About 25 percent sorbent sulfur loading in the METC 6-inch diameter absorber with a side-stream from the METC 4).-inch fixed bed gasifier at pressures of about $120 \mathrm{psig}$, temperatures of $1,000^{\circ} \mathrm{F}$, and space velocities of typically $1000 / \mathrm{hr}$ with various coals and few regeneration cycles (Underkoffler, 1986). Sorbent capacity appeared to decline after two regenerations to 14 percent.

- 30 percent sorbent sulfur loading in the bulk polishing mode with a superficial gas velocity of only $0.25 \mathrm{ft} / \mathrm{sec}$ in the KRW Energy Systems PDU (Smith, Haldipur, and Lucas, 1987) 
- 10 percent sorbent sulfur loading in polishing model with a superficial gas velocity of $0.7 \mathrm{ft} / \mathrm{sec}$ in the KRW Energy Systems PDU (Haldipur et al, 1988).

In the past few years, the assumptions for sulfur loading used in conceptual performance and cost studies of commercial-size units have decreased. Studies by Cincotta (1984), Corman (1986), sixerser (1986), and Smith and Smelser (1987) apparently used sorbent sulfur loadings shoung 30 percent (the actual assumptions are not reported). Klett et al (1986) used a loading of 22.3 percent. A more recent study explicitly states an assumption of 10 percent (Earley and Smelser, 1988). In this latter study, it is reported that KRW Energy Systems expects improved sorbent sulfur loading of 17 percent for commercial scale systems operating in polishing mode.

Commercial scale designs must be based on the expected long-term loading associated with many cycles of absorption and regeneration. In a recent METC paper, the recommended long term (i.e. more than 40 absorption and regeneration cycles) assumption for sorbent sulfur loading is 10 percent for bulk desulfurization mode. In the short term (i.e. the first cycle) a sulfur loading of 32 percent may be possible (Kasper, 1988), although few tests have apparently achieved such high loading levels, even in the saturated zone of the sactor closest to the coal gas inlet.

The sorbent loading capability is a function of temperature. To achieve maximum absorption, an absorption temperature window from 1,000 to 1,200 oF has been suggested by many researchers. As conditions such as reactor size and actual fuel gas composition change, a different optimum temperature may be established. At higher temperatures, sintering of the sorbent and zinc vapor carry-over is expected. Furthermore, the sorbent would no longer be in the magnetite composition region, weakening the sorbent (Underkoffler, 1986).

The sorbent capacity also may be a function of the inlet sulfur concentration. Data obtained by KRW Energy Systems suggest that the capacity in the saturated zone of the reactor increases as the inlet sulfur concentration increases (Haldipur, Schmidt, and Smith, 1989), presumably due to reaction kinetics considerations. However, the average capacity of the sorbent will be less than the capacity of the saturated zone, because $i$ i the absorption front zone the sorbent sulfur loading tapers to zero toward the gas exit prior to sulfur breakthrough.

Modeling results suggest that the reaction rate is limited by the effective diffusivity of the sorbent. This is the rate at which reactant gas diffuses through the pores of the 
sorbent. The effective diffusivity is expected to decrease gradually with sulfidation/regeneration cycling (Wang et al, 1988).

Absorption Superficial Gas Velocity. Bench scale and PDU tests have used relatively low superficial velocities. The superficial velocity in KRW Energy System tests ranged from 0.10 to $1.35 \mathrm{ft} / \mathrm{sec}$, with most tests well below $1 \mathrm{ft} / \mathrm{sec}$. The expectations for commercial scale systems appear to range from $1.2 \mathrm{ft} / \mathrm{sec}$ (Haldipur et al, 1988) to a maximum of $2 \mathrm{ft} / \mathrm{sec}$ (Kasper, 1988). It is unclear if these numbers depend on the desulfurization mode (e.g., polishing, bulk). However, it appears that no tests have been performed with the higher superficial velocities that are assumed as the basis for commercial scale designs.

Klett et al (1986) assumed superficial gas velocities of less than $1 \mathrm{ft} / \mathrm{sec}$ in a conceptual design study.

Absorption Space Velocity. The commonly recommended maximum space velocity is $2,000 / \mathrm{hr}$ (Kasper, 1988). The space velocity is related to the sorbent absorption cycle time and to the sorbent sulfur loading. For low sorbent sulfur loadings, a lower space velocity may be required.

Absorption Cycle Time. The design basis for the study by Earley and Smelser (1988) is for 168 hours of continuous sulfidation, followed by a regeneration cycle with a minimum time of 48 hours. Absorption time until sulfur breakthrough during testing by KRW in polishing mode has typically been 55 to 60 hours (Haldipur, Schmidt, and Smith, 1989).

Sorbent Replacement Rate. A recommended design basis value for sorbent attrition is 0.0022 weight fraction of sorbent per cycle (Kasper, 1988). This recommended value is apparently an average value from test results. The statistical or measurement error is not reported. The use of laboratory and PDU data to estimate commercial scale data implies that there are no scale up issues which would affect sorbent attrition. The validity of this assumption has not been discussed in the paper. Furthermore, the assumption appears to be that sorbent attrition is constant over each cycle.

Based on the above assumption, Kasper indicates that about 20 percent of the sorbent must be replaced every 80 cycles of absorption and regeneration. An earlier study assumed complete replacement of the sorbent every 300 cycles, which is equivalent to 0.0033 weight fraction per cycle (Klett et al, 1986). Sorbent may have to be replaced due to physical attrition and due to loss of chemical reactivity. 
Sorbent Bulk Density. For the purposes of sizing reactor vessels, a sorbent bulk density of $82 \mathrm{lb} / \mathrm{ft}^{3}$ has been suggested by Kasper (1988).

Absorber Pressure Drop. Tests by KRW Energy Systems with particle-laden (800 to 1,200 ppmw of char solids) fuel gas entering the absorber resulted in substantial pressure drop increases of 15 to 30 inches of water per hour depending on the superficial gas velocity and solids content. It was concluded that, for application with a KRW-based system with in-bed desulfurization, a nominally particle-free inlet gas is required (Haldipur et al, 1988). A later report concludes that barrier filtration (i.e. with a ceramic filter) is superior to the use of high efficiency cyclones and that the lower solids loading of $<15$ ppmv obtained from barrier filtration allows desulfurization to the full capacity of the bed without an increase in pressure drop (Haldipur, Schmidt, and Smith, 1989). However, others have assumed that high efficiency cyclones are sufficient. In particular, a clean coal technology program demonstration project featuring a hot gas cleanup system is based on the use of cyclones for particle removal (Hester and Pless, 1990).

In tests with the METC 6-inch zinc ferrite absorber using a sidestream from the 42inch fixed bed gasifier, pressure drops appeared to routinely increase substantially due to the deposition of particulates and coke in the absorber bed (Underkoffler, 1986).

Absorber pressure drop is also expected to increase as sorbent pellets disintegrate over time (attrition) (Kasper, 1988).

To overcome increases in pressure drop, it is expected that the pressure ratio of the boost air compressor must be increased, according to one report (Haldipur, Schmidt, and Smith, 1989).

Sulfidation Temperature. A temperature window of 1,000 to 1,200 o $\mathrm{F}$ has been commonly assumed. See section on sorbent sulfur loading.

Fuel Gas Conditioning. The formation of iron carbide $\left(\mathrm{Fe}_{3} \mathrm{C}\right)$ or wustite $(\mathrm{FeO})$ reduces the sulfur absorption capacity of the sorbent. The formation of soot deposits also interferes with sulfur absorption. The fuel gas must be conditioned such that wustite or carbides do not form and carbon is not deposited from the gas phase on the sorbent pellets (Haldipur, Schmidt, and Smith, 1989). A commonly-used assumption is that the $\mathrm{CO} /\left(\mathrm{CO}+\mathrm{CO}_{2}\right)$ ratio must be less than 0.4 , which can be achieved by steam conditioning of the fuel gas if necessary, which promotes the water-gas shift reaction. Because of the high moisture content of the raw fuel gas in the Lurgi-based system, it is not expected to be necessary to add steam if the water-gas shift reaction is in equilibrium. 
Qutlet Sulfur Concentration. The common assumption is that the zinc ferrite system in commercial scale application will achieve an outlet sulfur concentration of $10 \mathrm{ppmv}$ or less. The KRW Energy Systems tests often achieved outlet concentrations higher than this target. Some tests had outlet sulfur concentrations near 30 ppmv (Haldipur, Schmidt, and Smith, 1989).

The outlet sulfur concentration must remain low enough so that the plant complies with emission permits and to remain above the acid dew point limit of the heat recovery steam generator downstream of the gas turbine combustor (Haldipur, Schmidt, and Smith, 1989).

Lab scale testing using a side-stream of METC's fixed bed gasifier and a 6 inch diameter fixed-bed zinc ferrite reactor indicated that tars and oils or particulates in the fuel gas do not inhibit the level to which $\mathrm{H}_{2} \mathrm{~S}$ in the gas is removed (Underkoffler, 1986). However, only low molecular weight sulfur compounds were absorbed. For a fixed bed gasifier, Hester and Pless (1990) report that one to four percent of the sulfur in the coal feed is bound in long-chain organic tar vapor, which is not removed by the zinc ferrite process.

Alkali and Halides. The sorbent may remove alkali metals and halides to a large extent and release them during regeneration. Vanadiurn, calcium, and mercury were similarly removed to some extent. This removal may be associated with particulatis in the feed gas that are captured in the zinc ferrite absorber vessel. Ammonia may also be removed to some extent (Underkoffler, 1986). However, there is little documentation of such removal.

Regeneration. While regeneration is often assumed to occur at high pressure in fixed-bed systems, there may be a benefit to regenerating at low pressure in terms of plant efficiency and integration of the regeneration off-gas with a sulfuric acid byproduct recovery system. A two-step regeneration sequence is envisioned by Kasper (1988) and others. In the first step, regeneration occurs by reacting the sulfated sorbent with a stoichiometric amount of oxygen. Because this oxidative phase of regeneration is highly exothermic, steam is to be used as diluent to avoid sintering of the sorbent. It has been assumed that the regeneration bed temperature must not exceed 1,450 of to avoid sintering of the sorbent (Kasper, 1988).

During the oxidative regenesation phase, some of the absorbed sulfur may be converted to sulfates, which would be evolved as sulfur dioxide during the beginning of 
the following absorption cycle. Thus, a second reducing regeneration phase may be required, in which the sulfates react with either hydrogen or carbon monoxide. The reducing cycle may be about one hour of the total regeneration cycle time. Space velocities of 600 /hour for both the oxidation and reducing phases have been recommended (Kasper, 1988). Steam and air are assumed to be used for oxidative regeneration, while fuel gas is used for the reductive regeneration step to reduce sulfates in the sorbent.

Off Gas and Byproduct Recovery. Studies by General Electric of IGCC systems with the fixed bed zinc ferrite process have assumed off-gas pretreatment prior to entering a sulfuric acid plant. Pretreatment includes adiabatic cooling by humidification, further cooling in a tower with circulating weak sulfuric acid, acid mist removal, particulate removal, and drying in a drying tower (Cincotta, 1984).

Sorbent Cost. The assumed commercial cost of zinc ferrite sorbent has varied significantly in different studies. For example, in Banchik and Cover (1988), the cost is assumed to be vary from $\$ 4 / 1 \mathrm{~b}$ to $\$ 10 / 1 \mathrm{~b}$. Pitrolo and Bechtel (1987) indicate that current sorbent costs are $\$ 5 / 1 \mathrm{~b}$ and that the target cost for commercial sorbent is $\$ 2 / 1 \mathrm{lb}$. Kasper (1988) indicates that the projected commercial price is $\$ 3 / 1 \mathrm{~b}$.

Capital and Maintenance Costs. For commercial scale application, the zinc ferrite system must have a safe, reliable, and automatic system for proper valving of the fuel gas for sulfidation, regeneration gases for oxidative and reductive regeneration, inert gases for purging between cycles, and sorbent replacement. Thus, the valving, piping, and controls for the zinc ferrite system are complex. Furthermore, the cycling of pressure, temperature, and oxygen content in the reactor vessels may lead to long-run vessel damage (Koch, 1989).

As an aside, several studies by the Rand Corporation have examined the historical tendency for the capital sst of pioneer (first-of-a-kind) chemical process plants to be underestimated, especially in early stages of process development (e.g., Merrow et al, 1981, Milanese, 1987, Hess and Myers, 1989). The implication of these studies also appears to be that early cost estimates tend to underestimate the capital cost of a fifth-of-akind plant, based on limited data about cost improvement as more plants are built (Hess ard Myers, 1989). Costs estimates prepared early in process development may not capture all of the costs that would be revealed by a final estimate based on more detailed engineering analysis. Also, potential problems that could be encountered in a commercial-scale plant may not be anticipated. Therefore, one often expects that capital cost estimates are biased low, especially for preliminary cost estimates. This low bias can be compensated for by 
positively skewed uncertainties applied to the calculated process area direct capital costs in a cost model.

\section{A.3.3 Questionnaire for Fixed Bed Zinc Ferrite Desulfurization}

The text of Part 3 of the uncertainty briefing packet for the zinc ferrite process area is reproduced here. Part 3 consists of a questionaire regarding design assumptions and uncertainties in specific model parameters.

Here, you are asked to provide technically-informed judgments about probability distributions for parameters of the zinc ferrite performance and cost model. You are asked to consider the possibilities of potentially poor performance as well as the probability of obtaining favorable performance, based on current information about the system. The preceding sections provide an overview of uncertainty analysis and some of the technical considerations which might be used as the starting point. The default assumptions for the case studies are:

Space Velocity:

Superficial Gas Velocity:

Inlet Gas Temperature:

Inlet Gas Pressure:

Inlet Sulfur Concentration:

Maximum Vessel Diameter (D):

Maximum Vessel Length:

Absorption Cycle Time:

Fifth-of-a-kind plant

No additional research programs

Sorbent pellets are $3 / 16$ inch diameter extrudates of $1 / 2$ inch length containing equal molar amounts of zinc and iron.

Several questions follow. You may respond to the questions on these pages, or use additional paper as needed. See the Introduction for an example of how you might estimate uncertainty in each parameter.

\section{Question \#1.}

Do the default assumptions seem reasonable? For example, is a superficial velocity of $2 \mathrm{ft} / \mathrm{sec}$ a reasonable target for commercial operation? Is an absorption cycle time of one week a reasonable target? If not, adjust accordingly and explain the basis for the changes. Are there additional assumptions that you should be specified for this system? If so, please add these assumptions and explain why they are needed. Use your updated set of assumptions as the basis for answering the following questions.

\section{Question \#2.} are desired.

The following is a list of the specific parameters for which uncertainty distributions

- Sorbent sulfur loading

- Long term sorbent attrition rate 
- Absorber pressure drop

- Sorbent unit cost

Are you comfortable making estimates of uncertainty for these parameters? If you are not, who do you think should be approached (preferably within METC) to obtain these estimates?

Are there other parameters which you believe also should be treated probabilistically (whether or not you feel comfortable making the judgment yourself) hat are not included in this list? If so, please specify. Who can we ask to estimate uncertainties for these additional parameters?

\section{Question \#3.}

(a) What is the uncertainty in the long term sorbent sulfur loading (averaged over the entire sorbent bed) at breakthrough in a commercial-scale absorber over a large number of absorption and regeneration cycles (e.g., over 100) for bulk desulfurization at 1,100 oF and 300 psia? Consider that a typical commercial scale bed may be 12.5 feet in diameter and perhaps 25 to 50 feet deep. Consider also that the superficial gas velocity of $2 \mathrm{ft} / \mathrm{sec}$ assumed here and in other design studies is higher than any of the tests conducted to date. Be sure to explain the basis for your assumptions.

- Consider the best possible (highest) sorbent loading that could occur. Explain how such a result could be achieved (e.g., no channeling in the reactor or problems with flow distribution at the gas inlet, no deposition of particulates or other contaminants over the sorbent, etc.). How likely is this outcome?

- Consider the worst possible (lowest) sorbent loading that could occur. Explain, as above. How likely is it that the sulfur loading could be equal to or less than this value?

- What do you think is the median value of the sorbent sulfur loading (i.e. there is a 50-50 percent chance that the loading could be higher or lower than this value)? Note that the median value does not have to equally divide the best and worst possible values, nor does it have to be the same as the average (mean) rate that you expect. Alternatively, if you want to express your judgment as a triangle distribution, what is the most likely value that you expect?

- Can you draw a probability distribution to represent your judgment? You may draw the distribution as either a pdf or a cdf. Can the distribution be represented by one of the functions shown in Figure 1?

(b) Now consider a fuel gas with only $1,000 \mathrm{ppmv}$ of $\mathrm{H}_{2} \mathrm{~S}$. What is your judgment about the uncertainty in sorbent loading (if different from above)? (Use the same approach to estimate the best, worst, and median values, and to draw the probability distribution).

\section{Question \#4.}

What is the uncertainty in the long term sorbent attrition rate for this system (bulk desulfurization mode)?

- Consider the worst possible (highest) attrition rate that might occur. What is this rate and how could it happen? (e.g., thermal cycling of the sorbent, changes in 
chemical composition, effects of contaminants, etc.) Is attrition constant over the life of the sorbent? Is attrition uncertain, variable, or both (i.e. with ideal instrumentation would we always obtain the same rate, or is there variability in attrition related to, say, variability in coal properties?). How likely is the attrition to be worse than the number you have just estimated?

- Consider the best possible (lowest) attrition rate. What is this rate and how might it occur? What is the likelihood of obtain a lower rate than this?

- What is the median attrition rate?

- Can you estimate the 25 th fractile (i.e. there is a one in four chance that the sorbent attrition is less than this number) What about the 75 th fractile (i.e. a one in four chance that the value is higher than this number)?

- Can you draw a probability distribution to represent your judgment? You may draw the distribution as either a pdf or a cdf.

\section{Question \#5.}

What is the uncertainty in absorber pressure drop prior to sorbent replacement after a long period of absorption and regeneration cycles? Consider various factors contributing to pressure drop buildup, if any. Also consider the size of the commercial-scale bed. Thus, you must estimate the pressure drop for a commercial scale bed. Along with this, estimate the uncertainty associated with deposition of contaminants and the possibl: breakup of sorbent pellets into smaller pieces, as well as any other mechanisms you suggest.

- Consider the best possible (lowest) pressure drop that might occur. What factors are important to your judgment?

- Consider the worst possible (highest) pressure drop.

- What is the most likely (mode of the distribution) pressure drop?

\section{Question \#6.}

What is the uncertainty in the unit cost of the sorbent in $\$ / \mathrm{lb}$. Assume that the cost remains the same in constant dollars over the life of the power plant. For commercial use, the sorbent will have to be mass produced. A single $500 \mathrm{MW}$ plant may require severai million pounds of sorbent initially and several hundred thousand pounds annually for replacement.

-What is the lowest possible cost. Explain?

-What is the highest possible cost?

-What is the median or most likely (state which) cost?

\section{Question \#7.}

Please suggest other experts whom we should contact for judgments about uncertainties in this system. Please supply their names, titles, area of expertise, phone numbers, and addresses. 


\section{Question \#8}

We would like your comments on how easy/difficult it was to develop judgments about uncertainties and on these briefing materials. Is there any other information about uncertainty analysis you would like to see in Part 1? Was the summary of technical information in Part 2 a useful starting point for your thinking about uncertainties for this process? Was it difficult for you to develop estimates of the range or likelihood of various values for variables which you believe to be uncertain? Please discuss these or any other comments you may have.

\section{A.3.4 Elicited Technical Judgments About Uncertainties}

Technical judgments regarding the performance of a commercial-scale fifth-of-akind dual vessel fixed-bed zinc ferrite system were elicited from three engineers at DOE/METC. These engineers will be referred to as ZF-1, ZF-2, and ZF-3. Expert ZF-1 is the same engineer as LG-1, who made judgments regarding the Lurgi gasifier. Thus, the set of assumptions labeled LG-1 and ZF-1 are used together during case studies. The engineers were asked to explicitly consider the uncertainty involved in making predictions about a system that has not yet been built or operated at a commercial scale. The experts were provided with a three part briefing paper as discussed in Chapter 4 . The first part was a general introduction to uncertainty analysis. The second part was the review of published information given in the preceding sections here. The third part was a questionnaire, which is reproduced in the previous section. The results of the elicitations of uncertainty in model parameters from the three experts are described in the following sections.

\section{A.3.4.1 Expert ZF-1}

Expert ZF-1 provided detailed responses to the written questionnaire, and substantial additional detail during a follow-up phone conversation. In the questionnaire, the expert indicated that uncertainties "were difficult to evaluate." The expert added, "considerable thinking and a number of calculations were required in order to provide "good" judgments." Furthermore, he indicated that the summary of technical issues provided as Part 2 of the briefing packet "was useful, and perhaps essential to the exercise." The questionnaire provided several default assumptions (see previous section) and asked the expert to comment on them. Expert ZF-1 indicated that the absorption cycle time in the assumptions was excessive at 168 hours, and that a value of 30 hours is more appropriate and recommended. The expert indicated that a maximum superficial gas velocity of $2 \mathrm{ft} / \mathrm{sec}$ is reasonable. Also, the expert suggested an absorber vessel length-todiameter (L/D) ratio of 3 instead of 4 , but agreed that the maximum vessel diameter should be around 12.5 feet. 
Table A-10. Summary of Elicited Zinc Ferrite Technical Judgments from Expert ZF-1

\begin{tabular}{|c|c|c|c|c|c|c|}
\hline \multirow{2}{*}{$\begin{array}{l}\text { Description } \\
\text { Residual Sulfate After } \\
\text { Oxidative Regeneration }\end{array}$} & \multirow{2}{*}{$\begin{array}{l}\text { Units } \\
\begin{array}{l}\text { mol-\% of } \\
\text { captured S }\end{array}\end{array}$} & \multirow{2}{*}{$\frac{\text { Distribution }}{\text { Triangular }}$} & \multicolumn{4}{|c|}{ Parameters ${ }^{a}$} \\
\hline & & & 3 & to & 11 & $(7.5)$ \\
\hline $\begin{array}{l}\text { Residual Sulfide After } \\
\text { Reductive Regeneration }\end{array}$ & $\begin{array}{l}\text { mol-\% of } \\
\mathrm{S} \text { in sulfate }\end{array}$ & Triangular & 50 & to & 90 & (85) \\
\hline Sorbent Sulfur Loading & $\begin{array}{l}\text { wt-\% } S \text { in } \\
\text { sorbent }\end{array}$ & Normal & 2.16 & \multicolumn{2}{|c|}{ to 31.84} & (17) \\
\hline $\begin{array}{l}\text { Sorbent Attrition } \\
\text { Rate }\end{array}$ & $\begin{array}{l}\text { wt-\% sorbent } \\
\text { loss/cycle }\end{array}$ & Fractile & $\begin{array}{l}5 \%: \\
20 \%: \\
25 \%: \\
25 \%: \\
20 \%: \\
5 \%:\end{array}$ & $\begin{array}{r}0.17 \\
0.34 \\
0.5 \\
1 \\
1.5 \\
5\end{array}$ & $\begin{array}{l}\text { to } \\
\text { to } \\
\text { to } \\
\text { to } \\
\text { to } \\
\text { to }\end{array}$ & $\begin{array}{r}0.34 \\
0.5 \\
1 \\
1.5 \\
5 \\
25\end{array}$ \\
\hline $\begin{array}{l}\text { Absorber Pressure } \\
\text { Drop }\end{array}$ & psi/ft bed height & Triangular & 0.29 & to & 0.53 & $(0.4)$ \\
\hline
\end{tabular}

a For Uniform distributions, the lower and upper bounds are given. For the triangular distribution, the mode is given in parentheses. For the fractile distribution, the lower and upper bounds for each range are given, along with the probability of sampling within that range.

Four parameters (sorbent sulfur loading, sorbent attrition rate, absorber pressure drop, and sorbent unit cost) were selected for probabilistic analysis in preparing the questionnaire. Expert $\mathrm{ZF}-1$ suggested that two additional parameters be treated probabilistically. These are: (1) residual sulfate content of sorbent following oxidative regeneration; and (2) residual sulfide content of sorbent following reductive regeneration. The sulfate content affects the requirement for fuel gas used as a reductant to convert the sulfate to sulfide or released sulfur. The sulfide content affects the availability of sorbent for absorption in the following cycle. The quantitative judgments of uncertainty obtained from Expert ZF-1 are summarized in Table A-10.

The residual sulfate concentration is highly dependent on the pressure of the system and how regeneration is performed. At $600 \mathrm{psi}, 15$ percent of the absorbed sulfur has been found to remain in the sorbent as sulfate after oxidative regeneration. At $300 \mathrm{psi}$, the residual sulfate after oxidative regeneration would be less. Upon reductive regeneration, only about 15 percert of tile sulfate is released, leaving residual sulfide. The fraction of sulfate converted to sulfide may be independent of pressure. There is not yet data on how the residual sulfide content would vary with factors such as regeneration space velocity, temperature, or superficial velocity. The reductive regeneration tests at METC have been at 
$1 \mathrm{~atm}$ in packed bed reactors. Dirty gasifier product gas diluted with steam was used as the reductant gas. In contrast, in a "real" plant, clean desulfurized fuel gas would be used as the reductant.

The lower limit on residual sulfate after reductive regeneration is estimated by Expert ZF-1 to be approximately 3 percent of the absorbed sulfur in the sorbent. This outcome might result from optimized proper programming of the timing and temperature profile of the regeneration process. In particular, such an outcome would depend on obtaining high regeneration temperatures without sintering the sorbent, which is a significant control problem. In a separate technology, General Electric has reported good results regenerating zinc ferrite in a semi-batch process. A more likely vailue is 7 to 8 percent sulfur as residual sulfate. However, $i \hat{i}$ is possible that long term life cycle testing of sorbent may yield residual sulfate contents as high as 10 to 11 percent. Therefore, the expert agreed that a triangular distribution, ranging from 3 to 11 percent, with a mode of 7.5 percent, reasonably represented his judgment about the residual sulfur as sulfate after oxidative regeneration.

Expert ZF-1 was confidant that 85 percent of the sulfate would be converted to sulfide during reductive regeneration. However, after some discussion, the expert indicated that after more research, it may be possible to conduct reductive regeneration in such a way to obtain 30 to 40 percent sulfur release from the sulfate. Under some regeneration conditions, only 10 percent of the sulfur in the residual sulfate may be released, with the rest converted to sulfide. DOE/METC did not pursue research on the dual vessel fixed bed zinc ferrite process, but if it had, it would have looked more carefully at these regeneration issues. The expert agreed that a triangular distribution for the conversion of sulfatc to released sulfur during reductive regeneration would have a lower limit of 10 percent, an upper limit of 50 percent, and a mode of 15 percent. The unreleased sulfur would be retained as sulfide, which would reduce the absorption capacity of the sorbent. Thus, the uncertainty distribution for the fraction of sulfate converted to sulfide during reductive regeneration would be triangular with a lower limit of 50 percent, an upper limit of 90 percent, and a mode of 85 percent.

Expert ZF-1 indicated that there is only about a 10 percent chance that the weight percent sorbent sulfur loading could be more than 26 percent for a commercial bed, assuming an ideal reactor, that sorbent does not deactivate, and that breakthrough begins when the effective space velocity reaches $4000 / \mathrm{hr}$. Conversely, there is only about a 5 percent chance that the sorbent sulfur loading would be less than 5 or 6 weight percent, 
which could occur if there were severe channeling in the bed and deactivation of the sorbent. The most likely value is 17 weight percent sorbent sulfur loading, and the expert suggested that the distribution for this parameter should be normal with a mean of 17 . This implies a 99.8 percent range from 2.2 to 31.8 weight percent sorbent sulfur loading, with a standard deviation of 4.8 .

The expert indicated that the sorbent attrition rate would follow the traditional "bathtub" curve typical of failure rates in many applications. Fresh sorbent may have "a lot of rough edges" and "weak point" that show up as attrition within the first few cycles. Manufacturing steps may be possible to "pre-attrit" the sorbent. In addition, the sorbent may undergo "chemical stabilization" in the first 10 cycles that would be likely to affect its physical stability. During the middle of the sorbent life, it may behave quite well. As the sorbent ages, it may later enter a high attrition period.

Attrition has both physical and chemical dimensions. In physical attrition, the sorbent pellets break up and may leave the bed through entrainment in exiting gas streams. Sorbet deactivation occurs from loss of chemical activity, such as slow zinc loss from the sorbent. Attrition is related to the number of absorption/regeneration cycles, but may also be related to the duration of each cycle. For example, the zinc vapor pressure is a factor that influences chemical deactivation of the sorbent, and this deactivation depends more on duration than number of cycles.

In the questionn:ire, the expert indicated that there was only a 5 percent chance that the sorbent attrition rate would be greater than 5 percent per abscrption/regeneration cycle. Such a result might be obtained due to carbon deposition from excessive cracking of hydrocarbons and formation of iron carbides. Attrition rate is dependent on coal properties and gasifier type. There is a 10 percent chance, accordi ig to Expert ZF-1, that the sorbent attrition rate could be lower than 0.34 percent per cy le, which assumes one complete sorbent replacement every 292 cycles. The median attricion rate was estimated at 1 percent per cycle, while the 25 th and 75 th fractiles were estimated at 0.5 and 1.5 percent per cycle, respectively. In the follow-up phone conversation, the expert indicated that he "can't imagine it ever being worse than 25 percent--would take one heck of an upset." But such a case might be possible, for example, if there were ever water condensation in the reactor bed. Condensation might occur if the bed was off-line prior to regeneration and not kept warm, and then diluent steam prematurely introduced. The sorbent would "fall apart" and "go to dust" if it had any residual sulfate. As a ma.. mum lower limit, the expert indicated that 0.17 percent attrition/cycle might be assumed. 
Table A-11. Proposed Correlation Matrix for Judgments ZF-1

\begin{tabular}{|c|c|c|c|c|c|c|}
\hline \multirow[b]{2}{*}{ Parameter } & \multirow[b]{2}{*}{ Number } & \multicolumn{5}{|c|}{ Correlation Coefficients ${ }^{a}$} \\
\hline & & 1 & 2 & 3 & 4 & 5 \\
\hline $\begin{array}{l}\text { Residual Sulfate After } \\
\text { Oxidative Regeneration }\end{array}$ & 1 & 1.00 & & & & \\
\hline $\begin{array}{l}\text { Residual Sulfide After } \\
\text { Reductive Regeneration }\end{array}$ & 2 & -- & 1.00 & & & \\
\hline Sorbent Sulfur Loading & 3 & -- & -- & 1.00 & & \\
\hline $\begin{array}{l}\text { Sorbent Attrition } \\
\text { Rate }\end{array}$ & 4 & -- & -- & 0.50 & 1.00 & \\
\hline $\begin{array}{l}\text { Absorber Pressure } \\
\text { Drop }\end{array}$ & 5 & -- & -- & 0.25 & 0.50 & 1.00 \\
\hline
\end{tabular}

a For uncorrelated parameters, a dashed line "- -" is shown.

Expert ZF-1 provided a judgment regarding uncertainty in the absorber pressure drop. He assumed a sorbent bed depth of 37.5 feet, based on an absorber vessel length-todiameter ratio of 3 . However, he indicated over the phone that the estimates scale linearly with bed height. Therefore, the reported values were converted to a pressure drop per foot of bed height. The expert indicated that adequate removal of particulates upstream of the absorber is essential for maintaining low pressure drop. METC sidestream tests suggested that the absorber bed can tolerate up to $0.06 \mathrm{lb}$ particles per standard cubic foot of gas if the particles are less than 10 microns in size.

Expert ZF-1 did not provide any explicit indication of possible correlation among the uncertain parameters in Table A-10. However, it is plausible that several of these are correlated. Several "nominal" correlations have been assumed among sorbent sulfur loading, attrition, and absorber pressure drop as a "sensitivity" case. These correlations are shown in Table A-11. The probabilistic simulation of this system can be exercised both with and without the assumed correlations to determine if the model results are sensitive to assumptions regarding parameter correlation.

The sorbent sulfur loading and sorbent attrition rate may be related by chemical deactivation of the sorbent, which would reduce sorbent activity and possibly reduce the physical strength of the sorbent. Sorbent attrition and absorber vessel pressure drop may be related. As physical attrition proceeds, the sorbent breaks into smaller pieces and one effect of this is an expected increase in pressure drop. For example, the "Ergun 
correlation" indicates that pressure drop in a pellet bed is inversely proportional to the pellet diameter (Smith, 1988). Sorbent sulfur loading and pressure drop may be indirectly related through their relationships with sorbent attrition.

\section{A.3.4.2 Expert ZF-2}

Expert ZF-2 provided detailed responses to the questionnaire. The expert commented:

It was fairly easy to make the judgments of uncertainty; however, much thought was required to arrive at what seemed like meaningful inputs. The parameters are very much interrelated and therefore difficult to separately evaluate.

With respect to the briefing materials, the expert noted the following:

The briefing information was needed and about the right amount of depth to stimulate thought without being too cumbersome. The uncertainty analysis discussion [Part 1] seemed like a justification for the approach and more than necessary to elicit answers to the questionnaire. The examples were most useful to quickly understand what was expected.

The expert detailed the time required to review and respond to the briefing packet:

$\begin{array}{ll}\text { Read briefings, refresh technology issues } & 1.5 \mathrm{hr} \\ \text { Base questions \#1 and \#2 } & 3.0 \mathrm{hr} \\ \text { Uncertainty ratings } & 2.5 \mathrm{hr} \\ \text { Summarize, reflect, edit } & 2.0 \mathrm{hr} \\ \text { Total } & 8.0 \mathrm{hr}\end{array}$

Expert ZF-2 has significant background and experience with the zinc ferrite system, and provided the following comment:

The "informed" judgments are based upon first hand KRW experience from pilot plant equipment design through test completion and reporting of results plus follow up appication of the test resulis to several commercial scale designs.

The expert carefully reviewed the design assumptions given in the questionnaire and chose to suggest an alternative set of assumptions. However, he provided judgments both for the set of assumptions proposed in the questionnaire as well as for the set he recommended. These two sets will be referred to as $\mathrm{ZF}-2 \mathrm{P}$ and $\mathrm{ZF}-2 \mathrm{R}$, respectively. The proposed and recommended assumptions are given in Table A-12.

Expert ZF-2 suggested that vessel height should not exceed 30 to 35 feet in order not to exceed crush strength limits of the sorbent. Above this height, the vessel design must include internal sorbent supports. These supports, though undesirable, are less costly than additional vessels. A design target for sorbent life is one year between sorbent 
Table A-12. Summary of Zinc Ferrite System Default Assumptions Used by Expert ZF-2

\begin{tabular}{llrr}
\hline Description & Units & Proposed $^{\mathrm{a}}$ & Recommended $^{\mathrm{b}}$ \\
\hline Space Velocity & $1 / \mathrm{hr}$ & 2,000 & 2,000 \\
Superficial Gas Velocity & $\mathrm{ft} / \mathrm{sec}$ & 2 & 2 \\
Inlet Temperature & $\mathrm{oF}$ & 1,100 & 1,100 \\
Inlet Pressure & $\mathrm{psia}$ & 300 & 350 \\
Sulfur Concentration & $\mathrm{ppmv}$ & 5,000 & 5,000 \\
Vessel Outer Diameter & $\mathrm{ft}$ & 12.5 & 14 \\
Vessel Length & $\mathrm{ft}$ & 50 & 35 \\
Cycle Time & hours & 168 & 38 \\
& & & \\
Additional Assumptions & & & 14 \\
& & $\mathrm{NG}$ & 100 \\
Sulfur Loading & $\mathrm{wG}$ & $\mathrm{NG}$ & yearly \\
Life Cycles & & NG & 350 psi \\
Sorbent Replacement & & atm & 2 step \\
(at 85\% capacity factor) & NG & Yes \\
Regeneration Pressure & No & Yes \\
Regeneration Type & No & No \\
Chloride Guard & NG & \\
Upstream Barrier Filter & Downstream Turbine Guard & &
\end{tabular}

a Set of assumptions proposed by surveyor in the uncertainty questionnaire. NG $=$ Not Given

${ }^{b}$ Set of alternative assumptions recommended by expert.

replacement with about 100 absorption/regeneration cycles per year. 'This would lead to an absorption time of about 38 hours, if the plant is operated 85 percent of the year. This is about the same as the minimal time required to perform valve switching and two step (oxidative and reductive) regeneration.

The expert suggested that regeneration at atmospheric pressure is "considered high risk and not practical due to rapid pressure cycling of vessels and/or longer required cycle times." Redurtive regeneration is a necessary step in sorbent regeneration.

Illinois No. 6 coal contains high chlorine which "is likely to react with the zinc and render a portion of the zinc ferrite inactive." This leads to reduced sorbent activily over time.

Expert ZF-2 indicated that an upstream barrier filter is required in order for the fixed bed zinc ferrite system to be operable. "Fines escaping a conventional cyclone would lead to an unacceptable pressure drop increase that would control the cycle time and life cycle." The cleanup system might be rendered economically unviable in such a case. However, a 
Table A-13. Summary of Elicited Zinc Ferrite Technical Judgments ZF-2P from Expert ZF-2

\begin{tabular}{|c|c|c|c|c|c|c|}
\hline \multirow{2}{*}{$\begin{array}{l}\text { Description } \\
\begin{array}{l}\text { Sorbent Sulfur Loading } \\
\text { (Bulk Mode) }\end{array}\end{array}$} & \multirow{2}{*}{$\begin{array}{l}\text { Units } \\
\text { wt-\% S in } \\
\text { sorbent }\end{array}$} & \multirow{2}{*}{$\begin{array}{l}\text { Distribution } \\
\text { Fractile }\end{array}$} & \multicolumn{4}{|c|}{ Parameters $^{a}$} \\
\hline & & & $\begin{array}{l}50 \%: \\
50 \%:\end{array}$ & $\begin{array}{r}8 \\
15\end{array}$ & $\begin{array}{l}\text { to } \\
\text { to }\end{array}$ & $\begin{array}{l}15 \\
20\end{array}$ \\
\hline $\begin{array}{l}\text { Sorbent Attrition } \\
\text { Rate }\end{array}$ & $\begin{array}{l}\text { wt-\% sorbent } \\
\text { loss/cycle }\end{array}$ & Fractile & $\begin{array}{l}50 \%: \\
50 \%:\end{array}$ & $\begin{array}{l}0.05 \\
0.20\end{array}$ & $\begin{array}{l}\text { to } \\
\text { to }\end{array}$ & $\begin{array}{l}0.20 \\
1.00\end{array}$ \\
\hline $\begin{array}{l}\text { Absorber Pressure } \\
\text { Drop }\end{array}$ & $\mathrm{psi} / \mathrm{ft}$ bed height & Fractile & $\begin{array}{l}50 \%: \\
50 \%:\end{array}$ & $\begin{array}{l}0.14 \\
029\end{array}$ & $\begin{array}{l}\text { to } \\
\text { to }\end{array}$ & $\begin{array}{l}0.29 \\
1.43\end{array}$ \\
\hline Sorbent Unit Cost & $\$ / 1 b$ & Fractile & $\begin{array}{l}50 \%: \\
50 \%:\end{array}$ & $\begin{array}{l}2.50 \\
3.00\end{array}$ & $\begin{array}{l}\text { to } \\
\text { to }\end{array}$ & $\begin{array}{l}3.00 \\
5.00\end{array}$ \\
\hline Sorbent Life Cycles & & Fractile & $\begin{array}{l}50 \%: \\
50 \%:\end{array}$ & $\begin{array}{l}10 \\
50\end{array}$ & $\begin{array}{l}\text { to } \\
\text { to }\end{array}$ & $\begin{array}{r}50 \\
100\end{array}$ \\
\hline Chloride Attack & $\begin{array}{l}\text { ZF consumption } \\
\text { as wt-\% of coal }\end{array}$ & Fractile & $\begin{array}{l}\text { 50\%: } \\
50 \%:\end{array}$ & $\begin{array}{r}0.005 \\
0.05\end{array}$ & $\begin{array}{l}\text { to } \\
\text { to }\end{array}$ & $\begin{array}{r}0.05 \\
0.5\end{array}$ \\
\hline
\end{tabular}

${ }^{a}$ For Uniform distributions, the lower and upper bounds are given. For the triangular distribution, the mode is given in parentheses. For the fractile distribution, the lower and upper bounds for each range are given, along with the probability of sampling within that range.

downstream cyclone to protect the gas turbine from catastrophic loss of sorbent "is considered unnecessary for a fixed bed system."

Expert ZF-2 proposed two parameters for probabilistic analysis, in addition to the ones included in the questionnaire. The additional parameters include sorbent life cycles and sorbent consumption due to chloride attack. The uncertainty distributions for the "proposed" set of judgments ZF-2P are summarized in Table A-13. The distributions for the "recommended" set of judgments ZF-2R are summarized in Table A-14.

For sorbent sulfur loading, the expert indicated that high values would be obtained in large vessels with even temperature distributions, large gas volumes, routine and automated procedures for absorption/regeneration cycling, proven and reliable equipment, improved sorbent strength and porosity, and improved reductive regeneration methods. Low values would be obtained due to channeling, dust deposition, chloride reaction, temperature excursions, crushed pellets due to pressure drop surge, incomplete regeneration, steep absorption wave front (with small effective sorbent volume) and attrition loss. 
Table A-14. Summary of Elicited Zinc Ferrite Technical Judgments ZF-2R from Expert ZF-2

\begin{tabular}{|c|c|c|c|c|}
\hline Description & Units & Distribution & Parameters $^{\mathrm{a}}$ & \\
\hline $\begin{array}{l}\text { Sorbent Sulfur Loading } \\
\text { (Bulk Mode) }\end{array}$ & $\begin{array}{l}\text { wt-\% } S \text { in } \\
\text { sorbent }\end{array}$ & Fractile & $\begin{array}{l}50 \%: \\
50 \%:\end{array}$ & $\begin{array}{l}\text { to } \\
\text { to }\end{array}$ \\
\hline $\begin{array}{l}\text { Sorbent Attrition } \\
\text { Rate }\end{array}$ & $\begin{array}{l}\text { wt-\% sorbent } \\
\text { loss/cycle }\end{array}$ & Fractile & $\begin{array}{ll}50 \%: & 0.01 \\
50 \%: & 0.10\end{array}$ & $\begin{array}{ll}\text { to } & 0.10 \\
\text { to } & 0.20\end{array}$ \\
\hline $\begin{array}{l}\text { Absorber Pressure } \\
\text { Drop }\end{array}$ & psi/ft bed height & Fractile & $\begin{array}{l}50 \%: \\
50 \%:\end{array}$ & $\begin{array}{l}\text { to } \\
\text { to }\end{array}$ \\
\hline Sorbent Unit Cost & $\$ / 1 b$ & Fractile & $\begin{array}{ll}50 \%: & 2.50 \\
50 \%: & 3.00\end{array}$ & $\begin{array}{l}\text { to } 3.00 \\
\text { to } 5.00\end{array}$ \\
\hline Sorbent Life Cycles & & Fractile & $\begin{array}{l}50 \%: \\
50 \%: \\
50\end{array}$ & $\begin{array}{ll}\text { to } & 100 \\
\text { to } & 200\end{array}$ \\
\hline Chloride Attack & $\begin{array}{l}\text { ZF consumption } \\
\text { as wt } \% \text { of coal }\end{array}$ & Fractile & $\begin{array}{l}50 \%: 1 . \mathrm{E}-4 \\
50 \%: 5 . \mathrm{E}-4\end{array}$ & $\begin{array}{l}\text { to } 5 . \mathrm{E}-4 \\
\text { to } 0.001\end{array}$ \\
\hline
\end{tabular}

\footnotetext{
a For Uniform distributions, the lower and upper bounds are given. For the triangular distribution, the mode is given in parentheses. For the fractile distribution, the lower and upper bounds for each range are given, along with the probability of sampling within that range.
}

Low sorbent attrition is associated with the same conditions as for high sorbent sulfur loading, including even temperature distribution, routine procedures and automated controls, proven and reliable equipment and components, improved sorbent strength and shape, dust free gas, and minimal vessel height. High attrition would be associated with channeling, leading to a varying temperature profile, and other factors such as dust deposition, chloride reaction, temperature excursion, crushed pellets due to pressure drop surge or slugging of the bed, gas composition excursions, improper handling methods, and sorbent manufacturing problems.

Low absorber vessel pressure drop would result from the use of harrier filters or advanced cyclones. Also, pressure drop is associated with sorbent attrition. High pressure drop could be obtained due to dust accumulation, temperature excursion, crushed pellets due to slugging of the bed, and due to other causes of attrition with particles accumulating in the bed.

Sorbent cost could be low under conditions of large batch production, competition among suppliers, mature production methods, and many power plants to ensure continued large demand to provide incentive for supplier competition. Sorbent cost could be high due 
Table A-15. Proposed Correlation Matrix for Judgments ZF-2

\begin{tabular}{|c|c|c|c|c|c|c|}
\hline \multirow[b]{2}{*}{ Parameter ${ }^{b}$} & \multirow[b]{2}{*}{ Number } & \multicolumn{5}{|c|}{ Correlation Coefficients ${ }^{a}$} \\
\hline & & 1 & 2 & 3 & 4 & 5 \\
\hline Sorbent Sulfur Loading & 1 & 1.00 & & & & \\
\hline Sorbent Life Cycles & 2 & 0.9 & 1.00 & & & \\
\hline Absorber Pressure Drop & 3 & -- & 0.5 & 1.00 & & \\
\hline Chloride Attack & 4 & -- & -- & -- & 1.00 & \\
\hline Sorbent Unit Cost & 5 & -- & -- & -- & -- & 1.00 \\
\hline
\end{tabular}

a For uncorrelated parameters, a dashed line ". - -" is shown.

$\mathrm{b}$ For the case studies, the sorbent attrition rate is not needed because the overall sorbent life cycle has been specified in addition and supersedes the sorbent loss due only to attrition.

to lack of competition, possible new and more costly formulations needed to achieve higher sorbent strength and other market conditions affectirig raw material cost.

A low number of life cycles would be associated with excessive pressure drop and sulfidation periods reduced to less time than required for regeneration, leading to partially unregenerated sorbent. A high number of life cycles would be obtained from stable sulfur capacity over time, minimal attrition, no pressure drop buildup, and no plant parameter excursions to damage sorbent.

Finally, low chloride attack would be associated with the use of a chloride guard (see case ZF-2P vs. ZF-2R for comparison of a case with no guard to one with a guard), chlorine in the coal, and rate of $\mathrm{HCl}$ reaction with zinc ferrite. High chloride attach would be associated with no chloride guard, high coal chlorine content, and high rates of reaction of zinc ferrite with $\mathrm{HCl}$.

From the above discussion, it is apparent that there are strong interrelationships among the uncertain parameters, implying that these uncertainties are not uncorrelated. For example, the conditions that favor high sorbent sulfur loading also favor a high number oi absorption/regeneration cycles and high sorbent life. The conditions that lead to high sorbent attrition and reduced sorbent life also tend to lead to high sorbent bed pressure drops. Therefore, the sorbent life cycles and sorbent sulfur loadin $\hat{\underline{g}}$ were assimed to be strongly positively correlated, and the sorbent life cycles and pressure drop were assumed to be moderately negatively correlated (see Table A-15). These correlations are intended to be used in a "sensitivity" case study compared to an uncorrelated case to determine how significantly these assumed correlations affect the modeling results. 


\section{A.3.4.3 Expert ZF-3}

Expert ZF-3 did not comment on the uncertainty elicitation procedure. In reviewing the default design assumptions for the zinc ferrite system, the expert indicated that the assumptions were reasonable with the exception of the absorption cycle time. The expert suggested that a cycle time of no more than three days was appropriate, as opposed to the one week cycle time proposed in the questionnaire. The expert pointed out that cycle time could change over the life of the sorbent as the sorbent deactivates. The quantitative judgments regarding uncertainty obtained from Expert ZF-3 are summarized in Table A-16.

The expert provided judgments regarding sorbent sulfur loading indicating that an upper limit for a commercial system would be 20 weight percent of sulfur in the sulfated sorbent, with values around 10 percent more typical. Higher sulfur loadings would be associated with a sorbent formulation with a minimum amount of porous binder material, careful loading of sorbent in the absorber vessel, no tar dropout (presumably due to low temperature excursions during absorption), no carbon deposition, and avoidance of sharp changes in temperature and pressure. There is a small chance very low loadings of one to two weight percent might be obtained. Such a result would be due to swings in operating conditions due to sticky control valves or changes in coal composition. The expert indicated that there may be a difference between sulfur loading capacity in polishing vs. bulk desulfurization mode, but that there is no data to demonstrate such an effect.

With respect to sorbent attrition, the expert noted that there was one reported instance of catastrophic loss of nearly all of the sorbent. The cause of this loss was believed to be a sudden change in operating conditions. However, the median value for attrition is expected to be 0.22 weight percent sorbent per cycle, implying a life cycle of about 450 absorption/regeneration cy'cles. A maximum value for a commercial scale unit would be about two percent attrition per cycle, while a lower limit would be about 0.07 percent per cycle. Favorable attrition rates are expected under stable operating conditions.

Low pressure drop in the absorber vessel is expected in cases where there is no sticking or agglomeration of particles in the fuel gas within the sorbent bed, and in which very fine particles are entrained in the exi.nng fuel gas. Also, it is assumed that very small particles will be periodically removed from the sorbent bed by removing the sorbent, screening it, separating out fine sorbent, and returning the larger scrbent pellets to the absorber vessel. Pressure drops significantly higher may be encountered if fines build up in the sorbent bed. 
Table A-16. Summary of Elicited Zinc Ferrite Technical Judgments from Expert ZF-3

\begin{tabular}{|c|c|c|c|c|c|c|}
\hline \multirow{2}{*}{$\frac{\text { Description }}{\text { Sorbent Sulfur Loading }}$} & \multirow{2}{*}{$\begin{array}{l}\text { Units } \\
\text { wt-\% S in } \\
\text { sorbent }\end{array}$} & \multirow{2}{*}{$\begin{array}{l}\text { Distribution } \\
\text { Fractile }\end{array}$} & \multicolumn{4}{|c|}{ Parameters $^{\mathbf{a}}$} \\
\hline & & & $\begin{array}{l}\text { 1\%: } \\
4 \%: \\
90 \%: \\
5 \%:\end{array}$ & $\begin{array}{r}1 \\
2 \\
5 \\
15\end{array}$ & $\begin{array}{l}\text { to } \\
\text { to } \\
\text { to } \\
\text { to }\end{array}$ & $\begin{array}{r}2 \\
5 \\
15 \\
20\end{array}$ \\
\hline $\begin{array}{l}\text { Sorbent Attrition } \\
\text { Rate }\end{array}$ & $\begin{array}{l}\text { wt-\% sorbent } \\
\text { loss/cycle }\end{array}$ & Fractile & $\begin{array}{l}35 \%: \\
15 \%: \\
40 \%: \\
10 \%:\end{array}$ & $\begin{array}{l}0.07 \\
0.18 \\
0.20 \\
0.50\end{array}$ & $\begin{array}{l}\text { to } \\
\text { to } \\
\text { to } \\
\text { to }\end{array}$ & $\begin{array}{l}0.18 \\
0.20 \\
0.50 \\
2.00\end{array}$ \\
\hline $\begin{array}{l}\text { Absorber Pressure } \\
\text { Drop }\end{array}$ & $\mathrm{psi} / \mathrm{ft}$ bed height & Fractile & $\begin{array}{l}\text { 50\%: } \\
50 \%:\end{array}$ & $\begin{array}{l}0.4 \\
0.5\end{array}$ & $\begin{array}{l}\text { to } \\
\text { to }\end{array}$ & $\begin{array}{l}0.5 \\
1.0\end{array}$ \\
\hline Sorbent Unit Cost & $\$ / l b$ & Triangular & 0.75 & to & 5.00( & $3.00)$ \\
\hline
\end{tabular}

a For Uniform distributions, the lower and upper bounds are given. For the triangular distribution, the mode is given in parentheses. For the fractile distribution, the lower and upper bounds for each range are given, along with the probability of sampling within that range.

The minimum sorbent cost is assumed to be slightly higher than the cost for the iron oxide and zinc oxide which are used to manufacture the sorbent. Such ar outcome assumes regligible costs for binder material and manufacture of the sorbent pellets. A high cost would be associated with difficulty in scaling up production machinery.

\section{A.3.5 Other Uncertainties}

Two additional uncertainties in the zinc ferrite process area for which judgments are required include the direct capital cost and the annual maintenance cost. In the conceptual design studies from which the cost data used to develop the zinc ferrite direct cost model was taken, the process contingency factor assumed was ${ }^{1} 0$ percent (Smith and Smelser, 1987; Earley and Smelser, 1988). This is a comparatively high contingency factor, representative of the early stage of development of the zinc ferrite process, which has not been built on a commercial scale.

For the purpose of an initial screening study of uncertainties, it is assumed that the uncertainty in the capital cost of the zinc ferrite process is symmetric to the commonly assumed contingency factor. In this case, a uniformly distributed range of 100 to 180 percent of the process area capital cost is assumed, with a median value of 140 percent representative of the deterministic contingency factor. While this range of uncertainty is large compared to other process areas, it is also representative of the types of cost growth that might be expected for a process area currently in an early stage of development. A 
particular source of cost-related uncertainty in the zinc ferrite process area is the complexity of the valving required to properly control gas flows during absorption and the two stage regeneration. In particular, it is important to properly purge the reactor vessel between oxidative and reductive regeneration steps. The potential effects of contaminants on valve operation may necessitate expensive valves. In addition, there may be significant costs associated with the control system.

The typical maintenance cost factor assumed for the zinc ferrite process is 4.5 percent of the process area capital cost per year. As an initial characterization of uncertainty, it is assumed that this maintenance cost factor could be between 3 and 6 percent per year, with a triangular distribution and a mode at 4.5 percent per year. Maintenance costs might include such things as valve repair and replacement. 


\section{A.4 Technical Background and Uncertainty Estimates for the Gas Turbine Process Area}

In this section, the technical background information, uncertainty questionnaire, and characterizations of uncertainty in gas turbine performance and cost parameters are described. The technical background information is taken directly from Part 2 of the uncertainty briefing package distributed to selected process engineers at DOE/METC. The questionnaire was Part 3 of the gas turbine uncertainty briefing package. Originally, three IGCC systems were to be included as part of case studies. H', wever, one system, the ai-blown KRW-based IGCC system with hot gas cleanup, was not included in the final case studies due tu tirr: 2 and information constraints.

Pat 2 of the briefing packet reviews uncertainties in and potential problems of using state-of-the-art gas turbines designed for natural gas firing ir. an integrated gasification combined cycle (IGCC) process environment. This review considers the uncertainties which may arise from the application of high-firing temperature heavy-duty gas turbine technology $(2,300 \mathrm{o}$ turbine inlet temperature) designed for natural gas fuels to low- and medium-BTU coal gas integrated gasification combined cycle (IGCC) systems. In particular, we are interested in three IGCC systems. The key design and performance assumptions for these systems are summarized in Table A-17. These systems are: Case ALH, the Air-blown Lurgi-based system with Hot gas cleanup using external fixed-bed zinc ferrite desulfurization; Case AKH, the $\Delta$ ir-blown $\mathrm{KRW}$-based system with $\underline{H}$ ot gas cleanup using in-bed and external hxt gas desulfurization; and Case OKC, the Qxygenblown KRW-based system with Cold gas cleanup, which is a baseline case. This case is believed to represent the lowest technical risks.

\section{A.4.1 Key Design and Performance Assumptions}

The assumed system configuration for Case ALH is shown in Figure A-2 in Section A.2. Hot coal gas is fed directly to the gas turbines at a temperature of $1,200^{\circ} \mathrm{F}$. Two high efficiency cyclones, one upstream and one downstream of the zinc ferrite absorber, are assumed for particulate removal and for alkali control. The gas turbine will have pressurized air extraction at the compressor outlet for use as gasifier blast air. The gas turbine exhaust is cooled in a heat recovery steam generato: 
Table A-17. Gas Turbine Default Assumptions and Typical Performance Estimates for Case Studies

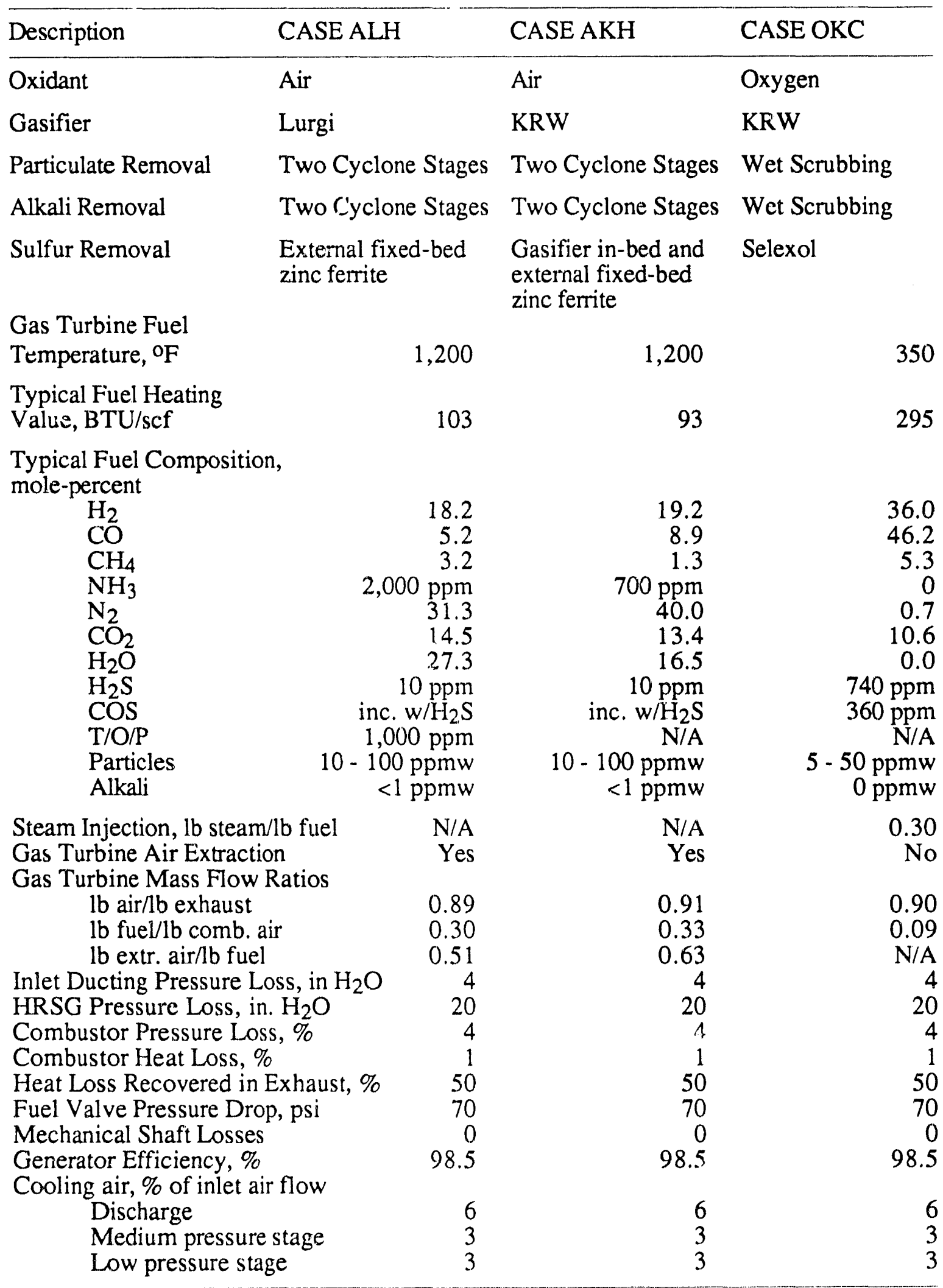




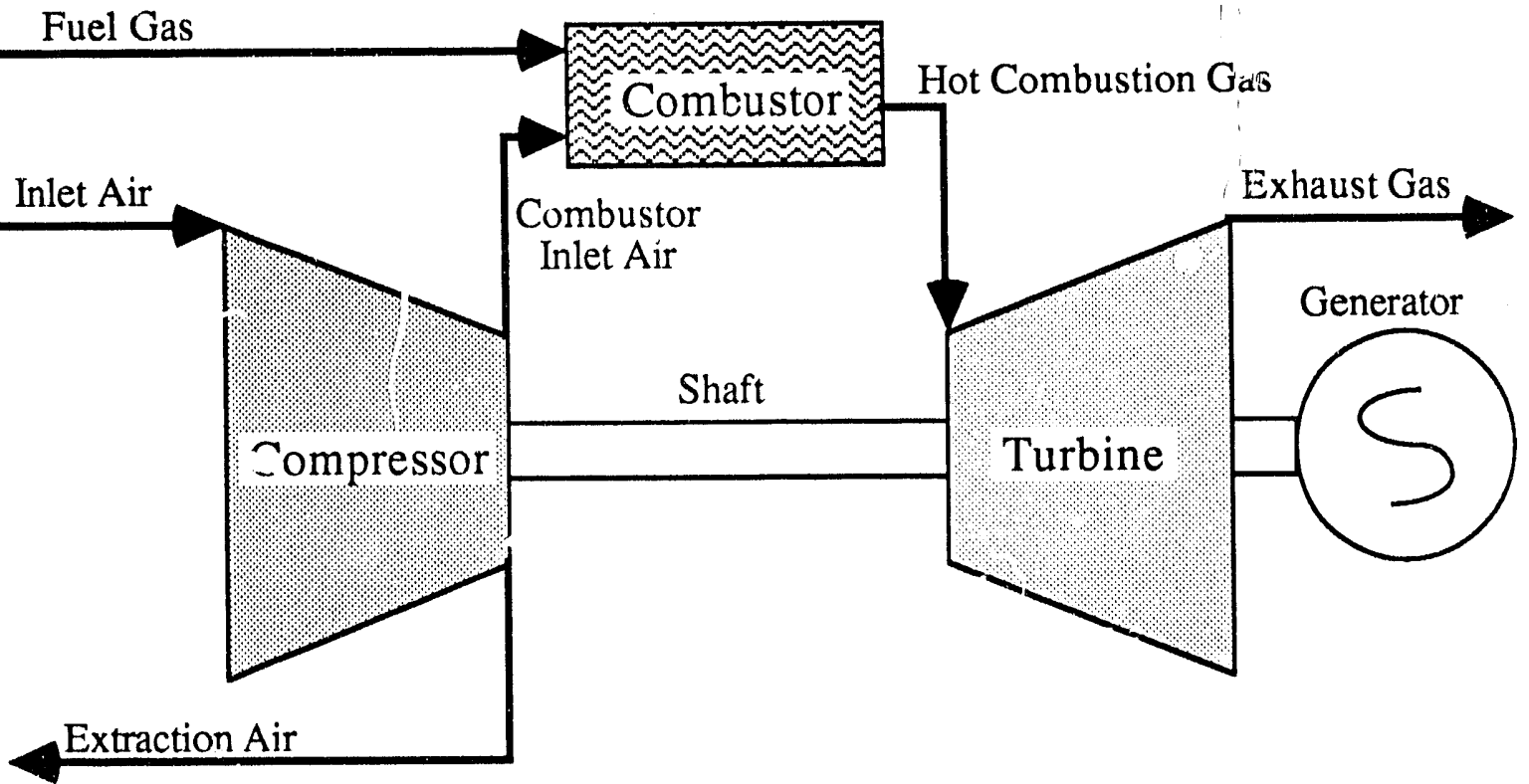

Figure A-14. Simple Schematic of Gas Turbine Mass Balance with Compressor Air Extraction.

The system configuration for Case OKC is shown in Section A.2 in Figure A-11. Case AKH is similar to Case ALH in that a low-BTU coal gas is fed to the gas turbine fuel valve at a temperature of $1,200 \mathrm{oF}$, air is extracted from the compressor discharge for use as gasifier blast air, and the gas turbine is downstream of zinc ferrite absorbers and two stages of cyclones. In Case OKC, the gas turbine operates on medium-BTU coal gas, which enters the fuel valve at a much lower temperature ( 350 oF) than Case ALH or Case $\mathrm{AKH}$. In Case $\mathrm{OKC}$, low temperature gas cleaning is used, featuring wet scrubbing for particulates and selective removal of hydrogen sulfide by the Selexol process.

The key default assumptions for systern design are summarized in Table A-17 for all three cases. In addition, typical modeling results, obtained from ASPEN simulations of these systems, are reported for fuel gas heating value, fuel gas composition at the turbine inlet, and mass flow ratios in the gas turbine. These ratios include the mass flow ratio of the compressor inlet air to the turbine exhaust air, the mass flow ratio of the fuel to the combustor inlet air, and the mass ratio of the extraction air flow to the fuel flow. The gas turbine mass balance is illustrated in Figure A-14.

\section{A.4.2 Commercial Offerings for 2,300 of Gas Turbines}

In this research, the modeling of IGCC systems is intended to include performance representative of typical high-firing temperature gas turbine technology. However, the intent is not to attempt to model exactly the performance of any one proprietary gas turbine 
Table A-18. Representative 2,300 of Firing Temperature Heavy-Duty Gas Turbine Commercial Offerings

\begin{tabular}{|c|c|c|}
\hline $\begin{array}{l}\text { Desion Specification } \\
\text { (Fuel: Natural Gas) }\end{array}$ & $\begin{array}{r}\text { General Electric } \\
\text { MS7001F }\end{array}$ & $\begin{array}{r}\text { Westinghouse/Mitsubishi } \\
501 \mathrm{~F}\end{array}$ \\
\hline Net Power, $\mathrm{kW}$ & 150,000 & 145,000 \\
\hline Heat Rate, BTU/kWh & 9880 & 10,000 \\
\hline Compressor Inlet Air, pps & 918.7 & 912 \\
\hline Pressure Ratio & 13.5 & 14.2 \\
\hline Exhaust Temp., of & 1,081 & 1,061 \\
\hline Compressor Stages & 18 & 16 \\
\hline Inlet Guide Vanes & Yes & Yes \\
\hline Variable Stator Vanes & No & No \\
\hline \multicolumn{3}{|l|}{ Compressor Cooling Air } \\
\hline Extraction (stage no.) & 13,17 , discharge & $13,10,6$, discharge \\
\hline Compressor Bleed (stage no.) & 13 & $6,10,13$ \\
\hline No. of Combustor Cans & 14 & 16 \\
\hline $\begin{array}{l}\text { Standard Combustor Design } \\
\text { (Natural Gas firing) }\end{array}$ & $\begin{array}{l}\text { multiple fucl nozzles, } \\
\text { wet injection--NO } \\
\text { ("quiet" combustor) }\end{array}$ & $\begin{array}{l}\text { pre-mix, two-stage } \\
\text { lean-burn low-NOx }\end{array}$ \\
\hline Turbine Stages & 3 & 4 \\
\hline \multicolumn{3}{|l|}{ Turi ine Conling: } \\
\hline Row 1 rotor vanes & internal convection & film, impingement, pin fin \\
\hline Row 2 rotor vanes & internal convection & similar to Row 1 \\
\hline Row 3 rotor vanes & uncorled & inlet cavity convection \\
\hline Row 4 rotor vanes & $\mathrm{N} / \mathrm{A}$ & uncooled \\
\hline
\end{tabular}

NOTES:

- The GE MS7001F apparently uses film cooling on the turbine stator vanes ("nozzles"), but not on the rotor vanes ("buckets").

- Both offerings use corrosion coatings on the hot gas path components.

Sources: Brandt, 1988; Brandt, 1989; Scalzo et al, 1989.

model. Instead, the goal is to achieve reasonable accuracy in reproducing the key performance characteristics of this class of gas turbines.

Currently, there are two 2,300 of turbine inlet temperature heavy-duty gas turbine models which are expected to be offered commercially in the next year or two. These are the General Electric MS7001F and the Westinghouse/Mitsubishi 501F. Some characteristics and design assumptions for these gas turbines are given in Table A-18.

The gas turbine model commonly assumed for IGCC system studies is the GE MS7001F. The prototype of this model reportedly began commercial c peration in June 1990 as part of a nacural gas-fired combined cycle unit at Virginia Pou er's Chesterfield Station in Richmond, VA. In addition, GE has reported sales of at least 10 more of these 
gas turbines. A proposed IGCC plant, to be located in Freetown, Massachusetts, using the Texaco gasifier, is planned to include a MS7001F (Smock, 1990).

The MS7001F is designed to fire either naturai gas or distillate oil at design point conditions of $59^{\circ} \mathrm{F}$ ambient temperature, 14.7 psia ambient pressure, and 60 percent relative humidity. The use of coal gas represents a departure from the desigr fuel. Because coal gas has a substantially lower heating value than natural gas, the fuel mass flow rate is significantly larger than the design basis for the gas turbine. Typically, the mass flow at the turbine inlet nozzle is limited by choking. Therefore, an increase in the fuel mass flow rate must be compensated by a reduction in the compressor air flow rate, for a given pressure ratio and firing temperature. This results in off-desigin operating conditions for the gas turbine, which has implications for gas turbine performance, such as efficiency, exhaust temperature, and other parameters.

Many IGCC studies were developed prior to the testing and delivery of the prototype ivis7001F. In these studies, a variety of assumptions regarding the projected performance of this unit were made regarding firing temperature, pressure ratio, efficiency, and other measures of performance. In most calses, these assumptions have proven to be different from the actual unit. This is an example of the difficulty involved in trying to predict the commercial scale performance of an advanced system for which no commercial experience is yet available. In many cases, the assumptions may have been unnecessarily conservative, while in other cases they may have been optimistic.

The studies appear to give only superficial consideration to the off-design nature of gas turbine operation on coal gas. Furthermore, the studies appear to give only superficial consideration to other factors associated with firing coal gas in a gas turbine.

Although a MS7001F is now in commercial service, the performance of this model with coal gas has yet to be demonstrated.

\section{A.4.3 Operating Strategies for Coal Gas Firing}

The primary issues discussed in this section are the interactions between fuel flow, compressor performance, and compressor air extraction.

A gas turbine is designed to meet a set of goals for a specific set of operating conditions. When any of these conditions are changed, the turbine is said to be in an "offdesign" mode. The response of the gas turbine to changes in operating conditions requires detailed knowledge which is specific to each machine. This type of information is closely 
held proprietary information. The design of a gas turbine, and prediction of its performance, involves a significant amount of empirical information. In many cases, offdesign information must be obtained from testing under various conditions, which is expensive. At a minimum, some testing is required to verify the accuracy of theoretical models. Becalise of the expense of testing needed to support gas turbine design and to verify the operation the gas turbine once built, detailed information about gas turbine design, such as compressor operating maps, are not published (Eustis and Johnson, 1990). Furthermore, gas turbine manufacturers usually try to adopt existing successful designs where feasible into new models, or to modularize the system (in the case of combustor cans, for example) so that a change in one component requires only a siniple substitution and no changes in other components (Cohen et al, 1987; Brandt, 1988; Scalzo et al, 198\%).

Because of the expense of developing and testing gas turbines, it is unlikely that, in the near term, the gas turbine industry will develop a machine designed specifically for operation with coal gas. Instead, they will try to develop an understanding of how a machine designed for larger markets (e.g., natural gas firing) will behave when firing coal gas. The manufacturers may be required to offer some modifications, such as for fuel valves or combustors. However, the manufacturers are also likely to impose limitations on fuel composition or gas turbine operation to which a customer must adhere. The development of such limitations is presumably based on some type of technical risk analysis of the gas turbine, supported either by theoretical models, empirical testing, both or neither.

Uncertainties are likely to remain, however, regarding the long term maintainability and performance of the gas turbines when firing coal gas. In particular, problems such as loss of output or shorter maintenance cycles (e.g., more frequent reblading) may be encountered in machines fired with coal gas for long periods of time (a complete life cycle). In some cases, these uncertainties can be represented solely as uncertainties in cost. However, there may be trade-offs between changing operating conditions and maintenance costs. A major concern for reliable operation of an integrated plant is the stability of the compressor and the control system, particularly when air is extracted for use in the gasifier.

A key difference between natural gas firing and coal gas firing is the heating value of the fuel. Natural gas has a heating value of about 1,000 BTU/scf. Medium-BTU coal zas (MBG) has a heating value of 300 to $500 \mathrm{BTU} / \mathrm{scf}$, and low-BTU coal gas (LBG) has heating values around $100 \mathrm{BTU} / \mathrm{scf}$. As a result, the mass flow rate of fuel required to 
supply a given amount of chemical energy is significantly larger for LBG than for natural gas.

The factor that usually limits the mass flow in a gas turbine is the area of the turbine inlet nozzles (Eustis and Johnson, 1990). When the flow is choked (sonic) the mass flow is at its maximum, and the maximum mass flow for an ideal gas is given by:

$$
\mathrm{m}_{\max }=\mathrm{PA}^{*} \sqrt{\frac{\mathrm{MW}}{\mathrm{T}}} \sqrt{\frac{\gamma}{\mathrm{R}}\left(\frac{2}{\gamma+1}\right)^{\frac{\gamma+1}{\gamma-1}}}
$$

where,

$$
\begin{array}{ll}
\mathrm{m}_{\max } & =\text { maximum mass flow rate } \\
\mathrm{P} & =\text { total pressure } \\
\mathrm{A}^{*} & =\text { critical area where flow is choked } \\
\mathrm{MW} & =\text { molecular weight of gas } \\
\mathrm{T} & =\text { total temperature } \\
\mathrm{R} & =\text { universal gas constant } \\
\gamma & =\text { ratio of specific heats for the gas }
\end{array}
$$

The molecular weight of the exhaust gas varies within about two percent for all three cases compared to the natural gas design point. The term under the radical varies about 5 percent as the ratio of specific heats varies from 1.2 to 1.4 . At $2,000 \mathrm{oF}$, the ratio of specific heats of nitrogen, the largest component in the exhaust gas, is about 1.3. The mass flow into the gas turbine is proportional to the critical area (which is fixed for a given gas turbine model) for a given pressure ratio and firing temperature.

For natural gas-fired operation, the air flow into the GE MS7001F compressor is about $919 \mathrm{lb} / \mathrm{sec}$. The natural gas flow rate is about $20 \mathrm{lb} / \mathrm{sec}$, yielding an exhaust flow rate of about $939 \mathrm{lb} / \mathrm{sec}$. However, in the case of low-BTU coal gas, the fuel flow rate is likely to be on the order of $200 \mathrm{lb} / \mathrm{sec}$. This would imply a turbine flow rate of over 1,100 lbisec, or a corispressor flow rate of about $720 \mathrm{lb} / \mathrm{sec}$, depending on the operating strategy employed and whether a substantially redesigned gas turbine is assumed.

Eustis and Johnson (1990) discuss several strat gies for firing coal gas in a gas turbine. These options include:

1) Increase the pressure ratio. This increases the maximum mass flow rate in the turbine nozzle. However, the compressor may not have enough surge margin to do this. Also, the increased mass flow would increase the thermal loads on the turbine blades and vanes, which may require a reduction in firing temperature.

2) Reduce compressor mass flow using inlet guide vanes (IGV). This reduces the compressor mass flow to compensate for the increased fuel flow. The flow reduction is limited by the compressor design. Compressors with variable stators 
and intermediate air bleed points in addition to IGVs are better able to achieve flow reductions without inducing stalling in any of the compressor stages.

3) Increase the inlet turbine nozzle critical area. This is a major redesign and would require a new gas turbine model. As a practical matter, it is unlikely that gas turbine manufacturers would develop such a machine.

4) Reduce the turbine inlet temperature. This would reduce the gas turbine efficiency and power output, but allow increased turbine mass flow.

5) Bleed air from the compressor. This is possible only where there is a use for high pressure air elsewhere in the plant. Otherwise, it is wasteful, and reduces plant efficiency.

In this study, a combination of Strategies 2 and 5 is assumed. Both the GE MS7001F and the Westinghouse/Mitsubishi 501F have IGVs. They do not have variable stator vanes. For the low-BTU coal gas systems, a portion of the compressor discharge air is assumed to be extracted for use as gasifier blast air. However, as noted in Table A-17, the ratio of extraction air to the fuel flow is about 0.5 to 0.6 . The extraction air does not fully compensate for the increased fuel mass flow. Thus, at full load, the IGVs would have to be partially closed.

IGVs are often used to respond to part load conditions without having to reduce firing temperature. At the point wlere the IGVs are "fully" closed, firing temperature must then be reduced to further reduce the load. In a coal gasification application, because the IGVs are already partially closed at full load, the gas turbine will be less efficient at part load operation, as the point at which firing temperature must be reduced will be at a higher load condition than for natural gas.

The paitial closure of IGVs will slightly affect the gas turbine pressure ratio. However, because the gas turbine model used in these case studies is based on mass and energy balances only, and not the aerodynamic characteristics of a gas turbine, pressure ratio is not predicted. Any change in pressure ratio must be specified by the model user.

Closure of IGVs also affects the compressor surge margin. At surge conditions, the compress $n^{*}$ is no longer able to generate a steady high pressure exit stream. Thus, any downstream pressurized gas, such as that in the combustor, will backflow into the compressor, possibly causing severe vibration and damage. Compressors are usually designed to operate at a point sufficiently removed from the "surge line" to reduce the possibility of encountering surge. However, the operation of the machine with IGVs closed may reduce the margin between the operating conditions and surge conditions (Eustis and Johnson, 1990). 
The determination of the surge line and the compressor characteristics requires exten ive testing under a variety of loads, corrected speeds, IGV settings, and mass flow rates. These data are summarized in compressor "maps." These maps are proprietary information due to the expense of developing them and the importance of the information to the competitive position of the manufacturer. General Electric reports that the MS7001F has a better surge margin than the MS7001E, which has been commercially available for years. GE reports that no in-service surges of the MS7001E have been reported. Thus, GE expects a superior surge margin for the MS7001F (Brandt, 1989). This may alleviate any concerns about using the IGVs to reduce the compressor mass flow. However, without a compressor map, it is difficult to make any quantitative assertions.

The use of air extraction for the low-BTU coal gas cases helps to improve the surge margin of the compressor, by reducing the amount of IGV closure needed at full load conditions. However, air extraction poses significart control problems for the IGCC plant, because it imposes a coupling between the gas turbine and the gasifier. Changes in coal composition can affect the fuel/air ratio, but can also affect the gasifier blast air requirement. This requires a sophisticated control system to regulate the IGVs, extraction air flow rate, and fuel flow rate. Advanced control systems may be required (Corman, 1986).

\section{A.4.4 Fuel Valve}

The pressure drop across the fuel valve system has an important effect on system efficiency. The gasifier pressure must be high enough to compensate for all pressure losses between the gasifier outlet and the gas turbine combustor. The pressure in the combustor is determined based on the gas turbine pressure ratio. Pressure losses in the system include the fuel gas piping, fuel valve, particulate removal devices (e.g., cyclones), and sulfur removal devices (e.g., zinc ferrite absorbers). Increasing the gasification pressure above that required for fuel gas delivery can reduce the system efficiency (Simbeck et al., 1983).

Reduction in the fuel valve pressure drop was reported to be one goal of a proposed demonstration plant. The typical pressure drop in the fuel valve was reported at about 70 psi. The goal was to achieve about $10 \mathrm{psi}$. The demonstration project proposes to use a GE MS7001E with a fuel gas temperature of about $1,000 \mathrm{~F}$. The material requirements for this system were claimed not to be a major problem (Hester and Pless, 1990). 
A design study of an IGCC system with hot gas cleanup assumed a gas tur ine fuel inlet temperature of $1,200 \mathrm{oF}$. The basis for this assumption was reported to be GE's expectation that by 1994 a fuel system for $1,200 \mathrm{oF}$ gas could be developed, although the highest fuel gas temperature tested to date has been 1,000 oF (Earley and Smelser, 1988).

The presence of particles in the fuel gas could lead to erosion or deposition in the fuel nozzles. Based on two-stage high-efficiency cyclones, a GE study concludes that the particle concentration and size distribution in the fuel gas would allow for "adequate" nozzle and control valve lives. However, any solids that deposit in the fuel nozzle can alter flow characteristics. This can result in reduced combustion efficiency. Solids deposits can also interfere with fuel valve operation. Naphthas, tars, and phenols can build up on valve internals (Cincotta, 1984).

Any liquids entering the combustor as large droplets may not burn completely within the combustor. They may carry over to, and burnout in, the first stage turbine nozzle. This can cause damage to the turbine (Cincotta, 1984).

The fuel control system poses a design challenge for an IGCC plant. The control system must account for changes in the heating value of the fuel gas during plant operaition, as well as differences in the load-following capability of the gasifier and gas turbine. The fuel control system could potentially depressurize the gasifier by demanding more fuel than the gasifier can supply during ramp-up (Cincotta, 1984). The addition of gas turbine air extraction for gasifier blast air further complicates the control system (Corman, 1986).

In the modeling studies, the effect of pressure drop in the fuel gas valve can be explicitly included in the ASPEN performance simulation. The effect of exotic fuel valve materials or designs on gas turbine cost can be incorporated in the cost model through, for example, a direct capital cost multiplier factor.

\section{A.4.5 Combustion and Emissions}

Gas turbine combustors have been developed in an empirical-based manner. Mathematical analysis and scale model testing apparently have been inadequate predictors of full-scale combustor performance (Dawkins et al, 1986). As a result, heavy-duty gas turbines have been developed using multiple modular "can" combustors. Typically, many of these combustors are arranged around the circumference of the machine between the compressor and the turbine. As part of a development program only one combustor can needs to be used in testing (Cincotta, 1984). In a commercial-scale gas turbine, such as the ones summarized in Table A-18, perhaps 16 to 18 combustor cans are utilized. Each one 
can be changed out for maintenance ard repair. The standard combustor can also can be replaced by improved versions as they become available. The same combustor design can be used in different size machines by using an appropriate number of the combustor cans.

There are a number of pollutant species that may be contained in the hot gas exiting the combustor which have received attention in the literature. These are:

- Thermal $\mathrm{NO}_{\mathrm{x}}$ resulting from thermal fixation of oxygen and nitroger in air.

- Fuel $\mathrm{NO}_{\mathrm{x}}$ resulting from conversion of chemically bound nitrogen in the fuel (e.g, ammonia).

- $\mathrm{SO}_{2}$ resulting from hydrogen sulfide, carbonyl sulfate, and sulfur contained in naphtha, tars, oils, and phenol.

- CO resulting from incomplete carbon conversion in the combustor.

- Uncombusted particles passing through the combustor.

- Alkali (sodium and potassium compounds) which may cause turbine blade corrosion.

The design of gas turbine combustors is undergoing changes in response to environmental constraints on $\mathrm{NO}_{\mathrm{x}}$ and $\mathrm{CO}$ emissions and an increasing array of potential gas turbine fuels. Currently, most efforts are focused on developing low-NOx combustors for natural gas applications (Angello and Lowe, 1989). However, some theoretical studies, bench scale research, and a few commercial-scale demonstrations have involved medium- and low-BTU gases, such as those derived from coal gasification. The design of combustors for coai gas applications may be fundamentally different from those for natural gas applications, particularly with respect to $\mathrm{NO}_{\mathrm{x}}$ emissions.

\section{A.4.5.1 $\mathrm{NO}_{\mathrm{x}}$ Emissions}

$\mathrm{NO}_{\mathrm{x}}$ emissions result primarily from the thermal fixation of nitrogen and oxygen in the inlet combustion air and from conversion of chemically-bound nitrogen in the fuel. The former is referred to as "thermal" $\mathrm{NO}_{\mathrm{x}}$, while the latter is referred to as "fuel" $\mathrm{NO}_{\mathrm{x}}$. Thermal $\mathrm{NO}_{\mathrm{x}}$ formation is sensitive mainly to the flame temperature of the burning fuel. Poor mixing of fuel and air can lead to localized "hot spots" which generate high flame temperatures and, hence, high thermal $\mathrm{NO}_{\mathrm{x}}$ emissions. Uniform mixing of fuel and air leads to more uniform flame temperatures, which reduces ihermal $\mathrm{NO}_{\mathbf{x}}$ formation. In addition, other measures which reduce flame temperatures, such as staged lean combustion or the addition of diluents such as water or steam, will reduce thermal $\mathrm{NO}_{\mathbf{x}}$ emissions (Davis et al, 1987; Touchton, 1984) 
Fuel $\mathrm{NO}_{\mathrm{x}}$ arises from the conversion of ammonia, $\mathrm{HCN}$, or other nitrogencontaining chemical species in the fuel. The formation of fuel $\mathrm{NO}_{\mathrm{x}}$ is relatively insensitive to temperature compared to thermal $\mathrm{NO}_{\mathrm{x}}$ formation. Fuel $\mathrm{NO}_{\mathrm{x}}$ formation depends primarily on the concentration of fuel-bound nitrogen in the fuel gas and the method of fuel/air contacting (Folsom et al, 1980). To reduce fuel $\mathrm{NO}_{\mathrm{x}}$ formation, two-stage rich/lean combustion has been proposed and tested by several (e.g., Folsom et al, 1980; Sato et al, 1989; Unnasch et al, 1988). In the rich combustion stage, fuel bound nitrogen is converted mostly to diatomic nitrogen. In the lean stage, fuel burnout is completed under conditions which minimize the formation of thermal $\mathrm{NO}_{\mathrm{x}}$.

The most widely used gas turbine fuel is natural gas, which contains negligible fuel-bound nitrogen. Most major gas turbine manufacturers are attempting to develop dry low- $\mathrm{NO}_{\mathbf{x}}$ combustors, to reduce the formation of "thermal" $\mathrm{NO}_{\mathbf{x}}$ by premixing the fuel and air and use of lean-burn or lean-lean two-staged combustion. The Westinghouse/Mitsubishi $501 \mathrm{~F}$ will be offered with a low $\mathrm{NO}_{\mathbf{x}}$ combustor featuring fuel and air premixing and a lean-burn combustor (Scalzo et al., 1989). The GE MS7001F is offered with a multiple fuel nozzle combustor can (Brandt, 1988). This is not a low-NO design per se, but it does allow increased levels of water or steam injection to achieve low $\mathrm{NO}_{\mathrm{x}}$ emissions with fuels that do not contain fuel-bound nitrogen. The multiple nozzle design has been referred to as the "quiet" combustor because it has a lower vibration and noise level than GE's single fuel-nozzle combustor. The reduced vibrations permit higher levels of water injection.

\section{Medium-BTU Coal Gas: Case OKC}

In the current modeling work, the only medium-BTU coal gas of concern is that produced from an oxygen-blown KRW gasifier in Case OKC. The Case OKC IGCC system features "cold" gas cleanup, which effectively removes any ammonia, the primary fuel-bound nitrogen species, from the raw coal gas. Thus, fuel $\mathrm{NO}_{\mathrm{x}}$ emissions are not expected to be a problem for this application. Thermal $\mathrm{NO}_{\mathrm{x}}$ emissions are of concern, however. MBG may have flame temperatures similar to that of distillate oil, and thus uncontrolled $\mathrm{NO}_{\mathrm{x}}$ emissions from firing $\mathrm{MBG}$ may be comparable or greater than uncontrolled emissions from firing distillate oil (Davis et al, 1987).

Most conceptual design studies assume that steam injection and/or fuel gas saturation can be used to reduce the combustor flame temperature and, hence, $\mathrm{NO}_{\mathrm{x}}$ emissions to meet current New Source Performance Standards (NSPS) for gas turbines (e.g., Gallaspy et al, 1990 and many of the other EPRI design studies). Wet injection is a standard technique for natural gas and oil fired gas turbines. The thermal diluent, steam or 
water, results in a reduction in peak combustion temperatures, thus reducing thermal $\mathrm{NO}_{\mathrm{x}}$ formation (e.g., Davis et al, 1987; Touchton, 1984; Touchton, 1985). Both steam injection and fuel gas saturation have been tested at the Cool Water demonstration plant, which uses MBG from a Texaco gasifier (Cool Water, 1988; Holt et al, 1989).

The NSPS is often quoted as $75 \mathrm{ppm}$ at 15 percent oxygen on a dry basis, but the standard actually includes a correction for plant efficiency. Thus, the actual allowable emissions under NSPS for a particular gas turbine model may be higher.

However, it is controversial whether the gas turbine NSPS is the applicable standard for IGCC power plants, or whether it is even a relevant standard. More likely, IGCC plants will be subject to local or EPA-mandated procedures such as Best Available Control Technology (BACT), which is determined on a plant-by-plant basis. The procedure for BACT analysis that is becoming increasingly common is known as the "topdown" approach. In this approach, a facility is asked to use the most stringent control system that has been demonstrated unless there are energy, environmental, or economic reasons to do otherwise. For natural gas-fired gas turbines, BACT may include combinations of low- $\mathrm{NO}_{\mathrm{x}}$ combustors, wet injection, and post-combustion $\mathrm{NO}_{\mathrm{x}}$ control using selective catalytic reduction (Smock, 1989: Moore-Staub et al, 1990). It is likely that an actual IGCC plant will be required to achieve very low $\mathrm{NO}_{\mathrm{x}}$ emissions on the order of $10 \mathrm{ppm}$, rather than the $75 \mathrm{ppm}$ (corrected) often assumed. Thus, SCR may be required. SCR has been applied to or required for a number of natural gas- and oil-fired gas turbines in California and a few other states (Radin and Boyles, 1987; Moore-Staub et al, 1990). $\mathrm{SCR}$ is expected to be capable of reducing IGCC system $\mathrm{NO}_{\mathrm{x}}$ emissions to $5 \mathrm{ppm}$ (Holt et al, 1989). At least one IGCC plant, a proposed demonstration plant in Florida, is to be permitted with SCR (Hester, 1990). This may set a BACT precedent for other IGCC plants.

For the purposes of the curreitt study, fuel gas saturation and/or steam injection for combustion $\mathrm{NO}_{\mathrm{x}}$ control is assumed for medium-BTU coal gases with no fuel-bound nitrogen. The effect of SCR would primarily be to increase the capital and operating costs of the system, with a slight penalty on plant efficiency due to increased HRSG backpressure and the auxiliary power requirements of the SCR ammonia injection and control systems. SCR may be more advantageous for application with fuel gases containing significant concentrations fuel-bound nitrogen.

The applicability or efficacy of dry low- $\mathrm{NO}_{\mathrm{x}}$ combustors designed for natural gas when converted to coal gas firing may merit some testing and evaluation. Whether the 
combustors can be used "as is", other than modifications for the fuel nozzles, might be the subject of further research.

\section{Low-BTU Coal Gas: Cases ALH and AKH}

Thermal $\mathrm{NO}_{\mathrm{x}}$ is not expected to be a major concern with LBG gases because of their low adiabatic flame temperatures resulting from the presence of thermal diluents in the fuel such as $\mathrm{N}_{2}$. The thermal $\mathrm{NO}_{x}$ emissions from LBG are often dismissed in the literature as being insignificant, particularly if peak flame temperatures are limited to less than 2,800 ${ }^{\circ}$ (Davis et al, 1987; Folsom et al, 1980; Notestein, 1989; Sato et al, 1989; Unnasch et al, 1988). Uncontrolled thermal $\mathrm{NO}_{\mathrm{x}}$ emissions from LBG combustion may in fact be on the order of 10 to $50 \mathrm{ppm}$, as suggesied by some small scale combustor tests (e.g., Unnasch et al, 1988).

A confounding factor for thermal $\mathrm{NO}_{\mathrm{x}}$ emissions from $\mathrm{LBG}$ is the expected high gas turbine fuel valve inlet temperatures associated with hot gas cleanup (HGCU) systems. Also, increasing pressure ratios for gas turbines may promote thermal $\mathrm{NO}_{\mathbf{x}}$ emissions (Folsom et al, 1980). Increasing the fuel gas temperature will tend to increase thermal $\mathrm{NO}_{\mathrm{x}}$ production because the flame temperatures will be marginally higher. However, this is not expected to significantly increase thermal $\mathrm{NO}_{\mathrm{x}}$ emissions for the fuel temperatures of cur rent interest (1,000 to $1,200 \mathrm{oF})$.

The primary concern regarding $\mathrm{NO}_{\mathrm{x}}$ emissions from LBG is fuel NOx resulting from ammonia, $\mathrm{HCN}$, or other fuel bound nitrogen species. LBG is derived from airblown gasification systems. Air-blown gasification is commonly envisioned in conjunction with HGCU. HGCU systems typically are based on dry pollutant removal processes, such as cyclones or barrier filters for particulate control and chemical sorption for sulfur control. Unlike "cold" gas cleanup wet scrubbing processes, these dry processes do not remove ammonia, the primary fuel-bound nitrogen specie, in the fuel gas. In conventional gas turbine combustors, most of the ammonia would be converted to $\mathrm{NO}_{\mathrm{x}}$. For example, Cincotta (1984) states that the conventional GE MS7001E combustor would convert about 70 percent of ammonia in a Lurgi fuel gas to $\mathrm{NO}_{\mathrm{x}}$. Another study reports a similar finding (Sato et al, 1989). In a conventional combustor, the conversion rate of ammonia to NOx may vary from 50 to 90 percent depending on the concentration of ammonia in the fuel gas (Pillsbury, 1989).

The ammonia concentration in the fuel gas depends on the gasifier type and operating conditions. Notestein (1989) indicates typical ranges of ammonia co.lcentration in coal gas as 200 to $600 \mathrm{ppmv}$ for fluidized bed gasifiers operating at 1,300 to $1,800{ }^{\circ} \mathrm{F}$, 
2,000 ppm for entrained flow gasifiers, and up to 5,000 ppm for fixed bed gasifiers operating below 1,200 oF. Holt et al (1989) suggest that about 50 to 60 percent of coalbound nitrogen is converted to ammonia in fixed bed gasifiers, while only 10 to 15 percent is converted in entrained-flow gasifiers. Some typical concentrations from ASPEN simulation models are given in Table A-17.

The most likely near-term solution for reducing fuel $N \mathrm{O}_{\mathrm{x}}$ emissions from $\mathrm{LBG}$ combustion appears to be staged rich/lean combustion (Cincotta, 1984; Folsom et al, 1980; Sato et al, 1989; Unnasch, 1988). In rich/lean combustion, the rich stage is used to convert ammonia to nitrogen, and the second stage is used for fuel burnout. The combination of a rich and lean stage also reduces the peak flame temperatures in the combustor, therety reducing thermal $\mathrm{NO}_{\mathrm{x}}$ emissions.

Some of the findings of several combustor research efforts have been:

- Temperature. Fuel $\mathrm{NO}_{\mathrm{x}}$ formation is relatively insensitive to temperature (Holt et al, 1989). Variation in fuel heating value appears to have little effect on conversion of ammonia to $\mathrm{NO}_{\mathrm{x}}$ (Folsom et al, 1980).

- Fuel-nitrogen concentration. The fraction of fuel-bound nitrogen converted to $\mathrm{NO}_{\mathrm{x}}$ decreases with increasing fuel-bound nitrogen concentration (Folsom et al, 1980; Sato et al, 1989; Unnasch et al, 1988). In the Unnasch et al (1988) tests, it was found that above 5,000 ppm ammonia concentration, there was very little marginal increase in $\mathrm{NO}_{\mathrm{x}}$ emissions.

- Stoichiometry. Fuel $\mathrm{NO}_{\mathrm{x}}$ formation is sensitive to the reaction stoichiometry. In an oxygen-deficient environment, a substantial portion of fuel-bound nitrogen can be converted to diatomic nitrogen. The optimal reactant stoichiometry (fuel/air ratio) in the rich stage to maximize conversion of fuel-bound nitrogen to $\mathrm{N}_{2}$ (minimize fuel $\mathrm{NO}_{\mathrm{x}}$ ) is influenced by reaction temperature (Folsom et al, 1980).

- Pre-Mixing. Uniform pre-mixing of fuel and air may be required to assura a uniform fuel/air ratio throughout the reaction mixture (Folsom et al, 1980).

- Hydrocarbons. The presence of hydrocarbons, such as methane, appears to promote the formation of fuel $\mathrm{NO}_{\mathbf{x}}$, due to reactions with intermediate reaction products which interfere with $\mathrm{N}_{2}$ formation. However, a hydrocarbon gas does appear to promote the conversion of $\mathrm{NO}$ to $\mathrm{N}_{2}$. This may have implications for the second stage (Folsom et al, 1980).

- Burnout. A rich stage for fuel-bound nitrogen "cracking" to $\mathrm{N}_{2}$ requires a second lean stage for fuel burnout (Folsom et a!, 1980).

- Thermal NQ ${ }_{x}$. The lean mixture in the second stage can be adjusted to reduce or minimize thermal $\mathrm{NO}_{\mathrm{x}}$ formation (Folsom et al, 1980). However, the rich/lean combustor may not reduce thermal $\mathrm{NO}_{\mathrm{x}}$ as effectively as a lean/lean combustor would for fuels without nitrogen compounds (Holt et al, 1989). Unnasch et al (1988) found that MBG combustion yielded higher thermal $\mathrm{NO}_{\mathrm{x}}$ emissions than LBG, and specuiated that this was attributable to higher flame temperatures. 
- Turbulence. Fuel $\mathrm{NO}_{\mathrm{x}}$ formation is expected to increase in turbulent flames. A laminar diffusion flame appears to allow for good conversion of ammonia to $\mathrm{N}_{2}$ (Folsom et al, 1980).

- Fuel heating value. If fuel heating value is too low, combustion may not start in the fuel-rich zone. If combustion begins in the fuel-lean zone, conversion of ammonia to $\mathrm{NO}_{\mathrm{x}}$ may be very high (Sato et al, 1989).

- Pressure. As combustor pressure increases, the conversion of ammonia to $\mathrm{NO}_{\mathrm{x}}$ appears to decrease slightly, based on testing from 1 to 14 atm using a half-scale conventional combustor model (Sato et al, 1989).

- Efficacy. Rich/lean combustor tests using small scale combustors at relatively low pressures have achieved up to 95 percent conversion of ammonia to $\mathrm{N}_{2}$ (Folsom et al, 1980; Unnasch, 1988; Notestein, 1989). Folsom et al attempted to develop ideal combustors of various designs on the bench-scale, but indicated that full-scale commercial designs may not be as successful in achieving $\mathrm{NO}_{\mathbf{x}}$ reductions. The tests by Sato et al (1989) did not appear to achieve such high conversion rates. These tests involved perhaps more realistic full- and half-scale gas turbine combustors. In the Sato tests, ammonia conversion to $\mathrm{N}_{2}$ was increased from a nominal value of 30 percent to a nominal value of 50 percent. This may be contrasted with the value of 30 percent typical of conventional combustors, discussed previously. These results imply that the efficacy of a commercial scale rich/lean combustor in reducing fuel $\mathrm{NO}_{\mathrm{x}}$ emissions may be in doubt.

- CO emissions. In the Sato et al (1989) tests, CO emissions were below 100 ppm.

Another concept that has received some attention is catalytic combustion. However, in the near term, rich/lean combustion appears to be receiving more attention and testing. Therefore, for this study, rich/lean combustion is assumed as the most likely alternative for fuel $\mathrm{NO}_{\mathrm{x}}$ control.

\section{A.4.5.2 Combustion Efficiency and $\mathrm{CO}$ Emissions}

CO emissions, which result from incomplete combustion of hydrocarbons or no combustion of $\mathrm{CO}$ in the fuel gas, are an indicator of poor combustion efficiency. Many of the measures which redure NOx emissions, such as reducing flame temperature through wet injection or staged combustion, also tend to increase $\mathrm{CO}$ emissions by reducing the combustion efficiency. Most heavy-duty natural gas-fired and distillate oil-fired gas turbines have very low CO emissions (less than 5-10 ppm).

CO emissions increase at part load as the gas turbine combustor firing temperature is reduced during load-following (Entrekin and Edwards, 1987). Becker and Shulten (1985) report on part-load gas turbine combustion of low-BTU blast furnace gas in which it was difficult to achieve conversion of $\mathrm{CO}$ in the gas. However, coal gas has a higher hydrogen content than blast furnace gas, and may tend to combust more completely. 
At the Cool Water demonstration plant, $\mathrm{CO}$ emissions were low with wet injection or fuel gas saturation. However, there are limits to fuel gas moisturization. As moisturization increases, the combustor flame becomes increasingly unstable, leading to pressure oscillations which can reduce the life of the combustor. At very high injection or moisturization rates, the combustion flame will ultimately blow out. Prior to the loss of flame, combustion efficiency will be low and CO emission will be high (Holt et al, 1989). The maximum fuel moisturization level is thus usually determined based on the point at which $\mathrm{CO}$ emissions begin to increase significantly.

A post-combustion flue gas $\mathrm{CO}$ catalyst can be used to convert $\mathrm{CO}$ to $\mathrm{CO}_{2}$. The $\mathrm{CO}$ catalyst is relatively low cost, compared to SCR catalyst for $\mathrm{NO}_{\mathrm{x}}$ control. However, the combination of reduced combustion efficiency and the exhaust gas pressure drop across the CO catalyst leads to reduced plant efficiency (Holt et al, 1989). The effects of flue gas from coal gas combustion on $\mathrm{CO}$ catalyst, such as catalyst masking or poisoning, may need to be assessed to determine the economics of $\mathrm{CO}$ catalysts in an IGCC process environment.

Incomplete combustion may occur due to local chilling of the flame, such as at points of secondary air entry (Cohen et al, 1987) or due to wet injection.

One advantage that coal gases have compared to natural gas or distillate oil with respect to combustion efficiency is the presence of hydrogen, which has a very high flame speed. This results in early ignition and promotes complete combustion (Holt et al, 1989).

\section{COEmissions With MBG: Case OKC}

For a medium-BTU gas, $\mathrm{CO}$ emissions are not expected to be a major concern at baseload operation, particularly if there is hydrogen in the fuel gas. $\mathrm{CO}$ emissions could become a problem at part load if firing temperature is significantly reduced, or could become significant if high levels of water injection or fuel moisturization are used.

\section{COEmissions with LBG: Cases ALH and AKH}

CO emissions are more of a concern for LBG than MBG. Corman (1986) reports an estimate for baseload $\mathrm{CO}$ emissions from a 100-MW class gas turbine firing LBG with a heating value of less than $150 \mathrm{BTU} / \mathrm{scf}$ to be approximately 10,000 tons/year. Corman implies the emissions would be higher for part-load gas turbine operation. However, in a phone conversation (1990) Corman appeared to have no concern about CO emissions with LBG. Pillsbury (1989) indicated that heating value is not the proper determinant of combustion efficiency, particularly because hydrogen is highly flammable and will tend to promote complete combustion even in LBG. Pillsbury and Corman both stated that the 
expected $\mathrm{CO}$ emissions are on the order of $10 \mathrm{ppm}$ or less when firing LBG at baseload conditions.

\section{A.4.5.3 Combustor Pressure Drop}

The combustor pressure drop is one of the significant losses in the gas turbine system. Pressure losses are due to skin friction and turbulence. The rise in temperature during combustion increases velocity and momentum of the gases in the combustor, which leads to temperature-related pressure losses. However, the pressure drop due to turbulence is usually much higher than the pressure loss associated with the temperature ratio in the combustor. The build-up of carbon or other deposits on the combustor liner may also affect skin friction and/or turbulence-related pressure losses. Furthermore, aerodynamically excited vibrations in the combustor could lead to deposits breaking away, which could result in turbine damage (Cohen et al, 1987).

\section{A.4.5.4 Particles}

The particle loading in the fuel gas may be considered to consist of refractory materials or carbonaceous materials. Refractory particles may pass through the combustor without alternation. They can split into smaller particles, or possibly agglomerate into larger particles. Carbonaceous material may be fully or partially combusted, leaving perhaps ash residues (Cincotta, 1984). The particle discharge from the combustor may affect turbine maintenance.

\section{A.4.5.5 Combustor Life}

The combustor life has an effect on maintenance and repair work and, hence, the cost of maintaining the gas turbine. For industrial gas turbines, combustor chamber lives of 100,000 hours are desirable (Cohen et al, 1987). However, deposition, erosion, corrosion, and vibrations can shorten the life of combustor components such as the liners, requiring more frequent liner replacement or more expensive materials. The modular nature of the combustor cans makes this type of maintenance routine. However, the cost will increase with the frequency of maintenance and repair. The possible presence of particulates and alkalis in the coal gas may lead to more costly maintenance compared to clean fuel (e.g., natural gas) fired gas turbines.

\section{A.4.6 Turbine}

The heavy-duty high firing temperature gas turbines assumed for this study typically employ three or four turbine rotor stages. The first two or three stages are subject to high thermal loadings due to the high temperature exhaust gas. Improvements in turbine rotor blade cooling technology have made possible increases in gas turbine firing (turbine 
inlet) temperatures while maintaining essentially constant bulk metal temperatures in the rotors and stators of the first turbine stage. Possible future improvements in materials and manufacturing processes (such as making turbine blades from a sirigle crystal with no grain boundaries) may allow higher blade bulk metal temperatures, due to the improved strength of the material, and further increases in firing temperature (Smock, 1989).

A number of potential problems with the effect of hot combustion gas on the turbine have been identified in various reports. These include:

- Corrosion of hot gas path components from alkali metals

- Erosion of material from airfoils (rotor and stator blades) due to ash particles of sufficient size and quantity. This would likely exacerbate corrosion as well, as the airfoils are often coated with a corrosion resistant layer.

- Deposition of ash on hot gas path components, changing the aerodynamic characteristics of th ? turbine and resulting in loss of efficiency. This would also affect film cooling and the heat transfer from the hot gas to the airfoils.

- Blockage of film cooling holes, reducing the efficiency of blade cooling. This could lead to localized thermal stresses arising from thermal gradients in the blade material, affecting the operating life and/or sustainable firing temperature of the turbine

All of these $\mathrm{f}$ ossible problems would affect the gas turbine maintenance cycle, thereby affecting maintenance costs. Some or all of these affects could also require changes in gas turbine operation, such as a reduction in firing temperature or strict specifications on fuel gas composition.

\section{A.4.6.1 Advanced Cooling Technology}

Aircraft derivative gas turbines, and particularly military engines, have employed a variety of advanced turbine cooling techniques. These machines fire clean jet fuel, and as such are not subject to the exhaust gas contaminants expected in coal gas-fired units. Turbine blades and stator vanes subject to high temperature environments may have hollow internal cooling passages, through which compressed air is passed for convective cooling. These passages may have pin fins, to promote heat transfer from the metal to the cooling air. The cooling air is typically exhausted from the blade through holes in the blade tip or the trailing edge of the blade. The cooling air exhausted at the blade tip does provide some aerodynamic advantages by blocking against external bypass flow of exhaust gases between the blade tip and the rotor shroud. To further promote heat transfer in the internal cooling circuits, high velocity impingement of cooling air against the inside surface of a highly heated area may be used (referred to as impingement cooling). In addition, film cooling, in which some cooling air from inside the blade is vented near the leading edge of 
the blade, may also be employed. Film cooling results in a boundary layer of cooling air over the blade surface (Cohen et al, 1987; Dawkins et al, 1986).

The amount of cooling air required depends on the firing temperature, cooling air temperature, heat transfer features of the rotor and stator vanes, the material properties, and the design life of the system (Dawkins et al, 1986).

Based on testing of a prototype MS7001F engine with high $(2,300 \mathrm{oF})$ firing temperature, GE reports that they expect their minimum hot gas component life design requirement to be met. The basis for this assertion is measurement of hot gas path metal temperatures to be 30 to $50 \mathrm{oF}$ below the design values. The test was conducted with natural gas (Brandt, 1989). The gas path metal temperatures in a coal gas application may be affected by deposition or hole plugging, which is discussed in a later section.

The design of blades is complicated due to the changes in hot gas temperature across the blade surfaces, and the changes in temperature of cooling air inside the blade. Thus, the design must account for thermal gradients. Stresses in the blades may arise from thermal gradients (Cohen et al, 1987).

Any particles or liquid droplets which pass through the combustor and burn-out in the turbine nozzle or turbine first-stage may have deleterious effects on the thermal stresses in the hot gas path componenis.

\section{A.4.6.2 Turbine Blade Materials}

The selection of firing temperature for a gas turbine depends on both the turbirie blade cooling technology employed and the blade materials. Three key criteria for selecting hot gas path materials, particularly for rotor blades, are: (1) creep-rupture propertios; (2) hot corrosion resistance; and (3) hot oxidation resistance. The creep strength of a metal is a function of the bulk metal temperature. The time to obtain a standard 0.2 percent creep strain decreases as temperature increases. Also, the fatigue strength of a metai subject to cyclic stresses decreases as temperature increases. To provide blade strength, nickel-based superalloys may be used for rotor blades. To provide corrosion and oxidation resistance, coatings may be applied to the blade surfaces. Typical coatings include platinumchromium-aluminide (Dawkins et al, 1986).

The GE MS7001F is reported to use a first-stage coating alloy containing cobalt, chromium, aluminum, and yttrium (Brandt, 1988). The blades for the GE turbine are reported to be manufactured using a technology called directional solidification that has been used for 20 years to make jet engine blades. In this casting method, the grain 
boundaries in the crystal structure of the metal are oriented to improve tensile strength, ductility, and fatigue strength. The use of this molding technology has permitted an increase in firing temperature of about $150{ }^{\circ} \mathrm{F}$. Possible future improvements would be the casting of a single-crystal blade with no grain boundary, which would permit another 50 to $150^{\circ} \mathrm{F}$ improvement in firing temperature (Smock, 1989). Inceases in firing temperature permit increased simple cycle efficiency. Such a design improvement is likely to be a long term development objective.

\section{A.4.6.3 Deposition}

Deposition of ash on surfaces in the hot gas path can restrict air flow, thus reducing turbine efficiency. Deposition of ash particles is expected to some extent in coal-fueled gas turbines (Cincotta, 1984). Deposits can also lead to plugging of cooling air outlet holes, particularly those used for film cooling, on the turbine rotor blades (Becker and Schulten, 1985; Dawkins et al, 1986). This can lead to increased localized temperature gradients that can result in thermal stress cracking, and can be exacerbated by the stress riser effect of the cooling air holes themselves. Also, film cooling can be affected by deposits on the turbine blades and hơ gas channels. Such deposits, of certain size and consistency, can significantly alter the flow and heat transfer characteristics of the blades (Becker and Schulten, 1985).

Hot gas path blockage is generally expected with any gas turbine application involving a fuel containing ash particles. GE predicted a blockage rate of about 0.4 percent of the first-stage turbine nozzle area per 100 hours of operation at a 2,300 $\mathrm{cF}$ firing temperature, based on a system with two-stages of high efficiency cyclones (Cincotta, 1984). This implies nozzle cleaning every 2,500 hours, if up to 10 percent blockage is allowed. The assumption appears to be that this cleaning can be accomplished using offline water washing, for example.

GE conducted some tests with a turbine simulator to determine possible effects of ash deposition. No measurable deposits were found on the airfoils. However, the tests were onily 57 hours in duration (Corman, 1986).

Evaluation of deposition appears to require a long term testing program, which in reality may not be realized until a demonstration plant is built and operating. The effect of deposition on the heat transfer characteristics of the turbine blades might be to require a redis : on in firing temperature or to increase the frequency of blade replacements. Thus, either performance and/or cost may be affected by these types of problems. 


\section{A.4.6.4 Erosion}

Erosion occurs due to contact of particles with sufficient mass or velocity to remove material from hot gas path surfaces, particularly rotor and stator vanes. Some possible sources of particles contributing to erosion include: particles not removed from the fuel gas in cyclones or barrier filters; break-away deposits from the fuel nozzle, fuel valves, combustor lining, transition piece, or turbine nozzles; and carry-over of sorbent material from the zinc ferrite sorbent bed and, if included in the system, alkali removal sorbent bed. GE reported that they expect to achieve a particle size distribution and loading using twostages of high efficiency cyclones to be within the erosion tolerance of the gas turbine materials (Cincotta, 1984).

However, some speculate that cyclones are insufficient to avoid the build up of particles and, hence, pressure drop in the zinc ferrite absorber bed. Therefore, barrier filtration upstream of the zinc ferrite unit may be required, in lieu of a single-stage cyclone. There is also speculation that a cyclone downstream of the zinc ferrite absorber may not be needed. Most design studies assume a cyclone between the absorber and the gas turbine combustor to capture any catastrophic loss of sorbent or unusual entrainment of sorbent, as well as to provide for additional removal of particles still present from the gasifier.

\section{A.4.6.5 Corrosion}

The most widely expressed concern regarding hot gas path corrosion is due to the presence of alkali in the exhaust gas. For systems with cold gas cleanup, alkali are not expected to pose a corrosion threat because it is believed that below 1,200 to $1,400 \mathrm{OF}$, alkali condense onto particles in the gas stream (METC, 1987; Notestein, 1989), which are in turn removed very effectively by wet scrubbing. For hot gas cleanup systems using the zinc ferrite process, the fuel gas temperature in the particulate removal device is typically expected to be about $1,100 \mathrm{oF}$. The removal efficiency of alkali which condense on particles depends on the alkali concentration on the particles as a function of particle size, and the particle removal efficiency as a function of particle size. The expectation is that, because the smaller particles have a larger surface area per unit mass, there will be a larger concentration of condensed alkali on the smaller particles (Cincotta, 1984).

Several have reported that there is evidence that the alkali in coal gas may not pose as much of a threat as an equivalent concentration of alkali in petroleum fuels. The suggestion is that alkali in the coal gas are "gettered" by alıminosilicate ash materials (METC, 1987; Notestein, 1989). This, combined with the absence of "catalytic" elements, such as vanadium and molybdenum, are believed to reduce the ability of the coal gas alkali to cause corrosion. 
In the event that particulate removal proves to be insufficient for alkali control, several alkali control technologies for hot gas cleanup systems have been explored (Notestein, 1989). Perhaps the most promising of these is an absorber utilizing emathlite, a naturally occurring clay (Bachovchin, 1987). 


\section{A.4.7 Questionnaire for Gas Turbine}

The following is the text of the questionnaire distributed to process engineers at DOE/METC for the purpose of eliciting expert judgments regarding uncertainties. The questionnaire was Part 3 of a three part briefing packet, as described previously. The questionnaire includes references to the air-blown KRW-based system with hot gas cleanup. However, as noted earlier, this system was not included in the case studies due to time constraints.

Here, you are asked to provide technically-informed judgments about probability distributions for parameters of a gas turbine performance and cost model. You are asked to consider the possibilities of potentially poor performance as well as the probability of obtaining favorable performance, based on current information about the system. The preceding sections provide an overview of uncertainty analysis and some of the technical considerations which might be used as the starting point. We are interest in three IGCC cases, as defined in Part 2 [see sections A.4.1 through A.4.6]:

- Case ALH: Air-blown dry-ash fixed bed Lurgi gasification with hot gas cleanup and gas turbine air extraction.

- Case AKH: Air-blown fluidized bed KRW gasification with hot gas cleanup and gas turbine air extraction.

- Case OKC: Oxygen-blown fluidized bed KRW gasification with cold gas cleanup.

The deterministic default assumptions for the three IGCC case studies are summarized in Table 1 of Part 2. The performance and cost modeling of the gas turbine process area is intended to be representative of current or near-term commercial offerings for high firing temperature $(2,300 \mathrm{oF}$ turbine inlet temperature gas turbines) as discussed in Part 2. Some performance information about this class of gas turbines is given in Table 2 of Part 2. The model considers mass and energy balances, but does not include gas turbine aerodynamics.

We are interested in your technically-based judgments about uncertainties in key performance and cost parameters of the gas turbine process area. We intend to model the uncertainty in performance and cost associated with a fifth-of-a-kind, or mature, system. Thus, we are asking you to make predictions about systems that have not yet been built or operated. We are asking you to express the range of possible outcomes for these systems using probability distributions, as discussed in Part 1.

Several questions follow. You may respond to the questions on these pages, or use additional paper as needed. See the Introduction for examples of how you might estimate uncertainty in each parameter.

\section{Question \#1. Comments on Default Assumptions}

Do the default assumptions seem reasonable? For example:

- Is an ammonia concentration of 2,000 ppm for the air-blown dry-ash Lurgi system reasonable? 
- Are the fuel gas inlet temperatures reasonable for a fifth-of-a-kind plant?

- Are the pressure and heat losses in the gas turbine reasonable?

- Are "high efficiency" cyclones sufficient for particle control in the gas turbine hot gas path?

If not, adjust accordingly and explain the basis for the changes. Are there additional assumptions that should be specified for these systems? If so, please add these assumptions and explain why they are needed. Use your updated set of assumptions as the basis for answering the following questions.

Question \#2. Uncertain Parameter Identification

The following is a list of the specific parameters for which uncertai ty distributions are desired.

- Fuel valve and nozzle pressure drop

- Thermal $\mathrm{NO}_{\mathrm{x}}$ emissions from MBG

- Thermal $\mathrm{NO}_{\mathrm{x}}$ emissions from LBG

- Fuel $\mathrm{NO}_{\mathrm{x}}$ emissions from LBG

- CO emissions

- Combustor pressure drop

- Turbine inlet temperature

- Maintenance costs

In the questions that follow, you are asked to provide estimates of uncertainty for each of these parameters? If you are not comfortable making a particular estimate, who do you think should be approached (preferably within METC) to obtain such estimates?

Are there other parameters which you believe also should be treated probabilistically (whether or not you feel comfortable making the judgment yourself) that are not included in the above list? If so, please specify what these parameters are and supply your judgments about them if you are comfortable doing so (see the following questions for examples of the types of judgments we are looking for). If not, who can we ask to estimate uncertainties for these additional parameters?

In addition, in Question 10 we ask you to comment on other aspects of gas turbine application with coal gas firing that may pose problems for commercial applications:

- Compressor surge margin and IGV closure

- Controllability of the fuel flow, extraction air, and compressor inlet air

- Fuel valve material requirements

- Particulate control system requirements

If you are not comfortable discussing any of these issues, could you suggest someone else who might be approached?

\section{Question \#3. Fuel Valve and Nozzle Pressure Drop}

(a) What is the uncertainty in the long term fuel valve and nozzle pressure drop over the life cycle of a gas turbine firing LEG in a Lurgi-based system (Case ALH). Consider the possibility of deposition in the valves or nozzle. Also consider the possibility of improved fuel valve and nozzle designs or control strategies that reduce the pressure drop (e.g, down to, say, 10 psi instead of the 70 psi or so typical of current designs). 
- Consider the best possible (lowest) pressure drop that could occur. Explain how such a result could be achieved (e.g., improved designs, high efficiency particulate control upstream, no deposition to block nozzle area). How likely is this outcome?

- Consider the worst possible (highest) pressure drop that could occur. Explain, as above. How likely is it that the pressure drop could be equal to or less than this value?

- What do you think is the median (or if you prefer, mean) value of the fuel valve pressure drop (recall that median implies a 50-50 percent chance that the piessure drop could be higher or lower than this value, while mean implies a probabilityweiglited average of possible outcomes)? Note that the median value does not have to equally divide the best and worst possible values, nor does it have to be the same as the average (mean) rate that you expect. Alternatively, if you want to express your judgment as a triangular distribution, what is the most likely value (mode) that you expect?

- Can you draw a probability distribution to represent your judgment? You may draw the distribution as either a pdf or a cdf. Can the distribution be represented by one of the functions shown in Figure 1 of Part 1? Please be sure to completely specify the range of possible outcomes in your distribution function (i.e. the distribution must consider the 100 percent range of possible outcomes). If your "worst" and "best" cases above bound only 80 or 90 percent of all outcomes, please consider how the range of outcomes is widened when considering 100 percent, or 99 percent of all outcomes.

(b) Does your judgment change if we are considering a LBG gas from the KRW system in Case $\mathrm{AKH}$ ? Or if we are considering a MBG gas from a KRW system as in Case OKC? If so, could you provide your judgments for these cases in a similar manner to that for Case ALH?

\section{Question \#4. Thermal NQ Emissions from MBG}

What is the uncertainty, if any, in the thermal $\mathrm{NO}_{\mathrm{x}}$ emission rate (please define the units that you are using, if not $\mathrm{lb} \mathrm{NO}_{\mathrm{x}}$ as $\mathrm{NO}_{2}$ per million BTU of coal feed) that can be achieved in a fifth-of-a-kind system firing MBG (as in Case OKC)? You may consider possible improvements in the next few years in either dry or wet $\mathrm{NO}_{\mathrm{x}}$ control, such as leanlean combustors or high levels of fuel gas moisturization or steam injection, that would be expecter to be employed in a fifth-of-a-kind plant.

- Consider the highest possible $\mathrm{NO}_{\mathrm{x}}$ emission rate that might occur. What is this rate and how might it be achieved (e.g., perhaps current combustor technology, slightly modified for $\mathrm{MBG}$, and steam injection). How likely is the emission rate to be worse than the number you have just estimated?

- Consider the lowest possible $\mathrm{NO}_{\mathrm{x}}$ emission rate that might occur. What is this rate and how might it be achieved (e.g., development of a lean-lean combustor for MBG applications, or use of existing combustor technology with modifications to allow for increased steam injection). How likely would it be to obtain actual emissions below this rate?

- What is the median (50-50 percent of getting higher or lower) emission rate? 
- Can you estiniate the 25 th fractile (i.e. therc is a one in four chance that the emission rate is less than this number)? What about the 75 th fractile (i.e. a one in four chance that the value is higher than this number)?

- Can you draw a probability distribution to represent your judgment? You may draw the distribution as either a pdf or a cdf. Can it be represented by one of the distributions in Figure 1 of Part 1 ?

\section{Question \#5. Thermal NO $x$ Emissions from LBG}

This is similar to Question 4, except now we are interested in your judgment about uncertainty in the thermal $\mathrm{NO}_{\mathrm{x}}$ emissions from LBG in systems such as Case ALH and Case AKH. What is the uncertainty, if any, in the thermal $\mathrm{NO}_{\mathrm{x}}$ emission rate (please define the units that you are using, if not $1 b \mathrm{NO}_{x}$ as $\mathrm{NO}_{2}$ per million BTU of coal feed) that can be achieved in a fifth-of-a-kind system firing LBG (as in Case ALH)? In this case, because we anticipate that rich/lean combustors may be employed for fuel- $\mathrm{NO}_{\mathrm{x}}$ control, we ask you to consider the effect of this technology on thermal $\mathrm{NO}_{\mathrm{x}}$ emissions. First, consider Case ALH, a gas turbine using LBG from an air-blown dry-ash Lurgi gasifier.

- Consider the highest possible $\mathrm{NO}_{\mathrm{x}}$ emission rate that might occur. What is this rate and how might it be achieved (e.g., perhaps fuel burns poorly in the rich combustion stage, leading to initiation of combustion in the lean zone resulting in high flame temperatures). How likely is the emission rate to be worse than the number you have just estimated?

- Consider the lowest possible $\mathrm{NO}_{\mathrm{x}}$ emission rate that might occur. What is this rate and how might it be achieved. How likely would it be to obtain actual emissions below this rate?

- What is the median (50-50 percent of getting higher or lower) emission rate? If you prefer to specify a particular type of probability distribution model, such as a triangle distribution, then provide appropriate judgments in lieu of the median (e.g., mode or "most likely" value for a triangle distribution).

- If you haven't already specified and defined the parameters of a probability distribution model (e.g., triangle, normal, lognormal), can you estimate the 25 th fractile (i.e. there is a one in four chance that the emission rate is less than this number)? What about the 75 th fractile (i.e. a one in four chance that the value is higher than this number)?

- Can yo $\$ draw a probability distribution to represent your judgement? You may draw the distribution as either a pdf or a cdf. Can it be represented by one of the distributions in Figure 1 of Part 1?

Does your answer differ in any way for a gas turbine firing LBG from an air-blown KRW gasifier (Case AKH)? If so, please provide similar information as for Case ALH.

\section{Question \#6. Fuel-NQ $x$ Emissions from LBG}

Please provide your judgment about the fraction of ammonia in the fuel gas that will be converted to NOx in the exhaust gas for Case ALH (air-blown Lurgi-based system). If your judgment is a function of the ammonia concentration of the inlet gas, we would appreciate if you could provide judgments for several ammonia concentrations: e.g., 500 $\mathrm{ppm}, 2,000 \mathrm{ppm}$, and 5,000 ppm. If there are any other key functional dependencies that you expect, such as hydrocarbon concentration in the fuel gas, pressure, or others, please 
appropriately caveat your judgments or, if you wish, provide a set of judgments for each combination of independent variable values that you select.

Because the set of judgments may involve several probability distributions, we suggest you might want to use a triangular distribution for simplicity. This requires estimates only for the lowest, highest, and most likely conversion rates. However, feel free to use any type of distribution which best represents your judgment.

- First, consider "conventional" combustors, such as those that are expected to be offered as standard equipment with the high-firing temperature gas turbines. What is the expected ammonia conversion rate for Case ALH? Please consider the worst, best, and most likely values that could be obtained for an ammonia concentration of $2,000 \mathrm{ppm}$. Can you provide some technical basis for your judgment? Does your answer change if the ammonia concentration is $500 \mathrm{ppm}$ ? $5,000 \mathrm{ppm}$ ? If so, could you provide your judgments for these cases as well?

- Now consider a possible commercial rich/lean combustor in combination with the high-firing temperature gas turbines. What is the expected ammonia conversion rate for Case ALH? Please consider the worst, best, and most likely values that could be obtained for an ammonia concentration of $2,000 \mathrm{ppm}$. What is the basis for your judgment (e.g., bench scale tests indicate very low conversion rates are possible, but in larger scale systems mixing problems may contribute to a higher emissicn rate). Does your answer change if the ammonia concentration is 500 ppm? 5,000 ppm? If so, could you provide your judgments for these cases as well?

- Finally, consider Case AKH, which involves a fuel gas from a KRW gasifier. Do your judgments for this system differ from those for the Lurgi based system for either the conventional or rich/lean combustors? If so, could you please provide a similar set of judgments and the basis for them?

\section{Question \#7.CO Emissions from LBG}

We would like your judgment about the possible emission rate of $\mathrm{CO}$ associated with both conventional and rich/lean combustor designs when firing LBG at baseload, as in Case ALH and Case AKH. Please define the type of unit you are assuming (e.g., fraction of $\mathrm{CO}$ in the fuel gas that is unconverted in the combustor, $\mathrm{CO}$ emissions in ppmv in the exhaust gas, uncorrected, etc).

- First, consider "conventional" combustors, such as those that are expected to be offered as standard equipment with the high-firing temperature gas turbines (see Table 2 of Part 2 . What is the expected CO emission rate for Case ALH? Please consider the worst, best, and most likely values that could be obtained. Can you provide some technical basis for your judgment?

- Does your answer differ for Case AKH? If so, please provide similar information.

- Consider now the use of a rich/lean combustor in a fifth-of-a-kind commercial plant. What is the uncertainty in the CO emission rate associated with Case ALH? Again, consider the worst, best, and most likely values (or otherwise specify the appropriate probability distribution to represent your judgment). Please explain the basis for your judgment. 
- Does your answer for the CO emissions from a rich/lean combustor change if the gas turbine burns the fuel gas of Case AKH rather than Case ALH? If so, please provide your judgment for this case also.

\section{Question \#8. Combustor. Pressure Drop}

We would like your judgment about the uncertainty involved in predicting the long term life cycle combustor pressure drop. The build up of any deposits on the combustor walls or in the transition piece may lead to an increase in pressure drop. The likelihood of this type of buildup may depend on upstream particulate control as well as combustion efficiency and conditions in the combustor. Please express your judgment about pressure drop either as a percentage of the compressor outlet pressure or as a pressure loss in psi.

- For Case ALH, consider the pressure drop expected in a rich/lean combustor? What might te the worst pressire drop? The lowest? The most likely, mean, or ne 1 in? Can you explain how these different values might be obtained?

- Would the pressure drop in a standard combustor for Case ALH differ in any way than that for a rich/lean combustor? Could you provide your judgments for this case?

- Do the answers to the two questions above differ for Case AKH? If so, could you provide your judgments for this case also?

- For Case OKC, consider the type of combustor you expect for a fifth-of-a-kind plant with this fuel (e.g., lean/lean combustor, multiple fuel nozzles with steam injection, one fuel nozzle per can, etc). What system are you assuming? What is the pressure drop you expect for this system? What is the worst case? Best case? Most likely pressure drop? Why?

\section{Question \#9. Turbine Inlet Temperature/Maintenance Costs}

In Part 2, a number of factors were discussed which might interfere with the advanced cooling systems in high firing temperature gas turbines firing coal gas. A possible effect of these problems might be to require a reduction in gas turbine firing temperature or a derating of the gas turbine (e.g., reduction in mass flow). Alrernatively, more expensive maintenance may be required.

- Do you think a reduction in gas turbine firing temperature may be required under some conditions for high firing temperature $(2,300 \mathrm{oF})$ gas turbines firing coal gas (consider Case ALH first)? If so, what are these conditions? How much might the firing temperature have to be reduced over the life of the plant? Can you provide a probability distribution to represent your judgment?

- If you don't think a reduction in firing temperature would ever be required, but an increase in maintenance cost may be incurred for more frequent blade cleaning or reblading, could you provide a judgment about what the uncertainty in maintenance cost might be? Or, if you think both a reduction in firing temperature and increased maintenance cost might occur, we would also like your judgment about maintenance costs. For screening studies, it is typical to express the annual maintenance cost as a fraction of the process area direct capital cost. For example, maintenance cost might be assumed to be 1.5 percent per year of direct capital cost with a clean fuel, but might increase to, say 3 or 4 percent per year if significant plugging, deposition, erosion, and corrosion occurs. What is your judgment about uncertainty in maintenance cost? (As with previous parameters, 
consider worst and best possible values and then consider the type of probability distribution which describes your judgment).

- Do your answers differ for Case AKH or Case OKC. For example, Case OKC might have less of a problem with plugging of film cooling air holes because a wet scrubber system is used, in contrast to the two-stages of cyclones assumed for Case ALH and Case AKH. This might reduce the plugging or deposition rates, and thus affect your answer.

\section{Question \#10. Other Considerations}

In Part 2, a number of concerns were discussed regarding using coal gas in gas turbines originally designed for natural gas firing. One concern is the possibility of compressor surging or stalling when operating in an off-design mode (e.g., firing coal gas at baseload). Another concern is the controllability of a gas turbine in an IGCC system, particularly with compressor discharge air extraction for gasifier blast air. The availability and reliability of materials for high temperature fuel valves may limit IGCC system design by imposing a ceiling on maximum fuel gas temperatures. The possibility of deposition, erosion, corrosion, and pligging in the hot gas path may require stringent controls for particulates and alkali, beyond the capability of components commonly assumed in conceptual design studies.

Do you foresee that these types of problems will impose serious limitations on the development of IGCC concepts such as Case ALH? If so, in what ways? How realistic is it to expect that commercial technology for this type of system will be developed and "inhand" within the next ten years? Please feel free to add any comments you think are relevant to our modeling effort.

\section{Question \#11. Other Experts}

Please suggest other experts (preferably at METC) whom we should contact for judgments about uncertainties in this system. Please supply their names, titles, area of expertise, phone numbers, and addresses.

\section{Question \#12. Feedback}

We would like your comments on these briefing materials and how easy/difficult it was to develop judgments about uncertainties. Is there any other information about uncertainty analysis you would like to see in Part 1? Was the summary of technical information in Fart 2 a useful starting point for your thinking about uncertainties for this process? Was it difficult for you to develop estimates of the range or likelihood of various values for variables which you believe to be uncertain? Please discuss these or any other comments you may have.

Thank you for your help and insights. 


\section{A.4.8 Judgments About Uncertainties}

Compared to the fixed bed gasifier and the zinc ferrite desulfurization process, the gas turbine process area proved to be the most difficult of the three with respect to obtaining expert judgments regarding uncertainties. Technical experts at both DOE/METC and a leading gas turbine manufacturer were approached regarding performance- and emissions-related uncertainties. The technical experts at DOE/METC were selected by DOE/METC management for participation in the survey. The authors followed-up the written survey responses with telephone calls. The experts at the gas turbine manufacturer were contacted directly by the authors by phone and by letter.

In most cases, it was not possible to obtain quantitative judgments regarding uncertainties from specific experts. The reasons for this are several. A pervading theme is the proprietary nature of gas turbine designs and performance information. A second pervading theme is the relative lack of information upon which an expert would base the types of judgments requested. One expert commented that the literature review given in the preceding sections was fairly comprehensive, and that if the review did not uncover the needed information, it is either not available or not published because it is proprietary. Some of the questions posed are the subject of current and ongoing research in preliminary stages, particularly with respect to combustor performance and emissions. The results of such work are not yet available to help an expert make an informed judgment. The experts at DOE/METC, some of whom previously worked for gas turbine manufacturers, may still be bound by confidentiality agreements with their former employers and, hence, may be unable to provide detailed information even if they had access to it.

The gas turbine process area questionnaire was distributed to three experts at DOE/METC, of whom two responded. The responses of these two experts, referred to as Expert GT-1 and Expert GT-2, are summarized in Sections A.4.8.1 and A.4.8.2, respectively. Furthermore, conversations with several other experts are summarized in Section A.4.8.3. The information obtained from the literature review in the previous sections and from the gas turbine experts was used to inform the development of judgments of uncertainties on the part of the authors. The basis for assigning uncertainties to gas turbine parameters is discussed in Section A.4.8.4.

\section{A.4.8.1 Expert GT-1}

A DOE engineer, Expert GT-1, who was given an uncertainty briefing packet responded, "I do not have any knowledge, data or information germane to answering these questions." However, the engineer did provide extensive comments on the default 
assumptions provided in the technical background paper, Part 2, of the briefing packet. With respect to estimating uncertainties, the engineer explained that "gas turbine manufacturers would be the prime source of this data, if it exists." However, such data "would be proprietary" because "manufacturers spend millions of dollars of internal R\&D funds to get reliable emissions data." Furthermore, the DOE engineer noted that 36 references were cited in Part 2 of the briefing packet. "If the contractor cannot find what they want in these references, manufacturers and users are not publishing the data because it is proprietary or because they don't have the information."

Expert GT-1 did provide gas turbine design information needed for the modeling studies. He indicated that a gas turbine fuel valve pressure drop of $70 \mathrm{psi}$ is reasonable, and that the GE MS7001F gas turbine cooling circuits used about 12 percent of the compressor inlet air. In a follow-up phone conversation, Expert GT-1 indicated that DOE/METC is seeking the development of a high temperature gas turbine fuel valve that would have a substantially lower pressure drop than conventional designs. The expert also indicated that, with proper upstream particulate control, he doesn't anticipate a problem with gas turbine combustor pressure drop build-up.

\section{A.4.8.2 Expert GT-2}

Another DOE engineer, Expert GT-2, provided mostly qualitative answers in response to some of the questions posed in the questionnaire. He indicated that "the preparation of Part 2 was excellent, Part 1 was more information than I needed or wanted, and Part 3 needs to be reevaluated." With respect to Part 2, the engineer stated, "the person or group who prepared this summary is to be commended for their objective and unbiased presentation of the material." However, the engineer indicated that Part 3, the questionnaire, was too time consuming as presented to him.

Expert G'T-2 did provide some quantitative information in his response to the questionnaire. He indicated that a "70 psi fuel valve pressure drop is typical of GE only." In a follow-up phone conversation, the expert indicated that Westinghouse and United Technologies claimed they could supply fuel valves with 20 to 30 psi pressure drops. A high pressure drop is preferred for control reasons, but may not be necessary. "A 20 psi pressure drop fuel gas valve is possible with a butterfly valve and if necessary a separate block valve arrangement."

High efficiency cyclones may not be adequate for overall particulate collection due to their pressure drop, which "will not be economically viable for overall particulate removal needs." Expert GT-2 indicated that barrier filtration would be needed upstream of 
the zinc ferrite process, but that a cyclone between the zinc ferrite bed and the gas turbine may be acceptable for removing entrained sorbent material. If barrier filtration is used, "particulate deposition will not be a factor in [fuel] valve design."

Expert GT-2 indicated that $\mathrm{NO}_{\mathrm{x}}$ and $\mathrm{CO}$ emissions will be held below the requirements of current regulations. "Testing of rich-lean combustors has indicated this is possible regardless of incoming ammonia concentrations below 8,000 ppm value." With respect to $\mathrm{NO}_{\mathrm{x}}$ emissions from rich/lean combustors firing fuel gas containing significant fuel-bound nitrogen, Expert GT-2 said that the "worst case fear" is 50 percent conversion of ammonia to $\mathrm{NO}_{\mathrm{x}}$. However, conversions of 10 percent or less are expected, with $\mathrm{CO}$ emissions below 100 to $200 \mathrm{ppm}$, based on early test results.

Fuel gas quality could be a key determinant of $\mathrm{NO}_{\mathrm{x}}$ and $\mathrm{CO}$ emissions. For the airblown systems, the fuel heating value is low. Lack of control over gasifier operations could lead to reductions in fuel gas quality which, in turn, could affect flammability and flame stability. Low flammability or flame instability could lead to problems with emissions. Fuel hearin: values of less than $80 \mathrm{BTU} / \mathrm{scf}$ could create problems with combustion efficiency and emissions. The fuel gas heating value is related to the coal supply: variability in coal properties could cause variation in fuel gas composition and heating value. Fluidized bed gasifiers tend to "bounce and slug," leading to variable fuel gas composition. Problems with fuel gas flammability would tend to be alleviated if partial air separation technology, such as membranes, become economically attractive. This would lead to a greater concentration of oxygen in the blast "air" to the gasifier, and thus increase the fuel gas heating value.

Expert GT-2 stated that the system with cold gas cleanup incorporates less risk than the two air-blown systems considered in this study.

Expert GT-2 indicated that reduction in gas turbine firing temperature could be used to suppress alkali deposition on the turbine blades. However, alkali cleanup using an emathlite absorber vessel would be recommended as a low technical risk alternative to low firing temperature or unconventional and probably uneconomical maintenance. Sulfur in the combustion product gas can react with alkali to form alkali sulfates, which are a source of corrosion on the gas turbine blades. The oxygen content of the exhaust gas in the turbine affects the rate of corrosion. For the nickel alloys typically employed on turbine blading, sulfidation of nickel alloys increases as the oxygen content decreases. The oxygen content of exhaust gas from air-blown systems is lower than that for oxygen-blown 
systems. To avoid turbine blade deposition and corrosion problems, an operator could try to switch to a lower-alkali coal.

Expert GT-2 also described gas turbine compressor air-extraction for gasifier blast air as "a pipe dream or government-funded." Until a large market appears, it is more likely that a separate booster compressor will be used than extracting air from the gas turbine compressor outlet.

\section{A.4.8.3 Other Experts}

Several other gas turbine experts were contacted, at two gas turbine manufacturers and an architect/engineer firm. One expert indicated that very little development effort would be made for gas turbines in IGCC service; instead, the manufacturer would provide a fuel specification to which the plant operator must adhere for gas turbine performance guarantees to be valid. However, the expert indicated that even with fuel specifications, it is still not certain what will happen over a 20 to 30 year life cycle with respect to performance and cost. Possibly loss of output or shorter maintenance cycles will be encountered for gas turbines in IGCC service in systems with hot gas cleanup. The same expert indicated that high efficiency cyclones are expected to be sufficient for upstream particulate removal, including alkali control, and that such cyclones are to be tested as part of a clean coal program demonstration project. With respect to $\mathrm{NO}_{\mathrm{x}}$ emissions, the expert indicated that it is not yet known what levels will be achieved with the air-blown systems, which feature significant concentrations of ammonia in the fuel gas. In the laboratory, it is possible to get less than $10 \mathrm{ppm} \mathrm{NO}$ emissions with fuel gas ammonia concentrations of $2,000 \mathrm{ppm}$. However, combustor technology may not easily scale-up from the lab to commercial applications. For example, a premix lean-burn system for reducing thermal $\mathrm{NO}_{\mathrm{x}}$ achieved less than $5 \mathrm{ppm}$ emissions in the lab, but in the field achieves only less than 25 ppm. A standard combustor on the GE Frame 6 model converts 50 to 60 percent of fuel-bound nitrogen to $\mathrm{NO}_{\mathrm{x}}$.

A second expert at a gas turbine manufacturer indicated that tests of new combustor cans typically cost in excess of $\$ 100,000$ per run. In testing of a staged lean-lean combustor for thermal $\mathrm{NO}_{\mathrm{x}}$ control, the manufacturer expected 50 percent $\mathrm{NO}_{\mathrm{x}}$ reduction compared to more conventional combustor designs, but obtained no reduction. This is an example of the difficulty of scaling-up combustor technology. Low $\mathrm{NO}_{\mathrm{x}}$ technology employs concepts such as premixing and staged combustion. However, these technologies cannot be designed by modeling studies; they must be empirically arrived at through testing, due to their complexity. For current combustor technology, about 90 percent of 
fuel-bound nitrogen is converted to $\mathrm{NO}_{\mathrm{x}}$. Normally, a customer is told to assume that 100 percent of fuel-bound nitrogen will be converted.

A third gas turbine manufacturer expert indicated that in the current combustor design for the default gas turbine used in this study, almost 100 percent conversion of fuelbound nitrogen to $\mathrm{NO}_{\mathrm{x}}$ may $\mathrm{l}$ is assumed. A target for development of rich/lean combustor technology would be achievement of fuel-bound nitrogen conversions of less than 10 percent, with 20 percent conversion being a possible worst case achievable value.

With respect to gas turbine cost, an industry engineer indicated that when demand for IGCC systems increases in the future, manufacturers of high efficiency heavy-duty gas turbines will be a position to significantly increase price, even beyond the cost of modifications needed for IGCC application.

\section{A.4.8.4 Discussion of Uncertainties}

While a comprehensive set of expert elicitations comparable to those for the Lurgi gasifier and fixed bed zinc ferrite process areas was not obtained for the gas turbine process area, a significant amount of information was gleaned from published literature, as reviewed in Sections A.4.1 through A.4.6. Also, a number of practical insights were obtained from discussions with several engineers, as discussed in the preceding sections. This information can be used to construct plausible estimates of uncertainty that can be used in initial uncertainty screening studies.

In the questionnaire given to the gas turbine experts at DOE, there were questions about eight technical or cost related subjects. These are:

- Fuel valve and nozzle pressure drop

- Thermal $\mathrm{NO}_{\mathrm{x}}$ emissions from MBG

- Thermal $\mathrm{NO}_{\mathrm{x}}$ emissions from LBG

- Fuel $\mathrm{NO}_{x}$ emissions from LBG

- CO emissions

- Combustor pressure drop

- Turbine inlet temperature

- Maintenance costs

Each of these will be discussed in turn. Not all of these will be treated probabilistically.

Fuel Valve and Nozzle Pressure Drop. While particle deposition could potentially have an effect on pressure drop on the fuel gas path, the experts who commented on this possibility indicated that it is not likely to be a concern. Proper particulate removal upstream of the gas turbine is believed to avoid such a problem. If such a problem were to occur, it could be corrected by increased irequency of maintenance, without significant 
degradation of performance. Thus, uncertainty due to fuel valve and nozzle deposition may more appropriately be reflected as an uncertainty in maintenance cost.

The primary effect on pressure drop is the design of the fuel valve. Most conceptual design studies have assumed a minimum pressure drop between the gasifier and gas turbine of about 75 psia (e.g., Corman, 1986), with other studies assuming much larger pressure drops. A design improvement sought by DOE is to reduce the fuel valve pressure drop. Therefore, rather than treat this design feature probabilistically, it would be more appropriate to evaluate "conventional" and "advanced" fuel valve designs as separate cases. The assumption used here is that current fuel valves have a pressure drop of about 70 psi, while advanced fuel valves would have a pressure drop of 20 psi. (Of course, uncertainty in the pressure drop that would be obtained with an advanced fuel valve system could be represented probabilistically. Such an uncertainty range might be 10 to 20 psi, based on conversations with several engineers.)

Thermal $\mathrm{NQ}_{x}$ Emissions from $\mathrm{MBG}$. The thermal $\mathrm{NO}_{\mathrm{x}}$ emissions from mediumBTU gas (MBG) fired gas turbines are expected to be within the current New Source Performance Standards (NSPS) for gas turbines, which require less than 75 ppmv $\mathrm{NO}_{\mathrm{x}}$ corrected to a dry, 15 percent oxygen basis and corrected to a gas turbine efficiency of 25 percent. The efficiency correction results in an increase in the allowable emission rate to over 100 ppmv on a dry, 15 percent oxygen basis for typical gas turbines used in IGCC application. The NSPS level can be achieved with either wet injection or low $\mathrm{NO}_{\mathbf{x}}$ combustor designs. In the Cool Water demonstration plant, actual $\mathrm{NO}_{\mathrm{x}}$ levels of $21 \mathrm{ppmv}$ were measured (Cool Water, 1986). Low emission levels may be achievable without wet injection using dry low $\mathrm{NO}_{\mathrm{x}}$ combustor designs.

For MBG, the thermal NOx emissions are assumed to be low, ranging from about 25 to 75 ppmv as an initial assumption.

Thermal $N Q_{x}$ Emissions from $L B G$. The thermal $N_{x}$ emissions from low-BTU gas (LBG) fired gas turbines are expected to be lower than $\mathrm{NO}_{\mathrm{x}}$ emissions from MBG. Uncontrolled emissions may be as low as 10 to 50 ppmv (Unnasch, 1988). Thermal $\mathrm{NO}_{\mathbf{x}}$ emissions in air-blown systems are expected to be significantly less than uncontrolled fuel NOx emissions. As an initial assumption, thermal $\mathrm{NO}_{\mathrm{x}}$ emissions from $\mathrm{LB}$ ( combustion are assumed to be between 10 and 75 ppmv on an actual basis at the gas turbine exit.

Fuel NQ ${ }_{x}$ Emissions from LBG. For combustors not employing rich/lean combustion, it is expected that between 50 and 100 percent of ammonia in the fuel will be 
converted to $\mathrm{NO}_{\mathrm{x}}$. The actual conversion rate may depend on the combustor design, fuel ammonia concentration, and other factors. Based on consideration of information in the literature and conversations with various engineers, an initial characterization of uncertainty is proposed. As an initial assumption, the ammonia conversion to $\mathrm{NO}_{\mathrm{x}}$ is assumed to range from 50 to 100 percent, with a mode at 90 percent. This characterization of uncertainty is represented with a triangular distribution. As more details regarding the performance of specific combustor cans become available, this estimate can be revised accordingly.

For rich/lean combustor technology, it is possible that very low levels of ammonia conversion can be achieved, according to some experts. Based on discussions with several experts, an initial uncertainty estimate ranging from a low of 0.1 percent ammonia conversion up to 20 percent ammonia conversion is proposed, with a mode at 10 percent conversion. The distribution for this uncertainty is assumed to be triangular.

COEmissions. CO emissions from systems firing MBG are not expected to be a concern. Data from Cool Water (1986) indicate that CO emissions for a MBG with steam injection for NOx control were 40 to $90 \mathrm{ppmv}$. CO emissions were higher in another reported emission test at Cool Water (1988), ranging from less than 100 to $190 \mathrm{ppmv}$ on three different coals. Several experts indicated that $\mathrm{CO}$ emissions are expected to be below 10 ppmv for mature commercial systems. Therefore, for $\mathrm{MBG}, \mathrm{CO}$ emissions are assumed to range from 1 to $200 \mathrm{ppmv}$, with a mode at $10 \mathrm{ppm}$.

For $\mathrm{LBG}$, less data are available regarding $\mathrm{CO}$ emissions. However, there is more concern that $\mathrm{CO}$ emissions may be a problem with low heating value fuels, particularly for high firing temperature gas turbines. The expected $\mathrm{CO}$ emission level for mature gas turbine combustors in LBG service is $10 \mathrm{ppmv}$ according to several experts. However, it is possible that $\mathrm{CO}$ emissions could be several hundred ppmv. One estimate was that $\mathrm{CO}$ could be as high as 10,000 tons/year for a Lurgi-based system (Corman, 1986), which is equivalent to about $350 \mathrm{ppmv}$. Therefore, $\mathrm{CO}$ emissions for $\mathrm{LBG}$ are assumed to range from about 1 to 350 ppmv.

Combustor Pressure Drop. While particulate deposition may potentially lead to an increase in combustor pressure drop, several experts indicated that this is not likely to be a problem for mature commeicial systems. If a problem is encountered, it can likely be handled through increased maintenance. Therefore, it was decided not to treat this parameter probabilistically in the current analysis. 
Turbine Inlet Temperature. One expert indicated that there might be conditions under which firing temperature would have to be reduced to avoid alkali deposition problems. However, a change in firing temperature may only change the location in the turbine where deposition occurs due to changing the temperature profile, as opposed to eliminating deposition altogether. Other measures, such as switching coal or changing maintenance procedures, could also be employed. Therefore, it was decided not to treat this parameter probabilistically in the current analysis.

Gas Turbine Capital Cost. Historically, gas turbines have been used mostly in applications involving relatively little risk. These applications involve use of relatively clean fuels for which the gas turbines were designed. IGCC systems, however, represent a new process environment for gas turbines. Oxygen-blown IGCC systems with cold gas cleanup pose relatively little risk to gas turbines compared to air-blown IGCC systems with hot gas cleanup. While the former systems may tend to be expensive, they are believed to result in high removal rates of all fuel gas contaminants that might harm the gas turbine, such as particles and alkali. Also, the relatively high heating value of MBG compared to LBG means that there is a smaller fuel gas volumetric flow rate that must be handled by the fuel valve system, resulting in lower fuel valve-related costs. The air-blown systems propose compressor air extraction for the gasifier blast air, which is an additional complication for the LBG-fired gas turbine. For these reasons, the capital cost of gas turbines for LBG application is expected to be higher than those for MBG.

While many conceptual design studies have been carefully prepared, there are often inherent biases. For example, equipment vendors for key process equipment are usually asked to provide a cost estimate in response to a specification provide by an architect/engineer firm. While these vendors may provide their best estimate at the time of the conceptual design study, such estimates may not fully anticipate the types of problems that would be revealed by a more detailed analysis for an actual, as opposed to conceptual, design project. Furthermore, an conceptual estimate prepared at a time when no machines are actually ordered may be different from the actual cost incurred in a competitive market. If the IGCC gas turbine market becomes supply-limited, the price of gas turbines, and particularly ones requiring special modifications for LBG, could increase substantially.

Because of both technical and market considerations, the capital cost of the gas turbine process area for all three IGCC cases is assigned an uncertainty. Typically, process contingency factors for gas turbines, which are the traditional approach to characterizing uncertainty in capital cost estimates, have been very low. This has been true even for 
IGCC conceptual design studies, in spite of needed modifications and a different process environment compared to typical gas turbine applications. For example, Corman (1986) uses a contingency of about two percent for gas turbines used in an air-blown system with hot gas cleanup, while a typical Fluor study (Fluor, 1985) uses a contingency of 5 percent for a gas turbine in an oxygen-blown system with cold gas cleanup. However, an industry expert indicated that gas turbine costs in a competitive market could increase as much as 50 percent from values used in conceptual design studies. Furthermore, low levels of contingency are inconsistent with even the rule-of-thumb values suggested by EPRI for systems that do not have commercial experience. As an initial estimate of uncertainty for gas turbine capital cost, for air-blown systems with compressor air extraction and LBG the uncertainty is assumed to be a zero to 50 percent increase in capital cost. For oxygenblown systems with MBG, the uncertainty is assumed to be 0 to 25 percent.

Of course, the model can be exercised with alternative judgments regarding uncertainties in any given parameter. These initial judgments regarding gas turbine uncertainty can be evaluated to see if they contribute significantly to overall uncertainty in total capital cost and the cost of electricity. If this uncertainty is found to be important, it may be worthwhile to seek more detailed expert judgments for this particular parameter. If it is not significant, then the model results would not be critically dependent on the specific assumptions used here. Thus, even with limited information, it is possible to perform a screening analysis of uncertainties to determine if additional data collection or expert elicitation is warranted.

Gas Turbine Maintenance Cost. The maintenance cost of the gas turbine may be significantly affected by particle deposition in the fuel valve, combustor, or hot gas path in the turbine. Maintenance cost may also be affected by corrosion on turbine rotor and stator vanes, requiring more frequent reblading than would be necessary for a gas turbine in a more conventional application. Therefore, while in the optimistic case maintenance costs would be similar to that for service with cleaner fuels such as natural gas, there is the possibility that maintenance costs could be higher, and little chance that costs would be lower. A typical maintenance cost factor for gas turbines in conventional service is 1.5 percent per year of the direct capital cost. As an initial characterization of uncertainty, it is assumed that the maintenance cost may be has high as 6 percent per year for the system with hot gas cleanup and as high as 3 percent per year for the system with cold gas cleanup. A most likely value of 2 percent per year is assumed for both systems, representing the tendency that maintenance costs for a gas turbine in IGCC service would be higher compared to conventional service. As with any other model parameter, this 
Table A-19. Summary of Assumed Gas Turbine Process Area Uncertainties

Description Units
Thermal NQ
Oxygen-blown system

Air-blown systems

$\begin{array}{lll}\text { Uniform } & 2.5 \times 10^{-5} \text { to } & 7.5 \times 10^{-5} \\ \text { Uniform } & 1.0 \times 10^{-5} \text { to } & 7.5 \times 10^{-5}\end{array}$

Fuel $\mathrm{NQ}_{4}, \%$ conversion of $\mathrm{NH}_{3}$ to $\mathrm{NO}_{x}$ Pre-mix lean-burn combustor $\mathrm{Rich} /$ lean staged combustor

Distribution

Parameters ${ }^{a}$

Unconverted CO, wt-\% of CO in fuel gas
Oxygen-blown system
Air-blown systems

Uniform

$1.0 \times 10^{-5}$ to

Triangular

Triangular

$\begin{array}{rlr}50 & \text { to } 100 \\ 0.001 & \text { to } 20\end{array}$

Uniform

0.9998 to

0.9999

Uniform

0.9772 to

0.9999

Gas Turbine Capital Cost

Uncertainty, \% of direct capital cost
Oxygen-blown system
Air-blown system
Uniform
0 to 25
Uniform

0 to 50

Gas Turbine Maintenance Cost, \%/yr of direct cost
Oxygen-blown system
Air-blown system
Triangular
1.5 to $3.0(2.0)$
Triangular
1.5 to $6.0(2.0)$

a For Uniform distributions, the lower and upper bounds are given. For the triangular distribution, the mode is given in parentheses. For the fractile distribution, the lower and upper bounds for each range are given, along with the probability of sampling within that range.

characterization of uncertainty can be revised as more data become available, or to represent the judgment of other experts. As part of an initial uncertainty screening study, the importance of uncertainty in gas turbine maintenance cost to uncertainty in overall operating and maintenance (O\&M) costs can be ascertained to determine whether revision to this parameter is warranted.

Table A-19 summarizes the uncertainties which have been assumed for the gas turbine process area. 


\section{A.5 Other IGCC IProcess Uncertainties}

In the previous three sections, uncertainties related to the performance and cost of the gasification, hot gas cleanup, and gas turbine process areas of selected IGCC systems have been discussed. In this section, uncertainties assigned to additional categories of parameters included in the probabilistic case studies of these IGCC systems are described. These categories include: (1) cost model parameters; (2) direct capital cost uncertainties; (3) maintenance cost factor uncertainty; (4) operating cost uncertainty in unit costs of consumables and unit prices of byproducts; and (5) statistical uncertainty in regression models for process area direct capital costs and auxiliary power requirements. These uncertainties are described in turn in the following sections.

\section{A.5.1 Cost Model Parameter Uncertainties}

An important feature of this work is the development of cost estimates for competing technologies on a consistent basis to permit comparative analysis. This section addresses the development of deterministic and probabilistic estimates for cost model parameters that are common to the IGCC systes is considered here. See the Task 2 Topical Report (Frey and Rubin, 1990) for more details regarding the structure of the capital, operating and maintenance $(\mathrm{O} \& \mathrm{M})$, and levelized cost models.

The cost model parameters can be grouped into three categories. These are: (1) capital cost; (2) operating cost; and (3) financial. The latter category of parameters influences the fixed charge factor (also called the "capital recovery factor") and variable cost levelization factor used to calculate the levelized plant cost of electricity production. For each parameter, a "best guess" value is assumed in deterministic modeling studies. In addition, for selected parameters, an uncertainty distribution is ascribed for probabilistic modeling studies. The best guess and uncertainty assumptions are summarized in Table A20.

Four capital cost paramaters are common to all of the IGCC systems. The engineering and home office cost factor is intended to include the costs of: (1) engineering, design, and procurement labor; (2) office expenses during design; (3) licensor costs for basic process engineering services; (4) office burdens, benefits, and overhead costs; and (5) fees or profit to the architect/engineer. In preliminary cost estimates, these costs are represented as a multiplier factor of other process-related capital costs. Standard industry practice, as recommended by the Electric Power Research Institute (EPRI), is to assume that engineering and home office costs is an additional cost ranging from 7 to 15 percent of 
Table A-20. Summary of Assumed Values and Uncertainties for IGCC Cost Model Parameters.

\begin{tabular}{|c|c|c|c|c|c|}
\hline Description & Units & "Best Guess" & Distribution & Param & $\operatorname{ers}^{a}$ \\
\hline Capital Cost Parameter & & & & & \\
\hline $\begin{array}{l}\text { Engineering and } \\
\text { Home Office Fee } \\
\text { Indirect Construction }\end{array}$ & fraction & 0.10 & Triangular & 007 & to $0.13(0.10)$ \\
\hline Cost Factor & fraction & 0.20 & Triangular & 0.15 & to $0.25(0.20$ \\
\hline $\begin{array}{l}\text { Project Uncertainty } \\
\text { General Facilities }\end{array}$ & $\begin{array}{l}\text { fraction } \\
\text { fraction }\end{array}$ & $\begin{array}{l}0.175 \\
0.20\end{array}$ & Uniform & 0.10 & to 0.25 \\
\hline Operating Cost Parame & eters & & & & \\
\hline Capacity Factor & fraction & 0.65 & & & \\
\hline Labor Rate & $\$ / h r$ & 19.70 & Normal & 17.70 & to 21.70 \\
\hline Number of Shifts & shifts/day & 4.25 & & & \\
\hline Cost Year and Financi: & & & & & \\
\hline Plant Cost Index & & 351.5 & & & \\
\hline $\begin{array}{l}\text { Chemicals Cost Index } \\
\text { Construction Interest }\end{array}$ & & $\begin{array}{l}411.3 \\
10\end{array}$ & & & \\
\hline $\begin{array}{l}\text { Construction Interest } \\
\text { Construction Years }\end{array}$ & $\% /$ yr & & & & \\
\hline $\begin{array}{l}\text { Construction Years } \\
\text { Booklife }\end{array}$ & years & 30 & & & \\
\hline Inflation Rate & $\% / \mathrm{yr}$ & $0.0^{\mathrm{b}}$ & & & \\
\hline Sales Tax & $\%$ & 5 & & & \\
\hline Real Return on Debt & $\% / y r$ & 4.6 & & & \\
\hline $\begin{array}{l}\text { Real Return on } \\
\text { Preferred Stock }\end{array}$ & $\% / y r$ & 5.2 & & & \\
\hline Real Return on Equity & $\% / y r$ & 8.7 & & & \\
\hline Debt Ratio & fraction & 0.50 & & & \\
\hline Pref. Stock Ratio & fraction & 0.15 & & & \\
\hline $\begin{array}{l}\text { Federal and State } \\
\text { Tax Rate }\end{array}$ & fraction & 0.38 & & & \\
\hline Investment Tax & & & & & \\
\hline Credit & fraction & 0.0 & & & \\
\hline $\begin{array}{l}\text { Property Taxes } \\
\text { and insurance }\end{array}$ & $\% / y r$ & 2.0 & & & \\
\hline
\end{tabular}

a For Uniform distributions, the lower and upper bounds are given. For the triangular distribution, the mode is given in parentheses. For the fractile distribution, the lower and upper bounds for each range are given, along with the probability of sampling within that range.

b An inflation rate of zero is used in "constant dollar" cost analyses. 
the total direct capital cost, indirect capital cost, and sales tax. Most conceptual design studies assume a factor of about 10 to 12.5 percent. These factors may be based either on the judgment of a cost estimator or on the historic cost estimating history of a company. However, in lieu of such experience, a symmetric triangular distribution representing uncertainty in the actual costs that would be incurred for a real project is assumed. The central value of this distribution (which is the median, mean and mode due to symmetry) is taken to be the 10 percent value representative of typical cost estimates. The minimum and maximum values are 7 and 13 percent, respectively. The mode is the single "most likely" value of the distribution, and is taken to be the same as the deterministic "best guess" estimate. The purpose of this distribution is to determine whether uncertainty in engineering and home office costs is an important consideration affecting total capital cost. Clearly, these costs would become better defined for an actual project. However, in a preliminary cost estimate, the details of engineering and home office costs may not be fully known and, hence, there may be uncertainty regarding the actual costs that would be incurred for a particular project.

The indirect construction cost factor used in preliminary cost estimates is intended to account for the costs of workers' benefits, supervision, administration, and other construction related costs which are not part of the permanent capital equipment at the plant (e.g., temporary construction offices). The indirect construction cost factor would be replaced by more detailed cost estimates in later stages of engineering analysis of a particular project. From conceptual design studies of IGCC systems, it appears that indirect construction costs range from about 15 to 25 percent of the total direct capital cost. Here it is assumed that the "best guess" value is 20 percent, with a symmetric triangular distribution. The uncertainty ascribed here is intended to represent the uncertainty in prediction actual indirect costs with the limited information available to develop a preliminary cost estimate.

The project uncertainty is intended to reflect the expected increase in capital cost that would result from a more detailed and comprehensive cost estimate at a later stage of a specific construction project. The project-related uncertainty is expected to be reduced as a particular project progresses to more detailed phases of design and cost estimating. For projects in preliminary stages of development, EPRI (1986) recommends a "project contingency" factor of 15 to 30 percent, while projects for which a "detailed" cost estimate has been developed may require a project contingency of 10 to 20 percert. For an initial estimate of project-related uncertainty, a range of 10 to 25 percent is assumed. This range is slightly lower than that for preliminary estimates, but wider than that for detailed 
estimates. This uncertainty is taken to be uniformly distributed. For deterministic estimates, the central value of 17.5 percent is used.

The cost of general facilities includes a long list of auxiliary equipment required at a power plant (see Task 2 Topical Report for more detail). This factor is typically around 20 percent of the direct cost of the major process areas.

In most conceptual design studies of baseload fossil-fuel electric power plants, it is assumed that the power plant produces the equivalent of full-load power 65 percent of the year. This assumption has historical roots in the annual average U.S. capacity factor for fossil fuel power plants.

The operating personnel labor rate is nominally about $\$ 19.70$ per hour. A modest uncertainty is assigned to this parameter to represent the variability in labor rates from one site to another. The number of shifts per day is based on an eight-hour shift plus some addition shifts to account for vacation/sick time.

The financial assumptions in Table A-20 are taken from the EPRI Technical Assessment Guide (1986) and represent standard assumptions used in many design studies. The costs in this work are reported in 1990 dollars based on the Chemical Engineering Plant Cost Index and Chemical Cost Index. Levelized costs are estimated based on constant dollars, in which inflation is taken to be zero. Constant dollars are used to eliminate confusion over often varying assumptions about inflation rates from one study to another, which can lead to large differences in the magnitude of reported costs. The financial assumptions are used to calculate the fixed charge factor for estimating annual capital recovery and the variable cost levelization factor according to EPRI guidelines. For these case studies, the financial assumptions are held at their single point-estimate values.

\section{A.5.2 Direct Capital Cost Uncertainties}

For technologies in early stages of development, there is often uncertainty in the cost of particular pieces of equipment or for entire process areas. One source of uncertainty is in the key performance variables that affect equipment design and sizing. For example, if a flow rate is uncertain, then the size of equipment needed to accommodate that flow is also uncertain. This type of interaction between uncertainty in performance and uncertainty in the cost of a process area is explicitly captured in the cost models developed for all of the clean coal technology systems studied in this work. 
However, even if key performance variables were known with certainty, uncertainty may still remain in the cost of equipment or a process area. For example, cost estimates dev loped in early stages of technology development may not capture all of the process area capital costs for two reasons. First, preliminary costs may not capture all of the costs that would be revealed by a finalized cost estimate based on more detailed engineering analysis of the system. This type of uncertainty is usually addressed using "project contingency factors" as discussed in the previous section. Second, even detailed estimates developed early in the development of a technology may not capture all of the costs that will become apparent after a demonstration or the first commercial scale plant has been built.

With respect to the latter source of uncertainty, potential problems that could be encountered in a first full-scale plant might include corrosion, fouling, effects on process chemistry due to trace contaminants or operating conditions not anticipated in design work, and so on. While these types of problems may seriously hamper the operability of a firstof-a-kind plant, design changes can be incorporated into later plants to minimize such problems. However, the capital cost of, say, a fifth-of-a-kind plant may tend to be higher than the estimated cost developed prior to building the first full-scale plant, because of scope changes in the capital cost as the technology matures and because preliminary cost estimates developed for innovative process technologies generally are biased low.

Studies by Rand Corporation have lent a quantitative basis to the notion that capital costs are often severely estimated in prel.'minary cost estimates for innovative technologies (e.g, Merrow et al, 1981; Milanese, 1987; Hess et al, 1989). Most of the Rand work has addressed difficulties in estimating the cost of the first full scale chemical process plant embodying new technology. However, Rand has also considered the effect of design improvements on the cost of later plants. It appears that, even assuming cost improvement occurs between the first- and fifth-of-a-kind plant, cost estimates developed prior to the first-of-a-kind plant still under-predict the cost of a fifth-of-a-kind plant.

In deterministic cost estimates, process area "contingency factors" are often used to represent the expected increase in cost that usually accompanies unproven technology. However, with the possible exception of propriety information held by architect/engineer firms, there is little historic cost estimating data available to verify the accuracy of any particular value for a contingency factor. For example, an important type of information rarely reported in design studies is the probability of cost overrun associated with any given contingency factor. There is no unique value of contingency cost unless the notion of risk 
is included; the selection of such a value should be based on the risk (in terms of probability of cost overrun or partial mean of a cost overrun) that a decision-maker is willing to take that costs will be higher than the budget estimate. Thus, the selection of a contingency factor is, in itself, an uncertain task. EPRI (1986) suggests some guidelines for ranges of contingency factors depending on the state of technology development. But EPRI does not provide any indication of how a contingency factor should be selected to correspond to a particular probability of cost overrun.

In this work, uncertainties in process area capital costs are expressed, on the same basis as the process contingency factor as defined by EPRI, as a percentage of the process area capital cost using the same formula as would be used to estimate contingency cost. However, rather than select a single point-estimate value for a "contingency factor," instead a range of values described by a probability distribution is used. The purpose of such probability distributions is to more appropriately represent the uncertainty in predicting the process area capital cost for a fifth-of-a-kind plant in a cost estimate developed before even a demonstration plant has been built.

Published values of contingency factors for each process area have been used as a guide in selecting the ranges of values for uncertainty in process area costs, particularly for assigning relative magnitudes of uncertainty between process areas in different stages of development. However, in some cases, such as already discussed for the Lurgi gasifier and the gas turbine process areas, these factors seem to be unreasonably low when considering the new process environment and operating conditions to which these technologies would be subject in an IGCC plant. Therefore, in some instances the author has revised the basis for both process contingency factors used in deterministic estimates and for the process area capital cost uncertainty ranges used in deterministic estimates.

The default approach taken here is to assume that there is some small probability that, for any given process area, costs may not increase significantly. However, for process areas that have not been proven at a full-scale, an upper bound of roughly 50 to 80 percent additional cost has been assumed. While these upper limits are much higher than values typically assumed for deterministic contingency factors, they may actually more accurately reflect the type of cost increase that usually accompanies innovative process technology, and particular technology which involves extensive handling of solids (such as gasifiers or hot gas desulfurization systems). In most cases, because little information was available to develop detailed judgments of uncertainty, uniform probability distributions are assumed. In all cases, the deterministic value of the contingency factor used in 
deterministic modeling studies is taken to be the mean value of process area capital cost uncertainty distribution. Table A-21 summarizes both the deterministic and probabilistic representations of uncertainty in process area direct cost for all three IGCC systems assumed in this work.

Process area costs with the largest ranges of uncertainty include the KRW gasifier, process condensate treatment for Case OKC, the Lurgi gasifier for Case ALH, the zinc ferrite process for Case ALH, and the gas turbine for Case ALH. The KRW gasifier has not yet been built on the scale currently envisioned for IGCC plants and, as discussed in Section A.4.3 and elsewhere in Section A.4, there is uncertainty regarding the scale-up of the combustion jet and in other aspects of the process area. In EPRI-sponsored design studies, a process contingency of 20 percent has bcen used for this process area. Assuming that this process contingency is intended to represent a 50 percent probability of cost overrun, and assuming that the range of uncertainty in process area cost could be from zero increase to 40 percent increase, a triangular distribution was assumed. The use of the triangular distribution here places more likelihood on outcomes near the 20 percent cost increase than at the lower or upper extremes, representing a degree of confidence in the judgment of the cost estimating team that developed the EPRI-sponsored estimate.

In Case $\mathrm{OKC}$, process condensate treatment is required to remove contaminants from liquid discharge streams. In an EPRI-sponsored study of a KRW-based system (Gallaspy et al, 1990), this process area was assigned a contingency factor of 30 percent, representing a relatively high level of uncertainty compared to other process areas. In a previous study (Dawkins et al, 1985), a process contingency of 50 percent was used. As an initial characterization of uncertainty, it is assumed that the cost may increase 50 percent compared to the base estimate for this process area, with a chance that there would be little or no cost increase. This uncertainty is represented as a triangular distribution.

The uncertainty in the capital cost of the Lurgi gasifier is discussed in Section A.3.5. Uncertainty in the capital cost of the gas turbine process area is discussed in Section A.4.7.4. 
Table A-21. Summary of Assumed Values and Uncertainties for IGCC Process Area Direct Capital Cost.

\begin{tabular}{|c|c|c|c|c|c|c|c|}
\hline Description & Units $^{a}$ & "Best Guess" & Distribution & \multicolumn{2}{|c|}{ Parameters ${ }^{b}$} & & \\
\hline \multicolumn{8}{|c|}{ Oxygen-Blown KRW-based System with Cold Gas Cleanup } \\
\hline Cóal Handling & $\%$ of DC & 5 & Uniform & 0 & to & 10 & \\
\hline Oxidant Feed & $\%$ of $\mathrm{DC}$ & 5 & Uniform & 0 & to & 10 & \\
\hline Gasification & $\%$ of DC & 20 & Triangular & 0 & to & 40 & (20) \\
\hline Selexol & $\%$ of DC & 10 & Triangular & 0 & to & 20 & (10) \\
\hline \multicolumn{8}{|l|}{ Low Temperature } \\
\hline Gas Cooling & $\%$ of DC & 0 & Triangular & -5 & to & 5 & $(0)$ \\
\hline Claus Plant & $\%$ of DC & 5 & Triangular & 0 & to & 10 & (5) \\
\hline Beavon-Stretford & $\%$ of DC & 10 & Triangular & 0 & to & 20 & (10) \\
\hline Boiler Feed Water & $\%$ of DC & 0 & & & & & \\
\hline \multicolumn{8}{|l|}{ Process Condensate } \\
\hline Treatment & $\%$ of $\mathrm{DC}$ & 30 & Triangular & 0 & to & 50 & (30) \\
\hline Gas Turbine & $\%$ of DC & 12.5 & Uniform & 0 & to & 25 & \\
\hline HRSG & $\%$ of $\mathrm{DC}$ & 2.5 & Uniform & 0 & to & 5 & \\
\hline Steam Turbine & $\%$ of $\mathrm{DC}$ & 2.5 & Uniform & 0 & to & 5 & \\
\hline General Facilities & $\%$ of $\mathrm{DC}$ & 5 & Uniform & 0 & to & 10 & (5) \\
\hline \multicolumn{8}{|c|}{ Air-Blown Lurgi-Based System with Hot Gas Cleanup } \\
\hline Coal Handling & $\%$ of DC & 5 & Uniform & 0 & to & 10 & \\
\hline Oxidant Feed & $\%$ of $\mathrm{DC}$ & 10 & Uniform & 0 & to & 20 & \\
\hline Gasification & $\%$ of $\mathrm{DC}$ & 20 & Uniform & 10 & to & 30 & \\
\hline Cyclones & $\%$ of DC & 5 & Uniform & 0 & to & 10 & \\
\hline Zinc Ferrite & $\%$ of DC & 40 & Uniform & 0 & to & 80 & \\
\hline Sulfuric Acid Plant & $\%$ of $\mathrm{DC}$ & 10 & Uniform & 0 & to & 20 & \\
\hline Boiler Feed Water & $\%$ of $\mathrm{DC}$ & 0 & & & & & \\
\hline Gas Turbine & $\%$ of DC & 25 & Uniform & 0 & to & 50 & \\
\hline HRSG & $\%$ of $\mathrm{DC}$ & 2.5 & Uniform & 0 & to & 5 & \\
\hline Steam Turbine & $\%$ of DC & 2.5 & Uniform & 0 & to & 5 & \\
\hline General Facilities & $\%$ of $\mathrm{DC}$ & 5 & Uniform & 0 & to & 10 & \\
\hline
\end{tabular}

a The "best guess" values represent deterministic "contingency factors" as defined by EPRI (1986) and others. For probabilistic studies, uncertainty in capital cost is represented by an uncertainty factor, which is described by a probability distribution. $\mathrm{DC}=$ process area direct cost.

$\mathrm{b}$ For Uniform distributions, the lower and upper bounds are given. For the triangular distribution, the mode is given in parentheses. For the fractile distribution, the lower and upper bounds for each range are given, along with the probability of sampling within that range. 
The zinc ferrite process has been evaluated also as part of studies prepared for the Gas Research Institute. The process contingency assumed for this process area has been 40 percent. Here, it is assumed that there is a chance there would be no cost growth and a chance that the cost could increase up to 80 percent. This wide range of uncertainty reflects the early stage of development of this process area, the potential troublesome nature of solids handling, potential difficulties with the complex piping and valving needed, and potential difficulty in developing a control system.

The other process areas shown in Table A-21 represent more conventional technologies which have seen applications hor ave been demonstrated at a full scale in similar process environments. For these process areas, the process contingency factors typically reported in the literature were assumed as the median values of uncertainty factors for capital cost. In most cases, a uniform distribution ranging from zero to twice the reported contingency factor was assumed as an initial estimate of uncertainty for each process area. The cost of the boiler feedwater process area was assumed to be certain; this process area is common to any steam power plant and represents standard, commercial, and proven technology. Low contingencies and uncertainties were assumed for process areas that are well-proven or not substantially affected by an IGCC process environment, such as coal handling, limestone handling, air separation, heat recovery steam generator, and steam turbine.

\section{A.5.3 Maintenance Cost Uncertainties}

While considerable attention is often devoted to representing uncertainty in capital cost estimates using "contingency factors," usually no attention is given to uncertainties in predicting maintenance costs. Uncertainty in maintenance cost may be particularly important for new technology involving solids handling and facing potential problems from trace contaminants.

In preliminary cost estimates, the typical approach to estimating maintenance cost is to use "maintenance cost factors," which are a multiplier based on process area costs. Typical values, based on previous experience with a process area, are assumed. For a new process area, a maintenance cost factor may be assumed based on experience with analogous systems or judgment about the cost of maintenance that may be requircd with the new system. In the probabilistic simulations developed here, rather than use a single value of maintenance cost factors, ranges of possible values are assumed for selected process areas. In all cases, triangular distributions have been assumed. These distributions require judgment about the lower and upper bounds and the "most likely" or modal value. The 
mode has been assumed to be the same as the maintenance cost factors commonly assumed for each process area in published design studies (see the Task 2 Topical Report). The deterministic and probabilistic values for maintenance cost factors used here are summarized in Table A-22.

In cases where there appears to be little uncertainty regarding maintenance cost, such as for process areas with which there is a long history of commercial experience, the maintenance costs are assumed to be known with certainty. An examples of this type of process area is coal handling. In cases where a new technology is used, or where an existing technology is adopted for the first time in a process environment like that of an IGCC system, wider ranges of uncertainty are assumed. Furthermore, for some process areas involving solids handling or that might be seriously affected by trace contaminants, positively skewed distributions for maintenance cost are assumed. These process areas include Selexol, process condensate treatment, zinc ferrite desulfurization, gas turbines in IGCC systems with hot gas cleanup, and Lurgi gasification. (Maintenance costs for the Lurgi gasifier and the gas turbine process areas have been discussed in Sections A.2 and A.4.7.4, respectively.) 
Table A-22. Summary of Assumed Values and Uncertainties for IGCC Process Area Maintenance Cost.

\begin{tabular}{|c|c|c|c|c|c|c|c|}
\hline Description & Units $a$ & "Best Guess" & Distribution & \multicolumn{4}{|c|}{ Parameters $^{b}$} \\
\hline \multicolumn{8}{|c|}{ Oxygen-Blown KRW-based Systein with Cold Gas Cleanup } \\
\hline Coal Handling & $\%$ of TC & 3 & & & & & \\
\hline Oxidant Feed & $\%$ of TC & 2 & & & & & \\
\hline Gasification & $\%$ of TC & 4.5 & Triangular & 3 & to & 6 & $(4.5)$ \\
\hline Selexol & $\%$ of $\mathrm{TC}$ & 2 & Triangular & 1.5 & to & & $(2)$ \\
\hline \multicolumn{8}{|l|}{ Low Temperature } \\
\hline Gas Cooling & $\%$ of $\mathrm{TC}$ & 3 & Triangular & 2 & to & 4 & (3) \\
\hline Claus Plant & $\%$ of TC & 2 & Triangular & 1.5 & to & 2.5 & (2) \\
\hline Beavon-Stretford & $\%$ of TC & 2 & Triangular & 1.5 & to & 2.5 & (2) \\
\hline Boiler Feed Water & $\%$ of TC & 1.5 & & & & & \\
\hline \multicolumn{8}{|l|}{ Process Condensate } \\
\hline Treatment & $\%$ of TC & 2 & Triangular & 1.5 & to & 4 & (2) \\
\hline Gas Turbine & $\%$ of TC & 1.5 & Triangular & 1.5 & to & 2.5 & $(1.5)$ \\
\hline HRSG & $\%$ of TC & 1.5 & & & & & \\
\hline Steam Turbine & $\%$ of TC & 1.5 & & & & & \\
\hline General Facilities & $\%$ of TC & 1.5 & & & & & \\
\hline \multicolumn{8}{|c|}{ Air-Blown Lurgi-Based System with Hot Gas Cleanup } \\
\hline Coal Handling & $\%$ of TC & 3 & & & & & \\
\hline Oxidant Feed & $\%$ of TC & 2 & Triangular & 1 & to & 3 & \\
\hline Gasification & $\%$ of TC & 3 & Triangular & 2 & to & 12 & (3) \\
\hline Cyclones & $\%$ of TC & 3 & Triangular & 1.5 & to & 4.5 & \\
\hline Zinc Ferrite & $\%$ of TC & 3 & Triangular & 3 & to & 6 & \\
\hline Sulfuric Acid Plant & $\%$ of TC & 2 & & & & & \\
\hline Boiler Feed Water & $\%$ of $\mathrm{TC}$ & 1.5 & & & & & \\
\hline Gas Turbine & $\%$ of $\mathrm{TC}$ & 2 & Triangular & 1.5 & to & 6 & (2) \\
\hline HRSG & $\%$ of TC & 1.5 & & & & & \\
\hline Steam Turbine & $\%$ of TC & 1.5 & & & & & \\
\hline General Facilities & $\%$ of TC & 1.5 & & & & & \\
\hline
\end{tabular}

a $\mathrm{TC}=$ process area total cost, including indirects and contingency

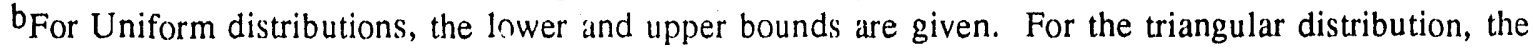
mode is given in parentheses. For the fractile distribution, the lower and upper bounds for each range are given, along with the probability of sampling within that range. 


\section{A.5.4 Variable Operating Cost Uncertainties}

There are two types of uncertainty in variable operating cost that are characterized in this modeling effort. The first relates to uncertainty in the quantity of consumables that are required to satisfy plant requirements. For example, uncertainty in factors which affect plant efficiency lead to uncertainty in the required flow rate of materials needed to produce a given power output. Uncertainty in the long term chemical and physical properties of zinc ferrite sorbent, used in the two IGCC systems with hot gas cleanup, leads to uncertainty in the annual requirement for makeup sorbent. Uncertainty in the coal feed rate required to produce a given amount of power also leads to uncertainty in the amount of sulfur that needs to be recovered from the coal gas and converted to a byproduct. These types of uncertainties are performance related and are explicitly estimated as part of probabilistic modeling of process flowsheets.

A second uncertainty relates to the unit cost of consumables or the unit price of byproducts. These costs are likely to be affected by site-specific market conditions. In generic evaluations of process technologies, which are not intended to be site-specific, it is appropriate to represent the variability of these costs from one location to another using probability distributions. To the extent that variation in, say, the unit price of a byproduct might lead to significant variation in the variable cost of the plant, then the modeling can provide insight into market niches in which the technology is likely to have competitive costs compared to other alternatives.

Judgments regarding uncertainties in variable operating cost parameters are summarized in Table A-23. The judgment about uncertainty regarding the zinc ferrite unit cost was obtained from Expert ZF-3, as discussed in Section A.3.4.3. The cost of ash disposal is often assumed to be $\$ 10 /$ ton, assuming readily a available landfill. However, this cost is also likely to increase. Increased costs of land, permitting, and potential concerns about trace species in the ash could increase the costs of disposal. Again, a positively skewed triangular distribution is used.

The price that may be obtained for either byproduct sulfur (Case OKC) or sulfuric acid (Case ALH) depends on plant location and proximity to customers. Many design studies assume that obtainable prices will be the same as current market prices for these products. However, such assumptions ignore the effect that additional production of these commodities would have on market prices, as well as the effect that large transportation distances would have on price that a particular plant could obtain. In addition, sulfuric acid sale is likely to be disadvantageous compared to sulfur, because currently the sulfur market 
Table A-23. Summary of Assumed Values and Uncertainties for IGCC Variable Operating Cost Parameters.

\begin{tabular}{|c|c|c|c|c|c|c|}
\hline \multirow{2}{*}{$\begin{array}{l}\text { Description } \\
\text { Zinc Ferrite Sorbent }\end{array}$} & \multirow{2}{*}{$\frac{\text { Units }^{\mathrm{a}}}{\$ / \mathrm{lb}}$} & \multirow{2}{*}{$\frac{\text { "Best Guess" }}{3.00}$} & \multirow{2}{*}{$\begin{array}{l}\text { Distribution } \\
\text { Triangular }\end{array}$} & \multicolumn{3}{|c|}{ Parameters $^{b}$} \\
\hline & & & & 0.75 & to & $5.00(3.00)$ \\
\hline $\begin{array}{l}\text { Ash Disposal } \\
\text { Sulfuric Acid }\end{array}$ & $\$ /$ ton & 10 & Triangular & 10 & to & $25 \quad(10)$ \\
\hline Byproduct Price & $\$ /$ ton & 40 & Triangular & 0 & to & $60 \quad(40)$ \\
\hline Sulfur Byproduct & $\$ /$ ton & 125 & Triangular & 60 & to & $125(125)$ \\
\hline Byproduct Marketing & fraction & 0.10 & Triangular & 0.05 & to & $0.15(0.10)$ \\
\hline
\end{tabular}

a Costs are in 1990 dollars

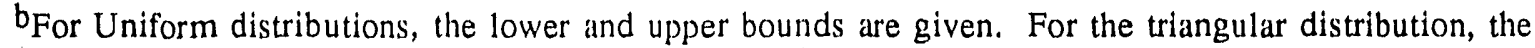
mode is given in parentheses. For the fractile distribution, the lower and upper bounds for each range are given, along with the probability of sampling within that range.

in the U.S. is "structurally larger" than the sulfuric acid market (Reiber, 1982). Over 80 percent of the sulfur consumed in the U.S. is used to produce sulfuric acid. However, a large portion of the sulfur comes from "discretionary" production at natural mines (Manderson and Cooper, 1982), which can be easily displaced by sulfur byproduct recovery. Moreover, solid sulfur is relatively easy to store and transport compared to sulfuric acid. Sulfur can be sold to sulfuric acid producers as well as to other end-users, and conceivably byproduct sulfur could be exported internationally.

In contrast, the costs associated with shipping sulfuric acid are likely to limit sale to markets relatively near the power plant. There are relatively few concentrations of industry were sulfuric acid is required in large quantities. This is particularly a concern in regions where high sulfur coal is likely to be consumed, where markets for sulfuric acid are weak (Burns and Roe, 1987). Furthermore, byproduct sulfuric acid production from smelters in Canada is likely to depress market prices for sulfuric acid (Burns and Roe, 1987, Manderson and Cooper, 1982).

Because sulfur is believed to be a less risky alternative economically, the uncertainty in byproduct price for sulfur is not as pessimistic as for sulfuric acid. While some studies (e.g., Corman, 1986) assume relatively high sulfuric acid byproduct prices of around $\$ 60 /$ ton, a more reasonable assumption would be $\$ 40 /$ ton, and it is possible that, at a particular site, a plant might obtained almost nil for the byproduct (Burns and Roe, 1987). In contrast, sulfur prices are expected to be relatively stable. A typically assumed value for sulfur price is about $\$ 125 /$ ton. However, at any given site, there may be some change that price could be lower, due either to expenses of transport or due :o fluctuations in the market price. For both sulfur and sulfuric acid, it is assumed that a portion of the 
byproduct proceeds are required for activities associated with byproduct marketing, as opposed to power plant operation. Therefore, a byproduct marketing factor is assumed.

\section{A.5.5 Regression Model Error Terms}

Regression analysis was used to develop models for performance and cost of a number of process areas in the IGCC systems. See Chapter 2 of the Task 2 Topical Report for a more detailed discussion of the use of regression analysis in model development. For all regression models, the standard error of the estimate can be used to measure the variance in the dependent variable that is not captured by the functional relationship to the selected independent variables. Thus, the standard error is a measure of how well the models predict the dependent variable. In many cases, the standard error from the regression models developing in this work is very small and negligible. The more significant standard errors are summarized in Table A-24. These standard errors may be included as uncertainties in the probabilistic simulation for specific process flowsheets. In Table A-24, the standard errors are grouped depending on whether they are associated with direct capital cost models or with auxiliary power load models. In two cases, non-linear regressions were used, resulting in lognormally distributed error terms.

For probabilistic analysis, several of the standard errors reported in Table A-24 were judged to be negligible and so were excluded. These are: Claus plant, BeavonStretford, boiler feedwater, and boost air compressor direct capital cost standard errors, and the Lurgi coal handling and KRW low temperature gas cooling auxiliary power standard errors. The standard errors for models of consumable requirements affecting variable operating cost were generally very small and are not reported in Table A-24 nor included in the probabilistic simulations. 
Table A-24. Summary of Regression Model Standard Errors for IGCC Cost and Auxiliary Power Equations.

\begin{tabular}{|c|c|c|c|c|c|c|}
\hline \multirow{2}{*}{\multicolumn{2}{|c|}{$\begin{array}{l}\text { Description Units } \\
\text { Direct Capital Cost Models }\end{array}$}} & \multirow[t]{2}{*}{ Mean Error } & \multirow[t]{2}{*}{ Distribution ${ }^{a}$} & \multicolumn{2}{|c|}{ Parameters $^{b}$} & \\
\hline & & & & & & \\
\hline KRW Coal Handling & \$Million & 0 & Normal & -10 & to & 10 \\
\hline $\begin{array}{l}\text { Oxygen Plant } \\
\text { KRW Gasification }\end{array}$ & multiplier & 1.012 & Lognormal & 0.78 & to & 1.29 \\
\hline (Cold Gas System) & \$ Million & 0 & Normal & -20.5 & to & 20.5 \\
\hline Low Temperature & & & & & & \\
\hline Gas Cooling & \$ Million & 0 & Normal & -1.5 & to & i. 5 \\
\hline Selexol & \$ Million & 0 & Normal & -5.1 & to & 5.1 \\
\hline Claus & $\$$ Million & 0 & Normal & -0.25 & to & 0.25 \\
\hline Beavon-Stretford & \$ Million & 0 & Normal & -0.26 & to & 0.26 \\
\hline Boiler Feedwater & multiplier & 1.002 & Lognormal & 0.90 & to & 1.10 \\
\hline Process Condensate & \$ Million & 0 & Normal & -0.01 & to & 0.01 \\
\hline HRSG & \$Million & 0 & Normal & -17.3 & to & 17.3 \\
\hline Steam Turbine & \$ Million & 0 & Normal & -15.8 & to & 15.8 \\
\hline Boost Air Compressor & $\$$ Million & 0 & Normal & -0.66 & to & 0.66 \\
\hline Lurgi Coal Handling & \$ Million & 0 & Normal & -14.4 & to & 14.4 \\
\hline Sulfuric Acid Plant & \$ Million & 0 & Normal & -4.0 & to & 4.0 \\
\hline \multicolumn{7}{|c|}{ Auxiliary Power Load Models } \\
\hline KRW Coal Handling & MW & 0 & Normal & -1.6 & to & 1.6 \\
\hline Oxygen Plant & MW & 0 & Normal & -6.6 & to & 6.6 \\
\hline $\begin{array}{l}\text { KRW Gasification } \\
\text { (cold gas system) }\end{array}$ & MW & 0 & Normal & & 0 & 52 \\
\hline \multicolumn{7}{|c|}{ Low Temperature } \\
\hline Gas Cooling & MW & 0 & Normal & -0.24 & to & 0.24 \\
\hline Selexol & MW & 0 & Normal & -0.55 & to & 0.55 \\
\hline Claus Plant & MW & 0 & $\mathrm{~N} / \mathrm{A}$ & & & \\
\hline Beavon-Stretford & MW & 0 & $\mathrm{~N} / \mathrm{A}$ & & & \\
\hline Boiler Feedwater & $\mathrm{MW}$ & 0 & N/A & & & \\
\hline Process Condensate & MW & 0 & $N / A$ & & & \\
\hline \multirow{2}{*}{\multicolumn{4}{|c|}{ KRW Gasification }} & & & \\
\hline & MW & 0 & & & & \\
\hline Lurgi Coal Handling & MW & 0 & Normal & -0.35 & to & 0.35 \\
\hline
\end{tabular}

$\mathrm{a}_{\mathrm{N}} / \mathrm{A}=$ not applicable. For these cases the standard error was sufficiently small to be judged negligible.

$b_{F}$ or Normal and Lognormal distributions, the upper and lower limits of the 99.8 percent probability range are given. 
This page left blank intentionally. 


\section{A.6 References for Appendix A}

Angello, L, and P. Lowe (1989). "Dry Low $\mathrm{NO}_{\mathrm{x}}$ Combustion Development for Electric Utility Gas Turbine Applications: A Status Report." ASME Paper No. 89-GT-254.

Bachovchin, D.M., M.A. Alvin, and L. M. Day (1987). "A Study of High Temperature Removal of Alkali in a Pressurized Gasification System." In Proceedings of the Seventh Annual Gasification and Gas Stream Cleanup Systems Contraciors Review Meeting, Volume II. U.S. Department of Energy. Morgantown, WV. June, 1987. p. 495-504

Banchik, I.N., J.W. Buckman, and L.K. Rath (1988). Status Update -- The Appalachian Project -- An Advanced Integrated Combined Cycle Power Generation Plant. Presented at the AIChE 1988 Summer National Meeting, Denver, CO. August 21-24, 1988.

Banchik, I.N., and A.E. Cover (1988). IGCC Economics Using the KRW Gasifier With Hot Gas Cleanup. Procetdings, Fifth Annual International Pittsburgh Coal Conference. Septemb:r 12-16, 1988.

Bechtel (1983). Design of Advanced Fossil Fuel Systems (DAFFS), A Study of Three Developing Technologies for Coal-Fired, Base-Load Electric Power Generation: Integrated Gasification Combined Cycle Power Plant With Westinghouse Gasification Process.

Prepared by Bechtel Group, Inc., and Westinghouse Electric Corporation, Synthetic Fuels Division, for the U.S. Department of Energy Argonne National Laboratory. Argonne, Illinois. ANL/FE-83-17. June. 1983.

Bechtel (1983a). Design of Advanced Fossil Fuel Systems (DAFFS), A Study of Three Developing Technologies for Coal-Fired, Base-Load Electric Power Generation: Integrated Gasification Combined Cycle Power Plant With BGC/Lurgi Gasification Process.

Prepared by Bechtel Group, Inc., and Burns and Roe/Humphreys-Glasgow Synthetic Fuels, Inc. for the U.S. Department of Energy Argonne National Laboratory. Argonne, Illinois. ANL/FE-83-16. June.

Bechtel et al. (1988). A 180-MWe British Gas/Lurgi-Based IGCC Power Plant: Feasibility Study at Virginia Power and Detroit Edison. Prepared by Bechtel Group, Inc., British Gas plc, Virginia Power, Babcock Woodall-Duckham, Ltd, and Lurgi GmbH for Electric Power Research Institute, Inc. Palo Alto, CA. EPRI A.P-6011. September 1988.

Becker, B., and W. Schulten (1985). "Advanced Gas Turbines for Efficient and Reliable Combined-Cycle Plants." In Proceedings: Conference on Coal Gasification Systems and Synthetic Fuels :For Power Generation, Volume 2. Electric Power Research Institute. AP4257-SR. December 1985. p. 25-1 to 25-21.

Blinn, M.B., A.E. Cover, G.B. Haldipur, S.C. Datta, J.D. Holmgren, G.K. Mathur, and R.K Agrawal (1989). Advanced Gasifier-Desulfurizer Process Development for SNG Application. Prepared by KRW Energy Systems for the Gas Research Institute. Chicago, IL. GRI-89/0011. June 1989.

Bostwick, L.E., D.A. Hubbard, R.W. Laramore, and T.R. Ethridge (1981). Technical and Economic Assessment of the Westinghouse Fluidized-Bed Coal Gasification Process. Prepared by the M.W. Kellogg Company for U.S. Department of Energy and Gas Research Institute. FE-2778-43. April 1981. 
Brandt, D.E (1988). "The Design and Development of an Advanced Heavy-Duty Gas Turbine" Journal of Engineering for Gas Turbines and Power 110 (1988): 243-250.

Brandt, D.E (1989). "MS7001F Prototype Test Results." ASME Paper No. 89-GT-102. 1989.

Burns and Roe (1987). PETC Flue Gas Cleanup Technologies By-Products. Prepared by Burns and Roe Services Corporation for the U.S. Department of Energy, Pittsburgh Energy Technology Center. September.

Cincotta, G.A. (1984). Gas Turbine Systems Research and Development Program. Prepared by the General Electric Company for the U.S. Department of Energy Morgantown Energy Technology Center. Morgantown, WV. DOE/MC/20315-1767. September 1984.

Cohen, H., G.F.C. Rogers, and H.I.H. Saravanamuttoo (1987). Gas Turbine Theory, 3rd Ed. Longman Scientific and Technical. New York. 1987.

Combs, R.T., D.T. Leaf, and G.A. Verno (1989). Virginia Power's Study of a ShellBased GCC Power Plant. Prepared for Electric Power Research Institute by Virginia Power and Electric Company. GS-6493. September 1989.

Cool Water (1988). Cool Water Coal Gasification Program: Fifth Progress Report. Electric Power Research Institute. AP-5931. October 1988.

Corman, J.C. (1986). System Analysis of Simplified IGCC Plants. Prepared by General Electric for U.S. Department of Energy Morgantown Energy Technology Center. Morgantown, WV. DOE/ET/14928-2233. September 1986.

Corman, J.C (1986a). "Simplified IGCC." Presented at the 13th Energy Technology Conference and Exhibition. Washington, DC. March 17-19, 1986.

Cover, A.E., D.A. Hubbard, S.K. Jain, E.W. Wong, and C.T. Baker (1985a). Design and Economics of a Lignite-to-SNG Facility Using Westinghouse Gasifiers. In: Advanced Coal Gasification Technical Analysis, Final Report. Volume 3Technical/Economic Evaluations. Prepared by Kellogg Rust Synfuels, Inc. for Gas Research Institute. Chicago, IL. GRI-86/0009.3. June 1985.

Cover, A.E., D.A. Hubbard, S.K. Jain, P.B. Koneru, and C.T. Baker (1985b). Design and Economics of a Lignite-to-SNG Facility Using Lurgi Gasifiers. In: Advanced Coal Gasification Technical Analysis, Final Report. Volume 3-Technical/Economic Evaluations. Prepared by Kellogg Rust Synfuels, Inc. for Gas Research Institute. Chicago, IL. GRI86/0009.3. November 1985.

Craig, K.R. (1988). ASPEN Input File: KRW Fluidized Bed IGCC Power Plant (Hot Gas Cleanup). U.S. Department of Energy Morgantown Energy Technology Center. Morgantown, West Virginia. June 22, 1988.

Dawkins, R.P., et al (1985). Cost and Performance of Kellogg Rust Westinghouse-based Gasification Combined Cycle Plants. Prepared by Fluor Engineers, Inc for Electric Power Research Institute. Palo Alto, CA. EPRI AP-4018. June 1985. 
Dawkins, R.P., et al. (1986). Screening Evaluation of Advanced Power Cycles. Prepared for Electric Power Research Institute by Fluor Technology, Inc. AP-4826. November 1986.

Davis, L.B., M.B. Hilt, and R.B. Schiefer (1987). "NO Emissions from Advanced Gas Turbines Fired on MBTU Gases." In Proceedings: Sixth Annual EPRI Contractors' Conference on Coal Gasification. Electric Power Research Institute. AP-5343-SR. October 1987. p. 16-1 to 16-16.

Earley, P.I., and S.C. Smelser (1988). Design and Economics of a Plant to Convert Eastern Bituminous Coal to Pipeline Gas or Power Using KRW Gasifiers with In-Bed Desulfurization. Prepared by Fluor Technology, Inc. for Gas Research Institute. Chicago, Ill. GRI-86/0166. September 1988.

Earley, P.I., and S.C. Smelser (1988a). Design and Economics of a Coal-to-Pipeline-Gas Facility Using KRW Gasifiers with Reduced Carbon Conversion. Prepared by Fluor Technology, Inc. for Gas Research Institute. Chicago, Illinois. GRI-87/0169. January 1988.

Entrekin, H.D., and T.R. Edwards (1987). Effects of Load Following on Gas Turbine Emissions and Ambient Air Quality. Presented at the 80th Annual Meeting of the Air and Waste Management Association, New York, NY. June 21-26.

EPRI (1986). TAG(tm) - Technical Assessment Guide, Volume 1: Electricity Supply 1986. EPRI P-4463-SR. Electric Power Research Institute, Inc. December.

Eustis, F.H., and M.S. Johnson (1990). Gas Turbine Effects on Integrated Gasification Combined Cycle Power Plant Operations. Piepared by Stanford University for the Electric Power Research Institute. Palo Alto, CA. Report GS/ER-6770. March 1990.

Farmer, R (1989). "150 MW Class 501F Design to Begin Full Load Factory Testing This Summer." Gas Turbine World. May-June 1989. pp. 12-17.

Floyd, F.M., and R.K. Agrawal (1989). Process Considerations in Commercial Applications of M.W. Kellogg's KRW Coal Gasification Technology. Proceedings, Sixth Annual International Pittsburgh Coal Conference. September 25-29, 1989.

Folsom, B.A., C.W. Courtney, and M.P. Heap (1980). "The Effect of LBG Composition and Combustor Characteristics on Fuel NOx Formation." Journal of Engineering for Power 102 (1980):459-467.

Frey, H.C. (1987). Performance and Economic Model of the Fluidized Bed Copper Oxide Process. Master's Thesis. Department of Mechanical Engineering, Carnegie-Mellon University. Pittsburgh, PA. May.

Frey, H.C., and E.S. Rubin (1990). Stochastic Modeling of Coal Gasification Combined Cycle Systems: Cost Models for Selected Integrated Gasification Combined Cycle (IGCC) Systems. Prepared by Carnegie-Mellon University for the U.S. Department of Energy, Morgantown, WV. Report No. DOE/MC/24248-2901 (NTIS No. DE90015345). June.

Gallaspy, D.T., T.W. Johnson, and R.E. Sears (1990). Southern Company Services' Study of a KRW-Based GCC Power Plant. Prepared by Southern Company Services for the Electric Power Research Institute, Palo Alto, CA. EPRI GS-6876. July 1990. 
Gallaspy, D.T., et al (1990). "Cost and Performance of Air-B̈Blown Gasification-Based Power Plants with Hot Gas Cleanup." Presented at the Tenth Annual Gasification and Gas Stream Cleanup Systems Contractors Review Meeting. U.S. Department of Energy. Morgantown, WV. August 28-30, 1990.

Ghate, M., and J. Longanbach, eds. Coal Gasification: Technology Status Report. U.S. Department of Energy Morgantown Energy Technology Center. Morgantown, WV. DOE/METC-88/0262. January 1988.

Haldipur, G.B., K.J. Smith, S. Datta, and P. Cherish (1988). Fluidized Bed Coal Gasification with Hot Gas Cleanup. Proceedings of the Eighth Annual Gasification and Gas Stream Cleanup Systems Contractors Review Meeting, Volume I. V.P. Kothari and J.R. Longanbach, Eds. U.S. Department of Energy Morgantown Energy Technology Center. Morgantown, WV. DOE/METC-88/6092. May 1988.

Haldipur, G.B., D.K. Schmidt, and K.J. Smith (1989). A 50-Month Gasifier Mechanistic Study and Downstream Unit Process Development Program for the Pressurized AshAgglomerating Fluidized-Bed Gasification System, Volumes 1 and 2. Final Report. Prepared by KRW Energy Systems, Inc. for the U.S. Department of Energy Morgantown Energy Technology Center. Morgantown, WV. DCE/MC/21063-2740. March 1989.

Haldipur, G.B., K.J. Smith, S. Datta, and P. Cherish (1988). Fluidized Bed Coal Gasification with Hot Gas Cleanup. Proceedings of the Eighth Annual Gasification and Gas Stream Cleanup Systems Contractors Review Meeting, Volume I. V.P. Kothari and J.R. Longanbach, Eds. U.S. Department of Energy Morgantown Energy Technology Center. Morgantown, WV. DOE/METC-88/6092. May 1988.

Hess, R.W., and C.W. Myers (1989). Assessing Initial Cost Growth and Subsequent Long-Term Cost Improvement in Coal-to-SNG Processes. Prepared by the Rand Corporation for Gas Research Institute. Chicago, Illinois. GRI-89/0129. June 1989.

Hester, J.C., and D.E. Pless (1990). Proposed Demonstration of An Air Blown Coal Gasification Combined Cycle Gas Turbine Concept. Presented at the Seventh Annual International Pittsburgh Coal Conference. September, 1990.

Holt, N.A., E.Clark, and A. Cohn (1989). "NO Control in Coal Gasification Combined Cycle Systems." In 1989 Symposium on Stationary Combustion Nitrogen Oxide Control, Volume 1. Electric Power Research Institute. CS-6423. July 1989. p. 5A-17 to 5A-28.

Kasper, S. (1988). Design Basis for Zinc Ferrite Hot Gas Desulfurization Systems. In: Proceedings of the Eight Annual Gasification and Gas Stream Cleanup Systems

Contractors Review Meeting, Volume 1. V.P. Kothari and J.R. Longanbach, Eds. U.S. Department of Energy, Morgantown Energy Technology Center, Morgantown, West Virginia. May 1988.

Klara, J.M., A. Rastogi, and K.R. Craig (1988). ASPEN Input File: Fixed-Bed (Gasification) With No In-Bed Sulfur Capture and Moving Bed Zinc Ferrite (Process). U.S. Department of Energy Morgantown Energy Technology Center. Morgantown, West Virginia. 1988. 
Klett, M.G., et al. (1986). Conceptual Designs of Advanced High-Temperature Desulfurization Processes: Volume II, Integrated Gasification Combined Cycle, Final Report. Prepared by Gilbert/Commonwealth for U.S. Department of Energy, Morgantown Energy Technology Center, Morgantown, West Virginia. DOE/MC/21098-2248, Vol. 2. December 1986.

Koch, R.W. Technical and Economic Comparison of Gas Desulfurization Processes. Proceedings of the Ninth Annual Gasification and Gas Stream Cleanup Systems Contractors Review Meeting, Volume 2. U.S. Department of Energy, Morgantown Energy Technology Center, Morgantown, West Virginia. June 1989.

Makansi, J (1990). "Special Section: Combined Cycle Power Plants." Power. June 1990. p. $91-126$.

Manderson, M.C., and C.D. Cooper (1982). Sulfur Supply and Demand and Its Relationship to New Energy Sources. In: Sulfur: New Sources and Uses. M.E.D. Raymont, ed. American Chemical Society Symposium Series. Washington, D.C.

Merrow, E.W., K.E. Phillips, and C.W. Myers (1981). Understanding Cost Growth and Performance Shortfalls in Pioneer Process Plants. Prepared by the Rand Corporation for the U.S. Department of Energy. Santa Monica, CA. Rand Publication No. R-2569-DOE. September 1981.

METC (1986). Hot Gas Cleanup for Electric Power Generating Systems. Morgantown Energy Technology Center, U.S. Department of Energy. Morgantown, WV. DOE/METC-86/6038. May 1986.

METC (1987). Gas Stream Cleanup: Technology Status Report. Morgantown Energy Technology Center, U.S. Department of Energy. Morgantown, WV. DOE/METC87/0255. October 1987.

Milanese, J.J. (1987). Process Industry Contingency Estimation: A Study of the Ability to Account for Unforeseen Costs. Prepared by the Rand Corporation for the Private Sector Sponsors Program. Rand Publication No. N-2386-PSSP. June 1987.

Moore-Staub, A.L., et al (1990). Gas Turbine Cogeneration Unit PSD BACT Determination: A 1990 Case Study. Presented at the 83rd Annual Meeting of the Air and Waste Management Association. Pittsburgh, PA. June.

Notestein, J.E (1989). "Update on Department of Energy Hot Gas Cleanup Programs." In Eighth Annual EPRI Conference on Coal Gasification. Electric Power Research Institute. GS-6485. August 1989. p. 14-1 to p. 14-43.

OECD (1987). Energy and Cleaner Air: Costs of Reducing Emissions. Organization for Economic Cooperation and Development, Paris.

Parsons (1985). Evaluation of the British Gas Corporation/Lurgi Slagging Gasifier in Gasification-Combined-Cycle Power Generation. Prepared by Ralph M. Parsons Company, British Gas Corporation, and Lurgi, GMBH for Electric Power Research Institute, Palo Alto, CA. EPRI AP-3980. March 1985.

Pillsbury, P (1989). Westinghouse. personal communication. 
Pitrolo, A.A., and T.F. Bechtel (1987). Simplified IGCC: Coal's "Adam Smith" Response to a Changing World. Proceedings, Seventh Annual EPRI Contractor's Conference on Coal Gasification. Electric Power Research Institute. Palo Alto, CA. EPRI AP-6007-SR. October 1988.

Plantz, A.R., C.J. Drummond, S.W. Hedges, and F.N. Gromicko (1986). Performance of the Fluidized Bed Copper Oxide Process in an Integrated Test Facility. Presented at the 79th Annual Meeting of the Air Pollution Control Association, Minneapolis, Minnesota. June 22-27.

Radin, M.G., and B. Boyles (1987). Turbine Exhaust DeNOx Using Selective Catalytic Reduction. Presented at the American Power Conference, Chicago, Illinois. April 27-29.

Rieber, M. (1982). New Sulfur Sources in the United States. In: Sulfur: New Sources and Uses. M.E.D. Raymont, ed. American Chemical Society Symposium Se ies. Washington, D.C.

Rubin, E.S., J.S. Salmento, J.G. Barrett, C.N. Bloyd, and H.C. Frey. (1986). Modeling and Assessment of Advanced Processess for Integrated Environmental Control of CoalFired Power Plants. Prepared by the Center for Energy and Environmental Studies, Carnegie-Mellon University, for the U.S. Department of Energy, Pittsburgh Energy Technology Center. July.

Rubin, E.S., J.S. Salmento, and H.C. Frey. (1988). Evaluating Combined SO2/NOx Processes. Presented at the Fourth Integrated Environmental Control Symposium, Sponsored by the Electric Power Research Institute, Washington, DC, March 2-4.

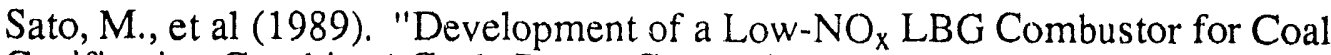
Gasification Combined Cycle Power Generation Systems." ASME Paper No. 89-GT-104. 1989.

Scalzo, A.J. et al (1989). "A New 150 MW High-Efficiency Heavy-Duty Combustion Turbine." Journal of Engineering for Gas Turbines and Power 111 (1989): 211-217.

Scheffel, F.A., and F.D. Skinner (1988). An Engineering Evaluation of Environmental Data From the KRW Coal Gasification Process Development Unit. Prepared by Radian Corporation for U.S. Department of Energy Morgantown Energy Technology Center. Morgantown, WV. DOE/MC/21046-2594. January 1988.

Schmidt, D.K., P. Sadhukhan, and Y.Y. Lin (1989). Desulfurization Using CalciumBased Sorbents in Transport-Bed Combustor and Fluidized Bed Gasifier. Proceedings, Sixth Annual International Pittsburgh Coal Conference. September 25-29, 1989.

SCS (1991). Assessment of Coal Gasification/Hot Gas Cleanup Based Advanced Gas Turbine Systems, Final Report. Prepared by Southern Company Services for U.S. Department of Energy.

Simbeck et al (1983). Coal Gasification Systems: A Guide to Status, Applications, and Economics. Prepared by Synthetic Fuels Associates, Inc. for the Electric Power Research Institute, Inc. Palo Alto, CA. EPRI AP-3109. June. 
Shinnar, R., A.I. Avidan, and L. Weng (1988). Evaluation of Fluidized Bed Coal Gasification: Present Status and Future Development Problems. Prepared by City College of the City University of New Y'ork for U.S. Department of Energy Morgantown Energy Technology Center. Morgantown, WV. DOE/MC/21259-2573. February 1988.

Shinnar, R., and L. Weng (1989). Novel Concepts of System Assessment in Coal Gasification. Proceedings of the Ninth Annual Gasification and Gas Stream Cleanup Systems Contractors Review Meeting, Volume I. R.A. Johnson and T.P. Dorchak, Eds. U.S. Department of Energy Morgantown Energy Technology Center. Morgantown, WV. DOE/METC-89/6107. June 1989.

Simbeck, D.R, R.L. Dickenson, and E.D. Oliver (1983). Coal Gasification Systems: A Guide to Status, Applications, and Economics. Prepared by Synthetic Fuels Associates for the Electric Power Research Institute. AP-3109. June 1983.

SMC (1984). Modeling of the Regenerator Reactor for the Fluidized Bed Copper Oxide Flue Gas Treatment Process. Prepared by Science Management Corporation for the U.S. Department of Energy, Pittsburgh Energy Technology Center, Pittsburgh, PA. May.

Smelser, S.C. (1986). Single-Train Demonstration Plant to Convert Eastern Bituminous Coal to Methane or Electricity Using Ash-Agglomerating, Fluidized Bed Gasification. Prepared by Fluor Technology, Inc. for Gas Research Institute. Chicago, Ill. GRI87/0154. October 1986.

Smelser, S.C. (1986a). Design and Economics of a Lignite-to-SNG Facility Using Lurgi Gasifiers With In-Line Conversion of By-Product Liquids to Methane. Prepared by Fluor Technology, Inc. for Gas Research Institute. Chicago, Ill. GRI-87/0159. November 1986.

Smelser, S.C. (1986b). Design and Economics of a Lignite-to-SNG Facility Using Lurgi Gasifiers For Lignite Gasification With KRW Gasifiers for Gasification of Coal Fines. Prepared by Fluor Technology, Inc. for Gas Research Institute. Chicago, Ill. GRI87/0156. January 1986.

Smith, D.P. (1988). Design Studies for Gasification/Hot Gas Desulfurization System Operating in a Load Following Mode. Prepared by General Electric for J.S. Department of Energy. June 1988.

Smith, D.P., E. Gal, C. Cook, A. Furman (1987). "Design Studies for Hot Gas Cleanup System in a Load Following Mode", in Proceedings of the Seventh Annual Gasification and Gas Stream Cleanup Systems Contractors Review Meeting, Volume II. U.S. Department of Energy Morgantown Energy Technology Center. Morgantown, WV. DOE/METC-87/6079. June 1987.

Smith, J.T., D.J. Hanny, and S.C. Smelser (1986). Design and Economics of a Plant to Convert Western Subbituminous Coal to SNG Using KRW Gasifiers. Prepared by Fluor Technology, Inc. for Gas Research Institute. Chicago, Ill. GRI-87/0155. January 1986.

Smith, J.T., and S.C. Smelser (1987). Designs and Economics of Plants to Convert Eastern Bituminous Coal to Methane Using KRW Gasifiers With and Without In-Bed Desulfurization, Topical Report. Prepared by Fluor Technology, Inc. for Gas Research Institute. Chicago, Ill. GRI-87/0160. January 1987. 
Smock, R (1989). "Gas Turbines Dominate New Capacity Ordering." Power Engineering. August 1989. p. 23-28.

Smock, R (1990). "New Gas Turbines Show High Efficiency, Low $\mathrm{NO}_{\mathrm{x}}$ Emission." Power Engineering. August 1990. p.43-46.

Stone, K.R. (1985). ASPEN Simulations of Fluidized-Bed and Entrained Flow Integrated Gasification Combined-Cycle Power Plants, Technical Note. U.S. Department of Energy, Morgantown Energy Technology Center, Morgantown, West Virginia. July 1985.

Touchton, G.L (1984). "An Experimentally 'veritied NOx Prediction Algorithm Incorporating the Effects of Steam Injection." Journal of Engineering for Gas Turbines and Power 106 (1984): 833-840.

Touchton, G.L (1985). "Influence of Gas Turbine Combustor Design and Operating Parameters on Effectiveness of NOx Suppression by Injected Steam or Water" Journal of Engineering for Gas Turbines and Power 107 (1985): 706-713.

Underkoffler, V.S. (1986). Summary and Assessment of METC Zinc Ferrite Hot Coal Gas Desulfurization Test Program, Final Report. Volume I and Volume II, Appendices. Prepared by Gilbert/Commonwealth for the U.S. Department of Energy Morgantown Energy Technology Center. Morgantown, WV. DOE/MC/21098-2247-Vol. 1 and -Vol. 2. December.

Unnasch, S., R. Chang, and H. Mason (1988). Study of Ammonia Removal in Coal Gasification Processes Using Integrated Systems Approach. Prepared by Acurex Corporation for the U.S. Department of Energy. DOE/MC/23275-2589. March 1988.

Wang, J., D. Cockrill, F.R. Groves, and D.P. Harrison. Dynamic Simulation Models for High-Temperature Desulfurization Processes. Prepared by Louisiana State University for the U.S. Department of Energy Morgantown Energy Technology Center. Morgantown, WV. DOE/MC/23089-2601. March 1988.

Williamson, R.R., J.A. Morici, and T.L LaCosse (1987). Sorbent Life Cycle Testing, Fluidized Bed Copper Oxide Process. Prepared by UOP, Inc., for the U.S. Department of Energy, Pittsburgh Energy Technology Center.

Yeh, J.T., and C.J. Drummond (1986). Process Simulation of the Fluidized Bed Copper Oxide Process Sulfation Reaction. Presented at the AIChE 1986 Spring National Meeting, New Orleans, LA, April 6-10.

Yeh, J.T., R.J. Demski, J.P. Strakey, and J.I. Joubert (1984). "PETC Fluidized-Bed Copper Oxide Process for Combined $\mathrm{SO}_{2} / \mathrm{NO}_{\mathrm{x}}$ Removal from Flue Gas," AIChE 1984 Winter National Meeting, Atlanta, March 11-14.

Zahnstecher, L.W. (1984). Coal Gasification Via the Lurgi Process. Volume 1. Production of SNG. Prepared by Foster Wheeler Synfuels Corporation for U.S. Department of Energy Morgantown Energy Technology Center. Morgantown, WV. DOE/FE/05081-2197. September 1984. 


\section{B.0 MODIFICATIONS TO DOE PERFORMANCE MODELS}

Appendix A contains details regarding the performance and cost models of the clean technologies discussed in the main body of the dissertation. A total of two such technologies are analyzed, and they include:

1) Oxygen-blown fluidized bed gasifier-based integrated gasification combined cycle (IGCC) system with cold gas cleanup;

2) Air-blown fixed bed gasifier-based IGCC system with hot gas cleanup.

The major focus of model development in this research has been the adaptation of a set of previously existing IGCC performance models and the development of new cost models for each system. As described in Chapter 3, the U.S. Department of Energy (DOE) had previously developed performance models for the IGCC systems selected for evaluation in this research. The performance models were developed in the ASPEN chemical process simulation environment. These models were obtained and adapted for use here. A number of modifications were made to the ASPEN performance models to include aspects of process performance not previously modeled, to improve some of the existing process area models, and to cleanup and organize the models.

Cost models for each of the IGCC systems were developed based on a detailed review of approximately 30 published performance and cost studies of IGCC and coal-tosubstitute natural gas systems, as well as review of other related design studies. The models characterize capital, operating and maintenance (O\&M), and levelized costs. The cost models are documented in the Task 2 Topical Report (Frey and Rubin, 1990).

This section describes newly developed features added to the performance models of the innovative clean coal technologies evaluated in this study. Some of the features are general to both IGCC systems, while a few are specific to just one flowsheet. These cases are noted. The changes are discussed by process area. The affected process areas include: gasification, external desulfurization, and gas turbine. In addition, a few modifications were made with respect to the way design parameters are initialized and how performance results are summarized.

\section{B.1 Gasification Process Area}

The modifications to the gasification process include specification of carbon and sulfur conversion, and specification of ammonia yield. 


\section{Oxygen-Blown KRW-based System}

The design pressure of the gasification process area, which affects a number of unit operation blocks in the ASPEN input file for this system, are initialized in one Fortran block. Thus, changes in the assumptions regarding system pressures can easily be made. A new design specification is used to adjust the amount of carbon in the inlet coal that is allocated to fines and bottom ash. The amount of carbon that is not retained in fines or bottom ash is fully consumed in the gasifier for fuel gas production. Therefore, carbon conversion is specified by appropriately selecting the fraction of carbon in the coal feed that is retained in fines and ash. Similarly, a portion of the sulfur in the coal is not gasified. A design specification is used to specify the fraction of sulfur in the coal feed that is retained in the bottom ash and fines.

\section{Air-Blown Lurgi Gasification Process Area}

The gasification process area pressures are initialized in a central Fortran block, to facilitate sensitivity analysis. The gasifier pressure for the Lurgi-based system is estimated based on the gas turbine combustor pressure and the pressure losses between the gasifier and the gas turbine.

A new Fortran block was added to specify the amount of ammonia that is produced during gasification. The Fortran block sets the value of a parameter used in the gasifier unit operation reaction model to achieve an ammonia yield according the the equivalent fraction of coal-bound nitrogen that would be converted, as specified by the user.

\section{B.2 Zinc Ferrite Desulfurization Process Area}

For the air-blown IGCC system, fixed bed zinc ferrite desulfurization is used to remove most of the hydrogen sulfide from the fuel gas. However, the original DOE model for the Lurgi-based system included a model of the moving bed zinc ferrite process. Cost data could not be obtained for the moving bed process, and therefore it was decided to replace the moving bed model with the fixed bed model. A fixed bed zinc ferrite process area performance model had been previously developed as part of another IGCC model. Therefore, the fixed bed zinc ferrite model was "borrowed" for use with the Lurgi-based IGCC model.

In addition, a modification to the model was made to more completely represent the zinc ferrite regeneration process. The original DOE model was based on a single step oxidative regeneration in which oxygen in an air stream reacts with the sorbent to generate an off-gas containing $\mathrm{SO}_{2}$. Steam is also added as a thermal diluent to prevent the reaction 
temperature from becoming too high and sintering the sorbent. However, oxidative regeneration is expected to leave some sulfur still retained in the sorbent as sulfates. These sulfates must be reduced prior to the next absorption cycle. Thus, a second reductive regeneration step is required. The reactants for this step may be either hydrogen or carbon monoxide, which are both available in the coal-derived fuel gas. Therefore, fuel gas has been proposed as the reactant for the reductive regeneration step.

The fuel gas requirement for reductive regeneration is estimated based on the amount of residual sulfate that would remain in the sorbent after oxidative regeneration, which is a new parameter added to the model. For each mole of sulfate in the sorbent, four moles of either hydrogen or carbon monixide are required as a reactant in reductive regeneration (Kasper, 1988). Therefore, the fuel gas requirement is estimated based on the fraction of absorbed sulfur that remains as sulfate, and the molar requirement for hydrogen and carbon monoxide. New unit operation blocks were added to represent reductive regeneration by converted the required amounts of hydrogen and carbon monoxide to water vapor and carhon dioxide, respectively, as would occur during reductive regeneration. Thus, the efficiency of the IGCC plant is sensitive to the energy penalty associated with reductive regeneration, which reduces the heating value of the fuel gas entering the gas turbine combustor. The effect, however, is slight in most cases.

\section{B.3 Gas Turbine Process Area}

The gas turbine process area models for both IGCC systems were substantially modified. All key design and performance parameters affecting the gas turbine process area are initialized in a single Fortran block, rather than in individual unit operation blocks. This greatly simplifies the specification of sensitivity and probabilistic case studies. These parameters include inlet turbine ("firing") temperature, pressure ratio (which affects about 10 unit operation blocks), $\mathrm{NO}_{\mathrm{x}}$ emission parameters, $\mathrm{CO}$ emissions, pressure drops in inlet and exit ducting, pressure drop in the gas turbine combustor, and the assumed isentropic efficiencies for the gas turbine model compressor and turbine stages.

Performance model changes include specification of choked conditions at the turbine inlet nozzle, which affects the gas turbine compressor inlet air requirement, characterization of $\mathrm{NO}_{\mathrm{x}}$ and $\mathrm{CO}$ emissions, and the addition of more detail regarding cooling air circuity.

\section{Estimating Compressor and Turbine Mass Flows}

In Appendix A.4.3, the assumption regarding choked conditions at the turbine inlet nozzle is discussed. The DOE models previously assumed that the gas turbine compressor 
inlet air was fixed. Therefore, changes in fuel heating value, or in the amount of compressor air extracted for gasification blast air, did not affect the compressor air demand. However, they substantially affected the mass flow of gases through the turbine. Because of the low heating value of coal-derived fuel gases, the mass flow of gases through the turbine will usually be greater than that through the compressor, even with gasifier blast air extraction. 'Therefore, specifying the compressor air flow as fixed will usually lead to an unrealistically large flow rate of gases in the turbine. Furthermore, the gas turbine cost model is based on a particular type of gas turbine. Therefore, for the performance and cost models to be properly matched, it is important to obtain proper sizing of the flows in the gas turbine.

As discussed in Appendix A.4.3, the expected operating practice for gas turbines in IGCC service is to adjust the air flow through the gas turbine compressor such that the flow at the turbine inlet nozzle is (approximately) choked. This usually involves the use of compressor inlet guide vanes to adjust the compressor air flow based on fuel flow and compressor air extraction (if any) to obtain design flow in the turbine.

Therefore, the approach taken here is to add a new design specification to the ASPEN IGCC performance models which adjusts the compressor inlet air flow rate to obtain choked air flow at the turbine inlet. The turbine inlet nozzle air flow is referenced to that of available data for the General Electric MS7001F operating on natural gas, based on published values of gas turbine inlet air and exhaust gas flow rates, gas turbine pressure ratio, and turbine inlet temperature (Allen, 1990; Brandt, 1989). However, the flow rate at the turbine inlet nozzle is less than the exhaust flow rate, because a portion of the compressor air is introduced in later turbine stages as part of the cooling air circuits. Therefore, the reference turbine inlet nozzle mass flow was estimated assuming that 12 percent of the compressor air was diverted for downstream turbine blade and vane cooling. The compressor air diverted for cooling is based on an estimate provided by a DOE engineer (Geiling, 1991).

Because a reference mass flow is assumed, the critical area of the nozzle does not need to be explicitly estimated. Instead, the choked mass flow rate for IGCC applications is estimated based on the reference mass flow adjusted for differences in gas pressure, temperature, and molecular weight. The adjustment is made according to Equation (A-1) presented in A.4.3, which is reproduced here for convenience:

$$
\mathrm{m}_{\max }=\mathrm{PA} A^{*} \sqrt{\frac{\mathrm{MW}}{\mathrm{T}}} \sqrt{\frac{\gamma}{\mathrm{R}}\left(\frac{2}{\gamma+1}\right)^{\frac{\gamma+1}{\gamma-1}}}
$$


where,

$$
\begin{array}{ll}
m_{\max } & =\text { maximum mass flow rate } \\
\mathrm{P} & =\text { total pressure } \\
\mathrm{A}^{*} & =\text { critical area where flow is choked } \\
\mathrm{MW} & =\text { molecular weight of gas } \\
\mathrm{T} & =\text { total temperature } \\
\mathrm{R} & =\text { universal gas constant } \\
\gamma & =\text { ratio of specific heats for the gas }
\end{array}
$$

Assuming that the term under the radical is approximately constant for both the reference case with natural gas firing and the IGCC cases, the mass flow of gas entering the turbine nozzle can be estimated for different pressure, temperature, and gas molecular weight:

$$
\mathrm{m}_{\mathrm{act}}=\mathrm{m}_{\mathrm{rcl}}\left(\frac{\mathrm{p}_{\mathrm{act}}}{\mathrm{P}_{\mathrm{rcf}}}\right) \sqrt{\left.\left(\frac{\mathrm{MW}_{\mathrm{act}}}{\mathrm{MW}_{\mathrm{rcf}}}\right) \frac{\overline{\mathrm{T}}_{\mathrm{rcf}}}{\mathrm{T}_{\mathrm{act}}}\right)}
$$

The new design specification adjusts the compressor air flow so that the ratio of the actual turbine inlet gas flow to the reference value, adjusted for temperature, pressure, and gas molecular weight, approaches unity to within a specified tolerance.

The effect of this new design specification is that the turbine inlet nozzle mass flow rate remains relatively constant even for varying values of fuel gas heating value and compressor air extraction. Thus, the gas turbine is more properly sized compared to the cost model.

\section{Gas Turbine Emissions}

The original DOE flowsheets did not characterize the emissions from the gas turbine process area. In particular, the primary pollutants of concern are $\mathrm{CO}$ and $\mathrm{NO}_{\mathrm{x}}$. Technical background on gas turbine emissions is given in Appendix A.4.5.

$\mathrm{CO}$ emissions can be easily characterized in the ASPEN simulation by specifying the fractional conversion of fuel gas $\mathrm{CO}$ in the gas turbine combustor to be less than 100 percent. Therefore, appropriate conversion rates were selected in the case studies to obtain desired estimates of $\mathrm{CO}$ emissions. $\mathrm{CO}$ emitted from the gas turbine represents incomplete combustion and an energy penalty on the combustor, because the heating value for conversion of $\mathrm{CO}$ to $\mathrm{CO}_{2}$ is not realized. However, the energy penalty associated with the $\mathrm{CO}$ emission rates used in the cases studies in this work is typically negligible.

$\mathrm{NO}_{\mathrm{x}}$ emissions were not characterized in the original DOE models. $\mathrm{NO}_{\mathrm{x}}$ is comprised of $\mathrm{NO}$ and $\mathrm{NO}_{2}$, and usually 95 percent of $\mathrm{NO}_{x}$ is in the form of $\mathrm{NO}$ when emitted at the stack. $\mathrm{NO}_{\mathrm{x}}$ is obtained from thermal fixation of nitrogen in the combustor 
inlet air and from conversion of nitrogen-bearing compounds in the fuel. In IGCC systems, particularly those with hot gas cleanup, the most significant fuel-bound nitrogen species is ammonia. Therefore, reactions representing both thermal $\mathrm{NO}_{\mathbf{x}}$ formation and fuel $\mathrm{NO}_{\mathrm{x}}$ formation were added to the gas turbine combustor model. These reactions were written in a general form to accomodate any assumptions regarding the fraction of $\mathrm{NO}_{\mathrm{x}}$ in the form of $\mathrm{NO}$ and the fractional conversion of combustor air nitrogen or ammonia to $\mathrm{NO}_{\mathbf{x}}$.

For thermal $\mathrm{NO}_{\mathrm{x}}$ formation, the following equation is used:

$$
\mathrm{N}_{2}+(2-x) \mathrm{O}_{2} \rightarrow 2 x \mathrm{NO}+2(1-\mathrm{x}) \mathrm{NO}_{2}
$$

where $\mathrm{x}$ is the molar fraction of $\mathrm{NO}_{\mathrm{x}}$ that is in the form of NO. The fractional conversion rate $\mathrm{cf} \mathrm{N}_{2}$ to $\mathrm{NO}_{\mathrm{x}}$ is specified through a parameter in the combustor unit operation block in the ASPEN simulation.

For fuel NOx formation, the following equation is used:

$2 \mathrm{NH}_{3}+\left[\frac{3}{2}+x y+2 y(1-x)\right] \mathrm{O}_{2} \rightarrow(1-\mathrm{y}) \mathrm{N}_{2}+2 x y \mathrm{NO}+2 \mathrm{y}(1-\mathrm{x}) \mathrm{NO}_{2}+3 \mathrm{H}_{2} \mathrm{O}$

where $y$ is the fractional conversion of ammonia to $\mathrm{NO}_{\mathrm{x}}$.

\section{Cooling Air Circuitry}

The turbine requires cooling air to keep the bulk metal temperatures of the blades and vanes, particularly in the first and second stages, sufficiently low to allow for long component life. See Appendix B.6.6 for more discussion. The DOE performance models of the IGCC systems contained provision for specifying cooling air flows. However, the models contained only two stages of unit operation blocks to represent the turbine. Furthermore, the model did not appear to account for pressure drops between the compressor air extraction point and the point at which the cooling air would be injected into the turbine gas stream. Therefore, a third stage was added to allow for better representation of the split of cooling air flows among the turbine stages and of the associated pressure drops. In addition, the total amount of compressor inlet air used for turbine blade and vane cooling was adjusted to 12 percent.

\section{Model Validation}

An effort was made to compare the results of the gas turbine performance model with published values for the performance of the MS7001F gas turbine. For these comparisons, the model was run using natural gas as a fuel. Ai a compressor inlet air 


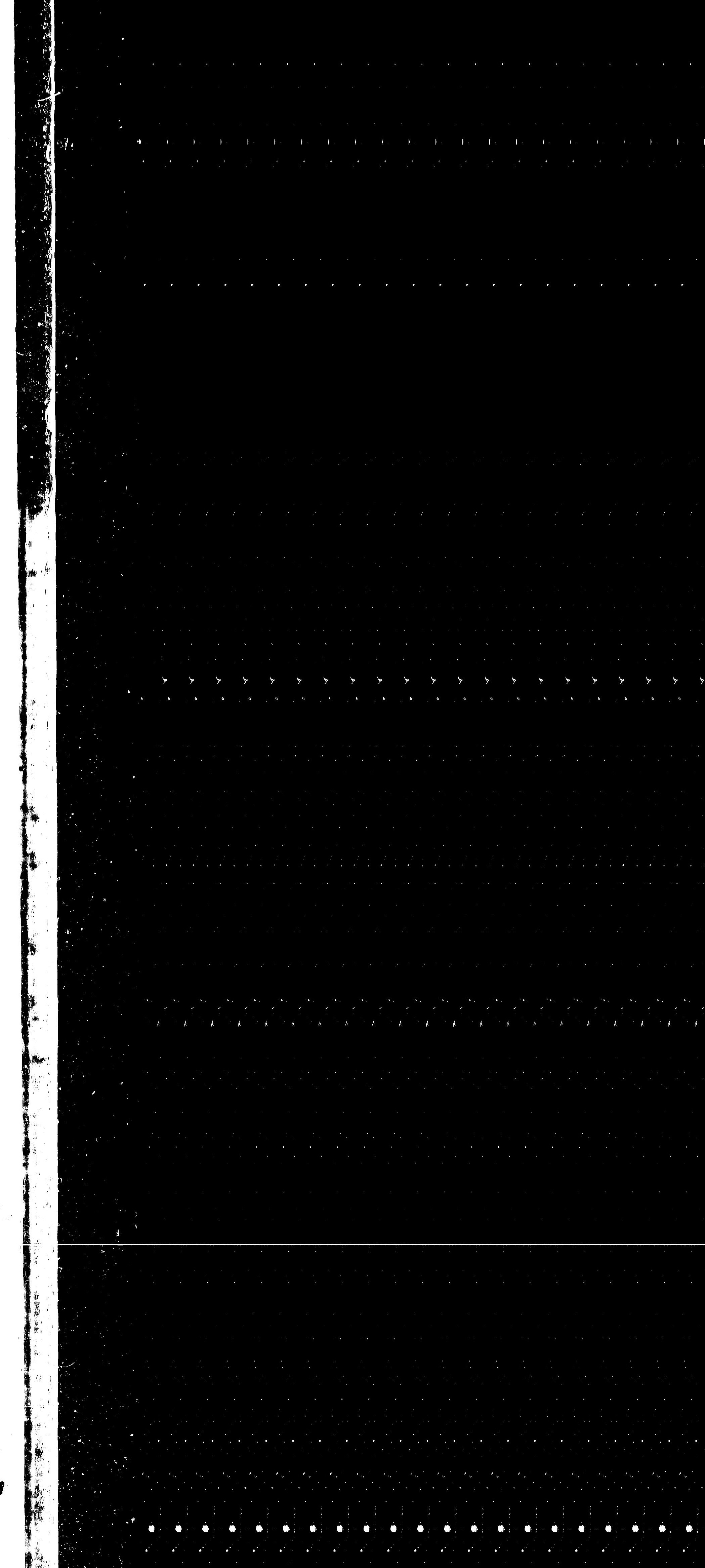


temperature of $590 \mathrm{~F}$, the model estimated that the gas turbine inlet air flow rate would be $919 \mathrm{lb} / \mathrm{sec}$, the exhaust flow would be $938 \mathrm{lb} / \mathrm{sec}$, the efficiency would be 34.68 percent, and that the power output would be $145 \mathrm{MW}$. The published values for the MS7001F are an inlet air flow of $981.7 \mathrm{lb} / \mathrm{sec}$, and exhaust flow of $937.5 \mathrm{lb} / \mathrm{sec}$, an efficiency of 34.57 percent, and a power output of $150 \mathrm{MW}$. While the model does not exactly reproduce the reported design values, it does estimate efficier.y within 0.4 percent and plant output within about 3 percent. The model also is qualitatively consistent with the performance of gas turbine at varying ambient temperatures. As ambienı temperature increases, both efficiency and the net power output decrease. However, no published data are currenlty available to compare with the model results at varying ambient temperature. 
This page left blank intentionally. 


\section{C.0 SAMPLE DETERMINISTIC OUTPUTS FOR IGCC COST MODELS}

\section{C.1 Oxygen-blown KRW IGCC with Cold Gas Cleanup}

$\begin{array}{rrrr}\text { A. COS'I MODEL PARAMETERS } & & & \\ \text { Plant Capacity Factor: } & 0.65 & \text { Cost Year: January } & 1989 \\ \text { General Facilities Factor: } & 0.20 & \text { Plant Cost Index: } & 351.5 \\ \text { Indirect Construction: } & 0.20 & \text { Chemicals Cost Index: } & 411.3 \\ \text { Sales Tax: } & 0.05 & \text { Escalation: } & 0.00 \\ \text { Engr \& Home Office Fee: } & 0.10 & \text { Interest: } & 0.10 \\ \text { Project Contingency: } & 0.17 & \text { Years of construction: } & 4 \\ \text { Number of Shifts: } & 4.25 & \text { Byproduct marketing: } & 0.10 \\ \text { Fixed Charge Factor: } & 0.1034 & \text { Average Labor Rate: } & 19.70 \\ \text { Variable Levelization Cost Factor: } & 1.0000 & \text { Book Life (years): } & 30\end{array}$

B. PROCESS CONTINGENCY AND MAINTENANCE COST FACTORS

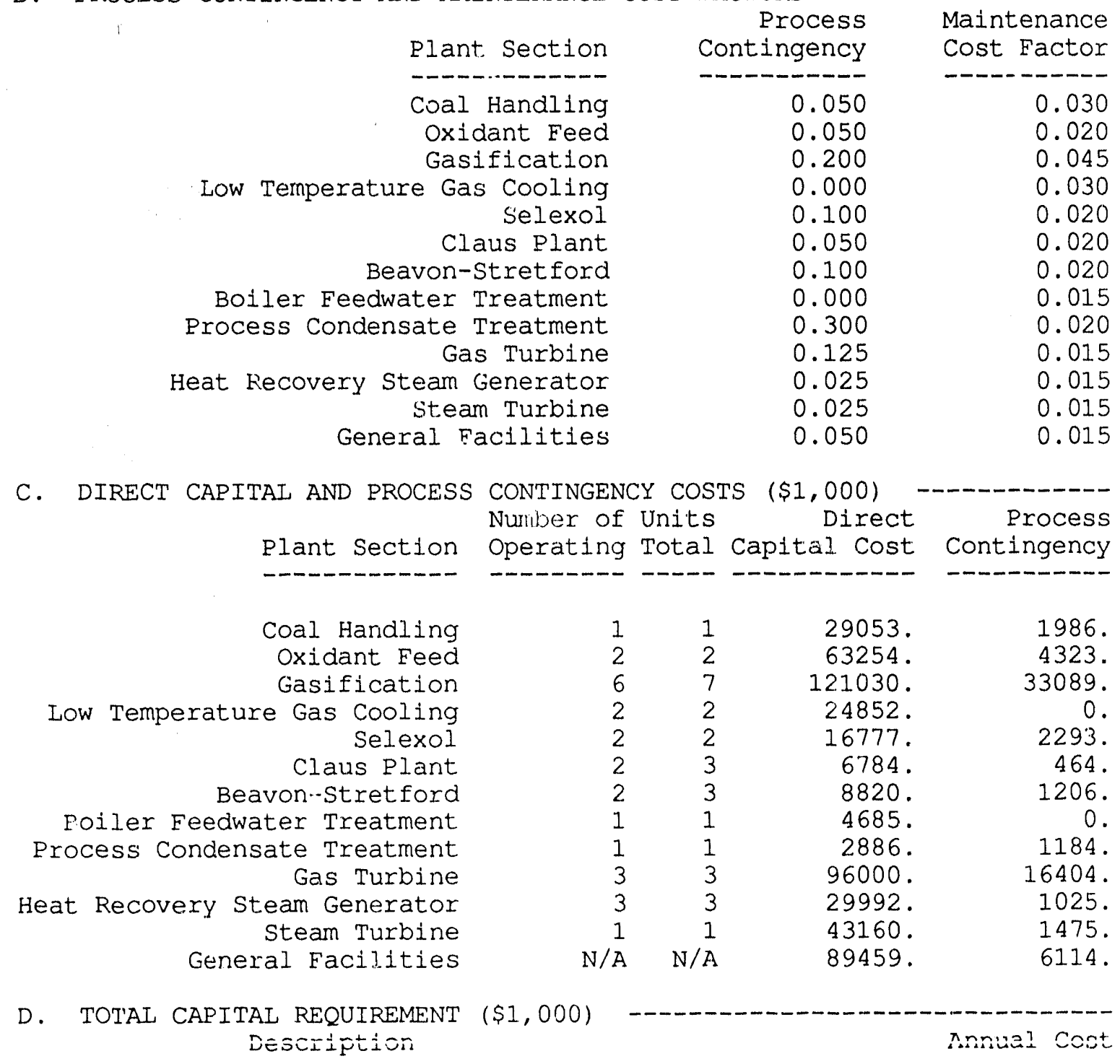


Total Direct Cost

Indirect Construction cost

Sales Tax

Engineering and Home Office Fees

Environmental Permitting

Total Indirect costs

Total Process Concingencies

Project Contingency

Total Plant Cost

AFDC

Total Plant Investment

Preproduction (Startup) Costs

Inventory Capital

Initial Catalysts and cnemicals

Land

TOTAL CAPITAL REQUIREMENT $(\$ 1,000) \ldots \ldots$

536752 .

107350 .

22007.

66611.

1000 .

196968 .

69562 .

140574 .

943857 .

151253.

1095110 .

27460 .

16264 .

5177.

2395.

1157357.

F. FIXED OPERATING COSTS (\$/year)

Description

Annual Cost

Operating Labor

7836660 .

Maintenance Costs

23261312 .

Administration and Supervision

5142355 .

TOTAL FIXED OPERATING COST (\$/year) -

F. VARIABLE OPERATING COSTS

1. CONSUMABLES (\$/year)

Description

---on----

Sulfuric Acid:

$\mathrm{NaOH}$ :

$\mathrm{Na} 2 \mathrm{HPO} 4:$

Hydrazine:

Morpholine:

Iime:

Soda Ash:

Corrosion Inh.:

Surfactant:

Chlorine:

Biocide:

Selexol Solv.:

Claus Catalyst:

Sul.. Acid Cat:

SCOT Catalyst:

SCOT Chemicals:

B/S Catalyst:

$B / S$ Chemicals:

Fuel Oil:

Plant Air Ads.:

Raw Water:

Waste Water:

IPG - Flare:

TOTAL CONSUMABLES
Unit Cost

$10.00 \mathrm{~s} / \mathrm{t}$

$110.00 \$ /$ ton

$220.00 \$ /$ ton

$0.70 \$ / 1 b$

$3.20 \$ / 1 b$

$1.30 \$ / 1 \mathrm{~b}$

$80.00 \$ /$ ton

$160.00 \$ / t o n$

$1.90 \$ / 1 \mathrm{~b}$

$1.25 \$ / 1 b$

$250.00 \$ /$ ton

$3.60 \$ / 1 b$

$1.80 \$ / 1 b$

$440.00 \$ /$ ton

1.90 \$/liter

$230.00 \$ /$ ft 3

$0.36 \mathrm{~s} / \mathrm{ft} 3$

170.00 s/ft 3

$\mathrm{N} / \mathrm{A}$

$42.00 \$ / \mathrm{bbl}$

$2.80 \$ / 1 b$

$0.73 \$ / \mathrm{Kgil}$

840.00 \$/gpin ww

$11.77 \$ / \mathrm{bbl}$

(\$/year)
Material

Requirement

1394.3 ton/yr

317.0 ton/yr

$1291.2 \mathrm{lb} / \mathrm{yr}$

$6207.2 \mathrm{lb} / \mathrm{yr}$

$5765.7 \mathrm{lb} / \mathrm{yr}$

$537.8 \mathrm{ton} / \mathrm{yr}$

597.4 ton/yr

$106984.4 \mathrm{lb} / \mathrm{yr}$

$106984.41 \mathrm{~b} / \mathrm{yr}$

17.2 ton/yr

$19101.7 \mathrm{lb} / \mathrm{yr}$

$41307.31 \mathrm{~b} / \mathrm{yr}$

$8.4 \mathrm{ton} / \mathrm{yr}$

0.01 iter/yr

$0.0 \mathrm{ft} 3 / \mathrm{yr}$

$0.0 \mathrm{ft} 3 / \mathrm{yr}$

$39.5 \mathrm{ft} 3 / \mathrm{yr}$

$\mathrm{N} / \mathrm{A}$

$37761.9 \mathrm{bbl} / \mathrm{yr}$

$2832.1 \mathrm{lb} / \mathrm{yr}$

$353851.4 \mathrm{Kgal} / \mathrm{yr}$

$145578.6 \mathrm{lb} / \mathrm{hr}$

$3304.2 \mathrm{bbl} / \mathrm{yr}$

$----------->>$
Annual

Operating Cost

153373.

69741.

904.

19863 .

7495 .

43024 .

95580 .

203270 .

133730 .

4293.

68766 .

74353 .

3690 .

0 .

0 .

0 .

6710.

78386 .

1585998 .

7930.

258312 .

158802 .

38659 .

3012880 .

2. FUEL, ASH DISPOSAL, AND BYPPODUCT CREDIT (\$/year)

Coal: $\quad 1.61 \%$ MMBtu $524716.4 \mathrm{lb} / \mathrm{hr}$

61446186 


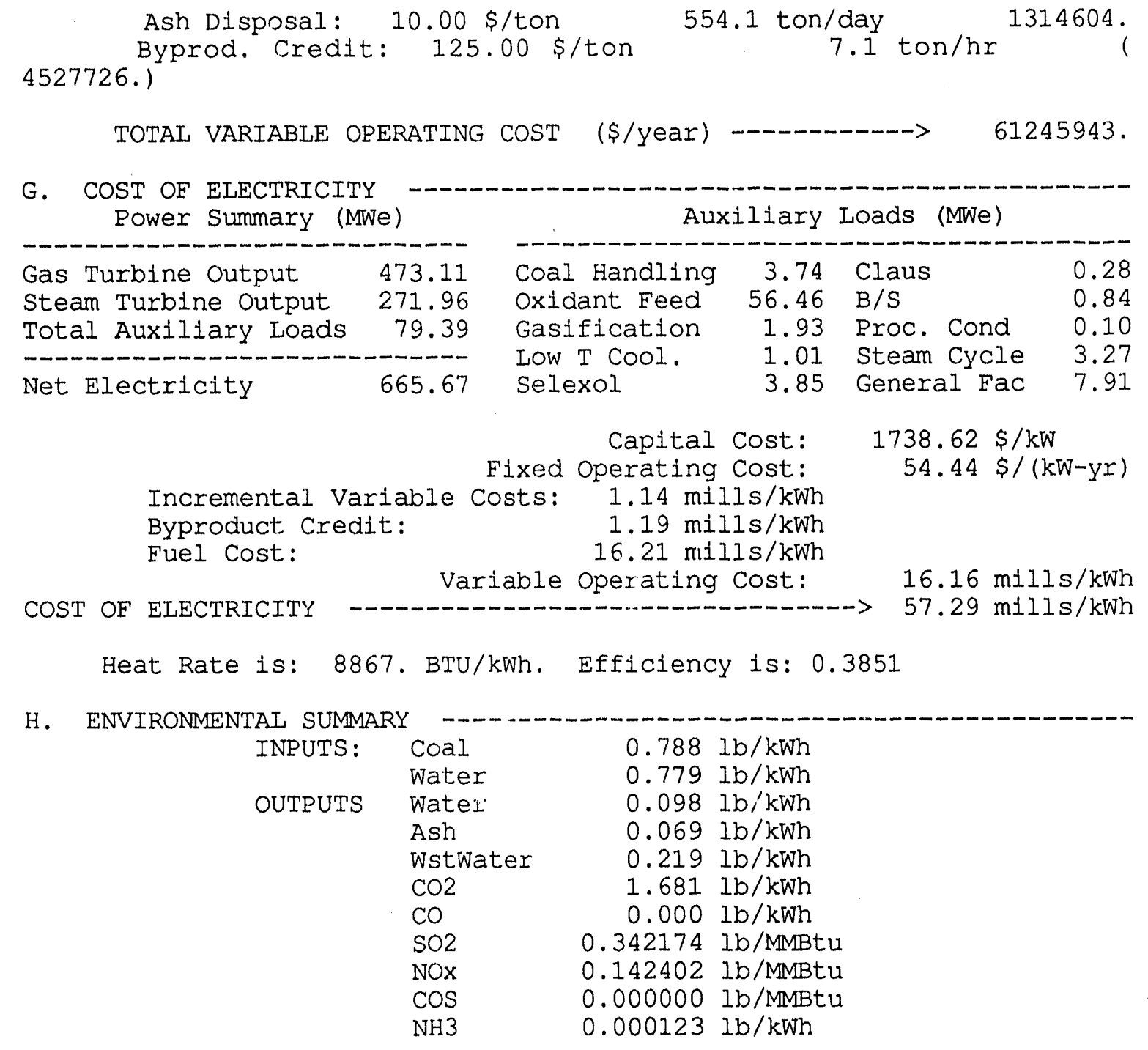




\section{C.3 Air-blown Lurgi-based IGCC with Hot Gas Cleanup}

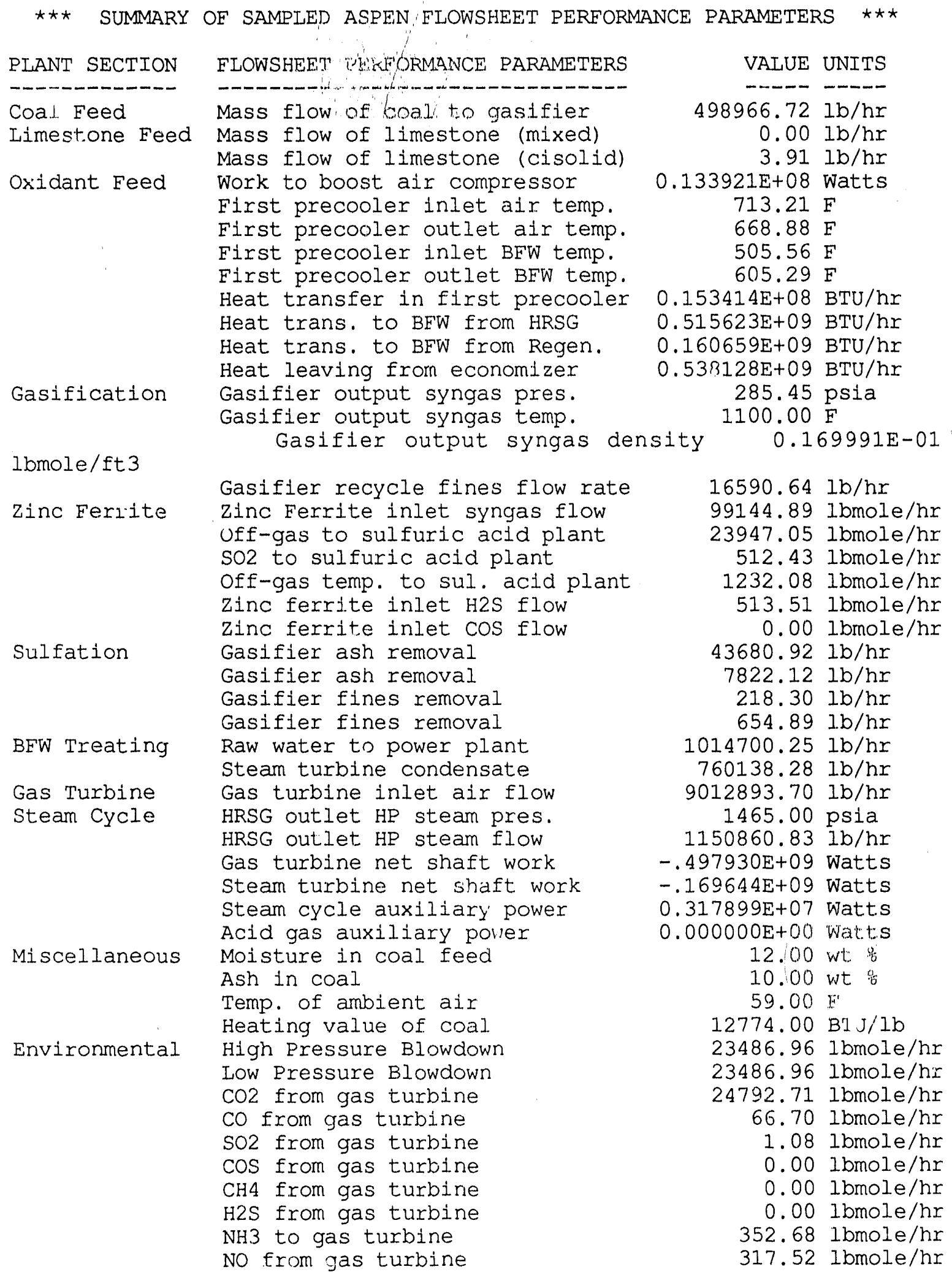


NO2 from gas turbine

Actual coal heating value

COST VAR WARNING -... Variable MCFGI value of

in DCSS above the upper Iimit of

COST VAR WARNING ---- Variable VSNZFI value of

in DCCY above the upper limit of

COST VAR WARNING ---- Variable MRW value of

in DCBF above the upper limit of
16.71 lbmole/hr

$11248.73 \mathrm{BTU} / \mathrm{lb}$

498966.719

433000.000

8836.921

6000.000

1014700.248

614000.000

COST SUMMARY

Air Blown Lurgi-Based IGCC System with Hot Gas Cleanup

A. KEY INPUT ASSUMPTIONS

Performance Assumptions:

Gasifier Availability:

Max. Desulf. Vessel Diameter: I/D Ratio:

Maximum Space Velocity (1/hr):

Sorb. Attrition Rate/80 cycles: Gasifier Coal Throughput:
0.87

12.50

3.00

2000 .

0.800

1.01
Sorb. Sulfur Loading: Superficial Velocity: Absorption Cycle Time: Sorbent Bulk Density: Generator Efficiency:

0.168 2.00 30.0 82.0 0.9850

Economic Assumptions:

Cost Year: January 1989

Plant Cost Index: 351.5

Chemicals cost Index: 411.3

Plant Capacity Factor: 0.65

General Facilities Factor: 0.20

Indirect Construction Factor:

Engr \& Home office Fees:

Project Contingency Factor:

Byproduct Marketing Factor:

Average Operating Labor Rate:

Number of Shifts:

Construction Interest Rate:

Years of Construction:
0.20

0.10

0.17

0.10

19.70

4.25

0.10

4
Inflation Rate: 0.000

Real Escalation Rate: 0.000

Plant Booklife: $\quad 30$

Sales Tax Rate: 0.05

Real Return on Debt: 0.046

Real Ret. on Pref.: 0.052

Debt Ratio: 0.500

Pref. Stock Ratio: 0.150

Fed. \& State Taxes: 0.380

Investment Tax Credit: 0.000

Prop. Taxes \& Insur.: 0.020
Real Ret. on Equity: 0.087

Process Contingency and Maintenance Cost Factors:

\begin{tabular}{rrr} 
Plant Section & $\begin{array}{r}\text { Process } \\
\text { Contingency }\end{array}$ & $\begin{array}{r}\text { Maintenance } \\
\text { Cost Factor }\end{array}$ \\
\hline Coal Handling & 0.050 & 0.030 \\
Limestone Handling & 0.000 & 0.030 \\
Oxidant Feed & 0.100 & 0.020 \\
Gasification & 0.200 & 0.030 \\
\& Bent. Subsystems & 0.050 & 0.020 \\
High Temp. Cyclones & 0.050 & 0.030 \\
Zinc Ferrite & 0.400 & 0.030 \\
Sulfuric Acid Plant & 0.100 & 0.020 \\
Sulfation & 0.600 & 0.045 \\
Feedwater Treatment & 0.000 & 0.015 \\
Gas Turbine & 0.250 & 0.020 \\
ry Steam Generator & 0.025 & 0.015 \\
Steam Turbine & 0.025 & 0.015 \\
General Facilities & 0.050 & 0.015
\end{tabular}


B. CALCULATED DIRECT CAPITAL AND PROCESS CONTINGENCY COSTS Number of Units Direct

Plant section Operating Total Capital Cost

$(\$ 1,000)$ Process Contingency

\section{miant section} perating rotal

Coal Handling Limestone Handling Oxidant Feed Gasification

Coke, Ash, \& Bent. Subsystems High Temp. Cyclones zinc Ferrite

Sulfuric Acid Plant Sulfation Boiler Feedwater Treatment Gas Turbine Heat Recovery Steam Generator Steam Turbine General Facilities

$\begin{array}{rr}1 & \\ 0 & \\ 3 & \\ 11 & 1 \\ 11 & 1 \\ 22 & 2 \\ 11 & 26 \\ 1 & \\ 0 & \\ 1 & \\ 3 & \\ 3 & \\ 1 & \\ \text { N/A } & \text { N/A }\end{array}$

21379

0 .

4703.

83663.

13769 .

6175.

11491.

23210 .

0.

5293.

96000 .

27691.

26519.

63978 .
1462 . 0. 22885 . 942 . 422. 6287. 3174 . 0 . 32825. 947. 907. 4375 .

C. CALCUIATED TOTAL CAPITAL REQUIREMENT $(\$ 1,000)$ Description

Capital Cost

Total Direct Cost

Indirect Construction cost Sales Tax Engineering and Home Office Fees Environmental Permitting

Total Indirect costs

Total Process Contingencies Project contingency

Total Plant Cost AFDC

Total Plant Investment Preproduction (Startup) Costs Inventory Capital Initial Catalysts and Chemicals Land

TOTAL CAPITAL REQUIREMENT $(\$ 1,000)-\cdots-\cdots$

Capital Cost
383870.
76774.
15739.
47638.
1.000.
141151.
74869.
104981.
704871.
112956.
817826.
22225.
17570.
23606.
2246.
891651.

D. CALCUIATED FIXED OPERATING COSTS (\$/year)

Description

Annual Cost

Operating Labor

Maintenance Costs

Administration and Supervision

8533252

15377427 .

4405267 .

TOTAL FIXED OPERATING COST (\$/year) - - - - -

E. CALCULATED VARIABLE OPERATING COSTS

1. CONSUMABLES (\$/Year)

\begin{tabular}{rr} 
Description & Unit Cost \\
\hline Sulfuric Acid: & $110.00 \mathrm{~s} / \mathrm{ton}$ \\
$\mathrm{NaOH}:$ & $220.00 \mathrm{~s} / \mathrm{ton}$ \\
$\mathrm{Na} 2 \mathrm{HPO}:$ & $0.70 \mathrm{\$} / \mathrm{b}$ \\
Hydrazine: & $3.20 \mathrm{\$} / \mathrm{bb}$ \\
Morpholine: & $1.30 \mathrm{\$} / \mathrm{lb}$
\end{tabular}

\begin{tabular}{rr} 
Calc. Material & $\begin{array}{r}\text { Calc. Annual } \\
\text { Requirement }\end{array}$ \\
\hdashline 2025.6 ton $/ y r$ & 222816. \\
426.1 ton/yr & 93748. \\
$2455.71 \mathrm{~b} / \mathrm{yr}$ & 1719. \\
$11820.1 \mathrm{lb} / \mathrm{yr}$ & 37824. \\
$11023.71 \mathrm{~b} / \mathrm{yr}$ & 14331.
\end{tabular}

Calc. Material Requirement $11023.71 \mathrm{~b} / \mathrm{yr}$ 


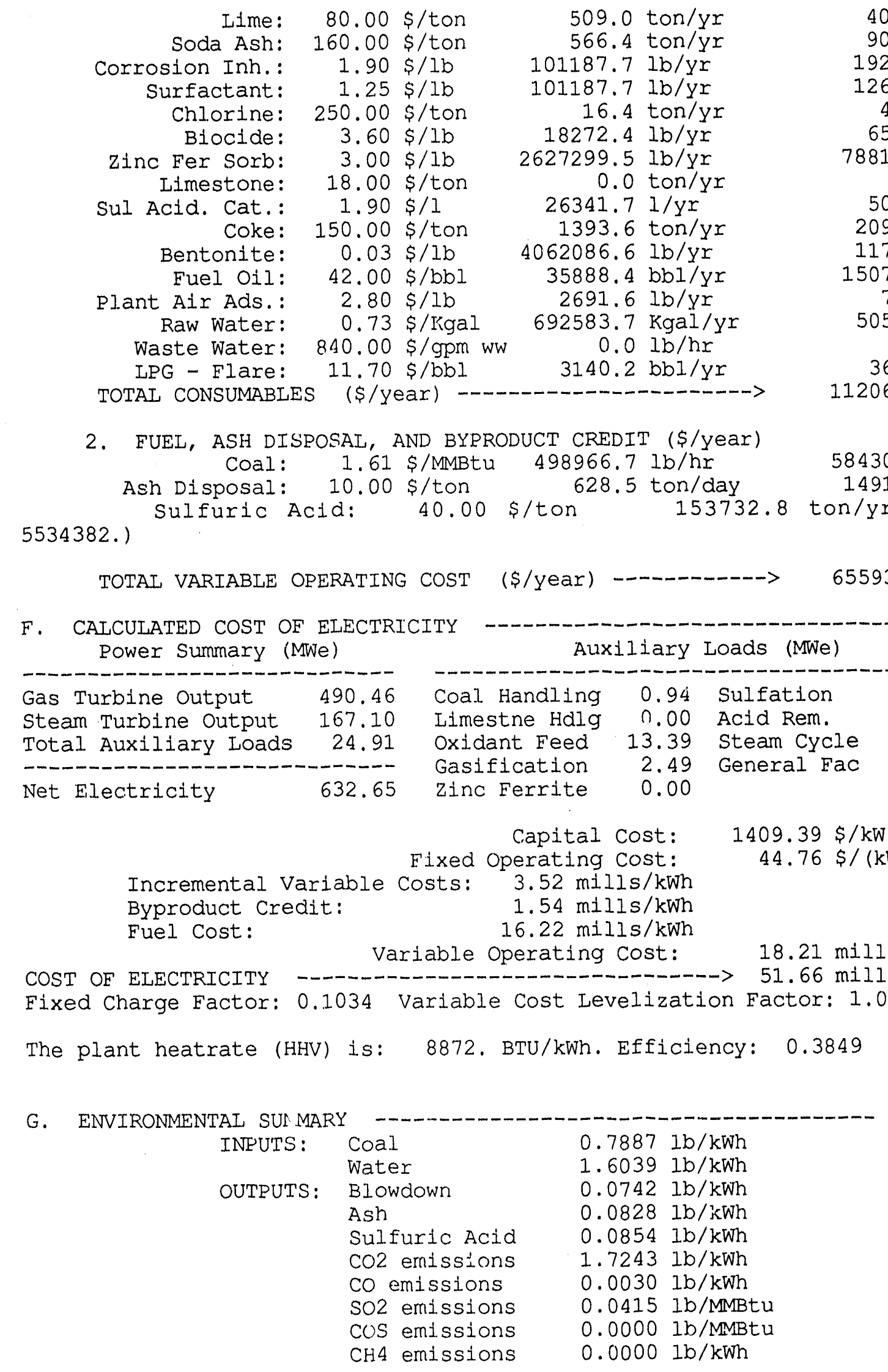


H2S emisstons NOx emissions
$0.00001 \mathrm{~b} / \mathrm{MMBtu}$

$2.7392 \mathrm{lb} / \mathrm{MMBtu}$ 
罟

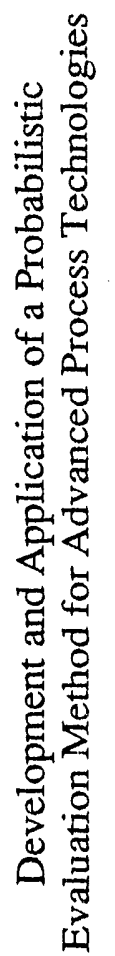

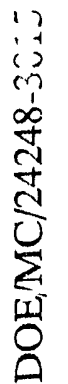



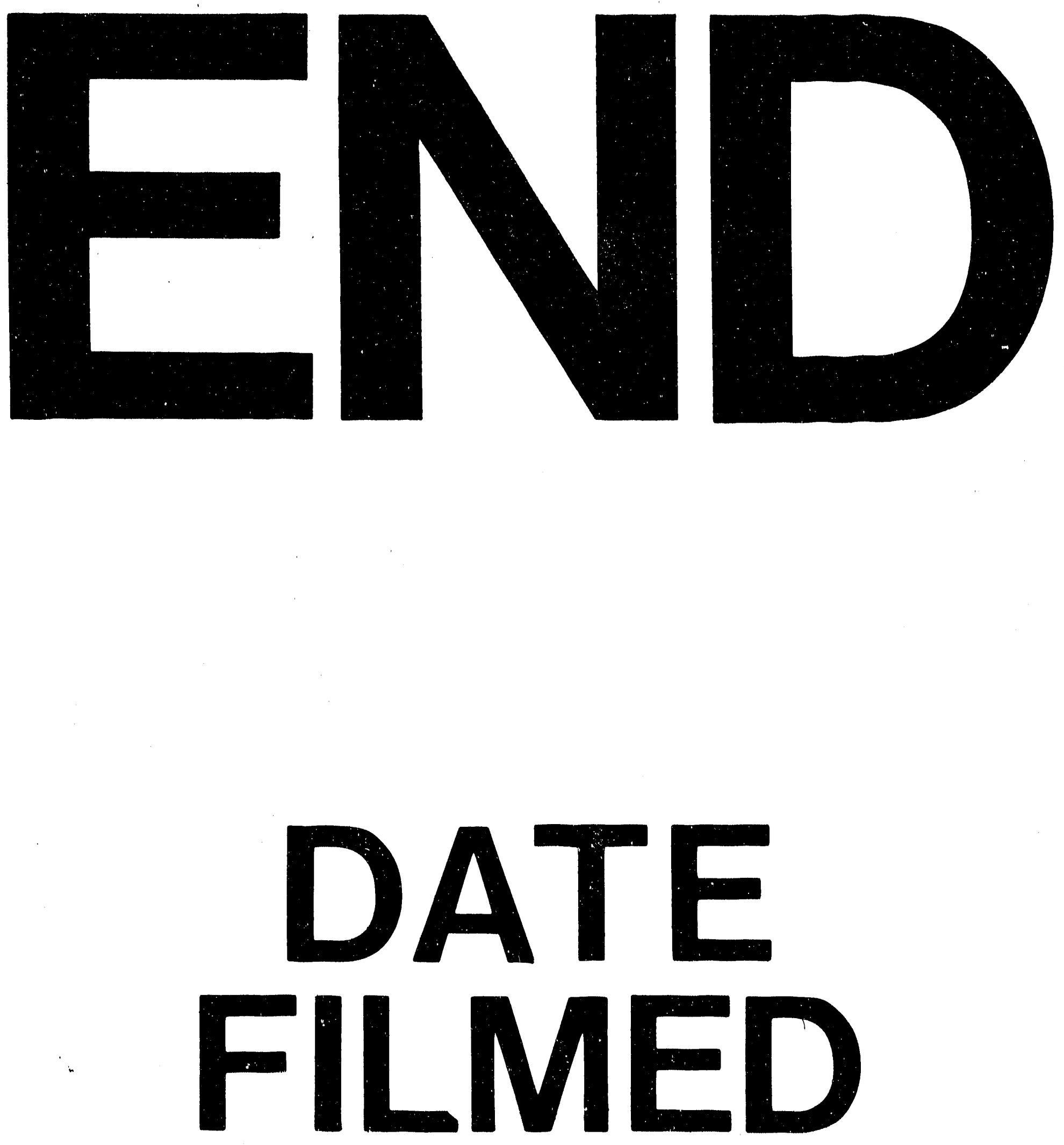

F

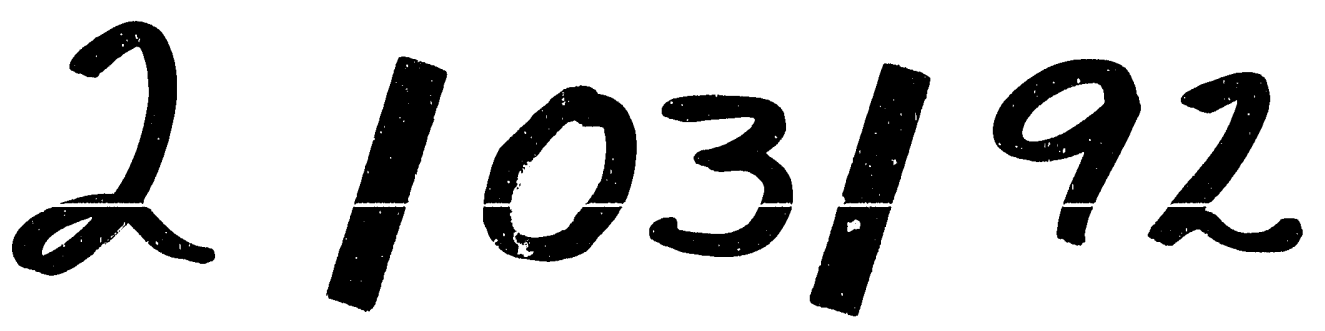


